\title{
Hygrothermal Analysis and Failure Analysis of Composite Beams under Moving Loads
}

Moiz Hanif

Follow this and additional works at: https://researchrepository.wvu.edu/etd

\section{Recommended Citation}

Hanif, Moiz, "Hygrothermal Analysis and Failure Analysis of Composite Beams under Moving Loads" (2014). Graduate Theses, Dissertations, and Problem Reports. 5753.

https://researchrepository.wvu.edu/etd/5753

This Thesis is protected by copyright and/or related rights. It has been brought to you by the The Research Repository @ WVU with permission from the rights-holder(s). You are free to use this Thesis in any way that is permitted by the copyright and related rights legislation that applies to your use. For other uses you must obtain permission from the rights-holder(s) directly, unless additional rights are indicated by a Creative Commons license in the record and/ or on the work itself. This Thesis has been accepted for inclusion in WVU Graduate Theses, Dissertations, and Problem Reports collection by an authorized administrator of The Research Repository @ WVU. For more information, please contact researchrepository@mail.wvu.edu. 
Hygrothermal Analysis and Failure Analysis of Composite Beams under Moving Loads

\author{
Moiz Hanif
}

Thesis submitted to the College of Engineering and Mineral Resources

At West Virginia University

In partial fulfillment of the requirements

For the degree of

\begin{abstract}
Master of Science
in

Mechanical Engineering

Nithi T. Sivaneri, Ph.D.

Kenneth H. Means, Ph.D.

Gergis W. William, Ph.D.
\end{abstract}

Department of Mechanical and Aerospace Engineering

Morgantown, West Virginia

2013

Keywords: Composite Beams, Hygrothermal Analysis, Failure Analysis, Moving Loads

Copyright $\odot 2013$ Moiz Hanif 


\title{
ABSTRACT \\ Hygrothermal Analysis and Failure Analysis of Composite Beams under Moving Loads
}

\begin{abstract}
Moiz Hanif
Excellent combination of high structural stiffness and low weight are the qualities of composite material leading to the extensive work on such materials. In order to achieve the desired performance requirements, the designer has to take into consideration the structural requirements and the functional characteristics. Thus, in this study, the effect of hygrothermal conditions on fiber reinforced composite laminates with moving loads have been extensively studied and has been carried out that accompanies Classical Laminate Plate Theory (CLPT) as well as First Order Shear Deformation Theory (FSDT) on MATLAB. A glass/epoxy composite system has been chosen for study with which similar results may be expected for other laminated composites. The hygrothermal effect is incorporated by adjusting the stiffness coefficients of the laminate to its level of moisture concentration using empirical relations. The failure analysis is done using the maximum normal stress criterion and the factor of safety for the lamina calculated and compared with respect to the corresponding maximum stresses and strengths. Different fiber volume fraction with varying fiber orientation of the plies in the laminate were modeled and studied. The results presented show the effect of stresses and strains in dry conditions, whereas for hygrothermal analysis, they also indicate that not all the laminates behave in a similar fashion and so it is possible by selecting the proper laminate configuration, the effect of moisture can be reduced. Also deducing, that due to hygrothermal effects, changes in the stiffness coefficients of a laminate do not appear to affect the deflection results significantly.
\end{abstract}




\section{ACKNOWLEDGEMENTS}

Like many things, the work presented here cannot define the amount of investment that was put into this thesis. After a long period of analysis and calculations and with tremendous efforts from my mentor, Dr. Sivaneri and I, this thesis was brought to a completion.

First and foremost, I would like to thank Dr. Nithi T. Sivaneri for his patient guidance and knowledgeable advices throughout the duration of my Master's program. Without his support, this work could not be completed with such finesse.

In addition, I would like to pay my respect to Dr. Victor Mucino for encouragements and moral support.

Also, my committee members, Dr. Kenneth Means and Dr. Gergis William, have served an important role throughout my research for their valuable input in directing me to the completion of my thesis.

Furthermore, I want to express my appreciation for my supporting family, my parents, sisters, brother-in-law and my niece. They helped me carry through the process of this thesis and success.

Last but not least, I would like to thank Nicole and my friends, Stella, Gouthami, Mona, Andres, Mohna, Aziz, Mamoun, Adil, Ali, Shafqat, Shrey, Supriya, Siim, Eri, Chio, Osuman, Luna and many more for their incredible lifting spirit and profound support and faith in me. 


\section{TABLE OF CONTENTS}

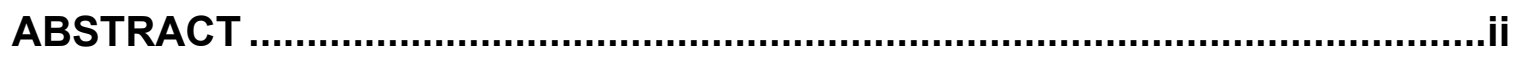

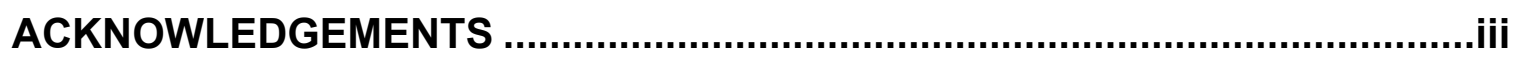

TABLE OF CONTENTS ................................................................................

LIST OF SYMBOLS ....................................................................................ii

LIST OF TABLES

LIST OF FIGURES ........................................................................................

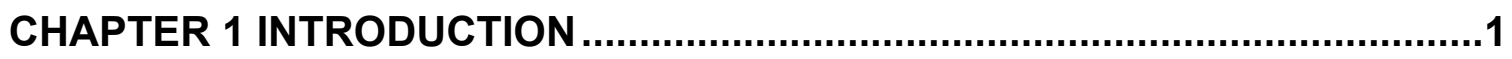

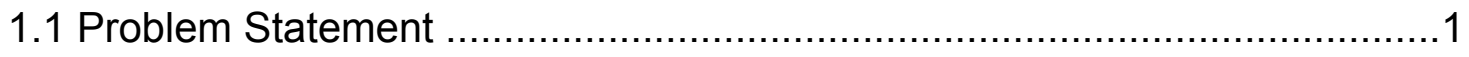

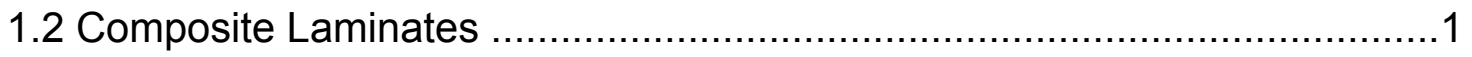

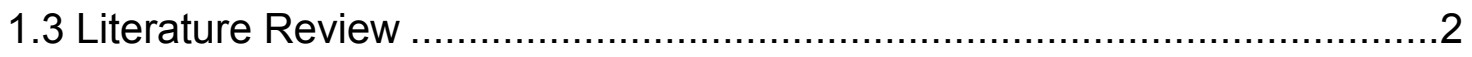

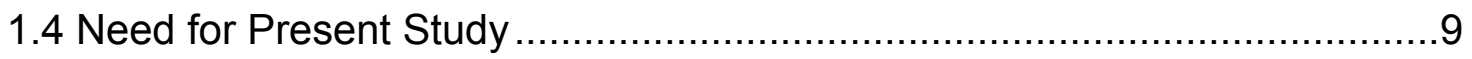

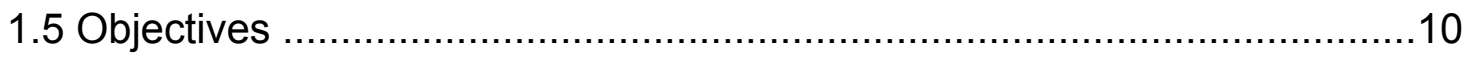

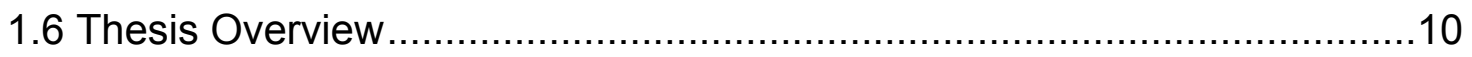

CHAPTER 2 THEORETICAL FORMULATION ...........................................12

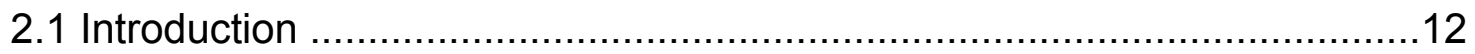

2.2 Composite Lay-up and Loading Configuration ......................................12

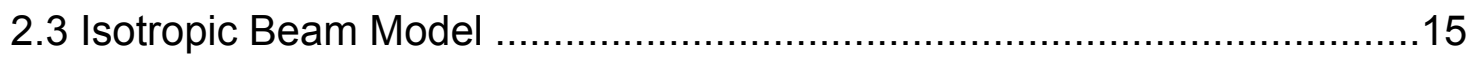

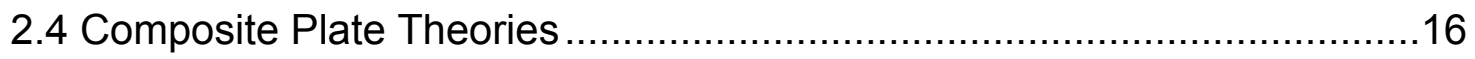

2.4.1 Classical Laminate Plate Theory (CLPT) ……............................16

2.4.2 First Order Shear Deformation Theory (FSDT) …..........................19

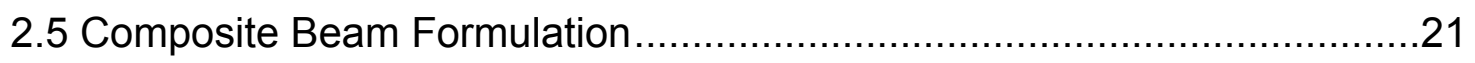

2.5.1 Beam Formulation using Classical Laminate Plate Theory ................22

2.5.2 Beam Formulation using First Order Shear Deformation Theory ........26

2.6 Kinetic Energy Formulation for Composite Beams ...................................29

2.6.1 Kinetic Energy Formulation for Isotropic case .................................30

2.6.2 Kinetic Energy Formulation for Beam Theory using CLPT .................31

2.6.3 Kinetic Energy Formulation for Beam Theory using FSDT .................33

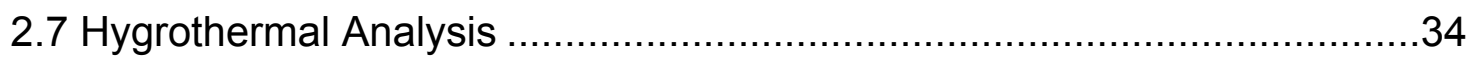

2.8.1 Rule of Mixtures and Inverse Rule of Mixtures ................................35 


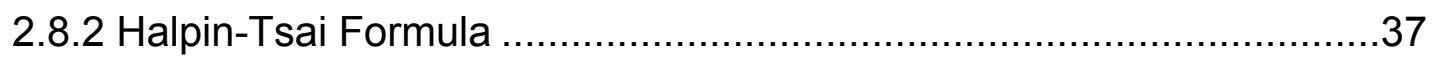

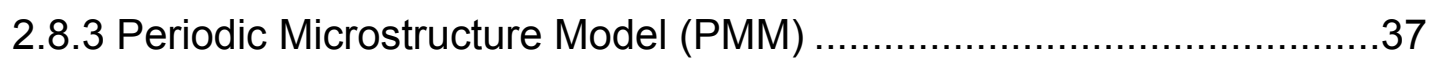

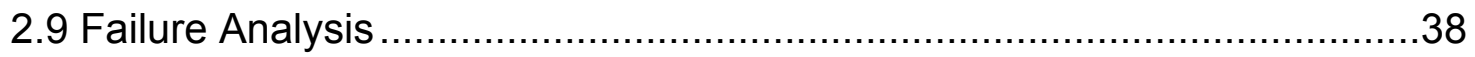

CHAPTER 3 FINITE ELEMENT FORMULATION ..........................................

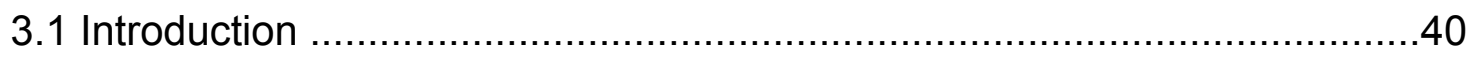

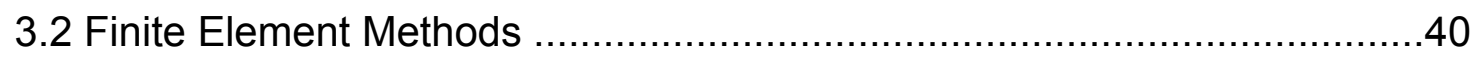

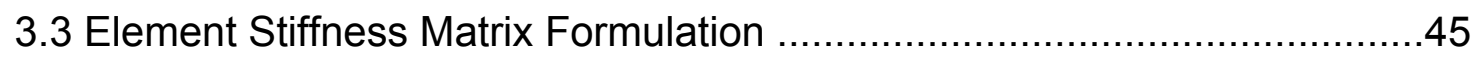

3.3.1 Stiffness Matrix Formulation for Isotropic beam ..............................46

3.3.2 Element Stiffness Matrix Formulation for Beam using CLPT .............47

3.3.3 Element Stiffness Matrix Formulation for Beam using FSDT .............50

3.4 Incremental Stiffness Matrix Formulation ...............................................53

3.5 Element Inertia Matrix Formulation ……..............................................55

3.5.1 Element Inertia Matrix Formulation for Isotropic case …....................55

3.5.2 Element Inertia Matrix Formulation for Beam using CLPT .................56

3.5.3 Element Inertia Matrix Formulation for FSDT ..................................57

3.6 Ply Stresses for a Composite Beam ...............................................58

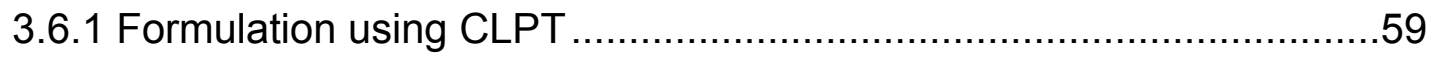

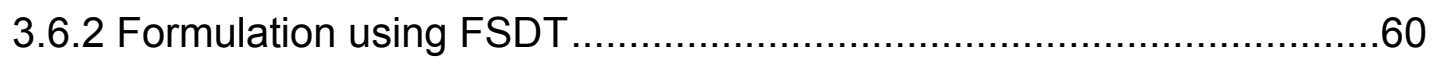

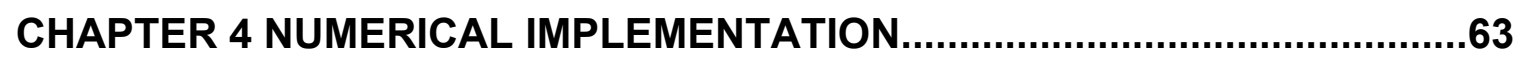

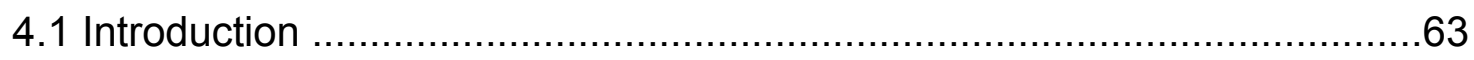

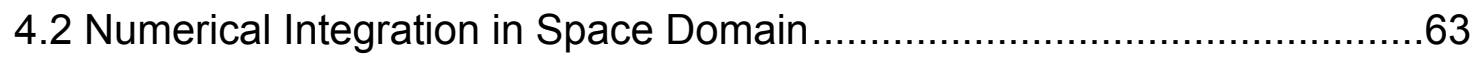

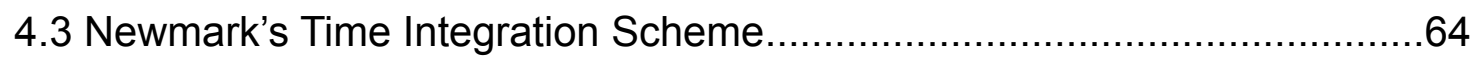

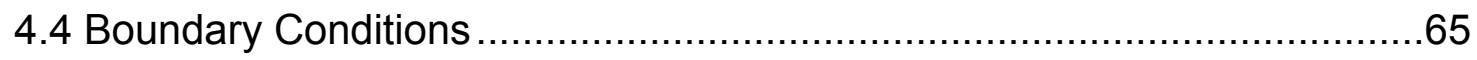

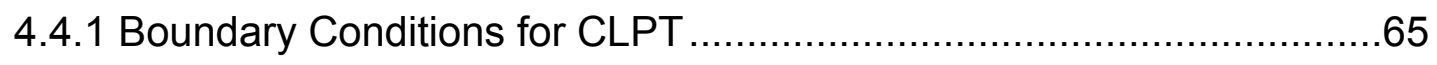

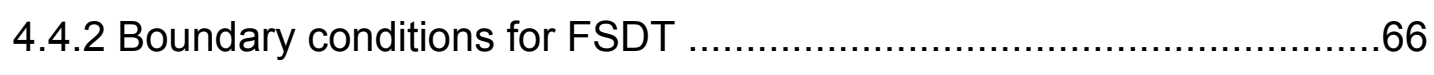

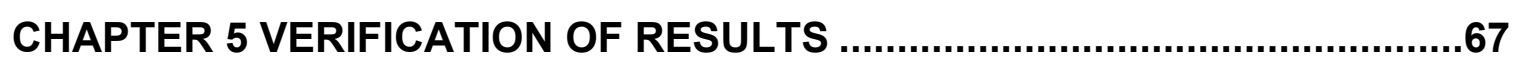

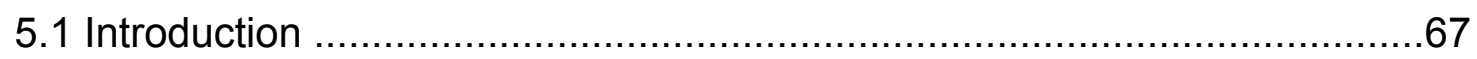

5.2 Isotropic Beam Subjected to a Moving Load..........................................67

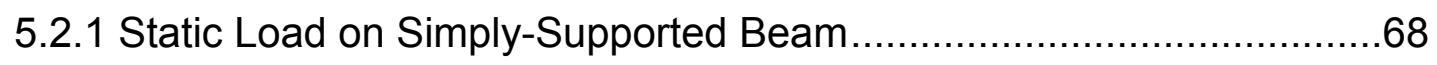

5.2.2 Moving Load on Simply-Supported Isotropic Beam ..........................69

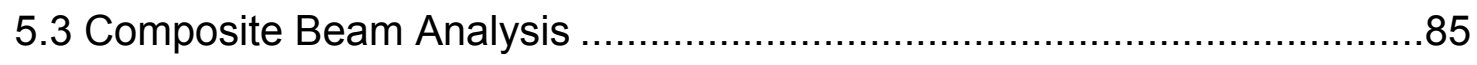


5.3.1 Verification of Results with Kadivar and Mohebpur (1997) ................85

5.3.1.1 Symmetric Cross-Ply Laminated Composite Beam ..........................86

5.3.1.2 [0/ $\pm 45 / 90]$ Laminated Composite Beam ......................................107

5.3.1.3 [ \pm 45$]$ Laminated Composite Beam .............................................131

5.3.2 Verification of Results with Kavipurapu (2005) ...............................152

5.4 Hygrothermal Analysis of Composite Beams .......................................172

5.4.1 Pinned-pinned laminate under uniformly distributed load.................174

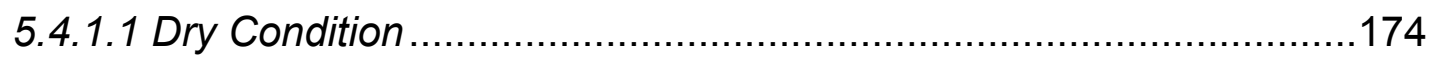

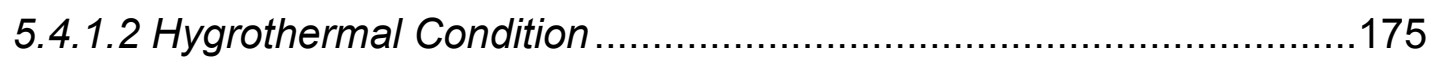

5.4.2 Clamped-clamped laminate under uniformly distributed load............175

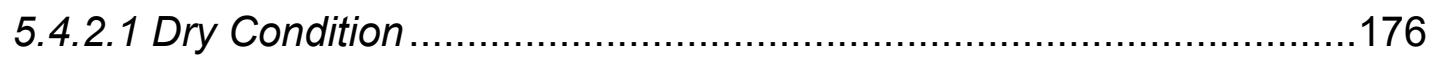

5.4.2.2 Hygrothermal Condition .........................................................176

5.5 Stress Analysis on Composite Beams .................................................177

5.5.1 Result verification with Borovkov et al. (1999)...............................177

5.5.2 Result Verification with Reddy (1997) .......................................... 182

5.5.2.1 $[0 / \pm 45 / 90]_{s}$ Laminated Composite Beam ......................................183

5.5.2.2 $[90 / \pm 45 / 0]_{s}$ Laminated Composite Beam .....................................187

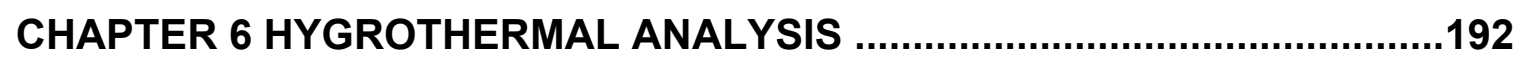

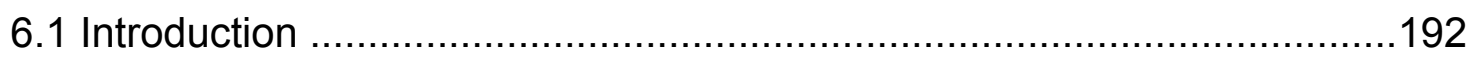

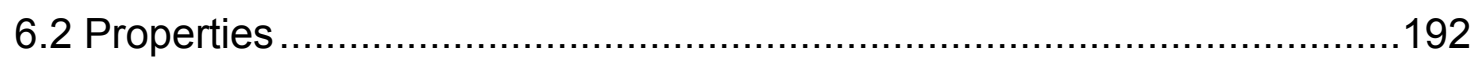

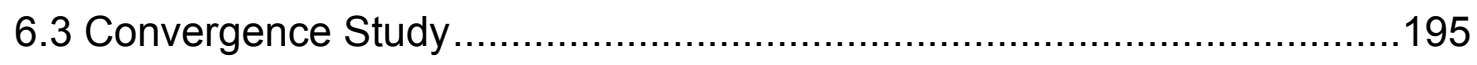

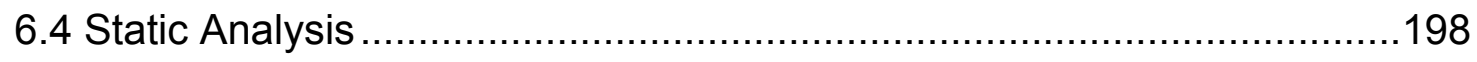

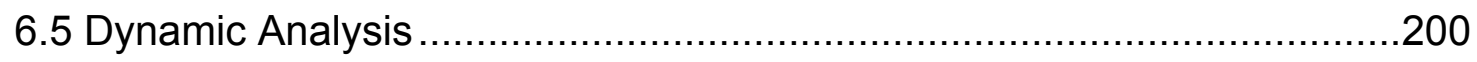

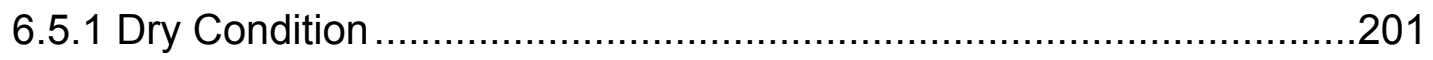

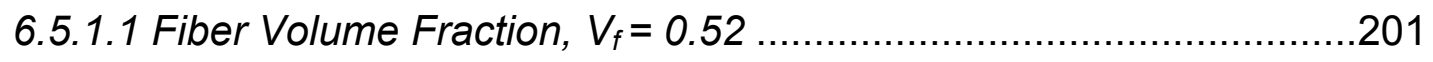

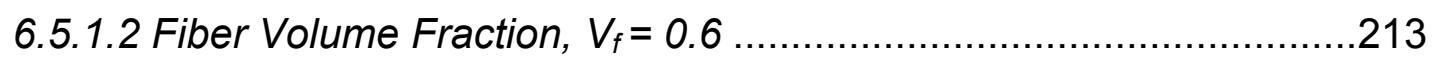

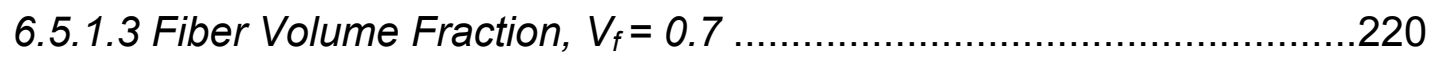

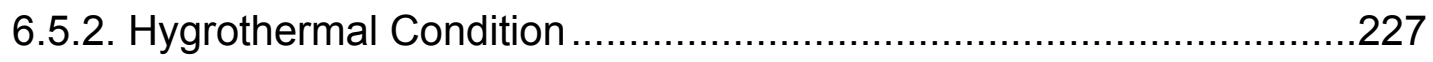

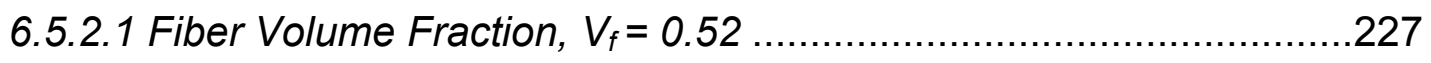

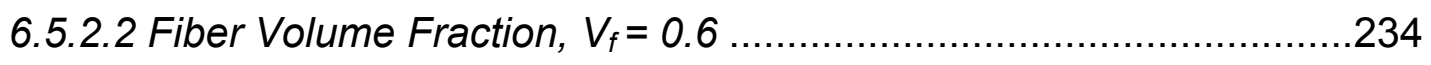

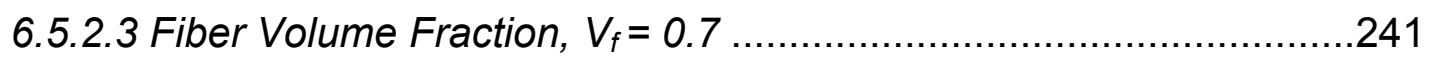

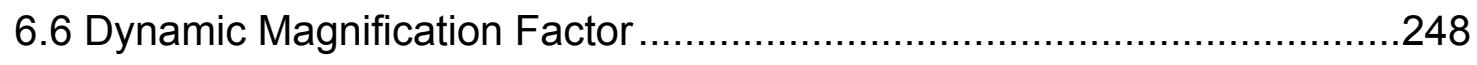




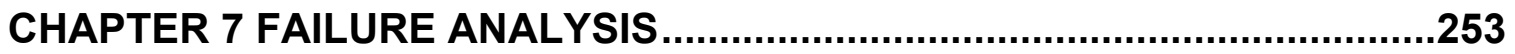

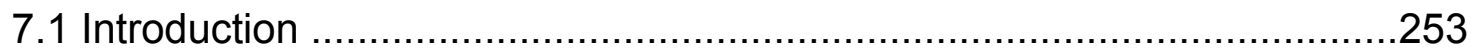

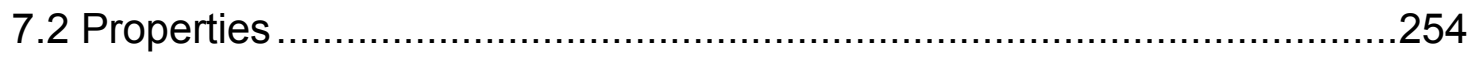

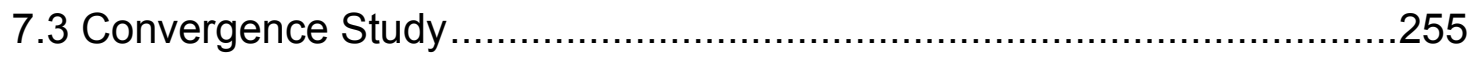

7.4 Stress Analysis for Different Lay-ups of a Composite Beam ..................257

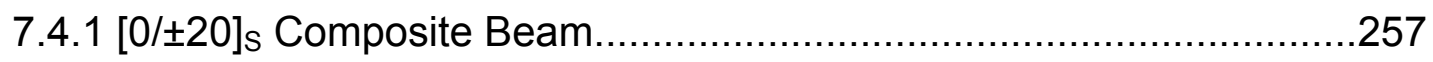

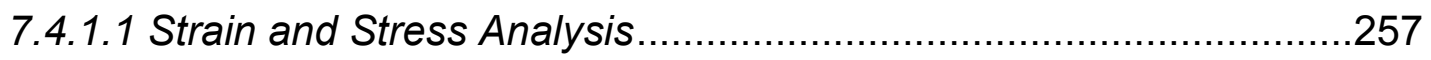

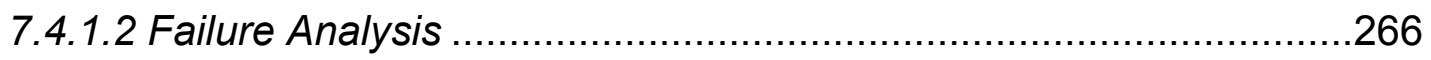

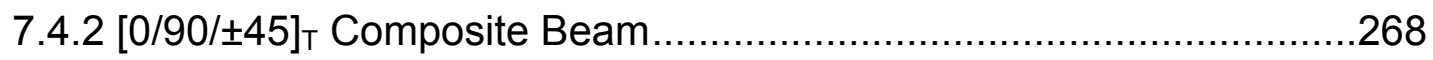

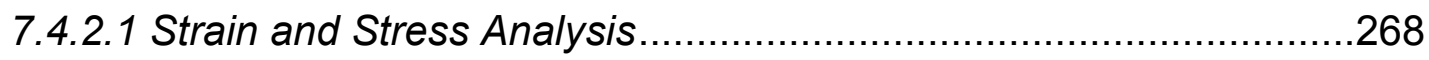

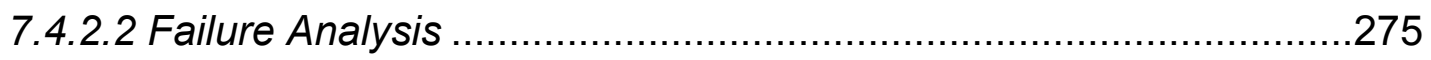

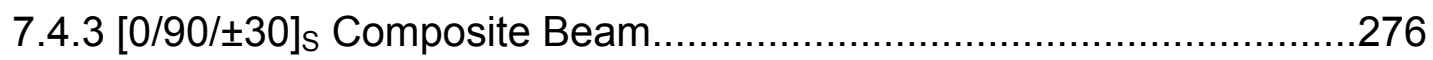

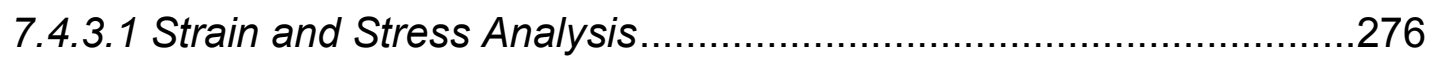

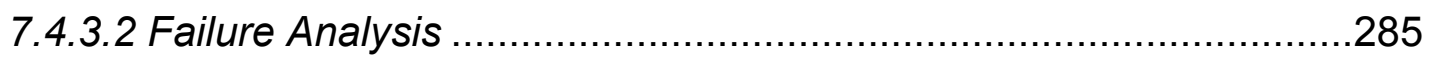

CHAPTER 8 CONCLUSIONS AND RECOMMENDATIONS.........................287

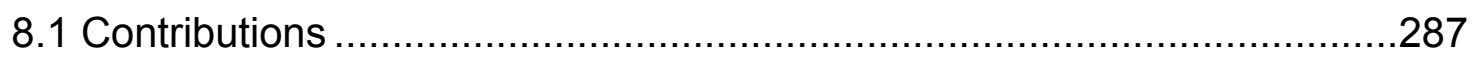

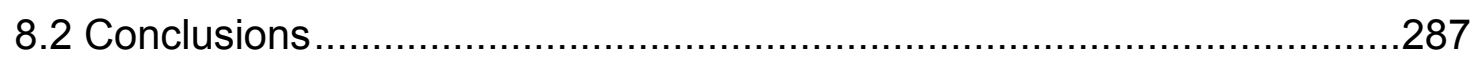

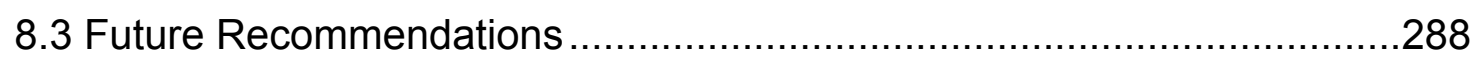

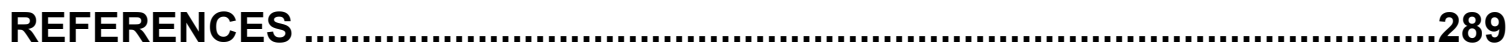




\section{LIST OF SYMBOLS}

A

$A_{i j}$

$A_{i j} *$

$a_{i}, b_{j}$

$b$

$B_{i j}$

$d$

$d x, d x_{1}$

$D_{i j}$

E

$E_{1}$

$E_{2}$

$E_{f}$ and $E_{m}$

$F_{x}$

$G_{f}$ and $G_{m}$

$h$

HTM

$H_{i}, H_{L i}$

$I, I_{0}, I_{1}, I_{2}$

$[k]$

$\left[k_{x x}\right]$

K

$[K]$

$\left[K_{\lambda}\right]$

$L$

$l_{e}$

$[m]$

$\left[m_{x x}\right]$

$[M]$

Area of cross section of the beam

Axial stiffness matrix

Shear stiffness matrices

Generalized co-ordinates

Breadth of the beam

Bending-extension stiffness matrix

Distance between supports

Length of deformed and undeformed element

Bending stiffness matrix

Modulus of elasticity

Longitudinal modulus

Transverse modulus

Modulus of elasticity of fiber and matrix

Axial force

In-plane shear modulus of fiber and matrix

Thickness of the beam

Hygrothermal Mechanical

Hermitian and Lagrangian shape functions

Moment of inertia, normal, coupled normal-rotary and rotary

inertia coefficients

Element Stiffness Matrix for Isotropic Material

Element Stiffness Matrix for Composite Material

Shear Correction Factor for FSDT

Global Stiffness Matrix

Lagrange multiplier matrix

Length of the beam

Element length

Element Inertia Matrix for Isotropic Material

Element Inertia Matrix for Composite Material

Global Inertia Matrix 


\begin{tabular}{|c|c|}
\hline$M_{x}, M_{y}, M_{x y}$ & Inplane moment resultants in $x y$ plane \\
\hline$M_{m}$ & Maximum moisture content \\
\hline$m$ & Moisture content \\
\hline$n$ & Layer number \\
\hline$N_{x}, N_{y}, N_{x y}$ & Inplane fore resultants in $x y$ plane \\
\hline$Q_{x}, Q_{y}$ & Transverse shear force resultants \\
\hline$\overline{Q_{i j}{ }^{k}}$ & Transformed reduced stiffness matrix \\
\hline$\{q\}$ & Nodal displacements vector \\
\hline$R^{i j}$ & $\begin{array}{l}\text { Elements of the reduced }[A B D] \text { matrix in full plane stress } \\
\text { formulations using CLPT }\end{array}$ \\
\hline$R_{i j}$ & $\begin{array}{l}\text { Elements of the reduced }[R] \text { matrix in full plane stress } \\
\text { formulation using CLPT }\end{array}$ \\
\hline$S^{i j}$ & $\begin{array}{l}\text { Partitions of reduced }[A B D] \text { matrix in partial plane stress } \\
\text { formulation using CLPT and FSDT }\end{array}$ \\
\hline$S_{i j}$ & $\begin{array}{l}\text { Elements of the reduced [S] matrix in partial plane stress } \\
\text { formulation using CLPT and FSDT }\end{array}$ \\
\hline$T_{0}$ & Room temperature \\
\hline$T_{g d r}$ and $T_{g w r}$ & Glass transition temperature of dry resin and wet resin \\
\hline$t$ & Time \\
\hline$t_{k}$ & Thickness of $k^{\text {th }}$ layer \\
\hline$T$ & Total kinetic energy \\
\hline$u(\xi)$ & Axial distribution functions \\
\hline$u_{0}, v_{0}, w_{0}$ & Mid-plane displacements along $\mathrm{x}, \mathrm{y}$ and $\mathrm{z}$ axis \\
\hline$U, U_{0}$ & Total strain energy and strain energy at the mid-plane \\
\hline$v_{B}{ }^{L}$ & Velocity of the Beam \\
\hline$V$ & Volume \\
\hline$V_{f}$ and $V_{m}$ & Volume fraction of fiber and matrix \\
\hline$w_{b}, w_{s}$ & Shear and bending components of transverse displacements \\
\hline$w(\xi)$ & Transverse distribution functions \\
\hline$x_{e}$ & Element longitudinal axis \\
\hline$X_{F}(t)$ & Axial displacement of moving beam \\
\hline$X, Y$ & Global axis \\
\hline$Z$ & Thickness co-ordinate \\
\hline$Z_{n}$ & Distance of the nth layer from the mid plane of a plate \\
\hline
\end{tabular}




$\begin{array}{ll}\overline{Z_{n}} & \begin{array}{l}\text { Distance of the mid-surface of the nth layer from the mid } \\ \text { plane of the plate }\end{array} \\ \overline{z_{k}} & \begin{array}{l}\text { Co-ordinate of the middle surface of the } k^{\text {th }} \text { layer with } \\ \text { reference to the middle surface of the laminate }\end{array} \\ \overline{\Delta_{P}} & \text { Total potential } \\ \Omega & \text { Frequency of axial motion imparted to the beaml } \\ \delta() & \text { Variation of ( ) } \\ \partial() & \text { Partial derivative of ( ) } \\ \varepsilon_{x}, \varepsilon_{y}, \varepsilon_{z} & \text { Axial strains in } \mathrm{x}, \mathrm{y}, \mathrm{z} \\ \{\varepsilon\} & \text { Strain vector for isotropic material } \\ \phi & \text { Relative humidity } \\ \phi_{x}, \phi_{y} & \text { Rotation about } \mathrm{x} \text { and } \mathrm{y} \\ \theta & \text { Angle/Direction of fibers in a lamina } \\ \gamma_{x y}, \gamma_{x z}, \gamma_{y z} & \text { Engineering shear strains } \\ \rho & \text { Density } \\ \sigma_{x}, \sigma_{y} & \text { Normal stresses in the respective } x \text { and } y \text { directions } \\ \tau_{x y} & \text { In-plane shear stress } \\ \{\sigma\} & \text { Stress vector for isotropic material } \\ \xi & \text { Non-dimensional co-ordinate } \\ ()^{T} & \text { Transpose of ( ) } \\ (\cdot)^{\prime},(*) & \text { First and second differential with respect to time } \\ ()^{\prime},()^{\prime \prime} & \text { First and second partial derivatives with respect to } \mathrm{x} \\ ()^{y},()^{y y} & \text { First and second partial derivatives with respect to } \mathrm{y} \\ & \end{array}$




\section{LIST OF TABLES}

Table 4.1 Sampling points and weights for seven-point Gauss quadrature integration scheme

Table 5.1 Dimensions and material properties of isotropic beam ......................68

Table 5.2 Mid-span static deflection of simply-supported beam ........................69

Table 5.3 Moving load velocities and time steps for isotropic beam ...................70

Table 5.4 Comparison of mid-span dynamic deflections various velocities.........71

Table 5.5 Dynamic magnification factor comparison at various time steps

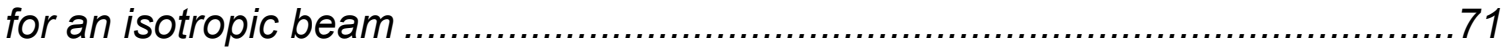

Table 5.6 Mid-span deflections at the end of each time-step for $V=15.60 \mathrm{~m} / \mathrm{s} . .76$

Table 5.7 Mid-span deflections at the end of each time-step for $V=31.20 \mathrm{~m} / \mathrm{s} . .78$

Table 5.8 Mid-span deflections at the end of each time-step for $V=62.40 \mathrm{~m} / \mathrm{s} \ldots 80$

Table 5.9 Mid-span deflections at the end of each time-step for $V=124.80 \mathrm{~m} / \mathrm{s} 82$

Table $5.10 \mathrm{Mid}$-span deflections at the end of each time-step

for $V=250.00 \mathrm{~m} / \mathrm{s}$

Table 5.11 Dimensions and material properties of glass/epoxy

composite beam

Table 5.12 Mid-span static deflection of glass/epoxy composite beam, [0/90]s...86

Table 5.13 Moving load velocities and time-steps for composite beam, [0/90]s ..87

Table 5.14 Maximum mid-span dynamic deflections for

different velocities, [0/90]s....

Table 5.15 Dynamic magnification factors comparison for different velocities,

$[0 / 90]_{s}$

Table 5.16 Mid-span deflections at the end of each time-step for

$V_{C L P T}=39.84 \mathrm{~m} / \mathrm{s}$ and $V_{F S D T}=36.71 \mathrm{~m} / \mathrm{s}$.

Table 5.17 Mid-span deflections at the end of each time-step for

$V_{C L P T}=79.68 \mathrm{~m} / \mathrm{s}$ and $V_{F S D T}=73.41 \mathrm{~m} / \mathrm{s}$.

Table $5.18 \mathrm{Mid}$-span deflections at the end of each time-step for

$V_{C L P T}=159.36 \mathrm{~m} / \mathrm{s}$ and $V_{F S D T}=146.83 \mathrm{~m} / \mathrm{s}$.

Table $5.19 \mathrm{Mid}$-span deflections at the end of each time-step for

$V_{C L P T}=239.04 \mathrm{~m} / \mathrm{s}$ and $V_{F S D T}=220.24 \mathrm{~m} / \mathrm{s}$.

Table 5.20 Mid-span deflections at the end of each time-step for

$V_{C L P T}=318.73 \mathrm{~m} / \mathrm{s}$ and $V_{F S D T}=293.66 \mathrm{~m} / \mathrm{s}$.

Table 5.21 Dynamic mid-span deflection at $V_{C L P T}=398.41 \mathrm{~m} / \mathrm{s}$ and

$V_{F S D T}=367.07 \mathrm{~m} / \mathrm{s}$.

Table 5.22 Mid-span deflections at the end of each time-step for

$V_{C L P T}=637.45 \mathrm{~m} / \mathrm{s}$ and $V_{F S D T}=587.32 \mathrm{~m} / \mathrm{s}$. 
Table 5.23 Mid-span static deflection of glass/epoxy [0/ $\pm 45 / 90]$ composite beam

Table 5.24 Moving load velocities and time-steps for

composite beam, [0/ $\pm 45 / 90]$....

Table 5.25 Maximum dynamic deflections for different velocities, [0/ $\pm 45 / 90] . . .109$

Table 5.26 Dynamic magnification factors comparison for different velocities ..110 Table 5.27 Mid-span deflections at the end of each time-step for

$V=20.30 \mathrm{~m} / \mathrm{s}$.

Table 5.28 Mid-span deflections at the end of each time-step for

$V=39.60 \mathrm{~m} / \mathrm{s}$.

Table 5.29 Mid-span deflections at the end of each time-step for

$V=78.20 \mathrm{~m} / \mathrm{s}$.

Table 5.30 Mid-span deflections at the end of each time-step for

$V=118.00 \mathrm{~m} / \mathrm{s}$.

Table $5.31 \mathrm{Mid}$-span deflections at the end of each time-step for

$V=156.00 \mathrm{~m} / \mathrm{s}$.

Table 5.32 Mid-span deflections at the end of each time-step for

$V=197.00 \mathrm{~m} / \mathrm{s}$.

Table $5.33 \mathrm{Mid}$-span deflections at the end of each time-step for

$V=295.00 \mathrm{~m} / \mathrm{s}$.

Table 5.34 Mid-span deflections at the end of each time-step for

$V=344.00 \mathrm{~m} / \mathrm{s}$.

Table $5.35 \mathrm{Mid}$-span deflections at the end of each time-step for

$V=391.00 \mathrm{~m} / \mathrm{s}$.

Table 5.36 Mid-span static deflection of glass/epoxy [ \pm 45$]$ composite beam ....131

Table 5.37 Moving load velocities and time-steps for [ \pm 45$]$ composite beam ...132

Table 5.38 Maximum dynamic deflections for different velocities, [ \pm 45$]$.

Table 5.39 Dynamic magnification factors comparison for

different velocities, [ \pm 45$]$.

Table $5.40 \mathrm{Mid}$-span deflections at the end of each time-step for

$V=13.40 \mathrm{~m} / \mathrm{s}$.

Table $5.41 \mathrm{Mid}$-span deflections at the end of each time-step for

$V=33.90 \mathrm{~m} / \mathrm{s}$.

Table $5.42 \mathrm{Mid}$-span deflections at the end of each time-step for

$V=50.40 \mathrm{~m} / \mathrm{s}$.

Table 5.43 Mid-span deflections at the end of each time-step for

$V=74.80 \mathrm{~m} / \mathrm{s}$

Table 5.44 Mid-span deflections at the end of each time-step for

$V=99.60 \mathrm{~m} / \mathrm{s}$. 
Table $5.45 \mathrm{Mid}$-span deflections at the end of each time-step for

$V=126.00 \mathrm{~m} / \mathrm{s}$.

Table $5.46 \mathrm{Mid}$-span deflections at the end of each time-step for

$V=193.00 \mathrm{~m} / \mathrm{s}$.

Table 5.47 Mid-span deflections at the end of each time-step for

$V=255.00 \mathrm{~m} / \mathrm{s}$.

Table 5.48 Dimensions and material properties of glass/epoxy

composite beam

Table 5.49 Mid-span static deflection of [0/90]s glass/epoxy composite beam..153

Table 5.50 Moving load velocities and time steps for [0/90]s glass/epoxy

composite beam 153

Table 5.51 Maximum dynamic deflections for different velocities.

Table 5.52 Dynamic magnification factors for different velocities. 155

Table $5.53 \mathrm{Mid}$-span deflections at the end of each time-step for $V=15.6 \mathrm{~m} / \mathrm{s}$.

Table $5.54 \mathrm{Mid}$-span deflections at the end of each time-step for

$V=31.2 \mathrm{~m} / \mathrm{s}$.

Table $5.55 \mathrm{Mid}$-span deflections at the end of each time-step for

$V=62.4 \mathrm{~m} / \mathrm{s}$.

Table $5.56 \mathrm{Mid}$-span deflections at the end of each time-step for

$V=93.6 \mathrm{~m} / \mathrm{s}$.

Table 5.57 Mid-span deflections at the end of each time-step for

$V=124.8 \mathrm{~m} / \mathrm{s}$.

Table 5.58 Mid-span deflections at the end of each time-step for $V=156 \mathrm{~m} / \mathrm{s} .169$

Table $5.59 \mathrm{Mid}$-span deflections at the end of each time-step for $V=250 \mathrm{~m} / \mathrm{s} .171$

Table 5.60 Dimensions, material properties and temperatures of glass/epoxy composite beam

Table 5.61 Material properties of S2 glass-fiber and hercules 3501-6 epoxy matrix .

Table 5.62 Material properties for fiber volume fraction, $V_{f}=0.52$

Table 5.63 Mid-span deflection of a pinned-pinned laminate under uniformly distributed load in dry condition

Table 5.64 Mid-span deflection of a pinned-pinned laminate under uniformly distributed load in dry conditions

Table 5.65 Mid-span deflection for a clamped-clamped laminate under uniformly distributed load in dry conditions...

Table 5.66 Mid-span deflection for a clamped-clamped laminate under uniformly distributed load in hygrothermal conditions

Table 5.67 Dimensions and material properties of composite beam 
Table 5.68 Normal stress along the cross-section of a [0/90]s laminated composite beam

Table 5.69 Non-dimensional normal stress along the cross-section of a $[0 / 90]_{s}$ laminated composite beam.

Table 5.70 Dimensions and material properties of composite beam.

Table 5. 71 Normal stresses along the cross-section of a $[0 / \pm 45 / 90]_{s}$ laminated composite beam.

Table 5.72 Non-dimensional normal stress along the cross-section of a [0/45/-45/90]s laminated composite beam

Table $5.73 \mathrm{Normal}$ stresses along the cross-section of a $[90 / \pm 45 / 0]_{s}$

laminated composite beam

Table 5.74 Non-dimensional normal stress along the cross-section of a $[90 / \pm 45 / 0]_{s}$ laminated composite beam.

Table 6.1 Dimensions, material properties and temperatures of glass/epoxy composite beam 193

Table 6.2 Material properties of S2 glass-fiber and hercules 3501-6 epoxy matrix

Table 6.3 Material properties for fiber volume fraction, $V_{f}=0.52$ 194

Table 6.4 Material properties for fiber volume fraction, $V_{f}=0.6$ 195

Table 6.5 Material properties for fiber volume fraction, $V_{f}=0.7$. 195

Table 6.6 Maximum mid-span deflections for 3,4,5,6 and 7 elements 197 Table 6.7 Dynamic magnification factors for 3,4,5,6 and 7 elements 198

Table $6.8 \mathrm{Mid}$-span static deflections of various laminate configurations for a glass/epoxy composite beam 199

Table 6.9 Support reactions at the left-end of the $[0 / 90 / \pm 45]_{T}$

simply-supported composite beam 200

Table 6.10 Support reactions at the right-end of the [0/90/ \pm 45$]_{T}$

simply-supported composite beam 200

Table 6.11 Maximum mid-span dynamic deflections of various laminate configurations for a glass/epoxy composite beam.... 201

Table 6.12 Dynamic mid-span deflections a for a [0/\$20]s laminate under dry conditions.

Table 6.13 Left-end support reactions a for a $[0 / \pm 20]_{s}$ laminate under dry conditions 205

Table 6.14 Right-end support reactions a for a $[0 / \pm 20]_{s}$ laminate under dry conditions...... 206

Table 6.15 Dynamic mid-span deflections a for a $[0 / 90 / \pm 45]_{T}$ laminate under dry conditions. 208 
Table 6.16 Left-end support reactions a for a $[0 / 90 / \pm 45]_{T}$ laminate under dry conditions.

Table 6.17 Right-end support reactions a for a [0/90/\$45] laminate under dry conditions.

Table 6.18 Dynamic mid-span deflections a for a [0/90/ \pm 30$]_{s}$ laminate under dry conditions.

Table 6.19 Dynamic mid-span deflections a for a [0/\$20]s laminate under dry conditions.

Table 6.20 Dynamic mid-span deflections a for a $[0 / 90 / \pm 45]_{T}$ laminate under dry conditions.

Table 6.21 Dynamic mid-span deflections a for a [0/90/ \pm 30$]_{s}$ laminate under dry conditions.

Table 6.22 Dynamic mid-span deflections a for a [0/ \pm 20$]_{s}$ laminate under dry conditions

Table 6.23 Dynamic mid-span deflections a for a $[0 / 90 / \pm 45]_{T}$ laminate under dry conditions

Table 6.24 Dynamic mid-span deflections a for a [0/90/ \pm 30$]_{s}$ laminate under dry conditions

Table 6.25 Dynamic mid-span deflections a for a [0/\$20]s laminate under hygrothermal conditions.

Table 6.26 Dynamic mid-span deflections a for a $[0 / 90 / \pm 45]_{T}$ laminate under hygrothermal conditions.

Table 6.27 Dynamic mid-span deflection a for a [0/90/ \pm 30$]_{s}$ laminate under hygrothermal conditions

Table 6.28 Dynamic mid-span deflections a for a [0/ \pm 20$]_{s}$ laminate under hygrothermal conditions

Table 6.29 Dynamic mid-span deflections a for a $[0 / 90 / \pm 45]_{T}$ laminate under hygrothermal conditions.

Table 6.30 Dynamic mid-span deflections a for a [0/90/\$30]s laminate under hygrothermal conditions.

Table 6.31 Dynamic mid-span deflections a for a [0/士20]s laminate under hygrothermal conditions.

Table 6.32 Dynamic mid-span deflections a for a [0/90/ \pm 45$]_{T}$ laminate under hygrothermal conditions.

Table 6.33 Dynamic mid-span deflections a for a [0/90/ \pm 30$]_{s}$ laminate under hygrothermal conditions.

Table 6.34 Dynamic magnification factors of various laminate configurations for a glass/epoxy composite beam

Table 7.1 Dimensions and properties of S-glass/epoxy composite 
Table 7.2 Tensile, compressive and shear strengths of S-glass/epoxy composite

Table 7.3 Maximum normal stress for 3, 4, 5, 6, and 7 elements at $x=L / 4 \ldots . .256$

Table $7.4 \mathrm{Normal}$ strain at the top and bottom of a $[0 / \pm 20]_{s}$ laminated composite beam

Table 7.5 Transverse strain at the top and bottom of a $[0 / \pm 20]_{s}$ laminated composite beam

Table 7. 6 Shear strain at the top and bottom of a $[0 / \pm 20]_{s}$ laminated composite beam

Table 7.7 Longitudinal stress along the cross-section of a $[0 / \pm 20]_{s}$ laminated composite beam

Table 7.8 Transverse stress along the cross-section of a $[0 / \pm 20]_{s}$ laminated composite beam

Table 7.9 Shear stress along the cross-section of a $[0 / \pm 20]_{s}$ laminated composite beam

Table 7.10 On-axis longitudinal Stress of a $[0 / \pm 20]_{s}$ Composite Beam

Table 7.11 Transverse stress for the lamina of a [0/ \pm 20$]_{s}$ laminated composite beam

Table 7.12 Shear stress for the lamina of a $[0 / \pm 20]_{s}$ laminated composite beam.

Table 7.13 Maximum stresses in material co-ordinates for a $[0 / \pm 20]_{s}$ composite beam

Table 7.14 Factor of safety for the stresses with their corresponding strengths for a $[0 / \pm 20]_{s}$ laminated composite beam

Table $7.15 \mathrm{Normal}$ strain at the top and bottom of a [0/90/ \pm 45$]_{T}$ laminated composite beam

Table 7.16 Transverse strain at the top and bottom of a $[0 / 90 / \pm 45]_{T}$ laminated composite beam

Table 7.17 Shear strain at the top and bottom of a $[0 / 90 / \pm 45]_{T}$ laminated composite beam

Table 7.18 Longitudinal stress along the cross-section of a $[0 / 90 / \pm 45]_{T}$ laminated composite beam.

Table 7. 19 Transverse stress along the cross-section of a $[0 / 90 / \pm 45]_{T}$ laminated composite beam.

Table 7. 20 Shear stress along the cross-section of a [0/90/ \pm 45$]$ T laminated composite beam

Table 7. 21 Longitudinal stress for the lamina of a $[0 / 90 / \pm 45]_{T}$ laminated composite beam

Table 7.22 Transverse stress for the lamina of a $[0 / 90 / \pm 45]_{T}$ laminated composite beam 
Table 7.23 Shear stress for the lamina of a $[0 / 90 / \pm 45]_{T}$ laminated composite beam.

Table 7.24 Maximum stresses on material co-ordinates for a $[0 / 90 / \pm 45]_{T}$ laminated composite beam

Table 7. 25 Factor of safety for the stresses with their corresponding strengths for a $[0 / 90 / \pm 45]_{T}$ laminated composite beam

Table 7.26 Normal strain at the top and bottom of a [0/90/ \pm 30$]_{s}$ laminated composite beam

Table 7.27 Transverse strain at the top and bottom of a [0/90/ \pm 30$]_{s}$ laminated composite beam

Table 7.28 Shear strain at the top and bottom of a $[0 / 90 / \pm 30]_{s}$ laminated composite beam

Table 7.29 Longitudinal stress along the cross-section of a $[0 / 90 / \pm 30]_{s}$ laminated composite beam.

Table 7.30 Transverse stress along the cross-section of a $[0 / 90 / \pm 30]_{s}$ laminated composite beam .

Table 7.31 Shear stress along the cross-section of a [0/90/ \pm 30$]_{s}$ laminated composite beam

Table 7.32 Longitudinal stress for the lamina of a $[0 / 90 / \pm 30]_{s}$ laminated composite beam

Table 7.33 Transverse stress for the lamina of a $[0 / 90 / \pm 30]_{s}$ laminated composite beam

Table 7.34 Shear stress for the lamina of a $[0 / 90 / \pm 30]_{s}$ laminated composite beam.

Table 7.35 Maximum stresses on material co-ordinates for a $[0 / 90 / \pm 30]_{s}$

laminated composite beam.

Table 7.36 Factor of safety for the stresses with their corresponding strengths for a $[0 / 90 / \pm 30]_{s}$ laminated composite beam 


\section{LIST OF FIGURES}

Figure 2.1 Simply-supported beam subjected to a moving load.......................12

Figure 2.2 Composite lay-up configuration ..............................................13

Figure 2.3 Force and moment resultants [W.E. Haisler, (2012)] ......................14

Figure 2.4 Co-ordinate systems used for a unidirectional lamina......................14

Figure 2.5 Undeformed and deformed geometries of an edge of a plate under

Kirchhoff's assumption for CLPT [Reddy (1997)] ........................................18

Figure 2.6 Undeformed and deformed geometries of an edge of a plate under Kirchhoff's assumption for FSDT [Reddy (1997)] ..........................................21

Figure 2.7 Undeformed and deformed beam segments

[Chandrasekaran (2000)]...........................................................................22

Figure 3.1 Typical finite element with three internal nodes and two end nodes ..41

Figure 3.2 Element definition for CLPT ........................................................

Figure 3.3 Element definition for FSDT …..............................................

Figure 4.1 Newmark's Scheme [Chandrasekaran (2000)].............................65

Figure 5.1 Dynamic magnification factors comparison at various time-steps

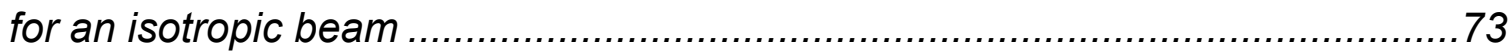

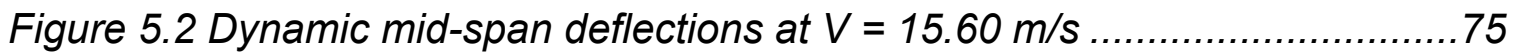

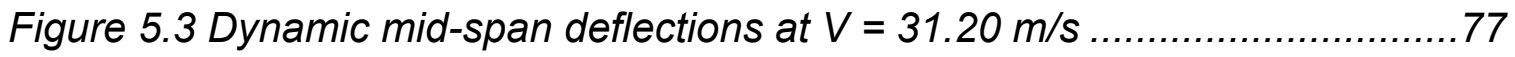

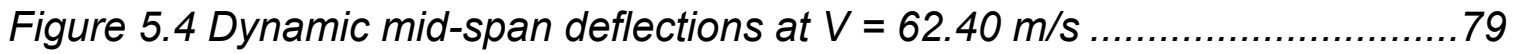

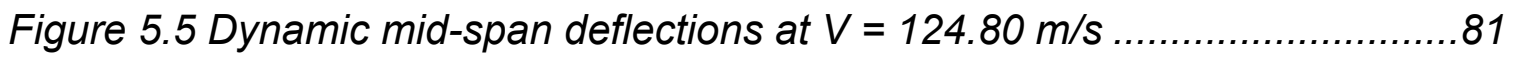

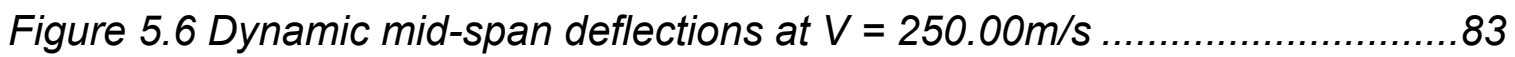

Figure 5.7 Dynamic comparison of magnification factors at various

velocity ratios for a $[0 / 90]_{s}$ composite beam under CLPT ...............................90

Figure 5.8 Dynamic comparison of magnification factors at various velocity ratios for a $[0 / 90]_{s}$ composite beam under FSDT ...............................91

Figure 5.9 Dynamic mid-span deflections at $V_{C L P T}=39.84 \mathrm{~m} / \mathrm{s}$

and $V_{F S D T}=36.71 \mathrm{~m} / \mathrm{s}$.

Figure 5.10 Dynamic mid-span deflections at $V_{C L P T}=79.68 \mathrm{~m} / \mathrm{s}$ and

$V_{F S D T}=73.41 \mathrm{~m} / \mathrm{s}$

Figure 5.11 Dynamic mid-span deflections at $V_{C L P T}=159.36 \mathrm{~m} / \mathrm{s}$ and

$V_{F S D T}=146.83 \mathrm{~m} / \mathrm{s}$

Figure 5.12 Dynamic mid-span deflections at $V_{C L P T}=239.04 \mathrm{~m} / \mathrm{s}$ and

$V_{F S D T}=220.24 \mathrm{~m} / \mathrm{s}$ 
Figure 5.13 Dynamic mid-span deflections at $V_{C L P T}=318.73 \mathrm{~m} / \mathrm{s}$ and

$V_{F S D T}=293.66 \mathrm{~m} / \mathrm{s}$ 101

Figure 5.14 Dynamic mid-span deflections at $V_{C L P T}=398.41 \mathrm{~m} / \mathrm{s}$ and $V_{F S D T}=367.07 \mathrm{~m} / \mathrm{s}$. 103

Figure 5.15 Dynamic mid-span deflections at $V_{C L P T}=637.45 \mathrm{~m} / \mathrm{s}$ and $V_{\text {FSDT }}=587.32 \mathrm{~m} / \mathrm{s}$. 105

Figure 5.16 Dynamic magnification factors comparison at different velocities for a $[0 / \pm 45 / 90]$ composite beam 111

Figure 5.17 Dynamic mid-span deflections at $V=20.30 \mathrm{~m} / \mathrm{s}$ 113

Figure 5.18 Dynamic mid-span deflections at $V=39.60 \mathrm{~m} / \mathrm{s}$ 115

Figure 5.19 Dynamic mid-span deflections at $V=78.20 \mathrm{~m} / \mathrm{s}$ 117

Figure 5.20 Dynamic mid-span deflections at $V=118.00 \mathrm{~m} / \mathrm{s}$ 119

Figure 5.21 Dynamic mid-span deflection at $V=156.00 \mathrm{~m} / \mathrm{s}$ 121

Figure 5.22 Dynamic mid-span deflections at $V=197.00 \mathrm{~m} / \mathrm{s}$ 123

Figure 5.23 Dynamic mid-span deflections at $V=295.00 \mathrm{~m} / \mathrm{s}$ 125

Figure 5.24 Dynamic mid-span deflections at $V=344.00 \mathrm{~m} / \mathrm{s}$ 127

Figure 5.25 Dynamic mid-span deflections at $V=391.00 \mathrm{~m} / \mathrm{s}$ 129

Figure 5.26 Dynamic magnification factors comparison at different velocities for a [ \pm 45$]$ composite beam. 134

Figure 5.27 Dynamic mid-span deflections at $V=13.40 \mathrm{~m} / \mathrm{s}$ 136

Figure 5.28 Dynamic mid-span deflections at $V=33.90 \mathrm{~m} / \mathrm{s}$ 138

Figure 5.29 Dynamic mid-span deflections at $V=50.40 \mathrm{~m} / \mathrm{s}$ 140

Figure 5.30 Dynamic mid-span deflections at $V=74.80 \mathrm{~m} / \mathrm{s}$ 142

Figure 5.31 Dynamic mid-span deflections at $V=99.60 \mathrm{~m} / \mathrm{s}$ 144

Figure 5.32 Dynamic mid-span deflections at $V=126.00 \mathrm{~m} / \mathrm{s}$ 146

Figure 5.33 Dynamic mid-span deflections at $V=193.00 \mathrm{~m} / \mathrm{s}$ 148

Figure 5.34 Dynamic mid-span deflections at $V=255.00 \mathrm{~m} / \mathrm{s}$ 150

Figure 5.35 Dynamic magnification factors comparison at various velocities for a $[0 / 90]_{s}$ composite beam 156 Figure 5.36 Dynamic mid-span deflections at $V=15.6 \mathrm{~m} / \mathrm{s}$ 158

Figure 5.37 Dynamic mid-span deflections at $V=31.2 \mathrm{~m} / \mathrm{s}$ 160

Figure 5.38 Dynamic mid-span deflections at $V=62.4 \mathrm{~m} / \mathrm{s}$ 162

Figure 5.39 Dynamic mid-span deflections at $V=93.6 \mathrm{~m} / \mathrm{s}$ 164

Figure 5.40 Dynamic mid-span deflections at $V=124.8 \mathrm{~m} / \mathrm{s} \ldots \ldots \ldots \ldots \ldots \ldots \ldots \ldots . .166$

Figure 5.41 Dynamic mid-span deflections at $V=156 \mathrm{~m} / \mathrm{s}$ 168

Figure 5.42 Dynamic mid-span deflections at $V=250 \mathrm{~m} / \mathrm{s}$ 170 Figure 5.43 Normal longitudinal stress distribution, $\sigma_{x}$, for a $[0 / 90]_{s}$ laminated composite beam. 180

Figure 5.44 Non-dimensional normal stress distribution, $\sigma_{x}^{*}$, for a $[0 / 90]_{s}$ laminated composite beam. 181 
Figure 5.45 Normal stress distribution, $\sigma_{x}$, for a [0/ $\left.\pm 45 /-45 / 90\right]_{s}$ laminated composite beam 185

Figure 5.46 Non-dimensional normal longitudinal stress distribution, $\overline{\sigma_{x}}$, for a [0/ $\pm 45 / 90]_{s}$ laminated composite beam. 186

Figure 5.47 Normal longitudinal stress distribution, $\sigma_{x}$, for a $[90 / \pm 45 / 0]_{s}$ laminated composite beam. 189

Figure 5.48 Non-dimensional normal longitudinal stress distribution, $\overline{\sigma_{x}}$, for a $[90 / \pm 45 / 0]_{s}$ laminated composite beam 190

Figure 6.1 Maximum mid-span deflections for 3, 4, 5, 6 and 7 elements 196 Figure 6.2 Dynamic magnification factors for 3,4,5,6 and 7 elements 197 Figure 6.3 Dynamic mid-span deflections a for a [0/ \pm 20$] S$ laminate under dry conditions. 203

Figure 6.4 Dynamic mid-span deflections a for a [0/90/ \pm 45$]_{T}$ laminate under dry conditions 207

Figure 6.5 Dynamic mid-span deflections a for a [0/90/ \pm 30$]_{s}$ laminate under dry conditions

Figure 6.6 Dynamic mid-span deflections a for a $[0 / \pm 20]_{s}$ laminate under dry conditions 214

Figure 6.7 Dynamic mid-span deflections a for a $[0 / 90 / \pm 45]_{T}$ laminate under dry conditions 216

Figure 6.8 Dynamic mid-span deflections a for a [0/90/ \pm 30$]_{s}$ laminate under dry conditions 218

Figure 6.9 Dynamic mid-span deflections a for a $[0 / \pm 20]_{s}$ laminate under dry conditions 221

Figure 6.10 Dynamic mid-span deflections a for a [0/90/ 445$]_{T}$ laminate under dry conditions 223

Figure 6.11 Dynamic mid-span deflections a for a [0/90/ \pm 30$]_{s}$ laminate under dry conditions 225

Figure 6.12 Dynamic mid-span deflections a for a $[0 / \pm 20]_{s}$ laminate under hygrothermal conditions 228

Figure 6.13 Dynamic mid-span deflections a for a $[0 / 90 / \pm 45]_{T}$ laminate under hygrothermal conditions 230

Figure 6.14 Dynamic mid-span deflections a for a [0/90/ \pm 30$]_{s}$ laminate under hygrothermal conditions .... 232

Figure 6.15 Dynamic mid-span deflections a for a [0/ \pm 20$]_{s}$ laminate under hygrothermal conditions 235 Figure 6.16 Dynamic mid-span deflections a for a [0/90/ \pm 45$]_{T}$ laminate under hygrothermal conditions 237 
Figure 6.17 Dynamic mid-span deflections a for a [0/90/ $\$ 30]_{s}$ laminate under hygrothermal conditions

Figure 6.18 Dynamic mid-span deflections a for a [0/ \pm 20$]_{s}$ laminate under hygrothermal conditions

Figure 6.19 Dynamic mid-span deflections a for a [0/90/ \pm 45$]_{T}$ laminate under hygrothermal conditions 244

Figure 6.20 Dynamic mid-span deflections a for a [0/90/ \pm 30$]_{s}$ laminate under hygrothermal conditions 246

Figure 6.21 Dynamic magnification factor for a $[0 / \pm 20]_{s}$ laminate 249

Figure 6.22 Dynamic magnification factor for a $[0 / 90 / \pm 45]_{T}$ laminate 250 Figure 6.23 Dynamic magnification factor for a $[0 / 90 / \pm 30]_{s}$ laminate 251

Figure 7.1 Maximum normal stress at $x=L / 4$ for 3, 4, 5, 6, and 7 elements.....256 Figure 7.2 Longitudinal stress distribution, $\sigma_{x}$, for a $[0 / \pm 20]_{s}$ composite beam .259 Figure 7.3 Transverse stress distribution, $\sigma_{y}$, for a $[0 / \pm 20]_{s}$ laminated composite beam 260

Figure 7.4 Shear stress distribution, $\tau_{x y}$, for a $[0 / \pm 20]_{s}$ laminated composite beam 260

Figure 7.5 Longitudinal stress distribution, $\sigma_{x}$, for a [0/90/ \pm 45$] T$ laminated composite beam 270

Figure 7.6 Transverse stress distribution, $\sigma_{y}$, for a [0/90/ 445$]$ T laminated composite beam 270

Figure 7. 7 Shear stress distribution, $\tau_{x y}$, for a [0/90/ \pm 45$] T$ laminated composite beam 271

Figure 7.8 Longitudinal stress distribution, $\sigma_{x}$, for a $[0 / 90 / \pm 30]_{s}$ laminated composite beam 278

Figure 7.9 Transverse stress distribution, $\sigma_{y}$, for a $[0 / 90 / \pm 30]_{s}$ laminated composite beam

Figure 7.10 Shear stress distribution, $\tau_{x y}$, for a $[0 / 90 / \pm 30]_{s}$ laminated composite beam 279 


\section{CHAPTER 1 \\ INTRODUCTION}

\subsection{Problem Statement}

The extensive use of composite materials is due to their high strength to weight ratio and the ability to tailor material and structural properties. Factors that affect the material properties and stresses on such materials are thus of high interest. These properties are affected by environmental conditions such as moisture and temperature, needing to perform analyses of composites under hygrothermal conditions.

\subsection{Composite Laminates}

Layers of fibrous composite materials can be stacked to achieve desired engineering properties such as in-plane stiffness, bending stiffness, strength and coefficient of thermal expansion as some examples that could not be achieved by the monolithic materials alone. Such assemblies are the components of a composite laminates. Composite materials are classified based on fiber geometry, namely continuous fiber, whiskers, and particulates; the classification based on matrices correspond to polymer, metal, and ceramic composites.

Layers of different materials are sometimes used and such materials are called hybrid laminates. The different laminate types are symmetric and unsymmetric, cross-ply and angle-ply, balanced and unbalanced laminates. 
Several theories are available for analyzing such complicated composite structures. Since composite laminates have larger planar dimensions than the thickness, they can be treated as plate elements and therefore plate theories are adopted. The plate theories can be systematically reduced to analyze beams made of composite materials.

\subsection{Literature Review}

Polymer matrix composite structures, when subjected to high temperature in a moist environment (hygrothermal condition), behave very differently from that of metals. There are two main effects on composite materials in a hygrothermal environment; one is the generation of residual stresses and the other is the degradation of stiffness and strength properties of the matrix.

In a study by Pipes, Vinson and Chou (1976), it is shown that when a composite laminate is exposed to high-temperature environments, which enhance moisture diffusion, there is a reduction in both strength and constitutive properties of fiber-reinforced polymeric composites. This degradation may be magnified even more by the residual stresses induced by both the hygroscopic and thermoelastic characteristics on the unidirectional composite. A unified treatment of the hygrothermal response of the laminated composite plate element is derived. The analysis develops effective moisture in-plane force resultants and bending resultants, which when coupled with mechanical and thermal loadings, yield laminate stresses resulting from the total hygrothermal and mechanical loading environment. 
Shen and Springer discuss moisture distribution and the moisture content as a function of time of homogeneous and composite materials exposed either on one side or on both sides to humid air or to water. Experiments and analysis are done for determining the values of the moisture content diffusivity of composite materials by submerging the materials in moist air, with humidity ranging from 0 to $100 \%$, and in water. The test data supported the analytical results. The ultimate tensile strengths of Thornel 30/Fiberite 1034 graphite epoxy composites are measured with material temperature ranging from $200 \mathrm{~K}$ to $422 \mathrm{~K}$ and the moisture contents from $0 \%$ (dry) to $1.5 \%$ (fully saturated). All measurements are performed using $0^{\circ}, 90^{\circ}$ and $45^{\circ}$ laminates. It is shown that the mechanical properties of composite materials might suffer when the material is exposed to high temperatures and high humidity environments. It was found that for $0^{\circ}$ and $\pi / 4$ laminates, changes in temperature in the range $200 \mathrm{~K}$ to 380 $\mathrm{K}$ appear to have negligible effect on the ultimate tensile strength of the laminate, regardless of the moisture content of the material whereas after raising to in between $380 \mathrm{~K}$ and $450 \mathrm{~K}$, there might be a slight decrease in strength. But they have a small effect on the ultimate tensile strength due to moisture content. And for $90^{\circ}$ laminates, the increase in temperature from $200 \mathrm{~K}$ to $450 \mathrm{~K}$, there is a significant decrease in ultimate tensile strength. This decrease depends on both the temperature and moisture content and may be up to 90 percent. For such laminates, the moisture content affects significantly the ultimate tensile strength.

Chamis (1983) has introduced a unified set of composite micromechanics equations that could also be used to predict moisture absorption along with other 
geometric, thermal, mechanical and hygral properties. Empirical relations between the moisture content and temperature level are also developed.

It is observed in a research by Bouadi and Sun (1989) on the hygrothermal effects on the stress field of laminated composites that some of the stress components induced by hygrothermal change are significant to cause failure of the laminate. This is done by plotting numerical results of threedimensional stress field for [90/0] laminates. A three-dimensional finite element program based on displacement field is developed for this analysis and the stress field induced by hygrothermal and/or initial strain is evaluated.

Borovkov, Avdeev and Artemyev (1999) conduct stress, vibration, and buckling analyses of laminated composite beams using the finite element method. The classical laminate plate theory (CLPT), first-order shear deformation theory (FSDT), third-order theory of Reddy (TSDT-R) and third-order theory of Kant (TSDT-K) with the use of Lanczos method are used. A higher-order hierarchical element for the calculation of the shear stress is proposed.

In a study by Sarae, et al. (2010), it is proposed that it takes decades to reach moisture steady-state equilibrium in composite laminates and thus hourly fluctuating boundary moisture and temperature conditions require several millions of time steps to reach a state of equilibrium.

Wang and Tsai (2010), develop a process to derive the dynamic distribution of moisture content in a carbon/epoxy composite laminate based on theories of thermal conduction and moisture diffusion. The results show that the moisture content in a composite laminate is low and assumed not to affect the 
thermometric conductivity. However, the local material temperature directly affects the moisture diffusivity.

Whitcomb and Tang (2002), determine the effect of fiber volume fraction on effective moisture diffusivity using the finite element method. It is also found that for low to moderate fiber fractions $\left(V_{f}<40 \%\right)$ the effective diffusivity is essentially the same for both hexagonal and square fiber arrangements. For high fiber-volume fractions $\left(\mathrm{V}_{f}>40 \%\right)$ there are significant differences. Similarly, in another paper by Todo, Nakamura and Takahashi (2000), the effect of moisture absorption inter-laminar fracture behavior of two different kinds of carbon/epoxy composites at a low impact rate of $0.9 \mathrm{~m} / \mathrm{s}$ is studied. The results show that moisture absorption has an influence on the inter-laminar fracture toughness values of the composites. The experimental results also indicate that the impact loading condition tends to decrease the inter-laminar fracture toughness values. It is of fundamental importance to develop tools that allow the designer to obtain optimal layups considering the structural requirements, functional characteristics and restrictions imposed by the production process. Tita, Carvalho, and Lirani (2003), consider the dynamic behavior of components manufactured from fiber reinforced composite materials. Some beams are made using the hand-lay-up process followed by a molding under pressure and heating. Experimental dynamic tests are carried out using specimens with different fiber orientations and stacking sequences. These experiments are used to validate the theoretical model and the results obtained from the finite element analysis. It is shown that changes in the laminate stacking sequences result in different dynamic behavior 
of the component, that is, different natural frequencies and damping factor for the same geometry, mass, and boundary conditions. This possibility makes once more these materials very attractive since it makes possible to obtain the desired natural frequencies and damping factors without increasing mass or changing geometry.

Moisture and temperature are our primary areas of focus in this study that, after a prolonged exposure to the hygrothermal environment, affect the materials properties and residual stresses. It also affects the polymer matrix composite structure. The coefficient of thermal expansion is usually higher for the matrix. Upadhyay and Lyons (2000) study the hygrothermal degradation effect on cylindrical bending of plates with large deflections. Pinned-pinned and clampedclamped laminates are considered in this study and large deflection theory is implemented to calculate the deflections and the results are compared to that of the linear theory. In-plane and uniform transverse load are applied on these laminates. Their conclusion is that the hygrothermal effect is more pronounced in the linear model than in the large-deflection model. Upadhyay, Murthy, and Lyons (1996) conclude that the load carrying capacity of a polymer matrix composite is significantly reduced due to the presence of residual stresses caused by a hygrothermal environment.

Shokrieh and Kamali (2005) study residual stresses of composites at the macroscopic and microscopic level, and it is shown that moisture and temperature are the two of the few factors responsible for the build up of residual stresses. The classical laminate plate theory (CLPT) is used for calculation of 
residual stresses in each layer of laminated composites. As long as the temperature-dependent properties are not considered, the CLPT is adequate for analyzing the residual stresses.

In a study by Upadhyay and Lyons (2000), the effect of hygrothermal residual stresses on the large deflection of plates is considered.

In another study, Shokrieh and Kamali study residual stresses of composites at a macroscopic and microscopic level, and it was shown that moisture and temperature are the two of the few factors responsible for the build up of residual stresses.

Pipes, Vinson and Chou have studied the hygrothermal response of laminated composite systems. A plate element is used to analyze the laminate stresses resulting from hygrothermal and mechanical loading. A six-ply graphite epoxy laminate is considered for the analysis of hygrothermal effects. The effective moisture bending and in plane force resultants are developed and combined with thermal loads. One of the main focuses was on the reduction in strength and constitutive properties of fiber-reinforced composites when subjected to environments that alleviate moisture diffusion at elevated temperatures. This apparent degradation in elevated temperature properties may be magnified even more by residual stresses. Results showed once again that failure of the laminate is probable due to the changes induced by hygrothermal effects. [Pipes, Vinson and Chou (1976)]

In another study by Shen and Springer, it was defined that the maximum moisture content $\left(M_{m}\right)$ of a material when exposed to humid air can be 
calculated to a high approximation by the equation

$$
M_{m}=a \phi^{b}
$$

Where $a$ and $b$ are constants

$\phi$ being the relative humidity

With this, increasing temperatures alleviate the moisture absorption as well as intensifying the residual stresses, thus temperature makes a great affect. The glass transition temperature, $T_{g}$, is defined as the temperature at which the glassy form of a polymer changes to rubbery form.

Taheri (1987) has studied the dynamic response of beams and plates subjected to moving loads. Dynamic interactions between moving vehicles and supporting guide-way systems are studied. The numerical results are verified with analytical solutions. It is noted that the deflection curve due to a moving load and a due to a static load are very different.

Kadivar and Mohebpur (1997 and 1998), use the finite element method to study the dynamic response of an asymmetric laminated composite moving beam subjected to moving loads. The moving load moves from one end to the other at different velocities. The response is compared with other numerical results from other studies. In this study, a one-dimensional finite element based on classical laminate theory first order shear deformation theory and higher-order shear deformation theory having 16, 20 and 24 degrees of freedom, respectively for an element is developed. 
Kiral, Kiral, and Baba (2004) have studied the dynamic behavior of laminated composite subjected to a single force traveling at a constant velocity. A three-dimensional model based on classical laminate theory is used and the results show that the traveling velocities and ply orientations have significant influence on the dynamic responses of composite beams.

Kavipurapu (2005) investigates the dynamic response of glass/epoxy beams subjected to moving loads under dry and wet environmental conditions using the general purpose finite element program ANSYS. The ply properties are calculated using the rule of mixtures and a parametric study is conducted by varying the fiber volume fraction and the fiber orientations of the angle plies in the laminate. The results indicate that the dynamic magnification factors generally increase due to hygrothermal effects but all the laminates considered did not behave in a similar manner. It is deduced that it is possible to minimize the environmental effect by judiciously selecting the laminate configuration.

\subsection{Need for Present Study}

In order to achieve desired performance requirements, the designer has to take into consideration the structural requirements and the functional characteristics. Structures such as towers, poles, and bridges are a few examples of their application where hygrothermal conditions greatly affect their performance. Studying the previous work done in this field, it appears that the stress distribution across the thickness of a composite beam subjected to moving loads has received little attention. The one analysis of deflection of composite 
beams under moving loads uses the general-purpose finite element program ANSYS. Setting this problem in MATLAB gives more flexibility and an opportunity to verify earlier results.

\subsection{Objectives}

The main objectives of this thesis are

- Model and analyze the effect of static and moving loads in dry and wet conditions

- Analyze the cross-sectional stresses at any cross section along the beam made of fiber reinforced composite laminates.

- MATLAB will be used extensively for simulating the effect of moving load which will be basically done on simply supported homogenous/isotropic beams as well as composite beams with varying velocities.

- Transverse deflections of the beam under different conditions, dry and wet, isotropic and non-isotropic, static and moving loads will be studied and the stresses analyzed for failure analysis.

\subsection{Thesis Overview}

The first chapter summarizes the background and the need for this study. In Chapter 2, the various theories that govern the composite behavior, composite lay-up and the theoretical study of this research are defined in accordance with the equations that shall be used for modeling and analysis.

In Chapter 3, the finite element formulation of the problem in MATLAB is 
detailed.

Chapter 4 discusses the numerical implementation with different integration scheme.

Chapter 5 presents the verification of the model by comparing with previous authors.

Chapter 6 shows the results obtained for the present study, mainly a hygrothermal analysis for a moving load for various laminate stacking sequences, namely $[0 / 20 /-20]_{\mathrm{s}},[0 / 90 / 45 /-45]_{\mathrm{T}}$ and $[0 / 90 / 30 /-30]_{\mathrm{s}}$.

Chapter 7 includes results from the present study, in the form of crosssectional stresses resulting in a failure analysis.

Finally, Chapter 8 consists of conclusions and recommendations for future work. 


\section{CHAPTER 2 \\ THEORETICAL FORMULATION}

\subsection{Introduction}

This chapter sets out the theoretical formulation for the analysis of a composite beam subjected to static and moving loads. Further, the equations that govern the response of composite materials subjected to hygrothermal conditions are discussed in this chapter along with two basic laminate theories, namely, the Classical Laminated Plate Theory (CLPT) and First-order Shear Deformation Theory (FSDT). A simply-supported beam is considered and Figure 2.1 shows such a beam under a moving load.

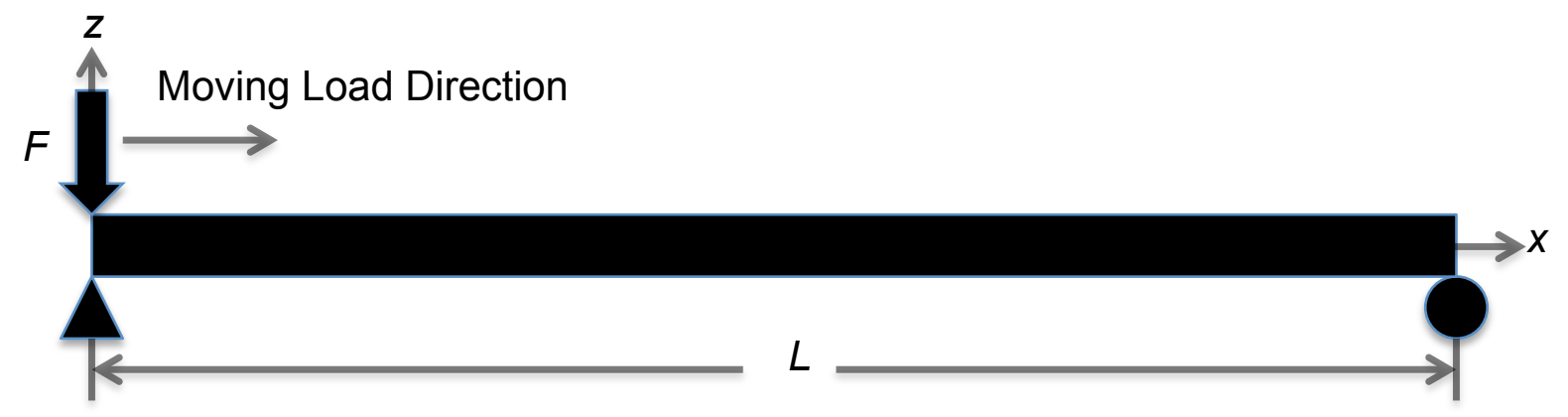

Figure 2.1 Simply-supported beam subjected to a moving load

\subsection{Composite Lay-up and Loading Configuration}

Figure 2.2 shows the geometry of a composite laminate with the different layers numbered from 1 to $N$. Since the thickness of the laminate is small compared to the in-plane dimensions of the plate, every layer is assumed to be under the state of plane stress. The $x-y$ co-ordinate plane is attached to the middle surface of the laminate with the positive $z$ axis up. The total thickness of 
the laminate is $h$. The $z$ co-ordinate of the top of the $k^{\text {th }}$ layer is denoted as $z_{k}$ while the quantity, $\overline{z_{k}}$, represents the $z$ co-ordinate of the middle surface of the $k^{\text {th }}$ layer. [Barbero (2011)]

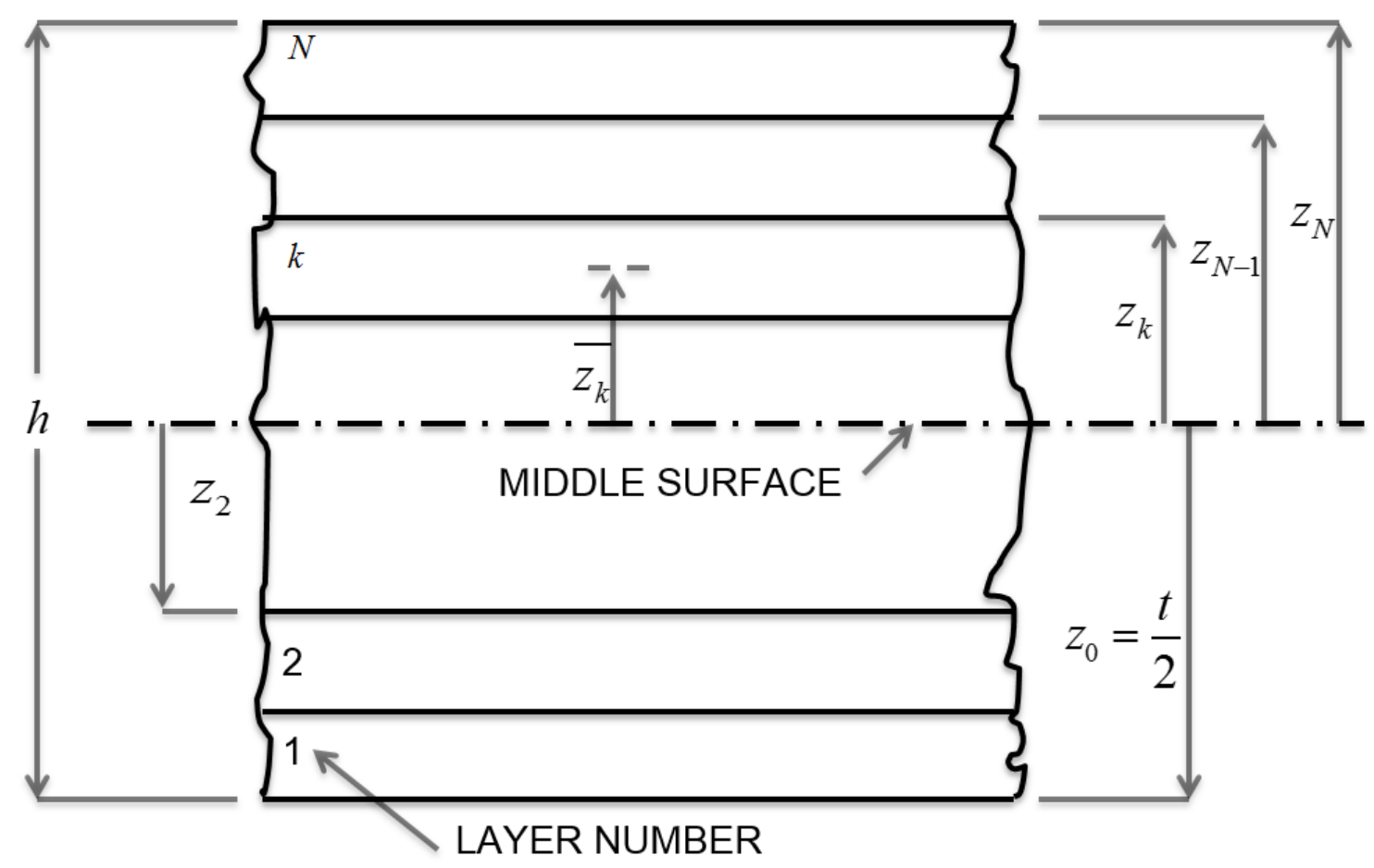

Figure 2.2 Composite lay-up configuration

Figure 2.3, shows the force and moment resultants acting on a laminate. These resultants shown in the figure are the positive quantities. The $N_{x}, N_{y}$ and $N_{x y}$ are the force resultants and $M_{x}, M_{y}, M_{x y}$ are the moment resultants with respect to the $x, y$ and $z$ axis. 


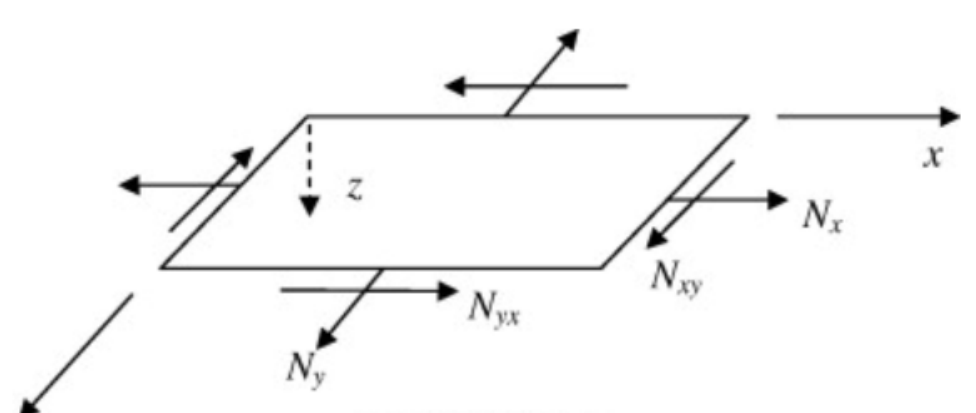

(a) In-plane loads

$y$

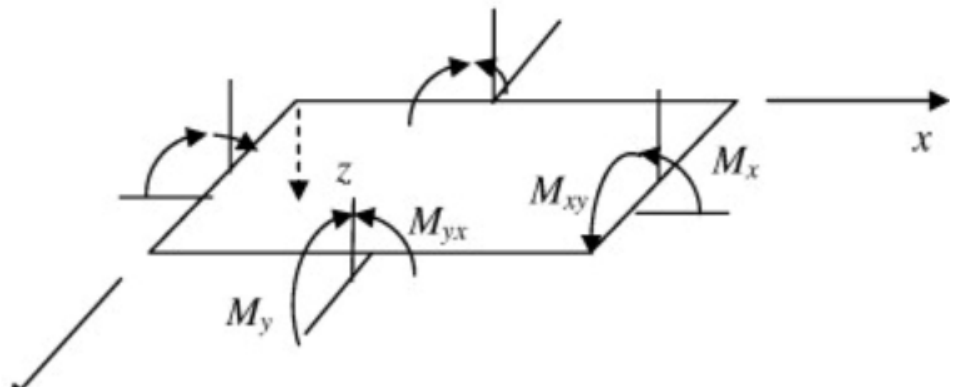

$y$

(b) Bending moments

Figure 2.3 Force and moment resultants [W.E. Haisler, (2012)]

Traditionally there are two distinct co-ordinate systems employed in association with a composite ply; these are an on-axis system consisting of $x_{1}$ and $x_{2}$ axes (with the $x_{1}$ axis aligned with the fiber) and an off-axis system consisting of $x$ and $y$ axes (Figure 2.4).

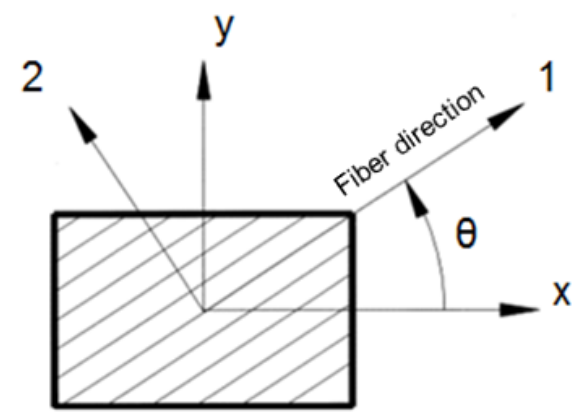

Figure 2.4 Co-ordinate systems used for a unidirectional lamina 


\subsection{Isotropic Beam Model}

The stress strain relation for a beam made of an isotropic material is given by [Chandrasekaran (2000)]

$$
\sigma_{x}=E \varepsilon_{x}
$$

where the strain in the $x$ direction is given by

$$
\varepsilon_{x}=u^{\prime}+\frac{1}{2} w^{\prime 2}-z w^{\prime \prime}
$$

The $u$ and $w$ are deflections in the $x$ and $z$ directions, respectively, and the ()' and ()" represent the first and second derivatives with respect to $x$. The variation in the strain is obtained as

$$
\delta \varepsilon_{x}=\delta u^{\prime}+w^{\prime} \delta w^{\prime}-z \delta w^{\prime \prime}
$$

The variation of strain energy is given by

$$
\delta U=\iiint_{V} \sigma_{x} \delta \varepsilon_{x}
$$

Substituting the expression for stress and variation in strain in the equation for variation of strain energy, we get

$$
\delta U=\iiint_{V} E\left(u^{\prime}+\frac{1}{2} w^{\prime 2}-z w^{\prime \prime}\right)\left(\delta u^{\prime}+w \delta w^{\prime}-z \delta w^{\prime \prime}\right) d V
$$


Expanding the terms in the integral, reducing the volume integral into three single integrals over the length, breadth and height and eliminating nonlinear and higher-order terms yields

$$
\delta u=\int_{0}^{L}\left(E A u^{\prime} \delta u^{\prime}+b N_{x} w^{\prime} \delta w^{\prime}+E I w^{\prime \prime} \delta w^{\prime \prime}\right) d x_{e}
$$

where $I$ is the moment of inertia and $A$ is the area of cross-section.

\subsection{Composite Plate Theories}

The details of the CLPT and FSDT are described in this section.

\subsubsection{Classical Laminate Plate Theory (CLPT)}

The classical laminate plate theory being the simplest one is one in which the displacement field is based on Kirchhoff hypothesis valid for thin plates with side-to-thickness ratio greater than 10 , which consists of the following assumptions.

- The transverse normals do not experience any elongation, which means they are inextensible $\left(\varepsilon_{z z}=0\right)$.

- The transverse normals rotate such that they remain perpendicular to the middle surface after deformation.

- The transverse normals, remain straight after deformation.

- The transverse strains, $\varepsilon_{x z}, \varepsilon_{y z}$ and $\varepsilon_{z z}$ are all zero.

- The strains and displacements are small with moderate rotations.

- The layers are perfectly bonded together as well as each layer is of 
uniform thickness.

- The material of each layer is linearly elastic and has two planes of materials asymmetry, i.e. Orthotropic.

- The transverse shear stresses on the top and bottom surfaces of the laminate are also zero.

The displacement equations are represented as follows Reddy (1997)

$$
\begin{aligned}
& u(x, y, z, t)=u_{0}(x, y, t)+z \phi_{x}(x, y, t) \\
& v(x, y, z, t)=v_{0}(x, y, t)+z \phi_{y}(x, y, t) \\
& w(x, y, x, t)=w_{0}(x, y, t)
\end{aligned}
$$

where the $u_{0}, v_{0}$ and $w_{0}$ represent the mid plane displacements independent of the thickness and $\phi_{x}$ and $\phi_{y}$ are the rotations about the $x$ and the $y$ axes, respectively. The rotation of the transverse normal is in such a way that the transverse normal is perpendicular to the mid-plane and hence the rotation can be represented as the rotation of $w$ with respect to the $x$ axis, which is $-\partial w_{0} / \partial x$. Similarly, the rotation of $w$ with respect to $y$ axis can be deduced as $-\partial w_{0} / \partial y$. The $w_{0}$ consists of only one component, which is the bending component since the transverse shear is not considered in the formulation of the theory. Substituting these in Eq. (2.6), the final displacements for the CLPT can be obtained as follows 


$$
\begin{aligned}
& u(x, y, z, t)=u_{0}(x, y, t)-z \frac{\partial w_{0}}{\partial x} \\
& v(x, y, z, t)=v_{0}(x, y, t)-z \frac{\partial w_{0}}{\partial x} \\
& w(x, y, z, t)=w_{0}(x, y, t)
\end{aligned}
$$

This means that once the mid-plane displacements are known, the displacements at any point $(x, y, z)$ in the 3D continuum can be determined. Figure 2.7 shows the undeformed and deformed geometries of an edge of a plate under the Kirchhoff assumption.

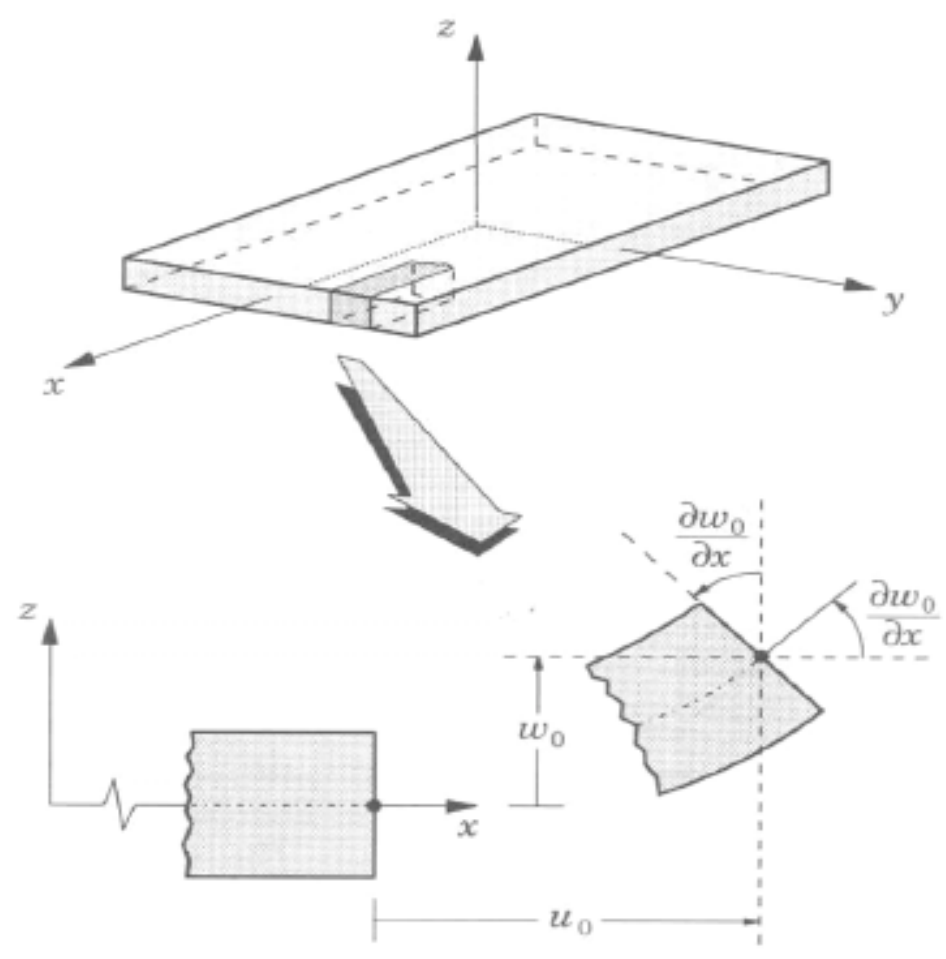

Figure 2.5 Undeformed and deformed geometries of an edge of a plate under Kirchhoff's assumption for CLPT [Reddy (1997)] 


\subsubsection{First Order Shear Deformation Theory (FSDT)}

The first order shear deformation theory, is more appropriate since the transverse shear strains may not be negligible due to the low shear modulus of composite materials. The assumptions of FSDT are the same as in that of the CLPT but for the third Kirchhoff's assumption, which states that, the transverse normal remains perpendicular to mid-plane. In FSDT, the transverse normal is no longer perpendicular to the mid-plane, thus introducing the transverse shear strain in the theory. The in-extensibility of transverse normal still keeps the $w$ independent of the thickness co-ordinate. The displacement equations can be defined in the same way as in CLPT with minor changes. The equations are as follows [Chandrasekaran (2000)]

$$
\begin{aligned}
& u(x, y, z, t)=u_{0}(x, y, t)+z \phi_{x}(x, y, t) \\
& v(x, y, z, t)=v_{0}(x, y, t)+z \phi_{y}(x, y, t) \\
& w(x, y, z, t)=w_{b}(x, y, t)+w_{s}(x, y, t)
\end{aligned}
$$

The $w$ displacement consists of two parts, the bending component $w_{b}$ and the shear component $w_{s}$. Figure 2.8 shows the undeformed and deformed geometries of an edge of a plate under the assumption of the FSDT. It can deduced from the figure that

$$
\phi_{x}=-\frac{\partial w}{\partial x}+\gamma_{x z}
$$


The $\gamma_{x z}$ component is taken to be $\partial w_{s} / \partial x$ because this is the rotation due to which the transverse normal is no longer perpendicular to mid-plane. In the case of the CLPT, the $w$ was made of only one component and it was the bending component and hence $\gamma_{x z}$ the transverse shear was taken to be zero keeping the transverse normal perpendicular to the mid-plane. But in FSDT, the $w$ is made of two parts namely the bending component $w_{b}$ and the shear component $w_{s}$ respectively. The rotation of the transverse normal, leading it to be no longer perpendicular to the mid-plane, is the rotation of the shear component with respect to the $x$ axis and can be represented as $\partial w_{s} / \partial x$. From Figure 2.8, this component is deciphered as $\gamma_{x z}$. Substituting the expression for $\gamma_{x z}$ in Equation (2.9), $\phi_{x}$ can be reduced to $\partial w_{b} / \partial x$. Similarly, $\phi_{y}$ can be reduced to $-\partial w_{s} / \partial y$. Substituting these in the displacement Equation (2.8), we get the equations final displacement equations for FSDT as [Chandrasekaran (2000)]

$$
\begin{aligned}
& u(x, y, z, t)=u_{0}(x, y, t)-z \frac{\partial w_{b}}{\partial x}(x, y, t) \\
& v(x, y, z, t)=v_{0}(x, y, t)-z \frac{\partial w_{b}}{\partial y}(x, y, t) \\
& w(x, y, z, t)=w_{b}(x, y, t)+w_{s}(x, y, t)
\end{aligned}
$$




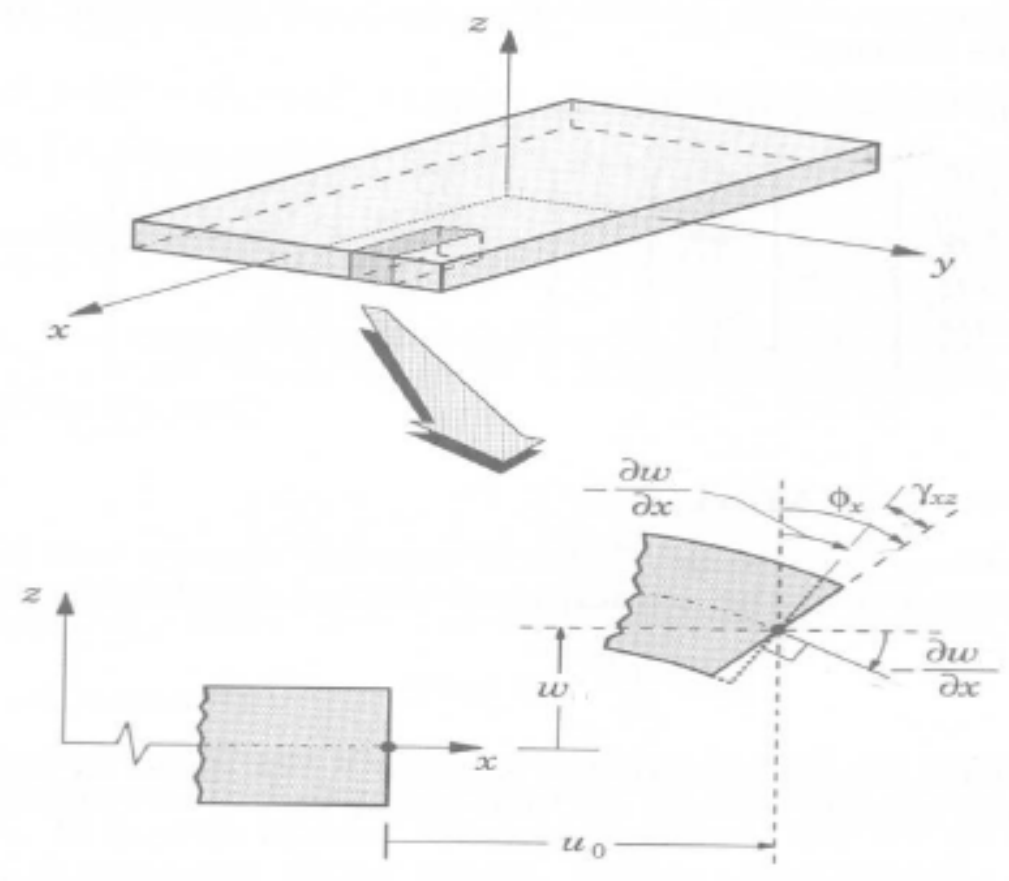

Figure 2.6 Undeformed and deformed geometries of an edge of a plate under Kirchhoff's assumption for FSDT [Reddy (1997)]

\subsection{Composite Beam Formulation [Chandrasekaran (2000)]}

Figure 2.7 shows an element of the undeformed beam of length $d x$ and in the deformed state with length $d x_{1}$. The axial and the transverse deflections are defined by $u$ and $w$ along the $x$ and $z$ axes, respectively. Two formulations using CLPT and using FSDT are considered in the present work for the composite beam. 


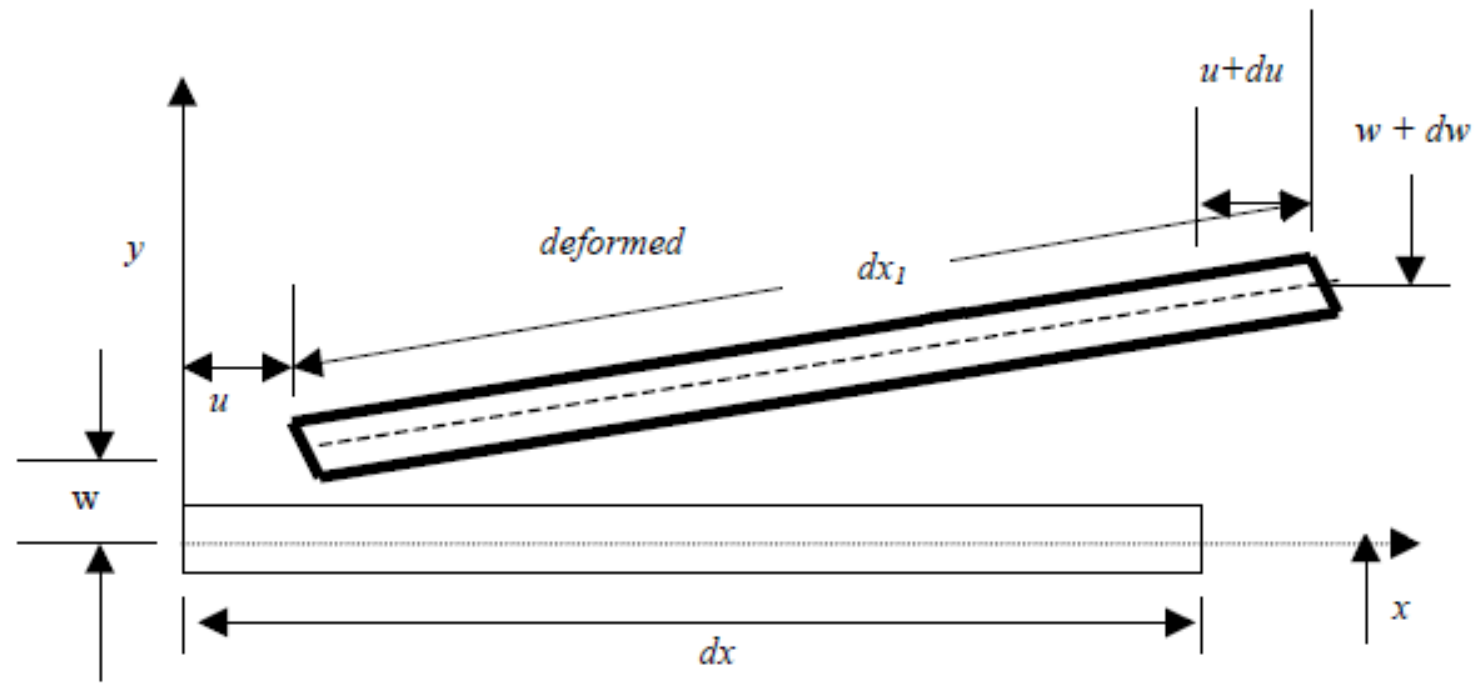

Undeformed

Figure 2.7 Undeformed and deformed beam segments [Chandrasekaran (2000)]

\subsubsection{Beam Formulation using Classical Laminate Plate Theory}

The reduction of the plate theory (CLPT) for the case of a beam can be addressed in two ways. The first method is by setting all the forces and moments other than $N_{x}$ and $M_{x}$ to be zeros and the second method is by setting only the force and moment $N_{y}$ and $M_{y}$ to be zeros, which is more practical in its approach. The following section deals with the formulation of the CLPT using the later approach. The constitutive equations are represented in matrix form as 


$$
\left[\begin{array}{l}
N_{x} \\
N_{y} \\
N_{x y} \\
M_{x} \\
M_{y} \\
M_{x y}
\end{array}\right]=\left[\begin{array}{llllll}
A_{11} & A_{12} & A_{16} & B_{11} & B_{12} & B_{16} \\
A_{12} & A_{22} & A_{26} & B_{12} & B_{22} & B_{26} \\
A_{16} & A_{26} & A_{66} & B_{16} & B_{26} & B_{66} \\
B_{11} & B_{12} & B_{16} & D_{11} & D_{12} & D_{16} \\
B_{12} & B_{22} & B_{26} & D_{12} & D_{22} & D_{26} \\
B_{16} & B_{26} & B_{66} & D_{16} & D_{26} & D_{66}
\end{array}\right]\left[\begin{array}{c}
\varepsilon_{x}^{(0)} \\
\varepsilon_{y}^{(0)} \\
\gamma_{x y}^{(0)} \\
\varepsilon_{x}^{(1)} \\
\varepsilon_{y}^{(1)} \\
\gamma_{x y}^{(1)}
\end{array}\right]
$$

where the superscript (0) represents the mid-plane strain terms while the (1) represents the curvature terms.

We also know that the variation in virtual strain energy is written

$$
\delta U=b \int_{0}^{L}\left(N_{x} \delta \varepsilon_{x}^{(0)}+M_{x} \delta \varepsilon_{x}^{(1)}+N_{y} \delta \varepsilon_{y}^{(0)}+M_{y} \delta \varepsilon_{y}^{(1)}+N_{x y} \delta \gamma_{x y}^{(0)}+M_{x y} \delta \gamma_{x y}^{(1)}\right) d x
$$

The strain components and the virtual strain components are obtained from displacement equations of CLPT, Equation (2.7) as

$$
\begin{aligned}
& \varepsilon_{x}=u_{0}^{\prime}+\frac{1}{2} w^{\prime 2}-z w^{\prime \prime}=\varepsilon_{x}^{(0)}+z \varepsilon_{x}^{(1)} \\
& \varepsilon_{y}=v_{0}^{y}+\frac{1}{2} w^{y^{2}}-z w^{y y}=\varepsilon_{y}^{(0)}+z \varepsilon_{y}^{(1)} \\
& \gamma_{x y}=u_{0}^{y}+v_{0}^{\prime}+y^{\prime} w^{y}-2 z w^{\prime y}=\gamma_{x y}^{(0)}+z \gamma_{x y}^{(1)} \\
& \varepsilon_{z}=\gamma_{y z}=\gamma_{x z}=0 \\
& \delta \varepsilon_{x}^{(0)}=\delta u_{0}^{\prime}+w \delta w^{\prime} \\
& \delta \varepsilon_{x}^{(1)}=-\delta w^{\prime \prime}
\end{aligned}
$$




$$
\begin{aligned}
& \delta \gamma_{x y}^{(0)}=\delta u_{0}^{y}=\delta \gamma_{0} \\
& \delta \gamma_{x y}^{(1)}=-2 \delta w^{\prime y}
\end{aligned}
$$

Where the ()' and () $)^{y}$ represent $\frac{\partial}{\partial x}$ and $\frac{\partial}{\partial y}$ respectively. The non-linear term in the strain $\gamma_{x y}$ is neglected.

The reduction of plate theory to beam theory formulation using CLPT is approached by forcing only the force and moment terms $N_{y}$ and $M_{y}$ to zero. Substituting this condition in the constitutive Eq. (2.11), and rearranging yields

$$
\left[\begin{array}{c}
N_{x} \\
N_{y} \\
N_{x y} \\
M_{x} \\
M_{y} \\
M_{x y}
\end{array}\right]=\left[\begin{array}{cccc:cc}
A_{11} & A_{12} & A_{16} & B_{11} & B_{12} & B_{16} \\
A_{12} & A_{22} & A_{26} & B_{12} & B_{22} & B_{26} \\
A_{16} & A_{26} & A_{66} & B_{16} & B_{26} & B_{66} \\
B_{11} & B_{12} & B_{16} & D_{11} & D_{12} & D_{16} \\
\hdashline B_{12} & B_{22} & B_{26} & D_{12} & D_{22} & D_{26} \\
B_{16} & B_{26} & B_{66} & D_{16} & D_{26} & D_{66}
\end{array}\right]\left[\begin{array}{c}
\varepsilon_{x}^{(0)} \\
\varepsilon_{y}^{(0)} \\
\gamma_{x y}^{(0)} \\
\varepsilon_{x}^{(1)} \\
\varepsilon_{y}^{(1)} \\
\gamma_{x y}^{(1)}
\end{array}\right]
$$

The four partitions of the matrix are represented as $\left[S^{11}\right\rfloor,\left[S^{21}\right\rfloor,\left\lfloor S^{12}\right\rfloor$, and $\left\lfloor S^{22}\right\rfloor$ respectively as 


$$
\left\{\begin{array}{l}
N_{x} \\
N_{x y} \\
M_{x} \\
M_{x y} \\
0 \\
0
\end{array}\right\}=\left[\begin{array}{ll}
S^{11} & S^{12} \\
S^{21} & S^{22}
\end{array}\right]\left\{\begin{array}{l}
\varepsilon_{x}^{(0)} \\
\gamma_{x y}^{(0)} \\
\varepsilon_{x}^{(1)} \\
\gamma_{x y}^{(1)} \\
\varepsilon_{y}^{(0)} \\
\varepsilon_{y}^{(1)}
\end{array}\right\}
$$

The top part of the Eq. (2.15) yields

$$
\left\lfloor\begin{array}{llll}
N_{x} & N_{x y} & M_{x} & M_{x y}
\end{array}\right]^{T}=[S]\left[\begin{array}{llll}
\varepsilon_{x}^{(0)} & \gamma_{x y}^{(0)} & \varepsilon_{x}^{(1)} & \gamma_{x y}^{(1)}
\end{array}\right]^{T}
$$

where

$$
\begin{aligned}
& \left.\left.[S]=\llbracket S^{11}\right]-\left[S^{12}\right] S^{22}\right]^{-1}\left[S^{21}\right] \\
& {\left[S^{21}\right]=\left[S^{12}\right]^{T}}
\end{aligned}
$$

Substituting Equation (2.12) in the virtual strain energy in Equation (2.13), we get

$$
\delta U=b \int_{0}^{L}\left(N_{x} \delta \varepsilon_{x}^{(0)}+N_{x y} \delta \gamma_{x y}^{(0)}+M_{x} \delta \varepsilon_{x}^{(1)}+M_{x y} \delta \gamma_{x y}^{(1)}\right) d x
$$

Substituting the strain-displacement relations, Equation (2.13), into Equation (2.17), we get the expression for variation in virtual strain energy for beam theory using CLPT as

$$
\delta U=b \int_{0}^{1}\left(N_{x}\left(\delta u_{0}^{\prime}+w^{\prime} \delta w^{\prime}\right)+N_{x y} \delta \gamma_{0}-M_{x} \delta w^{\prime \prime}-2 M_{x y} \delta w_{y}^{\prime}\right) d x
$$




\subsubsection{Beam Formulation using First Order Shear Deformation Theory}

The reduction of the first-order shear deformation composite laminate plate theory for beams is outlined in this section. First the strain components are obtained from the displacement relations by appropriate partial differentiation [Equation (2.10)]; then the virtual strain components are found by taking variations of the strains.

$$
\begin{aligned}
& \varepsilon_{x}=u_{0}^{\prime}+\frac{1}{2}\left(w_{b}^{\prime 2}+w_{s}^{\prime 2}+2 w_{/}^{\prime} / w_{s}^{\prime}\right)+z w_{b}^{\prime \prime}=\varepsilon_{x}^{(0)}+z \varepsilon_{x}^{(1)} \\
& \varepsilon_{y}=v_{0}^{y}+\frac{1}{2}\left(w_{b}^{y^{2}}+w_{s}^{y^{2}}+2 w / \frac{7}{w_{s}^{y}}\right)-z w_{b}^{\prime \prime}=\varepsilon_{y}^{(0)} \quad z \varepsilon_{y}^{(1)} \\
& \gamma_{x y}=u_{0}^{y}+v_{0}^{\prime}-2 z w_{b}^{\prime y}=\gamma_{x y}^{(0)}+z \gamma_{z y}^{(1)} \\
& \gamma_{x z}=\not y_{b}+w_{s}^{\prime}-\not y_{b}^{\lambda}=w_{s}^{\prime}=\gamma_{x z}^{(0)} \\
& \gamma_{y z}=y_{b} y_{t}+w_{s}^{y}-\not y_{b}^{\lambda}=w_{s}^{y}=\gamma_{y z}^{(0)} \\
& \delta \varepsilon_{x}^{(0)}=\delta u_{0}^{\prime}+w_{b}^{\prime} \delta w_{b}^{\prime}+w_{s}^{\prime} \delta w_{s}^{\prime} \\
& \delta \varepsilon_{x}^{(1)}=-\delta w_{b}^{\prime \prime} \\
& \delta \gamma_{x y}^{(0)}=\delta \gamma_{0} \\
& \delta \gamma_{x y}^{(1)}=-2 \delta w_{b}^{y^{\prime}}
\end{aligned}
$$




$$
\delta \gamma_{x z}^{(0)}=\delta w^{s^{\prime}}
$$

where the ()' and () $)^{y}$ represent $\frac{\partial}{\partial x}$ and $\frac{\partial}{\partial y}$ respectively. The nonlinear term in the strain $\gamma_{x y}$ is neglected. The constitutive equations for FSDT are made of two parts namely in-plane equations and inter-laminar equations. The in-plane equations are the same as in Equation (2.11). The inter-laminar equations are represented as follows:

$$
\left\{\begin{array}{l}
Q_{y} \\
Q_{x}
\end{array}\right\}=\left[\begin{array}{ll}
A_{44} & A_{45} \\
A_{45} & A_{55}
\end{array}\right]\left\{\begin{array}{l}
\gamma_{y z} \\
\gamma_{x z}
\end{array}\right\}
$$

The $2 \times 2$ matrix is the inter-laminar shear co-efficient matrix and the terms are given by

$$
\left[\begin{array}{ll}
A_{44} & A_{45} \\
A_{45} & A_{55}
\end{array}\right]=\sum_{k=1}^{N}\left(\bar{Q}_{i j}\right)_{k} t_{k} \quad i, j=4,5
$$

Reduction to beam case is realized for the FSDT by forcing the force, moment, and the shear resultants, $N_{y}, M_{y}$ and $Q_{y}$ to zero. The constitutive equations reduces to 


$$
\left\{\begin{array}{l}
N_{x} \\
N_{x y} \\
M_{x} \\
M_{x y} \\
0 \\
0
\end{array}\right\}=\left[\begin{array}{cccc:cc}
A_{11} & A_{16} & B_{11} & B_{16} & A_{12} & B_{12} \\
A_{16} & A_{66} & B_{16} & B_{66} & A_{26} & B_{26} \\
B_{11} & B_{16} & D_{11} & D_{16} & B_{12} & D_{12} \\
B_{16} & B_{66} & D_{16} & D_{66} & B_{26} & D_{12} \\
\hdashline A_{12} & A_{26} & B_{12} & B_{26} & A_{22} & B_{22} \\
B_{12} & B_{26} & D_{12} & D_{26} & B_{22} & D_{22}
\end{array}\right]\left[\begin{array}{l}
\varepsilon_{x}^{(0)} \\
\gamma_{x y}^{(0)} \\
\varepsilon_{x}^{(1)} \\
\gamma_{x y}^{(1)} \\
\varepsilon_{y}^{(0)} \\
\varepsilon_{y}^{(1)}
\end{array}\right\}
$$

and

$$
\left\{\begin{array}{l}
0 \\
Q_{x}
\end{array}\right\}=K\left[\begin{array}{ll}
A_{44} & A_{45} \\
A_{45} & A_{55}
\end{array}\right]\left\{\begin{array}{l}
\gamma_{y z} \\
\gamma_{x z}
\end{array}\right\}
$$

The first equation of Equation (2.22) can be reduced to four matrices very similar to that in the beam formulation using CLPT and hence would be represented by the same symbol $[S]$ and is given by the Equation (2.16). The second equation is manipulated to eliminate $\gamma_{y z}$ and write the equations in terms of $\gamma_{x z}$. The second equation of Eq. (2.22) reduces to

$$
Q_{x}=K A^{*} \gamma_{x z}
$$

where $\quad A^{*}=K\left(A_{55}-A_{45}{ }^{2} / A_{44}\right)$ and $K$ is the shear correction factor.

Since the transverse shear strains are represented as a constant through the laminate thickness, it follows that the transverse shear stresses will also be constant. It is well known from elementary theory of homogeneous beams that the transverse shear stress varies parabolically through the thickness of the beam. In composite laminated beams and plates, the transverse shear stresses varies at least quadratically through the thickness of the layer. This discrepancy 
between the actual stress state and the constant stress state predicted by FSDT is often corrected in computing the transverse shear force resultants, i.e. the LHS of Equation (2.23) by multiplying the shear co-efficient matrix by a parameter $K$ which is the shear correction co-efficient. The factor $K$ is computed such that the strain energy due to transverse shear stresses equals the strain energy due to the true transverse stresses predicted by three-dimensional elasticity theory and the value for a rectangular cross section is taken to be $5 / 6$.

The expression for variation in strain energy including the transverse shear terms is

$$
\delta U=\int_{0}^{1}\left(N_{x} \delta \varepsilon_{x}^{(0)}+M_{x} \delta \varepsilon_{x}^{(1)}+N_{y} \delta \varepsilon_{y}^{(0)}+M_{y} \delta \varepsilon_{y}^{(1)}+N_{x y} \delta \gamma_{x y}^{(0)}+M_{x y} \delta \gamma_{x y}^{(1)}+Q_{x} \delta \gamma_{x z}^{(0)}+Q_{y} \delta \gamma_{(\mathbf{2}}^{(0)} \mathbf{2}\right) d x
$$

Substituting Equation (2.22) and Equation (2.23) in the expression for strain energy variation in Equation (2.24), the expression for strain energy variation using FSDT is obtained as

$$
\delta U=\int_{0}^{1}\left(N_{x} \delta \varepsilon_{x}^{(0)}+M_{x} \delta \varepsilon_{x}^{(1)}+N_{x y} \delta \gamma_{x y}^{(0)}+M_{x y} \delta \gamma_{x y}^{(1)}+\quad Q_{x} \delta \gamma_{x z}^{(0)}\right) d x
$$

\subsection{Kinetic Energy Formulation for Composite Beams [Chandrasekaran (2000)]}

The formulation of variation in kinetic energy is outlined in this section. The virtual kinetic energy, $\delta T$, is given by 


$$
\delta T=\iiint_{V} \rho[\dot{u} \delta \dot{u}+\dot{v} \delta \dot{v}+\dot{w} \delta \dot{w}] d V
$$

where $\rho$ is the mass density and $\left({ }^{\circ}\right)$ represents partial derivative with respect to time.

\subsubsection{Kinetic Energy Formulation for Isotropic case}

The variation in kinetic energy is given by Equation (2.26). Since we do not have a separate degree of freedom for $v$, it is dropped from Equation (2.26) to yield

$$
\delta T=\iiint_{V} \rho[\dot{u} \delta \dot{u}+\dot{w} \delta \dot{w}] d V
$$

When $\delta T$ is introduced into Hamilton's principle, we encounter the time integral

$$
\int_{t_{1}}^{t_{2}} \delta T d t=\int_{t_{1}}^{t_{2}} d t \iiint_{V} \rho[\dot{u} \delta \dot{u}+\dot{w} \delta \dot{w}] d V
$$

Integrating the resultant equation by parts with respect to time and grouping all the time boundary terms together results in

$$
-\int_{t}^{t_{2}} \delta T d t=\iiint_{V} \rho \int_{t_{1}}^{t_{2}}\left\{[\ddot{u} \delta u+\ddot{w} \delta w] d t+\left.(\cdots)\right|_{t_{1}} ^{t_{2}}\right\} d V
$$

Discarding the boundary terms which do not contribute the inertia matrix and pulling out the virtual quantities out of the integral owing to their independence of time derivative, yields 


$$
-\delta T=\iiint_{V} \rho[\ddot{u} \delta u+\ddot{w} \delta w] d V
$$

Defining $I_{0}$ keeping the beam width, $b$, as a constant, and reducing the volume integral yields the expression for variation in kinetic energy as

$$
\begin{aligned}
& I_{0}=\int_{-h / 2}^{h / 2} \rho d z \\
& -\delta T=b \int_{0}^{1} I_{0}[\ddot{u} \delta u+\ddot{w} \delta w] d x
\end{aligned}
$$

\subsubsection{Kinetic Energy Formulation for Beam Theory using CLPT}

The variation in kinetic energy for beam theory formulation using CLPT is shown in Equation (2.26). The variation in kinetic energy can be written in terms of the mid-plane displacements from Equation (2.13) as

$$
\delta T=\iiint_{V} \rho\left[\left(\dot{u}_{0}-z \dot{w}^{\prime}\right)\left(\delta \dot{u}_{0}-z \delta \dot{w}^{\prime}\right)+\left(\dot{v}_{0}-z \dot{w}^{y}\right)\left(\delta \dot{v}_{0}-z \delta w^{y}\right)+\dot{w} \delta \dot{w}\right] d V
$$

Expanding the above equation gives

$$
\delta T=\iiint_{V}\left(\begin{array}{cccc}
\rho \dot{u}_{0} \delta \dot{u}_{0}- & z \dot{u}_{0} \delta \dot{w}^{\prime}- & z \dot{w}^{\prime} \delta \dot{u}_{0}+ & z^{2} \dot{w}^{\prime} \delta \dot{w}^{\prime}+\dot{v}_{0} \delta \dot{v}_{0} \\
-z \dot{y}_{0} \delta \dot{w}^{y}- & z \dot{w}^{y} \delta \dot{v}_{0}+ & z^{2} \dot{w}^{y} \delta w^{y}+ & \dot{w} \delta \dot{w}
\end{array}\right) d V
$$

Integrating the resultant equation by parts with respect to time and grouping all the time boundary terms together results in 
$-\int_{t_{1}}^{t_{2}} \delta T d t=\iiint_{V} \rho \int_{t_{1}}^{t_{2}}\left\{\left[\ddot{u}_{0} \delta u_{0}-z \ddot{u}_{0} \delta w^{\prime}+z^{2} \ddot{w} \delta w^{\prime}-z \ddot{w} \delta u_{0}+z^{2} \ddot{w}^{y} \delta w^{y}+\ddot{w} \delta w\right] d t+\left.(\cdots)\right|_{t_{1}} ^{t_{2}}\right\} d V$

Discarding the boundary terms which do not contribute to the inertia matrix and pulling out the virtual quantities out of the time integral owing to their independence of time derivative, yields

$-\delta T=\iiint_{V} \rho\left[\ddot{u}_{0} \delta u_{0}-z \ddot{u}_{0} \delta w^{\prime}+z^{2} \ddot{w}^{\prime} \delta w^{\prime}-z \ddot{w}^{\prime} \delta u_{0}+z^{2} \ddot{w}^{y} \delta w^{y}+\ddot{w} \delta w\right] d V$

Splitting the volume integral into integrals over the thickness, length and width; treating the width as a constant, and writing the above equation in terms of $I_{0}, I_{1}$ and $I_{2}$ results in the equation for variation in kinetic energy for beams based on CLPT.

$-\delta T=b \int_{0}^{1}\left(I_{0} \ddot{u}_{0} \delta u_{0}-I_{1} \ddot{u}_{0} \delta w^{\prime}+I_{2} \ddot{w}^{\prime} \delta w^{\prime}-I_{1} \ddot{w}^{\prime} \delta u_{0}+I_{2} \ddot{w}^{y} \delta w^{y}+I_{0} \ddot{w} \delta w\right) d x$

where $I_{0}, I_{1}$ and $I_{2}$ are defined as

$$
\begin{aligned}
& I_{0}=\int_{=h / 2}^{h / 2} \rho d z \\
& I_{1}=\int_{-h / 2}^{h / 2} \rho z d z
\end{aligned}
$$




$$
I_{2}=\int_{-h / 2}^{h / 2} \rho z^{2} d z
$$

\subsubsection{Kinetic Energy Formulation for Beam Theory using FSDT}

The kinetic energy formulation for the beam theory using FSDT is derived using the same approach detailed above using CLPT. The variation in the kinetic energy can be written in terms of the mid-plane displacements from Equation (2.14) as

$$
\delta T=\iiint_{V} \rho\left[\left(\dot{u}_{0}-z \dot{w}_{b}\right)\left(\delta \dot{u}_{0}^{\prime}-z \delta \dot{w}_{b}^{\prime}\right)+\left(\dot{v}_{0}-z \dot{w}_{b}^{y}\right)\left(\delta \dot{v}_{0}-z \delta \dot{w}_{b}^{y}\right)+\left(\dot{w}_{b}+\dot{w}_{s}\right)\left(\delta \dot{w}_{b}+\delta \dot{w}_{s}\right)\right] d V
$$

Expanding the terms inside the integral yields

$$
\delta T=\iiint_{V} \rho\left(\begin{array}{l}
\dot{u}_{0} \delta \dot{u}_{0}-z \dot{u}_{0} \delta \dot{w}_{b}^{\prime}-z \dot{w}_{b}^{\prime} \delta \dot{u}_{0}+z^{2} \dot{w}_{b} \delta \dot{w}_{b}^{\prime}+\dot{y} \delta \dot{v}_{0}-z \dot{v}_{\gamma} \delta \dot{w}_{b}^{y} \\
-z \dot{y}_{b}^{y} \delta \dot{v}_{0}+z^{2} \dot{w}_{b}^{y} \delta \dot{w}_{b}^{y}+\dot{w}_{b} \delta \dot{w}_{b}+\dot{w}_{b} \delta w_{s}+\dot{w}_{s} \delta \dot{w}_{b}+\dot{w}_{s} \delta \dot{w}_{s}
\end{array}\right) d V
$$

Eliminating the crossed-out terms reduces the problem to one-dimensional nature. Integrating the resultant equation by parts with respect to time and grouping all the time boundary terms together results in

$$
\left.-\int_{t_{1}}^{t_{2}} \delta T d t=\iiint_{V} \rho\left[\begin{array}{l}
\ddot{u}_{0} \delta u_{0}-z \ddot{u}_{0} \delta w_{b}^{\prime}-z \ddot{w}_{b} \delta u_{0}+z^{2} \ddot{w}_{b}^{\prime} \delta w_{b}^{\prime}+z^{2} \ddot{w}_{b}^{y} \delta w_{b}^{y} \\
+\ddot{w}_{b} \delta w_{b}+\ddot{w}_{b} \delta w_{s}+\ddot{w}_{s} \delta w_{b}+\ddot{w}_{s} \delta w_{s}
\end{array}\right)-\left.(\cdots)\right|_{t_{1}} ^{t_{2}}\right] d V
$$


Discarding the boundary terms which do not contribute to the inertia matrix and pulling out the virtual quantities out of the time integral owing to their independence of time derivative, yields

$$
-\delta T=\iiint_{V}\left(\begin{array}{l}
\ddot{u}_{0} \delta u_{0}-z \ddot{u}_{0} \delta w_{b}^{\prime}-z \ddot{w}_{b}^{\prime} \delta u_{0}+z^{2} \ddot{w}_{b}^{\prime} \delta w_{b}^{\prime}+z^{2} \ddot{w}_{b}^{y} \\
+\ddot{w}_{b} \delta w_{b}+\ddot{w}_{b} \delta w_{s}+\ddot{w}_{s} \delta w_{b}+\ddot{w}_{s} \delta w_{s}
\end{array}\right) d V
$$

Splitting the integral into two single integrals over the thickness and length, treating the width as a constant, and writing the above equation in terms of $I_{0}, I_{1}$ and $I_{2}$ results in

$$
-\delta T=b \int_{0}^{1}\left(\begin{array}{l}
I_{0} \ddot{u}_{0} \delta u_{0}-I_{1} \ddot{u}_{0} \delta w_{b}^{\prime}-I_{1} \ddot{w}_{b}^{\prime} \delta u_{0}+I_{2} \ddot{w}_{b}^{\prime} \delta w_{b}^{\prime}+I_{2} \ddot{w}_{b}^{y} \delta w_{b}^{y} \\
+I_{0} \ddot{w}_{b} \delta w_{b}+I_{0} \ddot{w}_{b} \delta w_{s}+I_{0} \ddot{w}_{s} \delta w_{b}+I_{0} \ddot{w}_{s} \delta w_{s}
\end{array}\right) d x
$$

where $I_{0}, I_{1}$ and $I_{2}$ have been defined in Equation (2.38).

\subsection{Hygrothermal Analysis}

Moisture and temperature are our primary areas of focus in this study; after a prolonged exposure to a hygrothermal environment, the materials properties are degraded and residual stresses are introduced. The coefficient of thermal expansion is usually higher for the matrix. The matrix absorbs moisture readily whereas fibers are hardly affected by a wet environment. This absorption is accelerated with increasing temperature. With increasing temperature or humidity level (or both), the matrix expands; with lower temperature or humidity level, the matrix contracts. A comparable phenomenon takes place at the 
laminate level due to the anisotropic nature of the laminate coefficient of thermal expansion and coefficient of hygroscopic expansion. The load carrying capacity of a polymer matrix composite is reduced due to such residual stresses.

A hygrothermal environment degrades both the stiffness and strength values of the matrix of the lamina while the fiber is not affected. Chamis (1983), gives the relationship between wet and dry resin mechanical properties of a matrix as

$$
\begin{aligned}
& \frac{P_{H T M}}{P_{0}}=\left[\frac{T_{g w r}-T}{T_{g d r}-T_{0}}\right]^{\frac{1}{2}} \\
& T_{g w r}=\left(0.005 m^{2}-0.1 m+1\right) T_{g d r}
\end{aligned}
$$

where $\quad T$ is the temperature of measurement of the property

$T_{0}$ is the dry temperature

$P$ is property to be measured

$H T M$ is the Hygrothermal Mechanical

$T_{g d r}$ and $T_{g w r}$ are the glass transition temperature of dry resin and wet resin

$m$ is the moisture content (by weight percent, $m \leq 10 \%$ )

\subsubsection{Rule of Mixtures and Inverse Rule of Mixtures}

Elastic constants of a composite ply can be calculated by the rule of mixtures and the inverse rule of mixtures [Barbero (1999)]. These formulas are outlined below 


$$
\begin{aligned}
& E_{1}=E_{f} V_{f}+E_{m} V_{m} \\
& E_{2}=\frac{E_{m} E_{f}}{E_{f} V_{f}+E_{m} V_{m}} \\
& G_{12}=\frac{G_{m}}{V_{m}+G_{m} V_{f} / G_{f}} \\
& v_{12}=v_{f} V_{f}+v_{m} V_{m} \\
& \rho=\rho_{f} V_{f}+\rho_{m} V_{m}
\end{aligned}
$$

where $E_{1}=$ the longitudinal modulus of elasticity

$E_{2}=$ the transverse modulus of elasticity

$E_{f}$ and $E_{m}=$ the modulus of elasticity of fiber and matrix, respectively

$V_{f}$ and $V_{m}=$ the volume fraction of fiber and matrix, respectively

$G_{12}=$ the longitudinal shear modulus

$G_{f}$ and $G_{m}=$ the In-plane shear modulus of fiber and matrix, respectively

$v_{12}$ is the major In-plane Poisson's ratio

$v_{f}$ and $v_{m}$ are Poisson's ratio of fiber and matrix, respectively

$\rho$ is the density of the composite ply

$\rho_{f}$ and $\rho_{m}$ are the densities of fiber and matrix, respectively 


\subsubsection{Halpin-Tsai Formula}

Another way of calculating the elastic constant, $E_{2}$, is by a semi-empirical formula called Halpin-Tsai formula. This gives a better prediction and is as follows. [Barbero (1999)]

$$
\begin{gathered}
E_{2}=E_{m}\left[\frac{1+\zeta \eta V_{f}}{1-\eta V_{f}}\right] \\
\eta=\left[\frac{\left(\frac{E_{f}}{E_{m}}\right)-1}{\left(\frac{E_{f}}{E_{m}}\right)+\zeta}\right]
\end{gathered}
$$

where $\xi=2$ for circular and square fibers

\subsubsection{Periodic Microstructure Model (PMM)}

The inverse rule of mixtures gives a simple and not as accurate of a prediction for the in-plane shear modulus, $G_{12}$; an improved prediction is realized by employing the periodic microstructure model [Barbero (1999)]:

$$
\begin{aligned}
& G_{12}=G_{m}\left[1+\frac{V_{f}\left(1-G_{m} / G_{f}\right)}{\left(G_{m} / G_{f}\right)+S_{3}\left(1-G_{m} / G_{f}\right)}\right] \\
& S_{3}=0.49247-0.47603 V_{f}-0.02748 V_{f}^{2}
\end{aligned}
$$




\subsection{Failure Analysis}

Since this study focuses on both the hygrothermal and the stress analysis for a composite beam, the theory that is used for prediction of failure is the maximum normal stress criterion. [Babero (1999)]. This theory predicts failure of

a layer when at least one of the stresses exceeds the corresponding value of strength; that is, failure occurs if any of the stresses in material co-ordinates exceeds the corresponding ultimate values of strength:

$$
\begin{array}{lll}
\sigma_{1}>F_{1 t} & \text { when } & \sigma_{1}>0 \\
\operatorname{abs}\left(\sigma_{1}\right)>F_{1 c} & \text { when } & \sigma_{1}<0 \\
\sigma_{2}>F_{2 t} & \text { when } & \sigma_{2}>0 \\
\operatorname{abs}\left(\sigma_{2}\right)>F_{2 c} & \text { when } & \sigma_{2}<0 \\
& & \\
\operatorname{abs}\left(\sigma_{4}\right)>F_{4} & & \\
a b s\left(\sigma_{5}\right)>F_{5} & & \\
& & \\
a b s\left(\sigma_{6}\right)>F_{6} & &
\end{array}
$$

where $F_{1 t}=$ Tensile strength in longitudinal fiber direction

$F_{1 c}=$ Compressive strength in longitudinal fiber direction

$F_{2 t}=$ Tensile strength in transverse fiber direction

$F_{2 c}=$ Compressive strength in transverse fiber direction 


$$
\begin{aligned}
& F_{4}=\text { Interlaminar shear strength } \\
& F_{5}=\text { Interlaminar shear strength } \\
& F_{6}=\text { Inplane shear strength }
\end{aligned}
$$

The compressive strength values are taken as positive numbers. The factor of safety, $n$, is calculated as

$$
\text { Factor Of Safety }=\frac{\sigma_{\text {ultimate }}}{\sigma_{\text {allowable }}}
$$

The various factors of safety, $n_{i}$, are

$$
\begin{aligned}
& n_{1 t}=\frac{F_{1 t}}{\sigma_{1}(\max +v e)} \\
& n_{1 c}=\frac{F_{1 c}}{\sigma_{1}(\max -v e)} \\
& n_{2 t}=\frac{F_{2 t}}{\sigma_{2}(\max +v e)} \\
& n_{2 c}=\frac{F_{2 c}}{\sigma_{2}(\max -v e)} \\
& n_{6}=\frac{F_{6}}{\sigma_{6}}
\end{aligned}
$$




\section{CHAPTER 3 \\ FINITE ELEMENT FORMULATION}

\subsection{Introduction}

The numerical modeling of the moving load problem is carried out with the aid of a higher-order finite element method. Steps are outlined for determining not only the traditional output of the displacement field in moving beam formulations but also the stress fields.

\subsection{Finite Element Methods}

Three types of finite element methods are found in the literature, namely, $h-, p$ - and $h-p$ versions. In the $h$ - version on the accuracy of the results is improved by increasing the number of elements that are used to discretize the domain. The route for better accuracy in the $p$-version is by increasing the order of the shape function utilized for discretization; this means the introduction of internal nodes in the element. The $h-p$ version is a combination of the two wherein both the number of elements in the model and the number of internal nodes are increased in a judicious way. In this research, the $h-p$ version is employed. The shape functions are derived using Lagrange and Hermite polynomials depending on the type of the problem variable. In the past, Sreeram and Sivaneri (1997) have conducted a convergence study and concluded that a beam element with three internal nodes is sufficient for the dynamic analysis of beams. Taking their conclusions into consideration, in the present finite element 
model, beam elements with three internal nodes will be employed. Lagrangian interpolation functions are used where a $C^{0}$ continuity is required and Hermitian interpolation functions are used where a $C^{1}$ continuity, i.e., slope continuity is required at element junctions. Figure 3.1 shows the basic finite element that is used for the isotropic beam model employed for verification of results. An exploded view of a single element of the beam along with the end and internal nodes and the co-ordinates attached to the element are shown.

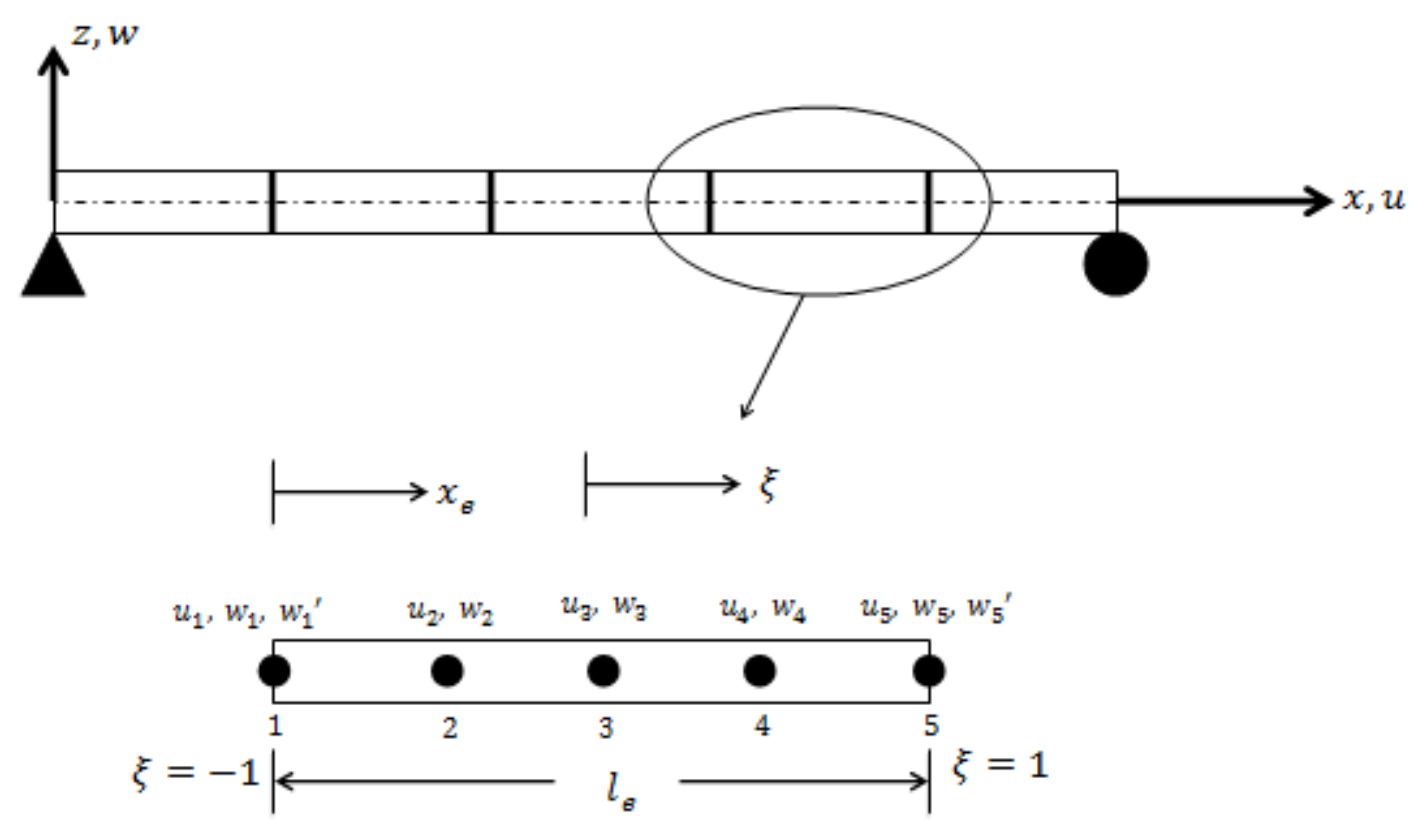

Figure 3.1 Typical finite element with three internal nodes and two end nodes

The local co-ordinate $x_{e}$ is fixed to the left end of the element and ranges from 0 to $l_{e}$, where $l_{e}$ is the length of the element. The non-dimensional coordinate $\xi$ is fixed to the midpoint of the element, i.e., at node 3 and it ranges 
from -1 to +1 . The co-ordinate transformation between the two co-ordinates is given by:

$$
\begin{aligned}
& x_{e}=\frac{l_{e}}{2}(\xi+1) \\
& d x_{e}=\frac{l_{e}}{2} d \xi
\end{aligned}
$$

The distribution $w(\xi)$ for the transverse degrees of freedom is assumed as

$$
w(\xi)=\sum_{i=0}^{6} a_{i} \xi^{i}
$$

The distribution $u(\xi)$ for the axial degrees of freedom is expressed as

$$
u(\xi)=\sum_{j=0}^{4} b_{i} \xi^{j}
$$

where $a_{i}$ and $b_{j}$ are generalized co-ordinates that are to be determined. In general, these equations can be written in matrix notations as

$$
\begin{aligned}
& w(\xi)=\left\lfloor\xi^{i}\right]\left\{a_{i}\right\} \\
& u(\xi)=\left\lfloor\xi^{j}\right\rfloor\left\{b_{j}\right\}
\end{aligned}
$$

To solve for $a_{i}$ and $b_{j}$, seven and five equations are needed respectively. To solve for the $a_{i}$, the transverse degree of freedom and its slope, i.e. $w$ and $w$ ' at the end nodes yields 


$$
\begin{aligned}
& w(-1)=w_{1} \\
& \frac{l_{e}}{2} w^{\prime}(-1)=w_{1}^{\prime} \\
& w(1)=w_{5} \\
& \frac{l_{e}}{2} w^{\prime}(1)=w_{5}^{\prime}
\end{aligned}
$$

The remaining three equations are obtained from the transverse deflection degrees of freedom at the internal nodes as shown below

$$
\begin{aligned}
& w(-1 / 2)=w_{2} \\
& w(0)=w_{3} \\
& w(1 / 2)=w_{4}
\end{aligned}
$$

Solving the above seven equations for $a_{i}$ and substituting in Equation (3.4a) yields

$$
w(\xi)=\left\lfloor H_{1}(\xi) \ldots H_{7}(\xi)\right]\left\{\begin{array}{l}
w_{1} \\
, \\
w_{1} \\
\vdots \\
w_{5} \\
w_{5}
\end{array}\right\}
$$

where $H_{1}(\xi), H_{2}(\xi)$, etc., are shape functions called Hermite polynomials and are derived from a seventh order polynomial as 


$$
\begin{aligned}
& H_{1}=\frac{1}{9}\left(\frac{17}{4} \xi-5 \xi^{2}-\frac{79}{4} \xi^{3}+\frac{47}{2} \xi^{4}+11 \xi^{5}-14 \xi^{6}\right) \\
& H_{2}=\frac{l_{e}}{6}\left(\frac{1}{4} \xi-\frac{1}{4} \xi^{2}-\frac{5}{4} \xi^{3}+\frac{5}{4} \xi^{4}+\xi^{5}-\xi^{6}\right) \\
& H_{3}=\frac{16}{9}\left(-\xi+2 \xi^{2}+2 \xi^{3}-4 \xi^{4}-\xi^{5}+2 \xi^{6}\right) \\
& H_{4}=1-6 \xi^{2}+9 \xi^{4}-4 \xi^{6} \\
& H_{5}=\frac{16}{9}\left(\xi+2 \xi^{2}-2 \xi^{3}+4 \xi^{4}+\xi^{5}+2 \xi^{6}\right) \\
& H_{6}=\frac{1}{9}\left(-\frac{17}{4} \xi-5 \xi^{2}+\frac{79}{4} \xi^{3}+\frac{47}{2} \xi^{4}-11 \xi^{5}-14 \xi^{6}\right) \\
& H_{7}\left(\frac{1}{4} \xi+\frac{1}{4} \xi^{2}-\frac{5}{4} \xi^{3}-\frac{5}{4} \xi^{4}+\xi^{5}+\xi^{6}\right)
\end{aligned}
$$

In a similar manner, the $b_{j}$, for the axial degrees of freedom are also solved from the following equations:

$$
\begin{aligned}
& u(-1)=u_{1} \\
& u(1)=u_{5} \\
& u(-1 / 2)=u_{2} \\
& u(0)=u_{3}
\end{aligned}
$$




$$
u(1 / 2)=u_{4}
$$

Solving the above five equations for $b_{j}$ and substituting in Equation (3.4b) yields

$$
u(\xi)=\left\lfloor H_{L 1}(\xi) \ldots H_{L 5}(\xi)\right\rfloor\left\{\begin{array}{l}
u_{1} \\
\vdots \\
u_{5}
\end{array}\right\}
$$

where $H_{L 1}(\xi), H_{L 2}(\xi)$, etc., are shape functions called Lagrange polynomials and are derived from a fifth order polynomial as

$$
\begin{aligned}
& H_{L 1}=\frac{1}{6} \xi-\frac{1}{6} \xi^{2}-\frac{2}{3} \xi^{3}+\frac{2}{3} \xi^{4} \\
& H_{L 2}=-\frac{4}{3} \xi+\frac{8}{3} \xi^{2}+\frac{4}{3} \xi^{3}-\frac{8}{3} \xi^{4} \\
& H_{L 3}=1-5 \xi^{2}+4 \xi^{4} \\
& H_{L 4}=\frac{4}{3} \xi+\frac{8}{3} \xi^{2}-\frac{4}{3} \xi^{3}-\frac{8}{3} \xi^{4} \\
& H_{L 5}=-\frac{1}{6} \xi-\frac{1}{6} \xi^{2}+\frac{2}{3} \xi^{3}+\frac{2}{3} \xi^{4}
\end{aligned}
$$

\subsection{Element Stiffness Matrix Formulation [Chandrasekaran (2000)]}

The element stiffness matrices for variation in virtual strain energy are formulated from the expressions derived in Section 2.5. For the various theories 
used in this research, this section elaborates the systematic procedure for deriving the element stiffness matrix.

\subsubsection{Stiffness Matrix Formulation for Isotropic beam}

For any element, the stiffness matrix can be obtained by applying variational approach to the total strain energy equation. The variation in strain energy for the isotropic beam is given earlier in Chapter 2, namely Equation (2.5a). It is also known that

$$
\begin{aligned}
& {[u]=\left\{H_{L}\right\}\left\lfloor q_{u}\right\rfloor} \\
& {[\delta u]=\left\{\delta q_{u}\right\}\left\lfloor H_{L}\right\rfloor} \\
& {[w]=\{H\}\left\lfloor q_{w}\right\rfloor} \\
& {[\delta w]=\left\{\delta q_{w}\right\}\lfloor H\rfloor}
\end{aligned}
$$

where

$$
\begin{aligned}
& \left\lfloor q_{u}\right\rfloor=\left\lfloor\begin{array}{lllll}
u_{1} & u_{2} & u_{3} & u_{4} & u_{5}
\end{array}\right\rfloor \\
& \lfloor\delta q\rfloor=\left\lfloor\begin{array}{lllll}
\delta u_{1} & \delta u_{2} & \delta u_{3} & \delta u_{4} & \delta u_{5}
\end{array}\right\rfloor \\
& \left\lfloor q_{w}\right\rfloor=\left\lfloor\begin{array}{lllllll}
w_{1} & w_{1}^{\prime} & w_{2} & w_{3} & w_{4} & w_{5} & w_{5}^{\prime}
\end{array}\right\rfloor
\end{aligned}
$$




$$
\left\lfloor\delta q_{w}\right\rfloor=\left\lfloor\begin{array}{lllllll}
\delta w_{1} & \delta w_{1}^{\prime} & \delta w_{2} & \delta w_{3} & \delta w_{4} & \delta w_{5} & \delta w_{5}^{\prime}
\end{array}\right\rfloor
$$

Substituting the above equations in $\delta U$ expression for the isotropic beam in Equation (2.5a), we get the $[k]$ matrix

$$
[k]=\left[\begin{array}{c:c}
{\left[k_{\text {uu }}\right]} & {[0]} \\
\hdashline[0] & \left.k_{w w}\right]
\end{array}\right]
$$

where the $[k]$ is partitioned into two parts namely $\left[k_{u u}\right]$ and $\left[k_{w w}\right]$ with the off diagonal terms of the above matrix as zeroes. The dimensions of the matrices are $5 \times 5$ and $7 \times 7$, respectively and are given by:

$$
\begin{aligned}
& {\left[k_{\text {uи }}\right]=\int_{0}^{l_{e}} E A\left\{H_{L}^{\prime}\right\}\left\lfloor H_{L}^{\prime}\right\rfloor d x_{e}} \\
& {\left[k_{w w}\right]=\int_{0}^{l_{e}} E I\left\{H^{\prime \prime}\right\}\left\lfloor H^{\prime \prime}\right\rfloor d x_{e}}
\end{aligned}
$$

where ()$^{\prime}$ and ()$^{\prime \prime}$ represent the first and the second partial derivatives with respect to $x$.

\subsubsection{Element Stiffness Matrix Formulation for Beam using CLPT}

The following figure, Figure 3.2, shows the element definition for the beam based on CLPT. The stiffness matrix for a beam theory can be formulated from the variation in strain energy expression. The independent variables in this 
formulation are $u, y, w$ and $w^{y}$ where the superscript $y$ represents partial differential of $w$ with respect to $y$. The $C^{0}$ continuity is assumed for $u, y$ and $w^{y}$ while $C^{1}$ continuity is taken for $w$.

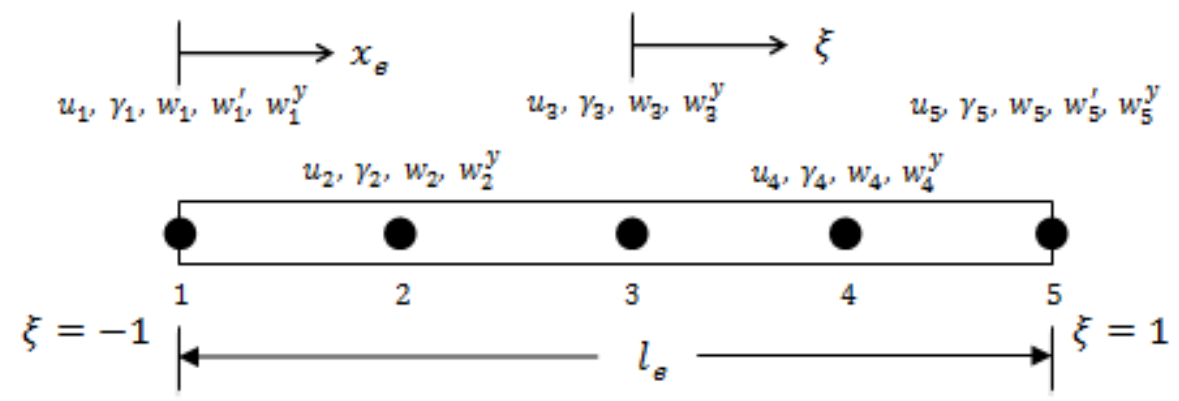

Figure 3.2 Element definition for CLPT

The stiffness matrix for this case is partitioned into sixteen sub matrices. The partitions are denoted as $\left[k_{u u}\right],\left[k_{u \psi}\right],\left[k_{u w}\right],\left[k_{u w^{y}}\right],\left[k_{\gamma \gamma}\right],\left[k_{\gamma w^{\prime}}\right],\left[k_{\gamma w^{y}}\right],\left[k_{w w}\right]$, $\left[k_{w w^{y}}\right],\left[k_{w^{\prime \prime}}\right]$ with dimensions of $5 \times 5,5 \times 5,5 \times 7,5 \times 5,5 \times 5,5 \times 7,5 \times 5,7 \times 7,7 \times 5$ and $5 \times 5$ respectively. The symmetric parts of the stiffness matrix are the transpose of their counterparts. By substituting variation in the strain-displacement relationship from Equation (2.13) in the expression for variation in strain energy given by Equation (2.18), the expressions for the different partitions of the stiffness matrix are obtained and are represented as

$$
\left.\left[k_{u u}\right]=b \int_{0}^{l_{e}} S_{11}\left\{H_{L}^{\prime}\right\} \mid H_{L}^{\prime}\right\rfloor d x_{e}
$$




$$
\begin{aligned}
& {\left[k_{u \gamma}\right]=b \int_{0}^{l_{e}} S_{12}\left\{H_{L}^{\prime}\right\}\left\lfloor H_{L}\right\rfloor d x_{e}} \\
& {\left[k_{u w}\right]=-b \int_{0}^{l_{e}} S_{13}\left\{H_{L}^{\prime}\right\}\left\lfloor H^{\prime \prime}\right\rfloor d x_{e}} \\
& \left.\left[k_{u w^{\prime}}\right]=-2 b \int_{0}^{l_{e}} S_{14}\left\{H_{L}^{\prime}\right\} \mid H_{L}^{\prime}\right\rfloor d x_{e} \\
& {\left[k_{r \gamma}\right]=b \int_{0}^{l_{e}} S_{22}\left\{H_{L}\right\}\left\lfloor H_{L}\right\rfloor d x_{e}} \\
& {\left[k_{\gamma w}\right]=-b \int_{0}^{l_{e}} S_{23}\left\{H_{L}\right\}\left\lfloor H^{\prime \prime}\right\rfloor d x_{e}} \\
& {\left[k_{\gamma w^{y}}\right]=-2 b \int_{0}^{l_{e}} S_{24}\left\{H_{L}\right\}\left\lfloor H^{\prime \prime}\right\rfloor d x_{e}} \\
& {\left[k_{w w}\right]=b \int_{0}^{l_{e}}\left(N_{x}\left\{H^{\prime}\right\}\left\lfloor H^{\prime}\right\rfloor+S_{33}\left\{H^{\prime \prime}\right\}\left\lfloor H^{\prime \prime}\right\rfloor\right) d x_{e}} \\
& {\left[k_{w w^{\prime}}\right]=2 b \int_{0}^{l_{e}} S_{34}\left\{H^{\prime \prime}\right\}\left\lfloor H_{L}^{\prime}\right\rfloor d x_{e}} \\
& \left.\left[k_{w^{\prime} w^{\prime}}\right]=4 b \int_{0}^{l_{e}} S_{44}\left\{H_{L}^{\prime}\right\} \mid H_{L}^{\prime}\right\rfloor d x_{e}
\end{aligned}
$$


where the $S_{i j}$ are obtained from the $[S]$ matrix defined in Equation (2.16a). The inertial force $N_{x}$ can be written in terms of the axial acceleration of the beam. The following equation shows the way in which the $[k]$ matrix is partitioned.

$$
[k]=\left[\begin{array}{r}
{\left[k_{u u}\right]\left[k_{u y}\right]\left[k_{u w}\right]\left[k_{u w^{y}}\right]} \\
{\left[k_{\gamma y}\right]\left[k_{\gamma w}\right]\left[k_{\gamma w^{y}}\right]} \\
\text { Symm }\left[k_{w w}\right]\left[k_{w w^{y}}\right] \\
{\left[k_{w^{y} w^{y}}\right]}
\end{array}\right]
$$

\subsubsection{Element Stiffness Matrix Formulation for Beam using FSDT}

The following figure, Figure 3.3, shows the element definition for FSDT. The stiffness matrix for FSDT is formulated from the variational strain energy expression derived in the energy formulation section of FSDT, Equation (2.25). In the FSDT formulation, as discussed earlier, the transverse shear is also considered. Hence the number of independent variables is more than that in the beam theory formulation using CLPT. The independent variables are identified to be $u, \gamma, w_{b}, w_{s}$ and $w_{b}^{y}$. The $C^{0}$ continuity is taken for $w_{b}$ and $w_{s}$ while $C^{1}$ continuity is assumed for $u, \gamma, w_{b}{ }^{y}$. 


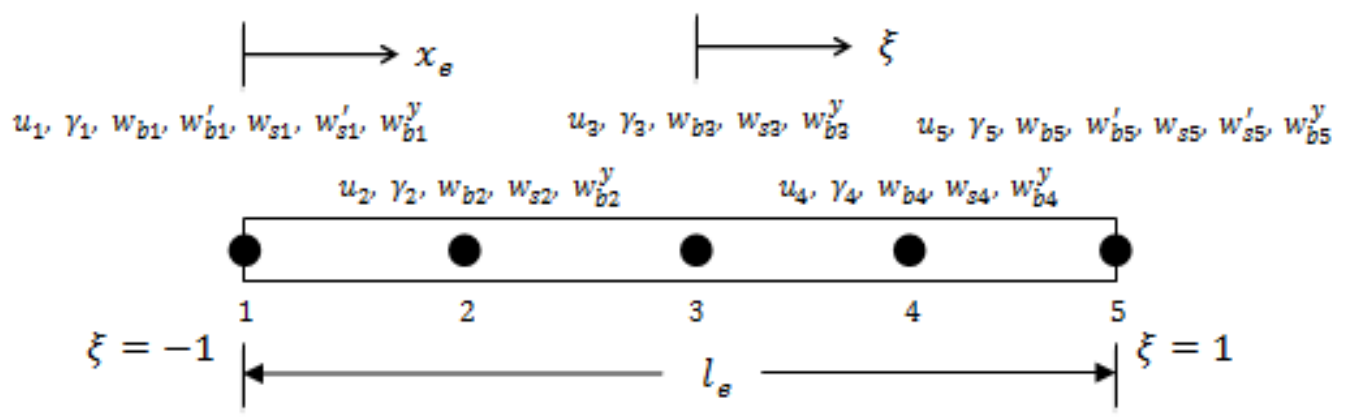

Figure 3.3 Element definition for FSDT

The stiffness matrix here is partitioned into twenty-five matrices that are symmetric about the main diagonal. The partitioned matrices are named $\left[k_{u u}\right]$, $\left[k_{u \gamma^{\prime}}\right],\left[k_{u w^{b}}\right],\left[k_{u w^{s}}\right],\left[k_{u w y_{b}^{y}}\right],\left[k_{\gamma u}\right],\left[k_{\gamma y}\right],\left[k_{\gamma w_{b}}\right],\left[k_{\gamma w_{s}}\right],\left[k_{\gamma w_{b}^{y}}\right],\left[k_{w_{b} u}\right],\left[k_{w_{b} \gamma^{\prime}}\right],\left[k_{w_{b} w_{b}}\right],\left[k_{w_{b} w_{s}}\right]$, $\left[k_{w_{b} w_{b}^{y}}\right],\left[k_{w_{s} u}\right],\left[k_{w_{s} y}\right],\left[k_{w_{s} w_{b}}\right],\left[k_{w_{s} w_{s}}\right],\left[k_{w_{s} w_{b}^{y}}\right],\left[k_{w_{b}^{y} u}\right],\left[k_{w_{b y}^{y}}\right],\left[k_{w_{b}^{y} w_{b}}\right],\left[k_{w_{b}^{y} w_{s}}\right],\left[k_{w_{b}^{y} w_{b}^{y}}\right]$ with dimensions $5 \times 5,5 \times 5,5 \times 7,5 \times 7,5 \times 5,5 \times 5,5 \times 5,5 \times 7,5 \times 7,5 \times 5,5 \times 5,5 \times 5,5 \times 7$, $5 \times 7,5 \times 5,5 \times 5,5 \times 5,5 \times 7,5 \times 7,5 \times 5,5 \times 5,5 \times 5,5 \times 7,5 \times 7,5 \times 5$ respectively. The arrangement of the different elements of the partitioned $[k]$ matrix is:

$$
[k]=\left[\begin{array}{r}
{\left[k_{u u}\right]\left[k_{u y}\right]\left[k_{u w_{b}}\right]\left[k_{u w_{s}}\right]\left[k_{u w_{b}^{y}}\right]} \\
{\left[k_{\gamma y}\right]\left[k_{\gamma w_{b}}\right]\left[k_{\gamma w_{s}}\right]\left[k_{\gamma w_{b}^{y}}\right]} \\
{\left[k_{w_{b} w_{b}}\right]\left[k_{w_{b} w_{s}}\right]\left[k_{w_{b} w_{b}^{y}}\right]} \\
{\left[k_{w_{s} w_{s}}\right]\left[k_{w_{s} w_{b}^{y}}\right]} \\
{\left[k_{w_{b}^{y} w_{b}^{y}}\right]}
\end{array}\right]
$$

As known, the symmetric parts of the matrix are the transpose of their counterparts. By substituting variation in the strain-displacement relationship 
from Equation (2.19) in the expression for variation in strain energy given by Equation (2.25) the expressions for the different partitions of the stiffness matrix are obtained and are represented as

$$
\begin{aligned}
& \left.\left[k_{u u}\right]=b \int_{0}^{l_{e}} S_{11}\left\{H_{L}^{\prime}\right\} \mid H_{L}^{\prime}\right\rfloor d x_{e} \\
& {\left[k_{u \gamma}\right]=b \int_{0}^{l_{e}} S_{12}\left\{H_{L}^{\prime}\right\}\left\lfloor H_{L}\right\rfloor d x_{e}} \\
& {\left[k_{u w^{b}}\right]=-b \int_{0}^{l_{e}} S_{13}\left\{H_{L}^{\prime}\right\}\left\lfloor H^{\prime \prime} \mid d x_{e}\right.} \\
& {\left[k_{u w_{s}}\right]=[0]} \\
& {\left[k_{u w_{b}^{\prime}}\right]=-2 b \int_{0}^{l_{e}} S_{14}\left\{H_{L}^{\prime}\right\}\left|H_{L}^{\prime}\right| d x_{e}} \\
& {\left[k_{r \gamma}\right]=b \int_{0}^{l_{e}} S_{22}\left\{H_{L}\right\}\left\lfloor H_{L}\right\rfloor d x_{e}} \\
& {\left[k_{\gamma w_{b}}\right]=-b \int_{0}^{l_{e}} S_{23}\left\{H_{L}\right\}\left[H^{\prime \prime}\right] d x_{e}} \\
& {\left[k_{\gamma w_{s}}\right]=[0]} \\
& \left.\left[k_{\gamma w_{b}^{\prime}}\right]=-2 b \int_{0}^{l_{e}} S_{24}\left\{H_{L}\right\} \mid H_{L}^{\prime}\right\rfloor d x_{e}
\end{aligned}
$$




$$
\begin{aligned}
& {\left[k_{w_{b} w_{b}}\right]=b \int_{0}^{l_{e}}\left(S_{33}\left\{H^{\prime \prime}\right\}\left\lfloor H^{\prime \prime}\right\rfloor+b \int_{0}^{l_{e}} N_{x}\left\{H^{\prime}\right\}\left\lfloor H^{\prime}\right\rfloor\right) d x_{e}} \\
& {\left[k_{w_{b} w_{s}}\right]=[0]} \\
& {\left[k_{w_{b} w_{b}^{y}}\right]=2 b \int_{0}^{l_{e}} S_{34}\left\{H^{\prime \prime}\right\}\left\lfloor H_{L}^{\prime}\right\rfloor d x_{e}} \\
& {\left[k_{w_{s} w_{w}}\right]=b \int_{0}^{l_{e}} N_{x}\left\{H^{\prime}\right\}\left\lfloor H^{\prime}\right] d x_{e}+b \int_{0}^{l_{e}} A^{*}\left\{H^{\prime}\right\}\left\lfloor H^{\prime}\right] d x_{e}} \\
& {\left[k_{w_{s} w_{b}^{y}}\right]=[0]} \\
& {\left[k_{w_{b}^{y} w_{b}^{y}}\right]=4 b \int_{0}^{l_{e}} S_{44}\left\{H_{L}^{\prime}\right\}\left\lfloor H_{L}^{\prime}\right\rfloor d x_{e}}
\end{aligned}
$$

\subsection{Incremental Stiffness Matrix Formulation [Chandrasekaran (2000)]}

The time dependent part of the stiffness matrix is denoted as the incremental stiffness matrix. The incremental stiffness matrix comes into the equation through the load $N_{x}$ that is represented as the axial inertial force $b . F(x)$.

The axial force acting on the beam, which results in its axial motion, is due to the rigid-body acceleration imparted to the beam. The acceleration of the beam is obtained by differentiating Equation (2.3) twice with respect to time. The incremental stiffness matrix is obtained from the strain energy due to axial forces corresponding to the an element and can be written as 


$$
U_{f e}=\frac{1}{2} \int_{0}^{l_{e}} F_{x} w^{\prime 2} d x
$$

Substituting the force in terms of the acceleration of the beam and mass per unit length and then taking the variation yields

$$
\delta U_{f e}=-a_{B}^{L} \int_{0}^{l_{e}} \gamma(L-x) w^{\prime} \delta w^{\prime} d x
$$

Writing the above equation in terms of the shape functions yields

$$
\delta U_{f e}=-a_{B}^{L} \int_{0}^{l_{e}} \gamma(L-x)\left\lfloor\delta q_{t}\right\rfloor\left\{H^{\prime}\right\}\left\lfloor H^{\prime}\right\rfloor\{q\} d x
$$

where $\left\{q_{t}\right\}$ and $\left\{\delta q_{t}\right\}$ are the vectors of transverse displacements and their variation. The incremental stiffness matrix can be written from Equation (3.24) as

$$
\left[k_{i}\right]=-a_{B}^{L} \int_{0}^{l_{e}} \gamma(L-x)\left\{H^{\prime}\right\}\left\lfloor H^{\prime}\right\rfloor d x_{e}
$$

The incremental stiffness matrix $\left[k_{i}\right]$ can be written in non-dimensional coordinates, as

$$
\left[k_{i}\right]=\frac{-2 a_{B}^{L}}{l_{e}} \int_{-1}^{1} \gamma\left\{L-\left[x_{b}+\frac{l_{e}}{2}(1+\xi)\right]\right\}\{H(\xi)\}[H(\xi)] d \xi
$$




\subsection{Element Inertia Matrix Formulation [Chandrasekaran (2000)]}

The element inertia matrix formulation is discussed in this section. The element inertia matrix is formulated from the variation in total kinetic energy defined earlier in Chapter 2.

\subsubsection{Element Inertia Matrix Formulation for Isotropic case}

The variation in kinetic energy for isotropic case is given by Equation (2.36). The element inertia matrix for an element is obtained by using Lagrange interpolation function $H_{L}$ with $C^{0}$ continuity for discretizing $u$ and Hermitian interpolation function $H$ with $C^{1}$ continuity for $w$. Substituting the interpolation functions into Equation (2.31) yields

$$
-\delta T=\lfloor\delta q][m]\{\ddot{q}\}
$$

Where

$$
[m]=\left[\begin{array}{c:c}
{\left[m_{u u}\right]} & {[0]} \\
\hdashline[0] & {\left[m_{w w}\right]}
\end{array}\right]
$$

The individual partitions of $[m]$ are given by

$$
\left[m_{u u}\right]=b \int_{0}^{l_{e}} I_{0}\left\{H_{L}\right\}\left\lfloor H_{L}\right\rfloor d x_{e}
$$




$$
\left[m_{w w}\right]=b \int_{0}^{l_{l}} I_{0}\{H\}\lfloor H\rfloor d x_{e}
$$

\subsubsection{Element Inertia Matrix Formulation for Beam using CLPT}

The variation in kinetic energy for beam based on CLPT is given by Equation (2.36). The element inertia matrix is obtained using Lagrangian interpolation function $H_{L}$ with $C^{0}$ continuity for discretizing $u_{0}, \gamma$ and $w^{y}$ and Hermitian interpolation function $H$ with $C^{1}$ continuity for $w$. Substituting the interpolation functions in Equation (2.36), further yields

$$
-\delta T=\lfloor\delta q][m]\{\ddot{q}\}
$$

where

$$
[m]=\left[\begin{array}{r}
{\left[m_{u u}\right]\left[m_{u \gamma}\right]\left[m_{u w}\right]\left[m_{u w^{y}}\right]} \\
{\left[m_{\gamma y}\right]\left[m_{\gamma w}\right]\left[m_{\gamma w^{y}}\right]} \\
\text { Symm }\left[m_{w w}\right]\left[m_{w w^{y}}\right] \\
{\left[m_{w^{y} w^{y}}\right]}
\end{array}\right]
$$

And the individual elements of the $[m]$ matrix are given by

$$
\begin{aligned}
& {\left[m_{u u}\right]=b \int_{0}^{l_{e}} I_{0}\left\{H_{L}\right\}\left[H_{L}\right] d x_{e}} \\
& {\left[m_{u w}\right]=-b \int_{0}^{l_{e}} I_{1}\left\{H_{L}\right\}\left[H^{\prime}\right] d x_{e}} \\
& {\left[m_{w u}\right]=\left[m_{u w}\right]^{T}}
\end{aligned}
$$




$$
\begin{aligned}
& {\left[m_{w w}\right]=b \int_{0}^{l_{e}}\left(I_{0}\{H\}[H]+I_{2}\left\{H^{\prime}\right\}\left\lfloor H_{L}\right\rfloor\right) d x_{e}} \\
& {\left[m_{w^{y} w^{y}}\right]=b \int_{0}^{l_{e}} I_{2}\left\{H_{L}\right\}\left[H_{L}\right] d x_{e}} \\
& {\left[m_{u \gamma}\right]=\left[m_{\gamma \gamma}\right]=\left[m_{\gamma w}\right]=\left[m_{\gamma w^{y}}\right]=\left[m_{w w^{y}}\right]=\left[m_{u w^{y}}\right]=0}
\end{aligned}
$$

\subsubsection{Element Inertia Matrix Formulation for FSDT}

The variation in kinetic energy for beam using FSDT is given by Equation (2.47). The element inertia matrix is obtained by using Lagrangian interpolation function $H_{L}$ with $C^{0}$ continuity for discretizing $u_{0}, \gamma$, and $w_{b}^{y}$ and Hermitian interpolation function $H$ with $C^{1}$ continuity for $w_{b}$ and $w_{s}$. Substituting the interpolation functions in Equation (2.47), further yields

$$
\begin{aligned}
-\delta T & =\lfloor\delta q][m]\{\ddot{q}\} \\
{[m] } & {\left[\begin{array}{r}
{\left[m_{u u}\right]\left[m_{u \gamma}\right]\left[m_{u w_{b}}\right]\left[m_{u w_{s}}\right]\left[m_{u w_{b}^{y}}\right]} \\
{\left[m_{\gamma \gamma}\right]\left[m_{\gamma w_{b}}\right]\left[m_{\gamma w_{s}}\right]\left[m_{\gamma w_{b}^{y}}\right]} \\
{\left[m_{w_{b} w_{b}}\right]\left[m_{w_{b} w_{s}}\right]\left[m_{w_{b} w_{b}^{y}}\right]} \\
{\left[m_{w_{s} w_{s}}\right]\left[m_{w_{s} w_{b}^{y}}\right]} \\
\text { Symm }\left[m_{w_{b}^{y} w_{b}^{y}}\right]
\end{array}\right] }
\end{aligned}
$$

Where $[m]$ is the element inertia matrix and its components are given by 


$$
\begin{aligned}
& {\left[m_{u u}\right]=b \int_{0}^{l_{e}} I_{0}\left\{H_{L}\right\}\left\lfloor H_{L}\right\rfloor d x_{e}} \\
& {\left[m_{u w_{b}}\right]=-b \int_{0}^{l_{b}} I_{1}\left\{H_{L}\right\}\left\lfloor H^{\prime}\right\rfloor d x_{e}} \\
& {\left[m_{w_{b} w_{b}}\right]=b \int_{0}^{l_{e}} I_{2}\left\{H^{\prime}\right\}\left\lfloor H^{\prime}\right\rfloor+I_{0}\{H\}\lfloor H\rfloor d x_{e}} \\
& {\left[m_{w_{b} w_{s}}\right]=b \int_{0}^{l_{e}} I_{0}\{H\}\lfloor H\rfloor d x_{e}} \\
& {\left[m_{w_{s} w_{s}}\right]=b \int_{0}^{l_{e}} I_{0}\{H\}\lfloor H\rfloor d x_{e}} \\
& {\left[m_{w_{b}^{y} w_{b}^{l}}\right]=b \int_{0}^{l_{e}} I_{2}\{H\}\lfloor H\rfloor d x_{e}} \\
& {\left[m_{u \gamma}\right]=\left[m_{u w_{s}}\right]=\left[m_{u w_{b}^{y}}\right]=\left[m_{\gamma \gamma}\right]=\left[m_{\gamma w_{b}}\right]=0} \\
& {\left[m_{\gamma w_{s}}\right]=\left[m_{\gamma w_{b}^{y}}\right]=\left[m_{w_{b} w_{b}^{y}}\right]=\left[m_{w_{s} w_{b}^{y}}\right]=0}
\end{aligned}
$$

\subsection{Ply Stresses for a Composite Beam}

This section shows the formulation for finding the ply stresses of a composite laminate at a given cross section of the beam. Since we focus on CLPT and FSDT, the following discusses the two theories. 


\subsubsection{Formulation using CLPT}

The strain components and the virtual strain components are obtained from displacement equations of CLPT as

$$
\begin{aligned}
& \varepsilon_{x}=\varepsilon_{x}^{(0)}+z \varepsilon_{x}^{(1)} \\
& \varepsilon_{y}=\varepsilon_{y}^{(0)}+z \varepsilon_{y}^{(1)} \\
& \gamma_{x y}=\gamma_{x y}^{(0)}+z \gamma_{x y}^{(1)}
\end{aligned}
$$

The following steps outline the way to find the ply stresses at $x=d$ along the length of the beam where $x$ is the distance from the left-end of the beam to the point of interest. First, locate the element corresponding to $x=d$ and then fine the following values for that element

$$
\begin{aligned}
& u_{0}^{\prime}(d)=\left[\begin{array}{lll}
H_{L 1}^{\prime}(d) & \ldots & H_{L 5}^{\prime}(d)
\end{array}\right]\left[\begin{array}{lll}
\bar{u}_{1} & \ldots & \bar{u}_{5}
\end{array}\right]^{T} \\
& w^{\prime}(d)=\left[\begin{array}{lll}
H_{1}^{\prime}(d) & \ldots & H_{7}^{\prime}(d)
\end{array}\right]\left[\begin{array}{lll}
\bar{w}_{1} & \ldots & \bar{w}_{5}^{\prime}
\end{array}\right]^{T} \\
& w^{\prime \prime}(d)=\left[\begin{array}{lll}
H_{1}^{\prime \prime}(d) & \ldots & H_{7}^{\prime \prime}(d)
\end{array}\right]\left[\begin{array}{lll}
\bar{w}_{1} & \ldots & \bar{w}_{5}^{\prime}
\end{array}\right]^{T} \\
& \gamma_{0}(d)=\left[\begin{array}{llll}
H_{L 1}(d) & \ldots & H_{L 5}(d)
\end{array}\right]\left[\begin{array}{lll}
\bar{\gamma}_{01} & \ldots & \bar{\gamma}_{05}
\end{array}\right]^{T} \\
& w_{y}^{\prime}(d)=\left[\begin{array}{llll}
H_{1}^{\prime}(d) & \ldots & H_{7}^{\prime}(d)
\end{array}\right]\left[\begin{array}{lll}
\bar{w}_{y_{1}} & \ldots & \bar{w}_{y_{5}}
\end{array}\right]^{T}
\end{aligned}
$$

Then the strains and curvatures are:

$$
\varepsilon_{x}^{(0)}=u_{0}^{\prime}(d)+\frac{1}{2}\left[w^{\prime}(d)\right]^{2}
$$




$$
\left.\begin{array}{l}
\delta \varepsilon_{x}^{(1)}=-\delta w^{\prime \prime} \\
\delta \gamma_{x y}^{(0)}=\delta \gamma_{0} \\
\delta \gamma_{x y}^{(1)}=-2 \delta w^{\prime y} \\
{\left[\begin{array}{ll}
\varepsilon_{y}^{(0)} & \varepsilon_{y}^{(1)}
\end{array}\right]^{T}=\left[-\left[S^{22}\right]^{-1}\left[S^{21}\left[\varepsilon_{x}^{(0)}(d) \quad \gamma_{x y}^{(0)}(d) \quad \varepsilon_{x}^{(1)}(d) \quad \gamma_{x y}^{(1)}(d)\right]\right.\right.}
\end{array}\right]
$$

The ply strains at the top of the $k^{\text {th }}$ ply, $\left[\begin{array}{llll}\varepsilon_{x} & \varepsilon_{y} & \gamma_{x y}\end{array}\right]_{k t}$, are found by Equation (3.35) and stresses at the top of the $k^{\text {th }}$ ply are found as:

$$
\begin{aligned}
& {\left[\begin{array}{lll}
\sigma_{x} & \sigma_{y} & \tau_{x y}
\end{array}\right]_{k t}^{T}=\left[\begin{array}{lll}
\bar{Q}
\end{array}\right]_{k}\left[\begin{array}{lll}
\varepsilon_{x} & \varepsilon_{y} & \gamma_{x y}
\end{array}\right]_{k t}^{T}} \\
& {\left[\begin{array}{lll}
\sigma_{1} & \sigma_{2} & \sigma_{6}
\end{array}\right]_{h t}^{T}=\left[T_{\sigma}\right]\left[\begin{array}{lll}
\sigma_{x} & \sigma_{y} & \tau_{x y}
\end{array}\right]_{k t}^{T}}
\end{aligned}
$$

Similarly to Equation (3.38), the ply strains and stresses could be found for the bottom of the $k^{\text {th }}$ ply.

\subsubsection{Formulation using FSDT}

The strain components and the virtual strain components are obtained from displacement equations of FSDT as

$$
\begin{aligned}
& \varepsilon_{x}=\varepsilon_{x}^{(0)}+z \varepsilon_{x}^{(1)} \\
& \varepsilon_{y}=\varepsilon_{y}^{(0)}+z \varepsilon_{y}^{(1)}
\end{aligned}
$$




$$
\gamma_{x y}=\gamma_{x y}^{(0)}+z \gamma_{x y}^{(1)}
$$

The following steps outline the steps to determine the ply stresses at $x=d$ along the length of the beam where $x$ is the distance from the left-end of the beam to the point of interest.

First locate the element corresponding to $x=d$ and then find the following values for that element

$$
\begin{aligned}
& u_{0}^{\prime}(d)=\left[\begin{array}{lll}
H_{L 1}^{\prime}(d) & \ldots & H_{L 5}^{\prime}(d)
\end{array}\right]\left[\begin{array}{lll}
\bar{u}_{1} & \ldots & \bar{u}_{5}
\end{array}\right]^{T} \\
& w_{b}^{\prime}(d)=\left[\begin{array}{lll}
H_{1}^{\prime}(d) & \ldots & H_{7}^{\prime}(d)
\end{array}\right]\left[\begin{array}{lll}
\bar{w}_{b 1} & \ldots & \bar{w}_{b 5}^{\prime}
\end{array}\right]^{T} \\
& w_{s}^{\prime}(d)=\left[\begin{array}{lll}
H_{1}^{\prime}(d) & \ldots & H_{7}^{\prime}(d)
\end{array}\right]\left[\begin{array}{lll}
\bar{w}_{s 1} & \ldots & \bar{w}_{s 5}^{\prime}
\end{array}\right]^{T} \\
& w_{b}^{\prime \prime}(d)=\left[\begin{array}{lll}
H_{1}^{\prime \prime}(d) & \ldots & H_{7}^{\prime \prime}(d)
\end{array}\right]\left[\begin{array}{lll}
\bar{w}_{b 1} & \ldots & \bar{w}_{b 5}^{\prime}
\end{array}\right]^{T} \\
& \gamma_{0}(d)=\left[\begin{array}{lll}
H_{L 1}(d) & \ldots & H_{L 5}(d)
\end{array}\right]\left[\begin{array}{lll}
\bar{\gamma}_{01} & \ldots & \bar{\gamma}_{05}
\end{array}\right]^{T} \\
& {\left[\begin{array}{lll}
w_{b}^{y}
\end{array}\right](d)=\left[\begin{array}{lll}
H_{1}^{\prime}(d) & \ldots & H_{7}^{\prime}(d)
\end{array}\right]\left[\begin{array}{lll}
\bar{w}_{y_{1}} & \ldots & \bar{w}_{y_{5}}
\end{array}\right]^{T}}
\end{aligned}
$$

The strains and curvatures are:

$$
\begin{aligned}
& \varepsilon_{x}^{(0)}(d)=u_{0}^{\prime}(d)+\frac{1}{2}\left[w_{b}^{\prime}(d)\right]^{2}+\frac{1}{2}\left[w_{s}^{\prime}(d)\right]^{2} \\
& \varepsilon_{x}^{(1)}(d)=-w_{b}^{\prime \prime}(d) \\
& \gamma_{x y}^{(0)}(d)=\gamma_{0}(d) \\
& \gamma_{x y}^{(1)}(d)=-2 w_{b}^{\prime}(d)
\end{aligned}
$$




$$
\begin{aligned}
& \gamma_{x z}^{(1)}(d)=-w_{s}^{\prime}(d) \\
& \gamma_{y z}^{(0)}(d)=-\frac{A_{45}}{A_{44}} w_{s}^{\prime}(d) \\
& {\left[\begin{array}{ll}
\varepsilon_{y}^{(0)} & \varepsilon_{y}^{(1)}
\end{array}\right]^{T}=\left\lfloor-\left[S^{22}\right]^{-1}\left[S^{21}\left[\varepsilon_{x}^{(0)}(d) \quad \gamma_{x y}^{(0)}(d) \quad \varepsilon_{x}^{(1)}(d) \quad \gamma_{x y}^{(1)}(d)\right]\right\rfloor\right.}
\end{aligned}
$$

The ply strains at the top of the $k^{\text {th }}$ ply, $\left[\begin{array}{lll}\varepsilon_{x} & \varepsilon_{y} & \gamma_{x y}\end{array}\right]_{k t}$, are found by Equation (3.39) and stresses at the top of the $k^{\text {th }}$ ply are found as given in Equation (3.42) below

$$
\begin{aligned}
& {\left[\begin{array}{lll}
\sigma_{x} & \sigma_{y} & \tau_{x y}
\end{array}\right]_{k t}^{T}=\left[\begin{array}{ll}
\bar{Q} & ]_{k}
\end{array}\left[\begin{array}{lll}
\varepsilon_{x} & \varepsilon_{y} & \gamma_{x y}
\end{array}\right]_{k t}^{T}\right.} \\
& {\left[\begin{array}{lll}
\sigma_{1} & \sigma_{2} & \sigma_{6}
\end{array}\right]_{k t}^{T}=\left[T_{\sigma}\right]\left[\begin{array}{lll}
\sigma_{x} & \sigma_{y} & \tau_{x y}
\end{array}\right]_{k t}^{T}}
\end{aligned}
$$

(3.42)

Similarly, the ply strains and stresses can be found for the bottom of the $k^{\text {th }}$ ply. The transverse shear stresses, $\left\lfloor\begin{array}{ll}\tau_{y z} & \tau_{x z}\end{array}\right\rfloor$, could also be found by:

$$
\left[\begin{array}{ll}
\tau_{y z} & \tau_{x z}
\end{array}\right]^{T}=\left[\begin{array}{cc}
\bar{Q}_{44}^{*} & \bar{Q}_{45}^{*} \\
\bar{Q}_{45}^{*} & \bar{Q}_{55}^{*}
\end{array}\right]\left[\begin{array}{ll}
\gamma_{y z} & \gamma_{x z}
\end{array}\right]
$$




\section{CHAPTER 4 \\ NUMERICAL IMPLEMENTATION}

\subsection{Introduction}

The finite element formulation of a moving load problem has been presented in the previous chapter. The Gauss quadrature technique for numerical integration in the space domain is enunciated in this chapter. Dividing the beam into finite elements results in the spatial discretization of the space-time governing equations. In this chapter, the solution procedure in the time domain is presented. A computer program in MATLAB is written based on an implicit scheme to solve the second-order differential equations in the time domain.

\subsection{Numerical Integration in Space Domain}

The computation of element inertial and stiffness matrices may be carried out by numerical integration in the space domain The Gauss quadrature scheme is a commonly used one in finite element codes. This scheme needs $n$ unequallyspaced sampling points to integrate a polynomial of order $(2 n-1)$ exactly. The highest order of polynomial representing the shape functions is seven. Considering a uniform beam, the highest order polynomial of 14 occurs in the inertia matrix. Thus, a seven-point Gauss-quadrature scheme is adopted in the present research. The sampling points and their respective weights for a sevenpoint integration scheme are shown in Table 4.1. The Gauss integration scheme is 


$$
\int_{-1}^{1} f(x) d x=\sum_{j=1}^{n} w_{j} f\left(a_{j}\right)
$$

where $n$ is the number of sampling points, $a_{j}$ is the $x$ co-ordinate of a sampling point and $w_{j}$ is the corresponding weight.

Table 4.1 Sampling points and weights for seven-point Gauss quadrature integration scheme

\begin{tabular}{|c|c|}
\hline Sampling Points & Weights \\
\hline \pm 0.9491079123 & 0.1294849661 \\
\hline \pm 0.7415311855 & 0.2797053914 \\
\hline \pm 0.4058451513 & 0.3813005051 \\
\hline 0.0000000000 & 0.4179591836 \\
\hline
\end{tabular}

The numerical integration of the stiffness and the inertia matrices are done by changing the limits from $\left(0, I_{e}\right)$ to $(-1,1)$ by non-dimensionalizing the independent variable.

\subsection{Newmark's Time Integration Scheme}

Newmark's method, based on an implicit technique has been a popular method for integrating the equations of motion in the time domain. The steps involved in Newmark's method are [Bathe and Wilson (1976)]:

$$
\dot{q}_{t+\Delta t}=\dot{q}_{t}+\left[(1-\delta) \ddot{q}_{t}+\delta \ddot{q}_{t+\Delta t}\right] \Delta t
$$




$$
q_{t+\Delta t}=q_{t}+\dot{q}_{t} \Delta t+\left[\left(\frac{1}{2}-\alpha\right) \ddot{q}_{t}+\alpha \ddot{q}_{t+\Delta t}\right] \Delta t^{2}
$$

where $\alpha$ and $\delta$ are Figure 4.1 is a representation of Newmark's scheme.

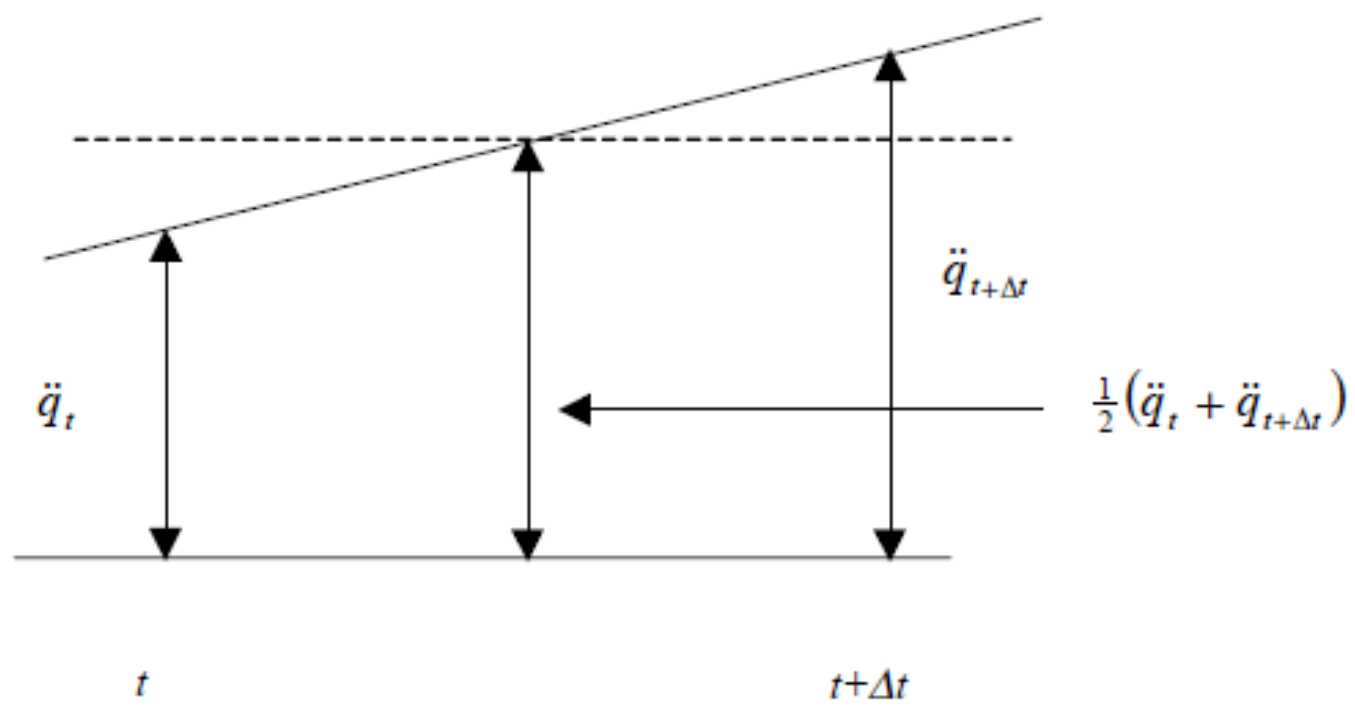

Figure 4.1 Newmark's Scheme [Chandrasekaran (2000)]

\subsection{Boundary Conditions [Chandrasekaran (2000)]}

The displacement boundary conditions corresponding to the three common support types of hinged, roller, and fixed for both the CLPT and FSDT cases are listed in this section.

\subsubsection{Boundary Conditions for CLPT}

In the CLPT case, the degrees of freedom at a node are $u, \gamma, w_{b}^{y}$ and $w$, of which, $w$ has slope continuity at the end nodes of each element. The boundary conditions are: 
Hinged support: $\quad u=w=w^{y}=0$

Roller support: $\quad w=w^{y}=0$

Fixed support: $\quad u=w=w^{y}=w^{\prime}=0$

\subsubsection{Boundary conditions for FSDT}

In the FSDT, the degrees of freedom at a node are $u, \gamma, w_{b}, w_{s}$ and $w_{b}^{y}$ of which, $w_{b}$ and $w_{s}$ have slope continuity at the end nodes of each element. The boundary conditions are:

Hinged support: $\quad u=w_{b}=w_{s}=w_{b}{ }^{y}=0$

Roller support: $\quad w_{b}=w_{s}=w_{b}{ }^{y}=0$

Fixed support: $\quad u=w_{b}=w_{s}=w_{b}{ }^{\prime}=w_{s}{ }^{\prime}=w_{b}{ }^{y}=0$ 


\section{CHAPTER 5 VERIFICATION OF RESULTS}

\subsection{Introduction}

A computer code is setup in MATLAB to solve the finite element equations of Chapter 3 utilizing the numerical techniques outlined in Chapter 4.The results, in the form of deflections and stresses, provided in this chapter deal with the verification of the formulation, including the numerical adaptations. This chapter is basically divided into two major parts; the first deals with deformations of composite beams under dry and under hygrothermal conditions while the second with the stresses under dry conditions.

The deformations part is further divided into two subparts. First one deals with dynamic magnification factors of the deflection of isotropic and laminated composite beams under moving load. The second subpart deals with beams, simply-supported (pinned-pinned) and fixed-fixed (clamped-clamped), under a hygrothermal environment with a comparison under dry conditions.

The stresses part deals with cross-sectional stresses of laminated composite beams under static and moving loads along the beam.

\subsection{Isotropic Beam Subjected to a Moving Load}

The verification of the problem of an isotropic simply-supported beam under moving load is done by obtaining the dynamic magnification factor. The dynamic magnification factor is the ratio of the maximum deflection at the mid- 
span of the beam due to a moving load to the static deflection at the mid-span of the beam.

The geometric and material properties of the model are the same as that used by Kadivar and Mohebpur (1998) as shown in Table 5.1

Table 5.1 Dimensions and material properties of isotropic beam

\begin{tabular}{|c|c|}
\hline Length, $L$ & $0.1018 \mathrm{~m}$ \\
\hline Width, $b$ & $0.00635 \mathrm{~m}$ \\
\hline Thickness, $h$ & $0.00635 \mathrm{~m}$ \\
\hline Density, $\rho$ & $10686.9 \mathrm{~kg} / \mathrm{m}^{3}$ \\
\hline Modulus of Elasticity, $E$ & $206.84 \mathrm{GPa}$ \\
\hline Poisson's ratio, $v$ & 0.25 \\
\hline
\end{tabular}

The applied load is in the form of a point load, $P=-4.45 \mathrm{~N}$. This load is applied at mid-span of the simply-supported isotropic beam in the static consideration while in the moving load case (Figure 2.1), it is initially at the left end of the beam and moves toward the right end of the simply-supported beam at specified velocities.

\subsubsection{Static Load on Simply-Supported Beam}

The static deflection due to a mid-span point load on a simply-supported beam is

$$
\delta_{s}=\frac{P L^{3}}{48 E I}
$$


The beam is divided into five higher-order elements (Figure 3.1), with each element consisting of 5 nodes and 12 degrees of freedom. As seen in Table 5.2, the results from the present higher-order beam element model agree well with the theoretical result.

Table 5.2 Mid-span static deflection of simply-supported beam

\begin{tabular}{|c|c|}
\hline Theoretical Result & Present study \\
\hline$-3.4694 \times 10^{-6} \mathrm{~m}$ & $-3.4711 \times 10^{-6} \mathrm{~m}$ \\
\hline
\end{tabular}

\subsubsection{Moving Load on Simply-Supported Isotropic Beam}

As in the static case, the simply-supported beam is divided into 5 higherorder elements; there are a total of 21 nodes since each element contains 5 nodes. The moving-load problem is simulated as a dynamic analysis with 20 time steps for the load to travel from the left end to the right end; that is, the load moves from one node to the next after each time step. Let $V$ be the velocity of the moving load and $T$ the corresponding time taken for the load to travel from one end of the beam to the other. If the fundamental time period of the beam is represented by $T_{f}$, then $V_{f}$ is the velocity required for the load to have a travel time of $T_{f}$. The velocity $V$ is taken as some factor times $T$. The velocity ratio $V / V_{f}$ and $T_{f} / T$ are related as

$$
\frac{V}{V_{f}}=\frac{V}{L} \times \frac{L}{V_{f}}=\frac{T_{f}}{T}
$$


The velocity ratio is used to calculate the time-step, $\Delta t$, which is the time for the load to move from one node to the next. By conducting a modal analysis, the fundamental period is obtained as $T_{f}=8.1488 \times 10^{-4} \mathrm{~s}$. Table 5.3 lists the different velocity ratios and the corresponding velocities, times, and time steps that are used to verify the dynamic magnification factors with previous authors. The value of the moving load is $P=-4.45 \mathrm{~N}$ as in the static case.

Table 5.3 Moving load velocities and time steps for isotropic beam

\begin{tabular}{|c|c|c|c|}
\hline \multirow{2}{*}{$\mathbf{T}_{\mathbf{f}} / \mathbf{T}$} & \multirow{2}{*}{ Velocity $(\mathbf{m} / \mathbf{s})$} & \multicolumn{2}{|c|}{ Isotropic Beam } \\
\cline { 3 - 4 } & & $\boldsymbol{T}(\mathbf{s})$ & $\boldsymbol{\Delta t}(\mathbf{s})$ \\
\hline 0.125 & 15.60 & $6.5128 \times 10^{-3}$ & $3.2564 \times 10^{-4}$ \\
\hline 0.25 & 31.20 & $3.2564 \times 10^{-3}$ & $1.6282 \times 10^{-4}$ \\
\hline 0.5 & 62.40 & $1.6282 \times 10^{-3}$ & $0.8141 \times 10^{-4}$ \\
\hline 1 & 124.80 & $0.8141 \times 10^{-3}$ & $0.4071 \times 10^{-4}$ \\
\hline 2 & 250.00 & $0.4064 \times 10^{-3}$ & $0.2032 \times 10^{-4}$ \\
\hline
\end{tabular}

Newmark's integration scheme is used to find the dynamic deflections at the nodes at each time step. The mid-span dynamic deflections from the present study are compared with that of Kavipurapu (2005) in Table 5.4. There are slight differences between the two sets of results and this is attributed to the fact that the present analysis is based on a higher-order element (and thus expected to be more accurate) while Kavipurapu used simple 2-noded elements. 
Table 5.4 Comparison of mid-span dynamic deflections various velocities

\begin{tabular}{|c|c|c|c|}
\hline \multirow{2}{*}{$\begin{array}{c}\text { Velocity } \\
(\mathbf{m} / \mathbf{s})\end{array}$} & \multirow{2}{*}{$\boldsymbol{t}(\mathbf{s})$} & \multicolumn{2}{|c|}{ Maximum mid-span dynamic deflections (m) } \\
\cline { 3 - 4 } & & Present study & Kavipurapu (2005) \\
\hline 15.60 & $3.2564 \times 10^{-4}$ & $-3.6506 \times 10^{-6}$ & $-3.6120 \times 10^{-6}$ \\
\hline 31.20 & $1.6282 \times 10^{-4}$ & $-3.9523 \times 10^{-6}$ & $-3.7617 \times 10^{-6}$ \\
\hline 62.40 & $0.8141 \times 10^{-4}$ & $-4.4028 \times 10^{-6}$ & $-4.4247 \times 10^{-6}$ \\
\hline 124.80 & $0.4071 \times 10^{-4}$ & $-5.8749 \times 10^{-6}$ & $-7.4702 \times 10^{-6}$ \\
\hline 250.00 & $0.2032 \times 10^{-4}$ & $-5.3307 \times 10^{-6}$ & $-5.2172 \times 10^{-6}$ \\
\hline
\end{tabular}

The dynamic magnification factors are compared with several previous authors in Table 5.4. The present results are in very good agreement with the references.

Table 5.5 Dynamic magnification factor comparison at various time steps for an isotropic beam

\begin{tabular}{|c|c|c|c|c|c|c|}
\hline \multirow{2}{*}{$\begin{array}{c}\text { Velocity } \\
(\mathbf{m} / \mathbf{s})\end{array}$} & $\boldsymbol{\Delta} \boldsymbol{t}(\mathbf{s})$ & $\begin{array}{c}\text { Dresent } \\
\text { study }\end{array}$ & $\begin{array}{c}\text { Kavipurapu } \\
\mathbf{( 2 0 0 5 )}\end{array}$ & $\begin{array}{c}\text { Taheri } \\
(\mathbf{1 9 8 7})\end{array}$ & Yoshida & Exact \\
\hline 15.6 & $3.2564 \times 10^{-4}$ & 1.052 & 1.042 & 1.042 & 1.055 & 1.045 \\
\hline 31.2 & $1.6282 \times 10^{-4}$ & 1.139 & 1.083 & 1.082 & 1.112 & 1.108 \\
\hline 62.4 & $0.8141 \times 10^{-4}$ & 1.268 & 1.266 & 1.266 & 1.252 & 1.250 \\
\hline 124.8 & $0.4071 \times 10^{-4}$ & 1.693 & 1.662 & 1.662 & 1.700 & 1.707 \\
\hline 250 & $0.2032 \times 10^{-4}$ & 1.536 & 1.518 & 1.518 & 1.54 & 1.55 \\
\hline
\end{tabular}

The dynamic magnification factor as a function of the velocity ratio is plotted in Fig. 5.1; the results from Kavipurapu (2005) are also shown in this figure for comparison and the agreement between the two plots is very good. It 
can be seen from Figure 5.1 that the dynamic magnification factor increases with increasing velocity up to a certain velocity, and then decreases; the increasing segment is called the undercritical region while the decreasing segment overcritical region. 

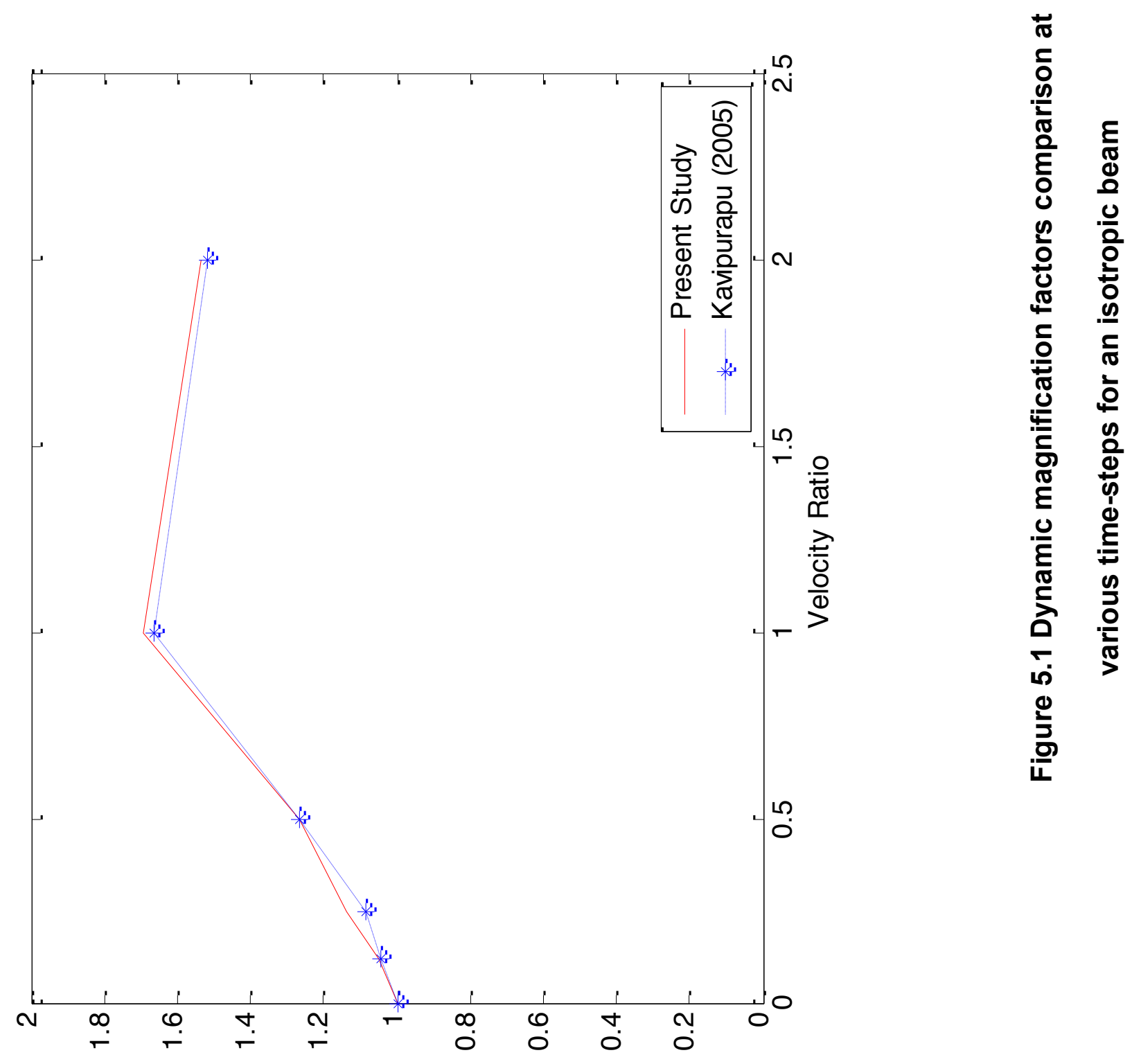
The dynamic deflections at each time step are listed in Tables 5.6 - 5.10 for moving load velocities of $15.60 \mathrm{~m} / \mathrm{s}, 31.20 \mathrm{~m} / \mathrm{s}, 62.40 \mathrm{~m} / \mathrm{s}, 124.80 \mathrm{~m} / \mathrm{s}$, and for $250.00 \mathrm{~m} / \mathrm{s}$, respectively. The corresponding plots are shown in Figures 5.2 - 5.6. It can be seen that in the first three cases the maximum mid-span deflection as a function of time precedes the arrival of the load at this location while it is just the opposite at the higher speeds. Further the curves become smoother as the moving-load velocity increases. For the first four velocity cases, the dynamic deflections as a function of time show a u-shaped curve implying the magnitude increases and then decreases as the moving load passes the mid-span; but in the highest velocity case $(250 \mathrm{~m} / \mathrm{s})$, due to the high speed, the deflection has not had sufficient time to go into the decreasing phase of the magnitude of the deflection. As a comparison, these graphs include is the equivalent plots taken from Kavipurapu (2005), and the agreement from the two sets is very good. The graphs from Kavipurapu (2005) study are read through a program called Digitizelt. To make sure, Digitizelt works properly, the present time varying plot at $V=15.60 \mathrm{~m} / \mathrm{s}$ is read through the program (Table 5.6) and plotted against the present results (Figure 5.2); it is concluded that Digitizelt reads the plots very accurately. It can also be noted that for $V=124.80 \mathrm{~m} / \mathrm{s}$ (Figure 5.5 ), there is no comparison with that of Kavipurapu, since he has not provided results. 


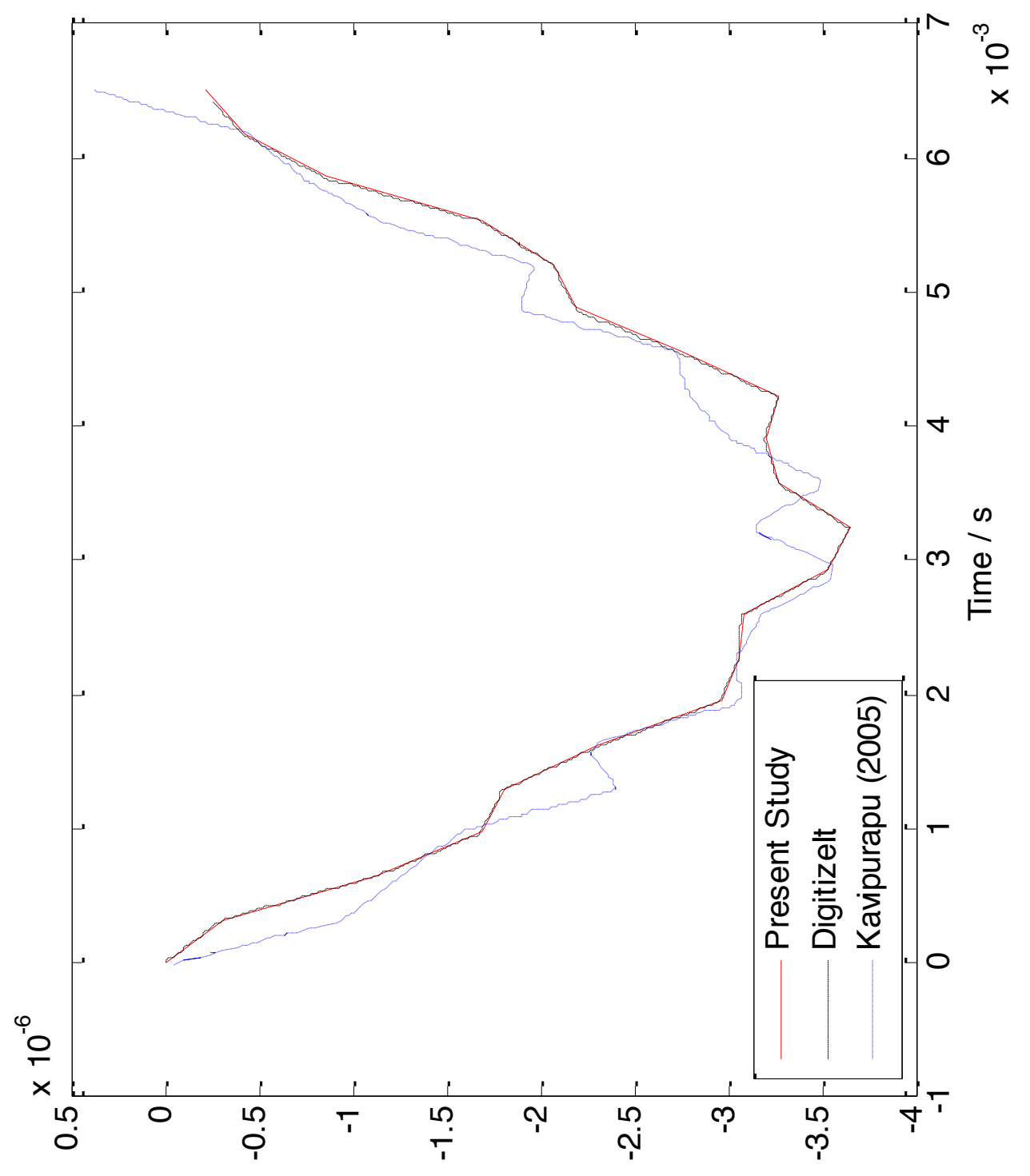

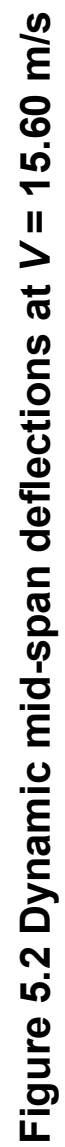


Table 5.6 Mid-span deflections at the end of each time-step for $V=15.60 \mathrm{~m} / \mathrm{s}$

\begin{tabular}{|c|c|c|}
\hline \multirow{2}{*}{ Time at the end of each load-step (s) } & \multicolumn{2}{|c|}{ Mid-span dynamic deflection (m) } \\
\cline { 2 - 3 } & Present & Digitizelt \\
\hline 0 & 0 & 0 \\
\hline $3.2564 \times 10^{-4}$ & $-3.1135 \times 10^{-7}$ & $-3.1135 \times 10^{-7}$ \\
\hline $6.5128 \times 10^{-4}$ & $-1.1252 \times 10^{-6}$ & $-1.1253 \times 10^{-6}$ \\
\hline $9.7692 \times 10^{-4}$ & $-1.6896 \times 10^{-6}$ & $-1.6896 \times 10^{-6}$ \\
\hline $1.3026 \times 10^{-3}$ & $-1.8101 \times 10^{-6}$ & $-1.8101 \times 10^{-6}$ \\
\hline $1.6828 \times 10^{-3}$ & $-2.3044 \times 10^{-6}$ & $-2.3046 \times 10^{-6}$ \\
\hline $1.9538 \times 10^{-3}$ & $-2.9696 \times 10^{-6}$ & $-2.9697 \times 10^{-6}$ \\
\hline $2.2795 \times 10^{-3}$ & $-3.0606 \times 10^{-6}$ & $-3.0607 \times 10^{-6}$ \\
\hline $2.6051 \times 10^{-3}$ & $-3.0794 \times 10^{-6}$ & $-3.0793 \times 10^{-6}$ \\
\hline $2.9308 \times 10^{-3}$ & $-3.5306 \times 10^{-6}$ & $-3.5307 \times 10^{-6}$ \\
\hline $3.2564 \times 10^{-3}$ & $-3.6506 \times 10^{-6}$ & $-3.6508 \times 10^{-6}$ \\
\hline $3.5821 \times 10^{-3}$ & $-3.2651 \times 10^{-6}$ & $-3.2652 \times 10^{-6}$ \\
\hline $3.9077 \times 10^{-3}$ & $-3.1982 \times 10^{-6}$ & $-3.1983 \times 10^{-6}$ \\
\hline $4.2333 \times 10^{-3}$ & $-3.2727 \times 10^{-6}$ & $-3.2729 \times 10^{-6}$ \\
\hline $4.5590 \times 10^{-3}$ & $-2.7562 \times 10^{-6}$ & $-2.7563 \times 10^{-6}$ \\
\hline $4.8846 \times 10^{-3}$ & $-2.1873 \times 10^{-6}$ & $-2.1873 \times 10^{-6}$ \\
\hline $5.2103 \times 10^{-3}$ & $-2.0763 \times 10^{-6}$ & $-2.0763 \times 10^{-6}$ \\
\hline $5.5359 \times 10^{-3}$ & $-1.6870 \times 10^{-6}$ & $-1.6871 \times 10^{-6}$ \\
\hline $5.8615 \times 10^{-3}$ & $-8.6070 \times 10^{-7}$ & $-8.6071 \times 10^{-7}$ \\
\hline $6.1872 \times 10^{-3}$ & $-4.3163 \times 10^{-7}$ & $-4.3164 \times 10^{-7}$ \\
\hline $6.5128 \times 10^{-3}$ & $-2.1133 \times 10^{-7}$ & $-2.1134 \times 10^{-7}$ \\
\hline
\end{tabular}




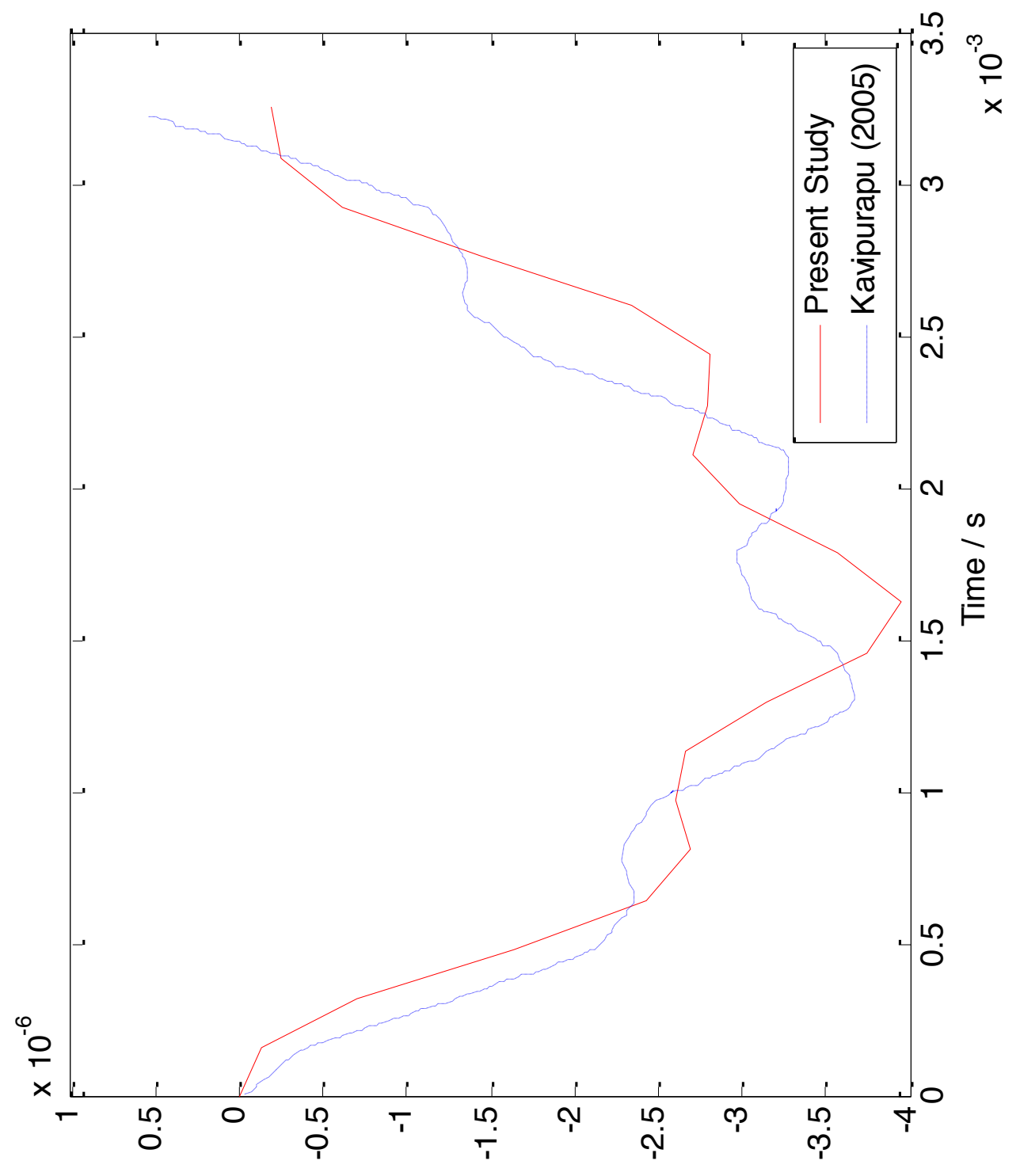

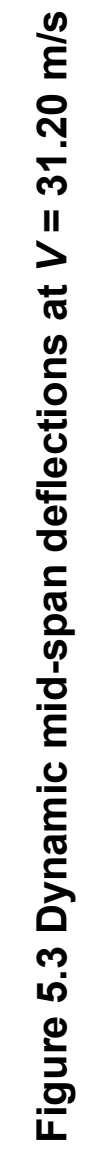


Table 5.7 Mid-span deflections at the end of each time-step for

$V=31.20 \mathrm{~m} / \mathrm{s}$

\begin{tabular}{|c|c|}
\hline Time at the end of each load-step (s) & Mid-span dynamic deflection (m) \\
\hline 0 & 0 \\
\hline $1.6282 \times 10^{-4}$ & $-1.3562 \times 10^{-7}$ \\
\hline $3.2564 \times 10^{-4}$ & $-7.0200 \times 10^{-7}$ \\
\hline $4.8846 \times 10^{-4}$ & $-1.6373 \times 10^{-6}$ \\
\hline $6.5128 \times 10^{-4}$ & $-2.4265 \times 10^{-6}$ \\
\hline $8.1410 \times 10^{-4}$ & $-2.6999 \times 10^{-6}$ \\
\hline $9.7692 \times 10^{-4}$ & $-2.6049 \times 10^{-6}$ \\
\hline $1.1397 \times 10^{-3}$ & $-2.6635 \times 10^{-6}$ \\
\hline $1.3026 \times 10^{-3}$ & $-3.1365 \times 10^{-6}$ \\
\hline $1.4654 \times 10^{-3}$ & $-3.7438 \times 10^{-6}$ \\
\hline $1.6282 \times 10^{-3}$ & $-3.9523 \times 10^{-6}$ \\
\hline $1.7910 \times 10^{-3}$ & $-3.5748 \times 10^{-6}$ \\
\hline $1.9538 \times 10^{-3}$ & $-2.9928 \times 10^{-6}$ \\
\hline $2.1167 \times 10^{-3}$ & $-2.7015 \times 10^{-6}$ \\
\hline $2.2795 \times 10^{-3}$ & $-2.7898 \times 10^{-6}$ \\
\hline $2.4423 \times 10^{-3}$ & $-2.8134 \times 10^{-6}$ \\
\hline $2.6051 \times 10^{-3}$ & $-2.3495 \times 10^{-6}$ \\
\hline $2.7679 \times 10^{-3}$ & $-1.4487 \times 10^{-6}$ \\
\hline $2.9308 \times 10^{-3}$ & $-6.2113 \times 10^{-7}$ \\
\hline $3.0936 \times 10^{-3}$ & $-2.5062 \times 10^{-7}$ \\
\hline $3.2564 \times 10^{-3}$ & $-1.8090 \times 10^{-7}$ \\
\hline
\end{tabular}




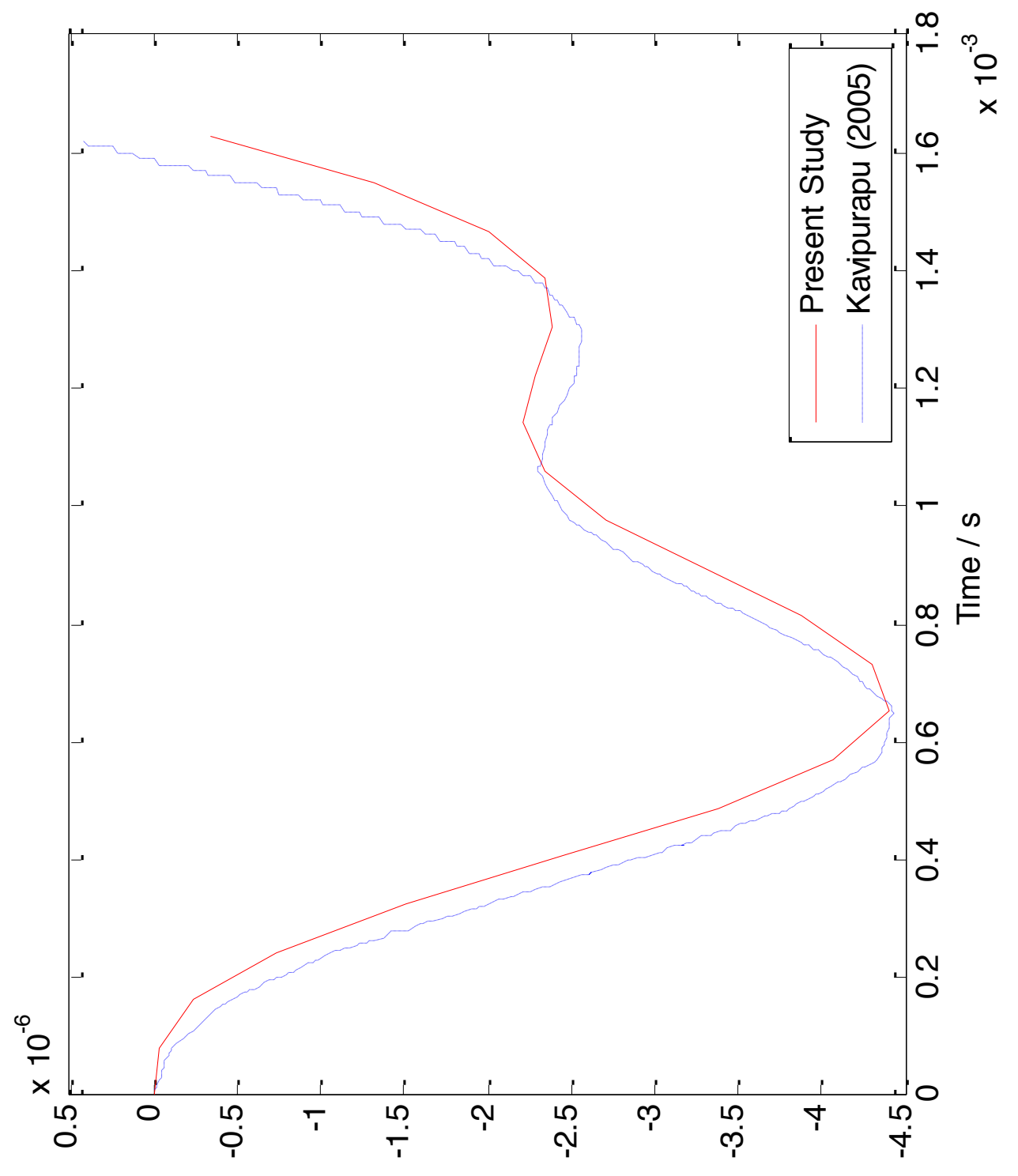

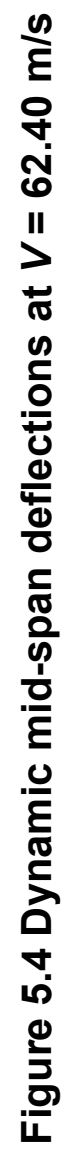


Table 5.8 Mid-span deflections at the end of each time-step for $V=62.40 \mathrm{~m} / \mathrm{s}$

\begin{tabular}{|c|c|}
\hline Time at the end of each load-step (s) & Mid-span dynamic deflection (m) \\
\hline 0 & 0 \\
\hline $8.1410 \times 10^{-5}$ & $-3.3852 \times 10^{-8}$ \\
\hline $1.6282 \times 10^{-4}$ & $-2.3624 \times 10^{-7}$ \\
\hline $2.4423 \times 10^{-4}$ & $-7.3611 \times 10^{-7}$ \\
\hline $3.2564 \times 10^{-4}$ & $-1.5093 \times 10^{-6}$ \\
\hline $4.0705 \times 10^{-4}$ & $-2.4557 \times 10^{-6}$ \\
\hline $4.8846 \times 10^{-4}$ & $-3.3832 \times 10^{-6}$ \\
\hline $5.6987 \times 10^{-4}$ & $-4.0726 \times 10^{-6}$ \\
\hline $6.5128 \times 10^{-4}$ & $-4.4028 \times 10^{-6}$ \\
\hline $7.3269 \times 10^{-4}$ & $-4.3095 \times 10^{-6}$ \\
\hline $8.1410 \times 10^{-4}$ & $-3.8818 \times 10^{-6}$ \\
\hline $8.9551 \times 10^{-4}$ & $-3.2885 \times 10^{-6}$ \\
\hline $9.7692 \times 10^{-4}$ & $-2.7139 \times 10^{-6}$ \\
\hline $1.0583 \times 10^{-3}$ & $-2.3420 \times 10^{-6}$ \\
\hline $1.1397 \times 10^{-3}$ & $-2.2127 \times 10^{-6}$ \\
\hline $1.2212 \times 10^{-3}$ & $-2.2748 \times 10^{-6}$ \\
\hline $1.3026 \times 10^{-3}$ & $-2.3864 \times 10^{-6}$ \\
\hline $1.3840 \times 10^{-3}$ & $-2.3421 \times 10^{-6}$ \\
\hline $1.4654 \times 10^{-3}$ & $-2.0134 \times 10^{-6}$ \\
\hline $1.5468 \times 10^{-3}$ & $-1.3313 \times 10^{-6}$ \\
\hline $1.6282 \times 10^{-3}$ & $-3.5427 \times 10^{-7}$ \\
\hline
\end{tabular}




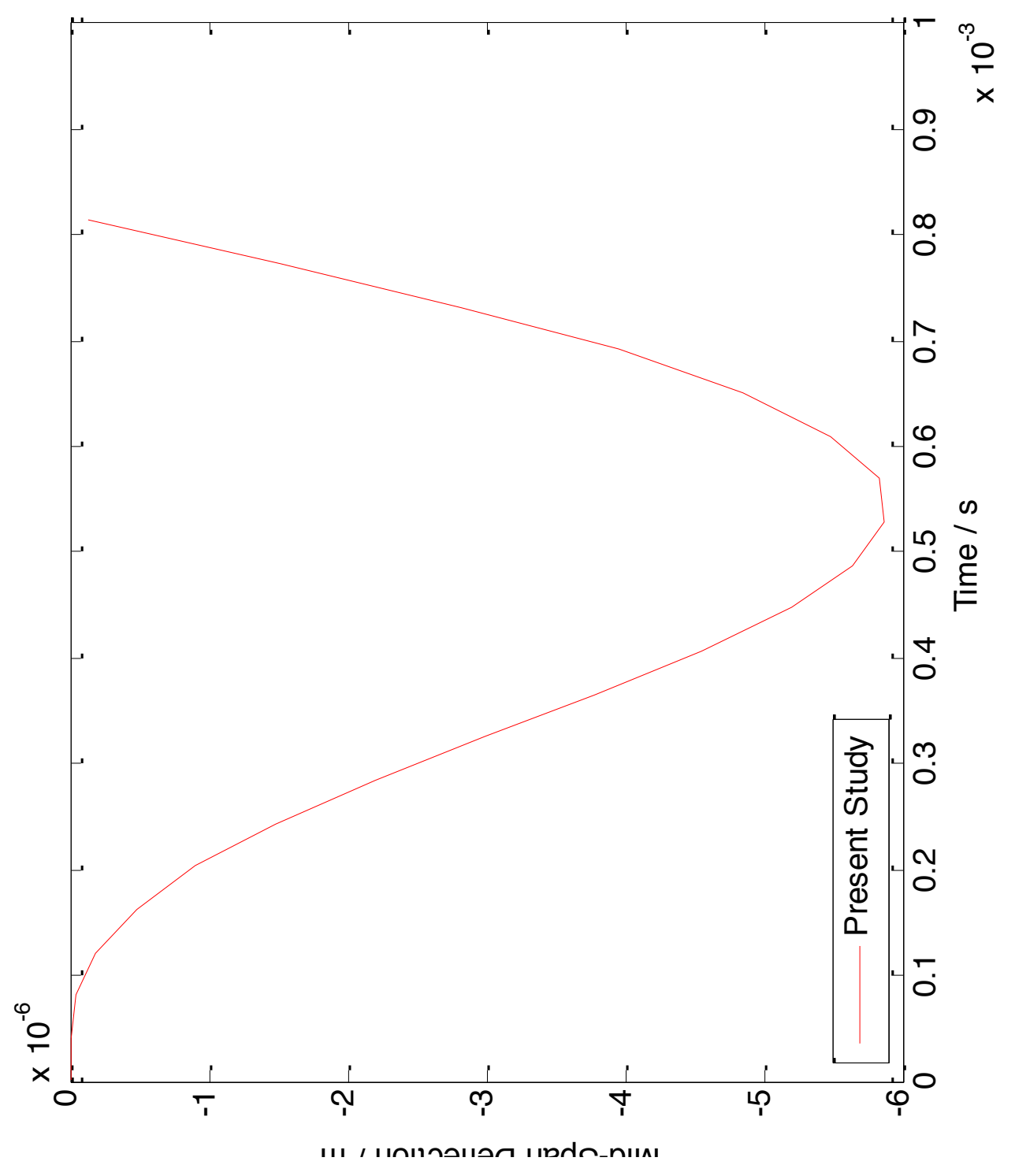

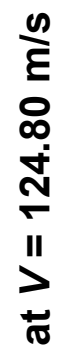

o

은

뜸

동 
Table 5.9 Mid-span deflections at the end of each time-step for

$$
V=124.80 \mathrm{~m} / \mathrm{s}
$$

\begin{tabular}{|c|c|}
\hline Time at the end of each load-step (s) & Mid-span dynamic deflection (m) \\
\hline 0 & 0 \\
\hline $4.0705 \times 10^{-5}$ & $-2.8313 \times 10^{-9}$ \\
\hline $8.1410 \times 10^{-5}$ & $-4.0803 \times 10^{-8}$ \\
\hline $1.2212 \times 10^{-4}$ & $-1.8860 \times 10^{-7}$ \\
\hline $1.6282 \times 10^{-4}$ & $-4.8202 \times 10^{-7}$ \\
\hline $2.0353 \times 10^{-4}$ & $-9.0529 \times 10^{-7}$ \\
\hline $2.4423 \times 10^{-4}$ & $-1.4804 \times 10^{-6}$ \\
\hline $2.8494 \times 10^{-4}$ & $-2.1986 \times 10^{-6}$ \\
\hline $3.2564 \times 10^{-4}$ & $-2.9844 \times 10^{-6}$ \\
\hline $3.6635 \times 10^{-4}$ & $-3.7870 \times 10^{-6}$ \\
\hline $4.0705 \times 10^{-4}$ & $-4.5581 \times 10^{-6}$ \\
\hline $4.4776 \times 10^{-4}$ & $-5.2040 \times 10^{-6}$ \\
\hline $4.8846 \times 10^{-4}$ & $-5.6482 \times 10^{-6}$ \\
\hline $5.2917 \times 10^{-4}$ & $-5.8749 \times 10^{-6}$ \\
\hline $5.6987 \times 10^{-4}$ & $-5.8367 \times 10^{-6}$ \\
\hline $6.1058 \times 10^{-4}$ & $-5.4852 \times 10^{-6}$ \\
\hline $6.5128 \times 10^{-4}$ & $-4.8511 \times 10^{-6}$ \\
\hline $6.9199 \times 10^{-4}$ & $-3.9589 \times 10^{-6}$ \\
\hline $7.3269 \times 10^{-4}$ & $-2.8237 \times 10^{-6}$ \\
\hline $7.7340 \times 10^{-4}$ & $-1.5157 \times 10^{-6}$ \\
\hline $8.1410 \times 10^{-4}$ & $-1.3331 \times 10^{-7}$ \\
\hline
\end{tabular}




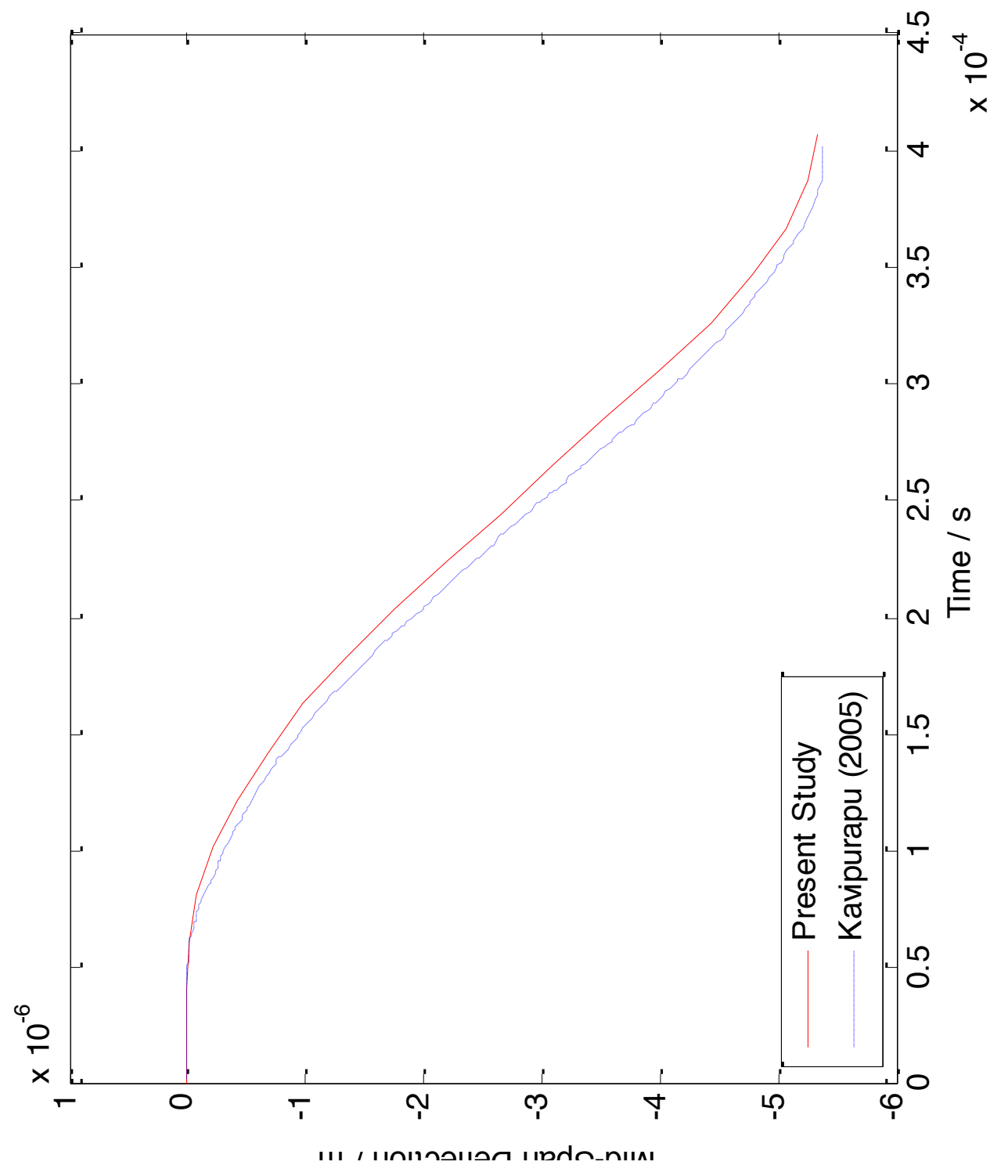

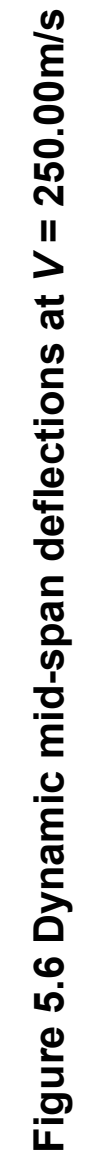


Table 5.10 Mid-span deflections at the end of each time-step for

$$
V=250.00 \mathrm{~m} / \mathrm{s}
$$

\begin{tabular}{|c|c|}
\hline Time at the end of each load-step (s) & Mid-span dynamic deflection (m) \\
\hline 0 & 0 \\
\hline $2.0320 \times 10^{-5}$ & $-8.7431 \times 10^{-10}$ \\
\hline $4.0640 \times 10^{-5}$ & $-3.2156 \times 10^{-9}$ \\
\hline $6.0960 \times 10^{-5}$ & $-8.9516 \times 10^{-9}$ \\
\hline $8.1280 \times 10^{-5}$ & $-7.7026 \times 10^{-8}$ \\
\hline $1.0160 \times 10^{-4}$ & $-2.2350 \times 10^{-7}$ \\
\hline $1.2192 \times 10^{-4}$ & $-4.2961 \times 10^{-7}$ \\
\hline $1.4224 \times 10^{-4}$ & $-6.8137 \times 10^{-7}$ \\
\hline $1.6256 \times 10^{-4}$ & $-9.7869 \times 10^{-7}$ \\
\hline $1.8288 \times 10^{-4}$ & $-1.3317 \times 10^{-6}$ \\
\hline $2.0320 \times 10^{-4}$ & $-1.7485 \times 10^{-6}$ \\
\hline $2.2352 \times 10^{-4}$ & $-2.1947 \times 10^{-6}$ \\
\hline $2.4384 \times 10^{-4}$ & $-2.6386 \times 10^{-6}$ \\
\hline $2.6416 \times 10^{-4}$ & $-3.0800 \times 10^{-6}$ \\
\hline $2.8448 \times 10^{-4}$ & $-3.5261 \times 10^{-6}$ \\
\hline $3.0480 \times 10^{-4}$ & $-3.9788 \times 10^{-6}$ \\
\hline $3.2512 \times 10^{-4}$ & $-4.4120 \times 10^{-6}$ \\
\hline $3.4544 \times 10^{-4}$ & $-4.7779 \times 10^{-6}$ \\
\hline $3.6576 \times 10^{-4}$ & $-5.0508 \times 10^{-6}$ \\
\hline $3.8608 \times 10^{-4}$ & $-5.2379 \times 10^{-6}$ \\
\hline $4.0640 \times 10^{-4}$ & $-5.3307 \times 10^{-6}$ \\
\hline
\end{tabular}




\subsection{Composite Beam Analysis}

In this section the verification of the theoretical formulation, finite element formulation, and the numerical implementation in MATLAB are verified for the case of composite beams under CLPT and FSDT.

\subsubsection{Verification of Results with Kadivar and Mohebpur (1997)}

The geometric and composite-material (glass/epoxy) properties for this part of the analysis are taken from Kadivar and Mohebpur (1997) and are given in Table 5.11. Three different lay-ups, namely, $[0 / 90]_{s},[0 / \pm 45 / 90]$ and $[ \pm 45]$, are considered.

Table 5.11 Dimensions and material properties of glass/epoxy composite beam

\begin{tabular}{|c|c|}
\hline Length, $L$ & $0.1018 \mathrm{~m}$ \\
\hline Width, $b$ & $0.00635 \mathrm{~m}$ \\
\hline Total Thickness, $h$ & $0.00745 \mathrm{~m}$ \\
\hline Density, $\rho$ & $1389.297 \mathrm{~kg} / \mathrm{m}^{3}$ \\
\hline Longitudinal Modulus of Elasticity, $E_{1}$ & $144.8 \mathrm{GPa}$ \\
\hline Longitudinal Modulus of Elasticity, $E_{2}$ & $9.650 \mathrm{GPa}$ \\
\hline Inplane Shear Modulus, $G_{12}$ & $4.136 \mathrm{GPa}$ \\
\hline Transverse Shear Modulus, $G_{13}$ & $4.136 \mathrm{GPa}$ \\
\hline Transverse Shear Modulus, $G_{23}$ & $3.447 \mathrm{GPa}$ \\
\hline Poisson's ratio, $v_{12}$ & 0.25 \\
\hline
\end{tabular}




\subsubsection{Symmetric Cross-Ply Laminated Composite Beam}

The analysis is done on a symmetric cross-ply laminated simply-supported beam, $[0 / 90]_{s}$, with four layers each having equal thickness with a total thickness of $7.45 \mathrm{~mm}$. A static analysis is run first, with a load of $P=-4.45 \mathrm{~N}$ applied at the mid-span of the beam and the results are listed below in Table 5.12

Table 5.12 Mid-span static deflection of glass/epoxy composite beam, $[0 / 90]_{s}$

\begin{tabular}{|c|c|}
\hline \multicolumn{2}{|c|}{ Present study } \\
\hline CLPT & FSDT \\
\hline$-3.4674 \times 10^{-6} \mathrm{~m}$ & $-4.2088 \times 10^{-6} \mathrm{~m}$ \\
\hline
\end{tabular}

By modal analysis, it is found that the simply-supported composite beam has a fundamental time period of $T_{f}=3.1877 \times 10^{-4} \mathrm{~s}$ for CLPT and $T_{f}=3.4598 \times$ $10^{-4} \mathrm{~s}$ for FSDT. Similar to the isotropic beam, Table 5.13 lists the different total times and time-steps with their corresponding velocities for both CLPT and FSDT. These are used to achieve the dynamic magnification factors for comparison with Kadivar and Mohebpur. In their paper, they compare isotropic beam and composite beam all in one table and it can easily be misinterpreted since the velocities and the velocity ratios do not result in the same value for the time steps. Thus, in the present work, Table 5.13 lists the corrected time-steps with the corresponding velocities for comparison with Kadivar and Mohebpur. 
Table 5.13 Moving load velocities and time-steps for composite beam, $[0 / 90]_{s}$

\begin{tabular}{|c|c|c|c|c|c|c|}
\hline \multirow{2}{*}{\multicolumn{2}{|c|}{ Velocity (m/s) }} & \multirow{3}{*}{$T_{f} / T$} & \multicolumn{4}{|c|}{ Composite beam $[0 / 90]_{\underline{s}}$} \\
\hline & & & \multicolumn{2}{|c|}{$T(\mathbf{s})$} & \multicolumn{2}{|c|}{$\Delta t(\mathrm{~s})$} \\
\hline CLPT & FSDT & & CLPT & FSDT & CLPT & FSDT \\
\hline 39.84 & 36.71 & 0.125 & $2.5502 \mathrm{E}-3$ & $2.7676 \mathrm{E}-3$ & $1.2751 \mathrm{E}-4$ & $1.3838 \mathrm{E}-4$ \\
\hline 79.68 & 73.41 & 0.25 & $1.2748 \mathrm{E}-3$ & $1.3840 \mathrm{E}-3$ & $0.6374 \mathrm{E}-4$ & $0.6920 \mathrm{E}-4$ \\
\hline 159.36 & 146.83 & 0.5 & $0.6374 \mathrm{E}-3$ & $0.6920 \mathrm{E}-3$ & $0.3187 \mathrm{E}-4$ & $0.3460 \mathrm{E}-4$ \\
\hline 239.04 & 220.24 & 0.75 & $0.4249 \mathrm{E}-3$ & $0.4613 E-3$ & $0.2125 \mathrm{E}-4$ & $0.2307 E-4$ \\
\hline 318.73 & 293.66 & 1 & $0.3187 \mathrm{E}-3$ & $0.3460 \mathrm{E}-3$ & $0.1594 \mathrm{E}-4$ & $0.1730 \mathrm{E}-4$ \\
\hline 398.41 & 367.07 & 1.25 & $0.2550 \mathrm{E}-3$ & $0.2768 \mathrm{E}-3$ & $0.1275 E-4$ & $0.1384 \mathrm{E}-4$ \\
\hline 637.45 & 587.32 & 2 & $0.1594 \mathrm{E}-3$ & $0.1730 \mathrm{E}-3$ & $0.0797 \mathrm{E}-4$ & $0.0865 \mathrm{E}-4$ \\
\hline
\end{tabular}

The applied load as before is $P=-4.45 \mathrm{~N}$. Table 5.14 , lists the maximum dynamic mid-span deflection at different velocities. Since Kadivar and Mohebpur do not list these, it is not possible to show a comparison in this table. 
Table 5.14 Maximum mid-span dynamic deflections for different velocities, $[0 / 90]_{s}$

\begin{tabular}{|c|c|c|c|}
\hline \multirow{2}{*}{ Velocity $(\mathbf{m} / \mathbf{s})$} & \multicolumn{2}{c|}{ Maximum mid-span dynamic deflections $(\mathrm{m})$} \\
\cline { 3 - 4 } & & \multicolumn{2}{|c|}{ Present study } \\
\hline CLPT & FSDT & CLPT & FSDT \\
\hline 39.84 & 36.71 & $-3.6452 \times 10^{-6}$ & $-4.4187 \times 10^{-6}$ \\
\hline 79.68 & 73.41 & $-3.9471 \times 10^{-6}$ & $-4.7803 \times 10^{-6}$ \\
\hline 159.36 & 146.83 & $-4.3964 \times 10^{-6}$ & $-5.1840 \times 10^{-6}$ \\
\hline 239.04 & 220.24 & $-5.4419 \times 10^{-6}$ & $-6.5112 \times 10^{-6}$ \\
\hline 318.73 & 293.66 & $-5.8667 \times 10^{-6}$ & $-7.0034 \times 10^{-6}$ \\
\hline 398.41 & 367.07 & $-5.9553 \times 10^{-6}$ & $-7.0091 \times 10^{-6}$ \\
\hline 637.45 & 587.32 & $-5.3286 \times 10^{-6}$ & $-6.2593 \times 10^{-6}$ \\
\hline
\end{tabular}

The dynamic magnification factors for this example are listed in Table 5.15. They are compared with the results from Kadivar and Mohebpur (1997). 
Table 5.15 Dynamic magnification factors comparison for different velocities, $[0 / 90]_{s}$

\begin{tabular}{|c|c|c|c|c|c|}
\hline \multirow{2}{*}{ Velocity (m/s) } & \multicolumn{4}{|c|}{ Dynamic magnification factors } \\
\cline { 3 - 6 } & \multicolumn{2}{|c|}{ Present study } & \multicolumn{2}{c|}{$\begin{array}{c}\text { Kadivar and } \\
\text { Mohebpur }\end{array}$} \\
\hline CLPT & FSDT & CLPT & FSDT & CLPT & FSDT \\
\hline 39.84 & 36.71 & 1.051 & 1.050 & 1.052 & 1.063 \\
\hline 79.68 & 73.41 & 1.138 & 1.136 & 1.133 & 1.151 \\
\hline 159.36 & 146.83 & 1.268 & 1.232 & 1.265 & 1.281 \\
\hline 239.04 & 220.24 & 1.569 & 1.547 & 1.571 & 1.586 \\
\hline 318.73 & 293.66 & 1.692 & 1.664 & 1.692 & 1.704 \\
\hline 398.41 & 367.07 & 1.718 & 1.665 & 1.717 & 1.727 \\
\hline 637.45 & 587.32 & 1.537 & 1.487 & 1.535 & 1.542 \\
\hline
\end{tabular}

It can be seen, in Table 5.15 and Figure 5.7 that the present CLPT results are in excellent agreement with that of the previous authors. The results for FSDT differ slightly - a presumed reason for this is the use of higher order beam elements in the present research while Kadivar and Mohebpur use conventional 2-noded elements. 

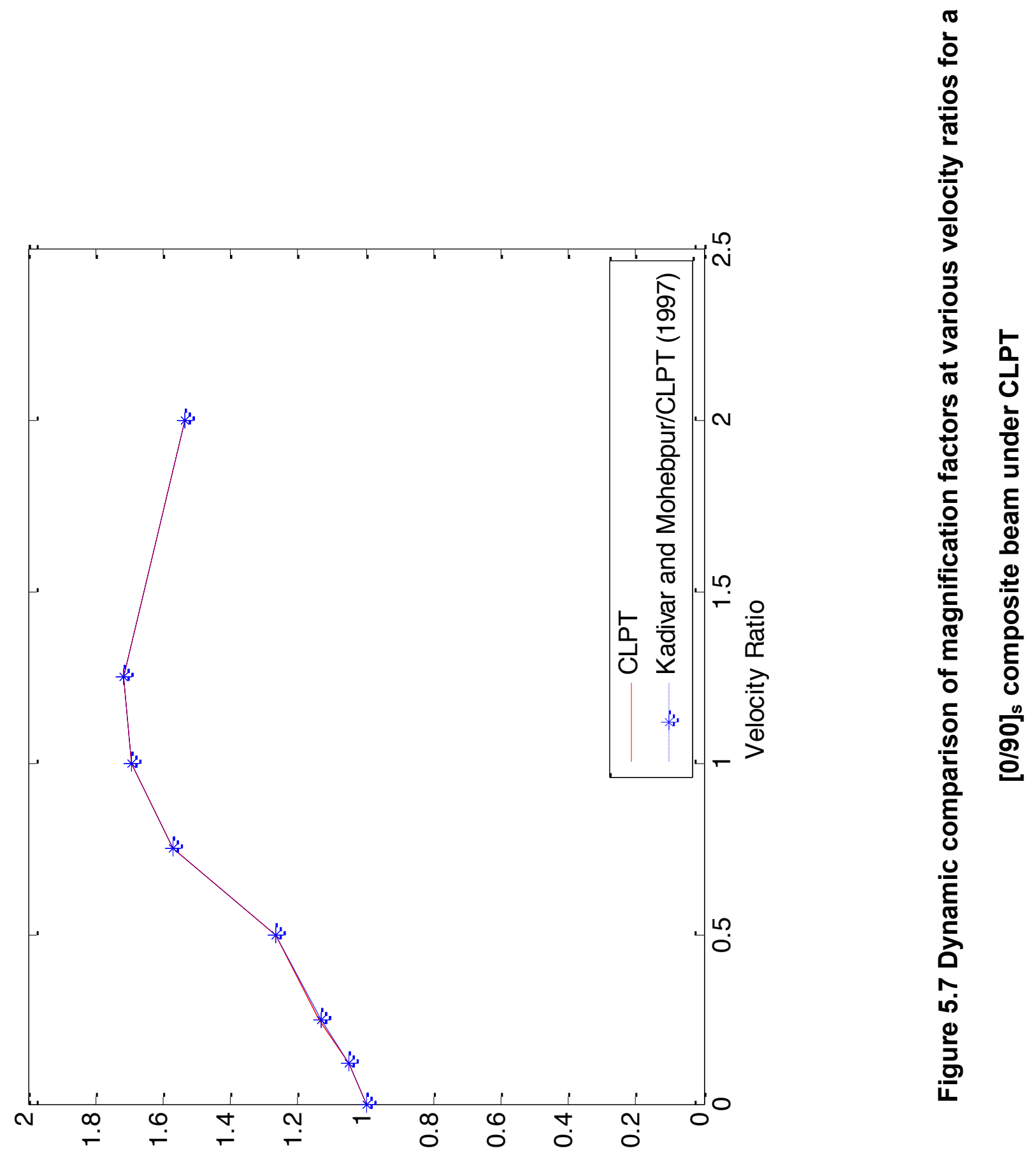

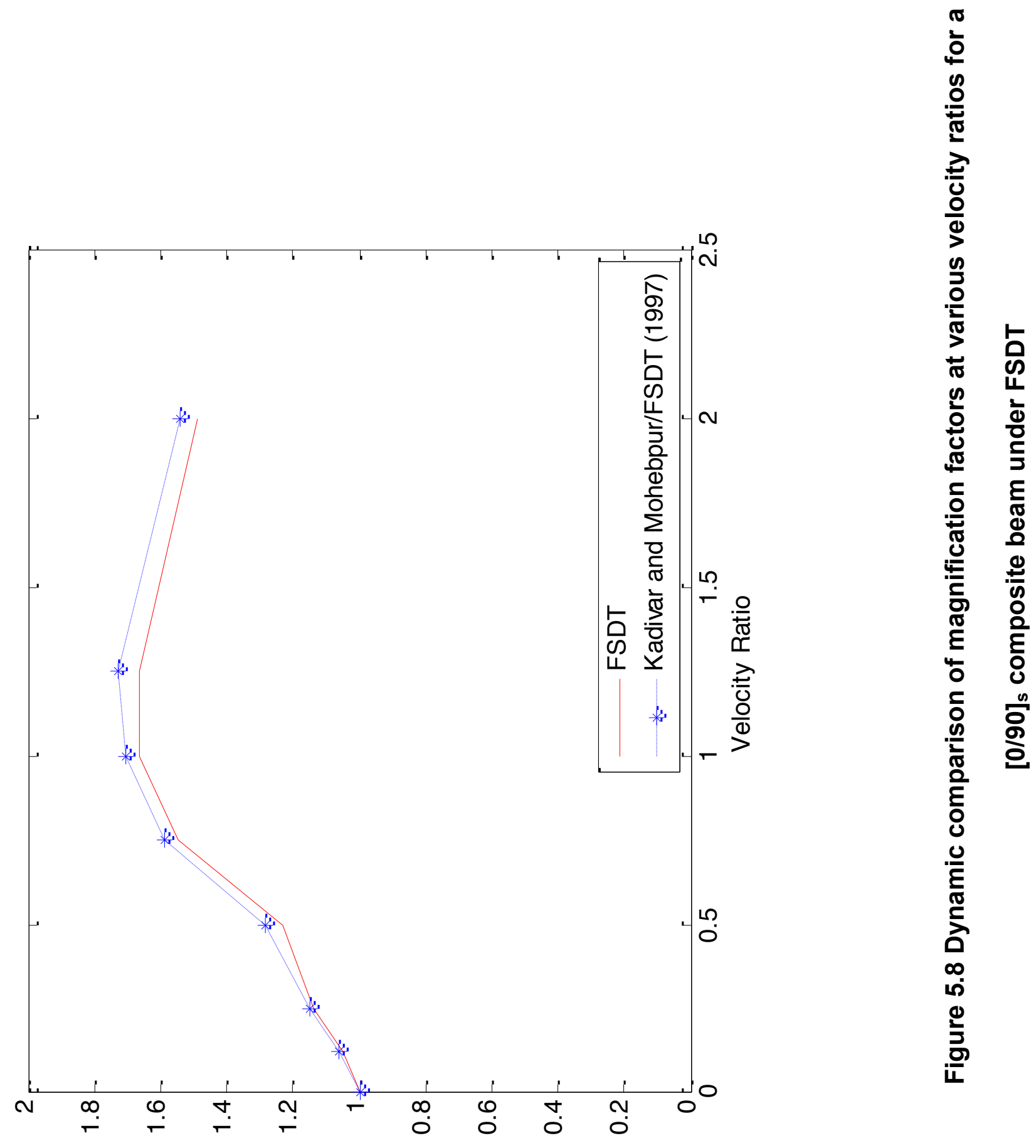
Figures 5.8 to 5.14 show the dynamic deflections for the load of $P=4.45$ $\mathrm{N}$ moving at the velocities listed in Table 5.15. Each of these graphs has two plots for the present study; one is for CLPT and the other for FSDT. Tables 5.16 to 5.22 list the values of the mid-span dynamic deflection at the end of each timestep at different velocities for the composite beam $[0 / 90]_{s}$. 


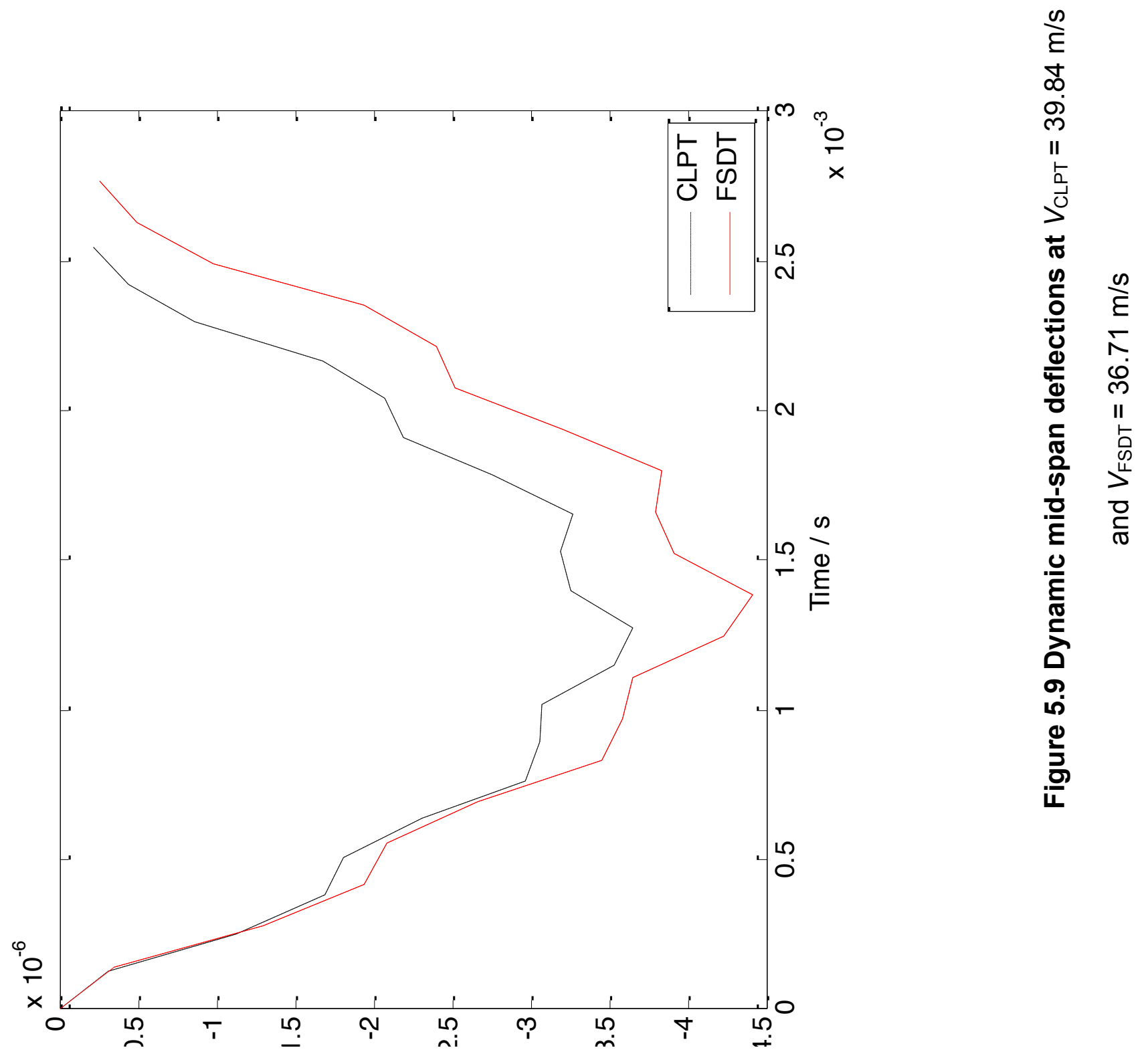


Table 5.16 Mid-span deflections at the end of each time-step for

$$
V_{\mathrm{CLPT}}=39.84 \mathrm{~m} / \mathrm{s} \text { and } V_{\mathrm{FSDT}}=36.71 \mathrm{~m} / \mathrm{s}
$$

\begin{tabular}{|c|c|c|c|}
\hline \multicolumn{2}{|c|}{ Time at the end of each load step (s) } & \multicolumn{2}{c|}{ Mid-span dynamic deflection (m) } \\
\hline CLPT & FSDT & CLPT & FSDT \\
\hline 0 & 0 & 0 & 0 \\
\hline $1.2751 \mathrm{E}-04$ & $1.3838 \mathrm{E}-04$ & $-3.1127 \mathrm{E}-07$ & $-3.5031 \mathrm{E}-07$ \\
\hline $2.5502 \mathrm{E}-04$ & $2.7676 \mathrm{E}-04$ & $-1.1242 \mathrm{E}-06$ & $-1.2918 \mathrm{E}-06$ \\
\hline $3.8253 \mathrm{E}-04$ & $4.1515 \mathrm{E}-04$ & $-1.6872 \mathrm{E}-06$ & $-1.9470 \mathrm{E}-06$ \\
\hline $5.1004 \mathrm{E}-04$ & $5.5353 \mathrm{E}-04$ & $-1.8077 \mathrm{E}-06$ & $-2.0792 \mathrm{E}-06$ \\
\hline $6.3755 \mathrm{E}-04$ & $6.9191 \mathrm{E}-04$ & $-2.3029 \mathrm{E}-06$ & $-2.6687 \mathrm{E}-06$ \\
\hline $7.6506 \mathrm{E}-04$ & $8.3029 \mathrm{E}-04$ & $-2.9664 \mathrm{E}-06$ & $-3.4575 \mathrm{E}-06$ \\
\hline $8.9257 \mathrm{E}-04$ & $9.6867 \mathrm{E}-04$ & $-3.0558 \mathrm{E}-06$ & $-3.5895 \mathrm{E}-06$ \\
\hline $1.0201 \mathrm{E}-03$ & $1.1071 \mathrm{E}-03$ & $-3.0765 \mathrm{E}-06$ & $-3.6463 \mathrm{E}-06$ \\
\hline $1.1476 \mathrm{E}-03$ & $1.2454 \mathrm{E}-03$ & $-3.5282 \mathrm{E}-06$ & $-4.2308 \mathrm{E}-06$ \\
\hline $1.2751 \mathrm{E}-03$ & $1.3838 \mathrm{E}-03$ & $-3.6452 \mathrm{E}-06$ & $-4.4187 \mathrm{E}-06$ \\
\hline $1.4026 \mathrm{E}-03$ & $1.5222 \mathrm{E}-03$ & $-3.2603 \mathrm{E}-06$ & $-3.9137 \mathrm{E}-06$ \\
\hline $1.5301 \mathrm{E}-03$ & $1.6606 \mathrm{E}-03$ & $-3.1970 \mathrm{E}-06$ & $-3.7910 \mathrm{E}-06$ \\
\hline $1.6576 \mathrm{E}-03$ & $1.7990 \mathrm{E}-03$ & $-3.2694 \mathrm{E}-06$ & $-3.8371 \mathrm{E}-06$ \\
\hline $1.7851 \mathrm{E}-03$ & $1.9373 \mathrm{E}-03$ & $-2.7504 \mathrm{E}-06$ & $-3.2080 \mathrm{E}-06$ \\
\hline $1.9127 \mathrm{E}-03$ & $2.0757 \mathrm{E}-03$ & $-2.1859 \mathrm{E}-06$ & $-2.5253 \mathrm{E}-06$ \\
\hline $2.0402 \mathrm{E}-03$ & $2.2141 \mathrm{E}-03$ & $-2.0768 \mathrm{E}-06$ & $-2.4018 \mathrm{E}-06$ \\
\hline $2.1677 \mathrm{E}-03$ & $2.3525 \mathrm{E}-03$ & $-1.6828 \mathrm{E}-06$ & $-1.9367 \mathrm{E}-06$ \\
\hline $2.2952 \mathrm{E}-03$ & $2.4909 \mathrm{E}-03$ & $-8.5778 \mathrm{E}-07$ & $-9.8252 \mathrm{E}-07$ \\
\hline $2.4227 \mathrm{E}-03$ & $2.6293 \mathrm{E}-03$ & $-4.3471 \mathrm{E}-07$ & $-4.9185 \mathrm{E}-07$ \\
\hline $2.5502 \mathrm{E}-03$ & $2.7676 \mathrm{E}-03$ & $-2.1172 \mathrm{E}-07$ & $-2.5198 \mathrm{E}-07$ \\
\hline
\end{tabular}



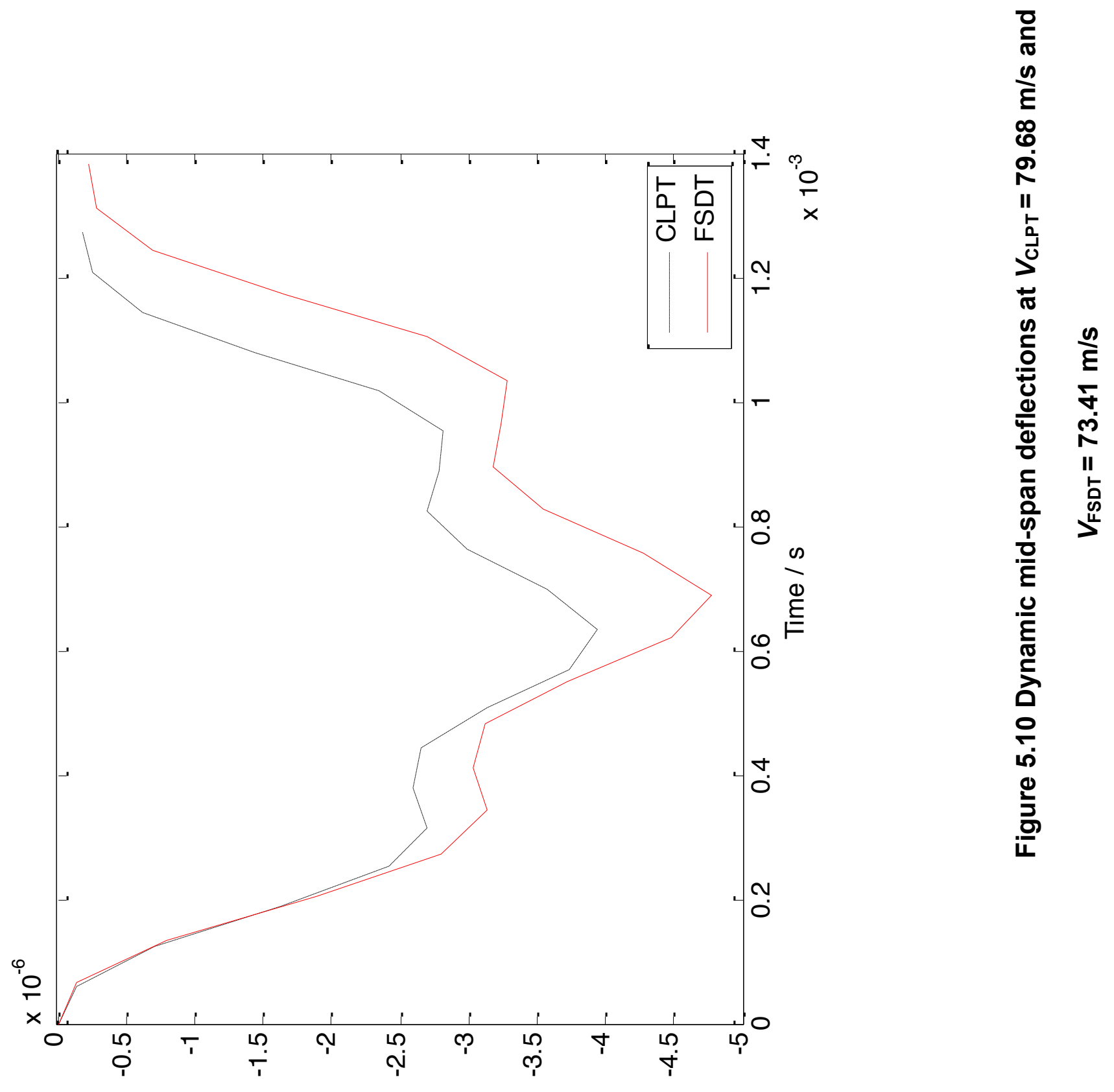
Table 5.17 Mid-span deflections at the end of each time-step for

$$
V_{\mathrm{CLPT}}=79.68 \mathrm{~m} / \mathrm{s} \text { and } V_{\mathrm{FSDT}}=73.41 \mathrm{~m} / \mathrm{s}
$$

\begin{tabular}{|c|c|c|c|}
\hline \multicolumn{2}{|c|}{ Time at the end of each load step (s) } & \multicolumn{2}{c|}{ Mid-span dynamic deflection (m) } \\
\hline CLPT & FSDT & CLPT & FSDT \\
\hline 0 & 0 & 0 & 0 \\
\hline $6.3739 \mathrm{E}-05$ & $6.9200 \mathrm{E}-05$ & $-1.3565 \mathrm{E}-07$ & $-1.4493 \mathrm{E}-07$ \\
\hline $1.2748 \mathrm{E}-04$ & $1.3840 \mathrm{E}-04$ & $-7.0178 \mathrm{E}-07$ & $-7.9096 \mathrm{E}-07$ \\
\hline $1.9122 \mathrm{E}-04$ & $2.0760 \mathrm{E}-04$ & $-1.6362 \mathrm{E}-06$ & $-1.8895 \mathrm{E}-06$ \\
\hline $2.5496 \mathrm{E}-04$ & $2.7680 \mathrm{E}-04$ & $-2.4237 \mathrm{E}-06$ & $-2.8044 \mathrm{E}-06$ \\
\hline $3.1870 \mathrm{E}-04$ & $3.4600 \mathrm{E}-04$ & $-2.6957 \mathrm{E}-06$ & $-3.1296 \mathrm{E}-06$ \\
\hline $3.8243 \mathrm{E}-04$ & $4.1520 \mathrm{E}-04$ & $-2.6007 \mathrm{E}-06$ & $-3.0300 \mathrm{E}-06$ \\
\hline $4.4617 \mathrm{E}-04$ & $4.8440 \mathrm{E}-04$ & $-2.6608 \mathrm{E}-06$ & $-3.1161 \mathrm{E}-06$ \\
\hline $5.0991 \mathrm{E}-04$ & $5.5360 \mathrm{E}-04$ & $-3.1353 \mathrm{E}-06$ & $-3.7253 \mathrm{E}-06$ \\
\hline $5.7365 \mathrm{E}-04$ & $6.2280 \mathrm{E}-04$ & $-3.7413 \mathrm{E}-06$ & $-4.4753 \mathrm{E}-06$ \\
\hline $6.3739 \mathrm{E}-04$ & $6.9200 \mathrm{E}-04$ & $-3.9471 \mathrm{E}-06$ & $-4.7803 \mathrm{E}-06$ \\
\hline $7.0113 \mathrm{E}-04$ & $7.6120 \mathrm{E}-04$ & $-3.5677 \mathrm{E}-06$ & $-4.2732 \mathrm{E}-06$ \\
\hline $7.6487 \mathrm{E}-04$ & $8.3040 \mathrm{E}-04$ & $-2.9877 \mathrm{E}-06$ & $-3.5399 \mathrm{E}-06$ \\
\hline $8.2861 \mathrm{E}-04$ & $8.9960 \mathrm{E}-04$ & $-2.7003 \mathrm{E}-06$ & $-3.1752 \mathrm{E}-06$ \\
\hline $8.9235 \mathrm{E}-04$ & $9.6881 \mathrm{E}-04$ & $-2.7907 \mathrm{E}-06$ & $-3.2447 \mathrm{E}-06$ \\
\hline $9.5609 \mathrm{E}-04$ & $1.0380 \mathrm{E}-03$ & $-2.8119 \mathrm{E}-06$ & $-3.2783 \mathrm{E}-06$ \\
\hline $1.0198 \mathrm{E}-03$ & $1.1072 \mathrm{E}-03$ & $-2.3437 \mathrm{E}-06$ & $-2.7018 \mathrm{E}-06$ \\
\hline $1.0836 \mathrm{E}-03$ & $1.1764 \mathrm{E}-03$ & $-1.4427 \mathrm{E}-06$ & $-1.6613 \mathrm{E}-06$ \\
\hline $1.1473 \mathrm{E}-03$ & $1.2456 \mathrm{E}-03$ & $-6.1936 \mathrm{E}-07$ & $-6.9419 \mathrm{E}-07$ \\
\hline $1.2110 \mathrm{E}-03$ & $1.3148 \mathrm{E}-03$ & $-2.5488 \mathrm{E}-07$ & $-2.8359 \mathrm{E}-07$ \\
\hline $1.2748 \mathrm{E}-03$ & $1.3840 \mathrm{E}-03$ & $-1.8548 \mathrm{E}-07$ & $-2.2666 \mathrm{E}-07$ \\
\hline
\end{tabular}



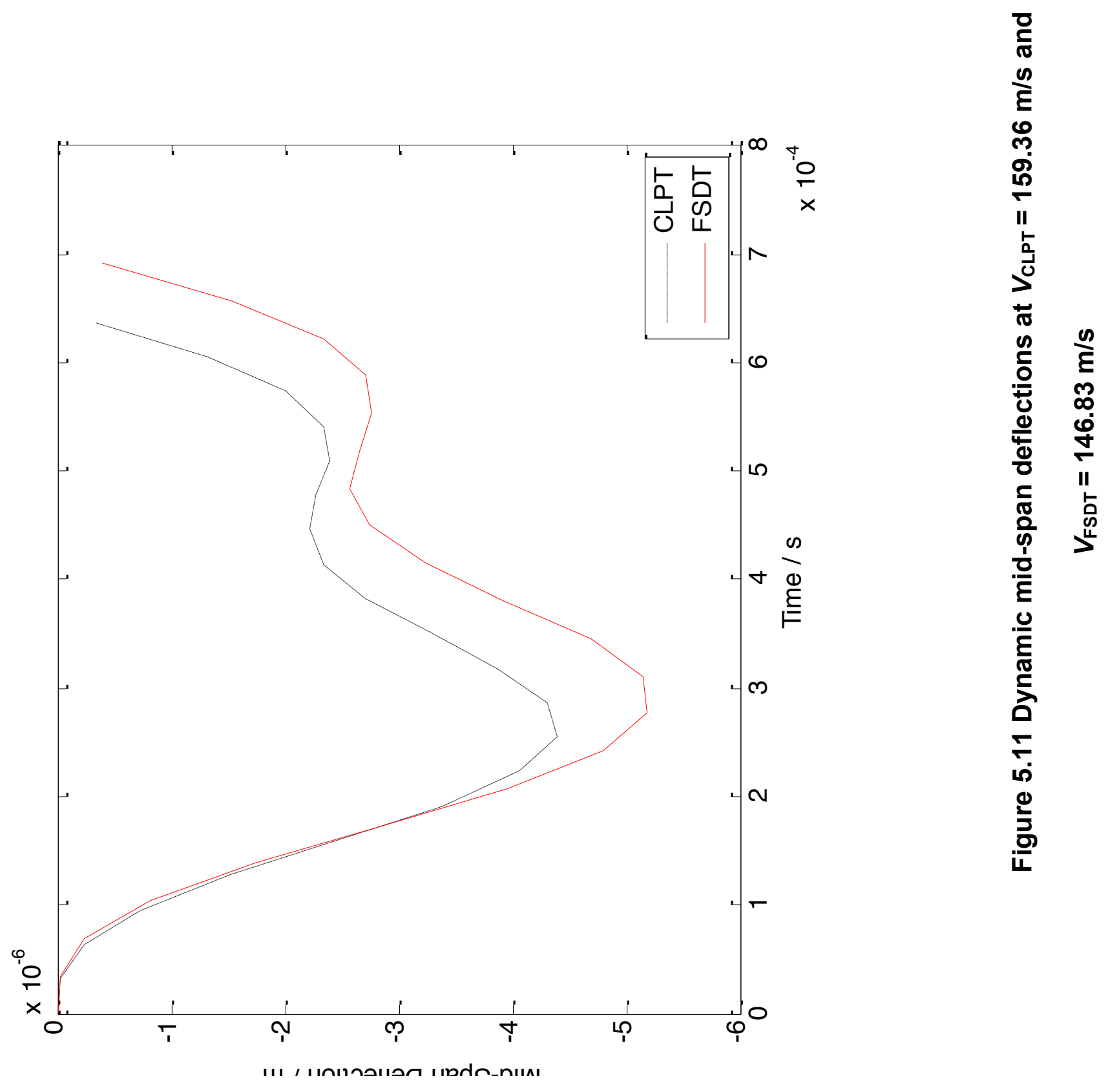
Table 5.18 Mid-span deflections at the end of each time-step for

$$
V_{\text {CLPT }}=159.36 \mathrm{~m} / \mathrm{s} \text { and } V_{\mathrm{FSDT}}=146.83 \mathrm{~m} / \mathrm{s}
$$

\begin{tabular}{|c|c|c|c|}
\hline \multicolumn{2}{|c|}{ Time at the end of each load step (s) } & \multicolumn{2}{c|}{ Mid-span dynamic deflection (m) } \\
\hline CLPT & FSDT & CLPT & FSDT \\
\hline 0 & 0 & 0 & 0 \\
\hline $3.1870 \mathrm{E}-05$ & $3.4598 \mathrm{E}-05$ & $-3.3937 \mathrm{E}-08$ & $-2.9872 \mathrm{E}-08$ \\
\hline $6.3739 \mathrm{E}-05$ & $6.9196 \mathrm{E}-05$ & $-2.3624 \mathrm{E}-07$ & $-2.3816 \mathrm{E}-07$ \\
\hline $9.5609 \mathrm{E}-05$ & $1.0379 \mathrm{E}-04$ & $-7.3613 \mathrm{E}-07$ & $-8.1991 \mathrm{E}-07$ \\
\hline $1.2748 \mathrm{E}-04$ & $1.3839 \mathrm{E}-04$ & $-1.5092 \mathrm{E}-06$ & $-1.7412 \mathrm{E}-06$ \\
\hline $1.5935 \mathrm{E}-04$ & $1.7299 \mathrm{E}-04$ & $-2.4545 \mathrm{E}-06$ & $-2.8321 \mathrm{E}-06$ \\
\hline $1.9122 \mathrm{E}-04$ & $2.0759 \mathrm{E}-04$ & $-3.3810 \mathrm{E}-06$ & $-3.9498 \mathrm{E}-06$ \\
\hline $2.2309 \mathrm{E}-04$ & $2.4218 \mathrm{E}-04$ & $-4.0683 \mathrm{E}-06$ & $-4.7953 \mathrm{E}-06$ \\
\hline $2.5496 \mathrm{E}-04$ & $2.7678 \mathrm{E}-04$ & $-4.3964 \mathrm{E}-06$ & $-5.1840 \mathrm{E}-06$ \\
\hline $2.8683 \mathrm{E}-04$ & $3.1138 \mathrm{E}-04$ & $-4.3020 \mathrm{E}-06$ & $-5.1553 \mathrm{E}-06$ \\
\hline $3.1870 \mathrm{E}-04$ & $3.4598 \mathrm{E}-04$ & $-3.8730 \mathrm{E}-06$ & $-4.6926 \mathrm{E}-06$ \\
\hline $3.5056 \mathrm{E}-04$ & $3.8058 \mathrm{E}-04$ & $-3.2813 \mathrm{E}-06$ & $-3.9216 \mathrm{E}-06$ \\
\hline $3.8243 \mathrm{E}-04$ & $4.1517 \mathrm{E}-04$ & $-2.7089 \mathrm{E}-06$ & $-3.2303 \mathrm{E}-06$ \\
\hline $4.1430 \mathrm{E}-04$ & $4.4977 \mathrm{E}-04$ & $-2.3398 \mathrm{E}-06$ & $-2.7394 \mathrm{E}-06$ \\
\hline $4.4617 \mathrm{E}-04$ & $4.8437 \mathrm{E}-04$ & $-2.2143 \mathrm{E}-06$ & $-2.5631 \mathrm{E}-06$ \\
\hline $4.7804 \mathrm{E}-04$ & $5.1897 \mathrm{E}-04$ & $-2.2772 \mathrm{E}-06$ & $-2.6513 \mathrm{E}-06$ \\
\hline $5.0991 \mathrm{E}-04$ & $5.5357 \mathrm{E}-04$ & $-2.3891 \mathrm{E}-06$ & $-2.7619 \mathrm{E}-06$ \\
\hline $5.4178 \mathrm{E}-04$ & $5.8816 \mathrm{E}-04$ & $-2.3430 \mathrm{E}-06$ & $-2.7132 \mathrm{E}-06$ \\
\hline $5.7365 \mathrm{E}-04$ & $6.2276 \mathrm{E}-04$ & $-2.0099 \mathrm{E}-06$ & $-2.3463 \mathrm{E}-06$ \\
\hline $6.0552 \mathrm{E}-04$ & $6.5736 \mathrm{E}-04$ & $-1.3261 \mathrm{E}-06$ & $-1.5424 \mathrm{E}-06$ \\
\hline $6.3739 \mathrm{E}-04$ & $6.9196 \mathrm{E}-04$ & $-3.4635 \mathrm{E}-07$ & $-3.9516 \mathrm{E}-07$ \\
\hline
\end{tabular}



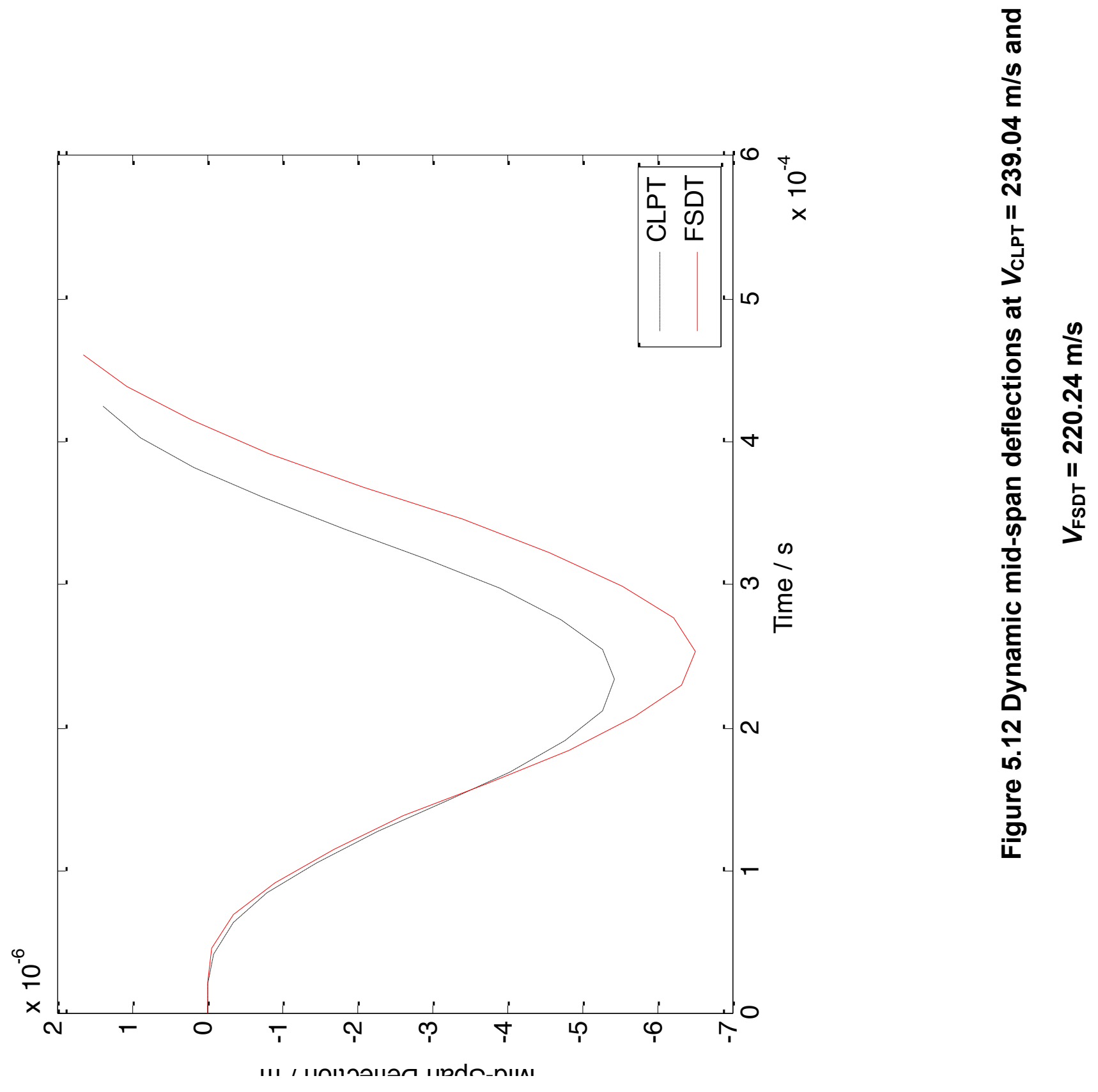
Table 5.19 Mid-span deflections at the end of each time-step for

$$
V_{\mathrm{CLPT}}=239.04 \mathrm{~m} / \mathrm{s} \text { and } V_{\mathrm{FSDT}}=220.24 \mathrm{~m} / \mathrm{s}
$$

\begin{tabular}{|c|c|c|c|}
\hline \multicolumn{2}{|c|}{ Time at the end of each load step (s) } & \multicolumn{2}{c|}{ Mid-span dynamic deflection (m) } \\
\hline CLPT & FSDT & CLPT & FSDT \\
\hline 0 & 0 & 0 & 0 \\
\hline $2.1246 \mathrm{E}-05$ & $2.3066 \mathrm{E}-05$ & $-1.0441 \mathrm{E}-08$ & $-6.8717 \mathrm{E}-09$ \\
\hline $4.2493 \mathrm{E}-05$ & $4.6131 \mathrm{E}-05$ & $-9.5403 \mathrm{E}-08$ & $-7.7427 \mathrm{E}-08$ \\
\hline $6.3739 \mathrm{E}-05$ & $6.9197 \mathrm{E}-05$ & $-3.5477 \mathrm{E}-07$ & $-3.5176 \mathrm{E}-07$ \\
\hline $8.4985 \mathrm{E}-05$ & $9.2263 \mathrm{E}-05$ & $-8.1285 \mathrm{E}-07$ & $-9.1643 \mathrm{E}-07$ \\
\hline $1.0623 \mathrm{E}-04$ & $1.1533 \mathrm{E}-04$ & $-1.4577 \mathrm{E}-06$ & $-1.6873 \mathrm{E}-06$ \\
\hline $1.2748 \mathrm{E}-04$ & $1.3839 \mathrm{E}-04$ & $-2.2803 \mathrm{E}-06$ & $-2.6212 \mathrm{E}-06$ \\
\hline $1.4872 \mathrm{E}-04$ & $1.6146 \mathrm{E}-04$ & $-3.1776 \mathrm{E}-06$ & $-3.7313 \mathrm{E}-06$ \\
\hline $1.6997 \mathrm{E}-04$ & $1.8453 \mathrm{E}-04$ & $-4.0424 \mathrm{E}-06$ & $-4.8185 \mathrm{E}-06$ \\
\hline $1.9122 \mathrm{E}-04$ & $2.0759 \mathrm{E}-04$ & $-4.7880 \mathrm{E}-06$ & $-5.7003 \mathrm{E}-06$ \\
\hline $2.1246 \mathrm{E}-04$ & $2.3066 \mathrm{E}-04$ & $-5.2801 \mathrm{E}-06$ & $-6.3400 \mathrm{E}-06$ \\
\hline $2.3371 \mathrm{E}-04$ & $2.5372 \mathrm{E}-04$ & $-5.4419 \mathrm{E}-06$ & $-6.5112 \mathrm{E}-06$ \\
\hline $2.5496 \mathrm{E}-04$ & $2.7679 \mathrm{E}-04$ & $-5.2638 \mathrm{E}-06$ & $-6.2285 \mathrm{E}-06$ \\
\hline $2.7620 \mathrm{E}-04$ & $2.9985 \mathrm{E}-04$ & $-4.7361 \mathrm{E}-06$ & $-5.5506 \mathrm{E}-06$ \\
\hline $2.9745 \mathrm{E}-04$ & $3.2292 \mathrm{E}-04$ & $-3.9172 \mathrm{E}-06$ & $-4.5751 \mathrm{E}-06$ \\
\hline $3.1870 \mathrm{E}-04$ & $3.4599 \mathrm{E}-04$ & $-2.9210 \mathrm{E}-06$ & $-3.4147 \mathrm{E}-06$ \\
\hline $3.3994 \mathrm{E}-04$ & $3.6905 \mathrm{E}-04$ & $-1.8269 \mathrm{E}-06$ & $-2.0808 \mathrm{E}-06$ \\
\hline $3.6119 \mathrm{E}-04$ & $3.9212 \mathrm{E}-04$ & $-7.6014 \mathrm{E}-07$ & $-8.3806 \mathrm{E}-07$ \\
\hline $3.8243 \mathrm{E}-04$ & $4.1518 \mathrm{E}-04$ & $1.5900 \mathrm{E}-07$ & $2.0743 \mathrm{E}-07$ \\
\hline $4.0368 \mathrm{E}-04$ & $4.3825 \mathrm{E}-04$ & $8.9035 \mathrm{E}-07$ & $1.0637 \mathrm{E}-06$ \\
\hline $4.2493 \mathrm{E}-04$ & $4.6131 \mathrm{E}-04$ & $1.3803 \mathrm{E}-06$ & $1.6437 \mathrm{E}-06$ \\
\hline
\end{tabular}



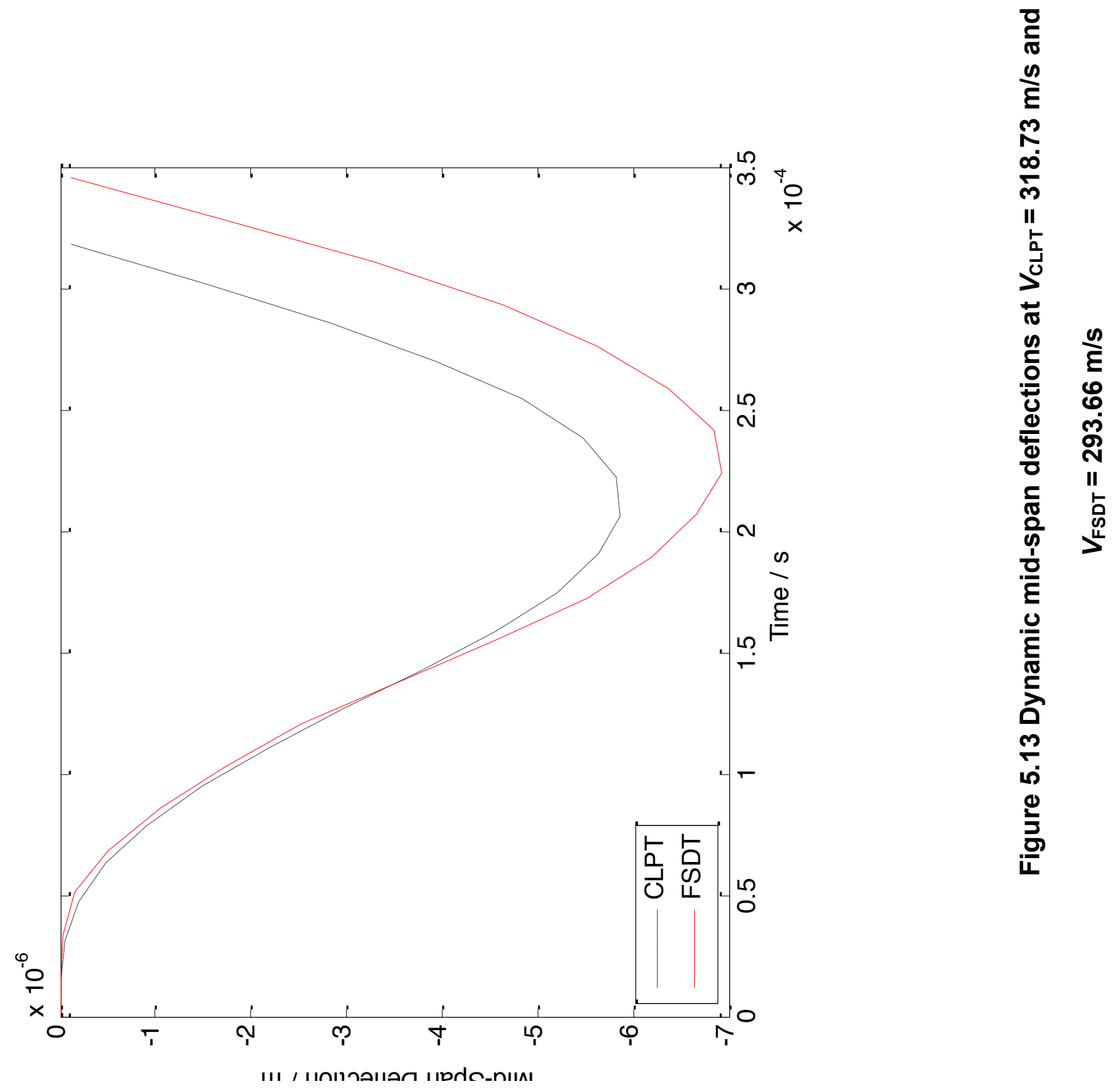
Table 5.20 Mid-span deflections at the end of each time-step for $V_{\text {CLPT }}=318.73 \mathrm{~m} / \mathrm{s}$ and $V_{\text {FSDT }}=293.66 \mathrm{~m} / \mathrm{s}$

\begin{tabular}{|c|c|c|c|}
\hline \multicolumn{2}{|c|}{ Time at the end of each load step (s) } & \multicolumn{2}{c|}{ Mid-span dynamic deflection (m) } \\
\hline CLPT & FSDT & CLPT & FSDT \\
\hline 0 & 0 & 0 & 0 \\
\hline $1.5935 \mathrm{E}-05$ & $1.7299 \mathrm{E}-05$ & $-2.9689 \mathrm{E}-09$ & $-1.2611 \mathrm{E}-09$ \\
\hline $3.1870 \mathrm{E}-05$ & $3.4598 \mathrm{E}-05$ & $-4.0969 \mathrm{E}-08$ & $-2.4023 \mathrm{E}-08$ \\
\hline $4.7804 \mathrm{E}-05$ & $5.1897 \mathrm{E}-05$ & $-1.8828 \mathrm{E}-07$ & $-1.4945 \mathrm{E}-07$ \\
\hline $6.3739 \mathrm{E}-05$ & $6.9196 \mathrm{E}-05$ & $-4.8212 \mathrm{E}-07$ & $-4.9170 \mathrm{E}-07$ \\
\hline $7.9674 \mathrm{E}-05$ & $8.6495 \mathrm{E}-05$ & $-9.0605 \mathrm{E}-07$ & $-1.0496 \mathrm{E}-06$ \\
\hline $9.5609 \mathrm{E}-05$ & $1.0379 \mathrm{E}-04$ & $-1.4800 \mathrm{E}-06$ & $-1.7225 \mathrm{E}-06$ \\
\hline $1.1154 \mathrm{E}-04$ & $1.2109 \mathrm{E}-04$ & $-2.1982 \mathrm{E}-06$ & $-2.5351 \mathrm{E}-06$ \\
\hline $1.2748 \mathrm{E}-04$ & $1.3839 \mathrm{E}-04$ & $-2.9847 \mathrm{E}-06$ & $-3.5342 \mathrm{E}-06$ \\
\hline $1.4341 \mathrm{E}-04$ & $1.5569 \mathrm{E}-04$ & $-3.7860 \mathrm{E}-06$ & $-4.5746 \mathrm{E}-06$ \\
\hline $1.5935 \mathrm{E}-04$ & $1.7299 \mathrm{E}-04$ & $-4.5551 \mathrm{E}-06$ & $-5.5104 \mathrm{E}-06$ \\
\hline $1.7528 \mathrm{E}-04$ & $1.9029 \mathrm{E}-04$ & $-5.2014 \mathrm{E}-06$ & $-6.1887 \mathrm{E}-06$ \\
\hline $1.9122 \mathrm{E}-04$ & $2.0759 \mathrm{E}-04$ & $-5.6445 \mathrm{E}-06$ & $-6.6599 \mathrm{E}-06$ \\
\hline $2.0715 \mathrm{E}-04$ & $2.2489 \mathrm{E}-04$ & $-5.8667 \mathrm{E}-06$ & $-6.9292 \mathrm{E}-06$ \\
\hline $2.2309 \mathrm{E}-04$ & $2.4218 \mathrm{E}-04$ & $-5.8286 \mathrm{E}-06$ & $-6.8480 \mathrm{E}-06$ \\
\hline $2.3902 \mathrm{E}-04$ & $2.5948 \mathrm{E}-04$ & $-5.4768 \mathrm{E}-06$ & $-6.3824 \mathrm{E}-06$ \\
\hline $2.5496 \mathrm{E}-04$ & $2.7678 \mathrm{E}-04$ & $-4.8385 \mathrm{E}-06$ & $-5.6275 \mathrm{E}-06$ \\
\hline $2.7089 \mathrm{E}-04$ & $2.9408 \mathrm{E}-04$ & $-3.9456 \mathrm{E}-06$ & $-4.6266 \mathrm{E}-06$ \\
\hline $2.8683 \mathrm{E}-04$ & $3.1138 \mathrm{E}-04$ & $-2.8130 \mathrm{E}-06$ & $-3.2844 \mathrm{E}-06$ \\
\hline $3.0276 \mathrm{E}-04$ & $3.2868 \mathrm{E}-04$ & $-1.5039 \mathrm{E}-06$ & $-1.7513 \mathrm{E}-06$ \\
\hline $3.1870 \mathrm{E}-04$ & $3.4598 \mathrm{E}-04$ & $-1.2054 \mathrm{E}-07$ & $-1.0930 \mathrm{E}-07$ \\
\hline
\end{tabular}



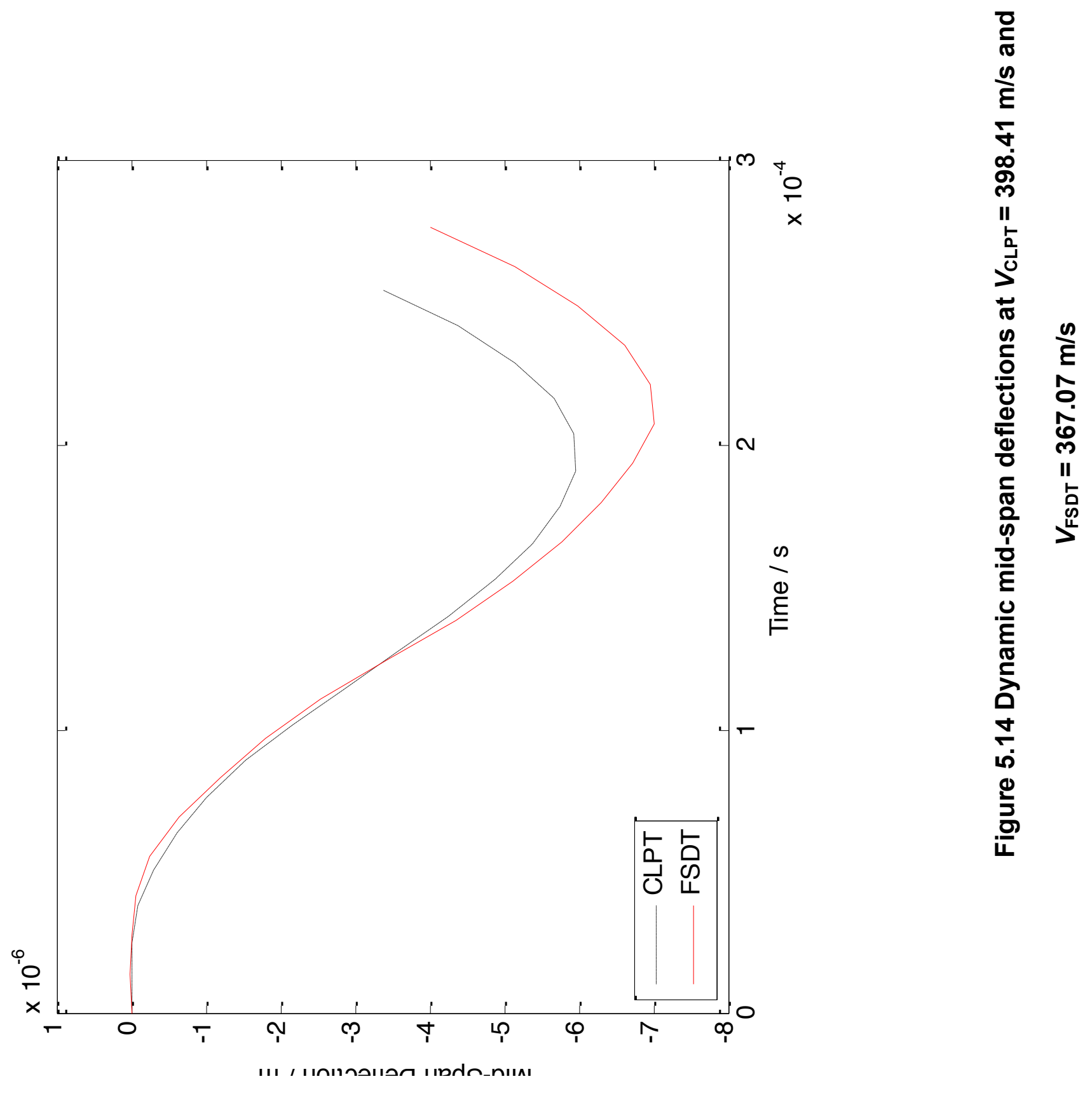
Table 5.21 Dynamic mid-span deflection at $V_{\mathrm{CLPT}}=398.41 \mathrm{~m} / \mathrm{s}$ and

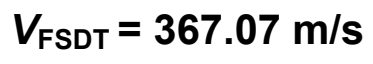

\begin{tabular}{|c|c|c|c|}
\hline \multicolumn{2}{|c|}{ Time at the end of each load step (s) } & \multicolumn{2}{c|}{ Mid-span dynamic deflection (m) } \\
\hline CLPT & FSDT & CLPT & FSDT \\
\hline 0 & 0 & 0 & 0 \\
\hline $1.2748 \mathrm{E}-05$ & $1.3839 \mathrm{E}-05$ & $-3.2224 \mathrm{E}-10$ & $8.3376 \mathrm{E}-11$ \\
\hline $2.5496 \mathrm{E}-05$ & $2.7679 \mathrm{E}-05$ & $-1.6567 \mathrm{E}-08$ & $-5.8079 \mathrm{E}-09$ \\
\hline $3.8244 \mathrm{E}-05$ & $4.1518 \mathrm{E}-05$ & $-1.0258 \mathrm{E}-07$ & $-5.8282 \mathrm{E}-08$ \\
\hline $5.0992 \mathrm{E}-05$ & $5.5357 \mathrm{E}-05$ & $-3.0462 \mathrm{E}-07$ & $-2.5304 \mathrm{E}-07$ \\
\hline $6.3741 \mathrm{E}-05$ & $6.9197 \mathrm{E}-05$ & $-6.0815 \mathrm{E}-07$ & $-6.5761 \mathrm{E}-07$ \\
\hline $7.6489 \mathrm{E}-05$ & $8.3036 \mathrm{E}-05$ & $-1.0104 \mathrm{E}-06$ & $-1.2036 \mathrm{E}-06$ \\
\hline $8.9237 \mathrm{E}-05$ & $9.6875 \mathrm{E}-05$ & $-1.5397 \mathrm{E}-06$ & $-1.8121 \mathrm{E}-06$ \\
\hline $1.0198 \mathrm{E}-04$ & $1.1071 \mathrm{E}-04$ & $-2.1759 \mathrm{E}-06$ & $-2.5456 \mathrm{E}-06$ \\
\hline $1.1473 \mathrm{E}-04$ & $1.2455 \mathrm{E}-04$ & $-2.8629 \mathrm{E}-06$ & $-3.4320 \mathrm{E}-06$ \\
\hline $1.2748 \mathrm{E}-04$ & $1.3839 \mathrm{E}-04$ & $-3.5589 \mathrm{E}-06$ & $-4.3534 \mathrm{E}-06$ \\
\hline $1.4023 \mathrm{E}-04$ & $1.5223 \mathrm{E}-04$ & $-4.2485 \mathrm{E}-06$ & $-5.1282 \mathrm{E}-06$ \\
\hline $1.5298 \mathrm{E}-04$ & $1.6607 \mathrm{E}-04$ & $-4.8848 \mathrm{E}-06$ & $-5.7885 \mathrm{E}-06$ \\
\hline $1.6573 \mathrm{E}-04$ & $1.7991 \mathrm{E}-04$ & $-5.3935 \mathrm{E}-06$ & $-6.3096 \mathrm{E}-06$ \\
\hline $1.7847 \mathrm{E}-04$ & $1.9375 \mathrm{E}-04$ & $-5.7561 \mathrm{E}-06$ & $-6.7153 \mathrm{E}-06$ \\
\hline $1.9122 \mathrm{E}-04$ & $2.0759 \mathrm{E}-04$ & $-5.9553 \mathrm{E}-06$ & $-7.0091 \mathrm{E}-06$ \\
\hline $2.0397 \mathrm{E}-04$ & $2.2143 \mathrm{E}-04$ & $-5.9388 \mathrm{E}-06$ & $-6.9598 \mathrm{E}-06$ \\
\hline $2.1672 \mathrm{E}-04$ & $2.3527 \mathrm{E}-04$ & $-5.6645 \mathrm{E}-06$ & $-6.6274 \mathrm{E}-06$ \\
\hline $2.2947 \mathrm{E}-04$ & $2.4911 \mathrm{E}-04$ & $-5.1406 \mathrm{E}-06$ & $-5.9955 \mathrm{E}-06$ \\
\hline $2.4221 \mathrm{E}-04$ & $2.6295 \mathrm{E}-04$ & $-4.3878 \mathrm{E}-06$ & $-5.1321 \mathrm{E}-06$ \\
\hline $2.5496 \mathrm{E}-04$ & $2.7679 \mathrm{E}-04$ & $-3.3875 \mathrm{E}-06$ & $-4.0111 \mathrm{E}-06$ \\
\hline
\end{tabular}



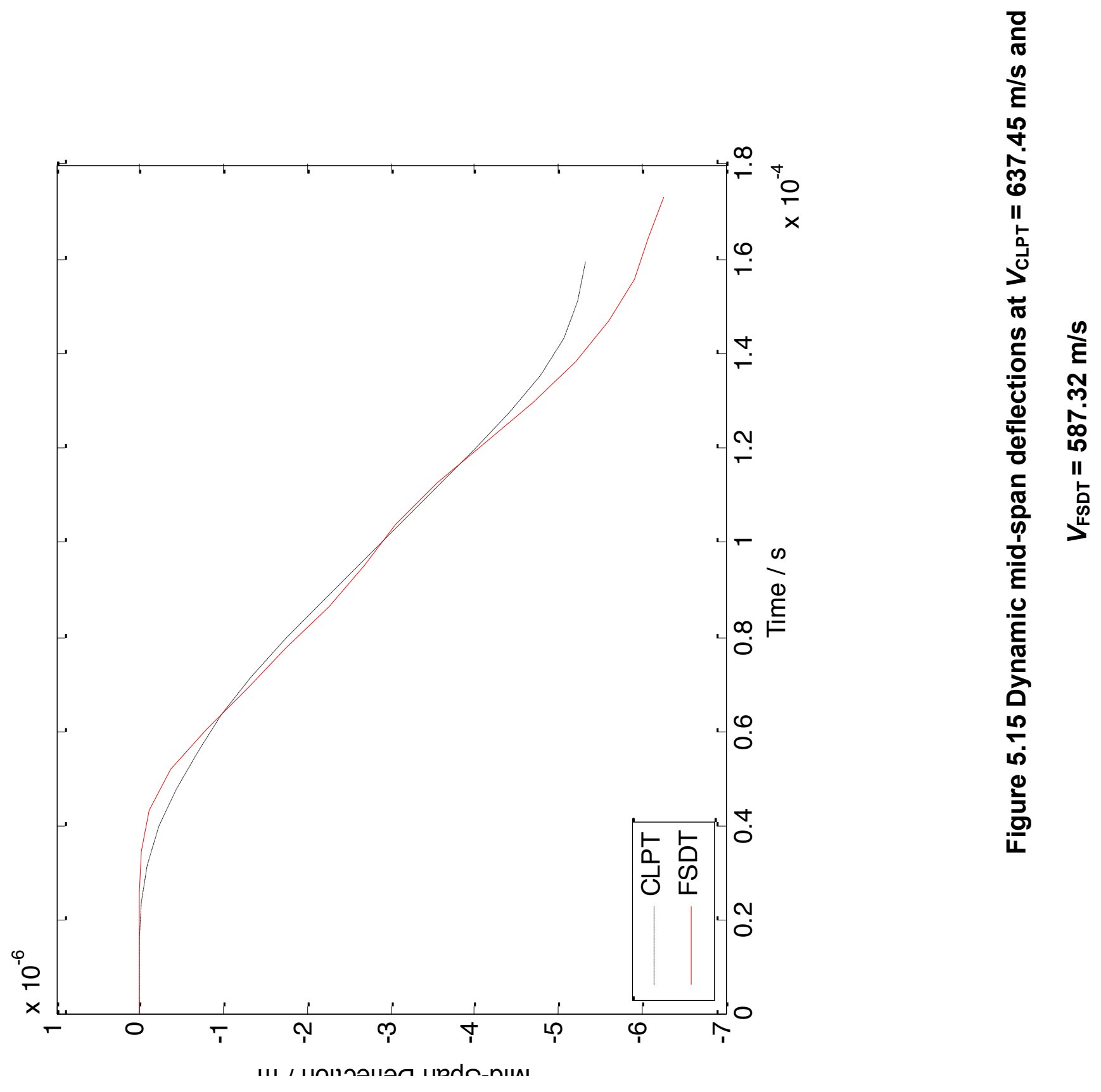
Table 5.22 Mid-span deflections at the end of each time-step for

$$
V_{\mathrm{CLPT}}=637.45 \mathrm{~m} / \mathrm{s} \text { and } V_{\mathrm{FSDT}}=587.32 \mathrm{~m} / \mathrm{s}
$$

\begin{tabular}{|c|c|c|c|}
\hline \multicolumn{2}{|c|}{ Time at the end of each load step (s) } & \multicolumn{2}{c|}{ Mid-span dynamic deflection (m) } \\
\hline CLPT & FSDT & CLPT & FSDT \\
\hline 0 & 0 & 0 & 0 \\
\hline $7.9675 \mathrm{E}-06$ & $8.6495 \mathrm{E}-06$ & $7.8194 \mathrm{E}-10$ & $2.0651 \mathrm{E}-10$ \\
\hline $1.5935 \mathrm{E}-05$ & $1.7299 \mathrm{E}-05$ & $2.6974 \mathrm{E}-09$ & $1.4908 \mathrm{E}-09$ \\
\hline $2.3903 \mathrm{E}-05$ & $2.5948 \mathrm{E}-05$ & $-9.6344 \mathrm{E}-09$ & $2.9583 \mathrm{E}-09$ \\
\hline $3.1870 \mathrm{E}-05$ & $3.4598 \mathrm{E}-05$ & $-7.6754 \mathrm{E}-08$ & $-1.3724 \mathrm{E}-08$ \\
\hline $3.9838 \mathrm{E}-05$ & $4.3247 \mathrm{E}-05$ & $-2.2309 \mathrm{E}-07$ & $-1.0789 \mathrm{E}-07$ \\
\hline $4.7805 \mathrm{E}-05$ & $5.1897 \mathrm{E}-05$ & $-4.3086 \mathrm{E}-07$ & $-3.5921 \mathrm{E}-07$ \\
\hline $5.5773 \mathrm{E}-05$ & $6.0546 \mathrm{E}-05$ & $-6.8441 \mathrm{E}-07$ & $-7.7986 \mathrm{E}-07$ \\
\hline $6.3740 \mathrm{E}-05$ & $6.9196 \mathrm{E}-05$ & $-9.8361 \mathrm{E}-07$ & $-1.2712 \mathrm{E}-06$ \\
\hline $7.1708 \mathrm{E}-05$ & $7.7845 \mathrm{E}-05$ & $-1.3359 \mathrm{E}-06$ & $-1.7547 \mathrm{E}-06$ \\
\hline $7.9675 \mathrm{E}-05$ & $8.6495 \mathrm{E}-05$ & $-1.7509 \mathrm{E}-06$ & $-2.2619 \mathrm{E}-06$ \\
\hline $8.7643 \mathrm{E}-05$ & $9.5144 \mathrm{E}-05$ & $-2.1998 \mathrm{E}-06$ & $-2.6861 \mathrm{E}-06$ \\
\hline $9.5610 \mathrm{E}-05$ & $1.0379 \mathrm{E}-04$ & $-2.6472 \mathrm{E}-06$ & $-3.0688 \mathrm{E}-06$ \\
\hline $1.0358 \mathrm{E}-04$ & $1.1244 \mathrm{E}-04$ & $-3.0900 \mathrm{E}-06$ & $-3.5607 \mathrm{E}-06$ \\
\hline $1.1155 \mathrm{E}-04$ & $1.2109 \mathrm{E}-04$ & $-3.5347 \mathrm{E}-06$ & $-4.1002 \mathrm{E}-06$ \\
\hline $1.1951 \mathrm{E}-04$ & $1.2974 \mathrm{E}-04$ & $-3.9837 \mathrm{E}-06$ & $-4.7016 \mathrm{E}-06$ \\
\hline $1.2748 \mathrm{E}-04$ & $1.3839 \mathrm{E}-04$ & $-4.4163 \mathrm{E}-06$ & $-5.2024 \mathrm{E}-06$ \\
\hline $1.3545 \mathrm{E}-04$ & $1.4704 \mathrm{E}-04$ & $-4.7866 \mathrm{E}-06$ & $-5.5969 \mathrm{E}-06$ \\
\hline $1.4342 \mathrm{E}-04$ & $1.5569 \mathrm{E}-04$ & $-5.0605 \mathrm{E}-06$ & $-5.9064 \mathrm{E}-06$ \\
\hline $1.5138 \mathrm{E}-04$ & $1.6434 \mathrm{E}-04$ & $-5.2413 \mathrm{E}-06$ & $-6.0724 \mathrm{E}-06$ \\
\hline $1.5935 \mathrm{E}-04$ & $1.7299 \mathrm{E}-04$ & $-5.3286 \mathrm{E}-06$ & $-6.2593 \mathrm{E}-06$ \\
\hline
\end{tabular}




\subsubsection{2 [0/ $\$ 45 / 90]$ Laminated Composite Beam}

The next set of results relate to the laminated composite beam, $[0 / \pm 45 / 90]$, with four layers each having the same thickness and a total thickness of $7.45 \mathrm{~mm}$. Kadivar and Mohebpur (1997) show a plot of the dynamic magnification factors at different velocities for higher order shear deformation theory (HSDT), which are read through the program called Digitizelt. The material properties are the same as given earlier in Table 5.11.A static analysis is run first, with a load of $P=-4.45 \mathrm{~N}$ applied at the mid-span of the beam and the results are listed below in Table 5.23.

Table 5.23 Mid-span static deflection of glass/epoxy $[0 / \pm 45 / 90]$ composite beam

\begin{tabular}{|c|c|}
\hline \multicolumn{2}{|c|}{ Present study } \\
\hline CLPT & FSDT \\
\hline$-1.3276 \times 10^{-5} \mathrm{~m}$ & $-1.4018 \times 10^{-5} \mathrm{~m}$ \\
\hline
\end{tabular}

Table 5.24 lists the different total times and time steps with their corresponding velocities. These are used to achieve the dynamic magnification factors for comparison with Kadivar and Mohebpur (1997). 
Table 5.24 Moving load velocities and time-steps for composite beam,

$[0 / \pm 45 / 90]$

\begin{tabular}{|c|c|c|}
\hline \multirow{2}{*}{ Velocity $(\mathbf{m} / \mathbf{s})$} & \multicolumn{2}{|c|}{ Composite beam $\left[\mathbf{0} \mathbf{\pm 4 5 / 9 0 ] _ { \underline { T } }}\right.$} \\
\cline { 2 - 3 } & $\boldsymbol{T}(\mathbf{s})$ & $\boldsymbol{\Delta t}(\mathbf{s})$ \\
\hline 20.30 & $5.0049 \times 10^{-3}$ & $2.5025 \times 10^{-4}$ \\
\hline 39.60 & $2.5657 \times 10^{-3}$ & $1.2828 \times 10^{-4}$ \\
\hline 78.20 & $1.2992 \times 10^{-3}$ & $6.4962 \times 10^{-5}$ \\
\hline 118.00 & $8.6102 \times 10^{-4}$ & $4.3051 \times 10^{-5}$ \\
\hline 156.00 & $6.5128 \times 10^{-4}$ & $3.2564 \times 10^{-5}$ \\
\hline 197.00 & $5.1574 \times 10^{-4}$ & $2.5787 \times 10^{-5}$ \\
\hline 295.00 & $3.4441 \times 10^{-4}$ & $1.7220 \times 10^{-5}$ \\
\hline 344.00 & $2.9535 \times 10^{-4}$ & $1.4767 \times 10^{-5}$ \\
\hline 391.00 & $2.5985 \times 10^{-4}$ & $1.2992 \times 10^{-5}$ \\
\hline
\end{tabular}

The applied point load is the same as before, namely, $P=-4.45 \mathrm{~N}$, which moves from one node to another in 20 times steps, starting from the left end of the simply-supported beam to the right end. Table 5.25 lists the maximum dynamic mid-span deflection at different velocities. Since Kadivar and Mohebpur (1997) do not list these, it is not possible to show a comparison in this table. 
Table 5.25 Maximum dynamic deflections for different velocities, [0/ $445 / 90]$

\begin{tabular}{|c|c|c|}
\hline \multirow{2}{*}{ Velocity $(\mathrm{m} / \mathbf{s})$} & \multicolumn{2}{|c|}{ Maximum mid-span dynamic deflections (m) } \\
\cline { 2 - 3 } & \multicolumn{2}{|c|}{ Present study } \\
\cline { 2 - 3 } & CLPT & FSDT \\
\hline 20.30 & $-1.3956 \times 10^{-5}$ & $-1.4851 \times 10^{-5}$ \\
\hline 39.60 & $-1.4936 \times 10^{-5}$ & $-1.5926 \times 10^{-5}$ \\
\hline 78.20 & $-1.6473 \times 10^{-5}$ & $-1.7477 \times 10^{-5}$ \\
\hline 118.00 & $-2.0544 \times 10^{-5}$ & $-2.1834 \times 10^{-5}$ \\
\hline 156.00 & $-2.2353 \times 10^{-5}$ & $-2.3468 \times 10^{-5}$ \\
\hline 197.00 & $-2.2837 \times 10^{-5}$ & $-2.3802 \times 10^{-5}$ \\
\hline 295.00 & $-2.1202 \times 10^{-5}$ & $-2.2072 \times 10^{-5}$ \\
\hline 344.00 & $-1.9730 \times 10^{-5}$ & $-2.0387 \times 10^{-5}$ \\
\hline 391.00 & $-1.7660 \times 10^{-5}$ & $-1.7894 \times 10^{-5}$ \\
\hline
\end{tabular}

The dynamic magnification factors for moving load on a $[0 / \pm 45 / 90]$ glass/epoxy composite beam are listed in Table 5.26 and compared with the results from Kadivar and Mohebpur (1997). 
Table 5.26 Dynamic magnification factors comparison for different velocities

\begin{tabular}{|c|c|c|c|}
\hline \multirow{3}{*}{ Velocity (m/s) } & \multicolumn{3}{|c|}{ Dynamic magnification factors } \\
\hline & \multicolumn{2}{|c|}{ Present study } & \multirow{2}{*}{$\begin{array}{l}\text { Kadivar and Mohebpur } \\
\text { (1997), HSDT }\end{array}$} \\
\hline & CLPT & FSDT & \\
\hline 20.30 & 1.051 & 1.059 & 1.040 \\
\hline 39.60 & 1.125 & 1.136 & 1.120 \\
\hline 78.20 & 1.241 & 1.247 & 1.240 \\
\hline 118.00 & 1.547 & 1.558 & 1.540 \\
\hline 156.00 & 1.684 & 1.674 & 1.660 \\
\hline 197.00 & 1.720 & 1.698 & 1.690 \\
\hline 295.00 & 1.597 & 1.575 & 1.560 \\
\hline 344.00 & 1.486 & 1.454 & 1.460 \\
\hline 391.00 & 1.330 & 1.277 & 1.280 \\
\hline
\end{tabular}

It can be seen that the present study results are in excellent agreement with that of the previous authors. The results for CLPT are slightly off since Kadivar and Mohebpur show results for HSDT, which is expected to be more accurate than FSDT and CLPT. 

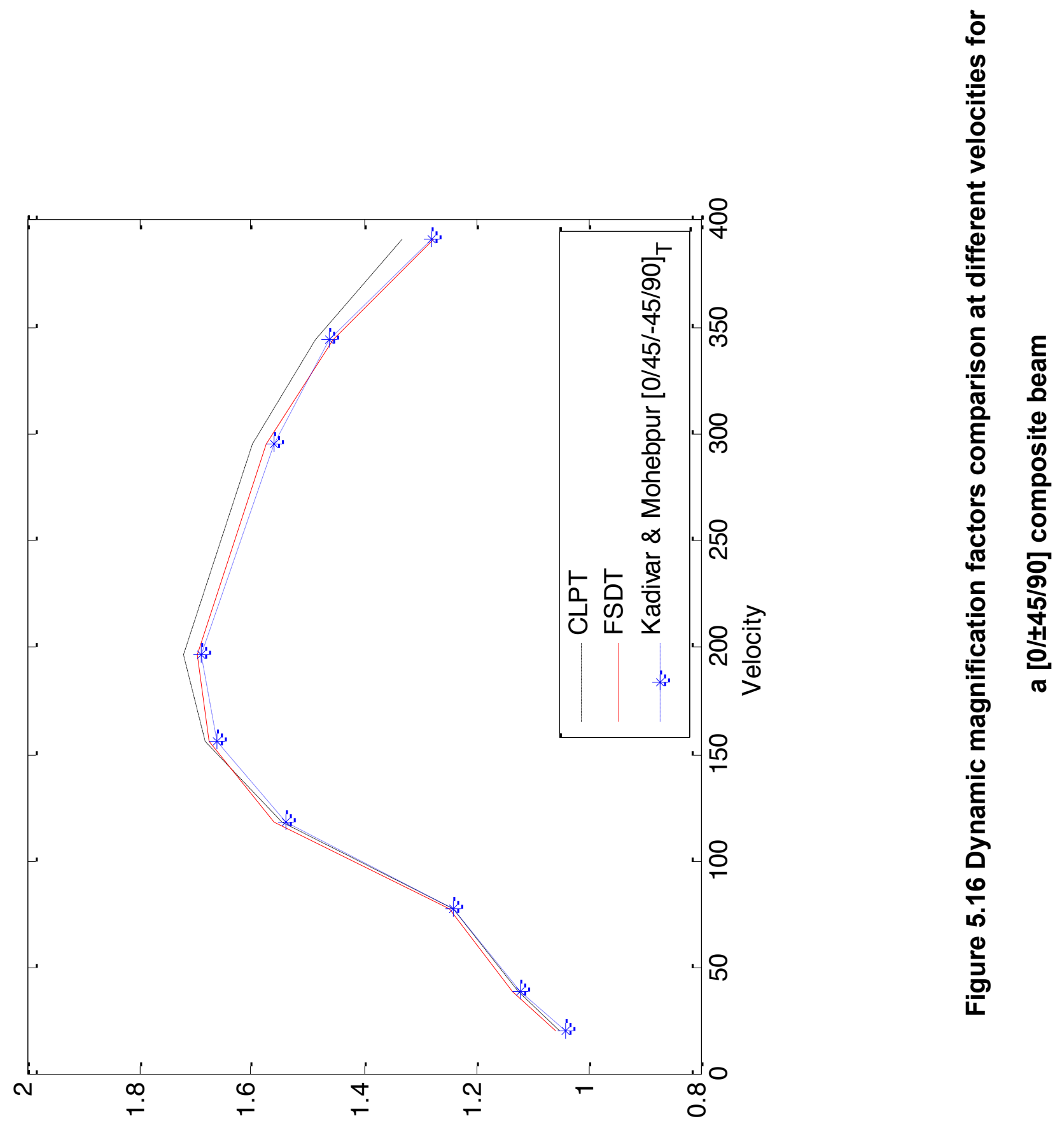
Figures 5.17 to 5.25 and Tables 5.27 to 5.35 show the values of the midspan dynamic deflections at the end of each time-step at different velocities for the $[0 / \pm 45 / 90]$ composite beam, based on CLPT and FSDT. 


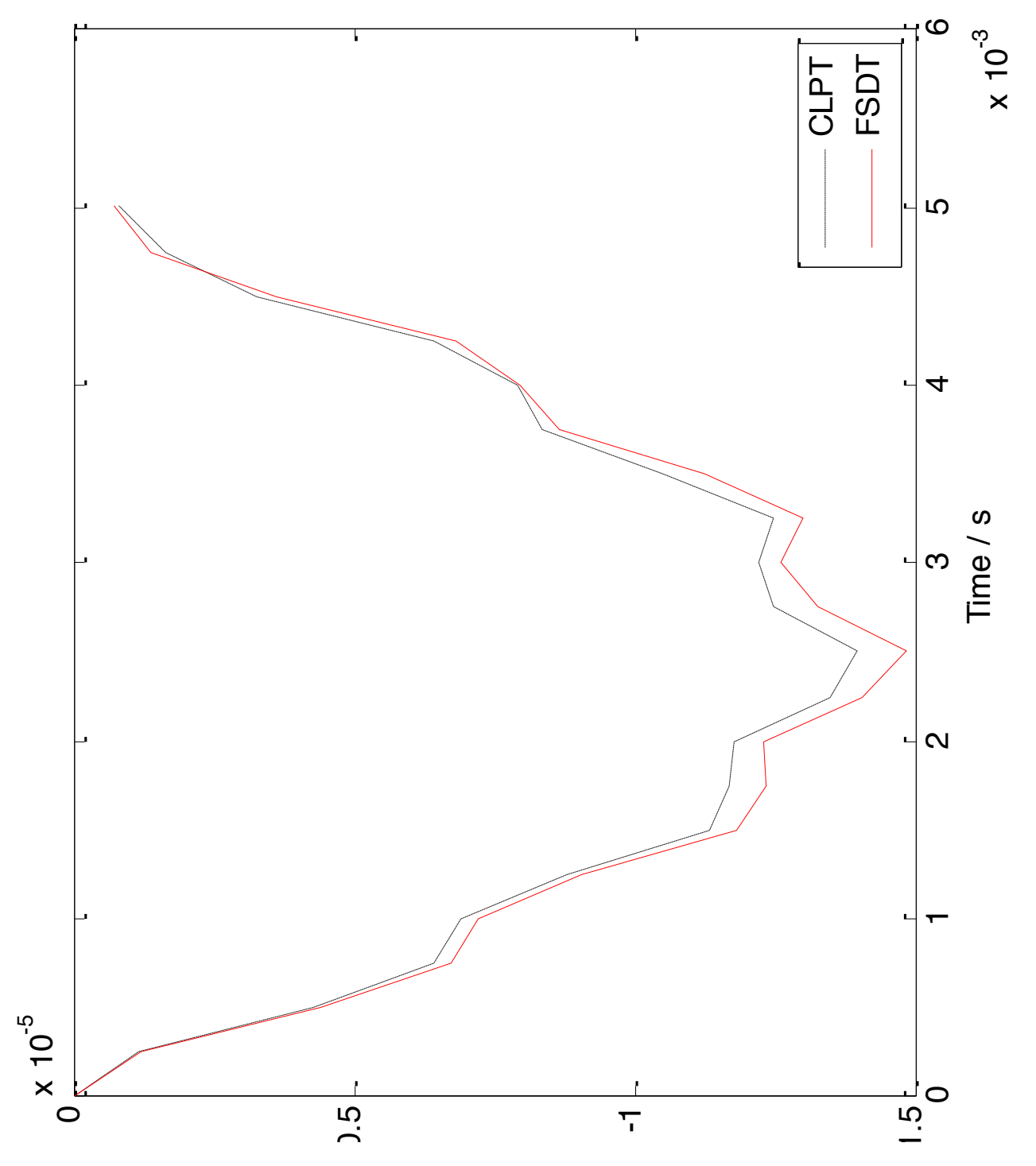

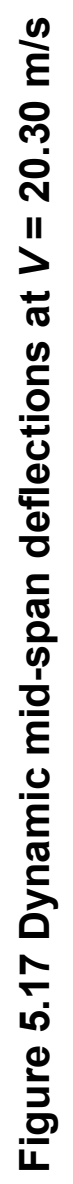


Table 5.27 Mid-span deflections at the end of each time-step for $V=20.30 \mathrm{~m} / \mathrm{s}$

\begin{tabular}{|c|c|c|}
\hline \multirow{2}{*}{ Time at the end of each load step (s) } & \multicolumn{2}{|c|}{ Mid-span dynamic deflection (m) } \\
\hline & CLPT & FSDT \\
\hline 0 & 0 & 0 \\
\hline $2.5025 \mathrm{E}-04$ & $-1.1764 \mathrm{E}-06$ & $-1.1928 E-06$ \\
\hline $5.0049 E-04$ & $-4.2681 \mathrm{E}-06$ & $-4.4102 E-06$ \\
\hline 7.5074E-04 & $-6.4225 \mathrm{E}-06$ & $-6.7328 E-06$ \\
\hline 1.0010E-03 & $-6.8907 \mathrm{E}-06$ & -7.1986E-06 \\
\hline $1.2512 \mathrm{E}-03$ & $-8.7883 \mathrm{E}-06$ & $-9.0634 \mathrm{E}-06$ \\
\hline $1.5015 \mathrm{E}-03$ & $-1.1328 \mathrm{E}-05$ & $-1.1809 E-05$ \\
\hline 1.7517E-03 & $-1.1690 \mathrm{E}-05$ & $-1.2359 \mathrm{E}-05$ \\
\hline $2.0020 \mathrm{E}-03$ & $-1.1777 \mathrm{E}-05$ & -1.2307E-05 \\
\hline $2.2522 \mathrm{E}-03$ & $-1.3502 \mathrm{E}-05$ & $-1.4056 E-05$ \\
\hline $2.5025 \mathrm{E}-03$ & $-1.3956 \mathrm{E}-05$ & $-1.4851 \mathrm{E}-05$ \\
\hline $2.7527 \mathrm{E}-03$ & $-1.2489 \mathrm{E}-05$ & $-1.3277 \mathrm{E}-05$ \\
\hline 3.0030E-03 & $-1.2233 \mathrm{E}-05$ & $-1.2626 E-05$ \\
\hline $3.2532 \mathrm{E}-03$ & $-1.2496 \mathrm{E}-05$ & $-1.3002 E-05$ \\
\hline $3.5034 \mathrm{E}-03$ & $-1.0515 \mathrm{E}-05$ & $-1.1237 \mathrm{E}-05$ \\
\hline $3.7537 \mathrm{E}-03$ & $-8.3415 \mathrm{E}-06$ & $-8.6410 \mathrm{E}-06$ \\
\hline 4.0039E-03 & $-7.9095 \mathrm{E}-06$ & -7.9531E-06 \\
\hline $4.2542 \mathrm{E}-03$ & $-6.4062 \mathrm{E}-06$ & $-6.8357 \mathrm{E}-06$ \\
\hline 4.5044E-03 & $-3.2611 \mathrm{E}-06$ & $-3.6258 E-06$ \\
\hline 4.7547E-03 & $-1.6383 \mathrm{E}-06$ & -1.3949E-06 \\
\hline $5.0049 E-03$ & $-8.0314 \mathrm{E}-07$ & $-7.1248 E-07$ \\
\hline
\end{tabular}




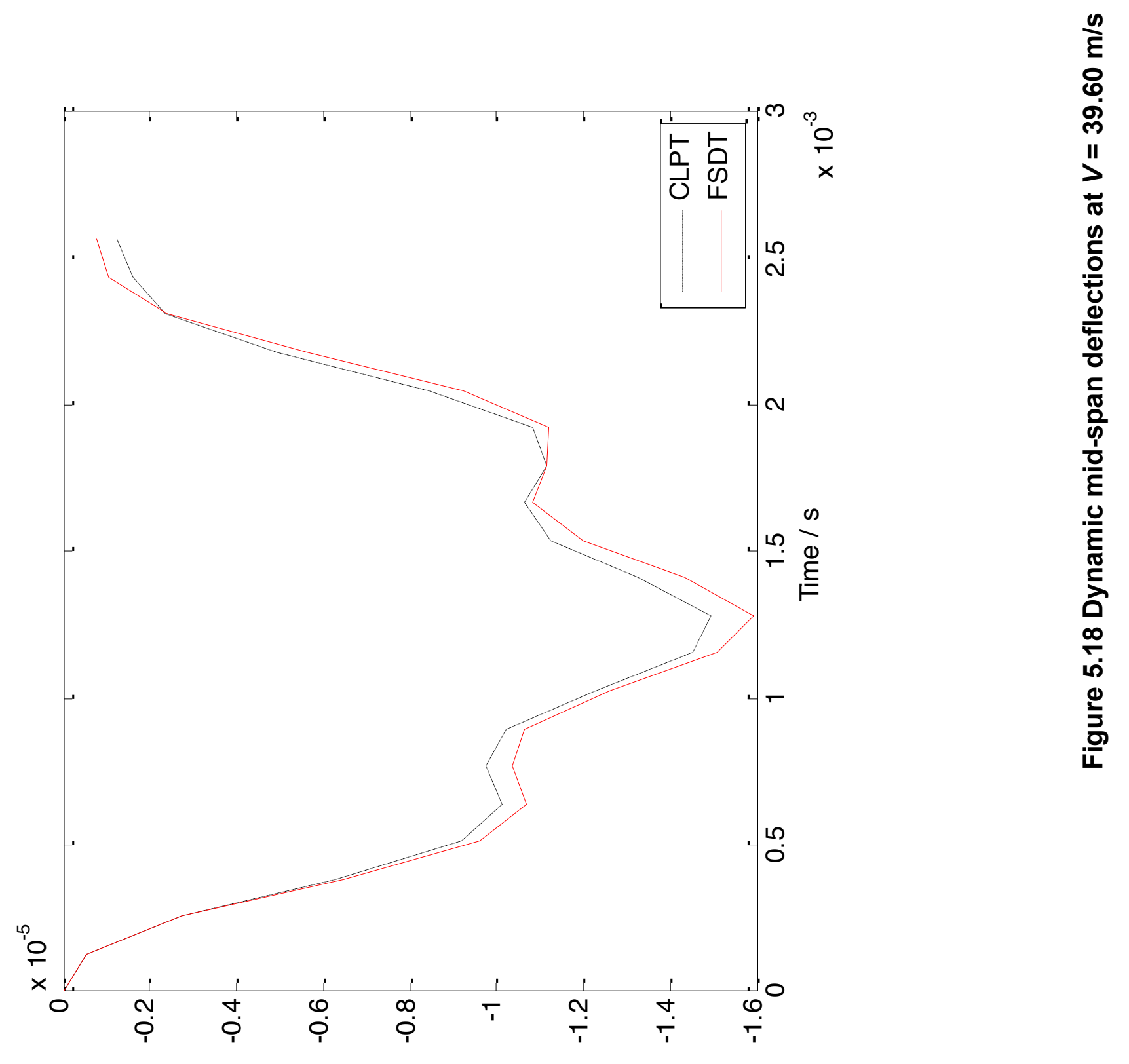


Table 5.28 Mid-span deflections at the end of each time-step for $V=39.60 \mathrm{~m} / \mathrm{s}$

\begin{tabular}{|c|c|c|}
\hline \multirow{2}{*}{ Time at the end of each load step (s) } & \multicolumn{2}{|c|}{ Mid-span dynamic deflection (m) } \\
\hline & CLPT & FSDT \\
\hline 0 & 0 & 0 \\
\hline $1.2828 \mathrm{E}-04$ & $-5.2967 \mathrm{E}-07$ & $-5.2017 \mathrm{E}-07$ \\
\hline 2.5657E-04 & $-2.7326 \mathrm{E}-06$ & $-2.7540 \mathrm{E}-06$ \\
\hline $3.8485 \mathrm{E}-04$ & $-6.3146 \mathrm{E}-06$ & $-6.4851 \mathrm{E}-06$ \\
\hline $5.1313 \mathrm{E}-04$ & $-9.2120 \mathrm{E}-06$ & $-9.6111 \mathrm{E}-06$ \\
\hline $6.4141 \mathrm{E}-04$ & $-1.0106 \mathrm{E}-05$ & $-1.0705 E-05$ \\
\hline 7.6970E-04 & $-9.7656 \mathrm{E}-06$ & $-1.0354 \mathrm{E}-05$ \\
\hline 8.9798E-04 & $-1.0234 \mathrm{E}-05$ & $-1.0644 \mathrm{E}-05$ \\
\hline 1.0263E-03 & $-1.2280 \mathrm{E}-05$ & $-1.2616 \mathrm{E}-05$ \\
\hline 1.1545E-03 & $-1.4512 \mathrm{E}-05$ & $-1.5071 \mathrm{E}-05$ \\
\hline $1.2828 \mathrm{E}-03$ & $-1.4936 \mathrm{E}-05$ & $-1.5926 \mathrm{E}-05$ \\
\hline 1.4111E-03 & $-1.3246 \mathrm{E}-05$ & $-1.4321 \mathrm{E}-05$ \\
\hline $1.5394 \mathrm{E}-03$ & $-1.1243 \mathrm{E}-05$ & $-1.1979 E-05$ \\
\hline 1.6677E-03 & $-1.0620 \mathrm{E}-05$ & $-1.0823 E-05$ \\
\hline 1.7960E-03 & $-1.1149 \mathrm{E}-05$ & $-1.1168 E-05$ \\
\hline 1.9242E-03 & $-1.0833 \mathrm{E}-05$ & -1.1207E-05 \\
\hline $2.0525 \mathrm{E}-03$ & $-8.4582 E-06$ & $-9.2452 E-06$ \\
\hline 2.1808E-03 & $-4.9388 \mathrm{E}-06$ & -5.6584E-06 \\
\hline 2.3091E-03 & $-2.3610 \mathrm{E}-06$ & $-2.4015 \mathrm{E}-06$ \\
\hline $2.4374 \mathrm{E}-03$ & $-1.5931 \mathrm{E}-06$ & $-1.0515 E-06$ \\
\hline $2.5657 \mathrm{E}-03$ & $-1.2405 \mathrm{E}-06$ & $-7.9073 \mathrm{E}-07$ \\
\hline
\end{tabular}



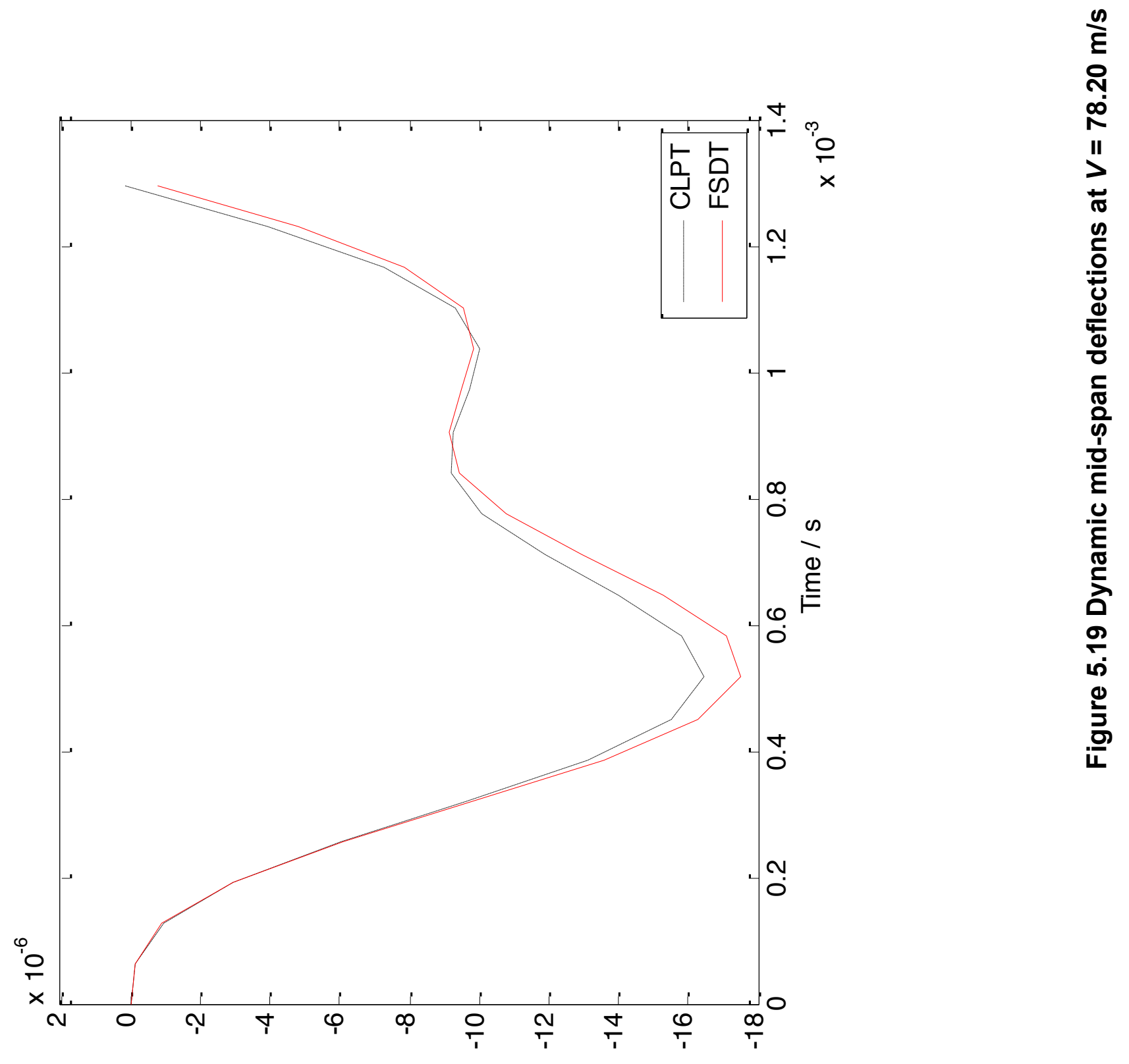
Table 5.29 Mid-span deflections at the end of each time-step for $V=78.20 \mathrm{~m} / \mathrm{s}$

\begin{tabular}{|c|c|c|}
\hline \multirow{2}{*}{ Time at the end of each load step (s) } & \multicolumn{2}{|c|}{ Mid-span dynamic deflection (m) } \\
\hline & CLPT & FSDT \\
\hline 0 & 0 & 0 \\
\hline $6.4962 E-05$ & $-1.3691 \mathrm{E}-07$ & $-1.2450 \mathrm{E}-07$ \\
\hline 1.2992E-04 & $-9.4930 \mathrm{E}-07$ & $-9.1216 \mathrm{E}-07$ \\
\hline $1.9488 \mathrm{E}-04$ & $-2.9569 \mathrm{E}-06$ & $-2.9447 \mathrm{E}-06$ \\
\hline $2.5985 \mathrm{E}-04$ & $-6.0262 \mathrm{E}-06$ & $-6.0885 E-06$ \\
\hline $3.2481 \mathrm{E}-04$ & $-9.6811 \mathrm{E}-06$ & $-9.8691 E-06$ \\
\hline 3.8977E-04 & $-1.3143 \mathrm{E}-05$ & -1.3587E-05 \\
\hline 4.5473E-04 & $-1.5543 \mathrm{E}-05$ & $-1.6265 \mathrm{E}-05$ \\
\hline $5.1969 E-04$ & $-1.6473 \mathrm{E}-05$ & -1.7477E-05 \\
\hline $5.8465 \mathrm{E}-04$ & $-1.5815 \mathrm{E}-05$ & $-1.7069 \mathrm{E}-05$ \\
\hline $6.4962 \mathrm{E}-04$ & $-1.4023 \mathrm{E}-05$ & $-1.5295 \mathrm{E}-05$ \\
\hline $7.1458 \mathrm{E}-04$ & $-1.1894 \mathrm{E}-05$ & $-1.2936 E-05$ \\
\hline 7.7954E-04 & $-1.0099 \mathrm{E}-05$ & $-1.0766 \mathrm{E}-05$ \\
\hline $8.4450 \mathrm{E}-04$ & $-9.2174 \mathrm{E}-06$ & $-9.4179 \mathrm{E}-06$ \\
\hline $9.0946 \mathrm{E}-04$ & $-9.2604 \mathrm{E}-06$ & $-9.1431 E-06$ \\
\hline $9.7442 \mathrm{E}-04$ & $-9.7456 \mathrm{E}-06$ & $-9.4919 \mathrm{E}-06$ \\
\hline 1.0394E-03 & $-1.0018 \mathrm{E}-05$ & $-9.8629 E-06$ \\
\hline 1.1043E-03 & $-9.3174 \mathrm{E}-06$ & -9.5334E-06 \\
\hline 1.1693E-03 & $-7.2626 \mathrm{E}-06$ & -7.8459E-06 \\
\hline 1.2343E-03 & $-3.9513 \mathrm{E}-06$ & $-4.8342 \mathrm{E}-06$ \\
\hline $1.2992 \mathrm{E}-03$ & $1.6145 \mathrm{E}-07$ & $-7.8895 \mathrm{E}-07$ \\
\hline
\end{tabular}




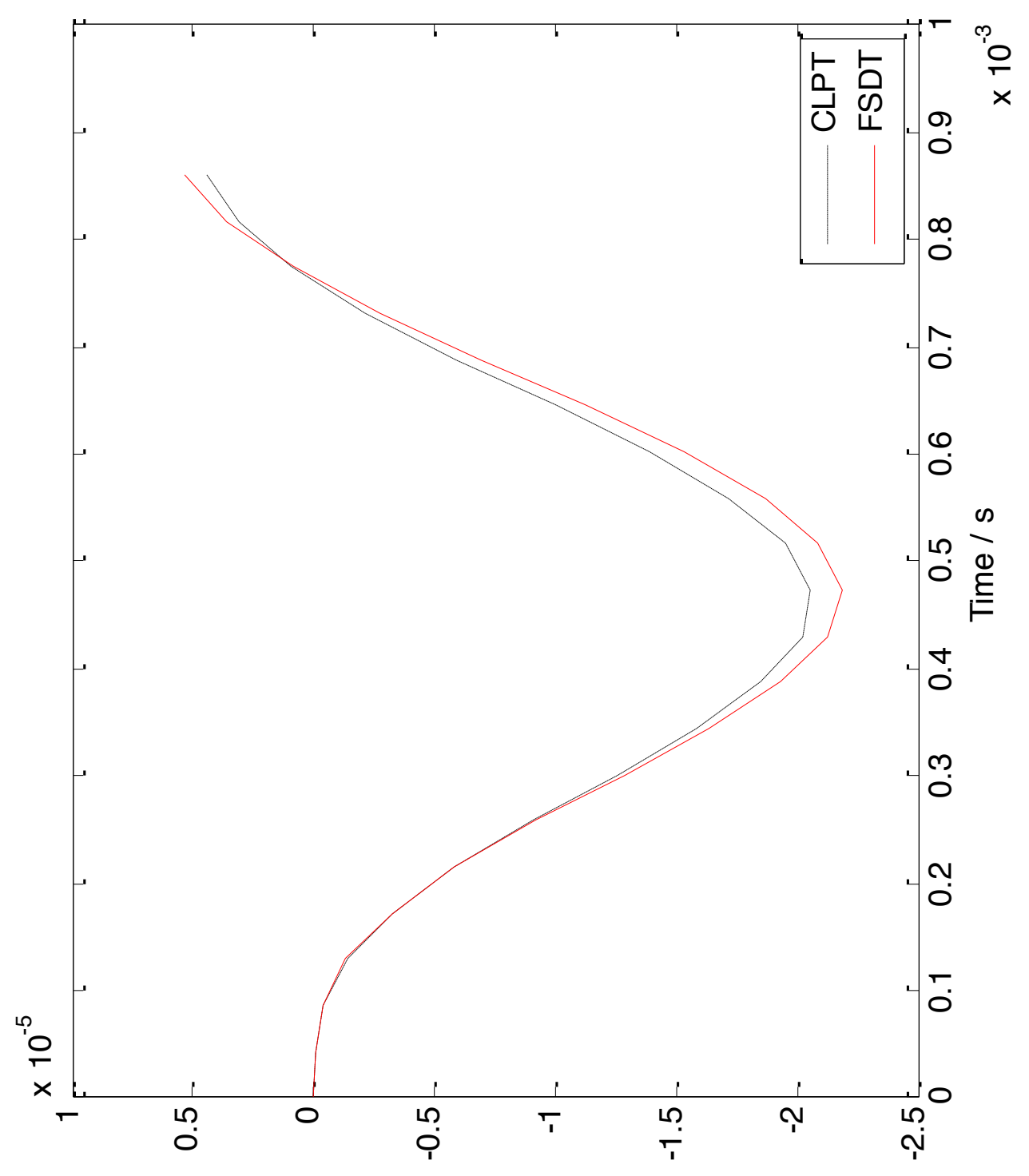

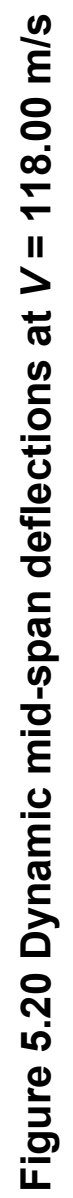


Table 5.30 Mid-span deflections at the end of each time-step for

$$
V=118.00 \mathrm{~m} / \mathrm{s}
$$

\begin{tabular}{|c|c|c|}
\hline \multirow{2}{*}{ Time at the end of each load step (s) } & \multicolumn{2}{c|}{ Mid-span dynamic deflection (m) } \\
\cline { 2 - 3 } & CLPT & FSDT \\
\hline 0 & 0 & 0 \\
\hline $4.3051 \mathrm{E}-05$ & $-4.2116 \mathrm{E}-08$ & $-3.3920 \mathrm{E}-08$ \\
\hline $8.6102 \mathrm{E}-05$ & $-3.7819 \mathrm{E}-07$ & $-3.3655 \mathrm{E}-07$ \\
\hline $1.2915 \mathrm{E}-04$ & $-1.4123 \mathrm{E}-06$ & $-1.3552 \mathrm{E}-06$ \\
\hline $1.7220 \mathrm{E}-04$ & $-3.2548 \mathrm{E}-06$ & $-3.2445 \mathrm{E}-06$ \\
\hline $2.1525 \mathrm{E}-04$ & $-5.8236 \mathrm{E}-06$ & $-5.8437 \mathrm{E}-06$ \\
\hline $2.5831 \mathrm{E}-04$ & $-9.0547 \mathrm{E}-06$ & $-9.1451 \mathrm{E}-06$ \\
\hline $3.0136 \mathrm{E}-04$ & $-1.2543 \mathrm{E}-05$ & $-1.2838 \mathrm{E}-05$ \\
\hline $3.4441 \mathrm{E}-04$ & $-1.5816 \mathrm{E}-05$ & $-1.6316 \mathrm{E}-05$ \\
\hline $3.8746 \mathrm{E}-04$ & $-1.8539 \mathrm{E}-05$ & $-1.9279 \mathrm{E}-05$ \\
\hline $4.3051 \mathrm{E}-04$ & $-2.0226 \mathrm{E}-05$ & $-2.1310 \mathrm{E}-05$ \\
\hline $4.7356 \mathrm{E}-04$ & $-2.0544 \mathrm{E}-05$ & $-2.1834 \mathrm{E}-05$ \\
\hline $5.1661 \mathrm{E}-04$ & $-1.9510 \mathrm{E}-05$ & $-2.0896 \mathrm{E}-05$ \\
\hline $5.5966 \mathrm{E}-04$ & $-1.7218 \mathrm{E}-05$ & $-1.8706 \mathrm{E}-05$ \\
\hline $6.0271 \mathrm{E}-04$ & $-1.3878 \mathrm{E}-05$ & $-1.5369 \mathrm{E}-05$ \\
\hline $6.4576 \mathrm{E}-04$ & $-9.9857 \mathrm{E}-06$ & $-1.1234 \mathrm{E}-05$ \\
\hline $6.8881 \mathrm{E}-04$ & $-5.9556 \mathrm{E}-06$ & $-6.9445 \mathrm{E}-06$ \\
\hline $7.3186 \mathrm{E}-04$ & $-2.1745 \mathrm{E}-06$ & $-2.7806 \mathrm{E}-06$ \\
\hline $7.7492 \mathrm{E}-04$ & $8.9862 \mathrm{E}-07$ & $8.7889 \mathrm{E}-07$ \\
\hline $8.1797 \mathrm{E}-04$ & $3.0914 \mathrm{E}-06$ & $3.5591 \mathrm{E}-06$ \\
\hline $8.6102 \mathrm{E}-04$ & $4.4164 \mathrm{E}-06$ & $5.3013 \mathrm{E}-06$ \\
\hline
\end{tabular}




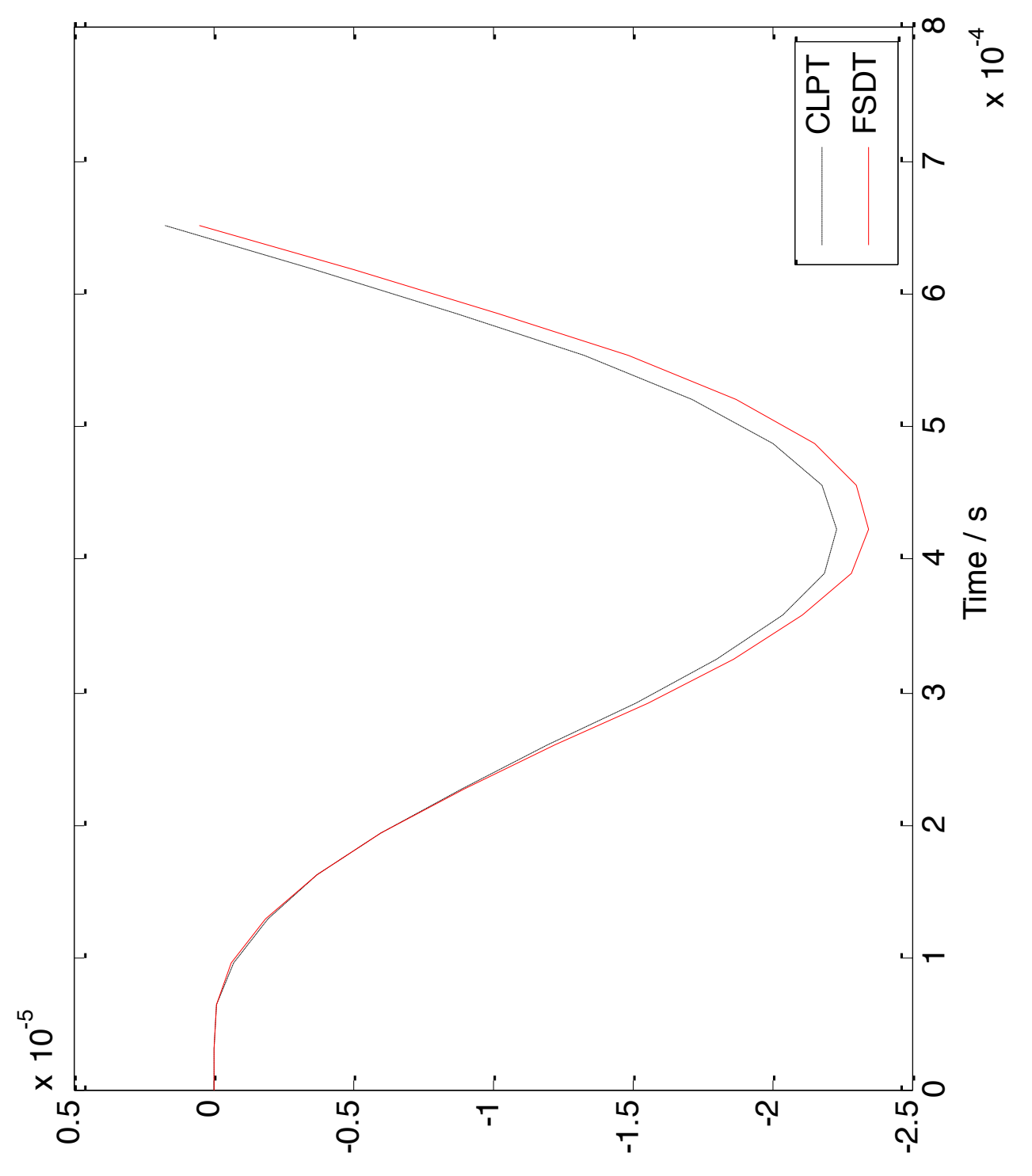

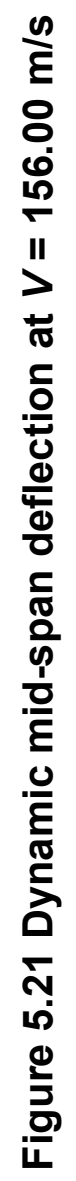


Table 5.31 Mid-span deflections at the end of each time-step for

$$
V=156.00 \mathrm{~m} / \mathrm{s}
$$

\begin{tabular}{|c|c|c|}
\hline \multirow{2}{*}{ Time at the end of each load step (s) } & \multicolumn{2}{c|}{ Mid-span dynamic deflection (m) } \\
\cline { 2 - 3 } & CLPT & FSDT \\
\hline 0 & 0 & 0 \\
\hline $3.2564 \mathrm{E}-05$ & $-1.3382 \mathrm{E}-08$ & $-8.8262 \mathrm{E}-09$ \\
\hline $6.5128 \mathrm{E}-05$ & $-1.6777 \mathrm{E}-07$ & $-1.3292 \mathrm{E}-07$ \\
\hline $9.7692 \mathrm{E}-05$ & $-7.6074 \mathrm{E}-07$ & $-6.8421 \mathrm{E}-07$ \\
\hline $1.3026 \mathrm{E}-04$ & $-1.9595 \mathrm{E}-06$ & $-1.9111 \mathrm{E}-06$ \\
\hline $1.6282 \mathrm{E}-04$ & $-3.6968 \mathrm{E}-06$ & $-3.7027 \mathrm{E}-06$ \\
\hline $1.9538 \mathrm{E}-04$ & $-6.0140 \mathrm{E}-06$ & $-6.0159 \mathrm{E}-06$ \\
\hline $2.2795 \mathrm{E}-04$ & $-8.8863 \mathrm{E}-06$ & $-8.9611 \mathrm{E}-06$ \\
\hline $2.6051 \mathrm{E}-04$ & $-1.2011 \mathrm{E}-05$ & $-1.2272 \mathrm{E}-05$ \\
\hline $2.9308 \mathrm{E}-04$ & $-1.5116 \mathrm{E}-05$ & $-1.5560 \mathrm{E}-05$ \\
\hline $3.2564 \mathrm{E}-04$ & $-1.8003 \mathrm{E}-05$ & $-1.8599 \mathrm{E}-05$ \\
\hline $3.5821 \mathrm{E}-04$ & $-2.0369 \mathrm{E}-05$ & $-2.1098 \mathrm{E}-05$ \\
\hline $3.9077 \mathrm{E}-04$ & $-2.1862 \mathrm{E}-05$ & $-2.2838 \mathrm{E}-05$ \\
\hline $4.2333 \mathrm{E}-04$ & $-2.2353 \mathrm{E}-05$ & $-2.3468 \mathrm{E}-05$ \\
\hline $4.5590 \mathrm{E}-04$ & $-2.1790 \mathrm{E}-05$ & $-2.3028 \mathrm{E}-05$ \\
\hline $4.8846 \mathrm{E}-04$ & $-2.0029 \mathrm{E}-05$ & $-2.1527 \mathrm{E}-05$ \\
\hline $5.2103 \mathrm{E}-04$ & $-1.7128 \mathrm{E}-05$ & $-1.8749 \mathrm{E}-05$ \\
\hline $5.5359 \mathrm{E}-04$ & $-1.3289 \mathrm{E}-05$ & $-1.4888 \mathrm{E}-05$ \\
\hline $5.8615 \mathrm{E}-04$ & $-8.7171 \mathrm{E}-06$ & $-1.0238 \mathrm{E}-05$ \\
\hline $6.1872 \mathrm{E}-04$ & $-3.6093 \mathrm{E}-06$ & $-5.0519 \mathrm{E}-06$ \\
\hline $6.5128 \mathrm{E}-04$ & $1.6781 \mathrm{E}-06$ & $5.2605 \mathrm{E}-07$ \\
\hline
\end{tabular}




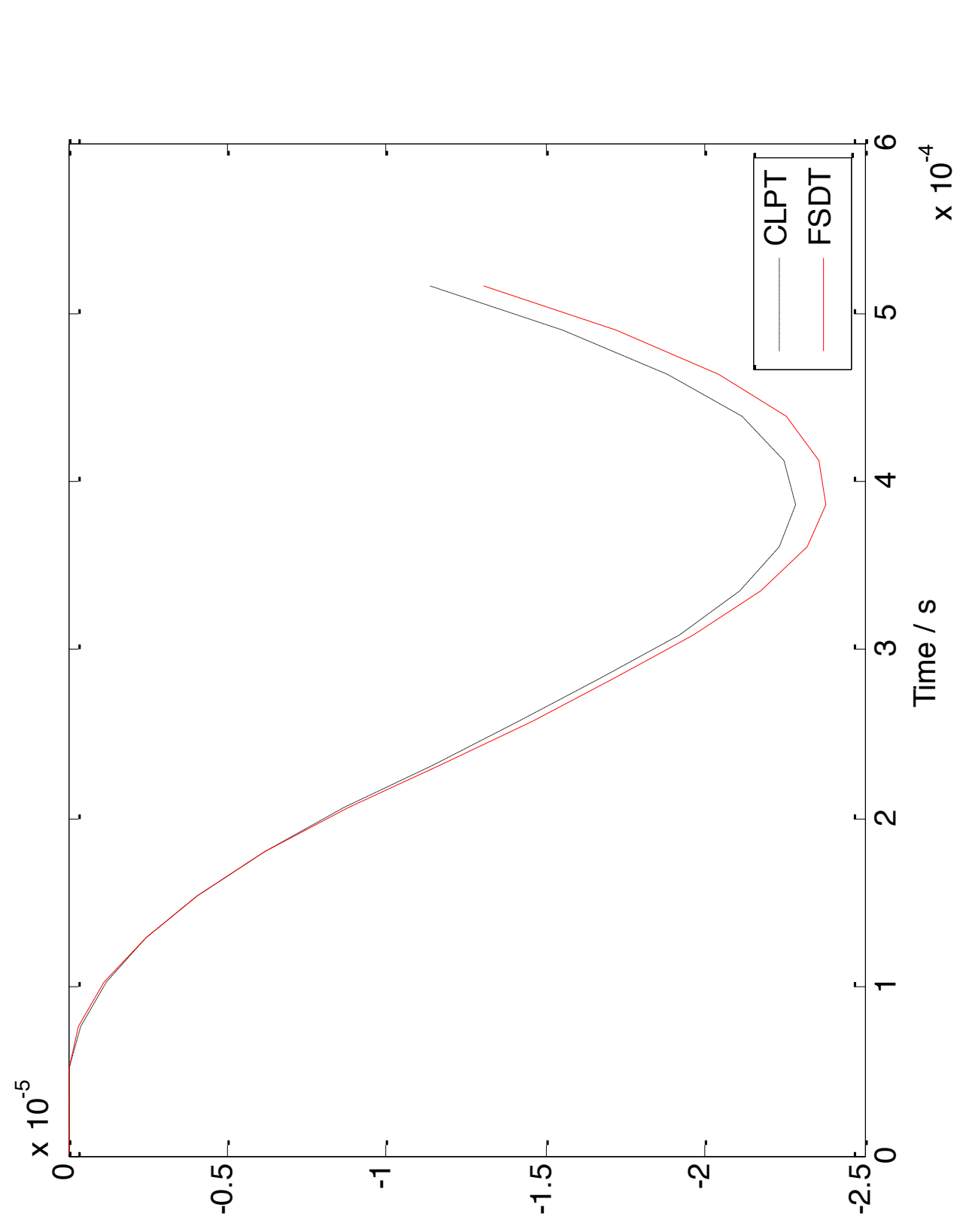

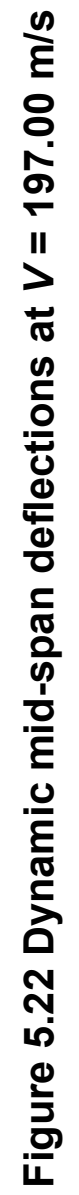


Table 5.32 Mid-span deflections at the end of each time-step for $V=197.00 \mathrm{~m} / \mathrm{s}$

\begin{tabular}{|c|c|c|}
\hline \multirow{2}{*}{ Time at the end of each load step (s) } & \multicolumn{2}{c|}{ Mid-span dynamic deflection (m) } \\
\cline { 2 - 3 } & CLPT & FSDT \\
\hline 0 & 0 & 0 \\
\hline $2.5787 \mathrm{E}-05$ & $-2.3688 \mathrm{E}-09$ & $-4.9653 \mathrm{E}-10$ \\
\hline $5.1574 \mathrm{E}-05$ & $-6.7212 \mathrm{E}-08$ & $-4.3100 \mathrm{E}-08$ \\
\hline $7.7360 \mathrm{E}-05$ & $-4.0210 \mathrm{E}-07$ & $-3.2290 \mathrm{E}-07$ \\
\hline $1.0315 \mathrm{E}-04$ & $-1.2044 \mathrm{E}-06$ & $-1.1136 \mathrm{E}-06$ \\
\hline $1.2893 \mathrm{E}-04$ & $-2.4357 \mathrm{E}-06$ & $-2.4194 \mathrm{E}-06$ \\
\hline $1.5472 \mathrm{E}-04$ & $-4.0590 \mathrm{E}-06$ & $-4.0783 \mathrm{E}-06$ \\
\hline $1.8051 \mathrm{E}-04$ & $-6.1622 \mathrm{E}-06$ & $-6.1745 \mathrm{E}-06$ \\
\hline $2.0629 \mathrm{E}-04$ & $-8.6914 \mathrm{E}-06$ & $-8.7730 \mathrm{E}-06$ \\
\hline $2.3208 \mathrm{E}-04$ & $-1.1432 \mathrm{E}-05$ & $-1.1682 \mathrm{E}-05$ \\
\hline $2.5787 \mathrm{E}-04$ & $-1.4157 \mathrm{E}-05$ & $-1.4613 \mathrm{E}-05$ \\
\hline $2.8365 \mathrm{E}-04$ & $-1.6774 \mathrm{E}-05$ & $-1.7215 \mathrm{E}-05$ \\
\hline $3.0944 \mathrm{E}-04$ & $-1.9174 \mathrm{E}-05$ & $-1.9613 \mathrm{E}-05$ \\
\hline $3.3523 \mathrm{E}-04$ & $-2.1084 \mathrm{E}-05$ & $-2.1740 \mathrm{E}-05$ \\
\hline $3.6102 \mathrm{E}-04$ & $-2.2331 \mathrm{E}-05$ & $-2.3179 \mathrm{E}-05$ \\
\hline $3.8680 \mathrm{E}-04$ & $-2.2837 \mathrm{E}-05$ & $-2.3802 \mathrm{E}-05$ \\
\hline $4.1259 \mathrm{E}-04$ & $-2.2502 \mathrm{E}-05$ & $-2.3601 \mathrm{E}-05$ \\
\hline $4.3838 \mathrm{E}-04$ & $-2.1193 \mathrm{E}-05$ & $-2.2528 \mathrm{E}-05$ \\
\hline $4.6416 \mathrm{E}-04$ & $-1.8834 \mathrm{E}-05$ & $-2.0433 \mathrm{E}-05$ \\
\hline $4.8995 \mathrm{E}-04$ & $-1.5530 \mathrm{E}-05$ & $-1.7220 \mathrm{E}-05$ \\
\hline $5.1574 \mathrm{E}-04$ & $-1.1403 \mathrm{E}-05$ & $-1.3045 \mathrm{E}-05$ \\
\hline
\end{tabular}




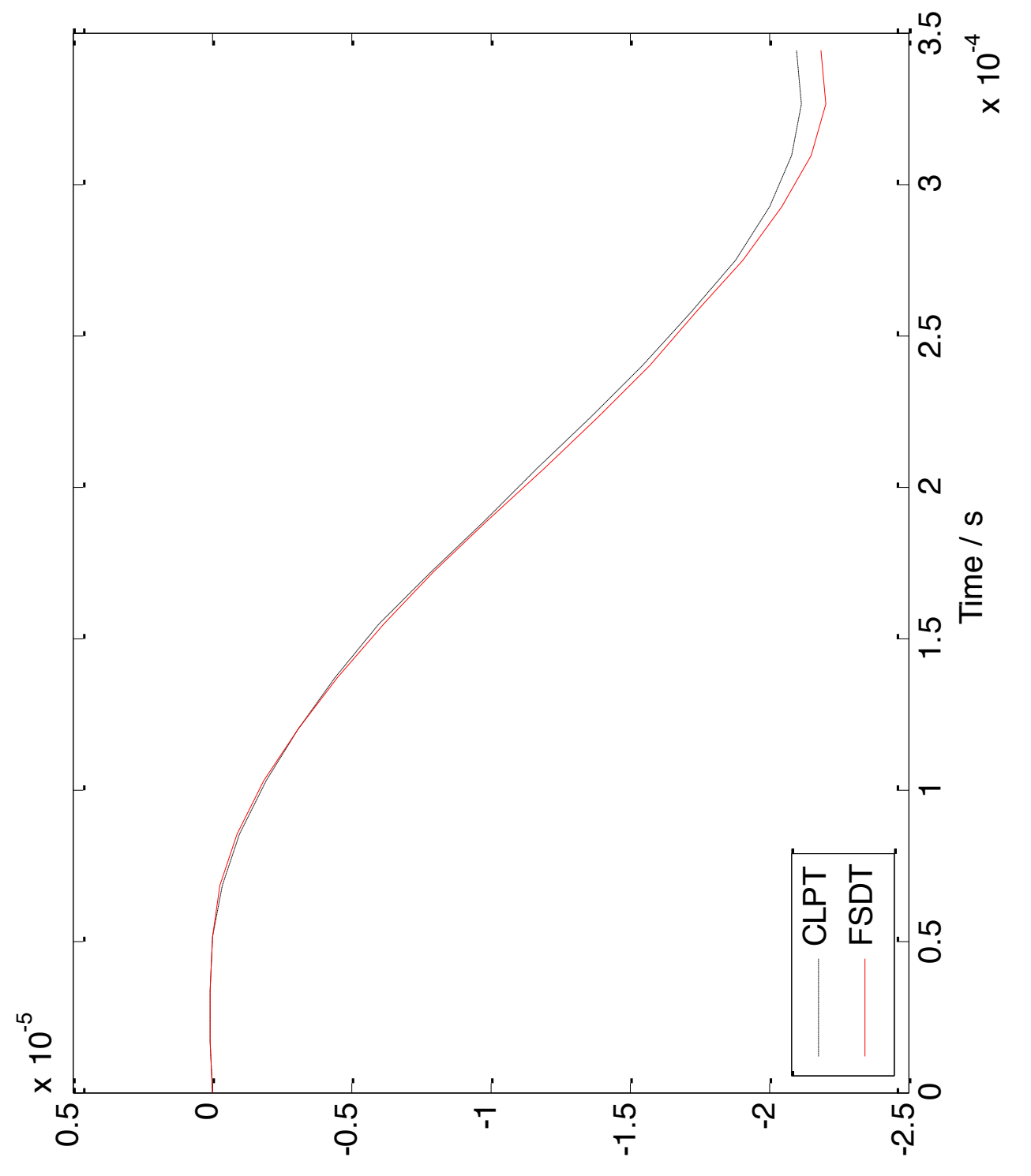

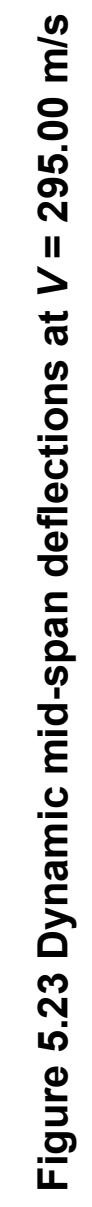


Table 5.33 Mid-span deflections at the end of each time-step for

$$
V=295.00 \mathrm{~m} / \mathrm{s}
$$

\begin{tabular}{|c|c|c|}
\hline \multirow{2}{*}{ Time at the end of each load step (s) } & \multicolumn{2}{c|}{ Mid-span dynamic deflection (m) } \\
\cline { 2 - 3 } & CLPT & FSDT \\
\hline 0 & 0 & 0 \\
\hline $1.7220 \mathrm{E}-05$ & $2.3578 \mathrm{E}-09$ & $1.7242 \mathrm{E}-09$ \\
\hline $3.4441 \mathrm{E}-05$ & $3.3551 \mathrm{E}-09$ & $7.5425 \mathrm{E}-09$ \\
\hline $5.1661 \mathrm{E}-05$ & $-7.0016 \mathrm{E}-08$ & $-2.4916 \mathrm{E}-08$ \\
\hline $6.8881 \mathrm{E}-05$ & $-3.8654 \mathrm{E}-07$ & $-2.6356 \mathrm{E}-07$ \\
\hline $8.6102 \mathrm{E}-05$ & $-1.0389 \mathrm{E}-06$ & $-9.0471 \mathrm{E}-07$ \\
\hline $1.0332 \mathrm{E}-04$ & $-1.9562 \mathrm{E}-06$ & $-1.9169 \mathrm{E}-06$ \\
\hline $1.2054 \mathrm{E}-04$ & $-3.0853 \mathrm{E}-06$ & $-3.1382 \mathrm{E}-06$ \\
\hline $1.3776 \mathrm{E}-04$ & $-4.4322 \mathrm{E}-06$ & $-4.5556 \mathrm{E}-06$ \\
\hline $1.5498 \mathrm{E}-04$ & $-6.0215 \mathrm{E}-06$ & $-6.1786 \mathrm{E}-06$ \\
\hline $1.7220 \mathrm{E}-04$ & $-7.8620 \mathrm{E}-06$ & $-7.9748 \mathrm{E}-06$ \\
\hline $1.8942 \mathrm{E}-04$ & $-9.8168 \mathrm{E}-06$ & $-9.9047 \mathrm{E}-06$ \\
\hline $2.0664 \mathrm{E}-04$ & $-1.1743 \mathrm{E}-05$ & $-1.1958 \mathrm{E}-05$ \\
\hline $2.2386 \mathrm{E}-04$ & $-1.3626 \mathrm{E}-05$ & $-1.3915 \mathrm{E}-05$ \\
\hline $2.4108 \mathrm{E}-04$ & $-1.5460 \mathrm{E}-05$ & $-1.5723 \mathrm{E}-05$ \\
\hline $2.5831 \mathrm{E}-04$ & $-1.7214 \mathrm{E}-05$ & $-1.7451 \mathrm{E}-05$ \\
\hline $2.7553 \mathrm{E}-04$ & $-1.8801 \mathrm{E}-05$ & $-1.9046 \mathrm{E}-05$ \\
\hline $2.9275 \mathrm{E}-04$ & $-2.0062 \mathrm{E}-05$ & $-2.0485 \mathrm{E}-05$ \\
\hline $3.0997 \mathrm{E}-04$ & $-2.0873 \mathrm{E}-05$ & $-2.1537 \mathrm{E}-05$ \\
\hline $3.2719 \mathrm{E}-04$ & $-2.1202 \mathrm{E}-05$ & $-2.2072 \mathrm{E}-05$ \\
\hline $3.4441 \mathrm{E}-04$ & $-2.1002 \mathrm{E}-05$ & $-2.1913 \mathrm{E}-05$ \\
\hline
\end{tabular}



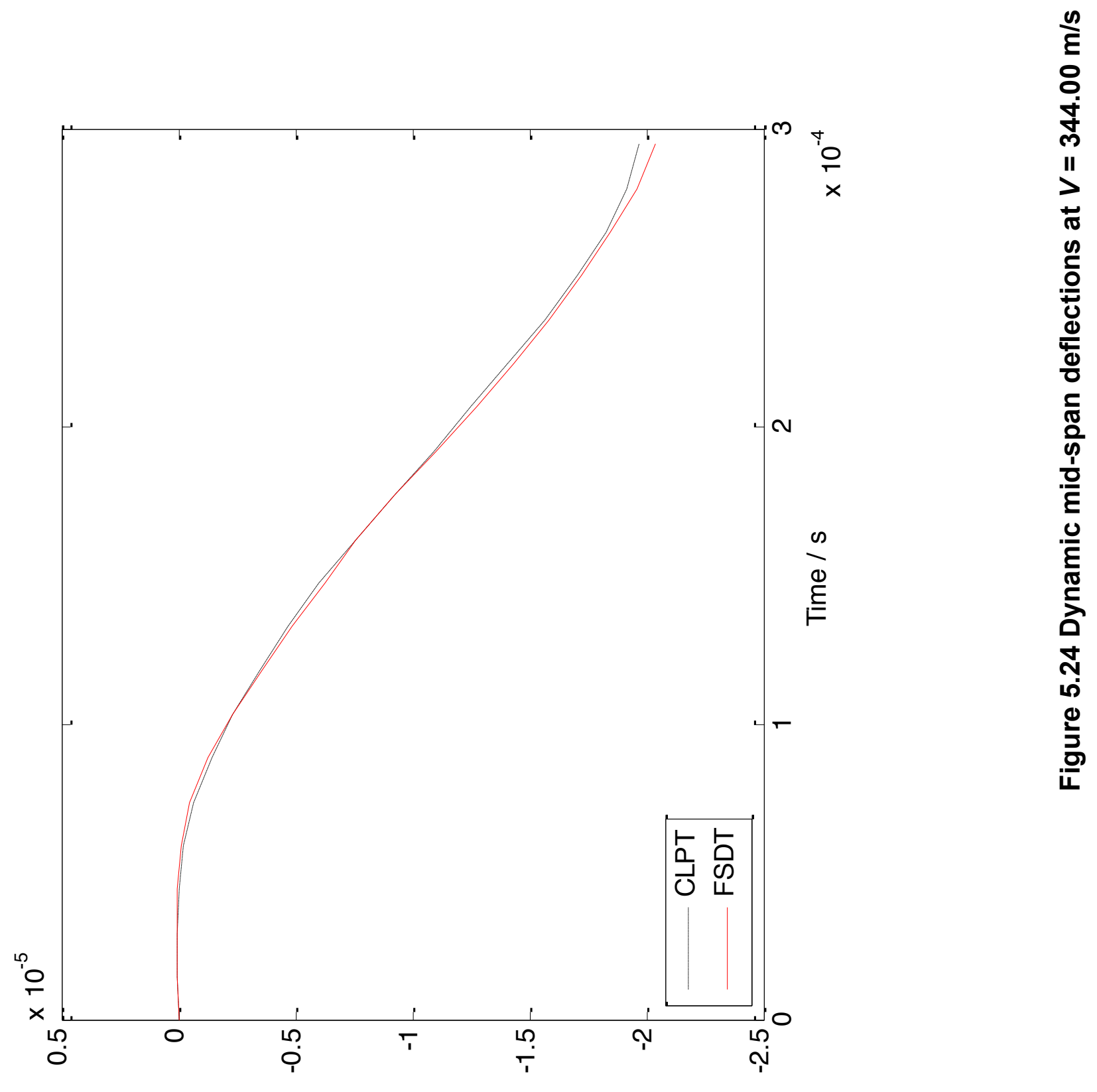
Table 5.34 Mid-span deflections at the end of each time-step for

$$
V=344.00 \mathrm{~m} / \mathrm{s}
$$

\begin{tabular}{|c|c|c|}
\hline \multirow{2}{*}{ Time at the end of each load step (s) } & \multicolumn{2}{c|}{ Mid-span dynamic deflection (m) } \\
\cline { 2 - 3 } & CLPT & FSDT \\
\hline 0 & 0 & 0 \\
\hline $1.4767 \mathrm{E}-05$ & $2.0993 \mathrm{E}-09$ & $1.2558 \mathrm{E}-09$ \\
\hline $2.9535 \mathrm{E}-05$ & $9.8323 \mathrm{E}-09$ & $9.1079 \mathrm{E}-09$ \\
\hline $4.4302 \mathrm{E}-05$ & $-1.4360 \mathrm{E}-08$ & $1.1379 \mathrm{E}-08$ \\
\hline $5.9070 \mathrm{E}-05$ & $-2.0273 \mathrm{E}-07$ & $-9.7067 \mathrm{E}-08$ \\
\hline $7.3837 \mathrm{E}-05$ & $-6.7950 \mathrm{E}-07$ & $-5.1369 \mathrm{E}-07$ \\
\hline $8.8605 \mathrm{E}-05$ & $-1.4202 \mathrm{E}-06$ & $-1.3135 \mathrm{E}-06$ \\
\hline $1.0337 \mathrm{E}-04$ & $-2.3524 \mathrm{E}-06$ & $-2.3588 \mathrm{E}-06$ \\
\hline $1.1814 \mathrm{E}-04$ & $-3.4393 \mathrm{E}-06$ & $-3.5529 \mathrm{E}-06$ \\
\hline $1.3291 \mathrm{E}-04$ & $-4.6514 \mathrm{E}-06$ & $-4.8901 \mathrm{E}-06$ \\
\hline $1.4767 \mathrm{E}-04$ & $-6.0259 \mathrm{E}-06$ & $-6.2734 \mathrm{E}-06$ \\
\hline $1.6244 \mathrm{E}-04$ & $-7.5847 \mathrm{E}-06$ & $-7.6261 \mathrm{E}-06$ \\
\hline $1.7721 \mathrm{E}-04$ & $-9.2423 \mathrm{E}-06$ & $-9.2112 \mathrm{E}-06$ \\
\hline $1.9198 \mathrm{E}-04$ & $-1.0910 \mathrm{E}-05$ & $-1.0983 \mathrm{E}-05$ \\
\hline $2.0674 \mathrm{E}-04$ & $-1.2543 \mathrm{E}-05$ & $-1.2721 \mathrm{E}-05$ \\
\hline $2.2151 \mathrm{E}-04$ & $-1.4115 \mathrm{E}-05$ & $-1.4385 \mathrm{E}-05$ \\
\hline $2.3628 \mathrm{E}-04$ & $-1.5623 \mathrm{E}-05$ & $-1.5869 \mathrm{E}-05$ \\
\hline $2.5105 \mathrm{E}-04$ & $-1.7050 \mathrm{E}-05$ & $-1.7272 \mathrm{E}-05$ \\
\hline $2.6581 \mathrm{E}-04$ & $-1.8291 \mathrm{E}-05$ & $-1.8507 \mathrm{E}-05$ \\
\hline $2.8058 \mathrm{E}-04$ & $-1.9204 \mathrm{E}-05$ & $-1.9583 \mathrm{E}-05$ \\
\hline $2.9535 \mathrm{E}-04$ & $-1.9730 \mathrm{E}-05$ & $-2.0387 \mathrm{E}-05$ \\
\hline
\end{tabular}




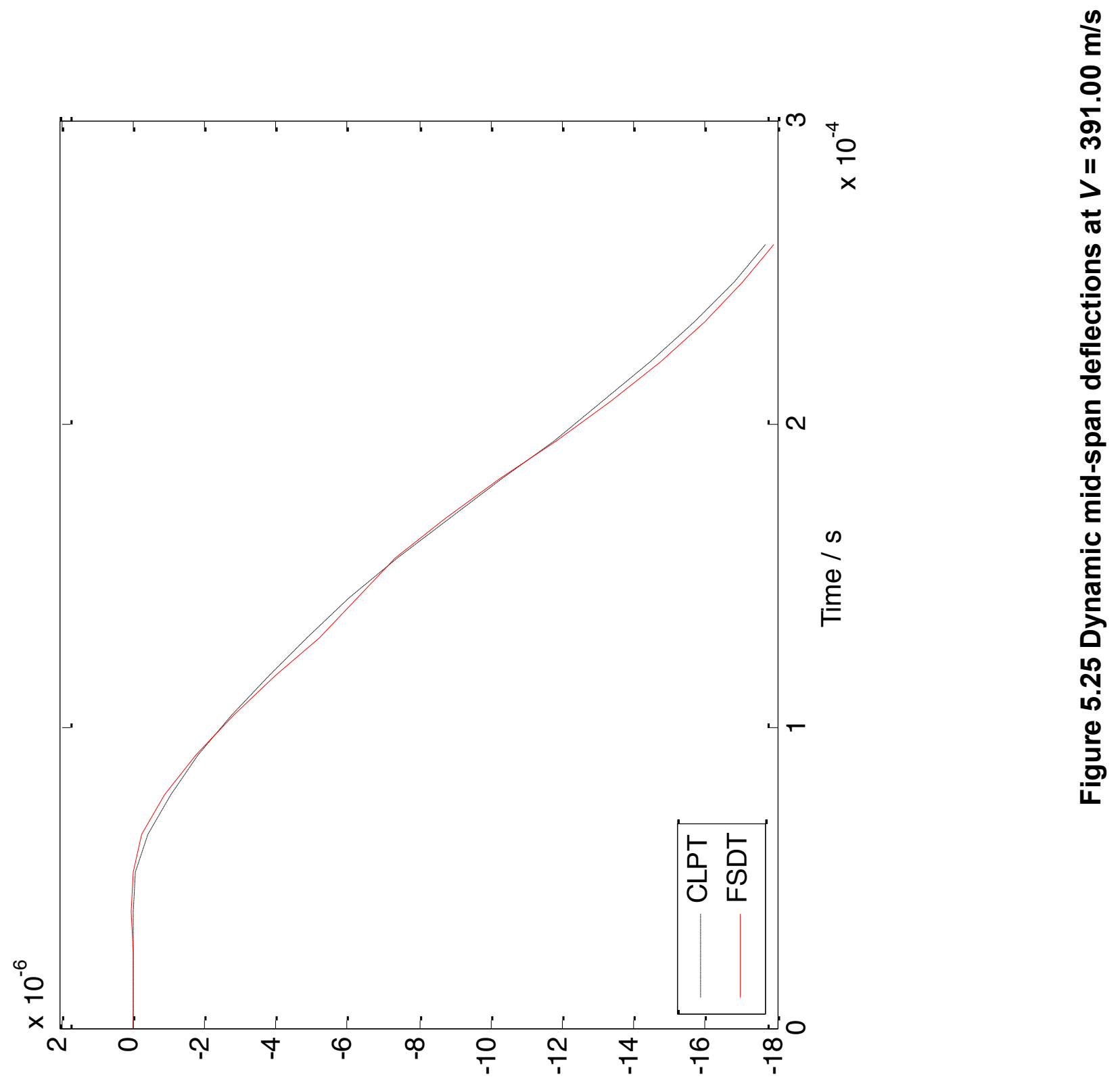


Table 5.35 Mid-span deflections at the end of each time-step for $V=391.00 \mathrm{~m} / \mathrm{s}$

\begin{tabular}{|c|c|c|}
\hline \multirow{2}{*}{ Time at the end of each load step (s) } & \multicolumn{2}{c|}{ Mid-span dynamic deflection (m) } \\
\cline { 2 - 3 } & CLPT & FSDT \\
\hline 0 & 0 & 0 \\
\hline $1.2992 \mathrm{E}-05$ & $1.6449 \mathrm{E}-09$ & $8.3780 \mathrm{E}-10$ \\
\hline $2.5985 \mathrm{E}-05$ & $1.0891 \mathrm{E}-08$ & $7.7537 \mathrm{E}-09$ \\
\hline $3.8977 \mathrm{E}-05$ & $1.1418 \mathrm{E}-08$ & $2.2509 \mathrm{E}-08$ \\
\hline $5.1969 \mathrm{E}-05$ & $-9.4802 \mathrm{E}-08$ & $-1.3816 \mathrm{E}-08$ \\
\hline $6.4962 \mathrm{E}-05$ & $-4.4039 \mathrm{E}-07$ & $-2.6865 \mathrm{E}-07$ \\
\hline $7.7954 \mathrm{E}-05$ & $-1.0442 \mathrm{E}-06$ & $-8.8316 \mathrm{E}-07$ \\
\hline $9.0946 \mathrm{E}-05$ & $-1.8409 \mathrm{E}-06$ & $-1.7901 \mathrm{E}-06$ \\
\hline $1.0394 \mathrm{E}-04$ & $-2.7819 \mathrm{E}-06$ & $-2.8461 \mathrm{E}-06$ \\
\hline $1.1693 \mathrm{E}-04$ & $-3.7991 \mathrm{E}-06$ & $-4.0225 \mathrm{E}-06$ \\
\hline $1.2992 \mathrm{E}-04$ & $-4.8653 \mathrm{E}-06$ & $-5.2303 \mathrm{E}-06$ \\
\hline $1.4292 \mathrm{E}-04$ & $-6.0488 \mathrm{E}-06$ & $-6.2569 \mathrm{E}-06$ \\
\hline $1.5591 \mathrm{E}-04$ & $-7.3861 \mathrm{E}-06$ & $-7.3546 \mathrm{E}-06$ \\
\hline $1.6890 \mathrm{E}-04$ & $-8.8286 \mathrm{E}-06$ & $-8.7159 \mathrm{E}-06$ \\
\hline $1.8189 \mathrm{E}-04$ & $-1.0307 \mathrm{E}-05$ & $-1.0228 \mathrm{E}-05$ \\
\hline $1.9488 \mathrm{E}-04$ & $-1.1762 \mathrm{E}-05$ & $-1.1849 \mathrm{E}-05$ \\
\hline $2.0788 \mathrm{E}-04$ & $-1.3145 \mathrm{E}-05$ & $-1.3352 \mathrm{E}-05$ \\
\hline $2.2087 \mathrm{E}-04$ & $-1.4443 \mathrm{E}-05$ & $-1.4741 \mathrm{E}-05$ \\
\hline $2.3386 \mathrm{E}-04$ & $-1.5682 \mathrm{E}-05$ & $-1.5976 \mathrm{E}-05$ \\
\hline $2.4685 \mathrm{E}-04$ & $-1.6790 \mathrm{E}-05$ & $-1.7015 \mathrm{E}-05$ \\
\hline $2.5985 \mathrm{E}-04$ & $-1.7660 \mathrm{E}-05$ & $-1.7894 \mathrm{E}-05$ \\
\hline
\end{tabular}




\subsubsection{3 [ \pm 45$]$ Laminated Composite Beam}

Next, an analysis is done for a moving load on the glass/epoxy laminatedcomposite simply-supported beam, [ \pm 45$]$, with two layers each having the same thickness and a total laminate thickness of $7.45 \mathrm{~mm}$. Kadivar and Mohebpur (1997) show a plot of the dynamic magnification factors at different velocities for higher order shear deformation theory which is read through the program Digitizelt. The present CLPT and FSDT results are compared with that of Kadivar and Mohebpur (1997). The material properties are the same as given earlier in Table 5.11.

A static analysis is run first, with a load of $P=-4.45 \mathrm{~N}$ applied at the midspan of the beam and the results are listed in Table 5.36

Table 5.36 Mid-span static deflection of glass/epoxy [ \pm 45$]$ composite beam

\begin{tabular}{|c|c|}
\hline \multicolumn{2}{|c|}{ Present study } \\
\hline CLPT & FSDT \\
\hline$-3.3411 \times 10^{-5} \mathrm{~m}$ & $-3.4152 \times 10^{-5} \mathrm{~m}$ \\
\hline
\end{tabular}

Table 5.37 lists the different total times and time steps with their corresponding velocities. These are used to achieve the dynamic magnification factors for comparison with Kadivar and Mohebpur (1997). 
Table 5.37 Moving load velocities and time-steps for [ \pm 45$]$ composite beam

\begin{tabular}{|c|c|c|}
\hline \multirow{2}{*}{ Velocity $(\mathbf{m} / \mathbf{s})$} & \multicolumn{2}{|c|}{ Composite beam [ $\mathbf{\pm 4 5 ]}$} \\
\cline { 2 - 3 } & $\boldsymbol{T}(\mathbf{s})$ & $\boldsymbol{\Delta t}(\mathbf{s})$ \\
\hline 13.40 & $7.5821 \times 10^{-3}$ & $3.7910 \times 10^{-4}$ \\
\hline 33.90 & $2.9971 \times 10^{-3}$ & $1.4985 \times 10^{-4}$ \\
\hline 50.40 & $2.0159 \times 10^{-3}$ & $1.0079 \times 10^{-4}$ \\
\hline 74.80 & $1.3583 \times 10^{-3}$ & $6.7914 \times 10^{-5}$ \\
\hline 99.60 & $1.0201 \times 10^{-3}$ & $5.1004 \times 10^{-5}$ \\
\hline 126.00 & $8.0635 \times 10^{-4}$ & $4.0317 \times 10^{-5}$ \\
\hline 193.00 & $5.2642 \times 10^{-4}$ & $2.6321 \times 10^{-5}$ \\
\hline 255.00 & $3.9843 \times 10^{-4}$ & $1.9922 \times 10^{-5}$ \\
\hline
\end{tabular}

Table 5.38, lists the maximum dynamic mid-span deflection at different velocities. Since Kadivar and Mohebpur do not list these, it is not possible to show a comparison in this table.

Table 5.38 Maximum dynamic deflections for different velocities, [ \pm 45$]$

\begin{tabular}{|c|c|c|}
\hline \multirow{2}{*}{ Velocity $(\mathbf{m} / \mathbf{s})$} & \multicolumn{2}{|c|}{ Maximum mid-span dynamic deflections (m) } \\
\cline { 2 - 3 } & \multicolumn{2}{|c|}{ Present study } \\
\cline { 2 - 3 } & CLPT & FSDT \\
\hline 13.40 & $-3.5627 \times 10^{-5}$ & $-3.6476 \times 10^{-5}$ \\
\hline 33.90 & $-3.7722 \times 10^{-5}$ & $-3.8325 \times 10^{-5}$ \\
\hline 50.40 & $-4.1953 \times 10^{-5}$ & $-4.2959 \times 10^{-5}$ \\
\hline 74.80 & $-5.1744 \times 10^{-5}$ & $-5.3011 \times 10^{-5}$ \\
\hline 99.60 & $-5.6404 \times 10^{-5}$ & $-5.7434 \times 10^{-5}$ \\
\hline 126.00 & $-5.7544 \times 10^{-5}$ & $-5.8414 \times 10^{-5}$ \\
\hline 193.00 & $-5.2754 \times 10^{-5}$ & $-5.3387 \times 10^{-5}$ \\
\hline 255.00 & $-4.3308 \times 10^{-5}$ & $-4.3606 \times 10^{-5}$ \\
\hline
\end{tabular}


The dynamic magnification factors for moving load on a [ \pm 45$]$ glass/epoxy composite beam are listed in Table 5.39 and are compared with the previously published results from Kadivar and Mohebpur (1997).

Table 5.39 Dynamic magnification factors comparison for different velocities, [ $\mathbf{4 5}$ ]

\begin{tabular}{|c|c|c|c|}
\hline \multirow{2}{*}{ Velocity $(\mathbf{m} / \mathbf{s})$} & \multicolumn{3}{|c|}{ Dynamic magnification factors } \\
\cline { 2 - 4 } & \multicolumn{2}{|c|}{ Present study } & \multirow{2}{*}{ Kadivar and Mohebpur } \\
\cline { 2 - 4 } & CLPT & FSDT & \\
\hline 13.40 & 1.066 & 1.068 & 1.060 \\
\hline 33.90 & 1.129 & 1.122 & 1.140 \\
\hline 50.40 & 1.256 & 1.258 & 1.250 \\
\hline 74.80 & 1.549 & 1.552 & 1.560 \\
\hline 99.60 & 1.688 & 1.682 & 1.680 \\
\hline 126.00 & 1.722 & 1.710 & 1.700 \\
\hline 193.00 & 1.579 & 1.563 & 1.560 \\
\hline 255.00 & 1.296 & 1.277 & 1.280 \\
\hline
\end{tabular}

It can be seen that the present study results are in excellent agreement with that of the previous authors. The results for CLPT are slightly off since Kadivar and Mohebpur show results for HSDT. 

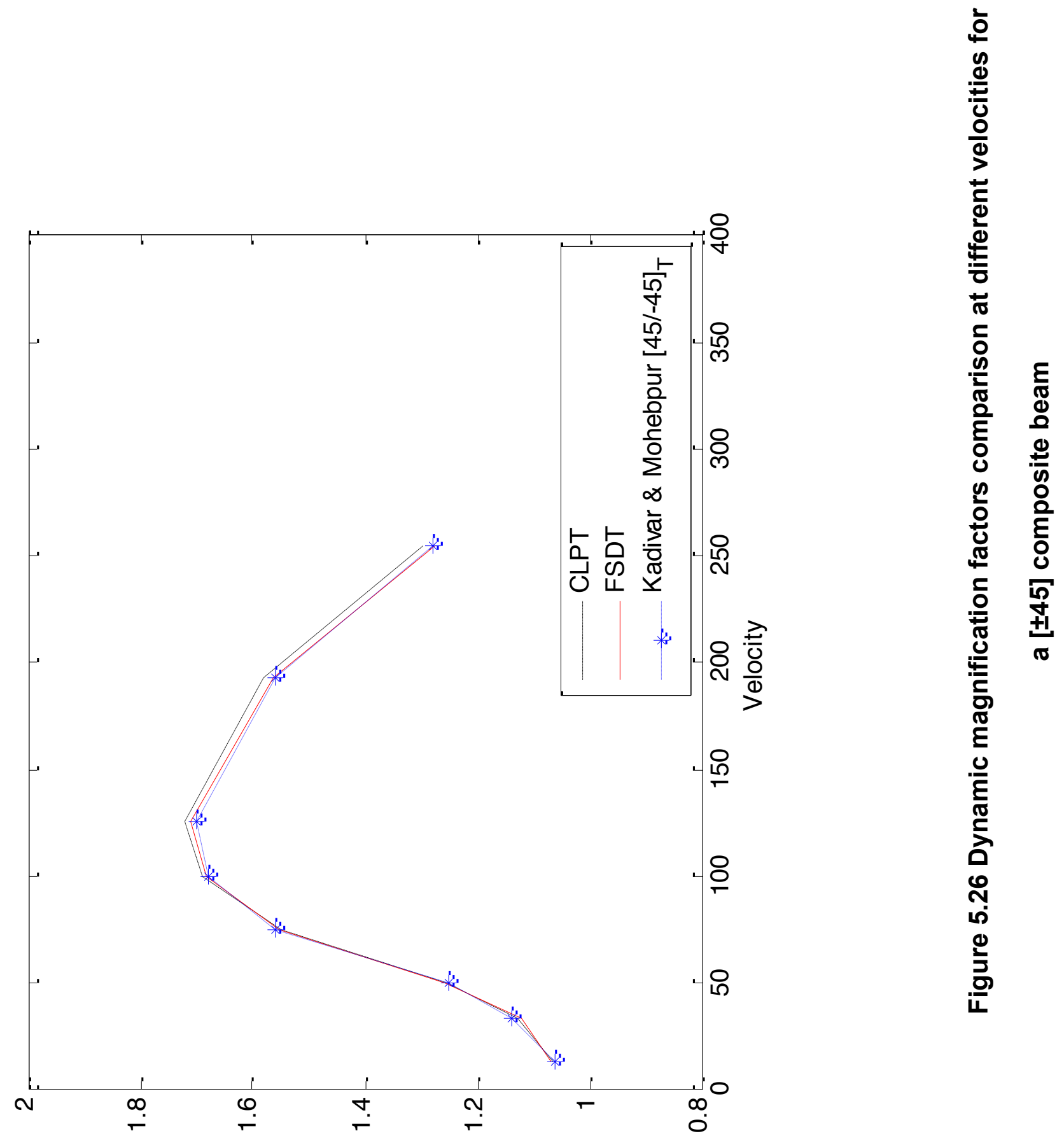
Figures 5.26 to 5.33 and Tables 5.40 to 5.47 show the values of the midspan dynamic deflections at the end of each time-step at different velocities for the $[ \pm 45]$ composite beam, based on CLPT and FSDT. 


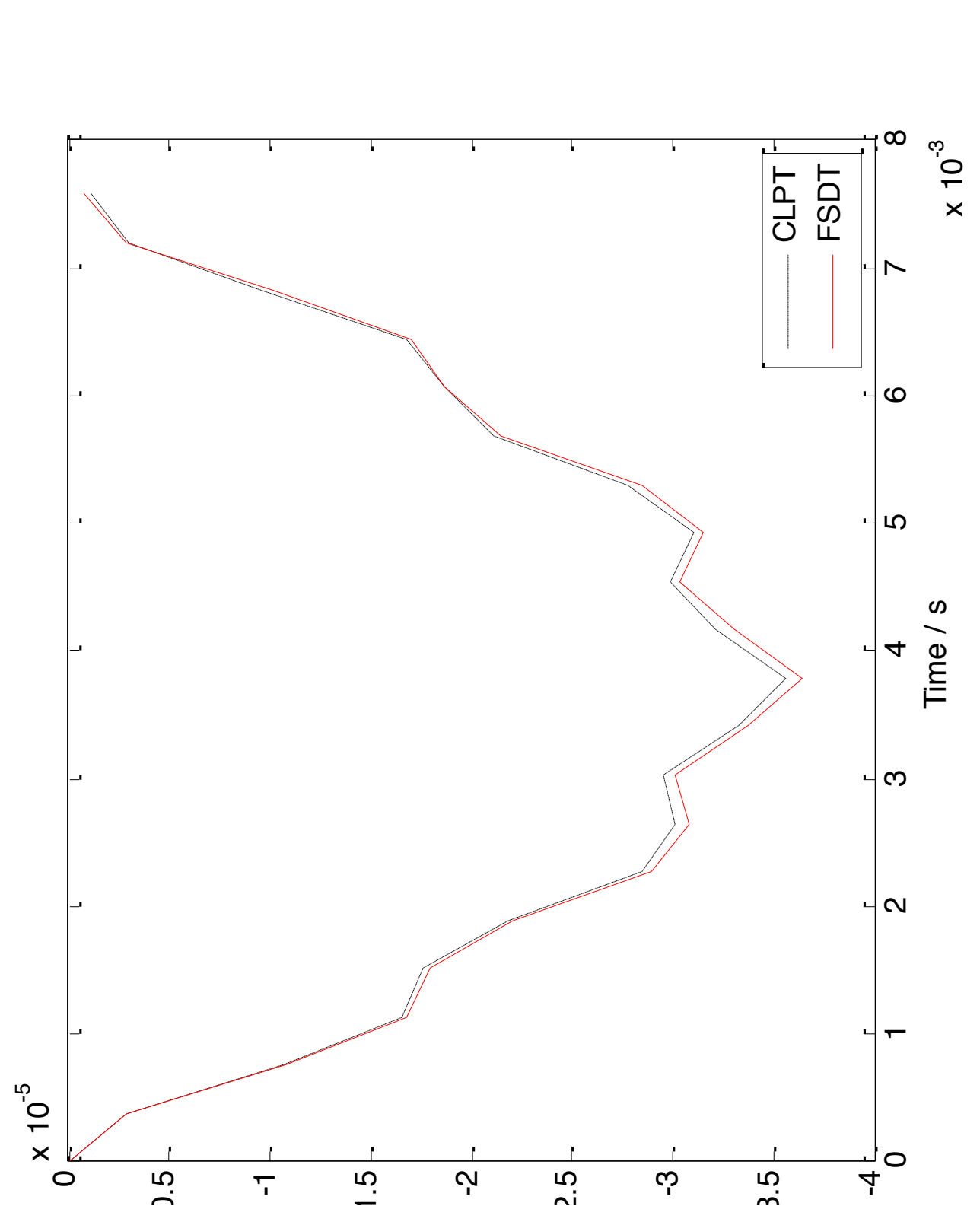

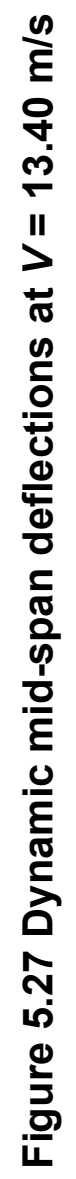


Table 5.40 Mid-span deflections at the end of each time-step for $V=13.40 \mathrm{~m} / \mathrm{s}$

\begin{tabular}{|c|c|c|}
\hline \multirow{2}{*}{ Time at the end of each load step (s) } & \multicolumn{2}{|c|}{ Mid-span dynamic deflection (m) } \\
\hline & CLPT & FSDT \\
\hline 0 & 0 & 0 \\
\hline 3.7910E-04 & $-2.8930 \mathrm{E}-06$ & $-2.9068 \mathrm{E}-06$ \\
\hline 7.5821E-04 & $-1.0709 \mathrm{E}-05$ & $-1.0845 E-05$ \\
\hline 1.1373E-03 & $-1.6493 \mathrm{E}-05$ & $-1.6807 \mathrm{E}-05$ \\
\hline $1.5164 \mathrm{E}-03$ & $-1.7601 \mathrm{E}-05$ & $-1.7924 \mathrm{E}-05$ \\
\hline 1.8955E-03 & $-2.1770 \mathrm{E}-05$ & $-2.2039 \mathrm{E}-05$ \\
\hline 2.2746E-03 & $-2.8501 \mathrm{E}-05$ & $-2.8955 E-05$ \\
\hline 2.6537E-03 & $-3.0086 \mathrm{E}-05$ & $-3.0773 \mathrm{E}-05$ \\
\hline $3.0328 \mathrm{E}-03$ & $-2.9514 \mathrm{E}-05$ & $-3.0084 E-05$ \\
\hline $3.4119 \mathrm{E}-03$ & $-3.3266 \mathrm{E}-05$ & $-3.3780 \mathrm{E}-05$ \\
\hline $3.7910 \mathrm{E}-03$ & $-3.5627 \mathrm{E}-05$ & $-3.6476 \mathrm{E}-05$ \\
\hline $4.1701 \mathrm{E}-03$ & $-3.2123 \mathrm{E}-05$ & $-3.2986 \mathrm{E}-05$ \\
\hline 4.5493E-03 & $-2.9935 \mathrm{E}-05$ & $-3.0365 \mathrm{E}-05$ \\
\hline 4.9284E-03 & $-3.1072 \mathrm{E}-05$ & $-3.1463 E-05$ \\
\hline $5.3075 \mathrm{E}-03$ & $-2.7725 \mathrm{E}-05$ & $-2.8444 \mathrm{E}-05$ \\
\hline $5.6866 \mathrm{E}-03$ & $-2.1063 E-05$ & $-2.1516 \mathrm{E}-05$ \\
\hline 6.0657E-03 & $-1.8644 \mathrm{E}-05$ & $-1.8632 E-05$ \\
\hline $6.4448 \mathrm{E}-03$ & $-1.6809 \mathrm{E}-05$ & $-1.7067 \mathrm{E}-05$ \\
\hline $6.8239 \mathrm{E}-03$ & $-9.5595 \mathrm{E}-06$ & -1.0064E-05 \\
\hline $7.2030 \mathrm{E}-03$ & $-2.9886 \mathrm{E}-06$ & $-2.9016 \mathrm{E}-06$ \\
\hline 7.5821E-03 & $-1.1244 \mathrm{E}-06$ & -8.0063E-07 \\
\hline
\end{tabular}




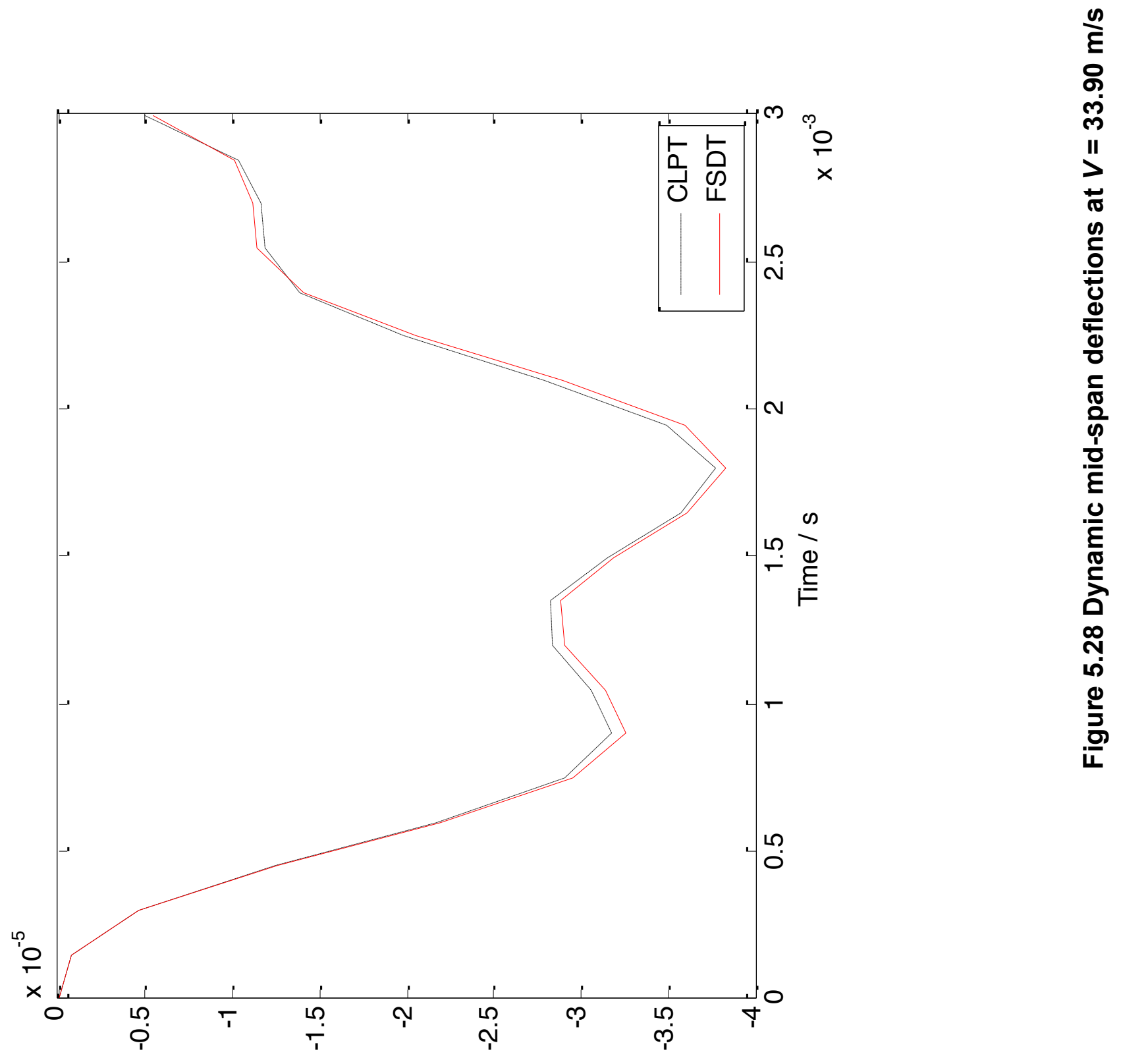


Table 5.41 Mid-span deflections at the end of each time-step for $V=33.90 \mathrm{~m} / \mathrm{s}$

\begin{tabular}{|c|c|c|}
\hline \multirow{2}{*}{ Time at the end of each load step (s) } & \multicolumn{2}{|c|}{ Mid-span dynamic deflection (m) } \\
\hline & CLPT & FSDT \\
\hline 0 & 0 & 0 \\
\hline 1.4985E-04 & $-8.0427 \mathrm{E}-07$ & $-7.9042 \mathrm{E}-07$ \\
\hline 2.9971E-04 & $-4.6746 \mathrm{E}-06$ & $-4.6587 \mathrm{E}-06$ \\
\hline 4.4956E-04 & $-1.2454 \mathrm{E}-05$ & $-1.2520 \mathrm{E}-05$ \\
\hline $5.9941 \mathrm{E}-04$ & $-2.1737 \mathrm{E}-05$ & $-2.1970 \mathrm{E}-05$ \\
\hline 7.4926E-04 & $-2.9035 E-05$ & $-2.9533 \mathrm{E}-05$ \\
\hline 8.9912E-04 & $-3.1774 \mathrm{E}-05$ & $-3.2529 \mathrm{E}-05$ \\
\hline 1.0490E-03 & $-3.0544 \mathrm{E}-05$ & $-3.1391 \mathrm{E}-05$ \\
\hline 1.1988E-03 & $-2.8335 \mathrm{E}-05$ & $-2.9097 \mathrm{E}-05$ \\
\hline $1.3487 \mathrm{E}-03$ & $-2.8276 \mathrm{E}-05$ & $-2.8787 \mathrm{E}-05$ \\
\hline 1.4985E-03 & $-3.1468 \mathrm{E}-05$ & $-3.1827 \mathrm{E}-05$ \\
\hline 1.6484E-03 & $-3.5714 \mathrm{E}-05$ & $-3.6058 E-05$ \\
\hline 1.7982E-03 & $-3.7722 \mathrm{E}-05$ & $-3.8325 \mathrm{E}-05$ \\
\hline 1.9481E-03 & $-3.4945 \mathrm{E}-05$ & $-3.5911 \mathrm{E}-05$ \\
\hline 2.0979E-03 & $-2.7946 \mathrm{E}-05$ & $-2.8995 E-05$ \\
\hline 2.2478E-03 & $-1.9799 \mathrm{E}-05$ & $-2.0572 E-05$ \\
\hline $2.3976 \mathrm{E}-03$ & $-1.3915 \mathrm{E}-05$ & $-1.4058 \mathrm{E}-05$ \\
\hline $2.5475 \mathrm{E}-03$ & $-1.1821 \mathrm{E}-05$ & $-1.1431 \mathrm{E}-05$ \\
\hline 2.6973E-03 & $-1.1695 \mathrm{E}-05$ & $-1.1190 \mathrm{E}-05$ \\
\hline 2.8472E-03 & $-1.0302 \mathrm{E}-05$ & -1.0166E-05 \\
\hline $2.9971 \mathrm{E}-03$ & $-4.9537 \mathrm{E}-06$ & $-5.4381 E-06$ \\
\hline
\end{tabular}




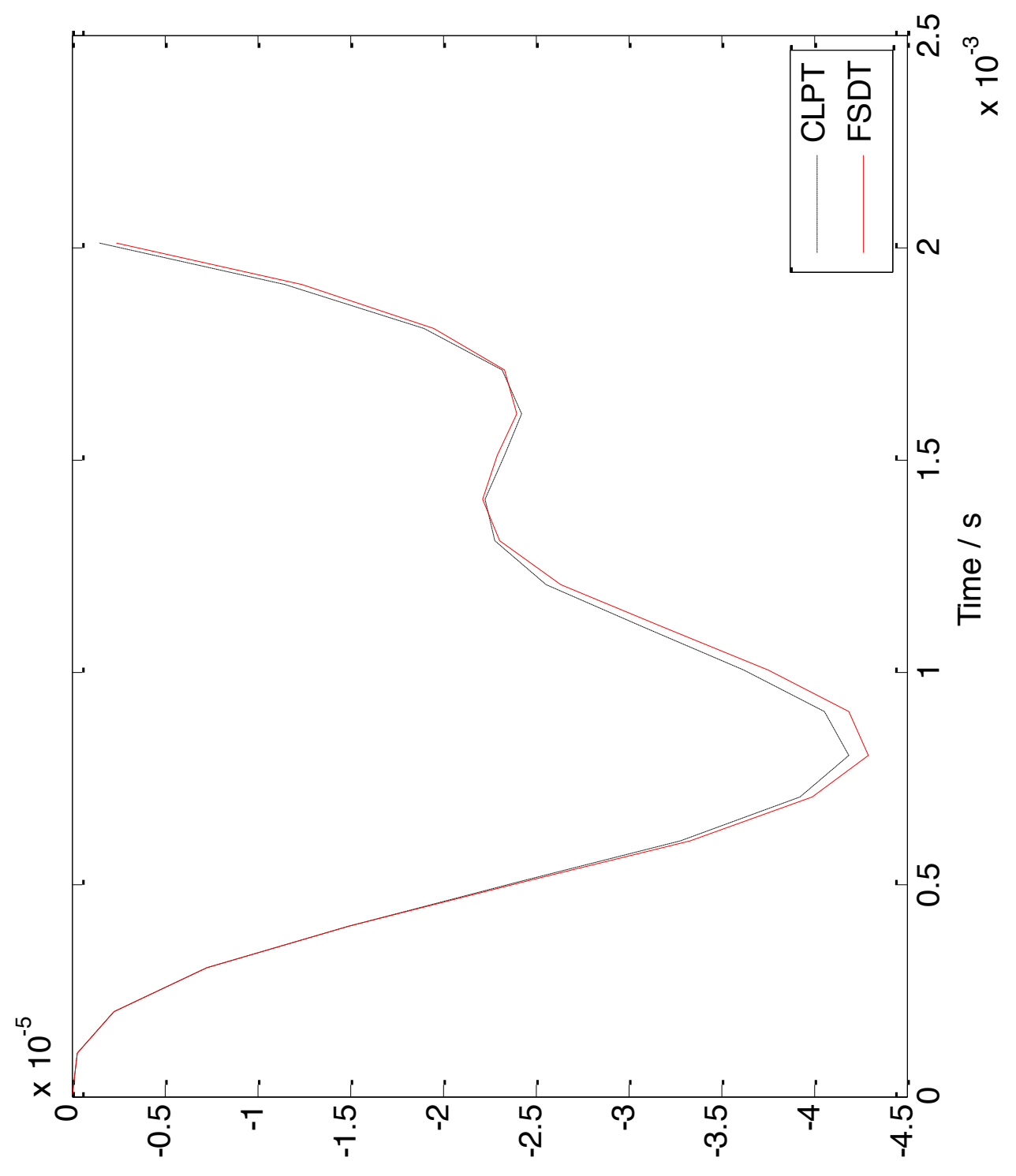

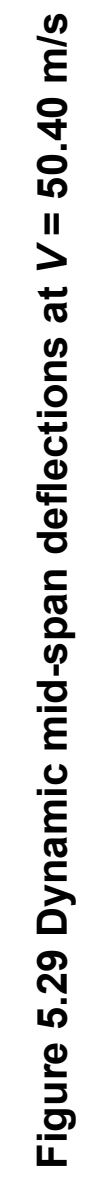


Table 5.42 Mid-span deflections at the end of each time-step for $V=50.40 \mathrm{~m} / \mathrm{s}$

\begin{tabular}{|c|c|c|}
\hline \multirow{2}{*}{ Time at the end of each load step (s) } & \multicolumn{2}{|c|}{ Mid-span dynamic deflection (m) } \\
\hline & CLPT & FSDT \\
\hline 0 & 0 & 0 \\
\hline 1.0079E-04 & $-3.4231 \mathrm{E}-07$ & $-3.2905 \mathrm{E}-07$ \\
\hline 2.0159E-04 & $-2.3610 \mathrm{E}-06$ & $-2.3218 \mathrm{E}-06$ \\
\hline 3.0238E-04 & $-7.3071 \mathrm{E}-06$ & $-7.2933 E-06$ \\
\hline 4.0317E-04 & $-1.4898 \mathrm{E}-05$ & $-1.4951 \mathrm{E}-05$ \\
\hline 5.0397E-04 & $-2.4073 \mathrm{E}-05$ & $-2.4250 \mathrm{E}-05$ \\
\hline 6.0476E-04 & $-3.2894 \mathrm{E}-05$ & $-3.3326 \mathrm{E}-05$ \\
\hline 7.0556E-04 & $-3.9221 \mathrm{E}-05$ & $-3.9924 \mathrm{E}-05$ \\
\hline 8.0635E-04 & $-4.1953 E-05$ & $-4.2959 \mathrm{E}-05$ \\
\hline $9.0714 \mathrm{E}-04$ & $-4.0625 \mathrm{E}-05$ & $-4.1885 E-05$ \\
\hline 1.0079E-03 & $-3.6284 \mathrm{E}-05$ & $-3.7577 \mathrm{E}-05$ \\
\hline 1.1087E-03 & $-3.0696 \mathrm{E}-05$ & $-3.1798 \mathrm{E}-05$ \\
\hline 1.2095E-03 & $-2.5658 \mathrm{E}-05$ & $-2.6361 \mathrm{E}-05$ \\
\hline 1.3103E-03 & $-2.2812 \mathrm{E}-05$ & $-2.3051 \mathrm{E}-05$ \\
\hline 1.4111E-03 & $-2.2283 \mathrm{E}-05$ & $-2.2192 E-05$ \\
\hline $1.5119 \mathrm{E}-03$ & $-2.3299 \mathrm{E}-05$ & $-2.2991 \mathrm{E}-05$ \\
\hline 1.6127E-03 & $-2.4279 \mathrm{E}-05$ & $-2.4067 E-05$ \\
\hline 1.7135E-03 & $-2.3220 \mathrm{E}-05$ & $-2.3340 \mathrm{E}-05$ \\
\hline 1.8143E-03 & $-1.9069 \mathrm{E}-05$ & $-1.9551 \mathrm{E}-05$ \\
\hline 1.9151E-03 & $-1.1508 \mathrm{E}-05$ & $-1.2394 \mathrm{E}-05$ \\
\hline 2.0159E-03 & $-1.4940 \mathrm{E}-06$ & $-2.4434 \mathrm{E}-06$ \\
\hline
\end{tabular}




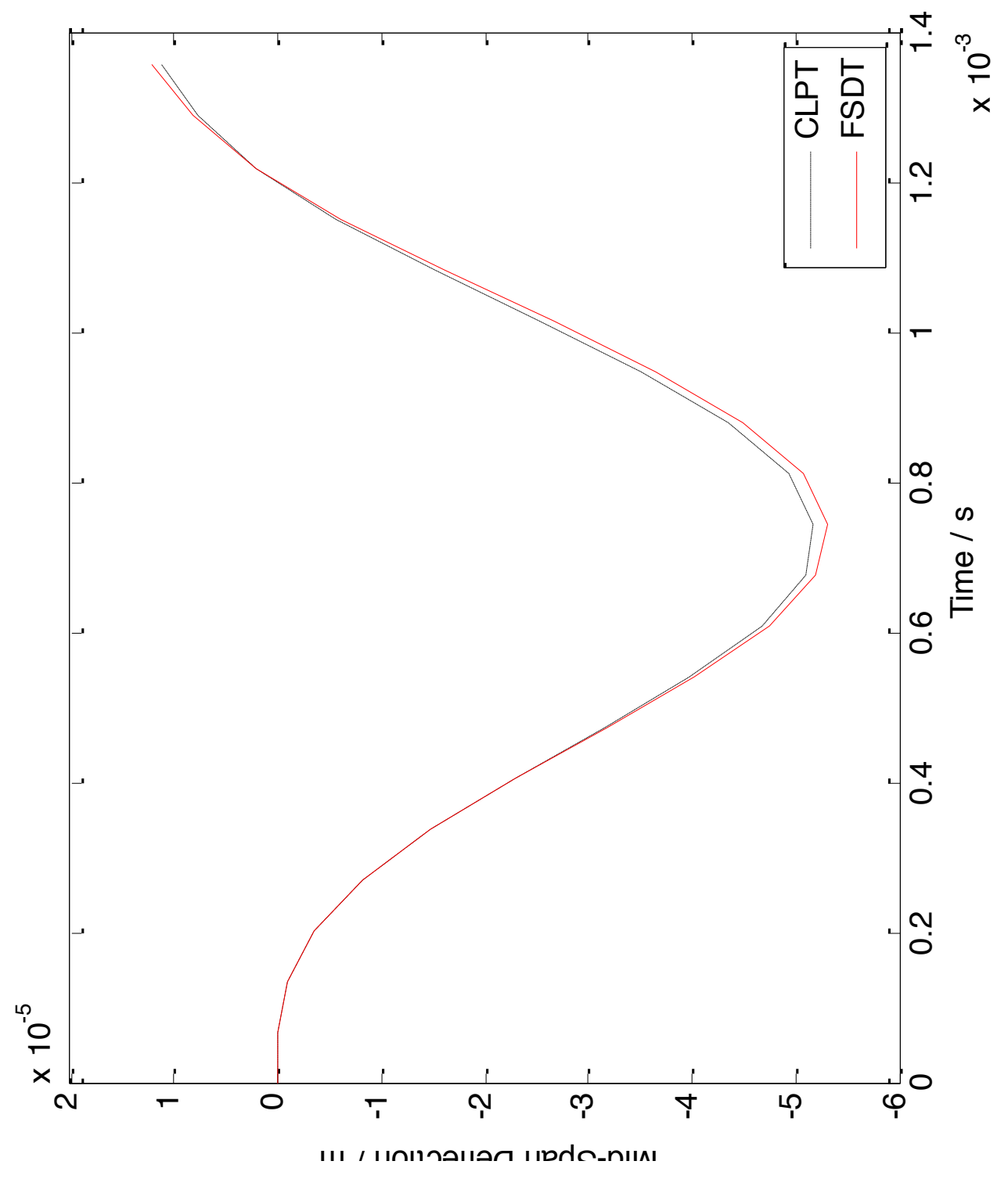

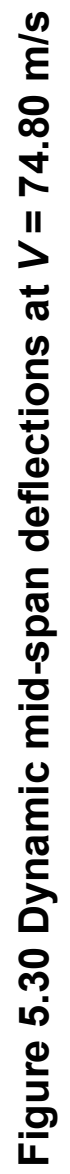


Table 5.43 Mid-span deflections at the end of each time-step for $V=74.80 \mathrm{~m} / \mathrm{s}$

\begin{tabular}{|c|c|c|}
\hline \multirow{2}{*}{ Time at the end of each load step (s) } & \multicolumn{2}{c|}{ Mid-span dynamic deflection (m) } \\
\cline { 2 - 3 } & CLPT & FSDT \\
\hline 0 & 0 & 0 \\
\hline $6.7914 \mathrm{E}-05$ & $-1.1130 \mathrm{E}-07$ & $-1.0225 \mathrm{E}-07$ \\
\hline $1.3583 \mathrm{E}-04$ & $-9.9026 \mathrm{E}-07$ & $-9.4546 \mathrm{E}-07$ \\
\hline $2.0374 \mathrm{E}-04$ & $-3.6239 \mathrm{E}-06$ & $-3.5686 \mathrm{E}-06$ \\
\hline $2.7166 \mathrm{E}-04$ & $-8.2322 \mathrm{E}-06$ & $-8.2232 \mathrm{E}-06$ \\
\hline $3.3957 \mathrm{E}-04$ & $-1.4689 \mathrm{E}-05$ & $-1.4698 \mathrm{E}-05$ \\
\hline $4.0749 \mathrm{E}-04$ & $-2.2830 \mathrm{E}-05$ & $-2.2926 \mathrm{E}-05$ \\
\hline $4.7540 \mathrm{E}-04$ & $-3.1561 \mathrm{E}-05$ & $-3.1862 \mathrm{E}-05$ \\
\hline $5.4332 \mathrm{E}-04$ & $-3.9821 \mathrm{E}-05$ & $-4.0301 \mathrm{E}-05$ \\
\hline $6.1123 \mathrm{E}-04$ & $-4.6700 \mathrm{E}-05$ & $-4.7458 \mathrm{E}-05$ \\
\hline $6.7914 \mathrm{E}-04$ & $-5.0882 \mathrm{E}-05$ & $-5.1996 \mathrm{E}-05$ \\
\hline $7.4706 \mathrm{E}-04$ & $-5.1744 \mathrm{E}-05$ & $-5.3011 \mathrm{E}-05$ \\
\hline $8.1497 \mathrm{E}-04$ & $-4.9251 \mathrm{E}-05$ & $-5.0650 \mathrm{E}-05$ \\
\hline $8.8289 \mathrm{E}-04$ & $-4.3435 \mathrm{E}-05$ & $-4.4980 \mathrm{E}-05$ \\
\hline $9.5080 \mathrm{E}-04$ & $-3.5092 \mathrm{E}-05$ & $-3.6537 \mathrm{E}-05$ \\
\hline $1.0187 \mathrm{E}-03$ & $-2.5379 \mathrm{E}-05$ & $-2.6630 \mathrm{E}-05$ \\
\hline $1.0866 \mathrm{E}-03$ & $-1.5133 \mathrm{E}-05$ & $-1.6167 \mathrm{E}-05$ \\
\hline $1.1545 \mathrm{E}-03$ & $-5.6642 \mathrm{E}-06$ & $-6.1619 \mathrm{E}-06$ \\
\hline $1.2225 \mathrm{E}-03$ & $2.0616 \mathrm{E}-06$ & $2.0591 \mathrm{E}-06$ \\
\hline $1.2904 \mathrm{E}-03$ & $7.7893 \mathrm{E}-06$ & $8.2211 \mathrm{E}-06$ \\
\hline $1.3583 \mathrm{E}-03$ & $1.1134 \mathrm{E}-05$ & $1.2130 \mathrm{E}-05$ \\
\hline
\end{tabular}




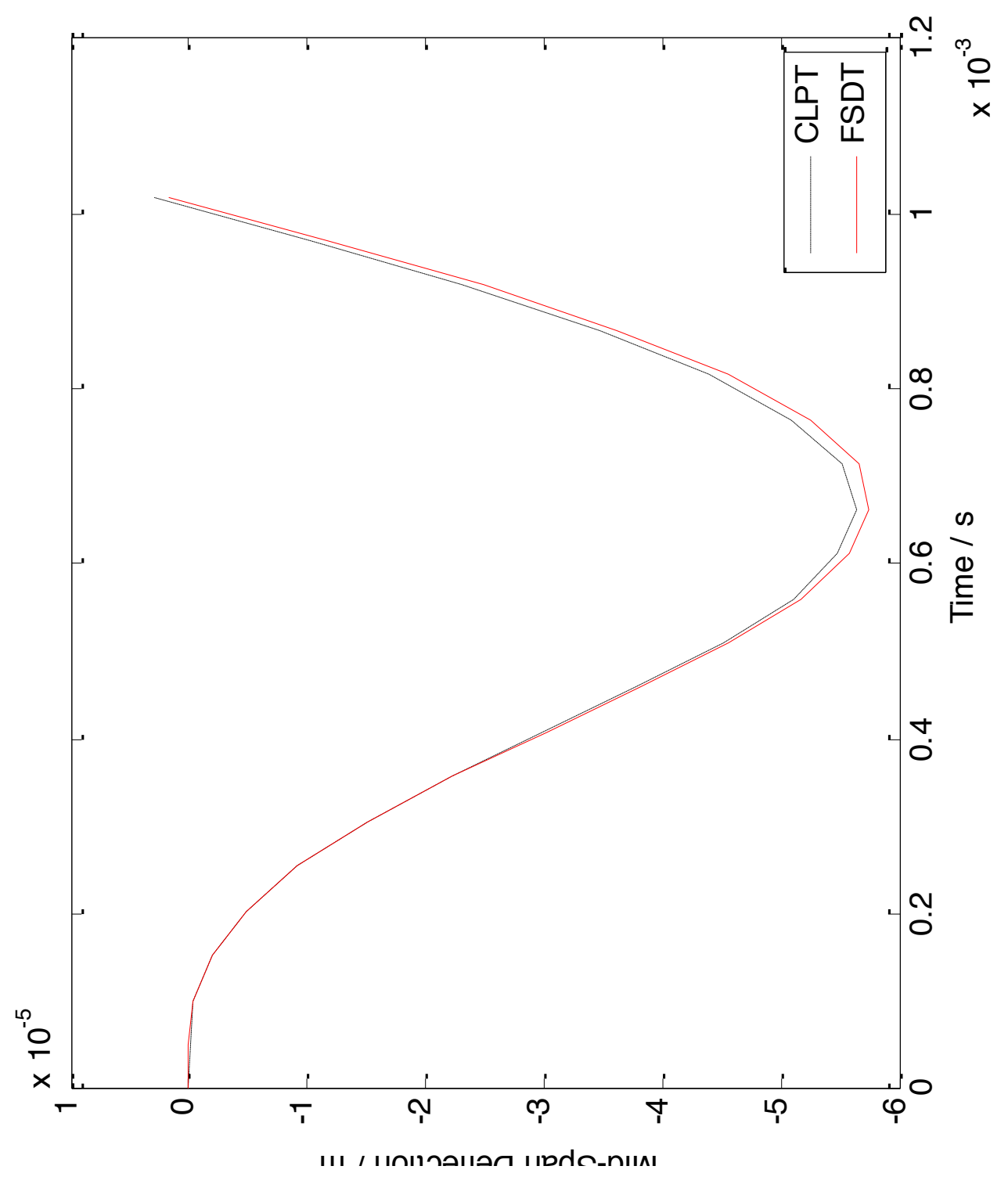

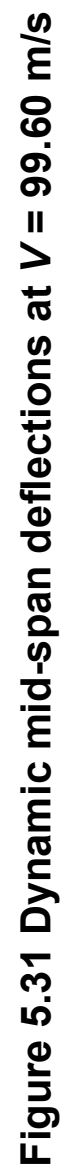


Table 5.44 Mid-span deflections at the end of each time-step for $V=99.60 \mathrm{~m} / \mathrm{s}$

\begin{tabular}{|c|c|c|}
\hline \multirow{2}{*}{ Time at the end of each load step (s) } & \multicolumn{2}{|c|}{ Mid-span dynamic deflection (m) } \\
\hline & CLPT & FSDT \\
\hline 0 & 0 & 0 \\
\hline $5.1004 \mathrm{E}-05$ & $-3.3855 \mathrm{E}-08$ & $-2.8884 \mathrm{E}-08$ \\
\hline 1.0201E-04 & $-4.3750 \mathrm{E}-07$ & $-3.9853 \mathrm{E}-07$ \\
\hline $1.5301 \mathrm{E}-04$ & $-1.9533 \mathrm{E}-06$ & $-1.8749 \mathrm{E}-06$ \\
\hline $2.0402 \mathrm{E}-04$ & $-4.9268 \mathrm{E}-06$ & $-4.8872 \mathrm{E}-06$ \\
\hline $2.5502 \mathrm{E}-04$ & $-9.2067 \mathrm{E}-06$ & $-9.2056 \mathrm{E}-06$ \\
\hline $3.0602 E-04$ & $-1.4994 \mathrm{E}-05$ & $-1.4978 \mathrm{E}-05$ \\
\hline 3.5703E-04 & $-2.2149 \mathrm{E}-05$ & $-2.2237 \mathrm{E}-05$ \\
\hline 4.0803E-04 & $-2.9890 \mathrm{E}-05$ & $-3.0160 \mathrm{E}-05$ \\
\hline 4.5904E-04 & $-3.7711 \mathrm{E}-05$ & $-3.8113 E-05$ \\
\hline 5.1004E-04 & $-4.5075 \mathrm{E}-05$ & $-4.5642 \mathrm{E}-05$ \\
\hline $5.6104 \mathrm{E}-04$ & $-5.1024 \mathrm{E}-05$ & $-5.1807 \mathrm{E}-05$ \\
\hline $6.1205 E-04$ & $-5.4849 \mathrm{E}-05$ & $-5.5817 \mathrm{E}-05$ \\
\hline $6.6305 \mathrm{E}-04$ & $-5.6404 \mathrm{E}-05$ & $-5.7434 \mathrm{E}-05$ \\
\hline 7.1406E-04 & $-5.5231 \mathrm{E}-05$ & $-5.6530 \mathrm{E}-05$ \\
\hline 7.6506E-04 & $-5.0960 \mathrm{E}-05$ & $-5.2508 \mathrm{E}-05$ \\
\hline 8.1606E-04 & $-4.4008 \mathrm{E}-05$ & $-4.5551 \mathrm{E}-05$ \\
\hline 8.6707E-04 & $-3.4648 \mathrm{E}-05$ & $-3.6247 E-05$ \\
\hline $9.1807 \mathrm{E}-04$ & $-2.3143 E-05$ & $-2.4808 E-05$ \\
\hline $9.6908 \mathrm{E}-04$ & $-1.0327 \mathrm{E}-05$ & $-1.1779 \mathrm{E}-05$ \\
\hline $1.0201 \mathrm{E}-03$ & 2.8445E-06 & $1.8119 \mathrm{E}-06$ \\
\hline
\end{tabular}




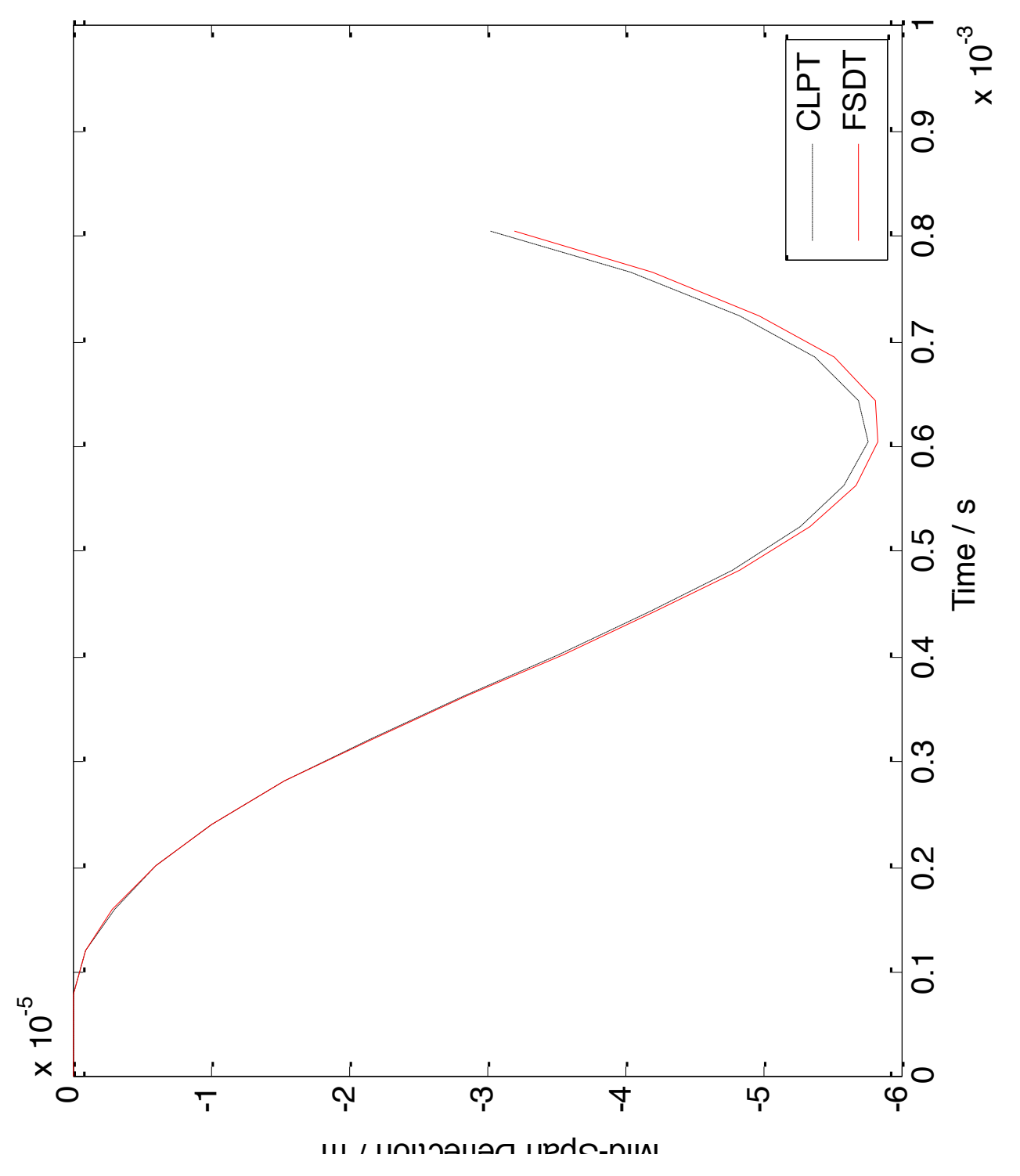

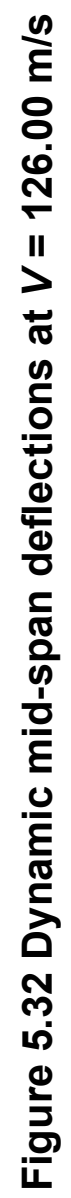


Table 5.45 Mid-span deflections at the end of each time-step for

$$
V=126.00 \mathrm{~m} / \mathrm{s}
$$

\begin{tabular}{|c|c|c|}
\hline \multirow{2}{*}{ Time at the end of each load step (s) } & \multicolumn{2}{c|}{ Mid-span dynamic deflection (m) } \\
\cline { 2 - 3 } & CLPT & FSDT \\
\hline 0 & 0 & 0 \\
\hline $4.0317 \mathrm{E}-05$ & $-4.5125 \mathrm{E}-09$ & $-2.6636 \mathrm{E}-09$ \\
\hline $8.0635 \mathrm{E}-05$ & $-1.7471 \mathrm{E}-07$ & $-1.4672 \mathrm{E}-07$ \\
\hline $1.2095 \mathrm{E}-04$ & $-1.0460 \mathrm{E}-06$ & $-9.5958 \mathrm{E}-07$ \\
\hline $1.6127 \mathrm{E}-04$ & $-3.0583 \mathrm{E}-06$ & $-2.9760 \mathrm{E}-06$ \\
\hline $2.0159 \mathrm{E}-04$ & $-6.0638 \mathrm{E}-06$ & $-6.0593 \mathrm{E}-06$ \\
\hline $2.4190 \mathrm{E}-04$ & $-1.0059 \mathrm{E}-05$ & $-1.0059 \mathrm{E}-05$ \\
\hline $2.8222 \mathrm{E}-04$ & $-1.5311 \mathrm{E}-05$ & $-1.5301 \mathrm{E}-05$ \\
\hline $3.2254 \mathrm{E}-04$ & $-2.1577 \mathrm{E}-05$ & $-2.1671 \mathrm{E}-05$ \\
\hline $3.6286 \mathrm{E}-04$ & $-2.8302 \mathrm{E}-05$ & $-2.8589 \mathrm{E}-05$ \\
\hline $4.0317 \mathrm{E}-04$ & $-3.5106 \mathrm{E}-05$ & $-3.5521 \mathrm{E}-05$ \\
\hline $4.4349 \mathrm{E}-04$ & $-4.1810 \mathrm{E}-05$ & $-4.2152 \mathrm{E}-05$ \\
\hline $4.8381 \mathrm{E}-04$ & $-4.7884 \mathrm{E}-05$ & $-4.8369 \mathrm{E}-05$ \\
\hline $5.2413 \mathrm{E}-04$ & $-5.2634 \mathrm{E}-05$ & $-5.3364 \mathrm{E}-05$ \\
\hline $5.6444 \mathrm{E}-04$ & $-5.5928 \mathrm{E}-05$ & $-5.6704 \mathrm{E}-05$ \\
\hline $6.0476 \mathrm{E}-04$ & $-5.7544 \mathrm{E}-05$ & $-5.8414 \mathrm{E}-05$ \\
\hline $6.4508 \mathrm{E}-04$ & $-5.6942 \mathrm{E}-05$ & $-5.8086 \mathrm{E}-05$ \\
\hline $6.8540 \mathrm{E}-04$ & $-5.3796 \mathrm{E}-05$ & $-5.5261 \mathrm{E}-05$ \\
\hline $7.2571 \mathrm{E}-04$ & $-4.8262 \mathrm{E}-05$ & $-4.9773 \mathrm{E}-05$ \\
\hline $7.6603 \mathrm{E}-04$ & $-4.0482 \mathrm{E}-05$ & $-4.2003 \mathrm{E}-05$ \\
\hline $8.0635 \mathrm{E}-04$ & $-3.0284 \mathrm{E}-05$ & $-3.2075 \mathrm{E}-05$ \\
\hline
\end{tabular}




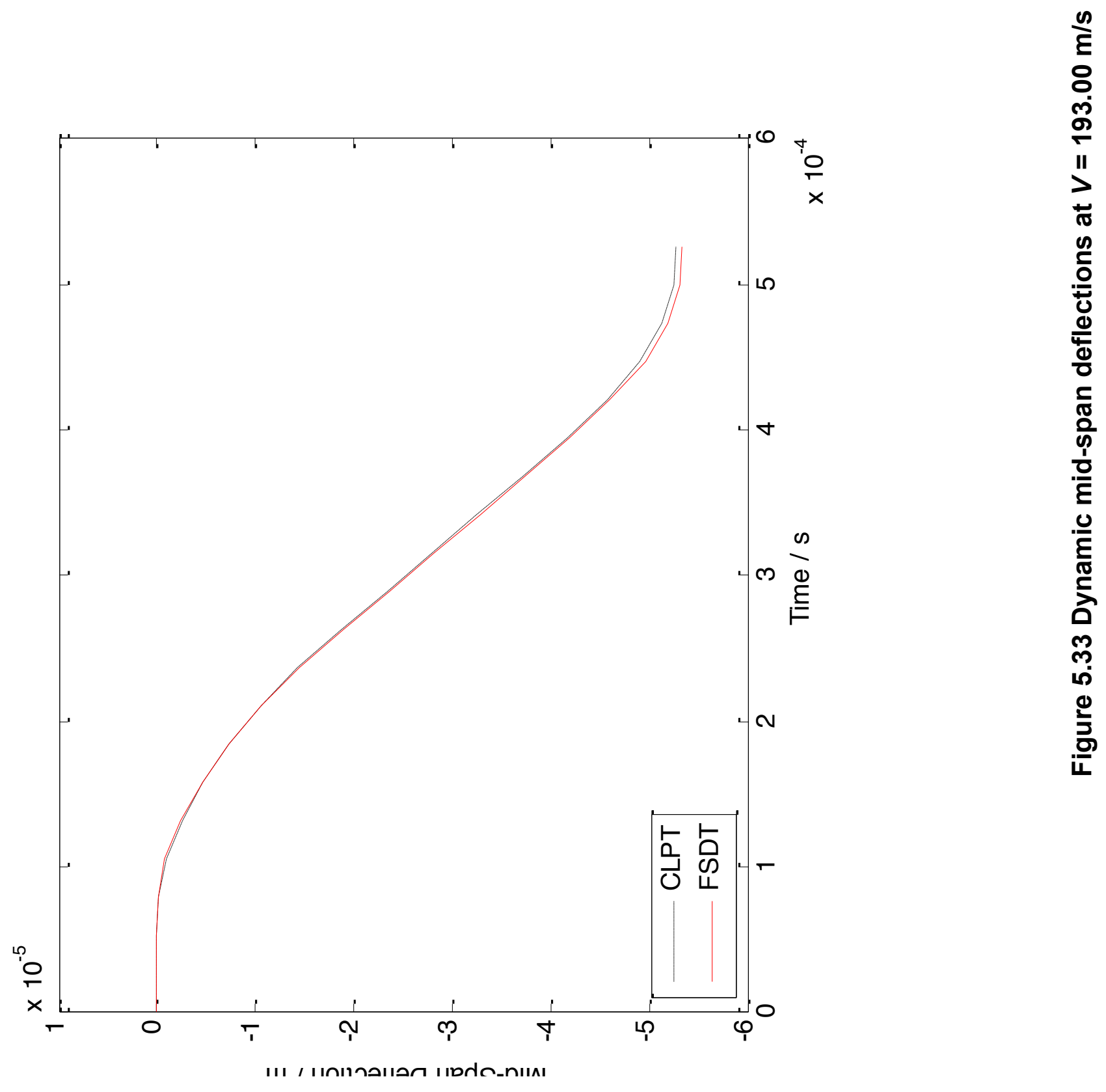


Table 5.46 Mid-span deflections at the end of each time-step for

$$
V=193.00 \mathrm{~m} / \mathrm{s}
$$

\begin{tabular}{|c|c|c|}
\hline \multirow{2}{*}{ Time at the end of each load step (s) } & \multicolumn{2}{c|}{ Mid-span dynamic deflection (m) } \\
\cline { 2 - 3 } & CLPT & FSDT \\
\hline 0 & 0 & 0 \\
\hline $2.6321 \mathrm{E}-05$ & $7.8385 \mathrm{E}-09$ & $6.5329 \mathrm{E}-09$ \\
\hline $5.2642 \mathrm{E}-05$ & $1.7648 \mathrm{E}-08$ & $2.1403 \mathrm{E}-08$ \\
\hline $7.8964 \mathrm{E}-05$ & $-1.5862 \mathrm{E}-07$ & $-1.0517 \mathrm{E}-07$ \\
\hline $1.0528 \mathrm{E}-04$ & $-9.4176 \mathrm{E}-07$ & $-8.0614 \mathrm{E}-07$ \\
\hline $1.3161 \mathrm{E}-04$ & $-2.5214 \mathrm{E}-06$ & $-2.3962 \mathrm{E}-06$ \\
\hline $1.5793 \mathrm{E}-04$ & $-4.6882 \mathrm{E}-06$ & $-4.6666 \mathrm{E}-06$ \\
\hline $1.8425 \mathrm{E}-04$ & $-7.3346 \mathrm{E}-06$ & $-7.3954 \mathrm{E}-06$ \\
\hline $2.1057 \mathrm{E}-04$ & $-1.0521 \mathrm{E}-05$ & $-1.0642 \mathrm{E}-05$ \\
\hline $2.3689 \mathrm{E}-04$ & $-1.4350 \mathrm{E}-05$ & $-1.4441 \mathrm{E}-05$ \\
\hline $2.6321 \mathrm{E}-04$ & $-1.8799 \mathrm{E}-05$ & $-1.8860 \mathrm{E}-05$ \\
\hline $2.8953 \mathrm{E}-04$ & $-2.3437 \mathrm{E}-05$ & $-2.3601 \mathrm{E}-05$ \\
\hline $3.1585 \mathrm{E}-04$ & $-2.7994 \mathrm{E}-05$ & $-2.8274 \mathrm{E}-05$ \\
\hline $3.4218 \mathrm{E}-04$ & $-3.2561 \mathrm{E}-05$ & $-3.2811 \mathrm{E}-05$ \\
\hline $3.6850 \mathrm{E}-04$ & $-3.7185 \mathrm{E}-05$ & $-3.7326 \mathrm{E}-05$ \\
\hline $3.9482 \mathrm{E}-04$ & $-4.1733 \mathrm{E}-05$ & $-4.1810 \mathrm{E}-05$ \\
\hline $4.2114 \mathrm{E}-04$ & $-4.5812 \mathrm{E}-05$ & $-4.6034 \mathrm{E}-05$ \\
\hline $4.4746 \mathrm{E}-04$ & $-4.9005 \mathrm{E}-05$ & $-4.9568 \mathrm{E}-05$ \\
\hline $4.7378 \mathrm{E}-04$ & $-5.1237 \mathrm{E}-05$ & $-5.1976 \mathrm{E}-05$ \\
\hline $5.0010 \mathrm{E}-04$ & $-5.2571 \mathrm{E}-05$ & $-5.3209 \mathrm{E}-05$ \\
\hline $5.2642 \mathrm{E}-04$ & $-5.2754 \mathrm{E}-05$ & $-5.3387 \mathrm{E}-05$ \\
\hline
\end{tabular}




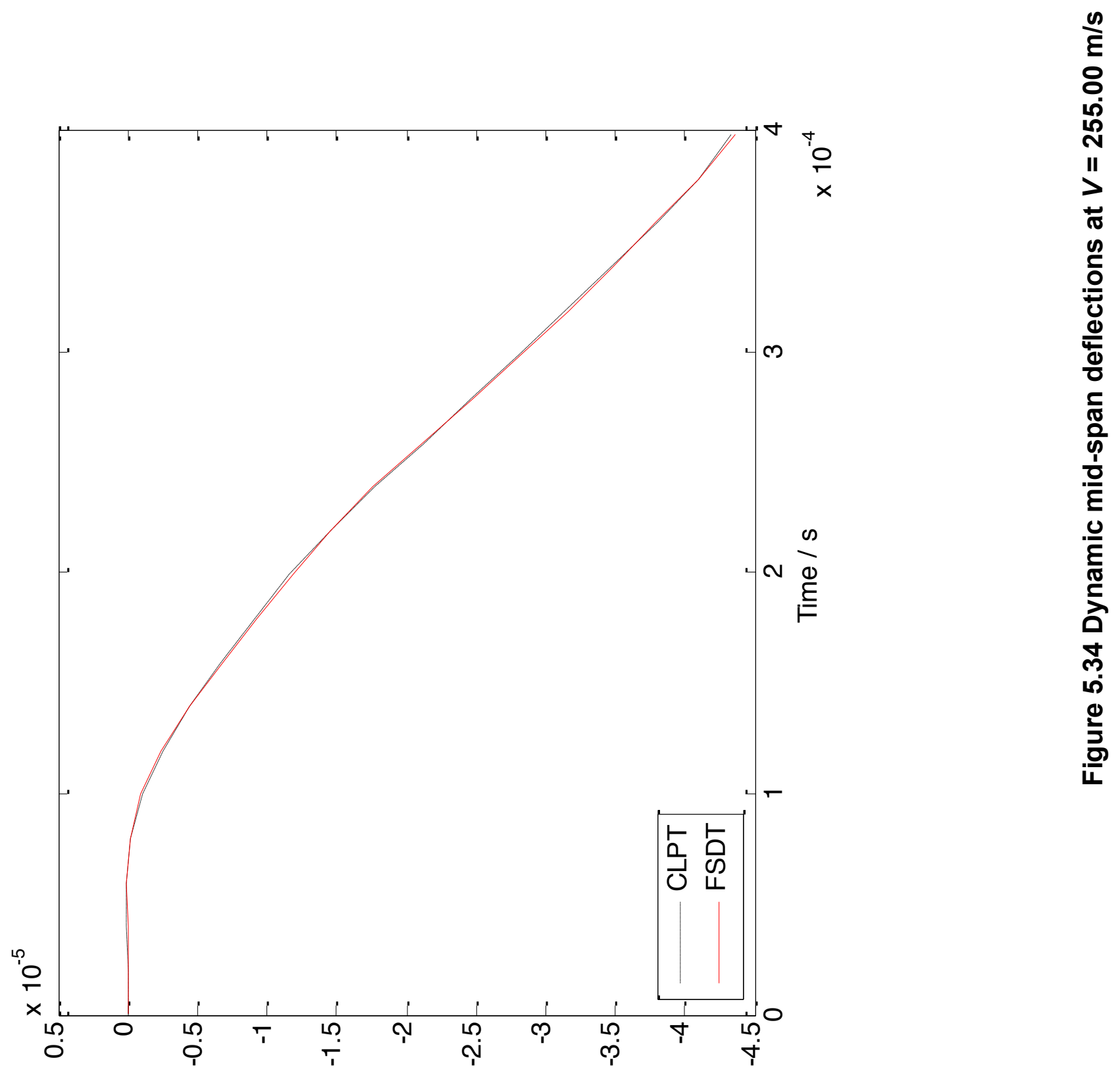


Table 5.47 Mid-span deflections at the end of each time-step for $V=255.00 \mathrm{~m} / \mathrm{s}$

\begin{tabular}{|c|c|c|}
\hline \multirow{2}{*}{ Time at the end of each load step (s) } & \multicolumn{2}{c|}{ Mid-span dynamic deflection (m) } \\
\cline { 2 - 3 } & CLPT & FSDT \\
\hline 0 & 0 & 0 \\
\hline $1.9922 \mathrm{E}-05$ & $5.2512 \mathrm{E}-09$ & $3.8422 \mathrm{E}-09$ \\
\hline $3.9843 \mathrm{E}-05$ & $3.4230 \mathrm{E}-08$ & $2.8756 \mathrm{E}-08$ \\
\hline $5.9765 \mathrm{E}-05$ & $4.4038 \mathrm{E}-08$ & $5.8178 \mathrm{E}-08$ \\
\hline $7.9686 \mathrm{E}-05$ & $-2.2247 \mathrm{E}-07$ & $-1.2186 \mathrm{E}-07$ \\
\hline $9.9608 \mathrm{E}-05$ & $-1.0857 \mathrm{E}-06$ & $-9.0248 \mathrm{E}-07$ \\
\hline $1.1953 \mathrm{E}-04$ & $-2.5548 \mathrm{E}-06$ & $-2.4132 \mathrm{E}-06$ \\
\hline $1.3945 \mathrm{E}-04$ & $-4.4578 \mathrm{E}-06$ & $-4.4167 \mathrm{E}-06$ \\
\hline $1.5937 \mathrm{E}-04$ & $-6.6742 \mathrm{E}-06$ & $-6.7590 \mathrm{E}-06$ \\
\hline $1.7929 \mathrm{E}-04$ & $-9.0448 \mathrm{E}-06$ & $-9.3251 \mathrm{E}-06$ \\
\hline $1.9922 \mathrm{E}-04$ & $-1.1582 \mathrm{E}-05$ & $-1.1905 \mathrm{E}-05$ \\
\hline $2.1914 \mathrm{E}-04$ & $-1.4468 \mathrm{E}-05$ & $-1.4542 \mathrm{E}-05$ \\
\hline $2.3906 \mathrm{E}-04$ & $-1.7720 \mathrm{E}-05$ & $-1.7622 \mathrm{E}-05$ \\
\hline $2.5898 \mathrm{E}-04$ & $-2.1182 \mathrm{E}-05$ & $-2.1093 \mathrm{E}-05$ \\
\hline $2.7890 \mathrm{E}-04$ & $-2.4675 \mathrm{E}-05$ & $-2.4708 \mathrm{E}-05$ \\
\hline $2.9882 \mathrm{E}-04$ & $-2.8085 \mathrm{E}-05$ & $-2.8275 \mathrm{E}-05$ \\
\hline $3.1875 \mathrm{E}-04$ & $-3.1388 \mathrm{E}-05$ & $-3.1667 \mathrm{E}-05$ \\
\hline $3.3867 \mathrm{E}-04$ & $-3.4688 \mathrm{E}-05$ & $-3.4905 \mathrm{E}-05$ \\
\hline $3.5859 \mathrm{E}-04$ & $-3.8002 \mathrm{E}-05$ & $-3.7953 \mathrm{E}-05$ \\
\hline $3.7851 \mathrm{E}-04$ & $-4.0984 \mathrm{E}-05$ & $-4.0977 \mathrm{E}-05$ \\
\hline $3.9843 \mathrm{E}-04$ & $-4.3308 \mathrm{E}-05$ & $-4.3606 \mathrm{E}-05$ \\
\hline
\end{tabular}




\subsubsection{Verification of Results with Kavipurapu (2005)}

The geometric and material properties used in this part of the analysis are from the previous study, Kavipurapu (2005), is glass/epoxy. The properties of which are as given in Table 5.48 .

Table 5.48 Dimensions and material properties of glass/epoxy composite beam

\begin{tabular}{|c|c|}
\hline Length, $L$ & $0.1018 \mathrm{~m}$ \\
\hline Width, $b$ & $0.00635 \mathrm{~m}$ \\
\hline Thickness, $h$ & $0.00635 \mathrm{~m}$ \\
\hline Density, $\rho$ & $1389.297 \mathrm{~kg} / \mathrm{m}^{3}$ \\
\hline Longitudinal Modulus of Elasticity, $E_{1}$ & $1.448 \times 10^{11} \mathrm{~N} / \mathrm{m}^{2}$ \\
\hline Longitudinal Modulus of Elasticity, $E_{2}$ & $9.650 \times 10^{9} \mathrm{~N} / \mathrm{m}^{2}$ \\
\hline Transverse Modulus of Elasticity, $G_{12}$ & $4.136 \times 10^{9} \mathrm{~N} / \mathrm{m}^{2}$ \\
\hline Transverse Modulus of Elasticity, $G_{13}$ & $4.136 \times 10^{9} \mathrm{~N} / \mathrm{m}^{2}$ \\
\hline Transverse Modulus of Elasticity, $G_{23}$ & $3.447 \times 10^{9} \mathrm{~N} / \mathrm{m}^{2}$ \\
\hline Poisson ratio, $v_{12}$ & 0.25 \\
\hline
\end{tabular}

The analysis is done on a symmetric cross-ply laminated beam, $[0 / 90]_{\mathrm{s}}$, with four layers each having the same thickness and a total thickness of 6.35 $\mathrm{mm}$. Kavipurapu's results are from an ANSYS model, which uses the first-order shear deformation theory (FSDT). The present results are based on both CLPT and FSDT.

A static analysis is run first, with a load of $P=-4.45 \mathrm{~N}$ applied at the midspan of the beam and the results are listed in Table 5.49. 
Table 5.49 Mid-span static deflection of $[0 / 90]_{s}$ glass/epoxy composite beam

\begin{tabular}{|c|c|c|}
\hline \multirow{2}{*}{ Kavipurapu (2005) } & \multicolumn{2}{|c|}{ Present study } \\
\cline { 2 - 3 } & CLPT & FSDT \\
\hline$-6.5532 \times 10^{-6} \mathrm{~m}$ & $-5.5995 \times 10^{-6} \mathrm{~m}$ & $-6.4694 \times 10^{-6} \mathrm{~m}$ \\
\hline
\end{tabular}

By modal analysis, it is found that the simply-supported composite beam has a fundamental time period of $T_{f}=3.1877 \times 10^{-4} \mathrm{~s}$. Table 5.50 lists the different total times and time-steps with their corresponding velocities. These are used to achieve the dynamic magnification factors for comparison with Kavipurapu. Table 5.50 lists the time-steps with the corresponding velocities for comparison with Kavipurapu.

Table 5.50 Moving load velocities and time steps for $[0 / 90]_{s}$ glass/epoxy composite beam

\begin{tabular}{|c|c|c|c|}
\hline \multirow{2}{*}{$\begin{array}{c}\text { Velocity } \\
(\mathbf{m} / \mathbf{s})\end{array}$} & \multirow{2}{*}{$\boldsymbol{T}_{\boldsymbol{f}} / \boldsymbol{T}$} & \multicolumn{2}{|c|}{ Composite Beam } \\
\cline { 3 - 4 } & & $\boldsymbol{T}(\mathbf{s})$ & $\boldsymbol{\Delta t}(\mathbf{s})$ \\
\hline 15.6 & 0.125 & $6.5128 \times 10^{-3}$ & $3.2564 \times 10^{-4}$ \\
\hline 31.2 & 0.25 & $3.2564 \times 10^{-3}$ & $1.6282 \times 10^{-4}$ \\
\hline 62.4 & 0.5 & $1.6282 \times 10^{-3}$ & $0.8141 \times 10^{-4}$ \\
\hline 93.6 & 0.75 & $1.0855 \times 10^{-3}$ & $0.5427 \times 10^{-4}$ \\
\hline 124.8 & 1 & $0.8141 \times 10^{-3}$ & $0.4071 \times 10^{-4}$ \\
\hline 156 & 1.25 & $0.6513 \times 10^{-3}$ & $0.3256 \times 10^{-4}$ \\
\hline 250 & 2 & $0.4064 \times 10^{-3}$ & $0.2032 \times 10^{-4}$ \\
\hline
\end{tabular}


Table 5.51, lists the maximum dynamic mid-span deflections at different velocities.

Table 5.51 Maximum dynamic deflections for different velocities

\begin{tabular}{|c|c|c|c|}
\hline \multirow{2}{*}{ Velocity $(\mathbf{m} / \mathbf{s})$} & \multirow{2}{*}{$\boldsymbol{\Delta t}(\mathbf{s})$} & \multicolumn{2}{|c|}{ Maximum mid-span dynamic deflections $(\mathbf{m})$} \\
\cline { 3 - 4 } & & \multicolumn{2}{|c|}{ Present study } \\
\cline { 3 - 4 } & & CLPT & FSDT \\
\hline 15.6 & $3.2564 \times 10^{-4}$ & $-5.7086 \times 10^{-6}$ & $-6.6455 \times 10^{-6}$ \\
\hline 31.2 & $1.6282 \times 10^{-4}$ & $-5.8355 \times 10^{-6}$ & $-6.7192 \times 10^{-6}$ \\
\hline 62.4 & $0.8141 \times 10^{-4}$ & $-6.2232 \times 10^{-6}$ & $-7.2727 \times 10^{-6}$ \\
\hline 93.6 & $0.5427 \times 10^{-4}$ & $-6.1844 \times 10^{-6}$ & $-6.8065 \times 10^{-6}$ \\
\hline 124.8 & $0.4071 \times 10^{-4}$ & $-6.7191 \times 10^{-6}$ & $-7.9228 \times 10^{-6}$ \\
\hline 156 & $0.3256 \times 10^{-4}$ & $-7.7366 \times 10^{-6}$ & $-9.1275 \times 10^{-6}$ \\
\hline 250 & $0.2032 \times 10^{-4}$ & $-9.3213 \times 10^{-6}$ & $-10.7221 \times 10^{-6}$ \\
\hline
\end{tabular}

The dynamic magnification factors for CLPT and FSDT for a moving load on a symmetric cross-ply glass/epoxy composite beam are listed in Table 5.52 and are plotted in Figure 5.34. 
Table 5.52 Dynamic magnification factors for different velocities

\begin{tabular}{|c|c|c|c|}
\hline \multirow{2}{*}{ Velocity $(\mathrm{m} / \mathbf{s})$} & \multirow{2}{*}{$\boldsymbol{t} \mathbf{( s )}$} & \multicolumn{2}{|c|}{ Dynamic magnification factors } \\
\cline { 3 - 4 } & & \multicolumn{2}{|c|}{ Present study } \\
\cline { 3 - 4 } & & CLPT & FSDT \\
\hline 15.6 & $3.2564 \times 10^{-4}$ & 1.019 & 1.027 \\
\hline 31.2 & $1.6282 \times 10^{-4}$ & 1.042 & 1.038 \\
\hline 62.4 & $0.8141 \times 10^{-4}$ & 1.111 & 1.124 \\
\hline 93.6 & $0.5427 \times 10^{-4}$ & 1.104 & 1.052 \\
\hline 124.8 & $0.4071 \times 10^{-4}$ & 1.200 & 1.225 \\
\hline 156 & $0.3256 \times 10^{-4}$ & 1.382 & 1.411 \\
\hline 250 & $0.2032 \times 10^{-4}$ & 1.665 & 1.657 \\
\hline
\end{tabular}




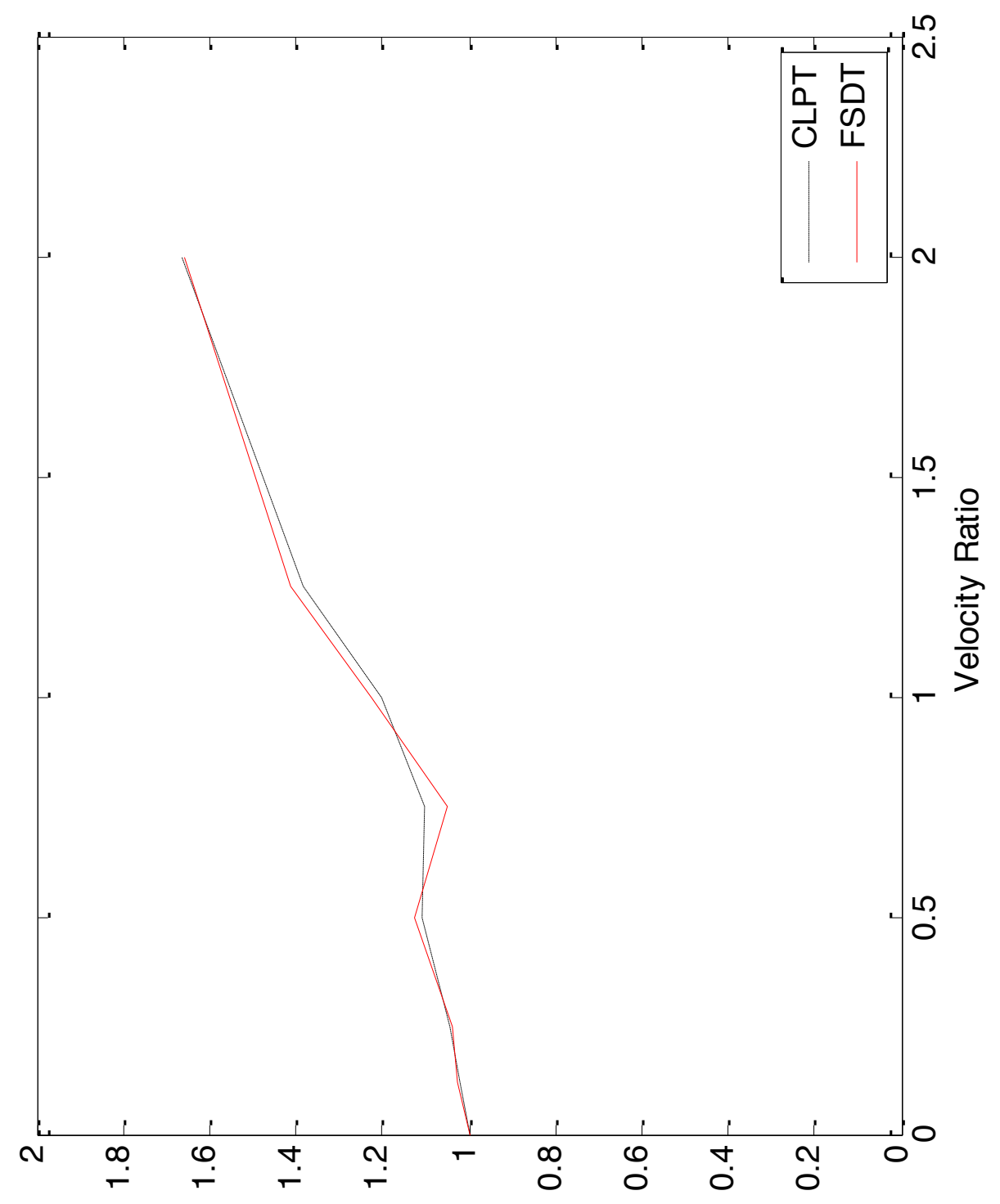

ᄒ

星

응

$\frac{17}{7}$

त

등

ํㅡㄴ ह

등ํㅇ

O

ํํำ

인

은

등

ह

을

हุ

مొ 
Figures 5.35 to 5.41 show the dynamic deflections for the load of $P=-4.45$ $\mathrm{N}$ moving at the velocities of $15.6 \mathrm{~m} / \mathrm{s}, 31.2 \mathrm{~m} / \mathrm{s}, 62.4 \mathrm{~m} / \mathrm{s}, 93.6 \mathrm{~m} / \mathrm{s}, 124.8 \mathrm{~m} / \mathrm{s}$, $156.0 \mathrm{~m} / \mathrm{s}$ and $250 \mathrm{~m} / \mathrm{s}$. These graphs include three plots, two are from the present study, namely, for CLPT and FSDT, and the third is taken from Kavipurapu (2005). The graphs from Kavipurapu (2005) study are read through the program called Digitizelt. Tables 5.53 to 5.59 list the values of the mid-span dynamic deflections at the end of each time step at different velocities for the above composite beam. 


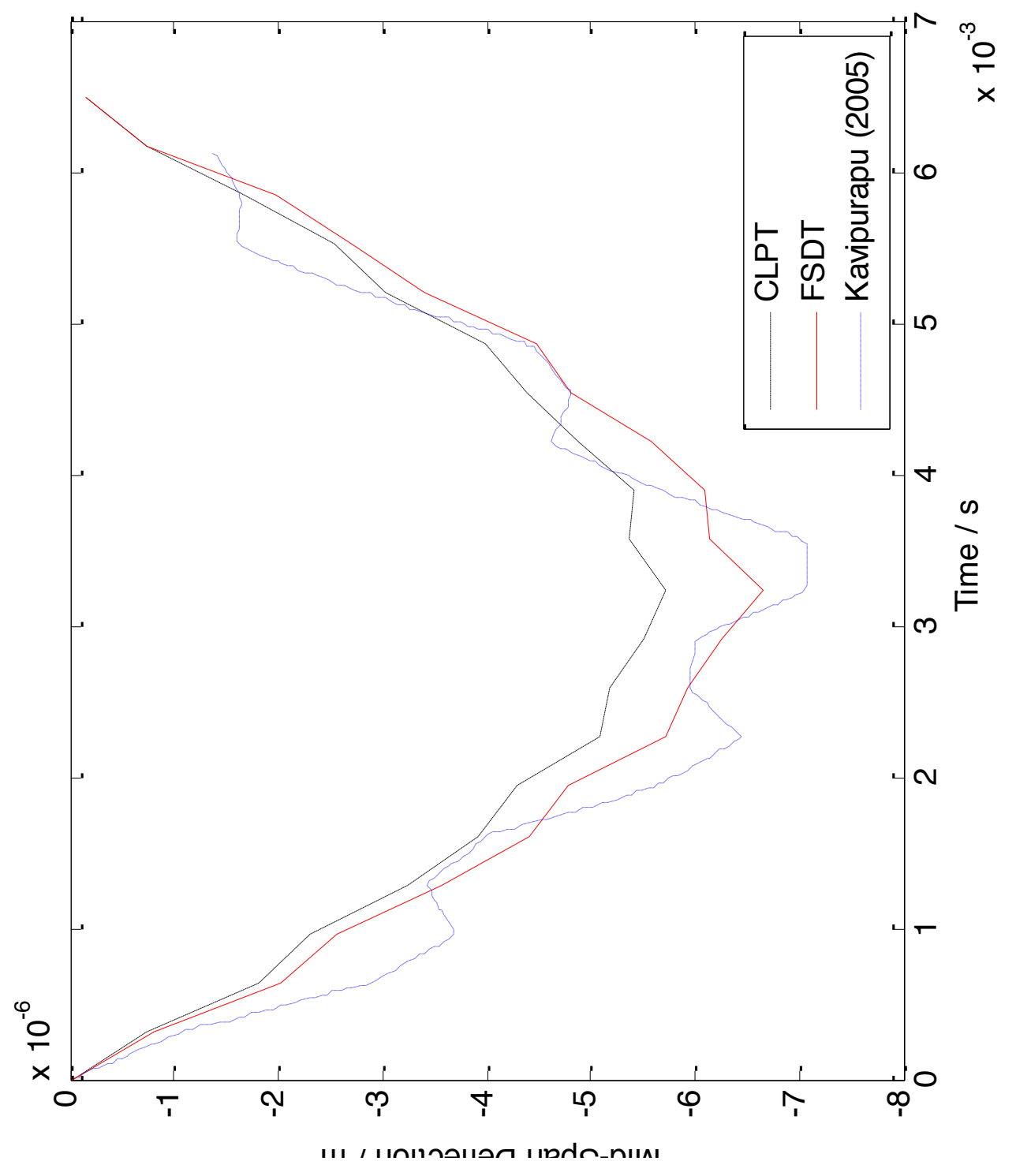

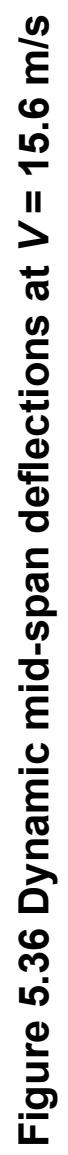


Table 5.53 Mid-span deflections at the end of each time-step for $V=15.6 \mathrm{~m} / \mathrm{s}$

\begin{tabular}{|c|c|c|}
\hline \multirow{2}{*}{$\begin{array}{l}\text { Time at the end of } \\
\text { each load step (s) }\end{array}$} & \multicolumn{2}{|c|}{ Mid-span dynamic deflection (m) } \\
\hline & CLPT & FSDT \\
\hline 0 & 0 & 0 \\
\hline $3.2564 \mathrm{E}-04$ & $-7.3553 E-07$ & $-7.9824 \mathrm{E}-07$ \\
\hline $6.5128 \mathrm{E}-04$ & $-1.8153 E-06$ & $-2.0264 \mathrm{E}-06$ \\
\hline $9.7692 \mathrm{E}-04$ & $-2.3095 E-06$ & $-2.5621 \mathrm{E}-06$ \\
\hline $1.3026 \mathrm{E}-03$ & $-3.2359 E-06$ & $-3.5719 \mathrm{E}-06$ \\
\hline $1.6282 \mathrm{E}-03$ & -3.9094E-06 & $-4.4006 \mathrm{E}-06$ \\
\hline $1.9538 \mathrm{E}-03$ & $-4.2996 \mathrm{E}-06$ & $-4.7867 \mathrm{E}-06$ \\
\hline 2.2795E-03 & $-5.0796 \mathrm{E}-06$ & $-5.7174 \mathrm{E}-06$ \\
\hline $2.6051 \mathrm{E}-03$ & $-5.1903 E-06$ & $-5.9349 \mathrm{E}-06$ \\
\hline 2.9308E-03 & $-5.5200 \mathrm{E}-06$ & $-6.2546 \mathrm{E}-06$ \\
\hline $3.2564 \mathrm{E}-03$ & $-5.7086 \mathrm{E}-06$ & $-6.6456 \mathrm{E}-06$ \\
\hline $3.5821 \mathrm{E}-03$ & $-5.3665 E-06$ & $-6.1435 \mathrm{E}-06$ \\
\hline 3.9077E-03 & $-5.4250 \mathrm{E}-06$ & $-6.0986 \mathrm{E}-06$ \\
\hline 4.2333E-03 & $-4.8743 E-06$ & $-5.5869 \mathrm{E}-06$ \\
\hline 4.5590E-03 & $-4.3786 \mathrm{E}-06$ & $-4.8154 \mathrm{E}-06$ \\
\hline 4.8846E-03 & -3.9939E-06 & $-4.4891 \mathrm{E}-06$ \\
\hline 5.2103E-03 & $-3.0274 \mathrm{E}-06$ & $-3.4122 \mathrm{E}-06$ \\
\hline $5.5359 \mathrm{E}-03$ & $-2.5439 E-06$ & $-2.7097 \mathrm{E}-06$ \\
\hline $5.8615 \mathrm{E}-03$ & $-1.6652 \mathrm{E}-06$ & $-1.9678 \mathrm{E}-06$ \\
\hline $6.1872 \mathrm{E}-03$ & $-7.3090 \mathrm{E}-07$ & $-7.3768 \mathrm{E}-07$ \\
\hline $6.5128 \mathrm{E}-03$ & $-1.5691 \mathrm{E}-07$ & $-1.4743 \mathrm{E}-07$ \\
\hline
\end{tabular}




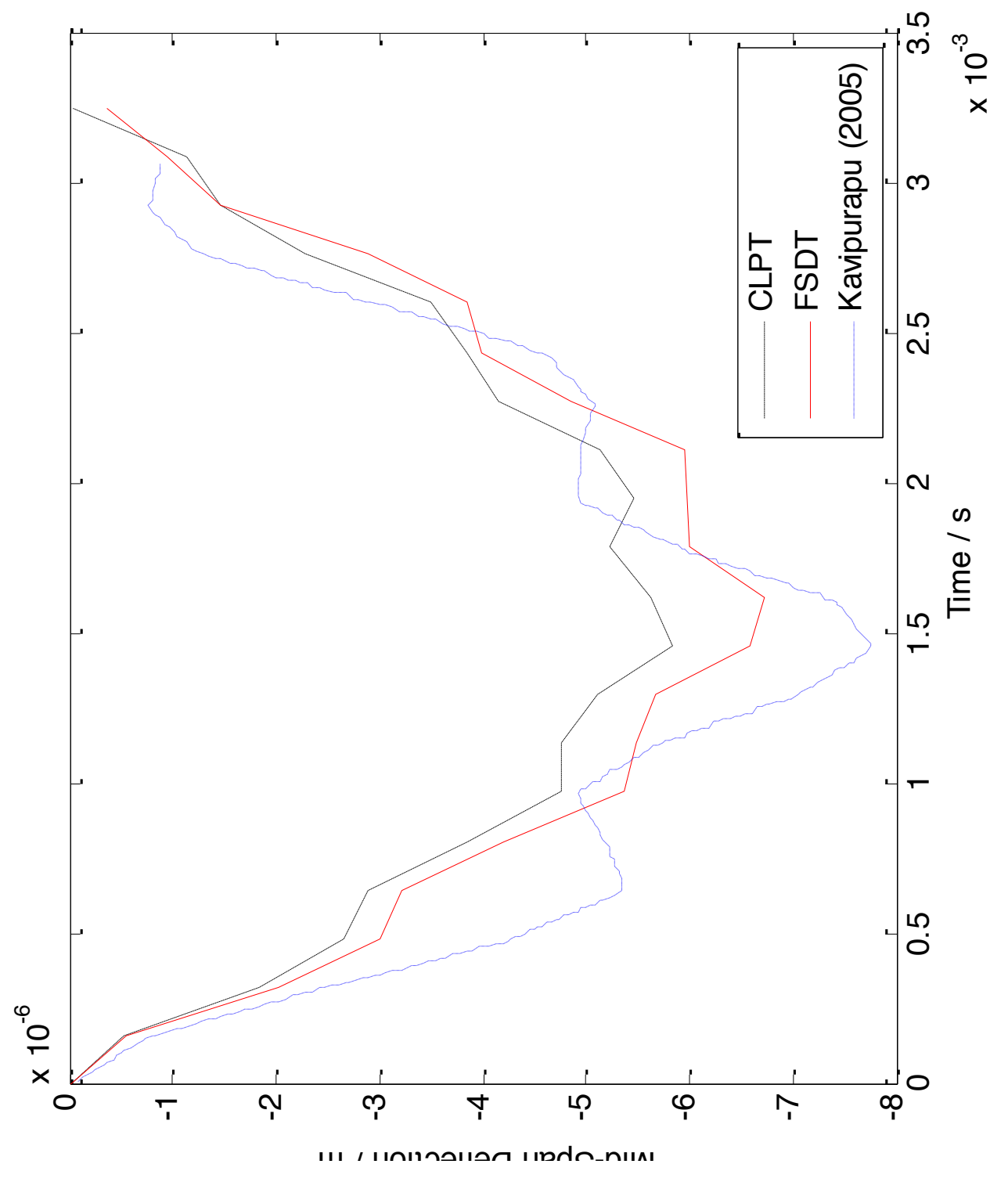

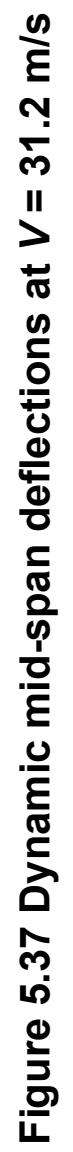


Table 5.54 Mid-span deflections at the end of each time-step for $V=31.2 \mathrm{~m} / \mathrm{s}$

\begin{tabular}{|c|c|c|}
\hline \multirow{2}{*}{$\begin{array}{l}\text { Time at the end of } \\
\text { each load step (s) }\end{array}$} & \multicolumn{2}{|c|}{ Mid-span dynamic deflection (m) } \\
\hline & CLPT & FSDT \\
\hline 0 & 0 & 0 \\
\hline $6.5128 \mathrm{E}-04$ & $-5.3685 E-07$ & $-5.5963 \mathrm{E}-07$ \\
\hline $8.1410 \mathrm{E}-04$ & $-1.8471 \mathrm{E}-06$ & $-2.0240 \mathrm{E}-06$ \\
\hline $9.7692 \mathrm{E}-04$ & $-2.6445 E-06$ & $-3.0035 E-06$ \\
\hline 1.1397E-03 & $-2.8899 E-06$ & $-3.2239 \mathrm{E}-06$ \\
\hline 1.3026E-03 & $-3.8550 \mathrm{E}-06$ & $-4.1933 E-06$ \\
\hline $1.4654 \mathrm{E}-03$ & $-4.7545 E-06$ & $-5.3642 E-06$ \\
\hline $1.6282 \mathrm{E}-03$ & $-4.7595 E-06$ & $-5.4968 \mathrm{E}-06$ \\
\hline 1.7910E-03 & $-5.1040 \mathrm{E}-06$ & $-5.6687 \mathrm{E}-06$ \\
\hline $1.9538 \mathrm{E}-03$ & $-5.8355 E-06$ & $-6.5855 E-06$ \\
\hline 2.1167E-03 & $-5.6338 E-06$ & $-6.7192 E-06$ \\
\hline $2.2795 \mathrm{E}-03$ & $-5.2297 E-06$ & $-5.9892 E-06$ \\
\hline $2.4423 \mathrm{E}-03$ & $-5.4722 \mathrm{E}-06$ & $-5.9661 \mathrm{E}-06$ \\
\hline $2.6051 \mathrm{E}-03$ & $-5.1415 E-06$ & $-5.9416 \mathrm{E}-06$ \\
\hline 2.7679E-03 & $-4.1543 E-06$ & $-4.8526 \mathrm{E}-06$ \\
\hline $2.9308 \mathrm{E}-03$ & $-3.8375 E-06$ & $-3.9943 E-06$ \\
\hline 3.0936E-03 & $-3.5009 E-06$ & $-3.8425 \mathrm{E}-06$ \\
\hline $3.2564 \mathrm{E}-03$ & $-2.2903 E-06$ & $-2.8870 \mathrm{E}-06$ \\
\hline $6.5128 \mathrm{E}-04$ & $-1.4516 \mathrm{E}-06$ & $-1.4722 \mathrm{E}-06$ \\
\hline $8.1410 \mathrm{E}-04$ & $-1.1310 \mathrm{E}-06$ & $-9.4057 \mathrm{E}-07$ \\
\hline 9.7692E-04 & $-3.4811 \mathrm{E}-08$ & $-3.7097 \mathrm{E}-07$ \\
\hline
\end{tabular}




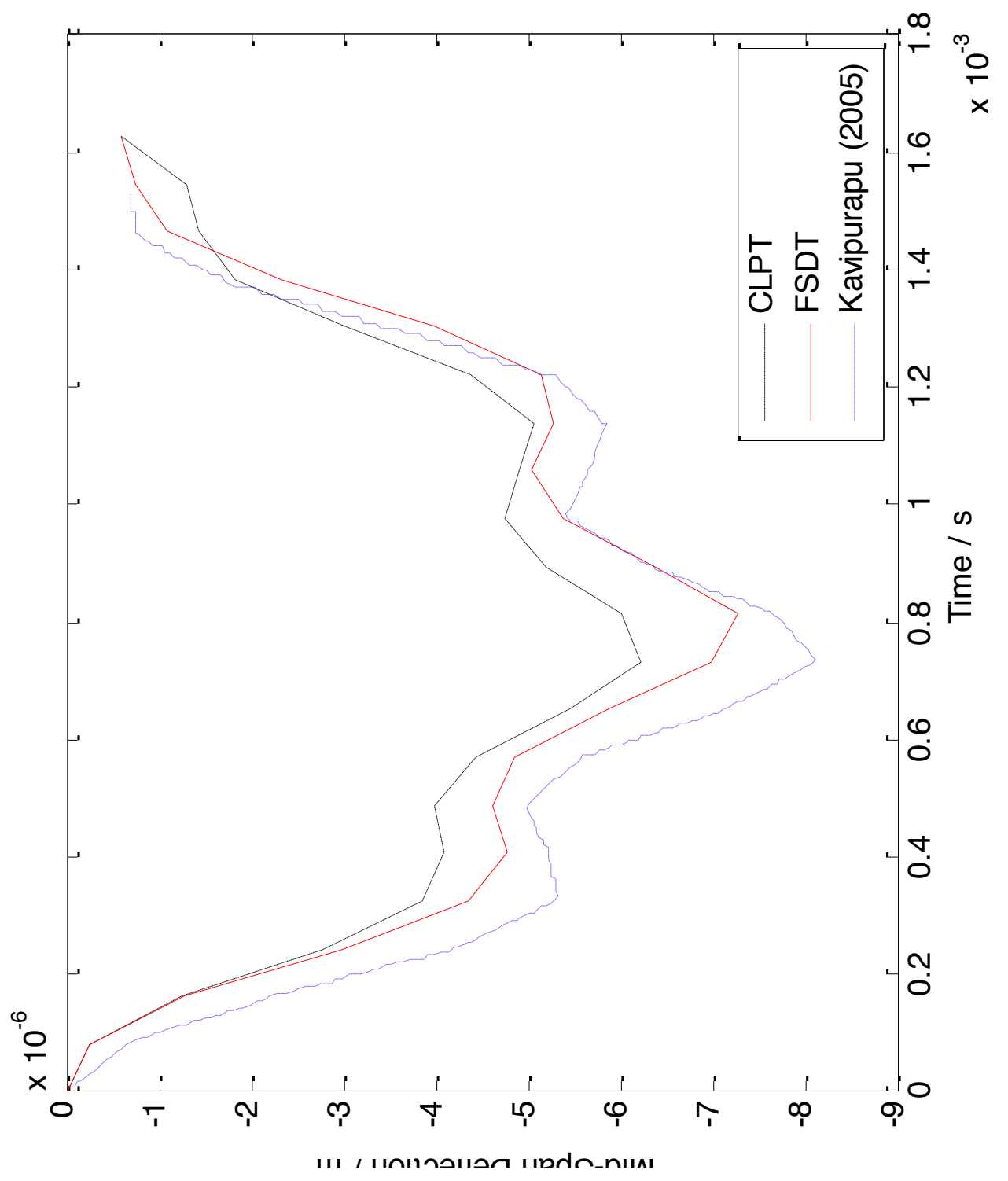

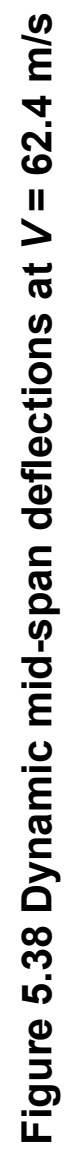


Table 5.55 Mid-span deflections at the end of each time-step for $V=62.4 \mathrm{~m} / \mathrm{s}$

\begin{tabular}{|c|c|c|}
\hline \multirow{2}{*}{$\begin{array}{l}\text { Time at the end of } \\
\text { each load step (s) }\end{array}$} & \multicolumn{2}{|c|}{ Mid-span dynamic deflection (m) } \\
\hline & CLPT & FSDT \\
\hline 0 & 0 & 0 \\
\hline $8.1410 \mathrm{E}-05$ & $-2.4995 \mathrm{E}-07$ & $-2.3935 \mathrm{E}-07$ \\
\hline 1.6282E-04 & $-1.2444 \mathrm{E}-06$ & $-1.2743 \mathrm{E}-06$ \\
\hline 2.4423E-04 & $-2.7649 \mathrm{E}-06$ & $-2.9823 E-06$ \\
\hline 3.2564E-04 & $-3.8622 \mathrm{E}-06$ & $-4.3507 \mathrm{E}-06$ \\
\hline 4.0705E-04 & $-4.0837 E-06$ & $-4.7781 \mathrm{E}-06$ \\
\hline 4.8846E-04 & $-3.9814 \mathrm{E}-06$ & $-4.6174 \mathrm{E}-06$ \\
\hline 5.6987E-04 & $-4.4378 E-06$ & $-4.8576 \mathrm{E}-06$ \\
\hline $6.5128 \mathrm{E}-04$ & $-5.4684 \mathrm{E}-06$ & $-5.8858 \mathrm{E}-06$ \\
\hline 7.3269E-04 & $-6.2232 E-06$ & $-6.9964 \mathrm{E}-06$ \\
\hline $8.1410 \mathrm{E}-04$ & $-6.0181 E-06$ & $-7.2727 \mathrm{E}-06$ \\
\hline $8.9551 \mathrm{E}-04$ & $-5.2084 E-06$ & $-6.3905 E-06$ \\
\hline $9.7692 \mathrm{E}-04$ & $-4.7378 \mathrm{E}-06$ & $-5.3824 \mathrm{E}-06$ \\
\hline 1.0583E-03 & $-4.9149 \mathrm{E}-06$ & $-5.0503 E-06$ \\
\hline 1.1397E-03 & $-5.0692 \mathrm{E}-06$ & $-5.2752 E-06$ \\
\hline $1.2212 \mathrm{E}-03$ & $-4.3810 \mathrm{E}-06$ & $-5.1364 \mathrm{E}-06$ \\
\hline 1.3026E-03 & $-3.0039 E-06$ & $-3.9820 \mathrm{E}-06$ \\
\hline 1.3840E-03 & $-1.8326 \mathrm{E}-06$ & $-2.3269 \mathrm{E}-06$ \\
\hline 1.4654E-03 & $-1.4383 E-06$ & $-1.0921 \mathrm{E}-06$ \\
\hline $1.5468 \mathrm{E}-03$ & $-1.3152 \mathrm{E}-06$ & $-7.5209 \mathrm{E}-07$ \\
\hline $1.6282 \mathrm{E}-03$ & $-5.8093 E-07$ & $-5.9907 E-07$ \\
\hline
\end{tabular}




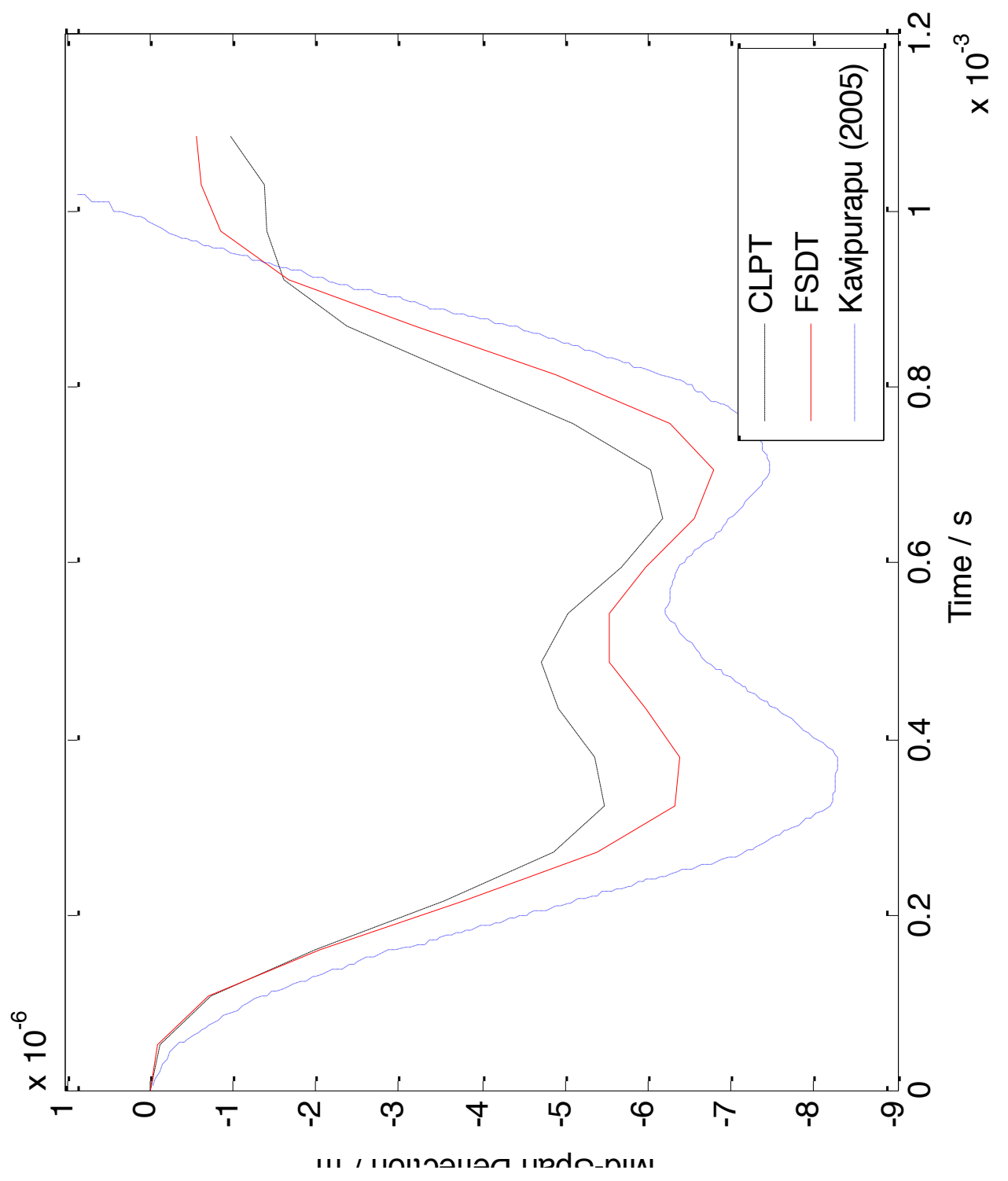

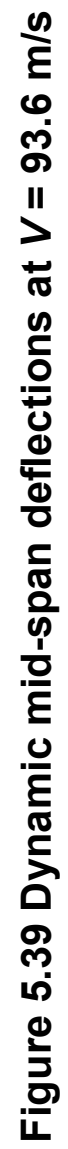


Table 5.56 Mid-span deflections at the end of each time-step for $V=93.6 \mathrm{~m} / \mathrm{s}$

\begin{tabular}{|c|c|c|}
\hline \multirow{2}{*}{$\begin{array}{l}\text { Time at the end of } \\
\text { each load step (s) }\end{array}$} & \multicolumn{2}{|c|}{ Mid-span dynamic deflection (m) } \\
\hline & CLPT & FSDT \\
\hline 0 & 0 & 0 \\
\hline 5.4274E-05 & $-1.2428 \mathrm{E}-07$ & $-1.0887 \mathrm{E}-07$ \\
\hline 1.0855E-04 & $-7.3486 \mathrm{E}-07$ & $-7.0807 \mathrm{E}-07$ \\
\hline $1.6282 \mathrm{E}-04$ & $-1.9921 \mathrm{E}-06$ & $-2.0469 \mathrm{E}-06$ \\
\hline 2.1709E-04 & $-3.5496 \mathrm{E}-06$ & $-3.7798 \mathrm{E}-06$ \\
\hline 2.7137E-04 & $-4.8626 \mathrm{E}-06$ & $-5.3769 \mathrm{E}-06$ \\
\hline $3.2564 \mathrm{E}-04$ & $-5.4657 E-06$ & $-6.3245 E-06$ \\
\hline 3.7991E-04 & $-5.3508 E-06$ & $-6.3958 \mathrm{E}-06$ \\
\hline $4.3419 \mathrm{E}-04$ & $-4.9251 \mathrm{E}-06$ & $-5.9739 \mathrm{E}-06$ \\
\hline $4.8846 \mathrm{E}-04$ & $-4.7116 \mathrm{E}-06$ & $-5.5286 \mathrm{E}-06$ \\
\hline $5.4274 \mathrm{E}-04$ & $-5.0264 \mathrm{E}-06$ & $-5.5335 \mathrm{E}-06$ \\
\hline $5.9701 \mathrm{E}-04$ & $-5.6734 \mathrm{E}-06$ & $-5.9760 \mathrm{E}-06$ \\
\hline $6.5128 \mathrm{E}-04$ & $-6.1844 E-06$ & $-6.5462 E-06$ \\
\hline 7.0556E-04 & $-6.0427 E-06$ & $-6.8065 \mathrm{E}-06$ \\
\hline 7.5983E-04 & $-5.1101 \mathrm{E}-06$ & $-6.2517 \mathrm{E}-06$ \\
\hline $8.1410 \mathrm{E}-04$ & -3.7078E-06 & $-4.9027 \mathrm{E}-06$ \\
\hline 8.6838E-04 & $-2.3888 \mathrm{E}-06$ & $-3.2042 E-06$ \\
\hline $9.2265 \mathrm{E}-04$ & $-1.6264 \mathrm{E}-06$ & $-1.6883 \mathrm{E}-06$ \\
\hline $9.7692 \mathrm{E}-04$ & $-1.4163 E-06$ & $-8.4212 \mathrm{E}-07$ \\
\hline 1.0312E-03 & $-1.3820 E-06$ & $-6.1380 \mathrm{E}-07$ \\
\hline $1.0855 \mathrm{E}-03$ & $-9.6963 E-07$ & $-5.6685 E-07$ \\
\hline
\end{tabular}




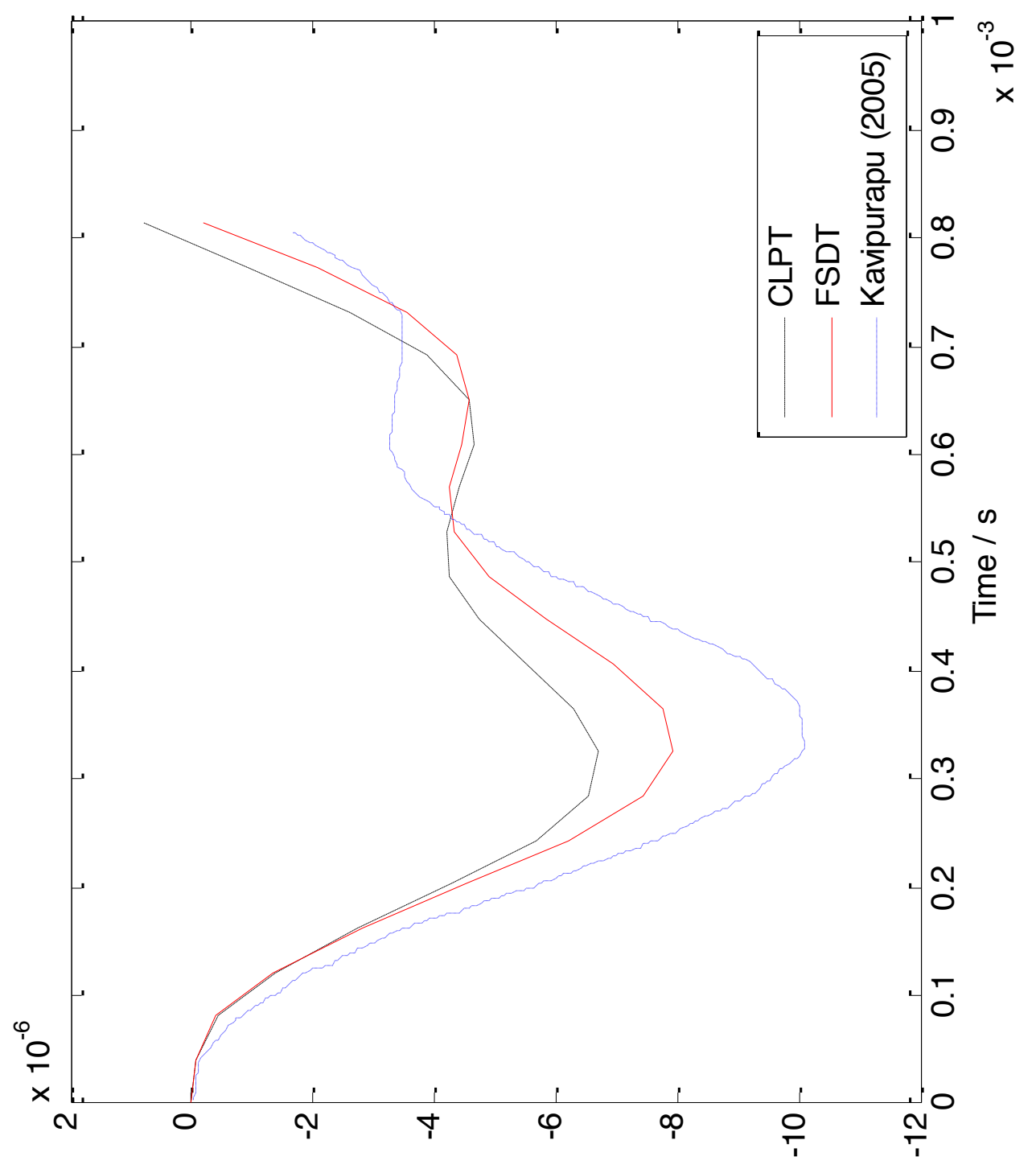

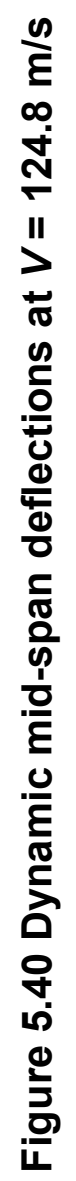


Table 5.57 Mid-span deflections at the end of each time-step for $V=124.8 \mathrm{~m} / \mathrm{s}$

\begin{tabular}{|c|c|c|}
\hline \multirow{2}{*}{$\begin{array}{l}\text { Time at the end of } \\
\text { each load step (s) }\end{array}$} & \multicolumn{2}{|c|}{ Mid-span dynamic deflection (m) } \\
\hline & CLPT & FSDT \\
\hline 0 & 0 & 0 \\
\hline 4.0705E-05 & $-6.7243 E-08$ & $-5.3058 \mathrm{E}-08$ \\
\hline $8.1410 \mathrm{E}-05$ & $-4.4948 E-07$ & $-4.0464 \mathrm{E}-07$ \\
\hline $1.2212 \mathrm{E}-04$ & $-1.3578 E-06$ & $-1.3430 \mathrm{E}-06$ \\
\hline $1.6282 \mathrm{E}-04$ & $-2.7109 E-06$ & $-2.7948 \mathrm{E}-06$ \\
\hline 2.0353E-04 & $-4.2737 \mathrm{E}-06$ & $-4.5101 \mathrm{E}-06$ \\
\hline 2.4423E-04 & $-5.6627 E-06$ & $-6.2111 \mathrm{E}-06$ \\
\hline 2.8494E-04 & $-6.5225 E-06$ & $-7.4176 \mathrm{E}-06$ \\
\hline $3.2564 \mathrm{E}-04$ & $-6.7191 \mathrm{E}-06$ & $-7.9228 \mathrm{E}-06$ \\
\hline $3.6635 \mathrm{E}-04$ & $-6.2791 E-06$ & $-7.7490 \mathrm{E}-06$ \\
\hline 4.0705E-04 & $-5.4993 E-06$ & $-6.9457 \mathrm{E}-06$ \\
\hline 4.4776E-04 & $-4.7218 E-06$ & $-5.8349 \mathrm{E}-06$ \\
\hline 4.8846E-04 & $-4.2361 \mathrm{E}-06$ & $-4.8841 \mathrm{E}-06$ \\
\hline 5.2917E-04 & $-4.1887 \mathrm{E}-06$ & $-4.3060 \mathrm{E}-06$ \\
\hline 5.6987E-04 & $-4.4222 \mathrm{E}-06$ & $-4.2390 \mathrm{E}-06$ \\
\hline $6.1058 \mathrm{E}-04$ & $-4.6679 E-06$ & $-4.4506 \mathrm{E}-06$ \\
\hline $6.5128 \mathrm{E}-04$ & $-4.5736 \mathrm{E}-06$ & $-4.5885 E-06$ \\
\hline 6.9199E-04 & $-3.8891 E-06$ & $-4.3844 \mathrm{E}-06$ \\
\hline 7.3269E-04 & $-2.6192 \mathrm{E}-06$ & $-3.5482 \mathrm{E}-06$ \\
\hline 7.7340E-04 & $-9.3613 E-07$ & $-2.0554 \mathrm{E}-06$ \\
\hline $8.1410 \mathrm{E}-04$ & 7.7977E-07 & $-1.8706 \mathrm{E}-07$ \\
\hline
\end{tabular}




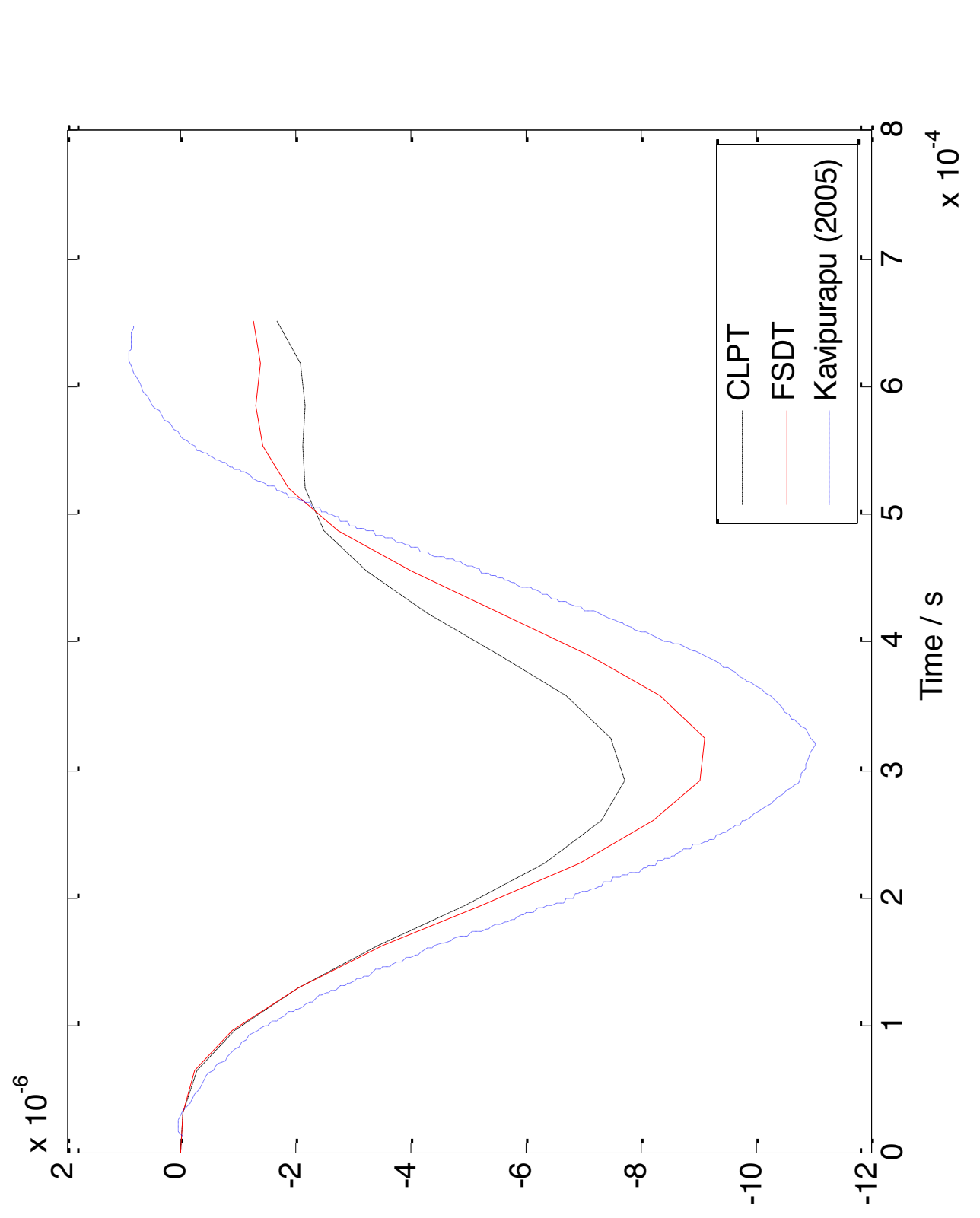

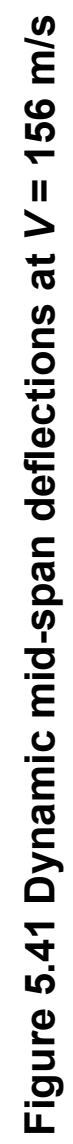


Table 5.58 Mid-span deflections at the end of each time-step for $V=156 \mathrm{~m} / \mathrm{s}$

\begin{tabular}{|c|c|c|}
\hline \multirow{2}{*}{$\begin{array}{c}\text { Time at the end of } \\
\text { each load step (s) }\end{array}$} & \multicolumn{2}{|c|}{ Mid-span dynamic deflection $(\mathbf{m})$} \\
\cline { 2 - 3 } & CLPT & FSDT \\
\hline 0 & 0 & 0 \\
\hline $3.2564 \mathrm{E}-05$ & $-3.8352 \mathrm{E}-08$ & $-2.6722 \mathrm{E}-08$ \\
\hline $6.5128 \mathrm{E}-05$ & $-2.8788 \mathrm{E}-07$ & $-2.3808 \mathrm{E}-07$ \\
\hline $9.7692 \mathrm{E}-05$ & $-9.4496 \mathrm{E}-07$ & $-8.9489 \mathrm{E}-07$ \\
\hline $1.3026 \mathrm{E}-04$ & $-2.0131 \mathrm{E}-06$ & $-2.0351 \mathrm{E}-06$ \\
\hline $1.6282 \mathrm{E}-04$ & $-3.4125 \mathrm{E}-06$ & $-3.5054 \mathrm{E}-06$ \\
\hline $1.9538 \mathrm{E}-04$ & $-4.9556 \mathrm{E}-06$ & $-5.2336 \mathrm{E}-06$ \\
\hline $2.2795 \mathrm{E}-04$ & $-6.3321 \mathrm{E}-06$ & $-6.9321 \mathrm{E}-06$ \\
\hline $2.6051 \mathrm{E}-04$ & $-7.3268 \mathrm{E}-06$ & $-8.2263 \mathrm{E}-06$ \\
\hline $2.9308 \mathrm{E}-04$ & $-7.7366 \mathrm{E}-06$ & $-9.0234 \mathrm{E}-06$ \\
\hline $3.2564 \mathrm{E}-04$ & $-7.4875 \mathrm{E}-06$ & $-9.1275 \mathrm{E}-06$ \\
\hline $3.5821 \mathrm{E}-04$ & $-6.6981 \mathrm{E}-06$ & $-8.3553 \mathrm{E}-06$ \\
\hline $3.9077 \mathrm{E}-04$ & $-5.5365 \mathrm{E}-06$ & $-7.0932 \mathrm{E}-06$ \\
\hline $4.2333 \mathrm{E}-04$ & $-4.2936 \mathrm{E}-06$ & $-5.5692 \mathrm{E}-06$ \\
\hline $4.5590 \mathrm{E}-04$ & $-3.2326 \mathrm{E}-06$ & $-4.0065 \mathrm{E}-06$ \\
\hline $4.8846 \mathrm{E}-04$ & $-2.4889 \mathrm{E}-06$ & $-2.7214 \mathrm{E}-06$ \\
\hline $5.2103 \mathrm{E}-04$ & $-2.1441 \mathrm{E}-06$ & $-1.8732 \mathrm{E}-06$ \\
\hline $5.5359 \mathrm{E}-04$ & $-2.0956 \mathrm{E}-06$ & $-1.4095 \mathrm{E}-06$ \\
\hline $5.8615 \mathrm{E}-04$ & $-2.1356 \mathrm{E}-06$ & $-1.2874 \mathrm{E}-06$ \\
\hline $6.1872 \mathrm{E}-04$ & $-2.0706 \mathrm{E}-06$ & $-1.3780 \mathrm{E}-06$ \\
\hline $6.5128 \mathrm{E}-04$ & $-1.6471 \mathrm{E}-06$ & $-1.2678 \mathrm{E}-06$ \\
\hline & & \\
\hline & & \\
\hline & & \\
\hline
\end{tabular}




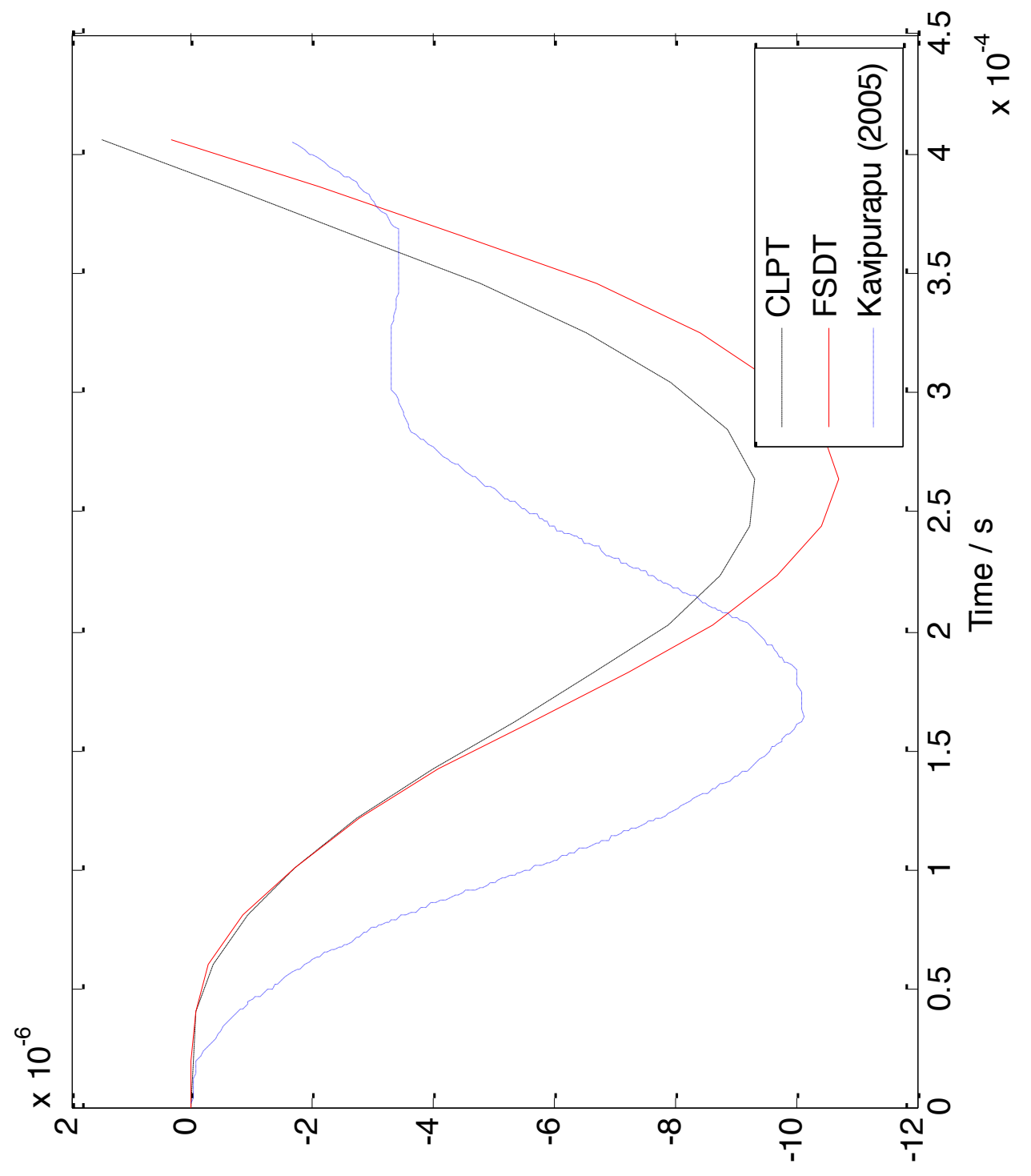

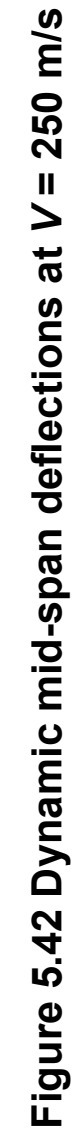


Table 5.59 Mid-span deflections at the end of each time-step for $V=250 \mathrm{~m} / \mathrm{s}$

\begin{tabular}{|c|c|c|}
\hline \multirow{2}{*}{$\begin{array}{l}\text { Time at the end of } \\
\text { each load step (s) }\end{array}$} & \multicolumn{2}{|c|}{ Mid-span dynamic deflection (m) } \\
\hline & CLPT & FSDT \\
\hline 0 & 0 & 0 \\
\hline $2.0320 \mathrm{E}-05$ & $-7.3528 \mathrm{E}-09$ & $-2.8800 \mathrm{E}-09$ \\
\hline 4.0640E-05 & $-8.6887 E-08$ & $-4.8592 \mathrm{E}-08$ \\
\hline 6.0960E-05 & $-3.7086 \mathrm{E}-07$ & $-2.7666 \mathrm{E}-07$ \\
\hline $8.1280 \mathrm{E}-05$ & $-9.1271 \mathrm{E}-07$ & $-8.4212 \mathrm{E}-07$ \\
\hline 1.0160E-04 & $-1.6901 \mathrm{E}-06$ & $-1.7034 \mathrm{E}-06$ \\
\hline 1.2192E-04 & $-2.7366 \mathrm{E}-06$ & $-2.7558 \mathrm{E}-06$ \\
\hline 1.4224E-04 & $-4.0007 E-06$ & $-4.0816 \mathrm{E}-06$ \\
\hline 1.6256E-04 & $-5.3396 \mathrm{E}-06$ & $-5.6500 \mathrm{E}-06$ \\
\hline $1.8288 \mathrm{E}-04$ & $-6.6692 \mathrm{E}-06$ & $-7.2106 \mathrm{E}-06$ \\
\hline 2.0320E-04 & $-7.8694 \mathrm{E}-06$ & $-8.6187 E-06$ \\
\hline $2.2352 \mathrm{E}-04$ & $-8.7623 E-06$ & $-9.6762 E-06$ \\
\hline $2.4384 \mathrm{E}-04$ & $-9.2558 \mathrm{E}-06$ & $-1.0412 \mathrm{E}-05$ \\
\hline $2.6416 \mathrm{E}-04$ & $-9.3213 E-06$ & $-1.0722 \mathrm{E}-05$ \\
\hline $2.8448 \mathrm{E}-04$ & $-8.8721 \mathrm{E}-06$ & $-1.0425 \mathrm{E}-05$ \\
\hline 3.0480E-04 & $-7.9074 \mathrm{E}-06$ & $-9.6562 E-06$ \\
\hline $3.2512 \mathrm{E}-04$ & $-6.5243 E-06$ & $-8.4351 \mathrm{E}-06$ \\
\hline 3.4544E-04 & $-4.7627 E-06$ & $-6.6839 \mathrm{E}-06$ \\
\hline 3.6576E-04 & $-2.7276 \mathrm{E}-06$ & $-4.4985 \mathrm{E}-06$ \\
\hline 3.8608E-04 & $-6.0055 E-07$ & $-2.1265 \mathrm{E}-06$ \\
\hline 4.0640E-04 & 1.4896E-06 & $3.4869 \mathrm{E}-07$ \\
\hline
\end{tabular}




\subsection{Hygrothermal Analysis of Composite Beams}

In this part, the hygrothermal effects are included to verify the hygrothermal aspect of the moving-load problem. As seen in Chapter 2, the empirical formula for degrading the matrix properties due to a hygrothermal environment is due to Chamis (1983), then micromechanics formulas, as given in Chapter 2, are used to calculate the modified ply elastic constants. For verification, a cross-ply $\left[0_{4} / 90_{4}\right]_{T}$ laminate of dimensions similar to that of the previous authors, Kavipurapu (2005), Vennam (2006) and Uphadyay (2000), is considered. This beam is subjected to a uniformly distributed load OwensCorning S2 Glass-Fiber and Hercules 3501-6 Epoxy Matrix are considered with the material properties as given by Cairns and Adams (1983). The dimensions, material properties of the fiber and matrix, dry and wet temperatures of the epoxy and other properties are given in Tables 5.60 and 5.61. 
Table 5.60 Dimensions, material properties and temperatures of glass/epoxy composite beam

\begin{tabular}{|c|c|}
\hline Length, $L$ & $0.2286 \mathrm{~m}$ \\
\hline Width, $b$ & $0.0381 \mathrm{~m}$ \\
\hline Total Thickness, $h$ & $0.001016 \mathrm{~m}$ \\
\hline Density, $\rho$ & $1389.297 \mathrm{~kg} / \mathrm{m}^{3}$ \\
\hline Moisture Content, $m$ & $5 \%$ \\
\hline Fiber Volume Fraction, $V_{f}$ & 0.52 \\
\hline Dry Resin Glass Transition Temperature, $T_{\text {gdr }}$ & $215.556{ }^{\circ} \mathrm{C}$ \\
\hline Wet Resin Glass Transition Temperature, $T_{\text {gwr }}$ & $134.723^{\circ} \mathrm{C}$ \\
\hline Initial Dry Temperature, $T_{0}$ & $22.222{ }^{\circ} \mathrm{C}$ \\
\hline Final Wet Temperature, $T$ & $67.889^{\circ} \mathrm{C}$ \\
\hline
\end{tabular}

Table 5.61 Material properties of S2 glass-fiber and hercules 3501-6 epoxy matrix

\begin{tabular}{|c|c|c|}
\hline Material Property & $\begin{array}{c}\text { Hercules 3501-6 } \\
\text { Epoxy Matrix } \\
\text { Owooms-Corning } \\
\text { S2 Glass-Fiber }\end{array}$ & $\begin{array}{c}\text { Temperature, } \\
\text { Dry) }\end{array}$ \\
\hline Modulus of Elasticity, $E$ & $86.2 \mathrm{GPa}$ & $4.27 \mathrm{GPa}$ \\
\hline Shear Modulus, $G$ & $35.3 \mathrm{GPa}$ & $1.59 \mathrm{GPa}$ \\
\hline Poisson's ratio, $v$ & 0.22 & 0.34 \\
\hline
\end{tabular}

The lamina properties of the glass/epoxy composite for a fiber-volume fraction of 0.52 under dry and hygrothermal conditions are calculated based on micromechanics and listed in Table 5.62.. 
Table 5.62 Material properties for fiber volume fraction, $V_{f}=0.52$

\begin{tabular}{|c|c|c|}
\hline Property & Dry condition & Hygrothermal condition \\
\hline Longitudinal modulus, $E_{1}$ & $46.8736 \mathrm{GPa}$ & $46.0291 \mathrm{GPa}$ \\
\hline Transverse modulus, $E_{2}$ & $8.4428 \mathrm{GPa}$ & $5.0704 \mathrm{GPa}$ \\
\hline In-plane shear modulus, $G_{12}$ & $3.1584 \mathrm{GPa}$ & $1.8933 \mathrm{GPa}$ \\
\hline Transverse shear Modulus, $\mathrm{G}_{13}$ & $3.1584 \mathrm{GPa}$ & $1.8933 \mathrm{GPa}$ \\
\hline $\begin{array}{c}\text { Major in-plane Poisson's Ratio, } \\
v_{12}\end{array}$ & 0.2776 & 0.2776 \\
\hline
\end{tabular}

Two different beams, namely, pinned-pinned and clamped-clamped, under a uniformly distributed load. The mid-span deflections are computed under both dry and hygrothermal environments.

\subsubsection{Pinned-pinned laminate under uniformly distributed load}

For CLPT, the boundary conditions of a pinned-pinned laminate are:

$$
u=w=w^{y}=0 \text { on both the left and the right ends of the beam. }
$$

For FSDT, the boundary conditions of a pinned-pinned laminate are:

$$
u=w_{b}=w_{s}=w^{y}=0 \text { on both ends. }
$$

\subsubsection{Dry Condition}

The moisture content and the dry room-temperature are taken as $0 \%$ and $22.22{ }^{\circ} \mathrm{C}$, respectively. The mid-span deflection under a uniformly distributed load is computed and presented in Table 5.63; as a verification, results from previous authors are also included. 
Table 5.63 Mid-span deflection of a pinned-pinned laminate under uniformly distributed load in dry condition

\begin{tabular}{|c|c|c|c|c|c|}
\hline \multirow{3}{*}{ Load } & \multicolumn{4}{|c|}{ Mid-span deflection $(\mathbf{m})$} \\
\cline { 2 - 5 } & $\begin{array}{c}\text { Kavipurapu } \\
\text { (2005) }\end{array}$ & \multirow{2}{*}{$\begin{array}{c}\text { Uphadyay } \\
\mathbf{( 2 0 0 0 )}\end{array}$} & \multicolumn{2}{|c|}{ Present study } & \multirow{2}{*}{ Exact } \\
\cline { 4 - 5 } & & CLPT & FSDT & \\
\hline $40 \mathrm{~N} / \mathrm{m}^{2}$ & $6.3246 \mathrm{E}-4$ & $6.3500 \mathrm{E}-4$ & $6.5379 \mathrm{E}-4$ & $6.5379 \mathrm{E}-4$ & $6.4609 \mathrm{E}-4$ \\
\hline
\end{tabular}

\subsubsection{Hygrothermal Condition}

The moisture content and the operating temperature are taken as $5 \%$ and $67.89^{\circ} \mathrm{C}$, respectively. The mid-span deflection under a Uniformly Distributed Load for hygrothermal environment is noted in the table below and compared with that of the previous authors.

Table 5.64 Mid-span deflection of a pinned-pinned laminate under uniformly distributed load in dry conditions

\begin{tabular}{|c|c|c|c|c|c|}
\hline \multirow{3}{*}{ Load } & \multicolumn{4}{|c|}{ Mid-span deflection $(\mathbf{m})$} \\
\cline { 2 - 5 } & $\begin{array}{c}\text { Kavipurapu } \\
\mathbf{( 2 0 0 5 )}\end{array}$ & $\begin{array}{c}\text { Uphadyay } \\
\mathbf{( 2 0 0 0 )}\end{array}$ & \multicolumn{2}{|c|}{ Present study } & \multirow{2}{*}{ Exact } \\
\cline { 4 - 6 } & & CLPT & FSDT & \\
\hline $40 \mathrm{~N} / \mathrm{m}^{2}$ & $7.1120 \mathrm{E}-4$ & $7.1120 \mathrm{E}-4$ & $7.5384 \mathrm{E}-4$ & $7.5384 \mathrm{E}-4$ & $7.4903 \mathrm{E}-4$ \\
\hline
\end{tabular}

5.4.2 Clamped-clamped laminate under uniformly distributed load

For CLPT, the boundary conditions of a clamped-clamped laminate are:

$$
u=w=w^{\prime}=w^{y}=0 \text { on both the left and right ends of the beam. }
$$

For FSDT, the boundary conditions of a clamped-clamped laminate are: as follows. 


$$
u=w_{b}=w_{b}^{\prime}=w_{s}=w_{s}^{\prime}=w_{b}^{y}=0 \text { on both the left and right-end of the }
$$

beam.

\subsubsection{Dry Condition}

The moisture content and the temperature are taken as $0 \%$ and $22.22{ }^{\circ} \mathrm{C}$, respectively. The mid-span deflection under a uniformly distributed load is presented in table 5.65 and compared with that of the previous authors.

Table 5.65 Mid-span deflection for a clamped-clamped laminate under uniformly distributed load in dry conditions

\begin{tabular}{|c|c|c|c|c|c|}
\hline \multirow{2}{*}{ Load } & \multicolumn{4}{|c|}{ Mid-span Deflections (m) } \\
\cline { 2 - 5 } & $\begin{array}{c}\text { Kavipurapu } \\
\mathbf{( 2 0 0 5 )}\end{array}$ & $\begin{array}{c}\text { Uphadyay } \\
\mathbf{( 2 0 0 0 )}\end{array}$ & \multicolumn{2}{|c|}{ Present study } & \multirow{2}{*}{ Exact } \\
\cline { 4 - 6 } & & CLPT & FSDT & \\
\hline $50 \mathrm{~N} / \mathrm{m}^{2}$ & $2.1000 \mathrm{E}-4$ & $2.2400 \mathrm{E}-4$ & $2.3007 \mathrm{E}-4$ & $2.3007 \mathrm{E}-4$ & $2.2737 \mathrm{E}-4$ \\
\hline
\end{tabular}

\subsubsection{Hygrothermal Condition}

The moisture content and the operating temperature are taken as $5 \%$ and $67.89^{\circ} \mathrm{C}$, respectively. The mid-span deflection under a uniformly distributed load for hygrothermal environment is presented in Table 5.66 and compared with that of the previous authors. 
Table 5.66 Mid-span deflection for a clamped-clamped laminate under uniformly distributed load in hygrothermal conditions

\begin{tabular}{|c|c|c|c|c|c|}
\hline \multirow{3}{*}{ Load } & \multicolumn{4}{|c|}{ Mid-span Deflections $(\mathbf{m})$} \\
\cline { 2 - 5 } & \multirow{2}{*}{$\begin{array}{c}\text { Kavipurapu } \\
\text { (2005) }\end{array}$} & \multirow{2}{*}{$\begin{array}{c}\text { Uphadyay } \\
\mathbf{( 2 0 0 0 )}\end{array}$} & \multicolumn{2}{|c|}{ Present study } & \multirow{2}{*}{ Exact } \\
\cline { 4 - 5 } & & CLPT & FSDT & \\
\hline $50 \mathrm{~N} / \mathrm{m}^{2}$ & $3.2004 \mathrm{E}-4$ & $3.0480 \mathrm{E}-4$ & $3.0667 \mathrm{E}-4$ & $3.0667 \mathrm{E}-4$ & $3.0473 \mathrm{E}-4$ \\
\hline
\end{tabular}

\subsection{Stress Analysis on Composite Beams}

In this section, the ply stresses at a cross section are computed based on both CLPT and FSDT. The examples considered are a cross-ply laminate, [0/90]s from Borovkov et al. (1999) as well as two symmetrical composite beams with the laminate stacking sequence of $[0 / 45 /-45 / 90]_{s}$ and $[90 / 45 /-45 / 0]_{s}$ from Reddy (1997).

\subsubsection{Result verification with Borovkov et al. (1999)}

The geometric and material properties used by Borovkov et al. (1999) are reproduced in Table 5.67. 
Table 5.67 Dimensions and material properties of composite beam

\begin{tabular}{|c|c|}
\hline Length, $L$ & $1 \mathrm{~m}$ \\
\hline Width, $b$ & $0.01 \mathrm{~m}$ \\
\hline Thickness, $h$ & $0.1 \mathrm{~m}$ \\
\hline Density, $\rho$ & $1600 \mathrm{~kg} / \mathrm{m}^{3}$ \\
\hline Longitudinal Modulus of Elasticity, $E_{1}$ & $25 \mathrm{GPa}$ \\
\hline Longitudinal Modulus of Elasticity, $E_{2}$ & $1 \mathrm{GPa}$ \\
\hline Transverse Modulus of Elasticity, $G_{12}$ & $0.5 \mathrm{GPa}$ \\
\hline Transverse Modulus of Elasticity, $G_{13}$ & $0.5 \mathrm{GPa}$ \\
\hline Transverse Modulus of Elasticity, $G_{23}$ & $0.2 \mathrm{GPa}$ \\
\hline Poisson's ratio, $v_{12}$ & 0.25 \\
\hline
\end{tabular}

The analysis is done on a symmetric cross-ply clamped-clamped laminated beam, $[0 / 90]_{s}$, with four layers, each having the same thickness and a total thickness of $10 \mathrm{~mm}$. A uniformly distributed load of $q_{0}=-10 \mathrm{KN} / \mathrm{m}^{2}$ is applied along the length of the beam. Borovkov et al. present results at $L / 4$ of the beam in terms of non-dimensional stresses defined as

$$
\sigma_{x}^{*}=\frac{\sigma_{x} b}{h q_{0}}
$$

where $\sigma_{x}$ is the normal stress and $\sigma_{x}^{*}$ is the non-dimensional normal stress .

For CLPT, the boundary conditions of a clamped-clamped laminate are:

$$
\begin{array}{ll}
u=w=w^{\prime}=w^{y}=0 & \text { on the left-end of the beam } \\
w=w^{\prime}=w^{y}=0 & \text { on the right-end of the beam }
\end{array}
$$


For FSDT, the boundary conditions of a clamped-clamped laminate are:

$$
\begin{array}{ll}
u=w_{b}=w_{b}^{\prime}=w_{s}=w_{s}^{\prime}=w_{b}^{y}=0 & \text { on the left-end of the beam } \\
w_{b}=w_{b}^{\prime}=w_{s}=w_{s}^{\prime}=w_{b}^{y}=0 & \text { on the right-end of the beam }
\end{array}
$$

The stress distribution, $\sigma_{x}$, along the cross-section of the beam at the quarter span of the beam, using both CLPT and FSDT, are shown in Figure 5.42 and listed in Table 5.68.

Table 5.68 Normal stress along the cross-section of a $[0 / 90]_{s}$ laminated composite beam

\begin{tabular}{|c|c|c|c|}
\hline \multirow{2}{*}{\multicolumn{2}{|c|}{}} & \multicolumn{2}{c|}{ Present study } \\
\cline { 3 - 4 } \multicolumn{2}{|c}{} & \multicolumn{2}{c|}{$\sigma_{x}\left(\mathbf{N} / \mathbf{m}^{2}\right)$} \\
\cline { 3 - 4 } & Top & $-7.1057 \mathrm{E}+04$ & $-7.0967 \mathrm{E}+04$ \\
\hline \multirow{2}{*}{$\begin{array}{c}0^{\circ} \\
\text { (Top of } \\
\text { Laminate) }\end{array}$} & Bottom & $-3.5517 \mathrm{E}+04$ & $-3.5427 \mathrm{E}+04$ \\
\hline \multirow{2}{9}{$90^{\circ}$} & Top & $-1.3994 \mathrm{E}+03$ & $-1.3958 \mathrm{E}+03$ \\
\cline { 2 - 4 } & Bottom & $9.0356 \mathrm{E}-01$ & $4.4739 \mathrm{E}+00$ \\
\hline \multirow{2}{*}{$90^{\circ}$} & Top & $9.0356 \mathrm{E}-01$ & $4.4739 \mathrm{E}+00$ \\
\cline { 2 - 4 } & Bottom & $1.4012 \mathrm{E}+03$ & $1.4047 \mathrm{E}+03$ \\
\hline $\begin{array}{c}0^{\circ} \\
(\text { Bottom of } \\
\text { Laminate })\end{array}$ & Top & $3.5563 \mathrm{E}+04$ & $3.5652 \mathrm{E}+04$ \\
\cline { 2 - 4 } & Bottom & $7.1102 \mathrm{E}+04$ & $7.1192 \mathrm{E}+04$ \\
\hline
\end{tabular}




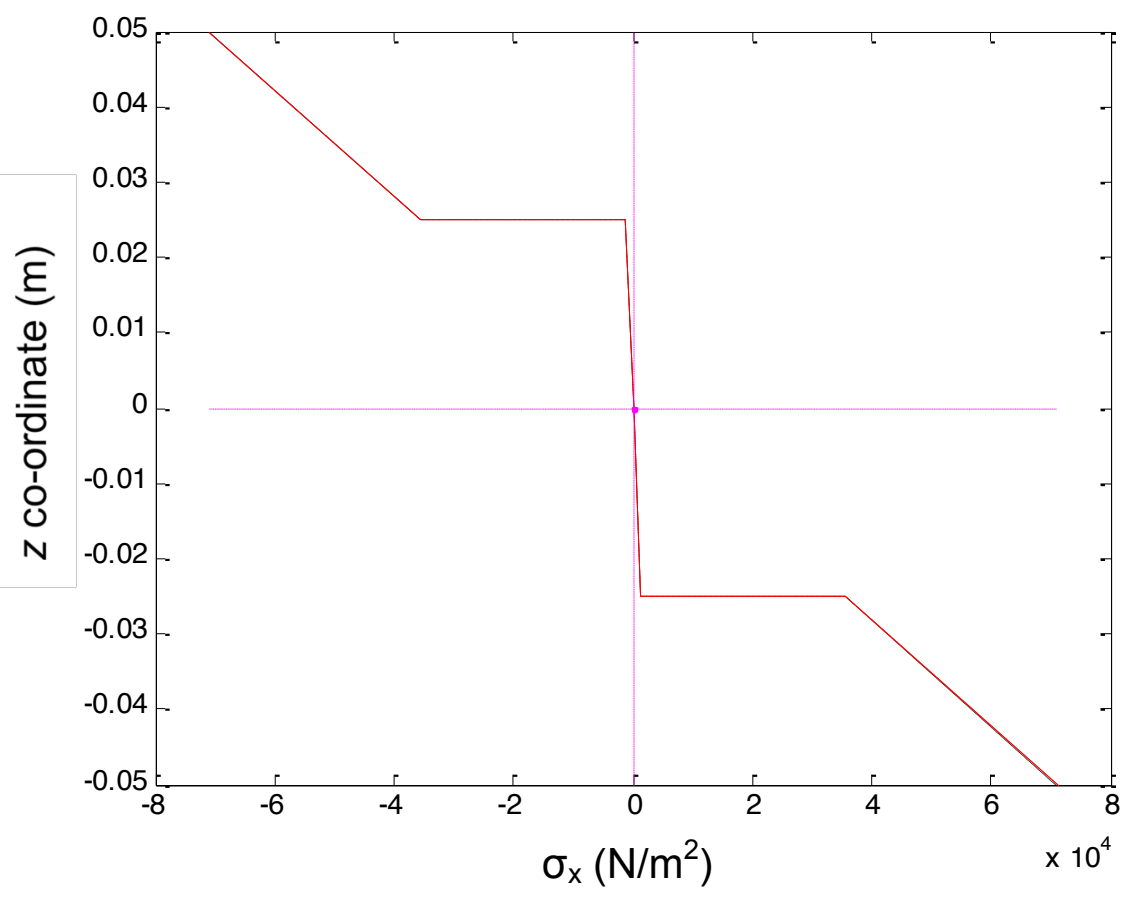

Figure 5.43 Normal longitudinal stress distribution, $\sigma_{x}$, for a $[0 / 90]_{\mathrm{s}}$ laminated composite beam

The non-dimensional normal stresses, $\sigma_{x}^{*}$, calculated by Equation (5.3) at various points across the thickness is listed in Table 5.69. These are used for comparison with Borovkov et al. (1999). The comparison is shown in Figure 5.43 and it can be seen that the results are in excellent agreement. 


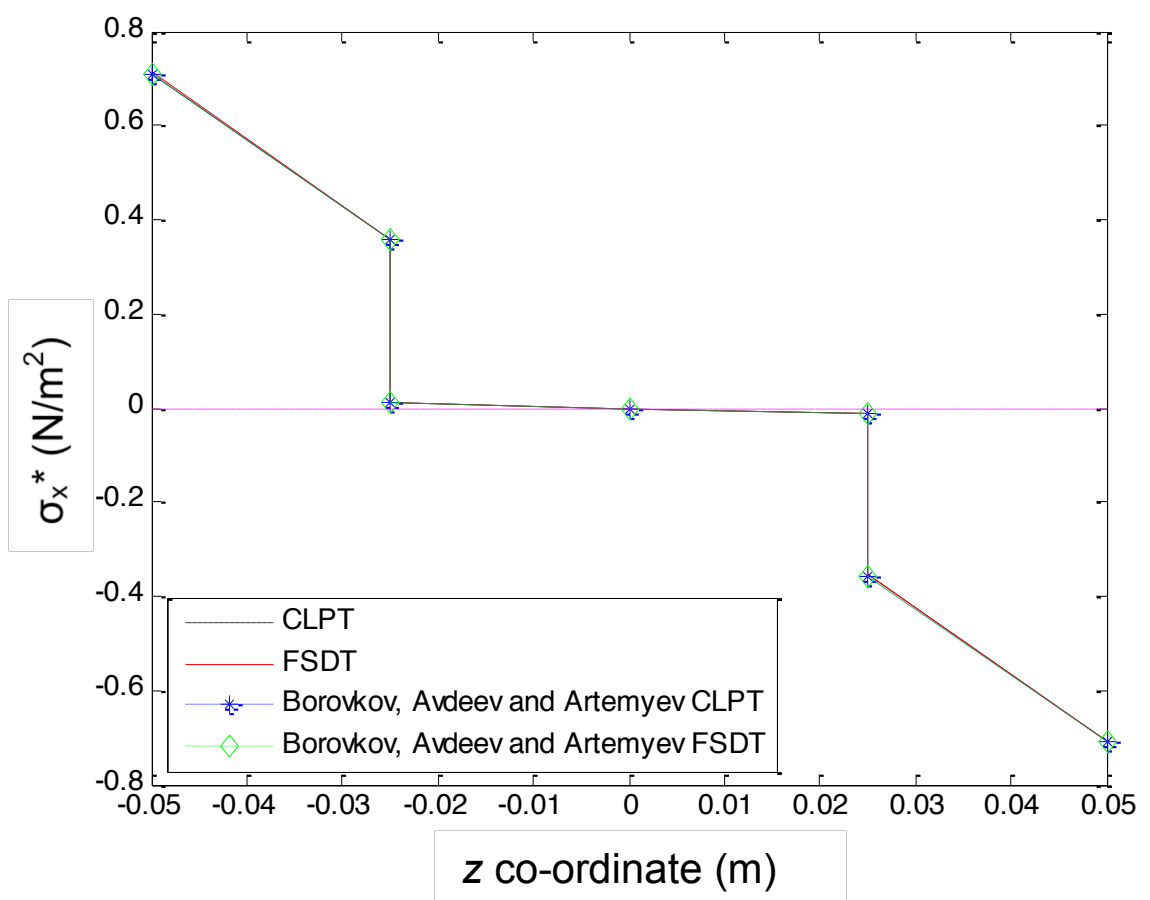

Figure 5.44 Non-dimensional normal stress distribution, $\sigma_{x}^{*}$, for a $[0 / 90]_{\mathrm{s}}$ laminated composite beam

Table 5.69 Non-dimensional normal stress along the cross-section of a $[0 / 90]_{s}$ laminated composite beam

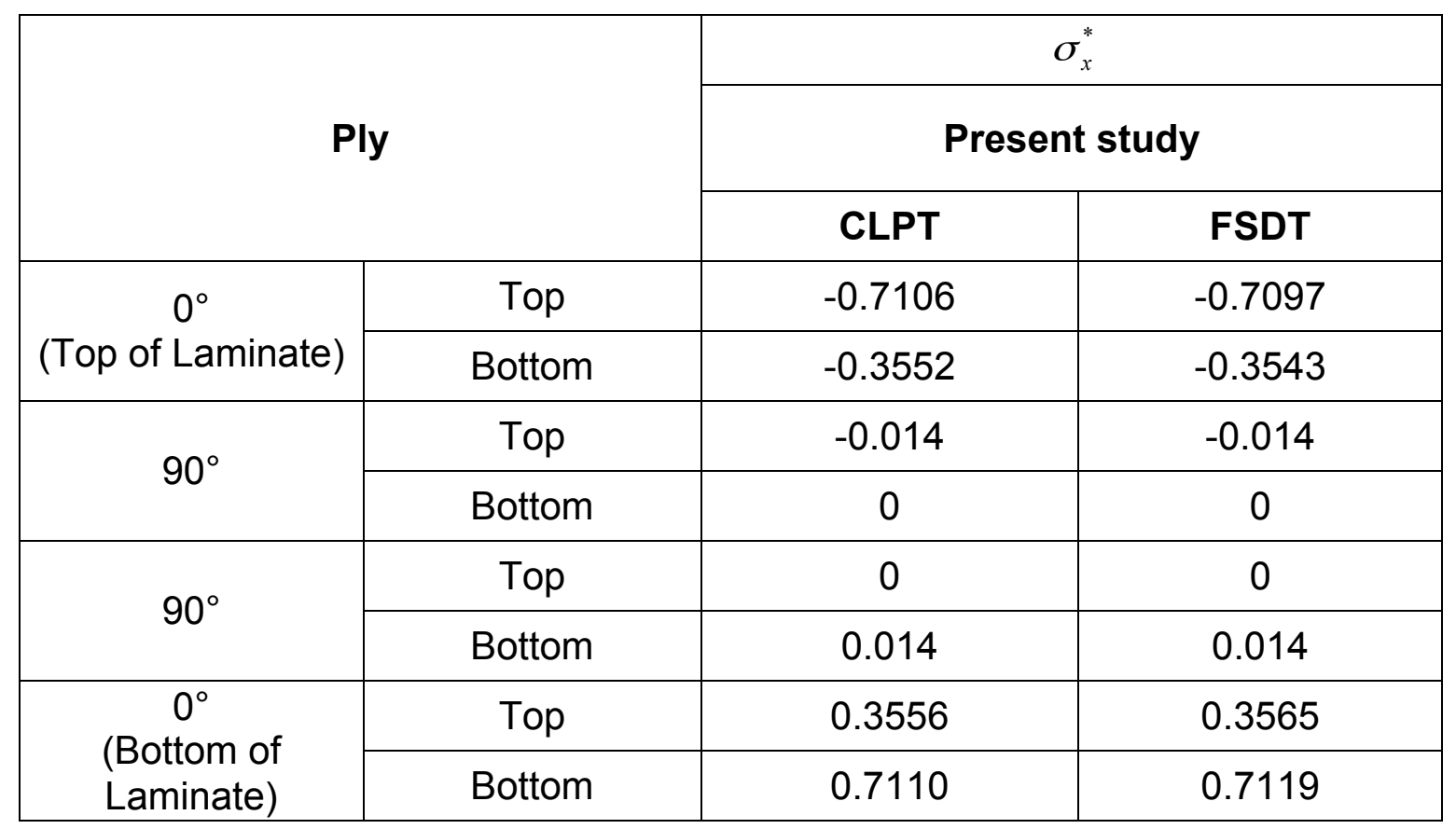




\subsubsection{Result Verification with Reddy (1997)}

The geometric and material properties from Reddy (1997) are given in Table 5.70.

Table 5.70 Dimensions and material properties of composite beam

\begin{tabular}{|c|c|}
\hline Length, $L$ & $1 \mathrm{~m}$ \\
\hline Width, $b$ & $0.2 \mathrm{~m}$ \\
\hline Thickness, $h$ & $0.1 \mathrm{~m}$ \\
\hline Density, $\rho$ & $1600 \mathrm{~kg} / \mathrm{m}^{3}$ \\
\hline Longitudinal Modulus of Elasticity, $E_{1}$ & $175 \mathrm{GPa}$ \\
\hline Longitudinal Modulus of Elasticity, $E_{2}$ & $7 \mathrm{GPa}$ \\
\hline Transverse Modulus of Elasticity, $G_{12}$ & $3.5 \mathrm{GPa}$ \\
\hline Transverse Modulus of Elasticity, $G_{13}$ & $3.5 \mathrm{GPa}$ \\
\hline Transverse Modulus of Elasticity, $G_{23}$ & $1.4 \mathrm{GPa}$ \\
\hline Poisson ratio, $v_{12}$ & 0.25 \\
\hline
\end{tabular}

The analysis is done on two different laminate stacking sequences, $[0 / \pm 45 / 90]_{s}$ and $[90 / \pm 45 / 0]_{s}$, with eight layers each having the same thickness and a total thickness of $10 \mathrm{~mm}$. A load of $1 \mathrm{~N} / \mathrm{m}$ is applied at the mid-span of the beam. Reddy presents mid-span non-dimensional stress as,

$$
\overline{\sigma_{x}}=\frac{\sigma_{x} b h}{F_{0}}
$$

where $\sigma_{x}$ is the normal longitudinal stress and $\overline{\sigma_{x}}$ is the non-dimensional normal stress. 
In this case, the laminate is simply-supported and the load is applied at mid-span. The boundary conditions for a simply-supported laminate using CLPT are:

$$
\begin{array}{ll}
u=w=w^{y}=0 & \text { on the left-end of the beam } \\
w=w^{y}=0 & \text { on the right-end of the beam }
\end{array}
$$

For FSDT, the boundary conditions of a simply-supported laminate are:

$$
\begin{array}{ll}
u=w_{b}=w_{s}=w_{b}^{y}=0 & \text { on the left-end of the beam } \\
w_{b}=w_{s}=w_{b}^{y}=0 & \text { on the right-end of the beam }
\end{array}
$$

\subsubsection{1 $[0 / \pm 45 / 90]_{s}$ Laminated Composite Beam}

Analysis on a $[0 / \pm 45 / 90]_{s}$ is run and the stress distribution, $\sigma_{x}$, along the cross-section of the beam, using both CLPT and FSDT, are shown in Figure 5.44 and listed in Table 5.71. 
Table 5. 71 Normal stresses along the cross-section of a $[0 / \pm 45 / 90]_{s}$ laminated composite beam

\begin{tabular}{|c|c|c|c|}
\hline \multirow{2}{*}{\multicolumn{2}{|c|}{ Ply }} & \multirow{2}{*}{\multicolumn{2}{|c|}{$\begin{array}{c}\text { Present study } \\
\sigma_{x}\left(\mathrm{~N} / \mathrm{m}^{2}\right)\end{array}$}} \\
\hline & & & \\
\hline & & CLPT & FSDT \\
\hline \multirow{2}{*}{$\begin{array}{c}0^{\circ} \\
\text { (Top of Laminate) }\end{array}$} & Top & $2.3426 \mathrm{E}+02$ & $2.3426 \mathrm{E}+02$ \\
\hline & Bottom & $1.7569 \mathrm{E}+02$ & 1.7569E+02 \\
\hline \multirow{2}{*}{$45^{\circ}$} & Top & $1.8833 E+01$ & $1.8833 E+01$ \\
\hline & Bottom & $1.2556 \mathrm{E}+01$ & $1.2556 \mathrm{E}+01$ \\
\hline \multirow{2}{*}{$-45^{\circ}$} & Top & $1.6302 \mathrm{E}+01$ & $1.6302 \mathrm{E}+01$ \\
\hline & Bottom & $8.1512 E+00$ & $8.1512 E+00$ \\
\hline \multirow{2}{*}{$90^{\circ}$} & Top & $1.9671 \mathrm{E}+00$ & $1.9671 \mathrm{E}+00$ \\
\hline & Bottom & 0 & 0 \\
\hline \multirow{2}{*}{$90^{\circ}$} & Top & 0 & 0 \\
\hline & Bottom & $-1.9671 E+00$ & $-1.9671 E+00$ \\
\hline \multirow{2}{*}{$-45^{\circ}$} & Top & $-8.1512 E+00$ & $-8.1512 E+00$ \\
\hline & Bottom & $-1.6302 E+01$ & $-1.6302 \mathrm{E}+01$ \\
\hline \multirow{2}{*}{$45^{\circ}$} & Top & $-1.2556 E+01$ & $-1.2556 \mathrm{E}+01$ \\
\hline & Bottom & $-1.8833 E+01$ & $-1.8833 E+01$ \\
\hline \multirow{2}{*}{$\begin{array}{c}0^{\circ} \\
\text { (Bottom of } \\
\text { Laminate) }\end{array}$} & Top & $-1.7569 E+02$ & $-1.7569 \mathrm{E}+02$ \\
\hline & Bottom & $-2.3426 \mathrm{E}+02$ & $-2.3426 \mathrm{E}+02$ \\
\hline
\end{tabular}




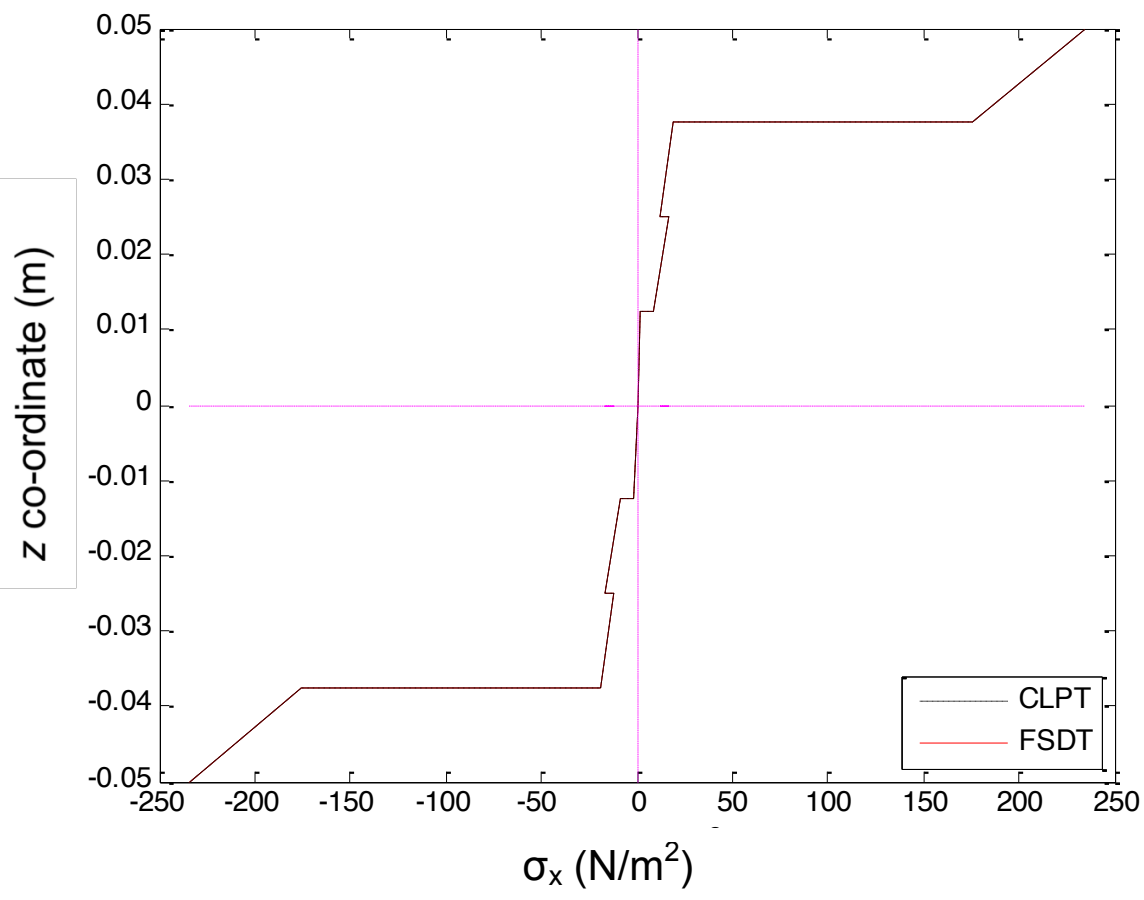

Figure 5.45 Normal stress distribution, $\sigma_{x}$, for a $[0 / \pm 45 /-45 / 90]_{s}$ laminated composite beam

The non-dimensional normal stress, $\overline{\sigma_{x}}$, calculated by Equation $(5.4)$ is listed in Table 5.72. These are used for comparison with Reddy (1997). The comparison is shown in Figure 5.45 also. It can be seen that the results are in excellent agreement, 


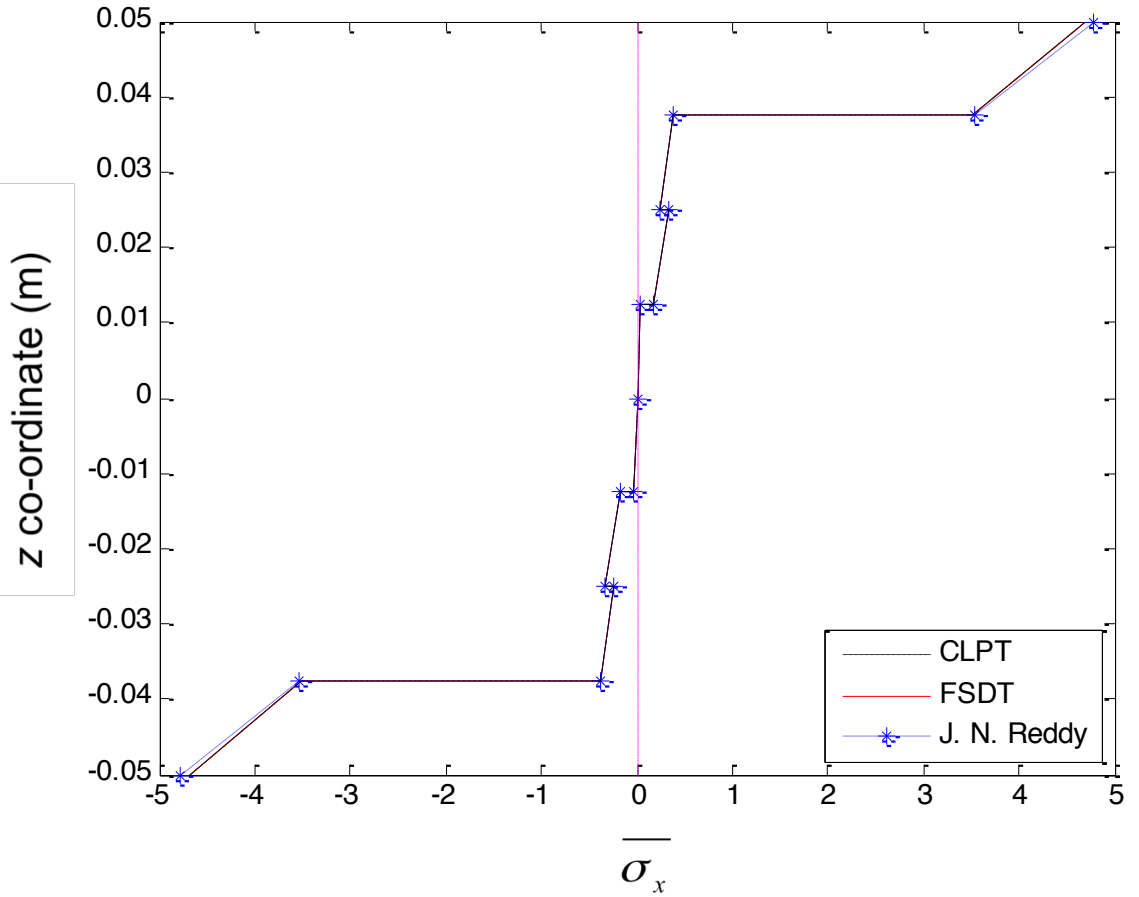

Figure 5.46 Non-dimensional normal longitudinal stress distribution, $\overline{\sigma_{x}}$, for a $[0 / \pm 45 / 90]_{s}$ laminated composite beam 
Table 5.72 Non-dimensional normal stress along the cross-section of a $[0 / 45 /-45 / 90]_{s}$ laminated composite beam

\begin{tabular}{|c|c|c|c|}
\hline \multirow{3}{*}{$\mathbf{P I}$} & & \multirow{2}{*}{\multicolumn{2}{|c|}{$\frac{\overline{\sigma_{x}}}{\text { Present study }}$}} \\
\hline & & & \\
\hline & & CLPT & FSDT \\
\hline \multirow{2}{*}{$\begin{array}{c}0^{\circ} \\
\text { (Top of Laminate) }\end{array}$} & Top & 4.6851 & 4.6851 \\
\hline & Bottom & 3.5139 & 3.5139 \\
\hline \multirow{2}{*}{$45^{\circ}$} & Top & 0.3767 & 0.3767 \\
\hline & Bottom & 0.2511 & 0.2511 \\
\hline \multirow{2}{*}{$-45^{\circ}$} & Top & 0.3260 & 0.3260 \\
\hline & Bottom & 0.1630 & 0.1630 \\
\hline \multirow{2}{*}{$90^{\circ}$} & Top & 0.0393 & 0.0393 \\
\hline & Bottom & 0 & 0 \\
\hline \multirow{2}{*}{$90^{\circ}$} & Top & 0 & 0 \\
\hline & Bottom & -0.0393 & -0.0393 \\
\hline \multirow{2}{*}{$-45^{\circ}$} & Top & -0.1630 & -0.1630 \\
\hline & Bottom & -0.3260 & -0.3260 \\
\hline \multirow{2}{*}{$45^{\circ}$} & Top & -0.2511 & -0.2511 \\
\hline & Bottom & -0.3767 & -0.3767 \\
\hline \multirow{2}{*}{$\begin{array}{c}0^{\circ} \\
\text { (Bottom of } \\
\text { Laminate) }\end{array}$} & Top & -3.5139 & -3.5139 \\
\hline & Bottom & -4.6851 & -4.6851 \\
\hline
\end{tabular}

\subsubsection{2 $[90 / \pm 45 / 0]_{s}$ Laminated Composite Beam}

Analysis on a $[90 / \pm 45 / 0]_{s}$ is run and the stress distribution, $\sigma_{x}$, along the cross-section of the beam, using both CLPT and FSDT are shown in Figure 5.46 are listed below in Table 5.73 . 
Table 5.73 Normal stresses along the cross-section of a $[90 / \pm 45 / 0]_{s}$ laminated composite beam

\begin{tabular}{|c|c|c|c|}
\hline \multirow{2}{*}{\multicolumn{2}{|c|}{ Ply }} & \multirow{2}{*}{\multicolumn{2}{|c|}{$\begin{array}{c}\text { Present study } \\
\sigma_{x}\left(\mathbf{N} / \mathbf{m}^{2}\right)\end{array}$}} \\
\hline & & & \\
\hline & & CLPT & FSDT \\
\hline \multirow{2}{*}{$\begin{array}{c}90^{\circ} \\
\text { (Top of Laminate) }\end{array}$} & Top & $4.2839 \mathrm{E}+01$ & $4.2839 \mathrm{E}+01$ \\
\hline & Bottom & $3.2129 \mathrm{E}+01$ & $3.2129 \mathrm{E}+01$ \\
\hline \multirow{2}{*}{$45^{\circ}$} & Top & $1.7472 E+02$ & $1.7472 E+02$ \\
\hline & Bottom & $1.1648 \mathrm{E}+02$ & $1.1648 \mathrm{E}+02$ \\
\hline \multirow{2}{*}{$-45^{\circ}$} & Top & $1.6150 \mathrm{E}+02$ & $1.6150 \mathrm{E}+02$ \\
\hline & Bottom & $8.0749 E+01$ & $8.0749 E+01$ \\
\hline \multirow{2}{*}{$0^{\circ}$} & Top & $2.7713 \mathrm{E}+02$ & $2.7713 E+02$ \\
\hline & Bottom & 0 & 0 \\
\hline \multirow{2}{*}{$0^{\circ}$} & Top & 0 & 0 \\
\hline & Bottom & $-2.7713 E+02$ & $-2.7713 E+02$ \\
\hline \multirow{2}{*}{$-45^{\circ}$} & Top & $-8.0749 E+01$ & $-8.0749 E+01$ \\
\hline & Bottom & $-1.6150 \mathrm{E}+02$ & $-1.6150 \mathrm{E}+02$ \\
\hline \multirow{2}{*}{$45^{\circ}$} & Top & $-1.1648 E+02$ & $-1.1648 \mathrm{E}+02$ \\
\hline & Bottom & $-1.7472 E+02$ & $-1.7472 E+02$ \\
\hline \multirow{2}{*}{$\begin{array}{c}90^{\circ} \\
\text { (Bottom of } \\
\text { Laminate) }\end{array}$} & Top & $-3.2129 E+01$ & $-3.2129 E+01$ \\
\hline & Bottom & $-4.2839 E+01$ & $-4.2839 E+01$ \\
\hline
\end{tabular}




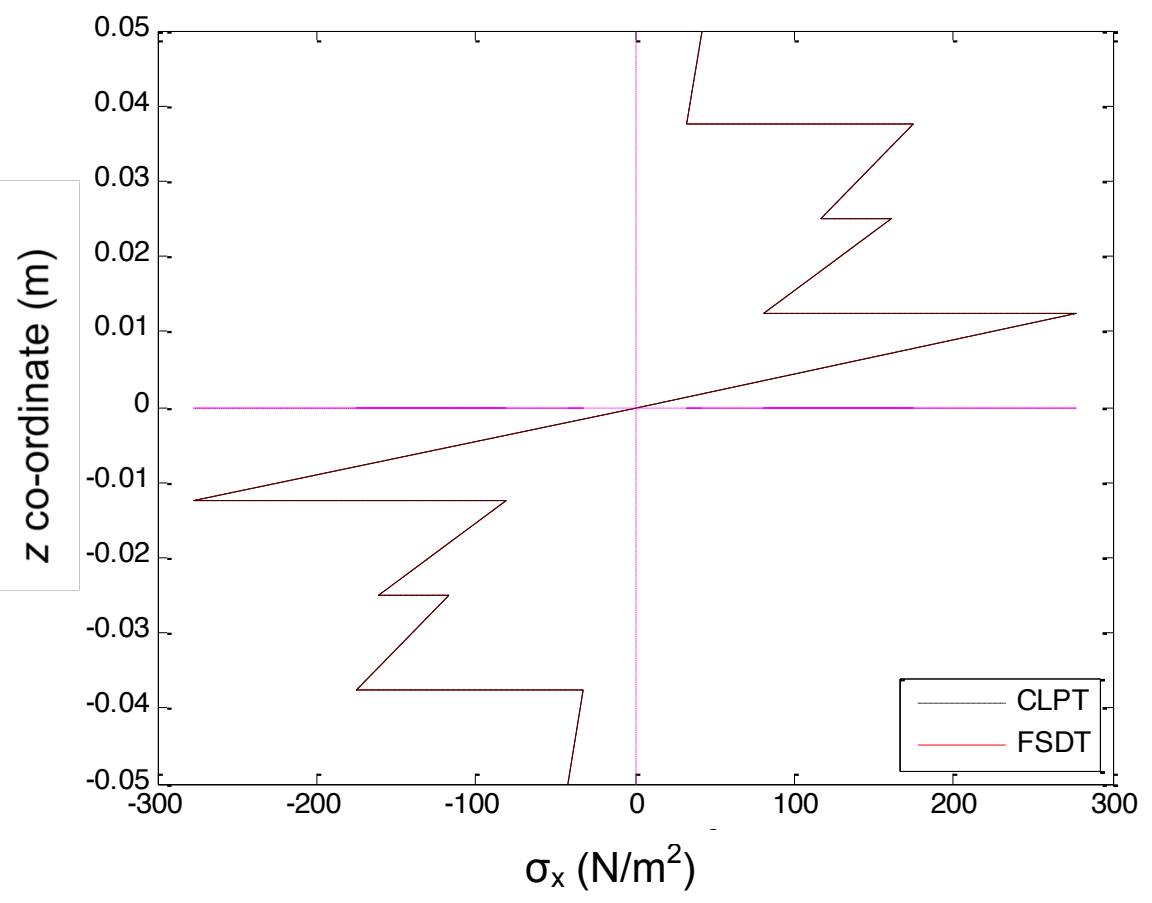

Figure 5.47 Normal longitudinal stress distribution, $\sigma_{x}$, for a $[90 / \pm 45 / 0]_{\mathrm{s}}$ laminated composite beam

The non-dimensional normal stress, $\overline{\sigma_{x}}$, calculated by Equation $(5.4)$ is listed in Table 5.74. These are used for comparison with. Reddy (1997) in Figure 5.47 with the J. N. Reddy plot read through the program called Digitizelt. It can be once again seen that the results are in excellent agreement. 


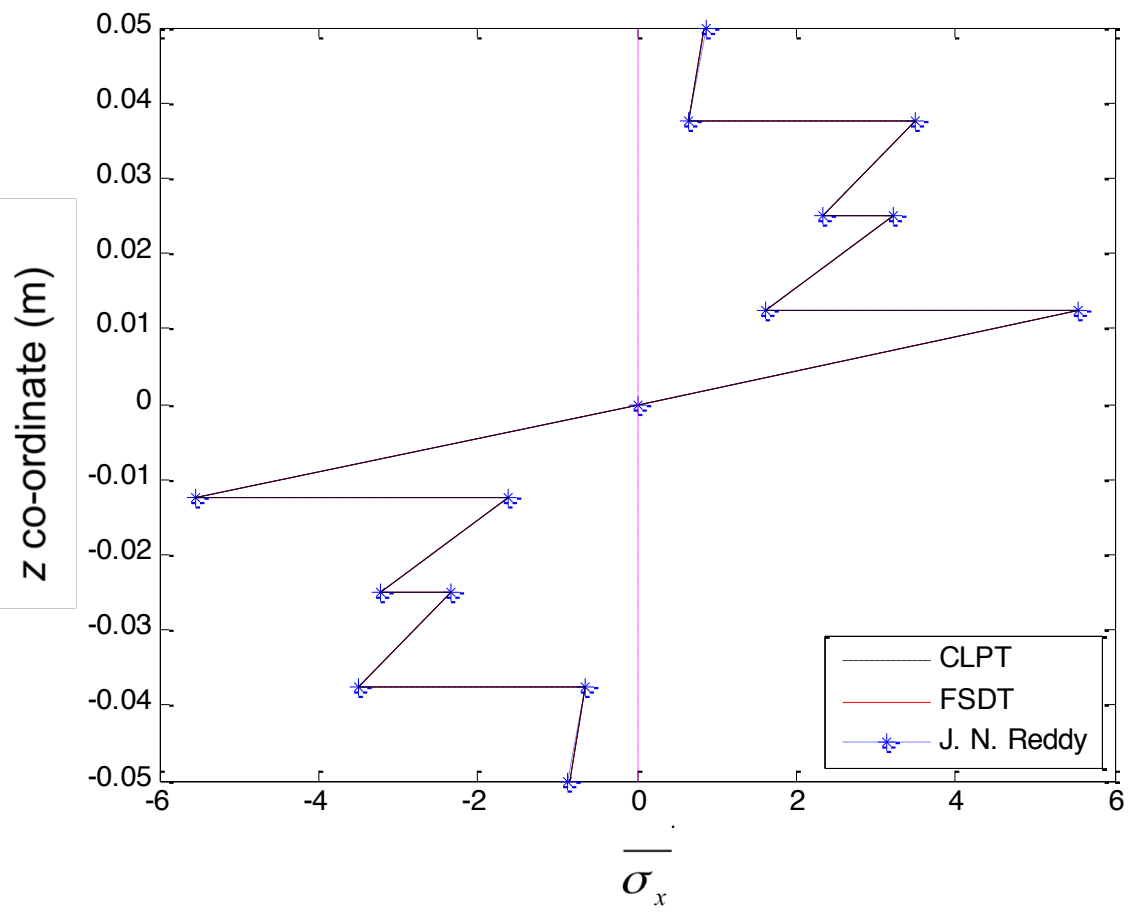

Figure 5.48 Non-dimensional normal longitudinal stress distribution, $\overline{\sigma_{x}}$, for a $[90 / \pm 45 / 0]_{s}$ laminated composite beam 
Table 5.74 Non-dimensional normal stress along the cross-section of a $[90 / \pm 45 / 0]_{s}$ laminated composite beam

\begin{tabular}{|c|c|c|c|}
\hline \multirow{3}{*}{$\mathrm{Pl}$} & & \multirow{2}{*}{\multicolumn{2}{|c|}{$\frac{\overline{\sigma_{x}}}{\text { Present study }}$}} \\
\hline & & & \\
\hline & & CLPT & FSDT \\
\hline \multirow{2}{*}{$\begin{array}{c}90^{\circ} \\
\text { (Top of Laminate) }\end{array}$} & Top & 0.8568 & 0.8568 \\
\hline & Bottom & 0.6426 & 0.6426 \\
\hline \multirow{2}{*}{$45^{\circ}$} & Top & 3.4944 & 3.4944 \\
\hline & Bottom & 2.3296 & 2.3296 \\
\hline \multirow{2}{*}{$-45^{\circ}$} & Top & 3.2300 & 3.2300 \\
\hline & Bottom & 1.6150 & 1.6150 \\
\hline \multirow{2}{*}{$0^{\circ}$} & Top & 5.5426 & 5.5426 \\
\hline & Bottom & 0 & 0 \\
\hline \multirow{2}{*}{$0^{\circ}$} & Top & 0 & 0 \\
\hline & Bottom & -5.5426 & -5.5426 \\
\hline \multirow{2}{*}{$-45^{\circ}$} & Top & -1.6150 & -1.6150 \\
\hline & Bottom & -3.2300 & -3.2300 \\
\hline \multirow{2}{*}{$45^{\circ}$} & Top & -2.3296 & -2.3296 \\
\hline & Bottom & -3.4944 & -3.4944 \\
\hline \multirow{2}{*}{$\begin{array}{c}90^{\circ} \\
\text { (Bottom of } \\
\text { Laminate) }\end{array}$} & Top & -0.6426 & -0.6426 \\
\hline & Bottom & -0.8568 & -0.8568 \\
\hline
\end{tabular}




\section{CHAPTER 6 HYGROTHERMAL ANALYSIS}

\subsection{Introduction}

In the previous chapter, the verification of the several aspects of the problem formulation has been accomplished by judiciously choosing examples. These sample problems have vouched for the validity of the finite element model, the moving beam simulation, the hygrothermal algorithm, and the computation of ply stresses at a given cross section. In this chapter, the focus will be on the moving load analysis of composite beams with in dry and hygrothermal environments. A parametric analysis is to be conducted by varying the fiber volume fraction and considering three different laminate stacking sequences. The results will be in the form of dynamic deflections and dynamic magnification factors at mid-span.

\subsection{Properties}

It should be noted that hygrothermal conditions mainly affect the matrix properties, when it comes to degradation. These degraded matrix properties are calculated using the empirical relationship given in Equation (2.44) based on the moisture content and the operating temperature.

In the present study, under both dry and hygrothermal environments, the ply properties, $E_{1}, v_{12}$ and $\rho_{\mathrm{c}}$ are calculated using the rule of mixtures [Equations (2.46), (2.49) and (2.50)]. The value of $E_{2}$ is calculated using the Halpin-Tsai 
Formula [Equation (2.51)] and the value of $G_{12}$ and $G_{13}$ are calculated using Periodic Microstructure Model given in Equation (2.53).

For the present study, the three different lay-ups considered are $[0 / \pm 20]_{s}$, $[0 / 90 / \pm 45]$ and $[0 / 90 / \pm 30]_{s}$. These are analyzed under dry and wet conditions with three different fiber volume fractions $\left(V_{f}\right)$, namely, $0.52,0.6$ and 0.7 .

Owens-Corning S2 glass fiber and Hercules 3501-6 epoxy matrix are considered with the material properties as given by Cairns and Adams (1983). The dry resin glass transition temperature and density for the Hercules 3501-6 Epoxy are taken from Hyer (1997) and by Hexcel Composites. The density of S2 Glass Fiber is from Barbero (1999). The dimensions, material properties of the fiber and matrix, dry and wet temperatures of the epoxy and other properties are given in the following tables.

Table 6.1 Dimensions, material properties and temperatures of glass/epoxy composite beam

\begin{tabular}{|c|c|}
\hline Length, $L$ & $1 \mathrm{~m}$ \\
\hline Width, $b$ & $0.05 \mathrm{~m}$ \\
\hline Total thickness, $h$ & $0.07 \mathrm{~m}$ \\
\hline Moisture content, $m$ & $5 \%$ \\
\hline Dry resin glass transition temperature, $T_{\text {gdr }}$ & $206{ }^{\circ} \mathrm{C}$ \\
\hline Wet resin glass transition temperature, $T_{\text {gwr }}$ & $128.75^{\circ} \mathrm{C}$ \\
\hline Initial dry temperature, $T_{0}$ & $21^{\circ} \mathrm{C}$ \\
\hline Final wet temperature, $T$ & $52{ }^{\circ} \mathrm{C}$ \\
\hline
\end{tabular}


Table 6.2 Material properties of S2 glass-fiber and hercules 3501-6 epoxy matrix

\begin{tabular}{|c|c|c|}
\hline Material property & $\begin{array}{c}\text { Owens-corning } \\
\text { S2 glass-fiber }\end{array}$ & $\begin{array}{c}\text { Hercules 3501-6 } \\
\text { epoxy matrix } \\
\text { (room } \\
\text { temperature, dry) }\end{array}$ \\
\hline Modulus of Elasticity, $E$ & $86.2 \mathrm{GPa}$ & $4.27 \mathrm{GPa}$ \\
\hline Longitudinal Shear Modulus, $G$ & $35.3 \mathrm{GPa}$ & $1.59 \mathrm{GPa}$ \\
\hline Density, $\rho$ & $2460 \mathrm{~kg} / \mathrm{m}^{3}$ & $1265 \mathrm{~kg} / \mathrm{m}^{3}$ \\
\hline Poisson's ratio, $v$ & 0.22 & 0.34 \\
\hline
\end{tabular}

The lamina material properties of the glass/epoxy composite are calculated using micromechanics for fiber-volume fractions of $0.52,0.6$ and 0.7 and listed in Tables 6.3 - 6.5,

Table 6.3 Material properties for fiber volume fraction, $V_{f}=0.52$

\begin{tabular}{|c|c|c|}
\hline Property & Dry condition & Hygrothermal condition \\
\hline Longitudinal Modulus, $E_{1}$ & $46.8736 \mathrm{GPa}$ & $46.1441 \mathrm{GPa}$ \\
\hline Transverse Modulus, $E_{2}$ & $14.7378 \mathrm{GPa}$ & $10.1621 \mathrm{GPa}$ \\
\hline Longitudinal Shear Modulus, $G_{12}$ & $4.4944 \mathrm{GPa}$ & $3.0158 \mathrm{GPa}$ \\
\hline Transverse Shear Modulus, $G_{13}$ & $4.4944 \mathrm{GPa}$ & $3.0158 \mathrm{GPa}$ \\
\hline In-Plane Poisson's Ratio, $v_{12}$ & 0.2776 & 0.2776 \\
\hline Density, $\rho_{\mathrm{c}}$ & \multicolumn{2}{|c|}{$1886.4 \mathrm{~kg} / \mathrm{m}^{3}$} \\
\hline
\end{tabular}


Table 6.4 Material properties for fiber volume fraction, $V_{f}=0.6$

\begin{tabular}{|c|c|c|}
\hline Property & Dry condition & Hygrothermal condition \\
\hline Longitudinal Modulus, $E_{1}$ & $53.4280 \mathrm{GPa}$ & $52.8201 \mathrm{GPa}$ \\
\hline Transverse Modulus, $E_{2}$ & $18.0850 \mathrm{GPa}$ & $12.6738 \mathrm{GPa}$ \\
\hline Longitudinal Shear Modulus, $G_{12}$ & $5.4978 \mathrm{GPa}$ & $3.7330 \mathrm{GPa}$ \\
\hline Transverse Shear Modulus, $G_{13}$ & $5.4978 \mathrm{GPa}$ & $3.7330 \mathrm{GPa}$ \\
\hline In-Plane Poisson's Ratio, $v_{12}$ & 0.2680 & 0.2680 \\
\hline Density, $\rho_{\mathrm{c}}$ & \multicolumn{2}{|c|}{$1982 \mathrm{~kg} / \mathrm{m}^{3}$} \\
\hline
\end{tabular}

Table 6.5 Material properties for fiber volume fraction, $V_{f}=0.7$

\begin{tabular}{|c|c|c|}
\hline Property & Dry condition & Hygrothermal condition \\
\hline Longitudinal Modulus, $E_{1}$ & $61.6210 \mathrm{GPa}$ & $61.1651 \mathrm{GPa}$ \\
\hline Transverse Modulus, $E_{2}$ & $23.9192 \mathrm{GPa}$ & $17.2302 \mathrm{GPa}$ \\
\hline Longitudinal Shear Modulus, $G_{12}$ & $7.3583 \mathrm{GPa}$ & $5.1051 \mathrm{GPa}$ \\
\hline Transverse Shear Modulus, $G_{13}$ & $7.3583 \mathrm{GPa}$ & $5.1051 \mathrm{GPa}$ \\
\hline In-Plane Poisson's Ratio, $v_{12}$ & 0.2560 & 0.2560 \\
\hline Density, $\rho_{\mathrm{c}}$ & \multicolumn{2}{|c|}{$2101.5 \mathrm{~kg} / \mathrm{m}^{3}$} \\
\hline
\end{tabular}

\subsection{Convergence Study}

A convergence study is done to decide on the number of elements to be used in the finite element discretization.. This convergence study is done on a [0/90/ \pm 45$]$ lay-up composite beam with a fiber volume fraction of $V_{f}=0.52$. Both static and dynamic analyses are conducted on a simply-supported beam subjected to a point load, $P=-10 \mathrm{kN}$. In the static case the load is applied at midspan while in the moving-load case, it moves from the left-end of the beam to the right-end at $V=30 \mathrm{~m} / \mathrm{s}$. For both cases the maximum mid-span deflections are 
noted and thus the dynamic magnification factors calculated. The number of elements considered for this convergence study are $3,4,5,6$ and 7 . The maximum mid-span deflections are plotted in Figure 6.1 and listed in Table 6.6. The dynamic magnification factors are shown in Figure 6.2 and Table 6.7.

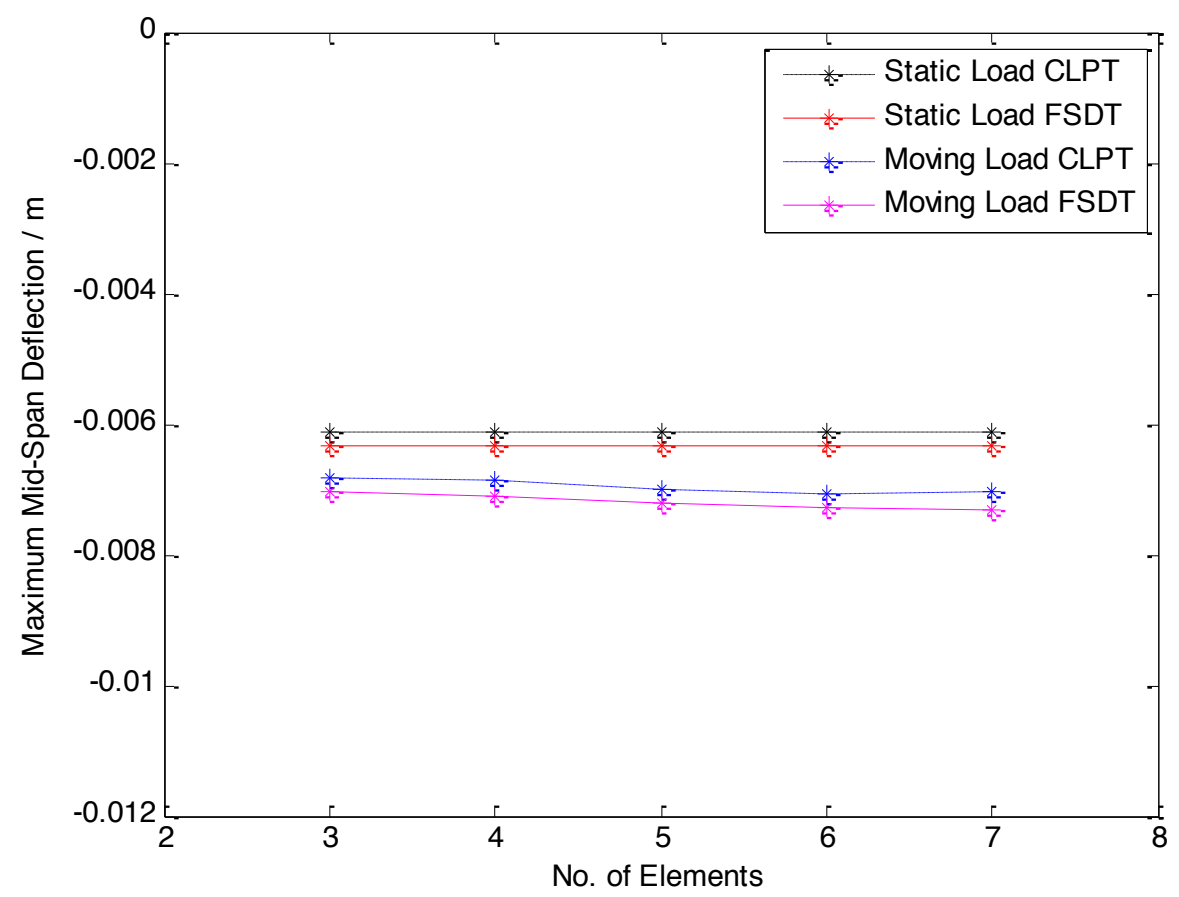

Figure 6.1 Maximum mid-span deflections for 3, 4, 5, 6 and 7 elements 


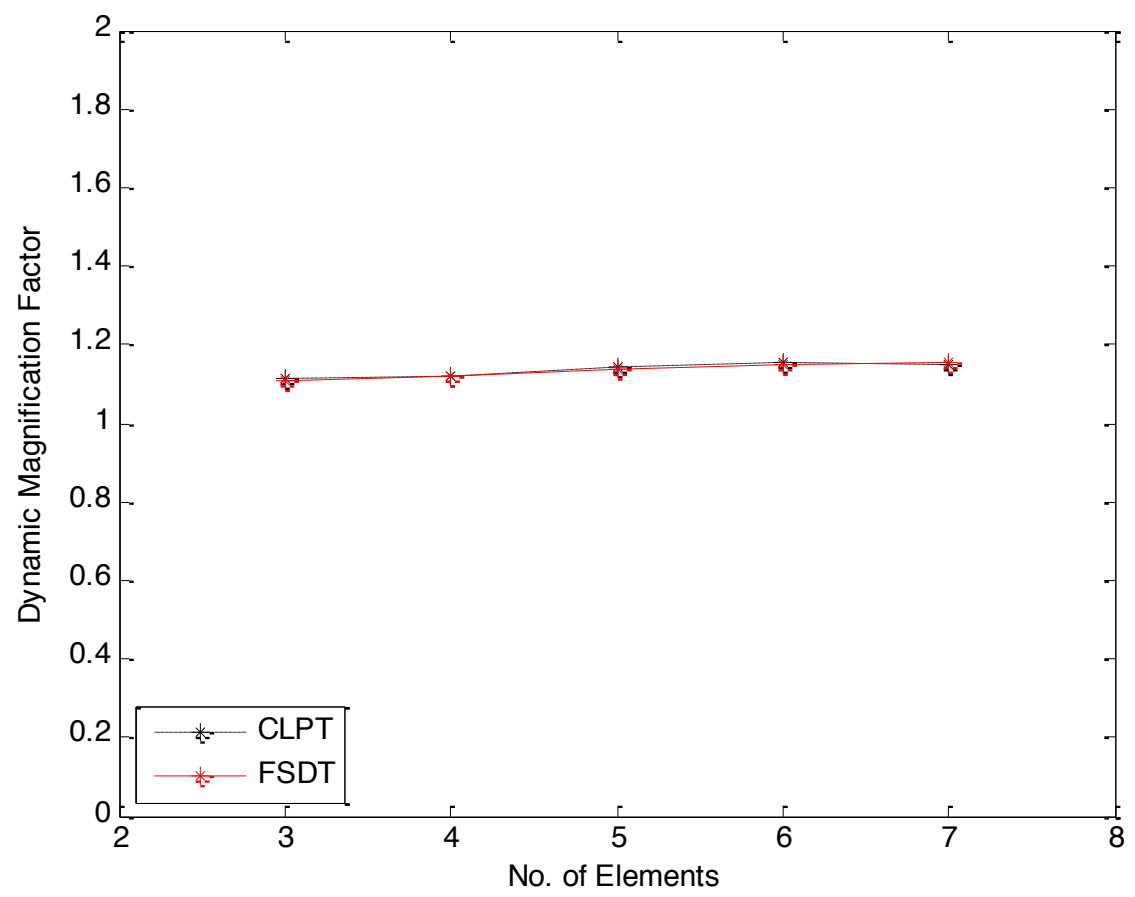

Figure 6.2 Dynamic magnification factors for $3,4,5,6$ and 7 elements

Table 6.6 Maximum mid-span deflections for 3,4,5,6 and 7 elements

\begin{tabular}{|c|c|c|c|c|}
\hline \multirow{2}{*}{$\begin{array}{c}\text { Number of } \\
\text { elements }\end{array}$} & \multicolumn{4}{|c|}{ Maximum mid-span deflections (m) } \\
\cline { 2 - 5 } & \multicolumn{2}{|c|}{ Static analysis } & \multicolumn{2}{c|}{ Dynamic analysis } \\
\cline { 2 - 5 } & CLPT & FSDT & CLPT & FSDT \\
\hline 3 & $-6.1225 \mathrm{E}-03$ & $-6.3313 \mathrm{E}-03$ & $-6.8095 \mathrm{E}-03$ & $-7.0181 \mathrm{E}-03$ \\
\hline 4 & $-6.1237 \mathrm{E}-03$ & $-6.3366 \mathrm{E}-03$ & $-6.8428 \mathrm{E}-03$ & $-7.1066 \mathrm{E}-03$ \\
\hline 5 & $-6.1235 \mathrm{E}-03$ & $-6.3352 \mathrm{E}-03$ & $-7.0056 \mathrm{E}-03$ & $-7.2178 \mathrm{E}-03$ \\
\hline 6 & $-6.1237 \mathrm{E}-03$ & $-6.3377 \mathrm{E}-03$ & $-7.0549 \mathrm{E}-03$ & $-7.2969 \mathrm{E}-03$ \\
\hline 7 & $-6.1237 \mathrm{E}-03$ & $-6.3366 \mathrm{E}-03$ & $-7.0404 \mathrm{E}-03$ & $-7.3039 \mathrm{E}-03$ \\
\hline
\end{tabular}


Table 6.7 Dynamic magnification factors for $3,4,5,6$ and 7 elements

\begin{tabular}{|c|c|c|}
\hline \multirow{2}{*}{ No. of elements } & \multicolumn{2}{|c|}{ Dynamic magnification factors } \\
\cline { 2 - 3 } & CLPT & FSDT \\
\hline 3 & 1.112 & 1.109 \\
\hline 4 & 1.117 & 1.122 \\
\hline 5 & 1.144 & 1.139 \\
\hline 6 & 1.152 & 1.151 \\
\hline 7 & 1.150 & 1.153 \\
\hline
\end{tabular}

After scrutinizing these two figures and tables, it is seen that excellence convergence at 6 elements $(<0.1 \%$ between 6 and 7 elements). The difference in the results between 5 and 6 elements is about $1 \%$ and thus it is decided to use 5 elements for the moving-beam analysis. This is an optimal choice considering accuracy and computational time.

\subsection{Static Analysis}

A static analysis is run first, with a load of $P=-10 \mathrm{kN}$ applied at the midspan of the beam. For dry conditions, the moisture content and the dry roomtemperature are taken as $0 \%$ and $21^{\circ} \mathrm{C}$, respectively; for hygrothermal conditions, the moisture content and the temperature are taken to be $5 \%$ and $52^{\circ} \mathrm{C}$, respectively. The results for three different fiber-volume fractions, $V_{f}$, of $0.52,0.6$ and 0.7 and for three different laminate stacking sequences, $[0 / \pm 20]_{s}$, $[0 / 90 / \pm 45]$ and $[0 / 90 / \pm 30]_{s}$, are listed in Table 6.8 . 
Table 6.8 Mid-span static deflections of various laminate configurations for a glass/epoxy composite beam

\begin{tabular}{|c|c|c|c|c|c|}
\hline \multirow{3}{*}{$\begin{array}{l}\text { Fiber } \\
\text { volume } \\
\text { fraction }\end{array}$} & \multirow{3}{*}{ Lay-up } & \multicolumn{4}{|c|}{ Mid-span deflections (m) } \\
\hline & & \multicolumn{2}{|c|}{ Dry condition } & \multicolumn{2}{|c|}{$\begin{array}{l}\text { Hygrothermal } \\
\text { condition }\end{array}$} \\
\hline & & CLPT & FSDT & CLPT & FSDT \\
\hline \multirow{3}{*}{$V_{f}=0.52$} & {$[0 / 20 /-20]_{s}$} & $-3.3377 \mathrm{E}-3$ & $-3.5282 \mathrm{E}-3$ & $-3.4281 \mathrm{E}-3$ & $-3.7037 \mathrm{E}-3$ \\
\hline & {$[0 / 90 / 45 /-45]_{\top}$} & $-6.1235 E-3$ & $-6.3352 \mathrm{E}-3$ & $-7.6205 E-3$ & $-7.8806 \mathrm{E}-3$ \\
\hline & {$[0 / 90 / 30 /-30]_{s}$} & $-4.1312 E-3$ & $-4.3361 \mathrm{E}-3$ & $-4.3853 \mathrm{E}-3$ & $-4.6498 E-3$ \\
\hline \multirow{3}{*}{$V_{f}=0.6$} & {$[0 / 20 /-20]_{s}$} & $-2.9210 \mathrm{E}-3$ & $-3.0785 E-3$ & $-2.9873 E-3$ & $-3.2138 \mathrm{E}-3$ \\
\hline & {$[0 / 90 / 45 /-45]_{T}$} & $-5.1789 \mathrm{E}-3$ & $-5.3669 E-3$ & $-6.3786 \mathrm{E}-3$ & $-6.6128 \mathrm{E}-3$ \\
\hline & {$[0 / 90 / 30 /-30]_{s}$} & $-3.5869 E-3$ & $-3.7646 E-3$ & $-3.7971 \mathrm{E}-3$ & $-4.0289 E-3$ \\
\hline \multirow{3}{*}{$V_{f}=0.7$} & {$[0 / 20 /-20]_{s}$} & $-2.5197 \mathrm{E}-3$ & $-2.6389 \mathrm{E}-3$ & $-2.5668 \mathrm{E}-3$ & $-2.7357 \mathrm{E}-3$ \\
\hline & {$[0 / 90 / 45 /-45]_{T}$} & $-4.1652 \mathrm{E}-3$ & $-4.3208 E-3$ & $-5.0426 \mathrm{E}-3$ & $-5.2391 \mathrm{E}-3$ \\
\hline & {$[0 / 90 / 30 /-30]_{s}$} & $-3.0432 E-3$ & $-3.1859 E-3$ & $-3.2170 \mathrm{E}-3$ & $-3.4045 E-3$ \\
\hline
\end{tabular}

Note that there's somewhat of a significant difference between the CLPT and FSDT results. This reinforces the notion that transverse shear effects play an important role in composites.

The support reactions at the left and right ends of the beam are listed in Tables 6.96 .10 , respectively. In a statics problem, the reactions are independent of the lay-up or the fiber volume fraction. 
Table 6.9 Support reactions at the left-end of the $[0 / 90 / \pm 45]_{T}$ simplysupported composite beam

\begin{tabular}{|c|c|c|c|c|}
\hline \multicolumn{5}{|c|}{ Reactions at the left-end of the beam } \\
\hline \multicolumn{2}{|c|}{ CLPT } & & \multicolumn{3}{c|}{ FSDT } \\
\hline$w(\mathrm{~N})$ & $w^{y}(\mathrm{Nm})$ & $w_{b}(\mathrm{~N})$ & $w_{s}(\mathrm{~N})$ & $w_{b}^{y}(\mathrm{Nm})$ \\
\hline 5000 & 147 & 5000 & 5000 & 147 \\
\hline
\end{tabular}

Table 6.10 Support reactions at the right-end of the $[0 / 90 / \pm 45]_{T}$ simplysupported composite beam

\begin{tabular}{|c|c|c|c|c|}
\hline \multicolumn{4}{|c|}{ Reactions at the right-end of the beam (N) } \\
\hline \multicolumn{3}{|c|}{ CLPT } & & \multicolumn{3}{c|}{ FSDT } \\
\hline$w(\mathrm{~N})$ & $w^{y}(\mathrm{Nm})$ & $w_{b}(\mathrm{~N})$ & $w_{s}(\mathrm{~N})$ & $w_{b}^{y}(\mathrm{Nm})$ \\
\hline 5000 & -147 & 5000 & 5000 & -147 \\
\hline
\end{tabular}

\subsection{Dynamic Analysis}

For the same fiber volume fractions and laminate stacking sequences, dynamic analyses are performed where a point load of $P=-10 \mathrm{kN}$ moves from the left-end of the simply-supported beam to the right end of the beam at a velocity of $30 \mathrm{~m} / \mathrm{s}$ or $108 \mathrm{kph}$. The maximum dynamic mid-span deflections under dry and hygrothermal conditions are shown in Table 6.11. It can be noted that, as expected, an increase in the fiber volume fraction results in a decrease in the deflection for the same laminate configuration. 
Table 6.11 Maximum mid-span dynamic deflections of various laminate configurations for a glass/epoxy composite beam

\begin{tabular}{|c|c|c|c|c|c|}
\hline \multirow{3}{*}{$\begin{array}{c}\text { Fiber } \\
\text { Volume } \\
\text { Fraction }\end{array}$} & \multirow{3}{*}{ Lay-up } & \multicolumn{4}{|c|}{ Maximum mid-span deflections (m) } \\
\hline & & \multicolumn{2}{|c|}{ Dry Condition } & \multicolumn{2}{|c|}{$\begin{array}{l}\text { Hygrothermal } \\
\text { Condition }\end{array}$} \\
\hline & & CLPT & FSDT & CLPT & FSDT \\
\hline \multirow{3}{*}{$V_{f}=0.52$} & {$[0 / \pm 20]_{s}$} & $-3.4985 \mathrm{E}-3$ & $-3.7084 \mathrm{E}-3$ & $-3.5898 \mathrm{E}-3$ & $-3.9462 \mathrm{E}-3$ \\
\hline & {$[0 / 90 / \pm 45]_{T}$} & $-7.0056 \mathrm{E}-3$ & $-7.2178 \mathrm{E}-3$ & $-8.7608 \mathrm{E}-3$ & $-9.0006 \mathrm{E}-3$ \\
\hline & {$[0 / 90 / \pm 30]_{s}$} & $-4.5626 \mathrm{E}-3$ & $-4.7922 \mathrm{E}-3$ & $-4.8706 \mathrm{E}-3$ & $-5.1400 \mathrm{E}-3$ \\
\hline \multirow{3}{*}{$V_{f}=0.6$} & {$[0 / \pm 20]_{s}$} & $-3.0524 \mathrm{E}-3$ & $-3.2038 E-3$ & $-3.1262 \mathrm{E}-3$ & $-3.3359 \mathrm{E}-3$ \\
\hline & {$[0 / 90 / \pm 45]_{T}$} & $-5.9058 \mathrm{E}-3$ & $-6.1402 E-3$ & $-7.2677 \mathrm{E}-3$ & $-7.5565 \mathrm{E}-3$ \\
\hline & {$[0 / 90 / \pm 30]_{\mathrm{s}}$} & $-3.8825 E-3$ & $-4.1021 E-3$ & $-4.1675 E-3$ & $-4.4371 \mathrm{E} 3$ \\
\hline \multirow{3}{*}{$V_{f}=0.7$} & {$[0 / \pm 20]_{s}$} & $-2.6226 \mathrm{E}-3$ & $-2.7252 \mathrm{E}-3$ & $-2.6700 \mathrm{E}-3$ & $-2.8291 \mathrm{E}-3$ \\
\hline & {$[0 / 90 / \pm 45]_{T}$} & $-4.6243 \mathrm{E}-3$ & $-4.7698 \mathrm{E}-3$ & $-5.7729 \mathrm{E}-3$ & $-6.0051 \mathrm{E}-3$ \\
\hline & {$[0 / 90 / \pm 30]_{\mathrm{s}}$} & $-3.1896 \mathrm{E}-3$ & $-3.3617 \mathrm{E}-3$ & $-3.4268 \mathrm{E}-3$ & $-3.6658 \mathrm{E}-3$ \\
\hline
\end{tabular}

\subsubsection{Dry Condition}

The moisture content and the dry room-temperature are taken to be $0 \%$ and $21^{\circ} \mathrm{C}$, respectively. For each of the different fiber volume fractions, $V_{f}=0.52$, $V_{f}=0.6$ and $V_{f}=0.7$, there are three different lay-ups considered namely $[0 / \pm 20]_{s}$, $[0 / 90 / \pm 45]_{\top}$ and $[0 / 90 / \pm 30]_{s}$.

\subsubsection{Fiber Volume Fraction, $V_{f}=0.52$}

The dynamic mid-span deflections for the three different laminate stacking sequences are plotted in Figures 6.3 - 6.5 and listed in Tables 6.12, 6.15 and 6.18 for both the theories, CLPT and FSDT. The reactions at the left-end of the 
simply-supported beam vary with time and are listed for two lay-ups, namely $[0 / \pm 20]_{S}$ and $[0 / 90 / \pm 45]_{T}$ in Tables 6.13 and 6.16 . Similarly for the right-end, the reactions varying with time for the two lay-ups are listed in Tables 6.14 and 6.17. It is seen, as expected, that as the load moves from the left end to the right-end of the beam, the reactions on the left-end decrease and the reactions on the right end increase. When the load is at any point along the beam, the reactions do not add up to the point load value, since part of it is used for the acceleration of the load. 

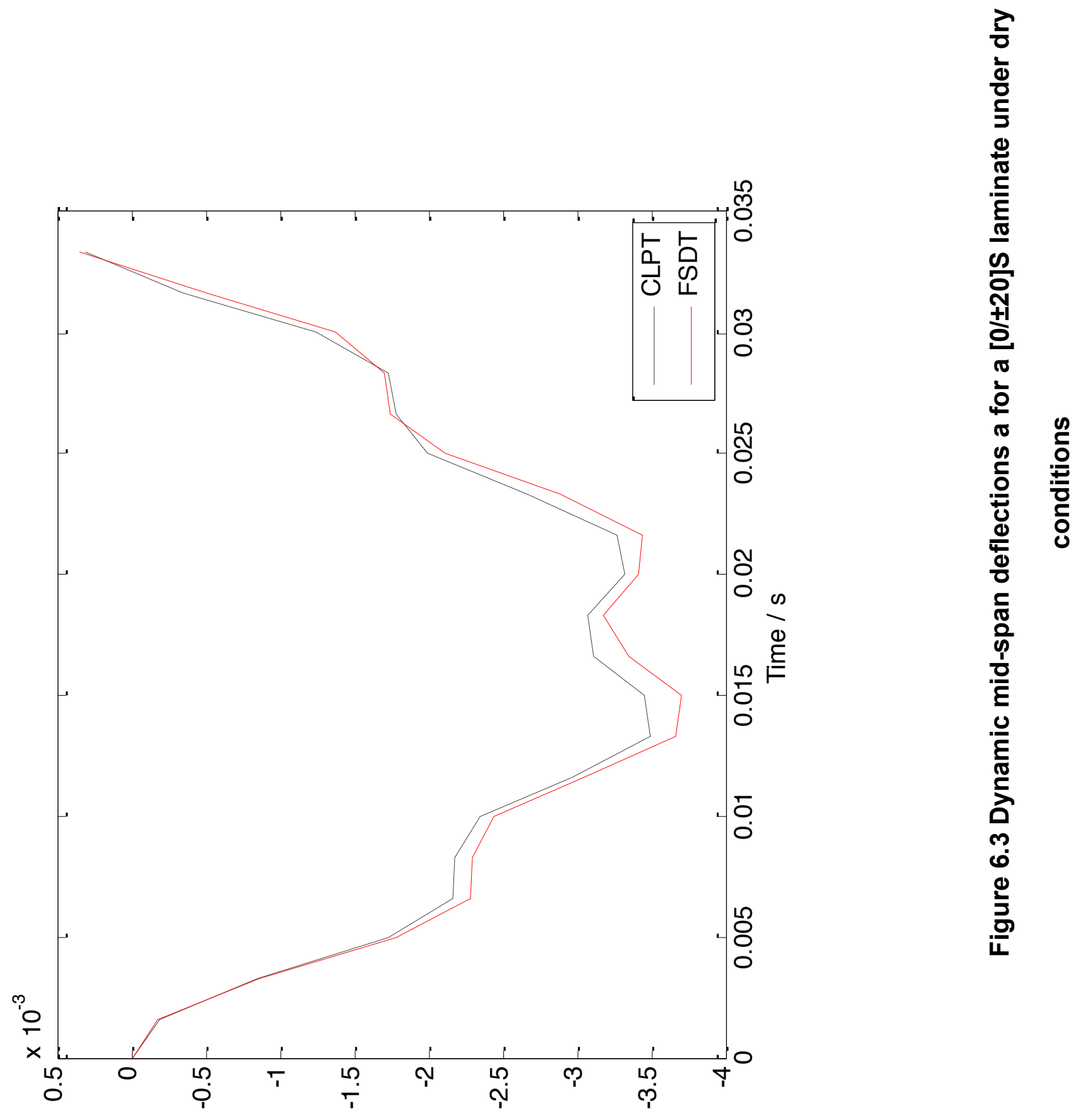
Table 6.12 Dynamic mid-span deflections a for a $[0 / \pm 20]_{s}$ laminate under dry conditions

\begin{tabular}{|c|c|c|}
\hline \multirow{2}{*}{$\begin{array}{c}\text { Time at the end of } \\
\text { each load step (s) }\end{array}$} & \multicolumn{2}{|c|}{ Mid-span dynamic deflections (m) } \\
\cline { 2 - 3 } & CLPT & FSDT \\
\hline 0 & 0 & 0 \\
\hline $1.6667 \mathrm{E}-03$ & $-1.8437 \mathrm{E}-04$ & $-1.8318 \mathrm{E}-04$ \\
\hline $3.3333 \mathrm{E}-03$ & $-8.5311 \mathrm{E}-04$ & $-8.6785 \mathrm{E}-04$ \\
\hline $5.0000 \mathrm{E}-03$ & $-1.7246 \mathrm{E}-03$ & $-1.7885 \mathrm{E}-03$ \\
\hline $6.6667 \mathrm{E}-03$ & $-2.1640 \mathrm{E}-03$ & $-2.2799 \mathrm{E}-03$ \\
\hline $8.3333 \mathrm{E}-03$ & $-2.1725 \mathrm{E}-03$ & $-2.2987 \mathrm{E}-03$ \\
\hline $1.0000 \mathrm{E}-02$ & $-2.3488 \mathrm{E}-03$ & $-2.4363 \mathrm{E}-03$ \\
\hline $1.1667 \mathrm{E}-02$ & $-2.9639 \mathrm{E}-03$ & $-3.0482 \mathrm{E}-03$ \\
\hline $1.3333 \mathrm{E}-02$ & $-3.4985 \mathrm{E}-03$ & $-3.6620 \mathrm{E}-03$ \\
\hline $1.5000 \mathrm{E}-02$ & $-3.4596 \mathrm{E}-03$ & $-3.7084 \mathrm{E}-03$ \\
\hline $1.6667 \mathrm{E}-02$ & $-3.1120 \mathrm{E}-03$ & $-3.3429 \mathrm{E}-03$ \\
\hline $1.8333 \mathrm{E}-02$ & $-3.0696 \mathrm{E}-03$ & $-3.1816 \mathrm{E}-03$ \\
\hline $2.0000 \mathrm{E}-02$ & $-3.3279 \mathrm{E}-03$ & $-3.4096 \mathrm{E}-03$ \\
\hline $2.1667 \mathrm{E}-02$ & $-3.2751 \mathrm{E}-03$ & $-3.4455 \mathrm{E}-03$ \\
\hline $2.3333 \mathrm{E}-02$ & $-2.6618 \mathrm{E}-03$ & $-2.8911 \mathrm{E}-03$ \\
\hline $2.5000 \mathrm{E}-02$ & $-1.9939 \mathrm{E}-03$ & $-2.1117 \mathrm{E}-03$ \\
\hline $2.6667 \mathrm{E}-02$ & $-1.7783 \mathrm{E}-03$ & $-1.7452 \mathrm{E}-03$ \\
\hline $2.8333 \mathrm{E}-02$ & $-1.7264 \mathrm{E}-03$ & $-1.7056 \mathrm{E}-03$ \\
\hline $3.0000 \mathrm{E}-02$ & $-1.2455 \mathrm{E}-03$ & $-1.3702 \mathrm{E}-03$ \\
\hline $3.1667 \mathrm{E}-02$ & $-3.5100 \mathrm{E}-04$ & $-5.0528 \mathrm{E}-04$ \\
\hline $3.3333 \mathrm{E}-02$ & $3.1498 \mathrm{E}-04$ & $3.4440 \mathrm{E}-04$ \\
\hline & & \\
\hline & & \\
\hline
\end{tabular}


Table 6.13 Left-end support reactions a for a $[0 / \pm 20]_{s}$ laminate under dry conditions

\begin{tabular}{|c|c|c|c|c|c|}
\hline \multirow{3}{*}{ Time (s) } & \multicolumn{5}{|c|}{ Reactions at the left-end of the beam } \\
\hline & \multicolumn{2}{|c|}{ CLPT } & \multicolumn{3}{|c|}{ FSDT } \\
\hline & $w(\mathrm{~N})$ & $w^{y}(\mathrm{Nm})$ & $w_{b}(\mathrm{~N})$ & $w_{s}(\mathrm{~N})$ & $w_{b}^{y}(\mathrm{Nm})$ \\
\hline 0 & $0000 E+4$ & 0 & $1.0000 \mathrm{E}+4$ & $1.0000 \mathrm{E}+4$ & 0 \\
\hline $1.6667 \mathrm{E}-3$ & $8.7762 E+3$ & $1250 E+1$ & $8.7313 \mathrm{E}+3$ & 8.7367E+3 & $-1.1010 \mathrm{E}+1$ \\
\hline 3.3 & $E+3$ & , & $9.0038 \mathrm{E}+3$ & $8.9984 \mathrm{E}+3$ & $-3.7583 E+1$ \\
\hline $5.0000 \mathrm{E}-3$ & $8.7882 E+3$ & $-7.2326 \mathrm{E}+1$ & $8.7070 \mathrm{E}+3$ & $8.7125 E+3$ & $-7.1946 \mathrm{E}+1$ \\
\hline $6.6667 \mathrm{E}-3$ & $8.7506 \mathrm{E}+3$ & $87315 \mathrm{~F}+1$ & $8.8583 \mathrm{E}+3$ & $8.8477 \mathrm{E}+3$ & $-8.8382 E+1$ \\
\hline 8.3333E-3 & $E+3$ & $344 \mathrm{E}$ & $7.1569 \mathrm{E}+3$ & $7.1653 \mathrm{E}+3$ & $-8.7446 \mathrm{E} 1$ \\
\hline $1.0000 \mathrm{E}-2$ & $6.5012 \mathrm{E}+3$ & $-9.0302 E+1$ & $6.5144 \mathrm{E}+3$ & $6.5094 \mathrm{E}+3$ & $-8.9886 \mathrm{E}+1$ \\
\hline 1.16 & $56 \varsigma$ & $-1.1127 \mathrm{E}+2$ & 3 & 42 & -1. \\
\hline 1.3333E-2 & $6.6619 \mathrm{E}+3$ & $-1.2924 \mathrm{E}+2$ & $6.7337 \mathrm{E}+3$ & $6.7237 \mathrm{E}+3$ & $-1.2890 \mathrm{E}+2$ \\
\hline $1.5000 \mathrm{E}-2$ & $5.8055 \mathrm{E}+3$ & $-1.2624 \mathrm{E}+2$ & $5.8040 \mathrm{E}+3$ & $5.8109 \mathrm{E}+3$ & $-1.2868 \mathrm{E}+2$ \\
\hline $1.6667 \mathrm{E}-2$ & $4.6585 \mathrm{E}+3$ & $-1.1202 E+2$ & $8894 \mathrm{E}+3$ & 4.881 & $-1.1378 E+2$ \\
\hline 1.8333E-2 & $3.8969 \mathrm{E}+3$ & $-1.1172 E+2$ & $3.6795 E+3$ & $3.6918 \mathrm{E}+3$ & $-1.0986 E+2$ \\
\hline $2.0000 \mathrm{E}-2$ & $4.5618 \mathrm{E}+3$ & $-1.2229 \mathrm{E}+2$ & $4.4769 \mathrm{E}+3$ & $4.4662 \mathrm{E}+3$ & $-1.1932 \mathrm{E}+2$ \\
\hline $2.1667 \mathrm{E}-2$ & $3.9385 E+3$ & $-1.2356 \mathrm{E}+2$ & $3.9699 \mathrm{E}+3$ & $3.9764 \mathrm{E}+3$ & $-1.2406 \mathrm{E}+2$ \\
\hline 2.3333E-2 & $3.1952 E+3$ & $-1.0195 E+2$ & $3.3433 E+3$ & $3.3352 E+3$ & $-1.0625 E+2$ \\
\hline $2.5000 \mathrm{E}-2$ & $1.8537 \mathrm{E}+3$ & $-7.9507 \mathrm{E}+1$ & $1.9928 \mathrm{E}+3$ & $2.0003 E+3$ & $-8.0471 \mathrm{E}+1$ \\
\hline 2.6667E-2 & $1.7319 \mathrm{E}+3$ & $-7.3094 \mathrm{E}+1$ & $1.4963 \mathrm{E}+3$ & $1.4935 \mathrm{E}+3$ & $-6.9558 E+1$ \\
\hline $2.8333 \mathrm{E}-2$ & $2.1417 \mathrm{E}+3$ & $-7.1775 E+1$ & $1.9281 \mathrm{E}+3$ & $1.9313 E+3$ & $-6.8232 \mathrm{E}+1$ \\
\hline $3.0000 \mathrm{E}-2$ & $1.3586 \mathrm{E}+3$ & $-5.3779 \mathrm{E}+1$ & $1.6410 \mathrm{E}+3$ & $1.6331 \mathrm{E}+3$ & $-5.6555 E+1$ \\
\hline $3.1667 \mathrm{E}-2$ & $3.1684 \mathrm{E}+2$ & $-1.7079 \mathrm{E}+1$ & $3.4522 \mathrm{E}+2$ & $3.5236 \mathrm{E}+2$ & $-2.2178 \mathrm{E}+1$ \\
\hline $3.3333 \mathrm{E}-2$ & $-6.2018 \mathrm{E}+2$ & $1.1697 \mathrm{E}+1$ & $-3.8220 E+2$ & $-3.8848 \mathrm{E}+2$ & $1.2168 \mathrm{E}+1$ \\
\hline
\end{tabular}


Table 6.14 Right-end support reactions a for a $[0 / \pm 20]_{s}$ laminate under dry conditions

\begin{tabular}{|c|c|c|c|c|c|}
\hline \multirow{2}{*}{ Time (s) } & \multicolumn{5}{|c}{ Reactions at the right-end of the beam } \\
\cline { 2 - 6 } & \multicolumn{2}{|c}{ CLPT } & \multicolumn{3}{c|}{ FSDT } \\
\cline { 2 - 6 } & $w(N)$ & $w^{y}(N m)$ & $w_{b}(N)$ & $w_{s}(N)$ & $w_{b}^{y}(N m)$ \\
\hline 0 & 0 & 0 & 0 & 0 & 0 \\
\hline $1.6667 \mathrm{E}-3$ & $-3.0474 \mathrm{E}+1$ & $1.0859 \mathrm{E}+1$ & $-3.1604 \mathrm{E}+1$ & $-3.0308 \mathrm{E}+1$ & $1.0624 \mathrm{E}+1$ \\
\hline $3.3333 \mathrm{E}-3$ & $6.2225 \mathrm{E}+2$ & $3.8942 \mathrm{E}+1$ & $5.8051 \mathrm{E}+2$ & $5.8307 \mathrm{E}+2$ & $3.8349 \mathrm{E}+1$ \\
\hline $5.0000 \mathrm{E}-3$ & $2.1302 \mathrm{E}+3$ & $7.1455 \mathrm{E}+1$ & $2.1090 \mathrm{E}+3$ & $2.1062 \mathrm{E}+3$ & $7.1142 \mathrm{E}+1$ \\
\hline $6.6667 \mathrm{E}-3$ & $2.4684 \mathrm{E}+3$ & $8.8153 \mathrm{E}+1$ & $2.5450 \mathrm{E}+3$ & $2.5427 \mathrm{E}+3$ & $8.9108 \mathrm{E}+1$ \\
\hline $8.3333 \mathrm{E}-3$ & $2.2210 \mathrm{E}+3$ & $8.5781 \mathrm{E}+1$ & $2.2356 \mathrm{E}+3$ & $2.2378 \mathrm{E}+3$ & $8.7018 \mathrm{E}+1$ \\
\hline $1.0000 \mathrm{E}-2$ & $2.5613 \mathrm{E}+3$ & $9.0620 \mathrm{E} 1$ & $2.5781 \mathrm{E}+3$ & $2.5779 \mathrm{E} 3$ & $9.0091 \mathrm{E}+1$ \\
\hline $1.1667 \mathrm{E}-2$ & $3.3688 \mathrm{E}+3$ & $1.1118 \mathrm{E}+2$ & $3.2535 \mathrm{E}+3$ & $3.2566 \mathrm{E}+3$ & $1.0922 \mathrm{E}+2$ \\
\hline $1.3333 \mathrm{E}-2$ & $4.8548 \mathrm{E}+3$ & $1.2928 \mathrm{E}+2$ & $4.8019 \mathrm{E}+3$ & $4.7976 \mathrm{E}+3$ & $1.2899 \mathrm{E}+2$ \\
\hline $1.5000 \mathrm{E}-2$ & $4.7017 \mathrm{E}+3$ & $1.2610 \mathrm{E}+2$ & $4.9108 \mathrm{E}+3$ & $4.9091 \mathrm{E}+3$ & $1.2844 \mathrm{E}+2$ \\
\hline $1.6667 \mathrm{E}-2$ & $4.5800 \mathrm{E}+3$ & $1.1238 \mathrm{E}+2$ & $4.5516 \mathrm{E}+3$ & $4.5549 \mathrm{E}+3$ & $1.1423 \mathrm{E}+2$ \\
\hline $1.8333 \mathrm{E}-2$ & $5.1709 \mathrm{E}+3$ & $1.1114 \mathrm{E}+2$ & $5.1901 \mathrm{E}+3$ & $5.1887 \mathrm{E} 3$ & $1.0932 \mathrm{E}+2$ \\
\hline $2.0000 \mathrm{E}-2$ & $6.1643 \mathrm{E}+3$ & $1.2296 \mathrm{E}+2$ & $5.9427 \mathrm{E}+3$ & $5.9461 \mathrm{E}+3$ & $1.1975 \mathrm{E}+2$ \\
\hline $2.1667 \mathrm{E}-2$ & $7.3846 \mathrm{E}+3$ & $1.2297 \mathrm{E}+2$ & $7.4119 \mathrm{E}+3$ & $7.4055 \mathrm{E}+3$ & $1.2392 \mathrm{E}+2$ \\
\hline $2.3333 \mathrm{E}-2$ & $6.8620 \mathrm{E}+3$ & $1.0223 \mathrm{E}+2$ & $7.1502 \mathrm{E}+3$ & $7.1513 \mathrm{E}+3$ & $1.0590 \mathrm{E}+2$ \\
\hline $2.5000 \mathrm{E}-2$ & $7.0415 \mathrm{E}+3$ & $7.9636 \mathrm{E}+1$ & $6.9797 \mathrm{E}+3$ & $6.9814 \mathrm{E}+3$ & $8.1257 \mathrm{E}+1$ \\
\hline $2.6667 \mathrm{E}-2$ & $7.7748 \mathrm{E}+3$ & $7.2456 \mathrm{E}+1$ & $7.7091 \mathrm{E} 3$ & $7.7092 \mathrm{E}+3$ & $6.8398 \mathrm{E}+1$ \\
\hline $2.8333 \mathrm{E}-2$ & $8.9756 \mathrm{E}+3$ & $7.2732 \mathrm{E}+1$ & $8.7275 \mathrm{E}+3$ & $8.7279 \mathrm{E}+3$ & $6.9442 \mathrm{E}+1$ \\
\hline $3.0000 \mathrm{E}-2$ & $9.6066 \mathrm{E}+3$ & $5.2599 \mathrm{E}+1$ & $9.7580 \mathrm{E}+3$ & $9.7533 \mathrm{E}+3$ & $5.5434 \mathrm{E}+1$ \\
\hline $3.1667 \mathrm{E}-2$ & $9.1490 \mathrm{E}+3$ & $1.8131 \mathrm{E}+1$ & $9.4581 \mathrm{E}+3$ & $9.4591 \mathrm{E}+3$ & $2.2927 \mathrm{E}+1$ \\
\hline $3.3333 \mathrm{E}-2$ & $9.4050 \mathrm{E}+3$ & $-1.2561 \mathrm{E}+1$ & $9.3242 \mathrm{E}+3$ & $9.3260 \mathrm{E}+3$ & $-1.2642 \mathrm{E}+1$ \\
\hline
\end{tabular}




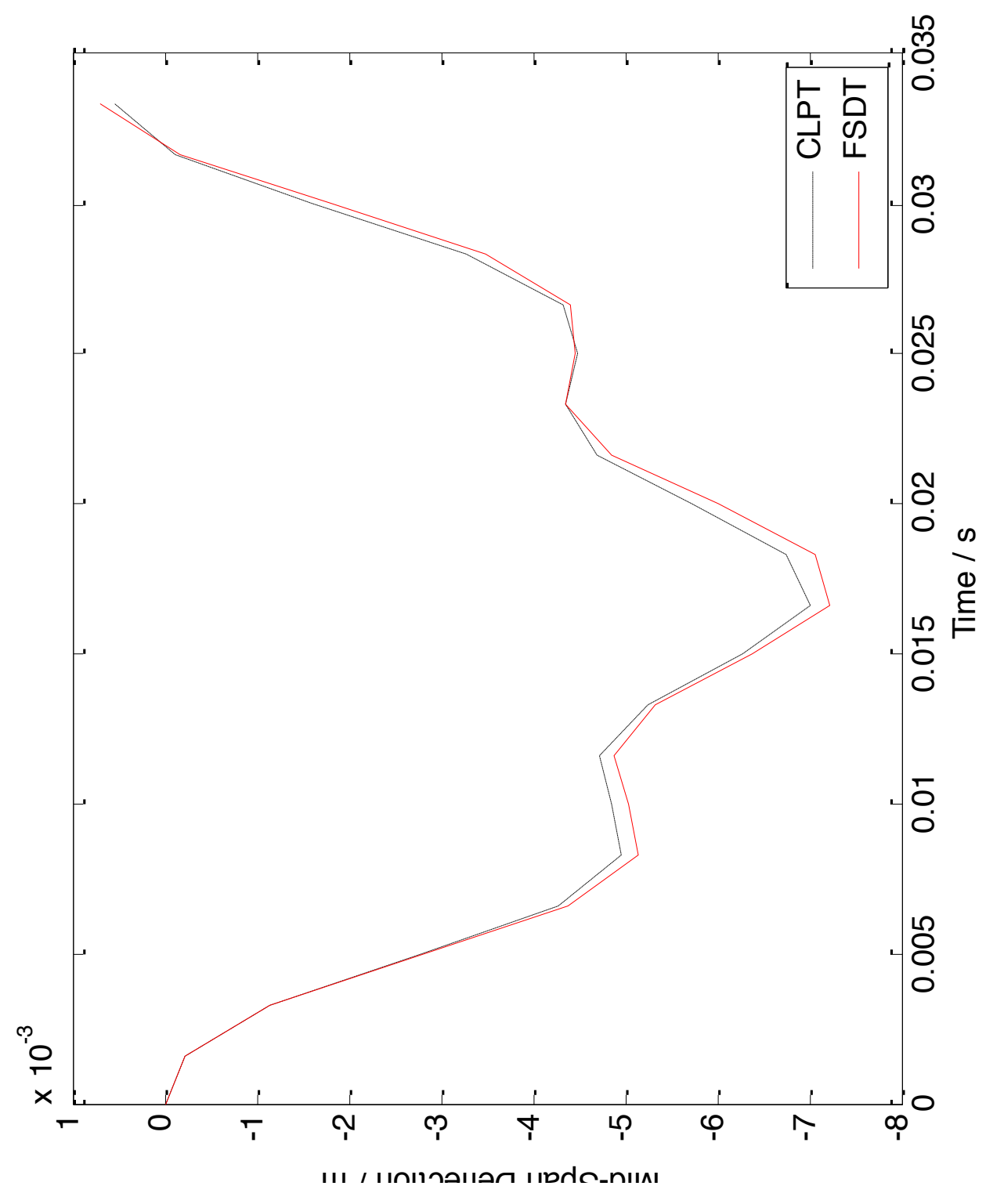

공

$\stackrel{0}{\pi}$

$\frac{5}{\frac{1}{\sigma}}$

둔

(ర)

ธั

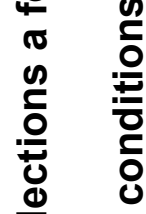

$\frac{1}{0}$

듬

움

ํㅗㄹ

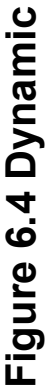


Table 6.15 Dynamic mid-span deflections a for a $[0 / 90 / \pm 45]_{T}$ laminate under dry conditions

\begin{tabular}{|c|c|c|}
\hline \multirow{2}{*}{$\begin{array}{l}\text { Time at the end of } \\
\text { each load step (s) }\end{array}$} & \multicolumn{2}{|c|}{ Mid-span dynamic deflections (m) } \\
\hline & CLPT & FSDT \\
\hline 0 & 0 & 0 \\
\hline 1.6667E-03 & $-2.1452 E-04$ & $-2.1121 \mathrm{E}-04$ \\
\hline 3.3333E-03 & $-1.1440 \mathrm{E}-03$ & $-1.1462 E-03$ \\
\hline $5.0000 \mathrm{E}-03$ & $-2.7633 E-03$ & $-2.8025 \mathrm{E}-03$ \\
\hline $6.6667 \mathrm{E}-03$ & $-4.2716 \mathrm{E}-03$ & $-4.3737 \mathrm{E}-03$ \\
\hline 8.3333E-03 & $-4.9599 \mathrm{E}-03$ & $-5.1316 \mathrm{E}-03$ \\
\hline 1.0000E-02 & $-4.8504 \mathrm{E}-03$ & $-5.0447 \mathrm{E}-03$ \\
\hline 1.1667E-02 & $-4.7231 \mathrm{E}-03$ & $-4.8777 \mathrm{E}-03$ \\
\hline 1.3333E-02 & $-5.2369 \mathrm{E}-03$ & $-5.3410 \mathrm{E}-03$ \\
\hline $1.5000 \mathrm{E}-02$ & $-6.2678 E-03$ & $-6.3779 \mathrm{E}-03$ \\
\hline 1.6667E-02 & $-7.0056 \mathrm{E}-03$ & $-7.2178 \mathrm{E}-03$ \\
\hline 1.8333E-02 & $-6.7615 E-03$ & $-7.0576 \mathrm{E}-03$ \\
\hline $2.0000 \mathrm{E}-02$ & $-5.7213 E-03$ & $-6.0198 E-03$ \\
\hline $2.1667 \mathrm{E}-02$ & $-4.6892 \mathrm{E}-03$ & $-4.8626 \mathrm{E}-03$ \\
\hline 2.3333E-02 & $-4.3462 E-03$ & $-4.3611 \mathrm{E}-03$ \\
\hline $2.5000 \mathrm{E}-02$ & $-4.4903 \mathrm{E}-03$ & $-4.4586 \mathrm{E}-03$ \\
\hline 2.6667E-02 & $-4.3333 \mathrm{E}-03$ & $-4.3979 \mathrm{E}-03$ \\
\hline 2.8333E-02 & $-3.2822 E-03$ & $-3.4946 \mathrm{E}-03$ \\
\hline $3.0000 \mathrm{E}-02$ & $-1.5917 \mathrm{E}-03$ & $-1.8088 \mathrm{E}-03$ \\
\hline 3.1667E-02 & $-1.2853 E-04$ & $-1.7948 \mathrm{E}-04$ \\
\hline 3.3333E-02 & 5.3526E-04 & 7.0174E-04 \\
\hline
\end{tabular}


Table 6.16 Left-end support reactions a for a $[0 / 90 / \pm 45]_{\mathrm{T}}$ laminate under dry conditions

\begin{tabular}{|c|c|c|c|c|c|}
\hline \multirow{2}{*}{ Time (s) } & \multicolumn{5}{|c}{ Reactions at the left-end of the beam } \\
\cline { 2 - 6 } & \multicolumn{2}{|c}{ CLPT } & \multicolumn{3}{c|}{ FSDT } \\
\cline { 2 - 6 } & $w(N)$ & $w^{y}(N m)$ & $w_{b}(N)$ & $w_{s}(N)$ & $w_{b}^{y}(N m)$ \\
\hline 0 & $1.0000 \mathrm{E}+4$ & 0 & $1.0000 \mathrm{E}+4$ & $1.0000 \mathrm{E}+4$ & 0 \\
\hline $1.6667 \mathrm{E}-3$ & $8.5628 \mathrm{E}+3$ & $1.0276 \mathrm{E}+1$ & $8.5222 \mathrm{E}+3$ & $8.5304 \mathrm{E}+3$ & $1.0118 \mathrm{E}+1$ \\
\hline $3.3333 \mathrm{E}-3$ & $8.6392 \mathrm{E}+3$ & $3.6143 \mathrm{E}+1$ & $8.6809 \mathrm{E}+3$ & $8.6731 \mathrm{E}+3$ & $3.5702 \mathrm{E}+1$ \\
\hline $5.0000 \mathrm{E}-3$ & $8.3305 \mathrm{E}+3$ & $7.7298 \mathrm{E}+1$ & $8.2505 \mathrm{E}+3$ & $8.2611 \mathrm{E}+3$ & $7.6501 \mathrm{E}+1$ \\
\hline $6.6667 \mathrm{E}-3$ & $9.0072 \mathrm{E}+3$ & $1.1433 \mathrm{E}+2$ & $9.0425 \mathrm{E}+3$ & $9.0282 \mathrm{E}+3$ & $1.1425 \mathrm{E}+2$ \\
\hline $8.3333 \mathrm{E}-3$ & $8.2933 \mathrm{E}+3$ & $1.2920 \mathrm{E}+2$ & $8.2940 \mathrm{E}+3$ & $8.3003 \mathrm{E}+3$ & $1.3017 \mathrm{E}+2$ \\
\hline $1.0000 \mathrm{E}-2$ & $6.9877 \mathrm{E}+3$ & $1.2352 \mathrm{E}+2$ & $7.1273 \mathrm{E}+3$ & $7.1168 \mathrm{E}+3$ & $1.2511 \mathrm{E}+2$ \\
\hline $1.1667 \mathrm{E}-2$ & $5.7729 \mathrm{E}+3$ & $1.1746 \mathrm{E}+2$ & $5.6886 \mathrm{E}+3$ & $5.7029 \mathrm{E}+3$ & $1.1806 \mathrm{E}+2$ \\
\hline $1.3333 \mathrm{E}-2$ & $5.6230 \mathrm{E}+3$ & $1.2692 \mathrm{E}+2$ & $5.6842 \mathrm{E}+3$ & $5.6728 \mathrm{E}+3$ & $1.2553 \mathrm{E}+2$ \\
\hline $1.5000 \mathrm{E}-2$ & $5.4503 \mathrm{E}+3$ & $1.5205 \mathrm{E}+2$ & $5.2776 \mathrm{E}+3$ & $5.2918 \mathrm{E}+3$ & $1.4987 \mathrm{E}+2$ \\
\hline $1.6667 \mathrm{E}-2$ & $6.2067 \mathrm{E}+3$ & $1.6855 \mathrm{E}+2$ & $6.1921 \mathrm{E}+3$ & $6.1755 \mathrm{E}+3$ & $1.6792 \mathrm{E}+2$ \\
\hline $1.8333 \mathrm{E}-2$ & $5.1083 \mathrm{E}+3$ & $1.6452 \mathrm{E}+2$ & $5.2313 \mathrm{E}+3$ & $5.2384 \mathrm{E}+3$ & $1.6641 \mathrm{E}+2$ \\
\hline $2.0000 \mathrm{E}-2$ & $3.8887 \mathrm{E}+3$ & $1.3916 \mathrm{E}+2$ & $3.9820 \mathrm{E}+3$ & $3.9743 \mathrm{E}+3$ & $1.4243 \mathrm{E}+2$ \\
\hline $2.1667 \mathrm{E}-2$ & $2.9363 \mathrm{E}+3$ & $1.1662 \mathrm{E}+2$ & $2.9371 \mathrm{E}+3$ & $2.9467 \mathrm{E}+3$ & $1.1744 \mathrm{E}+2$ \\
\hline $2.3333 \mathrm{E}-2$ & $2.2925 \mathrm{E}+3$ & $1.1079 \mathrm{E}+2$ & $2.3376 \mathrm{E}+3$ & $2.3319 \mathrm{E}+3$ & $1.0858 \mathrm{E}+2$ \\
\hline $2.5000 \mathrm{E}-2$ & $2.8192 \mathrm{E}+3$ & $1.1730 \mathrm{E}+2$ & $2.4467 \mathrm{E}+3$ & $2.4576 \mathrm{E}+3$ & $1.1339 \mathrm{E}+2$ \\
\hline $2.6667 \mathrm{E}-2$ & $3.0483 \mathrm{E}+3$ & $1.1607 \mathrm{E}+2$ & $3.2048 \mathrm{E}+3$ & $3.1877 \mathrm{E}+3$ & $1.1524 \mathrm{E}+2$ \\
\hline $2.8333 \mathrm{E}-2$ & $1.8489 \mathrm{E}+3$ & $9.0085 \mathrm{E}+1$ & $1.8774 \mathrm{E}+3$ & $1.8886 \mathrm{E}+3$ & $9.2956 \mathrm{E}+1$ \\
\hline $3.0000 \mathrm{E}-2$ & $1.0531 \mathrm{E}+3$ & $4.7985 \mathrm{E}+1$ & $1.2125 \mathrm{E}+3$ & $1.2010 \mathrm{E}+3$ & $5.2694 \mathrm{E}+1$ \\
\hline $3.1667 \mathrm{E}-2$ & $-4.9395 \mathrm{E}+2$ & $7.4834 \mathrm{E}+0$ & $-3.4285 \mathrm{E}+2$ & $-3.3172 \mathrm{E}+2$ & $8.5932 \mathrm{E}+0$ \\
\hline $3.3333 \mathrm{E}-2$ & $-5.5749 \mathrm{E}+2$ & $-1.2817 \mathrm{E}+1$ & $-7.8481 \mathrm{E}+2$ & $-7.8733 \mathrm{E}+2$ & $-1.6528 \mathrm{E}+1$ \\
\hline
\end{tabular}


Table 6.17 Right-end support reactions a for a $[0 / 90 / \pm 45]_{\mathrm{T}}$ laminate under dry conditions

\begin{tabular}{|r|c|c|c|c|c|}
\hline \multirow{2}{*}{ Time (s) } & \multicolumn{5}{|c}{ Reactions at the right-end of the beam } \\
\cline { 2 - 6 } & \multicolumn{2}{|c}{ CLPT } & \multicolumn{3}{c|}{ FSDT } \\
\cline { 2 - 6 } & $w(N)$ & $w^{y}(\mathrm{Nm})$ & $w_{b}(\mathrm{~N})$ & $w_{s}(\mathrm{~N})$ & $w_{b}^{y}(\mathrm{Nm})$ \\
\hline 0 & 0 & 0 & 0 & 0 & 0 \\
\hline $1.6667 \mathrm{E}-3$ & $-1.0843 \mathrm{E}+2$ & $-9.9150 \mathrm{E}+0$ & $-1.0493 \mathrm{E}+2$ & $-1.0374 \mathrm{E}+2$ & $-9.7622 \mathrm{E}+0$ \\
\hline $3.3333 \mathrm{E}-3$ & $1.3047 \mathrm{E}+2$ & $-3.6811 \mathrm{E}+1$ & $1.0709 \mathrm{E}+2$ & $1.1176 \mathrm{E}+2$ & $-3.6347 \mathrm{E}+1$ \\
\hline $5.0000 \mathrm{E}-3$ & $1.6628 \mathrm{E}+3$ & $-7.6698 \mathrm{E}+1$ & $1.6108 \mathrm{E}+3$ & $1.6107 \mathrm{E}+3$ & $-7.5950 \mathrm{E}+1$ \\
\hline $6.6667 \mathrm{E}-3$ & $2.9226 \mathrm{E}+3$ & $-1.1478 \mathrm{E}+2$ & $2.9540 \mathrm{E}+3$ & $2.9484 \mathrm{E}+3$ & $-1.1464 \mathrm{E}+2$ \\
\hline $8.3333 \mathrm{E}-3$ & $3.0446 \mathrm{E}+3$ & $-1.2899 \mathrm{E}+2$ & $3.0598 \mathrm{E}+3$ & $3.0605 \mathrm{E}+3$ & $-1.3001 \mathrm{E}+2$ \\
\hline $1.0000 \mathrm{E}-2$ & $3.2445 \mathrm{E}+3$ & $-1.2371 \mathrm{E}+2$ & $3.2896 \mathrm{E}+3$ & $3.2863 \mathrm{E}+3$ & $-1.2529 \mathrm{E}+2$ \\
\hline $1.1667 \mathrm{E}-2$ & $2.6715 \mathrm{E}+3$ & $-1.1714 \mathrm{E}+2$ & $2.7687 \mathrm{E}+3$ & $2.7717 \mathrm{E}+3$ & $-1.1773 \mathrm{E}+2$ \\
\hline $1.3333 \mathrm{E}-2$ & $3.3449 \mathrm{E}+3$ & $-1.2749 \mathrm{E}+2$ & $3.1884 \mathrm{E}+3$ & $3.1945 \mathrm{E}+3$ & $-1.2609 \mathrm{E}+2$ \\
\hline $1.5000 \mathrm{E}-2$ & $4.9832 \mathrm{E}+3$ & $-1.5132 \mathrm{E}+2$ & $4.9591 \mathrm{E}+3$ & $4.9528 \mathrm{E}+3$ & $-1.4925 \mathrm{E}+2$ \\
\hline $1.6667 \mathrm{E}-2$ & $5.6310 \mathrm{E}+3$ & $-1.6921 \mathrm{E}+2$ & $5.6100 \mathrm{E}+3$ & $5.6120 \mathrm{E}+3$ & $-1.6835 \mathrm{E}+2$ \\
\hline $1.8333 \mathrm{E}-2$ & $6.4600 \mathrm{E}+3$ & $-1.6416 \mathrm{E}+2$ & $6.4612 \mathrm{E}+3$ & $6.4553 \mathrm{E}+3$ & $-1.6638 \mathrm{E}+2$ \\
\hline $2.0000 \mathrm{E}-2$ & $5.9174 \mathrm{E}+3$ & $-1.3908 \mathrm{E}+2$ & $6.1551 \mathrm{E}+3$ & $6.1544 \mathrm{E}+3$ & $-1.4204 \mathrm{E}+2$ \\
\hline $2.1667 \mathrm{E}-2$ & $5.6724 \mathrm{E}+3$ & $-1.1703 \mathrm{E}+2$ & $5.6443 \mathrm{E}+3$ & $5.6494 \mathrm{E}+3$ & $-1.1804 \mathrm{E}+2$ \\
\hline $2.3333 \mathrm{E}-2$ & $6.6262 \mathrm{E}+3$ & $-1.1023 \mathrm{E}+2$ & $6.5262 \mathrm{E}+3$ & $6.5258 \mathrm{E}+3$ & $-1.0799 \mathrm{E}+2$ \\
\hline $2.5000 \mathrm{E}-2$ & $7.7639 \mathrm{E}+3$ & $-1.1773 \mathrm{E}+2$ & $7.6572 \mathrm{E}+3$ & $7.6582 \mathrm{E}+3$ & $-1.1377 \mathrm{E}+2$ \\
\hline $2.6667 \mathrm{E}-2$ & $8.8415 \mathrm{E}+3$ & $-1.1578 \mathrm{E}+2$ & $8.7800 \mathrm{E}+3$ & $8.7755 \mathrm{E}+3$ & $-1.1497 \mathrm{E}+2$ \\
\hline $2.8333 \mathrm{E}-2$ & $9.3116 \mathrm{E}+3$ & $-9.0240 \mathrm{E}+1$ & $9.3745 \mathrm{E}+3$ & $9.3725 \mathrm{E}+3$ & $-9.3223 \mathrm{E}+1$ \\
\hline $3.0000 \mathrm{E}-2$ & $8.6950 \mathrm{E}+3$ & $-4.7660 \mathrm{E}+1$ & $9.0462 \mathrm{E}+3$ & $9.0423 \mathrm{E}+3$ & $-5.2130 \mathrm{E}+1$ \\
\hline $3.1667 \mathrm{E}-2$ & $8.6144 \mathrm{E}+3$ & $-8.0410 \mathrm{E}+0$ & $8.4930 \mathrm{E}+3$ & $8.5012 \mathrm{E}+3$ & $-9.3899 \mathrm{E}+0$ \\
\hline $3.3333 \mathrm{E}-2$ & $9.6915 \mathrm{E}+3$ & $1.3759 \mathrm{E}+1$ & $9.6200 \mathrm{E}+3$ & $9.6163 \mathrm{E}+3$ & $1.7535 \mathrm{E}+01$ \\
\hline
\end{tabular}




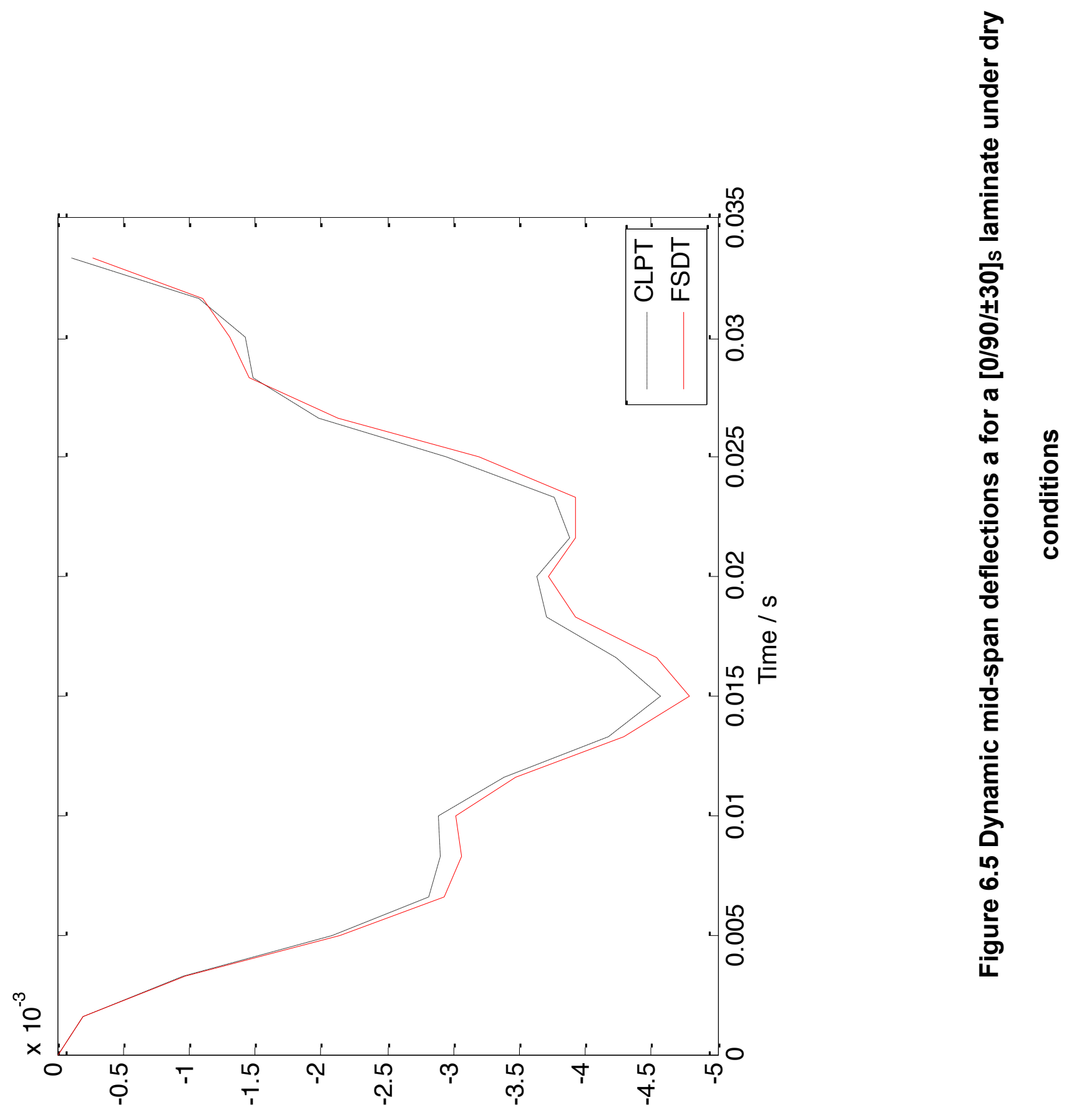


Table 6.18 Dynamic mid-span deflections a for a $[0 / 90 / \pm 30]_{s}$ laminate under dry conditions

\begin{tabular}{|c|c|c|}
\hline \multirow{2}{*}{$\begin{array}{l}\text { Time at the end of } \\
\text { each load step (s) }\end{array}$} & \multicolumn{2}{|c|}{ Mid-span dynamic deflections (m) } \\
\hline & CLPT & FSDT \\
\hline 0 & 0 & 0 \\
\hline 1.6667E-03 & $-1.9751 \mathrm{E}-04$ & $-1.9536 \mathrm{E}-04$ \\
\hline 3.3333E-03 & $-9.6198 E-04$ & $-9.7247 \mathrm{E}-04$ \\
\hline $5.0000 \mathrm{E}-03$ & $-2.0783 E-03$ & $-2.1366 \mathrm{E}-03$ \\
\hline $6.6667 \mathrm{E}-03$ & $-2.8081 \mathrm{E}-03$ & $-2.9291 \mathrm{E}-03$ \\
\hline 8.3333E-03 & $-2.9026 \mathrm{E}-03$ & $-3.0583 E-03$ \\
\hline 1.0000E-02 & $-2.8911 \mathrm{E}-03$ & $-3.0164 \mathrm{E}-03$ \\
\hline 1.1667E-02 & $-3.3801 \mathrm{E}-03$ & $-3.4657 \mathrm{E}-03$ \\
\hline 1.3333E-02 & $-4.1758 \mathrm{E}-03$ & $-4.2970 \mathrm{E}-03$ \\
\hline $1.5000 \mathrm{E}-02$ & $-4.5626 \mathrm{E}-03$ & $-4.7922 \mathrm{E}-03$ \\
\hline 1.6667E-02 & $-4.2337 E-03$ & $-4.5375 \mathrm{E}-03$ \\
\hline 1.8333E-02 & $-3.7119 E-03$ & $-3.9292 \mathrm{E}-03$ \\
\hline $2.0000 \mathrm{E}-02$ & $-3.6342 E-03$ & $-3.7182 \mathrm{E}-03$ \\
\hline $2.1667 \mathrm{E}-02$ & $-3.8782 E-03$ & $-3.9282 \mathrm{E}-03$ \\
\hline 2.3333E-02 & $-3.7596 \mathrm{E}-03$ & $-3.9199 \mathrm{E}-03$ \\
\hline $2.5000 \mathrm{E}-02$ & $-2.9511 \mathrm{E}-03$ & $-3.1935 \mathrm{E}-03$ \\
\hline 2.6667E-02 & $-1.9806 \mathrm{E}-03$ & $-2.1300 \mathrm{E}-03$ \\
\hline 2.8333E-02 & $-1.4905 E-03$ & $-1.4500 \mathrm{E}-03$ \\
\hline $3.0000 \mathrm{E}-02$ & $-1.4214 \mathrm{E}-03$ & $-1.3146 \mathrm{E}-03$ \\
\hline 3.1667E-02 & $-1.0734 \mathrm{E}-03$ & $-1.1105 \mathrm{E}-03$ \\
\hline 3.3333E-02 & $-1.0471 \mathrm{E}-04$ & $-2.7469 \mathrm{E}-04$ \\
\hline
\end{tabular}




\subsubsection{Fiber Volume Fraction, $V_{f}=0.6$}

The dynamic mid-span deflections for the three different laminate stacking sequences, $[0 / \pm 20]_{s},[0 / 90 / \pm 45]_{T}$ and $[0 / 90 / \pm 30]_{s}$, are plotted in Figures $6.6,6.7$ and 6.8, respectively and listed in Tables $6.19,6.20$ and 6.21, respectively for both CLPT and FSDT. 

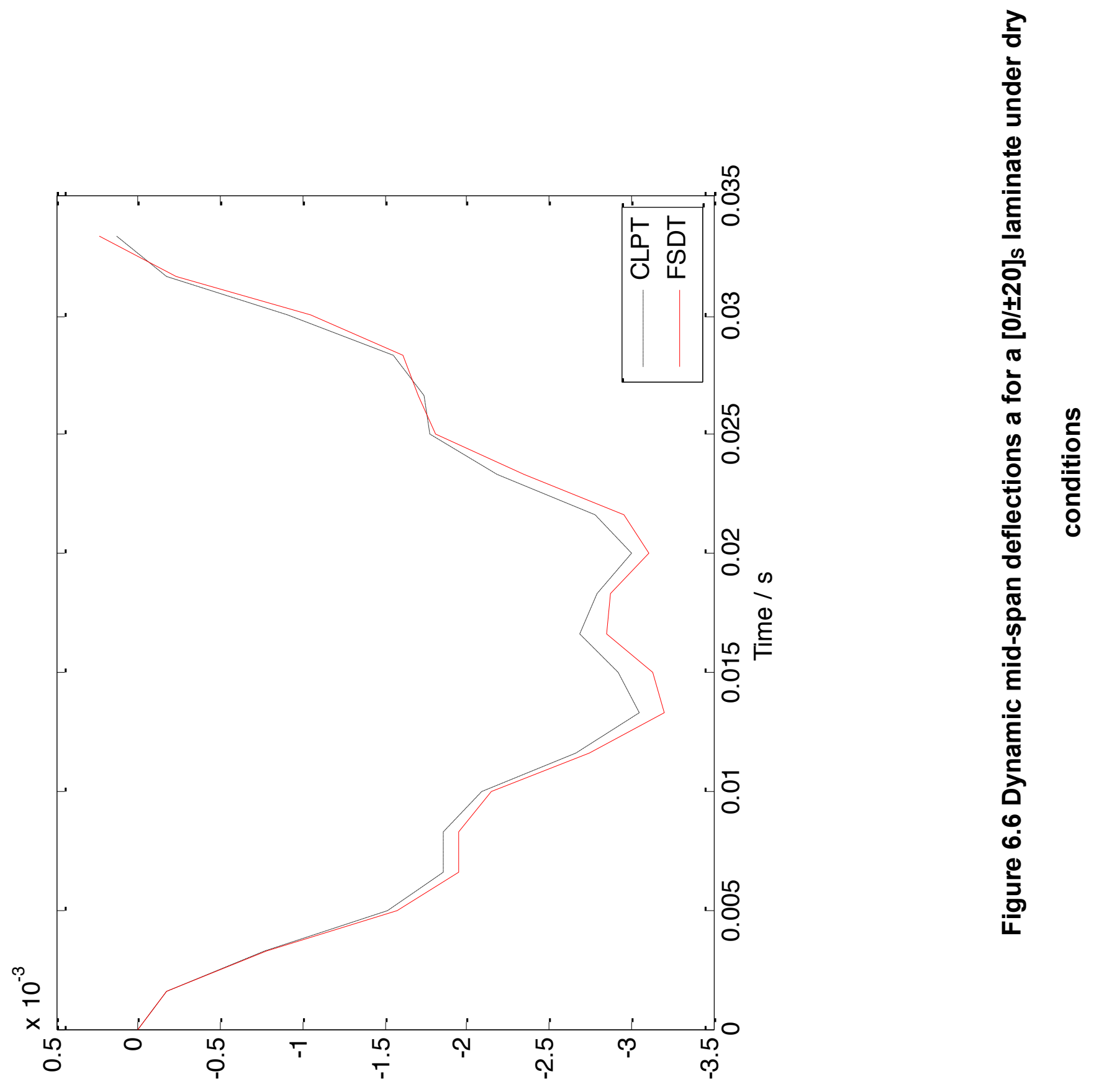
Table 6.19 Dynamic mid-span deflections a for a $[0 / \pm 20]_{s}$ laminate under dry conditions

\begin{tabular}{|c|c|c|}
\hline \multirow{2}{*}{$\begin{array}{c}\text { Time at the end of } \\
\text { each load step (s) }\end{array}$} & \multicolumn{2}{|c|}{ Mid-span dynamic deflections (m) } \\
\cline { 2 - 3 } & CLPT & FSDT \\
\hline 0 & 0 & 0 \\
\hline $1.6667 \mathrm{E}-03$ & $-1.7042 \mathrm{E}-04$ & $-1.6974 \mathrm{E}-04$ \\
\hline $3.3333 \mathrm{E}-03$ & $-7.7200 \mathrm{E}-04$ & $-7.8594 \mathrm{E}-04$ \\
\hline $5.0000 \mathrm{E}-03$ & $-1.5185 \mathrm{E}-03$ & $-1.5742 \mathrm{E}-03$ \\
\hline $6.6667 \mathrm{E}-03$ & $-1.8527 \mathrm{E}-03$ & $-1.9482 \mathrm{E}-03$ \\
\hline $8.3333 \mathrm{E}-03$ & $-1.8575 \mathrm{E}-03$ & $-1.9545 \mathrm{E}-03$ \\
\hline $1.0000 \mathrm{E}-02$ & $-2.0889 \mathrm{E}-03$ & $-2.1547 \mathrm{E}-03$ \\
\hline $1.1667 \mathrm{E}-02$ & $-2.6693 \mathrm{E}-03$ & $-2.7468 \mathrm{E}-03$ \\
\hline $1.3333 \mathrm{E}-02$ & $-3.0524 \mathrm{E}-03$ & $-3.2038 \mathrm{E}-03$ \\
\hline $1.5000 \mathrm{E}-02$ & $-2.9232 \mathrm{E}-03$ & $-3.1272 \mathrm{E}-03$ \\
\hline $1.6667 \mathrm{E}-02$ & $-2.6815 \mathrm{E}-03$ & $-2.8458 \mathrm{E}-03$ \\
\hline $1.8333 \mathrm{E}-02$ & $-2.7904 \mathrm{E}-03$ & $-2.8697 \mathrm{E}-03$ \\
\hline $2.0000 \mathrm{E}-02$ & $-3.0058 \mathrm{E}-03$ & $-3.1026 \mathrm{E}-03$ \\
\hline $2.1667 \mathrm{E}-02$ & $-2.7826 \mathrm{E}-03$ & $-2.9581 \mathrm{E}-03$ \\
\hline $2.3333 \mathrm{E}-02$ & $-2.1802 \mathrm{E}-03$ & $-2.3485 \mathrm{E}-03$ \\
\hline $2.5000 \mathrm{E}-02$ & $-1.7728 \mathrm{E}-03$ & $-1.8130 \mathrm{E}-03$ \\
\hline $2.6667 \mathrm{E}-02$ & $-1.7357 \mathrm{E}-03$ & $-1.7061 \mathrm{E}-03$ \\
\hline $2.8333 \mathrm{E}-02$ & $-1.5559 \mathrm{E}-03$ & $-1.6094 \mathrm{E}-03$ \\
\hline $3.0000 \mathrm{E}-02$ & $-9.0732 \mathrm{E}-04$ & $-1.0494 \mathrm{E}-03$ \\
\hline $3.1667 \mathrm{E}-02$ & $-1.7777 \mathrm{E}-04$ & $-2.3584 \mathrm{E}-04$ \\
\hline $3.3333 \mathrm{E}-02$ & $1.2934 \mathrm{E}-04$ & $2.3426 \mathrm{E}-04$ \\
\hline & & \\
\hline & & \\
\hline
\end{tabular}




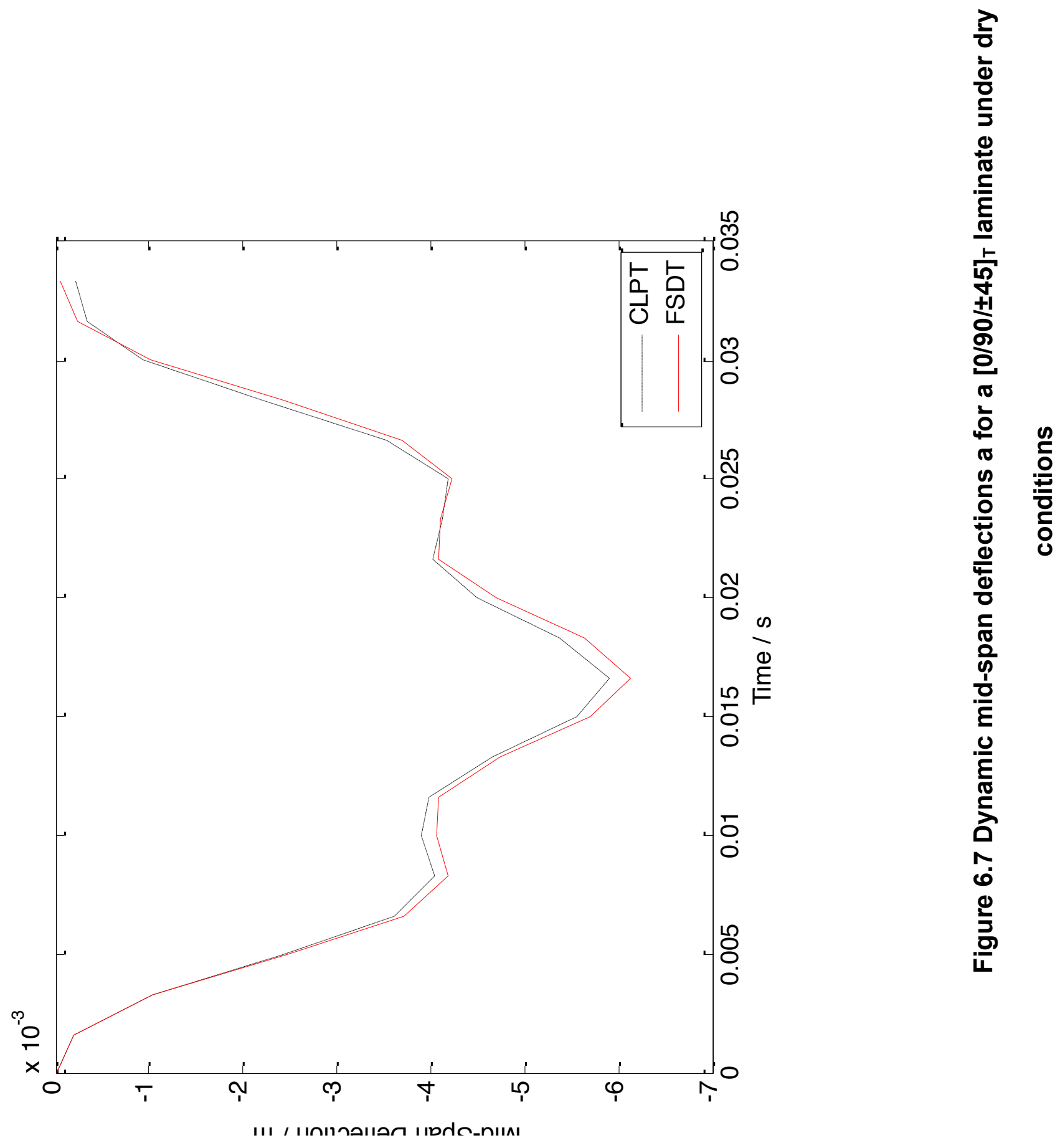


Table 6.20 Dynamic mid-span deflections a for a [0/90/ \pm 45$]_{T}$ laminate under dry conditions

\begin{tabular}{|c|c|c|}
\hline \multirow{2}{*}{$\begin{array}{l}\text { Time at the end of } \\
\text { each load step (s) }\end{array}$} & \multicolumn{2}{|c|}{ Mid-span dynamic deflections (m) } \\
\hline & CLPT & FSDT \\
\hline 0 & 0 & 0 \\
\hline 1.6667E-03 & $-1.9995 E-04$ & $-1.9725 \mathrm{E}-04$ \\
\hline 3.3333E-03 & $-1.0389 E-03$ & $-1.0430 \mathrm{E}-03$ \\
\hline $5.0000 \mathrm{E}-03$ & $-2.4321 \mathrm{E}-03$ & $-2.4725 \mathrm{E}-03$ \\
\hline $6.6667 \mathrm{E}-03$ & $-3.6171 \mathrm{E}-03$ & $-3.7153 \mathrm{E}-03$ \\
\hline 8.3333E-03 & $-4.0389 \mathrm{E}-03$ & $-4.1922 \mathrm{E}-03$ \\
\hline 1.0000E-02 & $-3.9002 E-03$ & $-4.0576 \mathrm{E}-03$ \\
\hline 1.1667E-02 & $-3.9712 \mathrm{E}-03$ & $-4.0845 \mathrm{E}-03$ \\
\hline 1.3333E-02 & $-4.6588 \mathrm{E}-03$ & $-4.7423 \mathrm{E}-03$ \\
\hline $1.5000 \mathrm{E}-02$ & $-5.5671 \mathrm{E}-03$ & $-5.6922 \mathrm{E}-03$ \\
\hline 1.6667E-02 & $-5.9058 E-03$ & $-6.1402 \mathrm{E}-03$ \\
\hline 1.8333E-02 & $-5.3651 \mathrm{E}-03$ & $-5.6429 \mathrm{E}-03$ \\
\hline $2.0000 \mathrm{E}-02$ & $-4.4862 E-03$ & $-4.7030 \mathrm{E}-03$ \\
\hline $2.1667 \mathrm{E}-02$ & $-4.0131 \mathrm{E}-03$ & $-4.0890 \mathrm{E}-03$ \\
\hline 2.3333E-02 & $-4.1212 \mathrm{E}-03$ & $-4.1128 \mathrm{E}-03$ \\
\hline $2.5000 \mathrm{E}-02$ & $-4.1776 \mathrm{E}-03$ & $-4.2248 \mathrm{E}-03$ \\
\hline 2.6667E-02 & $-3.5306 \mathrm{E}-03$ & $-3.7005 \mathrm{E}-03$ \\
\hline 2.8333E-02 & $-2.2064 \mathrm{E}-03$ & $-2.4185 \mathrm{E}-03$ \\
\hline $3.0000 \mathrm{E}-02$ & $-9.3491 \mathrm{E}-04$ & $-1.0124 \mathrm{E}-03$ \\
\hline 3.1667E-02 & $-3.3100 \mathrm{E}-04$ & $-2.2528 \mathrm{E}-04$ \\
\hline 3.3333E-02 & $-2.1731 \mathrm{E}-04$ & $-4.8982 E-05$ \\
\hline
\end{tabular}




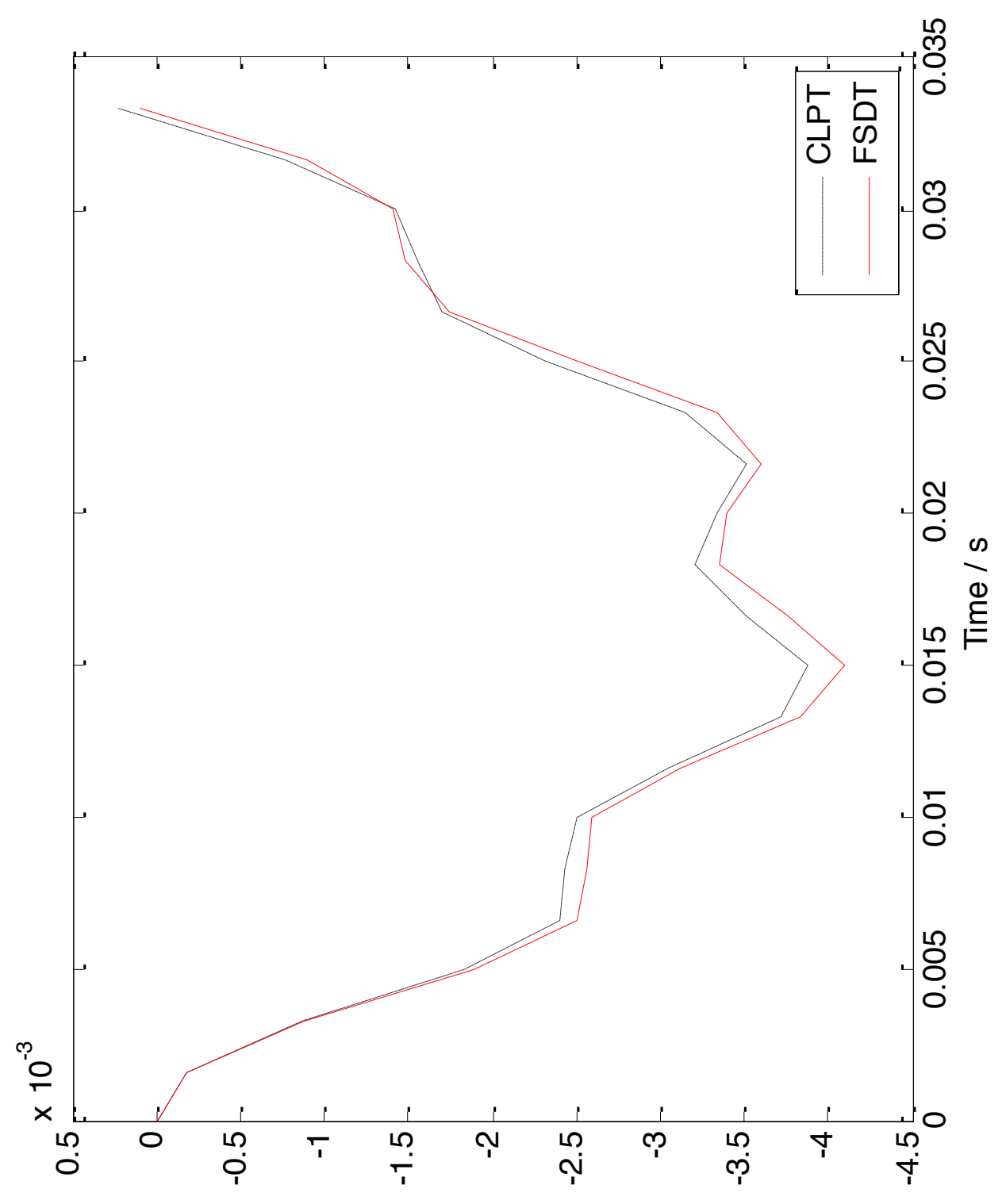

끙

$\stackrel{0}{\stackrel{0}{\pi}}$

듬

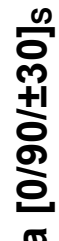

는

은

옹

过

등

응

$\frac{1}{0}$

'ㄹ

定

$\infty$

인

흐 
Table 6.21 Dynamic mid-span deflections a for a $[0 / 90 / \pm 30]_{s}$ laminate under dry conditions

\begin{tabular}{|c|c|c|}
\hline \multirow{2}{*}{$\begin{array}{l}\text { Time at the end of } \\
\text { each load step (s) }\end{array}$} & \multicolumn{2}{|c|}{ Mid-span dynamic deflections (m) } \\
\hline & CLPT & FSDT \\
\hline 0 & 0 & 0 \\
\hline 1.6667E-03 & $-1.8301 \mathrm{E}-04$ & $-1.8145 \mathrm{E}-04$ \\
\hline 3.3333E-03 & $-8.7204 E-04$ & $-8.8311 \mathrm{E}-04$ \\
\hline $5.0000 \mathrm{E}-03$ & $-1.8316 \mathrm{E}-03$ & $-1.8863 \mathrm{E}-03$ \\
\hline $6.6667 \mathrm{E}-03$ & $-2.3961 \mathrm{E}-03$ & $-2.5032 \mathrm{E}-03$ \\
\hline 8.3333E-03 & $-2.4348 \mathrm{E}-03$ & $-2.5631 \mathrm{E}-03$ \\
\hline 1.0000E-02 & $-2.4993 E-03$ & $-2.5950 \mathrm{E}-03$ \\
\hline 1.1667E-02 & $-3.0401 E-03$ & $-3.1128 \mathrm{E}-03$ \\
\hline 1.3333E-02 & $-3.7117 \mathrm{E}-03$ & $-3.8365 \mathrm{E}-03$ \\
\hline $1.5000 \mathrm{E}-02$ & $-3.8825 E-03$ & $-4.1021 \mathrm{E}-03$ \\
\hline 1.6667E-02 & $-3.5081 \mathrm{E}-03$ & $-3.7580 \mathrm{E}-03$ \\
\hline 1.8333E-02 & $-3.1997 E-03$ & $-3.3470 \mathrm{E}-03$ \\
\hline $2.0000 \mathrm{E}-02$ & $-3.3340 E-03$ & $-3.3921 E-03$ \\
\hline $2.1667 \mathrm{E}-02$ & $-3.5081 \mathrm{E}-03$ & $-3.5966 \mathrm{E}-03$ \\
\hline 2.3333E-02 & $-3.1437 E-03$ & $-3.3367 \mathrm{E}-03$ \\
\hline $2.5000 \mathrm{E}-02$ & $-2.3182 E-03$ & $-2.5082 \mathrm{E}-03$ \\
\hline 2.6667E-02 & $-1.6946 \mathrm{E}-03$ & $-1.7405 \mathrm{E}-03$ \\
\hline 2.8333E-02 & $-1.5500 \mathrm{E}-03$ & $-1.4781 \mathrm{E}-03$ \\
\hline $3.0000 \mathrm{E}-02$ & $-1.4237 E-03$ & $-1.4111 \mathrm{E}-03$ \\
\hline 3.1667E-02 & $-7.6620 \mathrm{E}-04$ & $-8.9902 \mathrm{E}-04$ \\
\hline 3.3333E-02 & $2.2344 \mathrm{E}-04$ & $1.0185 \mathrm{E}-04$ \\
\hline
\end{tabular}




\subsubsection{Fiber Volume Fraction, $V_{f}=0.7$}

The dynamic mid-span deflections for the three different laminate stacking sequences, $[0 / \pm 20]_{\mathrm{s}},[0 / 90 / \pm 45]_{\mathrm{T}}$ and $[0 / 90 / \pm 30]_{\mathrm{s}}$, are plotted in Figures

6.9, 6.10 and 6.11, respectively and listed in Tables 6.22, 6.23 and 6.24, respectively for both CLPT and FSDT. 


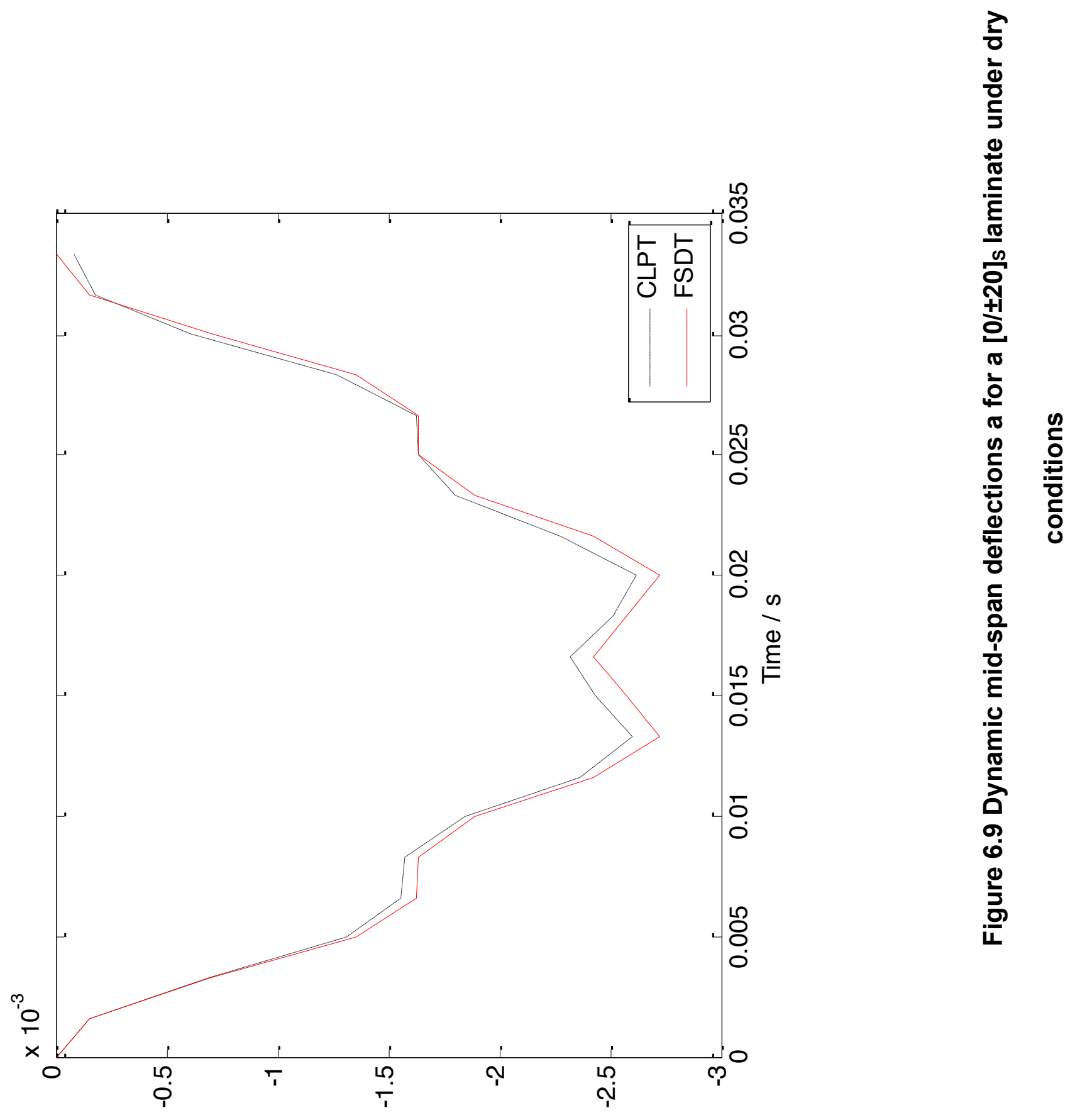


Table 6.22 Dynamic mid-span deflections a for a $[0 / \pm 20]_{s}$ laminate under dry conditions

\begin{tabular}{|c|c|c|}
\hline \multirow{2}{*}{$\begin{array}{l}\text { Time at the end of } \\
\text { each load step (s) }\end{array}$} & \multicolumn{2}{|c|}{ Mid-span dynamic deflections (m) } \\
\hline & CLPT & FSDT \\
\hline 0 & 0 & 0 \\
\hline 1.6667E-03 & $-1.5551 \mathrm{E}-04$ & $-1.5526 \mathrm{E}-04$ \\
\hline 3.3333E-03 & $-6.8837 E-04$ & $-7.0037 \mathrm{E}-04$ \\
\hline $5.0000 \mathrm{E}-03$ & $-1.3144 \mathrm{E}-03$ & $-1.3587 \mathrm{E}-03$ \\
\hline $6.6667 \mathrm{E}-03$ & $-1.5589 E-03$ & $-1.6303 \mathrm{E}-03$ \\
\hline 8.3333E-03 & $-1.5721 \mathrm{E}-03$ & $-1.6394 \mathrm{E}-03$ \\
\hline 1.0000E-02 & $-1.8439 E-03$ & $-1.8903 \mathrm{E}-03$ \\
\hline 1.1667E-02 & $-2.3603 E-03$ & $-2.4275 \mathrm{E}-03$ \\
\hline 1.3333E-02 & $-2.5984 \mathrm{E}-03$ & $-2.7235 \mathrm{E}-03$ \\
\hline $1.5000 \mathrm{E}-02$ & $-2.4311 \mathrm{E}-03$ & $-2.5777 \mathrm{E}-03$ \\
\hline 1.6667E-02 & $-2.3183 E-03$ & $-2.4217 \mathrm{E}-03$ \\
\hline 1.8333E-02 & $-2.5157 \mathrm{E}-03$ & $-2.5770 \mathrm{E}-03$ \\
\hline $2.0000 \mathrm{E}-02$ & $-2.6226 \mathrm{E}-03$ & $-2.7252 \mathrm{E}-03$ \\
\hline $2.1667 \mathrm{E}-02$ & $-2.2805 E-03$ & $-2.4250 \mathrm{E}-03$ \\
\hline 2.3333E-02 & $-1.8003 E-03$ & $-1.8930 \mathrm{E}-03$ \\
\hline $2.5000 \mathrm{E}-02$ & $-1.6367 \mathrm{E}-03$ & $-1.6365 \mathrm{E}-03$ \\
\hline 2.6667E-02 & $-1.6238 \mathrm{E}-03$ & $-1.6334 \mathrm{E}-03$ \\
\hline 2.8333E-02 & $-1.2638 \mathrm{E}-03$ & $-1.3560 \mathrm{E}-03$ \\
\hline $3.0000 \mathrm{E}-02$ & $-6.1322 \mathrm{E}-04$ & $-7.0231 \mathrm{E}-04$ \\
\hline 3.1667E-02 & $-1.8209 E-04$ & $-1.5394 \mathrm{E}-04$ \\
\hline 3.3333E-02 & $-8.5233 E-05$ & $-6.5000 \mathrm{E}-07$ \\
\hline
\end{tabular}



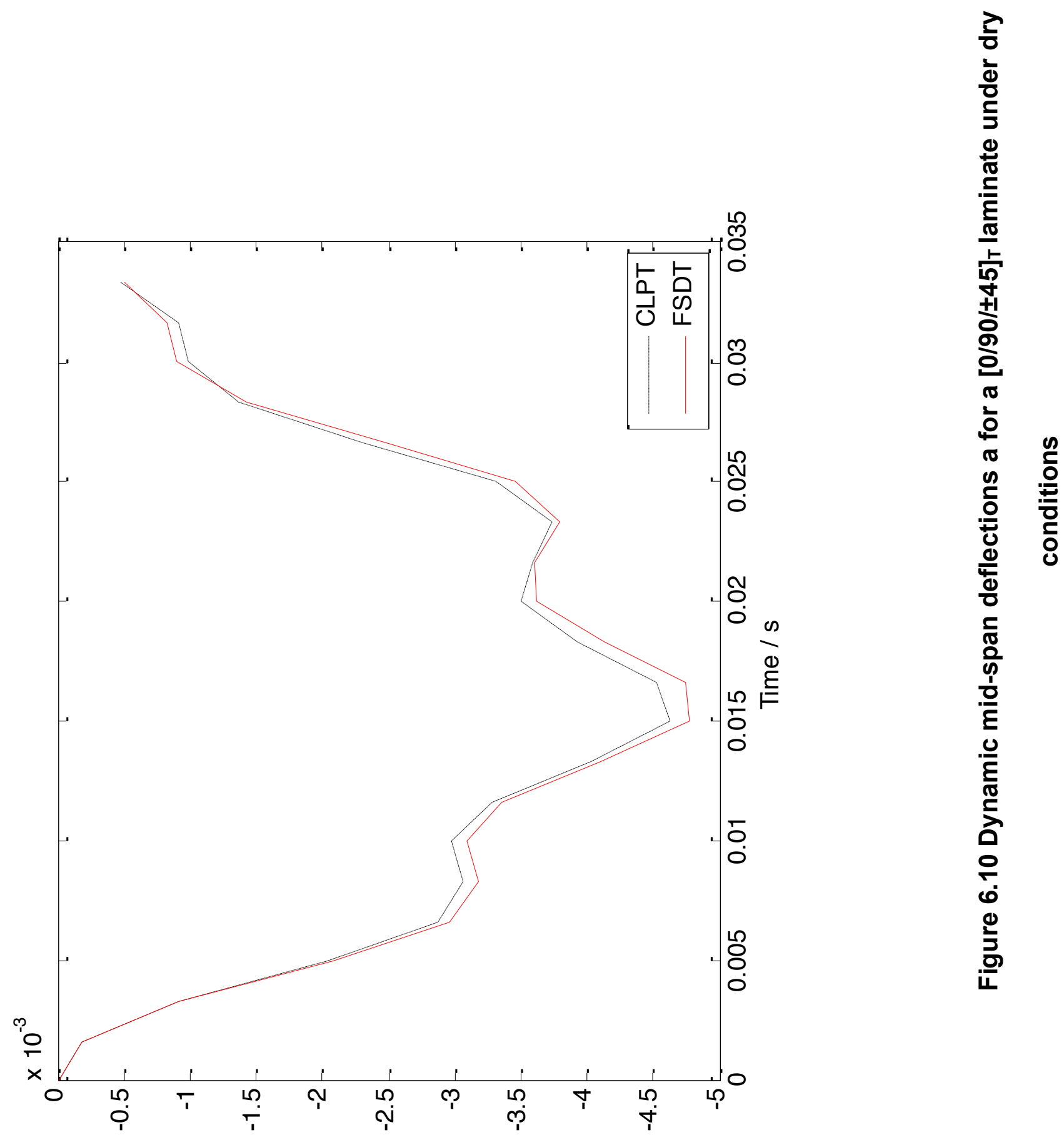
Table 6.23 Dynamic mid-span deflections a for a [0/90/ \pm 45$]_{T}$ laminate under dry conditions

\begin{tabular}{|c|c|c|}
\hline \multirow{2}{*}{$\begin{array}{l}\text { Time at the end of } \\
\text { each load step (s) }\end{array}$} & \multicolumn{2}{|c|}{ Mid-span dynamic deflections (m) } \\
\hline & CLPT & FSDT \\
\hline 0 & 0 & 0 \\
\hline 1.6667E-03 & $-1.8223 E-04$ & $-1.8032 \mathrm{E}-04$ \\
\hline 3.3333E-03 & $-9.1311 \mathrm{E}-04$ & $-9.1913 \mathrm{E}-04$ \\
\hline $5.0000 \mathrm{E}-03$ & $-2.0437 E-03$ & $-2.0835 \mathrm{E}-03$ \\
\hline $6.6667 \mathrm{E}-03$ & $-2.8779 \mathrm{E}-03$ & $-2.9662 \mathrm{E}-03$ \\
\hline 8.3333E-03 & $-3.0626 \mathrm{E}-03$ & $-3.1861 \mathrm{E}-03$ \\
\hline 1.0000E-02 & $-2.9768 E-03$ & $-3.0867 \mathrm{E}-03$ \\
\hline 1.1667E-02 & $-3.2797 E-03$ & $-3.3528 \mathrm{E}-03$ \\
\hline 1.3333E-02 & $-4.0294 \mathrm{E}-03$ & $-4.1056 \mathrm{E}-03$ \\
\hline $1.5000 \mathrm{E}-02$ & $-4.6243 E-03$ & $-4.7698 \mathrm{E}-03$ \\
\hline 1.6667E-02 & $-4.5222 \mathrm{E}-03$ & $-4.7500 \mathrm{E}-03$ \\
\hline 1.8333E-02 & $-3.9192 E-03$ & $-4.1240 \mathrm{E}-03$ \\
\hline $2.0000 \mathrm{E}-02$ & $-3.5082 E-03$ & $-3.6129 \mathrm{E}-03$ \\
\hline $2.1667 \mathrm{E}-02$ & $-3.5908 E-03$ & $-3.6107 \mathrm{E}-03$ \\
\hline 2.3333E-02 & $-3.7380 \mathrm{E}-03$ & $-3.7893 \mathrm{E}-03$ \\
\hline $2.5000 \mathrm{E}-02$ & $-3.3075 E-03$ & $-3.4566 \mathrm{E}-03$ \\
\hline 2.6667E-02 & $-2.3094 \mathrm{E}-03$ & $-2.4838 \mathrm{E}-03$ \\
\hline 2.8333E-02 & $-1.3661 \mathrm{E}-03$ & $-1.4318 \mathrm{E}-03$ \\
\hline $3.0000 \mathrm{E}-02$ & $-9.8534 \mathrm{E}-04$ & $-9.0569 \mathrm{E}-04$ \\
\hline 3.1667E-02 & $-9.0858 E-04$ & $-8.2007 \mathrm{E}-04$ \\
\hline 3.3333E-02 & $-4.6934 \mathrm{E}-04$ & $-5.0267 \mathrm{E}-04$ \\
\hline
\end{tabular}



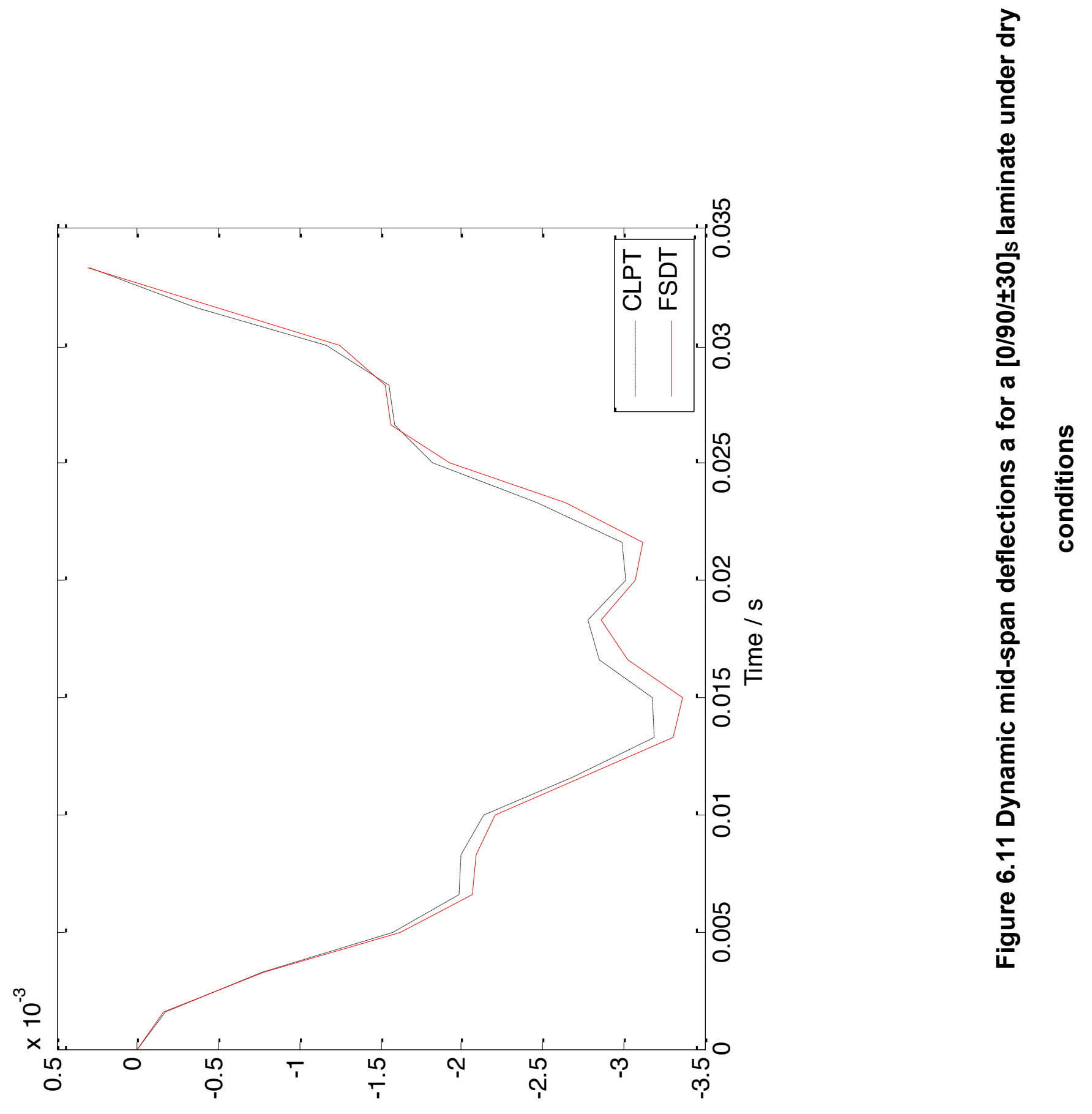
Table 6.24 Dynamic mid-span deflections a for a $[0 / 90 / \pm 30]_{s}$ laminate under dry conditions

\begin{tabular}{|c|c|c|}
\hline \multirow{2}{*}{$\begin{array}{l}\text { Time at the end of } \\
\text { each load step (s) }\end{array}$} & \multicolumn{2}{|c|}{ Mid-span dynamic deflections (m) } \\
\hline & CLPT & FSDT \\
\hline 0 & 0 & 0 \\
\hline 1.6667E-03 & $-1.6687 E-04$ & $-1.6593 \mathrm{E}-04$ \\
\hline 3.3333E-03 & $-7.7476 \mathrm{E}-04$ & $-7.8557 \mathrm{E}-04$ \\
\hline $5.0000 \mathrm{E}-03$ & $-1.5736 \mathrm{E}-03$ & $-1.6211 \mathrm{E}-03$ \\
\hline $6.6667 \mathrm{E}-03$ & $-1.9844 \mathrm{E}-03$ & $-2.0712 \mathrm{E}-03$ \\
\hline 8.3333E-03 & $-1.9925 \mathrm{E}-03$ & $-2.0880 \mathrm{E}-03$ \\
\hline 1.0000E-02 & $-2.1373 E-03$ & $-2.2038 \mathrm{E}-03$ \\
\hline 1.1667E-02 & $-2.6873 E-03$ & $-2.7495 \mathrm{E}-03$ \\
\hline 1.3333E-02 & $-3.1896 \mathrm{E}-03$ & $-3.3097 \mathrm{E}-03$ \\
\hline $1.5000 \mathrm{E}-02$ & $-3.1756 \mathrm{E}-03$ & $-3.3617 \mathrm{E}-03$ \\
\hline 1.6667E-02 & $-2.8505 E-03$ & $-3.0268 \mathrm{E}-03$ \\
\hline 1.8333E-02 & $-2.7808 E-03$ & $-2.8673 \mathrm{E}-03$ \\
\hline $2.0000 \mathrm{E}-02$ & $-3.0105 E-03$ & $-3.0686 \mathrm{E}-03$ \\
\hline $2.1667 \mathrm{E}-02$ & $-2.9970 \mathrm{E}-03$ & $-3.1191 \mathrm{E}-03$ \\
\hline 2.3333E-02 & $-2.4625 \mathrm{E}-03$ & $-2.6352 \mathrm{E}-03$ \\
\hline $2.5000 \mathrm{E}-02$ & $-1.8264 \mathrm{E}-03$ & $-1.9224 \mathrm{E}-03$ \\
\hline 2.6667E-02 & $-1.5889 \mathrm{E}-03$ & $-1.5674 \mathrm{E}-03$ \\
\hline 2.8333E-02 & $-1.5529 E-03$ & $-1.5291 \mathrm{E}-03$ \\
\hline $3.0000 \mathrm{E}-02$ & $-1.1662 \mathrm{E}-03$ & $-1.2511 \mathrm{E}-03$ \\
\hline 3.1667E-02 & $-3.6217 E-04$ & $-4.8304 \mathrm{E}-04$ \\
\hline 3.3333E-02 & 2.9862E-04 & $3.0705 \mathrm{E}-04$ \\
\hline
\end{tabular}




\subsubsection{Hygrothermal Condition}

The moisture content and the temperature are taken to be as $5 \%$ and $52^{\circ} \mathrm{C}$, respectively. For each of the different fiber volume fractions, $V_{f}=0.52$, $V_{f}=0.6$ and $V_{f}=0.7$, there are three different lay-ups considered, namely $[0 / \pm 20]_{\mathrm{s}},[0 / 90 / \pm 45]_{\mathrm{T}}$ and $[0 / 90 \pm 30]_{\mathrm{s}}$.

\subsubsection{Fiber Volume Fraction, $V_{f}=0.52$}

The dynamic mid-span deflections for the three different laminate stacking sequences, $[0 / \pm 20]_{s},[0 / 90 / \pm 45]_{T}$ and $[0 / 90 / \pm 30]_{s}$, are plotted in Figures 6.12, 6.13 and 6.14 and are listed below in Tables $6.25,6.26$ and 6.27 for both the theories, CLPT and FSDT. 

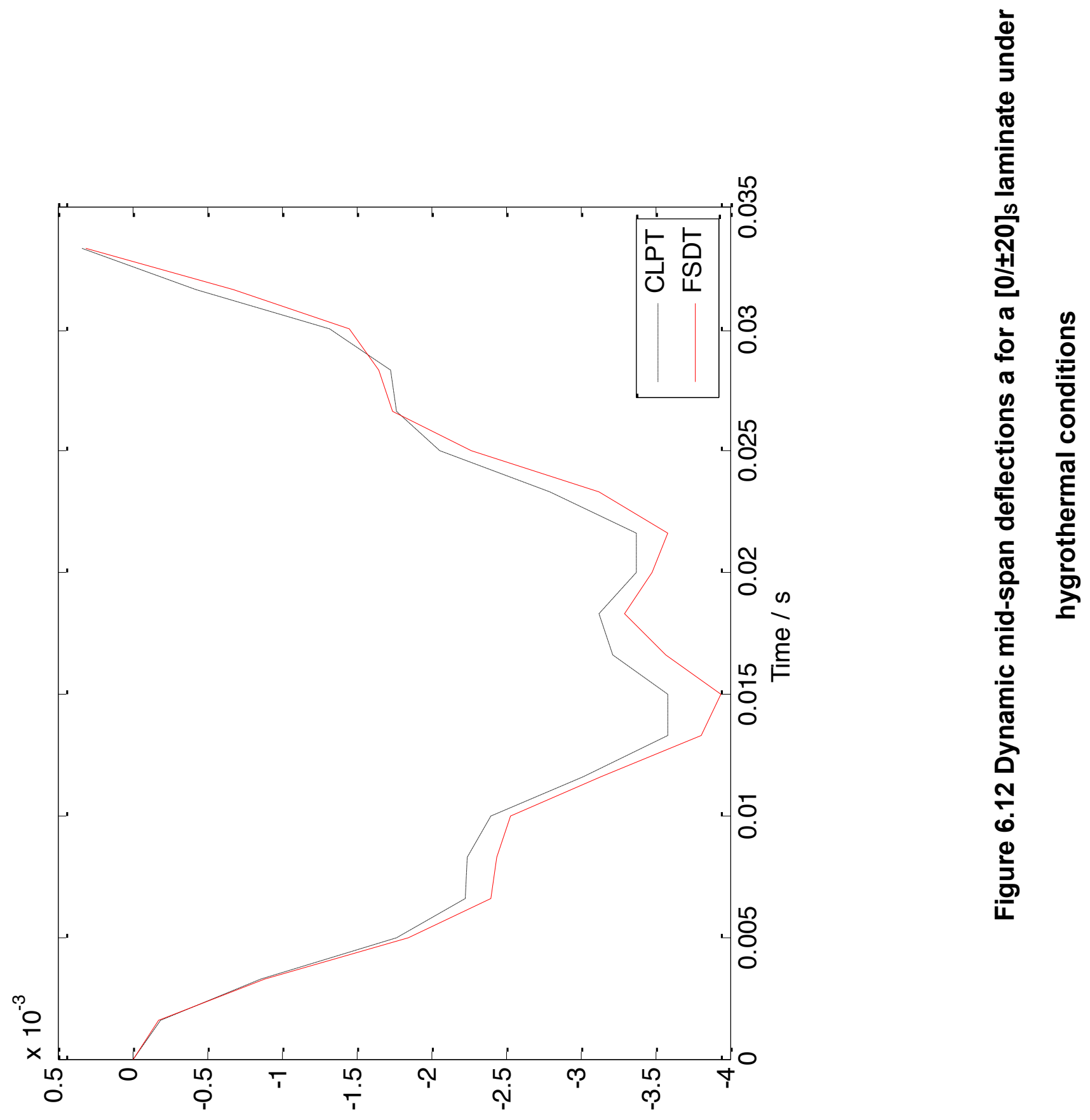
Table 6.25 Dynamic mid-span deflections a for a $[0 / \pm 20]_{s}$ laminate under hygrothermal conditions

\begin{tabular}{|c|c|c|}
\hline \multirow{2}{*}{$\begin{array}{c}\text { Time at the end of } \\
\text { each load step (s) }\end{array}$} & \multicolumn{2}{|c|}{ Mid-span dynamic deflections (m) } \\
\cline { 2 - 3 } & CLPT & FSDT \\
\hline 0 & 0 & 0 \\
\hline $1.6667 \mathrm{E}-03$ & $-1.8561 \mathrm{E}-04$ & $-1.8372 \mathrm{E}-04$ \\
\hline $3.3333 \mathrm{E}-03$ & $-8.6493 \mathrm{E}-04$ & $-8.8499 \mathrm{E}-04$ \\
\hline $5.0000 \mathrm{E}-03$ & $-1.7640 \mathrm{E}-03$ & $-1.8543 \mathrm{E}-03$ \\
\hline $6.6667 \mathrm{E}-03$ & $-2.2343 \mathrm{E}-03$ & $-2.4016 \mathrm{E}-03$ \\
\hline $8.3333 \mathrm{E}-03$ & $-2.2483 \mathrm{E}-03$ & $-2.4358 \mathrm{E}-03$ \\
\hline $1.0000 \mathrm{E}-02$ & $-2.4031 \mathrm{E}-03$ & $-2.5358 \mathrm{E}-03$ \\
\hline $1.1667 \mathrm{E}-02$ & $-3.0139 \mathrm{E}-03$ & $-3.1318 \mathrm{E}-03$ \\
\hline $1.3333 \mathrm{E}-02$ & $-3.5882 \mathrm{E}-03$ & $-3.8122 \mathrm{E}-03$ \\
\hline $1.5000 \mathrm{E}-02$ & $-3.5898 \mathrm{E}-03$ & $-3.9462 \mathrm{E}-03$ \\
\hline $1.6667 \mathrm{E}-02$ & $-3.2229 \mathrm{E}-03$ & $-3.5751 \mathrm{E}-03$ \\
\hline $1.8333 \mathrm{E}-02$ & $-3.1231 \mathrm{E}-03$ & $-3.3018 \mathrm{E}-03$ \\
\hline $2.0000 \mathrm{E}-02$ & $-3.3723 \mathrm{E}-03$ & $-3.4766 \mathrm{E}-03$ \\
\hline $2.1667 \mathrm{E}-02$ & $-3.3761 \mathrm{E}-03$ & $-3.5910 \mathrm{E}-03$ \\
\hline $2.3333 \mathrm{E}-02$ & $-2.7933 \mathrm{E}-03$ & $-3.1247 \mathrm{E}-03$ \\
\hline $2.5000 \mathrm{E}-02$ & $-2.0619 \mathrm{E}-03$ & $-2.2751 \mathrm{E}-03$ \\
\hline $2.6667 \mathrm{E}-02$ & $-1.7639 \mathrm{E}-03$ & $-1.7400 \mathrm{E}-03$ \\
\hline $2.8333 \mathrm{E}-02$ & $-1.7240 \mathrm{E}-03$ & $-1.6557 \mathrm{E}-03$ \\
\hline $3.0000 \mathrm{E}-02$ & $-1.3229 \mathrm{E}-03$ & $-1.4489 \mathrm{E}-03$ \\
\hline $3.1667 \mathrm{E}-02$ & $-4.3408 \mathrm{E}-04$ & $-6.7695 \mathrm{E}-04$ \\
\hline $3.3333 \mathrm{E}-02$ & $3.3826 \mathrm{E}-04$ & $3.0539 \mathrm{E}-04$ \\
\hline & & \\
\hline & & \\
\hline
\end{tabular}



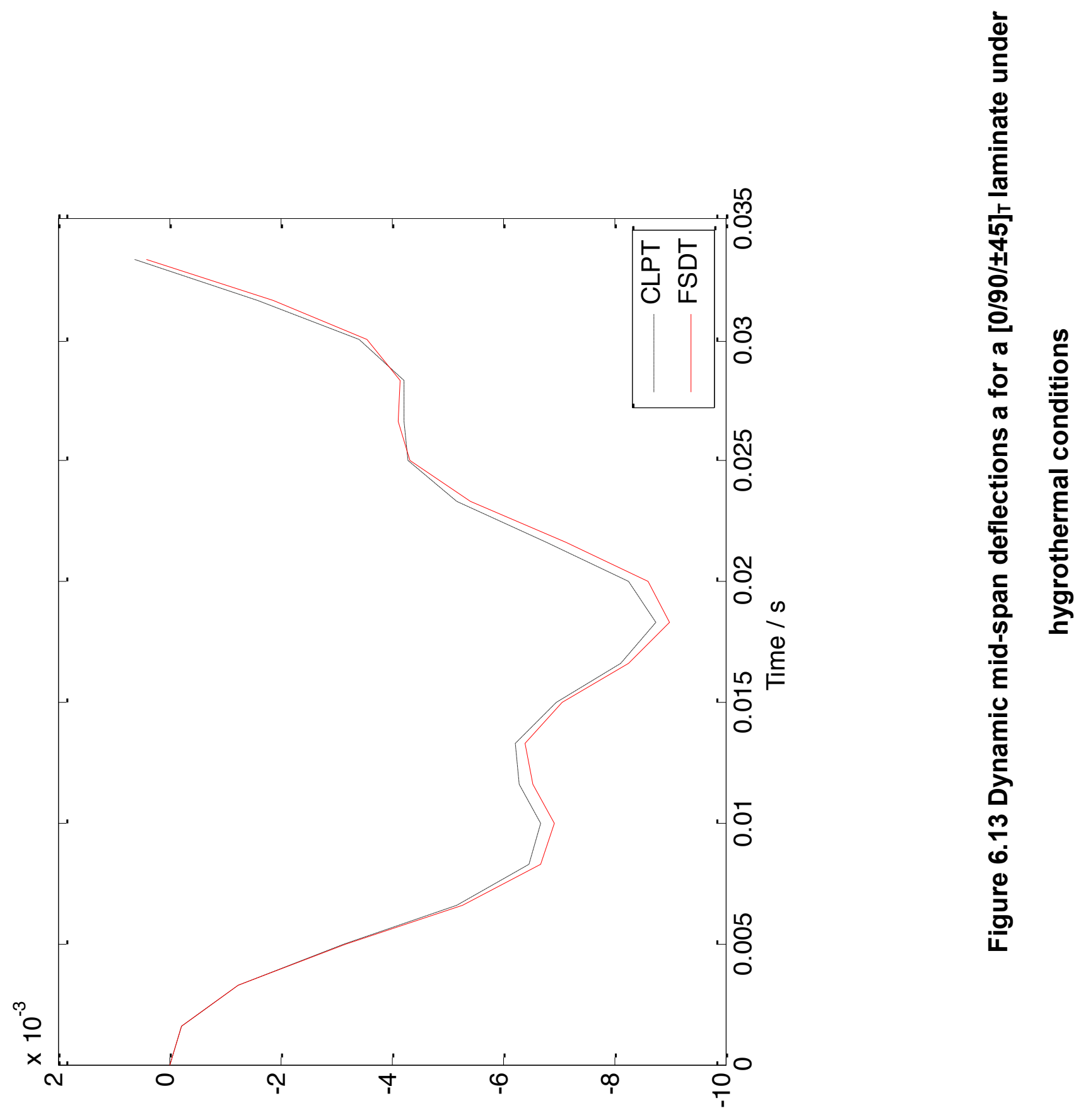
Table 6.26 Dynamic mid-span deflections a for a [0/90/ \pm 45$]_{T}$ laminate under hygrothermal conditions

\begin{tabular}{|c|c|c|}
\hline \multirow{2}{*}{$\begin{array}{l}\text { Time at the end of } \\
\text { each load step (s) }\end{array}$} & \multicolumn{2}{|c|}{ Mid-span dynamic deflections (m) } \\
\hline & CLPT & FSDT \\
\hline 0 & 0 & 0 \\
\hline 1.6667E-03 & $-2.1996 \mathrm{E}-04$ & $-2.1548 \mathrm{E}-04$ \\
\hline 3.3333E-03 & $-1.2305 E-03$ & $-1.2287 \mathrm{E}-03$ \\
\hline $5.0000 \mathrm{E}-03$ & $-3.1397 E-03$ & $-3.1743 E-03$ \\
\hline $6.6667 \mathrm{E}-03$ & $-5.1884 \mathrm{E}-03$ & $-5.2917 \mathrm{E}-03$ \\
\hline 8.3333E-03 & $-6.4892 E-03$ & $-6.6863 \mathrm{E}-03$ \\
\hline 1.0000E-02 & $-6.6744 \mathrm{E}-03$ & $-6.9368 \mathrm{E}-03$ \\
\hline 1.1667E-02 & $-6.2845 E-03$ & $-6.5378 \mathrm{E}-03$ \\
\hline 1.3333E-02 & $-6.2183 E-03$ & $-6.4083 E-03$ \\
\hline $1.5000 \mathrm{E}-02$ & $-6.9497 E-03$ & $-7.0732 \mathrm{E}-03$ \\
\hline 1.6667E-02 & $-8.1156 \mathrm{E}-03$ & $-8.2694 \mathrm{E}-03$ \\
\hline 1.8333E-02 & $-8.7608 \mathrm{E}-03$ & $-9.0006 \mathrm{E}-03$ \\
\hline $2.0000 \mathrm{E}-02$ & $-8.2683 E-03$ & $-8.6200 \mathrm{E}-03$ \\
\hline $2.1667 \mathrm{E}-02$ & $-6.7801 \mathrm{E}-03$ & $-7.1521 \mathrm{E}-03$ \\
\hline 2.3333E-02 & $-5.1927 E-03$ & $-5.4251 \mathrm{E}-03$ \\
\hline $2.5000 \mathrm{E}-02$ & $-4.3125 E-03$ & $-4.3430 \mathrm{E}-03$ \\
\hline 2.6667E-02 & $-4.2175 \mathrm{E}-03$ & $-4.1065 \mathrm{E}-03$ \\
\hline 2.8333E-02 & $-4.2158 \mathrm{E}-03$ & $-4.1603 \mathrm{E}-03$ \\
\hline $3.0000 \mathrm{E}-02$ & $-3.4185 \mathrm{E}-03$ & $-3.5456 \mathrm{E}-03$ \\
\hline 3.1667E-02 & $-1.6138 \mathrm{E}-03$ & $-1.8858 \mathrm{E}-03$ \\
\hline 3.3333E-02 & 6.1732E-04 & 3.9630E-04 \\
\hline
\end{tabular}




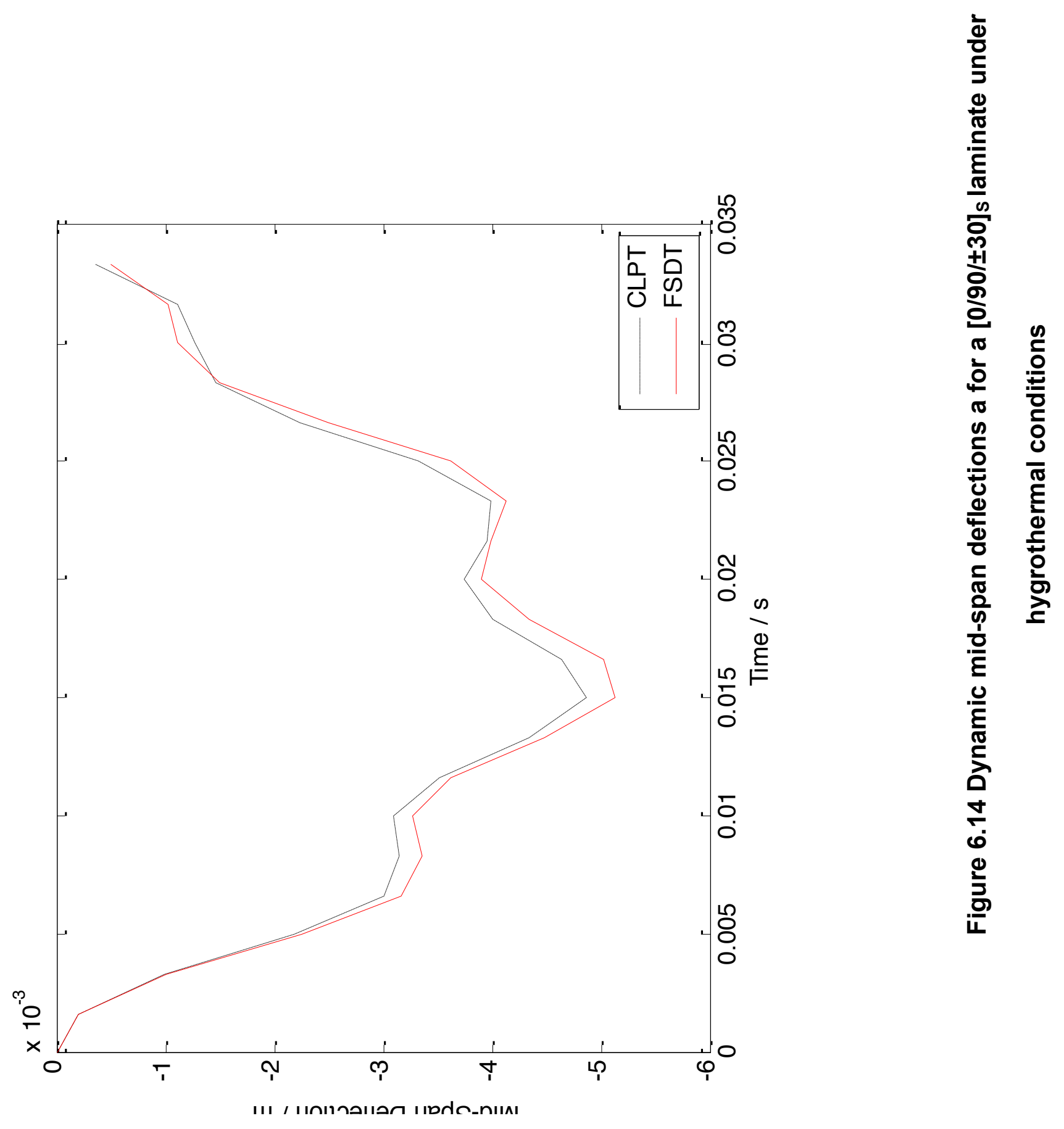


Table 6.27 Dynamic mid-span deflection a for a $[0 / 90 / \pm 30]_{s}$ laminate under hygrothermal conditions

\begin{tabular}{|c|c|c|}
\hline \multirow{2}{*}{$\begin{array}{c}\text { Time at the end of } \\
\text { each load step (s) }\end{array}$} & \multicolumn{2}{|c|}{ Mid-span dynamic deflections (m) } \\
\cline { 2 - 3 } & CLPT & FSDT \\
\hline 0 & 0 & 0 \\
\hline $1.6667 \mathrm{E}-03$ & $-2.0057 \mathrm{E}-04$ & $-1.9753 \mathrm{E}-04$ \\
\hline $3.3333 \mathrm{E}-03$ & $-9.9080 \mathrm{E}-04$ & $-1.0024 \mathrm{E}-03$ \\
\hline $5.0000 \mathrm{E}-03$ & $-2.1792 \mathrm{E}-03$ & $-2.2503 \mathrm{E}-03$ \\
\hline $6.6667 \mathrm{E}-03$ & $-3.0073 \mathrm{E}-03$ & $-3.1602 \mathrm{E}-03$ \\
\hline $8.3333 \mathrm{E}-03$ & $-3.1522 \mathrm{E}-03$ & $-3.3588 \mathrm{E}-03$ \\
\hline $1.0000 \mathrm{E}-02$ & $-3.0951 \mathrm{E}-03$ & $-3.2712 \mathrm{E}-03$ \\
\hline $1.1667 \mathrm{E}-02$ & $-3.5142 \mathrm{E}-03$ & $-3.6310 \mathrm{E}-03$ \\
\hline $1.3333 \mathrm{E}-02$ & $-4.3422 \mathrm{E}-03$ & $-4.4820 \mathrm{E}-03$ \\
\hline $1.5000 \mathrm{E}-02$ & $-4.8706 \mathrm{E}-03$ & $-5.1400 \mathrm{E}-03$ \\
\hline $1.6667 \mathrm{E}-02$ & $-4.6329 \mathrm{E}-03$ & $-5.0265 \mathrm{E}-03$ \\
\hline $1.8333 \mathrm{E}-02$ & $-4.0155 \mathrm{E}-03$ & $-4.3368 \mathrm{E}-03$ \\
\hline $2.0000 \mathrm{E}-02$ & $-3.7530 \mathrm{E}-03$ & $-3.8962 \mathrm{E}-03$ \\
\hline $2.1667 \mathrm{E}-02$ & $-3.9544 \mathrm{E}-03$ & $-3.9934 \mathrm{E}-03$ \\
\hline $2.3333 \mathrm{E}-02$ & $-3.9984 \mathrm{E}-03$ & $-4.1364 \mathrm{E}-03$ \\
\hline $2.5000 \mathrm{E}-02$ & $-3.3276 \mathrm{E}-03$ & $-3.6191 \mathrm{E}-03$ \\
\hline $2.6667 \mathrm{E}-02$ & $-2.2365 \mathrm{E}-03$ & $-2.4995 \mathrm{E}-03$ \\
\hline $2.8333 \mathrm{E}-02$ & $-1.4594 \mathrm{E}-03$ & $-1.4938 \mathrm{E}-03$ \\
\hline $3.0000 \mathrm{E}-02$ & $-1.2713 \mathrm{E}-03$ & $-1.1119 \mathrm{E}-03$ \\
\hline $3.1667 \mathrm{E}-02$ & $-1.1088 \mathrm{E}-03$ & $-1.0345 \mathrm{E}-03$ \\
\hline $3.3333 \mathrm{E}-02$ & $-3.5182 \mathrm{E}-04$ & $-5.0097 \mathrm{E}-04$ \\
\hline & & \\
\hline & & \\
\hline
\end{tabular}




\subsubsection{Fiber Volume Fraction, $V_{f}=0.6$}

The dynamic mid-span deflections for the three different laminate stacking sequences, $[0 / \pm 20]_{\mathrm{s}},[0 / 90 / \pm 45]_{\mathrm{T}}$ and $[0 / 90 / \pm 30]_{\mathrm{s}}$, are plotted in Figures 6.15, 6.16 and 6.17 and are listed below in Tables $6.28,6.29$ and 6.30 for both the theories, CLPT and FSDT. 


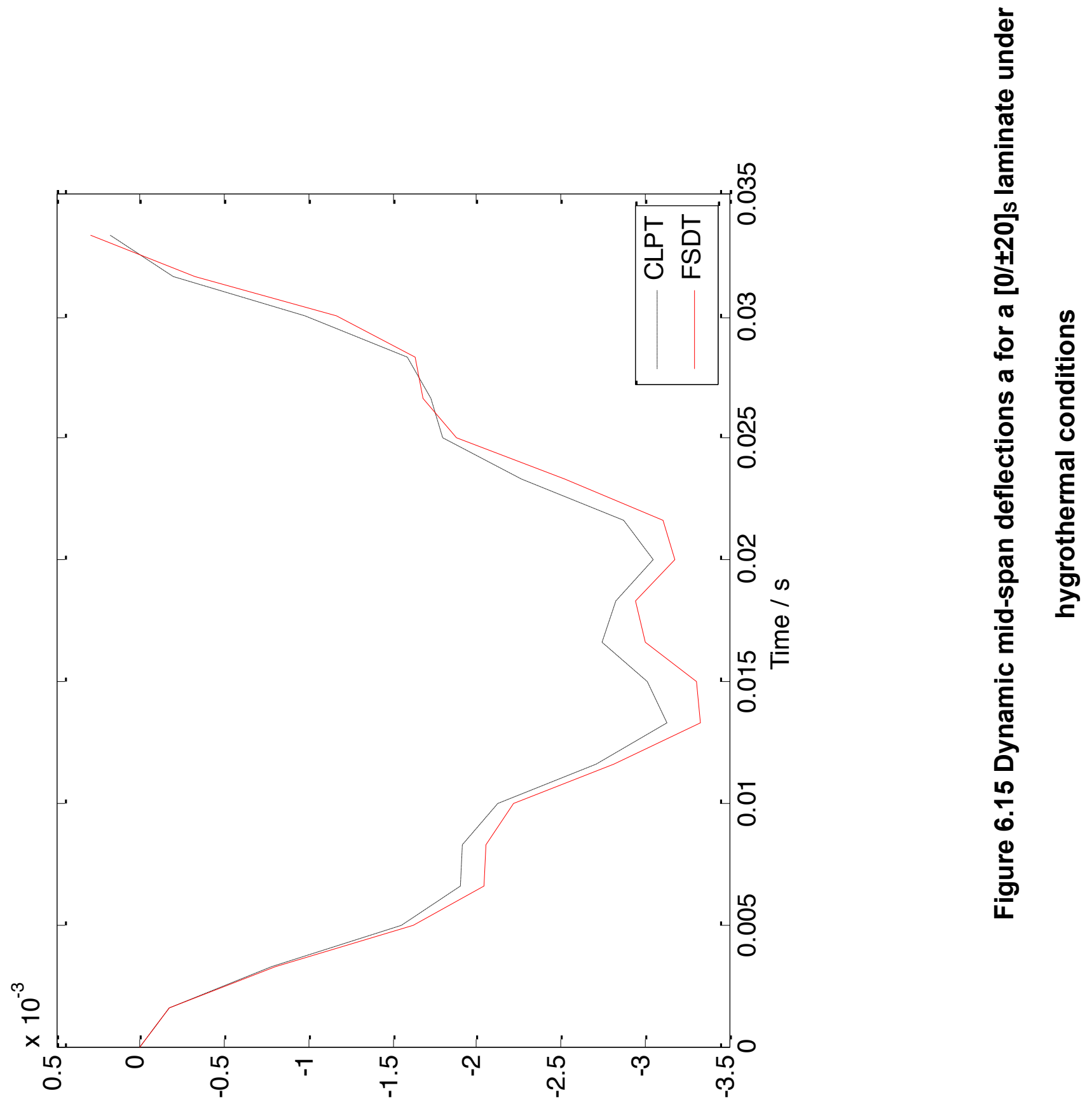


Table 6.28 Dynamic mid-span deflections a for a $[0 / \pm 20]_{s}$ laminate under hygrothermal conditions

\begin{tabular}{|c|c|c|}
\hline \multirow{2}{*}{$\begin{array}{c}\text { Time at the end of } \\
\text { each load step (s) }\end{array}$} & \multicolumn{2}{|c|}{ Mid-span dynamic deflections (m) } \\
\cline { 2 - 3 } & CLPT & FSDT \\
\hline 0 & 0 & 0 \\
\hline $1.6667 \mathrm{E}-03$ & $-1.7144 \mathrm{E}-04$ & $-1.7033 \mathrm{E}-04$ \\
\hline $3.3333 \mathrm{E}-03$ & $-7.8135 \mathrm{E}-04$ & $-8.0047 \mathrm{E}-04$ \\
\hline $5.0000 \mathrm{E}-03$ & $-1.5486 \mathrm{E}-03$ & $-1.6273 \mathrm{E}-03$ \\
\hline $6.6667 \mathrm{E}-03$ & $-1.9039 \mathrm{E}-03$ & $-2.0416 \mathrm{E}-03$ \\
\hline $8.3333 \mathrm{E}-03$ & $-1.9094 \mathrm{E}-03$ & $-2.0527 \mathrm{E}-03$ \\
\hline $1.0000 \mathrm{E}-02$ & $-2.1255 \mathrm{E}-03$ & $-2.2233 \mathrm{E}-03$ \\
\hline $1.1667 \mathrm{E}-02$ & $-2.7098 \mathrm{E}-03$ & $-2.8167 \mathrm{E}-03$ \\
\hline $1.3333 \mathrm{E}-02$ & $-3.1262 \mathrm{E}-03$ & $-3.3359 \mathrm{E}-03$ \\
\hline $1.5000 \mathrm{E}-02$ & $-3.0174 \mathrm{E}-03$ & $-3.3127 \mathrm{E}-03$ \\
\hline $1.6667 \mathrm{E}-02$ & $-2.7498 \mathrm{E}-03$ & $-3.0002 \mathrm{E}-03$ \\
\hline $1.8333 \mathrm{E}-02$ & $-2.8237 \mathrm{E}-03$ & $-2.9426 \mathrm{E}-03$ \\
\hline $2.0000 \mathrm{E}-02$ & $-3.0535 \mathrm{E}-03$ & $-3.1761 \mathrm{E}-03$ \\
\hline $2.1667 \mathrm{E}-02$ & $-2.8729 \mathrm{E}-03$ & $-3.1096 \mathrm{E}-03$ \\
\hline $2.3333 \mathrm{E}-02$ & $-2.2645 \mathrm{E}-03$ & $-2.5214 \mathrm{E}-03$ \\
\hline $2.5000 \mathrm{E}-02$ & $-1.7947 \mathrm{E}-03$ & $-1.8811 \mathrm{E}-03$ \\
\hline $2.6667 \mathrm{E}-02$ & $-1.7263 \mathrm{E}-03$ & $-1.6781 \mathrm{E}-03$ \\
\hline $2.8333 \mathrm{E}-02$ & $-1.5899 \mathrm{E}-03$ & $-1.6291 \mathrm{E}-03$ \\
\hline $3.0000 \mathrm{E}-02$ & $-9.7988 \mathrm{E}-04$ & $-1.1719 \mathrm{E}-03$ \\
\hline $3.1667 \mathrm{E}-02$ & $-2.0169 \mathrm{E}-04$ & $-3.2828 \mathrm{E}-04$ \\
\hline $3.3333 \mathrm{E}-02$ & $1.8355 \mathrm{E}-04$ & $3.0111 \mathrm{E}-04$ \\
\hline & & \\
\hline & & \\
\hline
\end{tabular}



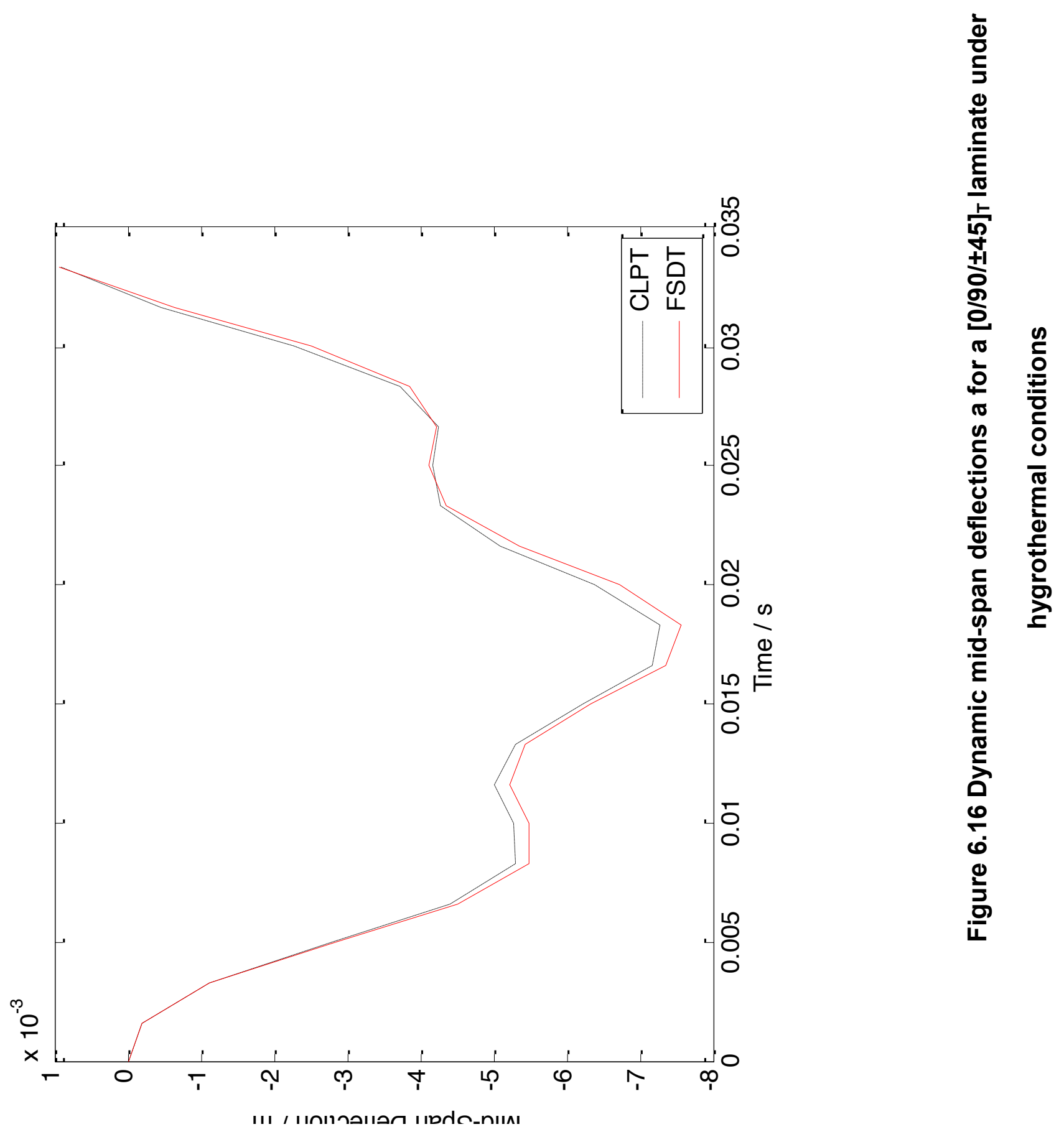
Table 6. 29 Dynamic mid-span deflections a for a $[0 / 90 / \pm 45]_{T}$ laminate under hygrothermal conditions

\begin{tabular}{|c|c|c|}
\hline \multirow{2}{*}{$\begin{array}{c}\text { Time at the end of } \\
\text { each load step (s) }\end{array}$} & \multicolumn{2}{|c|}{ Mid-span dynamic deflections (m) } \\
\cline { 2 - 3 } & CLPT & FSDT \\
\hline 0 & 0 & 0 \\
\hline $1.6667 \mathrm{E}-03$ & $-2.0635 \mathrm{E}-04$ & $-2.0252 \mathrm{E}-04$ \\
\hline $3.3333 \mathrm{E}-03$ & $-1.1232 \mathrm{E}-03$ & $-1.1239 \mathrm{E}-03$ \\
\hline $5.0000 \mathrm{E}-03$ & $-2.7781 \mathrm{E}-03$ & $-2.8162 \mathrm{E}-03$ \\
\hline $6.6667 \mathrm{E}-03$ & $-4.4191 \mathrm{E}-03$ & $-4.5239 \mathrm{E}-03$ \\
\hline $8.3333 \mathrm{E}-03$ & $-5.2926 \mathrm{E}-03$ & $-5.4787 \mathrm{E}-03$ \\
\hline $1.0000 \mathrm{E}-02$ & $-5.2682 \mathrm{E}-03$ & $-5.4944 \mathrm{E}-03$ \\
\hline $1.1667 \mathrm{E}-02$ & $-5.0183 \mathrm{E}-03$ & $-5.2138 \mathrm{E}-03$ \\
\hline $1.3333 \mathrm{E}-02$ & $-5.2982 \mathrm{E}-03$ & $-5.4322 \mathrm{E}-03$ \\
\hline $1.5000 \mathrm{E}-02$ & $-6.2294 \mathrm{E}-03$ & $-6.3377 \mathrm{E}-03$ \\
\hline $1.6667 \mathrm{E}-02$ & $-7.1642 \mathrm{E}-03$ & $-7.3534 \mathrm{E}-03$ \\
\hline $1.8333 \mathrm{E}-02$ & $-7.2677 \mathrm{E}-03$ & $-7.5565 \mathrm{E}-03$ \\
\hline $2.0000 \mathrm{E}-02$ & $-6.3816 \mathrm{E}-03$ & $-6.7270 \mathrm{E}-03$ \\
\hline $2.1667 \mathrm{E}-02$ & $-5.0953 \mathrm{E}-03$ & $-5.3629 \mathrm{E}-03$ \\
\hline $2.3333 \mathrm{E}-02$ & $-4.2764 \mathrm{E}-03$ & $-4.3621 \mathrm{E}-03$ \\
\hline $2.5000 \mathrm{E}-02$ & $-4.1737 \mathrm{E}-03$ & $-4.1259 \mathrm{E}-03$ \\
\hline $2.6667 \mathrm{E}-02$ & $-4.2590 \mathrm{E}-03$ & $-4.2234 \mathrm{E}-03$ \\
\hline $2.8333 \mathrm{E}-02$ & $-3.7231 \mathrm{E}-03$ & $-3.8502 \mathrm{E}-03$ \\
\hline $3.0000 \mathrm{E}-02$ & $-2.2682 \mathrm{E}-03$ & $-2.5190 \mathrm{E}-03$ \\
\hline $3.1667 \mathrm{E}-02$ & $-4.4991 \mathrm{E}-04$ & $-6.4940 \mathrm{E}-04$ \\
\hline $3.3333 \mathrm{E}-02$ & $8.9663 \mathrm{E}-04$ & $9.2580 \mathrm{E}-04$ \\
\hline & & \\
\hline & & \\
\hline
\end{tabular}



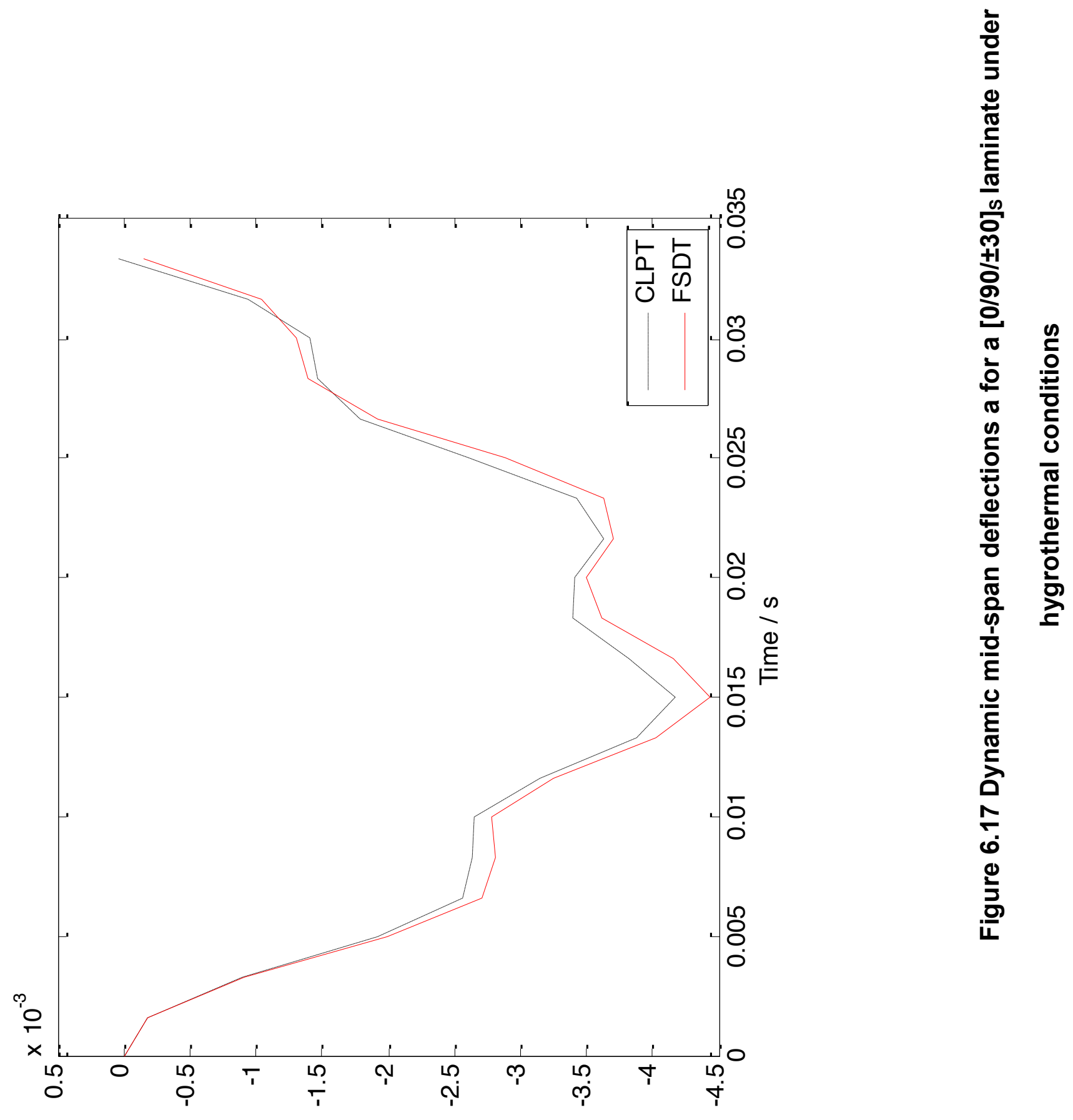
Table 6.30 Dynamic mid-span deflections a for a $[0 / 90 / \pm 30]_{s}$ laminate under hygrothermal conditions

\begin{tabular}{|c|c|c|}
\hline \multirow{2}{*}{$\begin{array}{l}\text { Time at the end of } \\
\text { each load step (s) }\end{array}$} & \multicolumn{2}{|c|}{ Mid-span dynamic deflections (m) } \\
\hline & CLPT & FSDT \\
\hline 0 & 0 & 0 \\
\hline 1.6667E-03 & $-1.8601 \mathrm{E}-04$ & $-1.8372 \mathrm{E}-04$ \\
\hline 3.3333E-03 & $-8.9862 \mathrm{E}-04$ & $-9.1131 \mathrm{E}-04$ \\
\hline $5.0000 \mathrm{E}-03$ & $-1.9210 \mathrm{E}-03$ & $-1.9889 E-03$ \\
\hline $6.6667 \mathrm{E}-03$ & $-2.5641 \mathrm{E}-03$ & $-2.7020 \mathrm{E}-03$ \\
\hline 8.3333E-03 & $-2.6319 \mathrm{E}-03$ & $-2.8052 E-03$ \\
\hline 1.0000E-02 & $-2.6493 \mathrm{E}-03$ & $-2.7853 \mathrm{E}-03$ \\
\hline 1.1667E-02 & $-3.1477 \mathrm{E}-03$ & $-3.2432 E-03$ \\
\hline 1.3333E-02 & $-3.8772 E-03$ & $-4.0224 \mathrm{E}-03$ \\
\hline $1.5000 \mathrm{E}-02$ & $-4.1675 E-03$ & $-4.4371 \mathrm{E}-03$ \\
\hline 1.6667E-02 & $-3.8211 \mathrm{E}-03$ & $-4.1608 \mathrm{E}-03$ \\
\hline 1.8333E-02 & $-3.3915 E-03$ & $-3.6193 E-03$ \\
\hline $2.0000 \mathrm{E}-02$ & $-3.4076 \mathrm{E}-03$ & $-3.4929 E-03$ \\
\hline $2.1667 \mathrm{E}-02$ & $-3.6329 E-03$ & $-3.7063 E-03$ \\
\hline $2.3333 \mathrm{E}-02$ & $-3.4212 \mathrm{E}-03$ & $-3.6289 \mathrm{E}-03$ \\
\hline $2.5000 \mathrm{E}-02$ & $-2.6081 \mathrm{E}-03$ & $-2.8803 E-03$ \\
\hline 2.6667E-02 & $-1.7866 \mathrm{E}-03$ & $-1.9198 \mathrm{E}-03$ \\
\hline 2.8333E-02 & $-1.4631 \mathrm{E}-03$ & $-1.3926 \mathrm{E}-03$ \\
\hline 3.0000E-02 & $-1.4049 \mathrm{E}-03$ & $-1.3107 \mathrm{E}-03$ \\
\hline 3.1667E-02 & $-9.4639 E-04$ & $-1.0387 E-03$ \\
\hline 3.3333E-02 & 4.0139E-05 & $-1.5645 \mathrm{E}-04$ \\
\hline
\end{tabular}




\subsubsection{Fiber Volume Fraction, $V_{f}=0.7$}

The dynamic mid-span deflections for the three different laminate stacking sequences, $[0 / \pm 20]_{s},[0 / 90 / \pm 45]_{T}$ and $[0 / 90 / \pm 30]_{s}$, are plotted in Figures 6.18, 6.19 and 6.20 and are listed below in Tables $6.31,6.32$ and 6.33 for both the theories, CLPT and FSDT. 

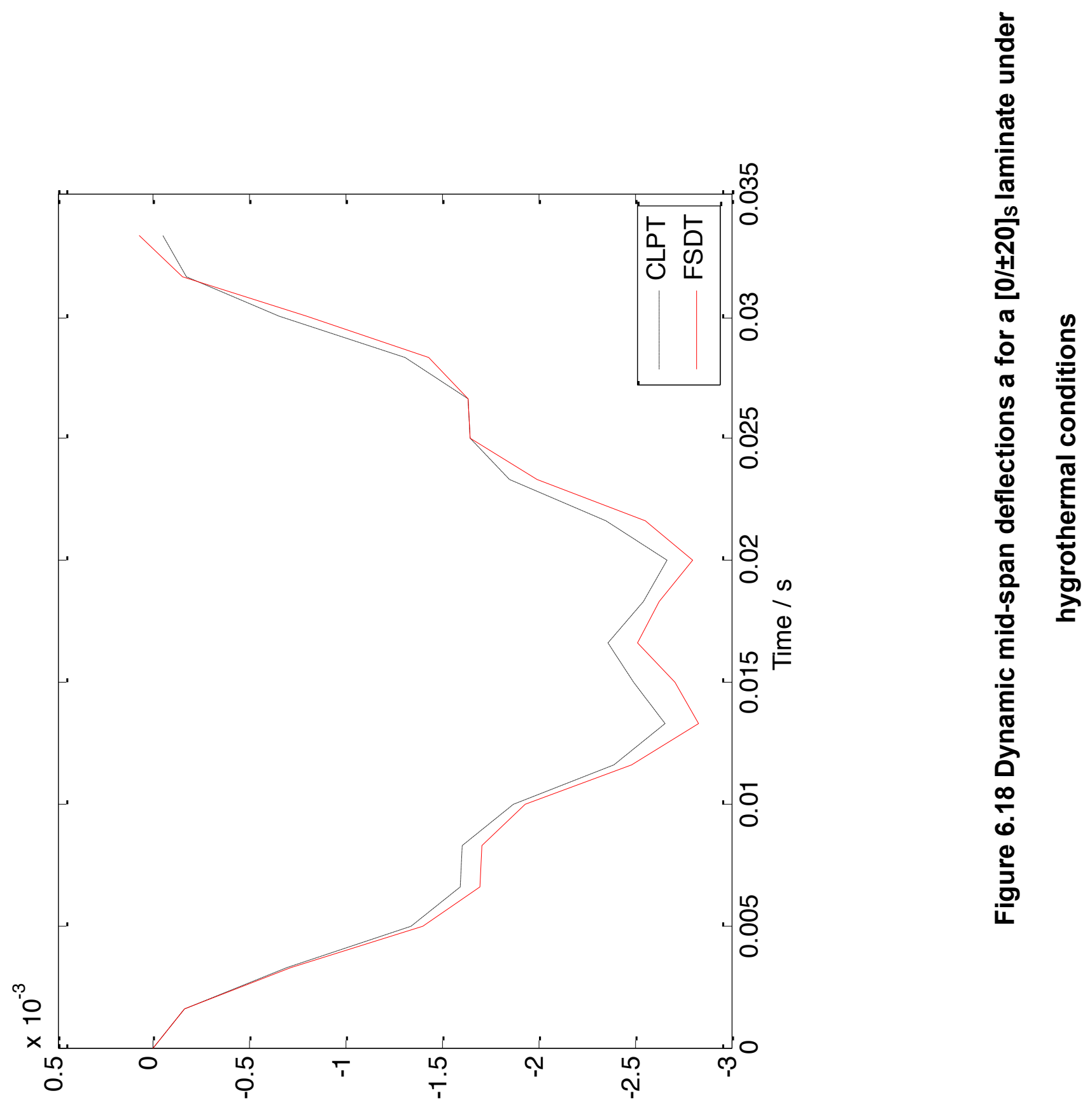
Table 6.31 Dynamic mid-span deflections a for a $[0 / \pm 20]_{s}$ laminate under hygrothermal conditions

\begin{tabular}{|c|c|c|}
\hline \multirow{2}{*}{$\begin{array}{l}\text { Time at the end of } \\
\text { each load step (s) }\end{array}$} & \multicolumn{2}{|c|}{ Mid-span dynamic deflections (m) } \\
\hline & CLPT & FSDT \\
\hline 0 & 0 & 0 \\
\hline 1.6667E-03 & $-1.5634 \mathrm{E}-04$ & $-1.5590 \mathrm{E}-04$ \\
\hline 3.3333E-03 & $-6.9560 \mathrm{E}-04$ & $-7.1203 E-04$ \\
\hline $5.0000 \mathrm{E}-03$ & $-1.3367 \mathrm{E}-03$ & $-1.3986 \mathrm{E}-03$ \\
\hline 6.6667E-03 & $-1.5948 \mathrm{E}-03$ & $-1.6964 \mathrm{E}-03$ \\
\hline 8.3333E-03 & $-1.6061 \mathrm{E}-03$ & $-1.7040 \mathrm{E}-03$ \\
\hline 1.0000E-02 & $-1.8684 \mathrm{E}-03$ & $-1.9353 E-03$ \\
\hline 1.1667E-02 & $-2.3929 \mathrm{E}-03$ & $-2.4845 \mathrm{E}-03$ \\
\hline 1.3333E-02 & $-2.6554 \mathrm{E}-03$ & $-2.8291 \mathrm{E}-03$ \\
\hline 1.5000E-02 & $-2.4942 E-03$ & $-2.7057 \mathrm{E}-03$ \\
\hline 1.6667E-02 & $-2.3574 \mathrm{E}-03$ & $-2.5119 \mathrm{E}-03$ \\
\hline 1.8333E-02 & $-2.5404 \mathrm{E}-03$ & $-2.6250 \mathrm{E}-03$ \\
\hline 2.0000E-02 & $-2.6700 \mathrm{E}-03$ & $-2.8038 \mathrm{E}-03$ \\
\hline 2.1667E-02 & $-2.3490 \mathrm{E}-03$ & $-2.5517 \mathrm{E}-03$ \\
\hline 2.3333E-02 & $-1.8438 \mathrm{E}-03$ & $-1.9903 E-03$ \\
\hline $2.5000 \mathrm{E}-02$ & $-1.6395 \mathrm{E}-03$ & $-1.6480 \mathrm{E}-03$ \\
\hline 2.6667E-02 & $-1.6330 \mathrm{E}-03$ & $-1.6302 E-03$ \\
\hline 2.8333E-02 & $-1.3105 E-03$ & $-1.4241 \mathrm{E}-03$ \\
\hline $3.0000 \mathrm{E}-02$ & $-6.5364 \mathrm{E}-04$ & $-7.9347 \mathrm{E}-04$ \\
\hline 3.1667E-02 & $-1.6673 \mathrm{E}-04$ & $-1.5385 E-04$ \\
\hline 3.3333E-02 & $-4.7865 \mathrm{E}-05$ & 7.9857E-05 \\
\hline
\end{tabular}




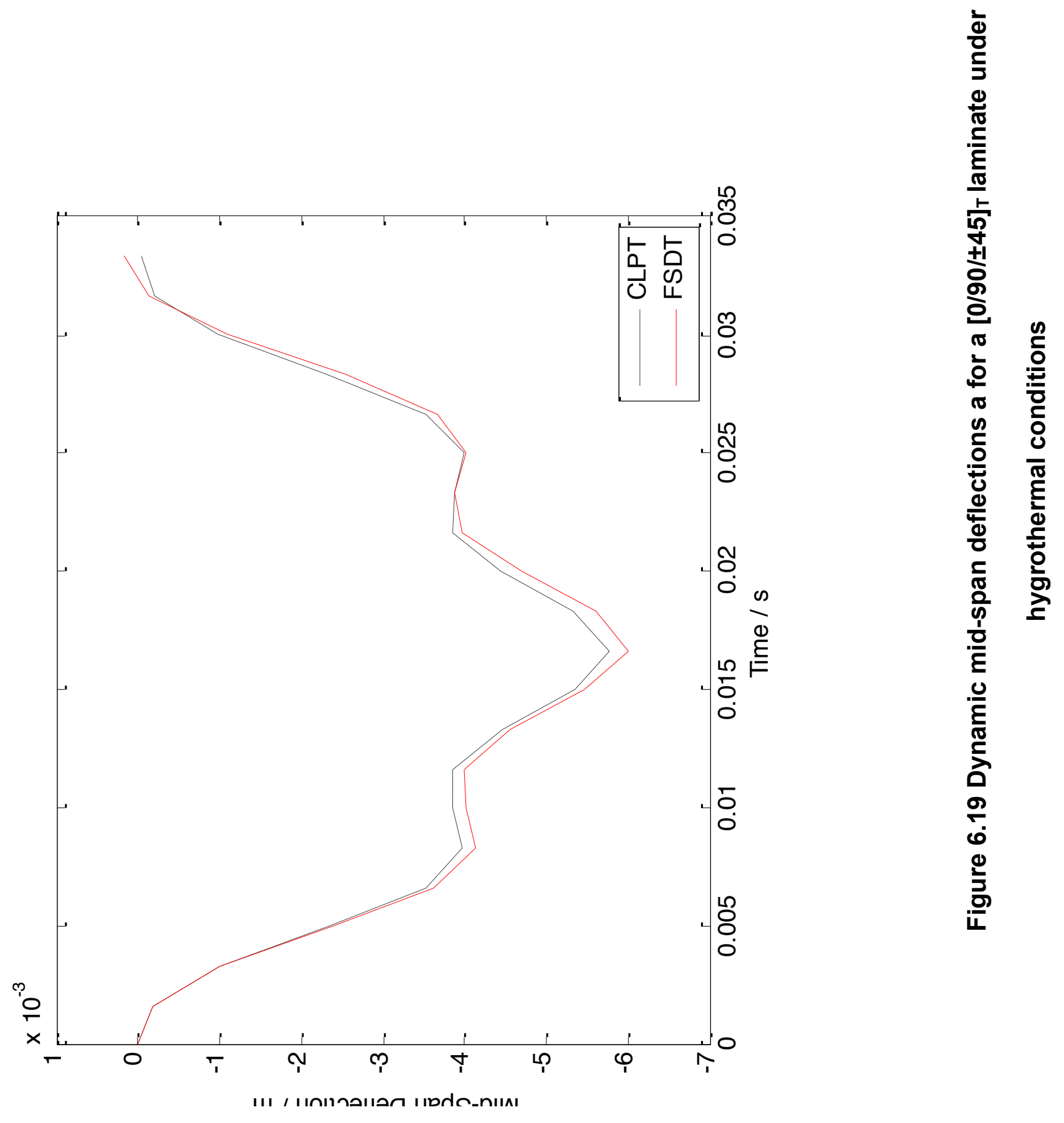


Table 6.32 Dynamic mid-span deflections a for a [0/90/ \pm 45$]_{T}$ laminate under hygrothermal conditions

\begin{tabular}{|c|c|c|}
\hline \multirow{2}{*}{$\begin{array}{l}\text { Time at the end of } \\
\text { each load step (s) }\end{array}$} & \multicolumn{2}{|c|}{ Mid-span dynamic deflections (m) } \\
\hline & CLPT & FSDT \\
\hline 0 & 0 & 0 \\
\hline 1.6667E-03 & $-1.8939 E-04$ & $-1.8651 \mathrm{E}-04$ \\
\hline 3.3333E-03 & $-9.9173 E-04$ & $-9.9543 \mathrm{E}-04$ \\
\hline $5.0000 \mathrm{E}-03$ & $-2.3429 E-03$ & $-2.3835 \mathrm{E}-03$ \\
\hline $6.6667 \mathrm{E}-03$ & $-3.5225 E-03$ & $-3.6231 \mathrm{E}-03$ \\
\hline 8.3333E-03 & $-3.9753 E-03$ & $-4.1357 \mathrm{E}-03$ \\
\hline $1.0000 \mathrm{E}-02$ & $-3.8476 \mathrm{E}-03$ & $-4.0169 \mathrm{E}-03$ \\
\hline 1.1667E-02 & $-3.8638 E-03$ & $-3.9892 E-03$ \\
\hline 1.3333E-02 & $-4.4697 \mathrm{E}-03$ & $-4.5584 \mathrm{E}-03$ \\
\hline $1.5000 \mathrm{E}-02$ & $-5.3576 \mathrm{E}-03$ & $-5.4790 \mathrm{E}-03$ \\
\hline 1.6667E-02 & $-5.7729 E-03$ & $-6.0051 \mathrm{E}-03$ \\
\hline 1.8333E-02 & $-5.3258 E-03$ & $-5.6153 \mathrm{E}-03$ \\
\hline $2.0000 \mathrm{E}-02$ & $-4.4455 \mathrm{E}-03$ & $-4.6895 \mathrm{E}-03$ \\
\hline 2.1667E-02 & $-3.8653 \mathrm{E}-03$ & $-3.9662 \mathrm{E}-03$ \\
\hline 2.3333E-02 & $-3.8841 \mathrm{E}-03$ & $-3.8749 \mathrm{E}-03$ \\
\hline $2.5000 \mathrm{E}-02$ & $-3.9944 E-03$ & $-4.0161 \mathrm{E}-03$ \\
\hline 2.6667E-02 & $-3.5150 \mathrm{E}-03$ & $-3.6628 \mathrm{E}-03$ \\
\hline 2.8333E-02 & -2.3070 E-03 & $-2.5341 \mathrm{E}-03$ \\
\hline $3.0000 \mathrm{E}-02$ & $-9.7313 \mathrm{E}-04$ & -1.0970E-03 \\
\hline 3.1667E-02 & $-2.0597 E-04$ & $-1.3261 \mathrm{E}-04$ \\
\hline 3.3333E-02 & $-3.1219 E-05$ & $1.5856 \mathrm{E}-04$ \\
\hline
\end{tabular}




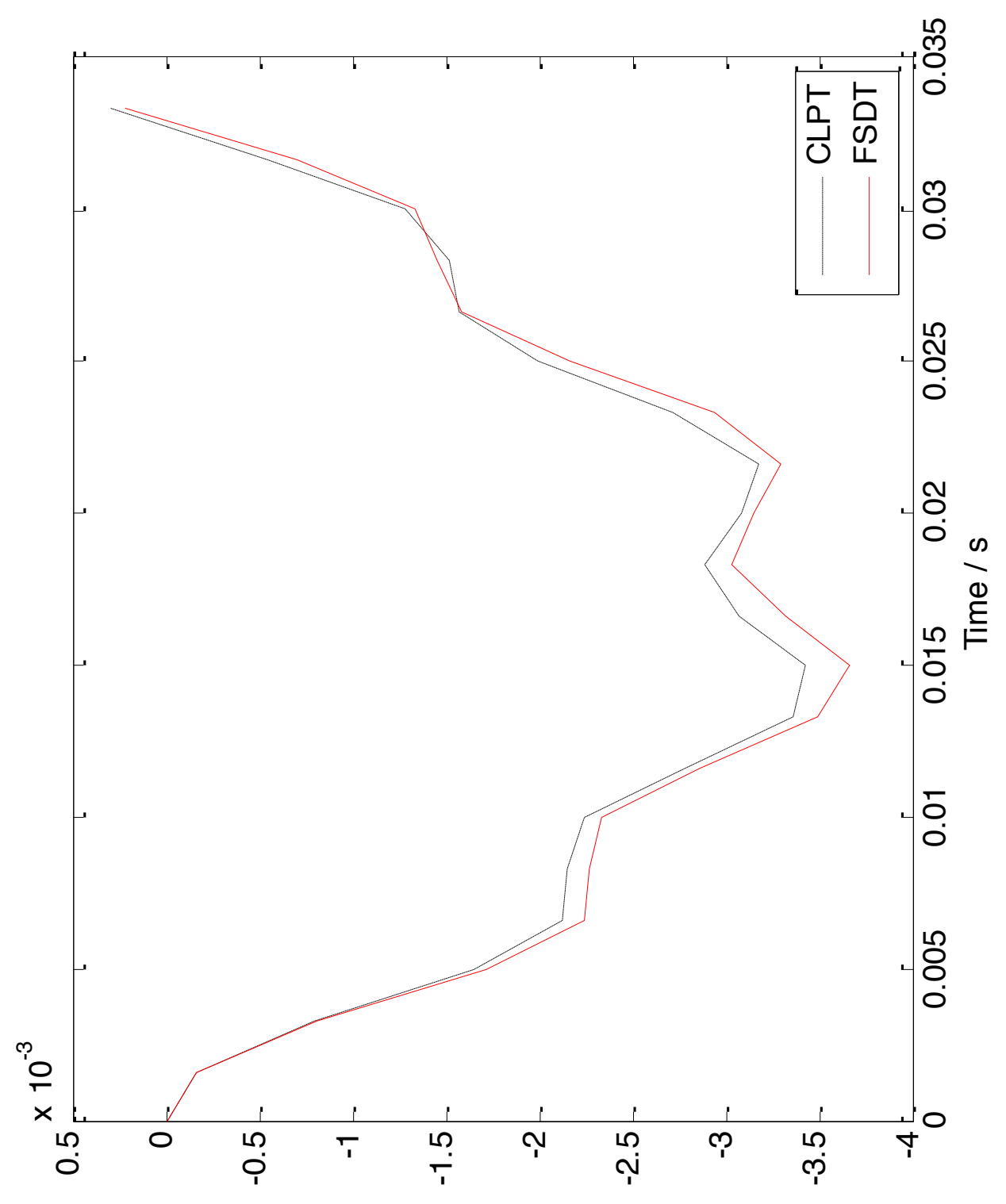

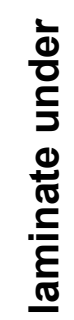

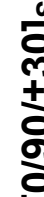

은

으 엄

은 항

웜 है

$\frac{9}{0}$

ㄷํำ 잉

힘

를

ํㅗㄴ 
Table 6.33 Dynamic mid-span deflections a for a $[0 / 90 / \pm 30]_{s}$ laminate under hygrothermal conditions

\begin{tabular}{|c|c|c|}
\hline \multirow{2}{*}{$\begin{array}{l}\text { Time at the end of } \\
\text { each load step (s) }\end{array}$} & \multicolumn{2}{|c|}{ Mid-span dynamic deflections (m) } \\
\hline & CLPT & FSDT \\
\hline 0 & 0 & 0 \\
\hline 1.6667E-03 & $-1.6985 E-04$ & $-1.6838 \mathrm{E}-04$ \\
\hline 3.3333E-03 & $-7.9952 E-04$ & $-8.1228 \mathrm{E}-04$ \\
\hline $5.0000 \mathrm{E}-03$ & $-1.6530 \mathrm{E}-03$ & $-1.7128 \mathrm{E}-03$ \\
\hline $6.6667 \mathrm{E}-03$ & $-2.1250 \mathrm{E}-03$ & $-2.2386 \mathrm{E}-03$ \\
\hline 8.3333E-03 & $-2.1449 \mathrm{E}-03$ & $-2.2760 \mathrm{E}-03$ \\
\hline 1.0000E-02 & $-2.2462 E-03$ & $-2.3409 \mathrm{E}-03$ \\
\hline 1.1667E-02 & $-2.7810 \mathrm{E}-03$ & $-2.8590 \mathrm{E}-03$ \\
\hline 1.3333E-02 & $-3.3557 \mathrm{E}-03$ & $-3.4988 \mathrm{E}-03$ \\
\hline $1.5000 \mathrm{E}-02$ & $-3.4268 E-03$ & $-3.6658 \mathrm{E}-03$ \\
\hline 1.6667E-02 & $-3.0758 \mathrm{E}-03$ & $-3.3270 \mathrm{E}-03$ \\
\hline 1.8333E-02 & $-2.8917 E-03$ & $-3.0269 \mathrm{E}-03$ \\
\hline $2.0000 \mathrm{E}-02$ & $-3.0848 E-03$ & $-3.1486 \mathrm{E}-03$ \\
\hline $2.1667 \mathrm{E}-02$ & $-3.1743 E-03$ & $-3.2970 \mathrm{E}-03$ \\
\hline 2.3333E-02 & $-2.7228 \mathrm{E}-03$ & $-2.9430 \mathrm{E}-03$ \\
\hline $2.5000 \mathrm{E}-02$ & $-1.9885 E-03$ & $-2.1609 \mathrm{E}-03$ \\
\hline 2.6667E-02 & $-1.5753 \mathrm{E}-03$ & $-1.5834 \mathrm{E}-03$ \\
\hline 2.8333E-02 & $-1.5226 \mathrm{E}-03$ & $-1.4556 \mathrm{E}-03$ \\
\hline $3.0000 \mathrm{E}-02$ & $-1.2887 E-03$ & $-1.3321 \mathrm{E}-03$ \\
\hline 3.1667E-02 & $-5.4472 \mathrm{E}-04$ & -7.0976E-04 \\
\hline 3.3333E-02 & 2.9463E-04 & $2.1987 \mathrm{E}-04$ \\
\hline
\end{tabular}




\subsection{Dynamic Magnification Factor}

The dynamic magnification factor (DMF) is the ratio of the maximum dynamic mid-span deflection to the static deflection at mid-span. These are calculated for the three different lay-ups, $[0 / \pm 20]_{s},[0 / 90 / \pm 45]_{T}$ and $[0 / 90 / \pm 30]_{S}$, and the three difference fiber volume fractions, $V_{f}=0.52, V_{f}=0.6$ and $V_{f}=0.7$ under dry and hygrothermal conditions using CLPT and FSDT. These are listed in Table 6.34 and plotted in Figures 6.21, 6.22 and 6.23 with respect to the fiber volume fraction for different lay-ups.

Table 6.34 Dynamic magnification factors of various laminate configurations for a glass/epoxy composite beam

\begin{tabular}{|c|c|c|c|c|c|}
\hline \multirow{2}{*}{$\begin{array}{c}\text { Fiber } \\
\text { volume } \\
\text { fraction }\end{array}$} & Lay-up & \multicolumn{3}{|c|}{ Dynamic magnification factor } \\
\cline { 3 - 6 } & & Dry condition & \multicolumn{2}{c|}{$\begin{array}{c}\text { Hygrothermal } \\
\text { condition }\end{array}$} \\
\cline { 3 - 6 } & & CLPT & FSDT & CLPT & FSDT \\
\hline \multirow{3}{*}{$\boldsymbol{V}_{\boldsymbol{f}}=\mathbf{0 . 5 2}$} & {$[0 / \pm 20]_{\mathrm{S}}$} & 1.048 & 1.051 & 1.047 & 1.065 \\
\cline { 2 - 6 } & {$[0 / 90 / \pm 45]_{\mathrm{T}}$} & 1.144 & 1.139 & 1.150 & 1.142 \\
\cline { 2 - 6 } & {$[0 / 90 / \pm 30]_{\mathrm{S}}$} & 1.104 & 1.105 & 1.111 & 1.105 \\
\hline \multirow{3}{*}{$\boldsymbol{V}_{\boldsymbol{f}}=\mathbf{0 . 6}$} & {$[0 / \pm 20]_{\mathrm{S}}$} & 1.045 & 1.041 & 1.046 & 1.038 \\
\cline { 2 - 6 } & {$[0 / 90 / \pm 45]_{\mathrm{T}}$} & 1.140 & 1.144 & 1.139 & 1.143 \\
\cline { 2 - 6 } & {$[0 / 90 / \pm 30]_{\mathrm{S}}$} & 1.082 & 1.090 & 1.098 & 1.101 \\
\hline \multirow{3}{*}{$\boldsymbol{V}_{\boldsymbol{f}=\mathbf{0 . 7}}$} & {$[0 / \pm 20]_{\mathrm{S}}$} & 1.041 & 1.033 & 1.040 & 1.034 \\
\cline { 2 - 6 } & {$[0 / 90 / \pm 45]_{\mathrm{T}}$} & 1.110 & 1.104 & 1.145 & 1.146 \\
\cline { 2 - 6 } & {$[0 / 90 / \pm 30]_{\mathrm{s}}$} & 1.048 & 1.055 & 1.065 & 1.077 \\
\hline
\end{tabular}




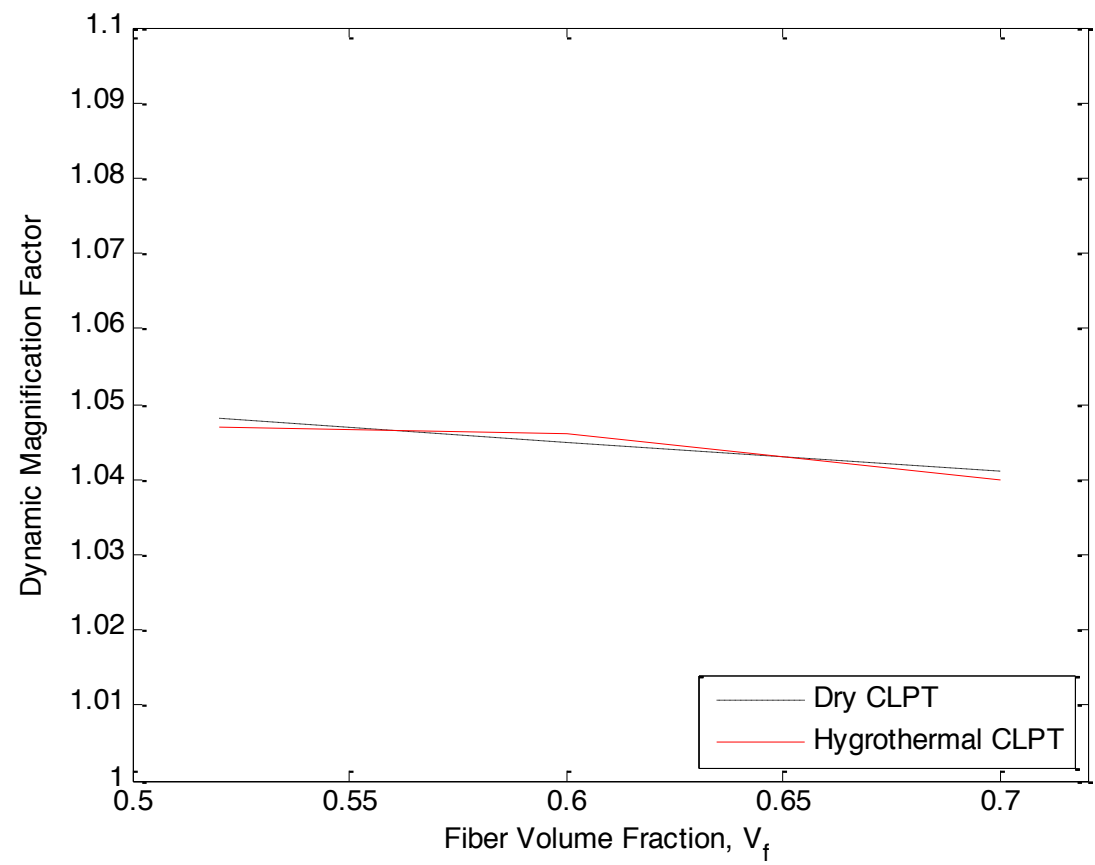

(a) CLPT

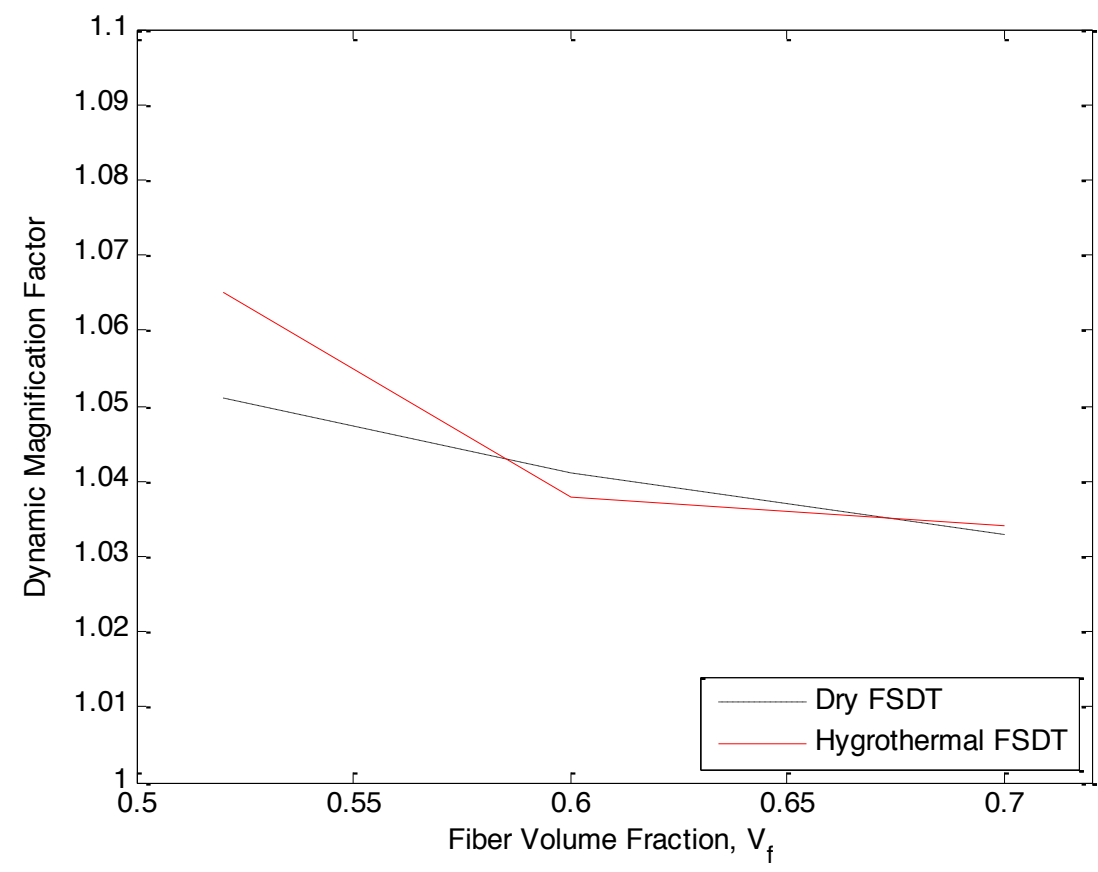

(b) FSDT

Figure 6.21 Dynamic magnification factor for a $[0 / \pm 20]_{s}$ laminate 


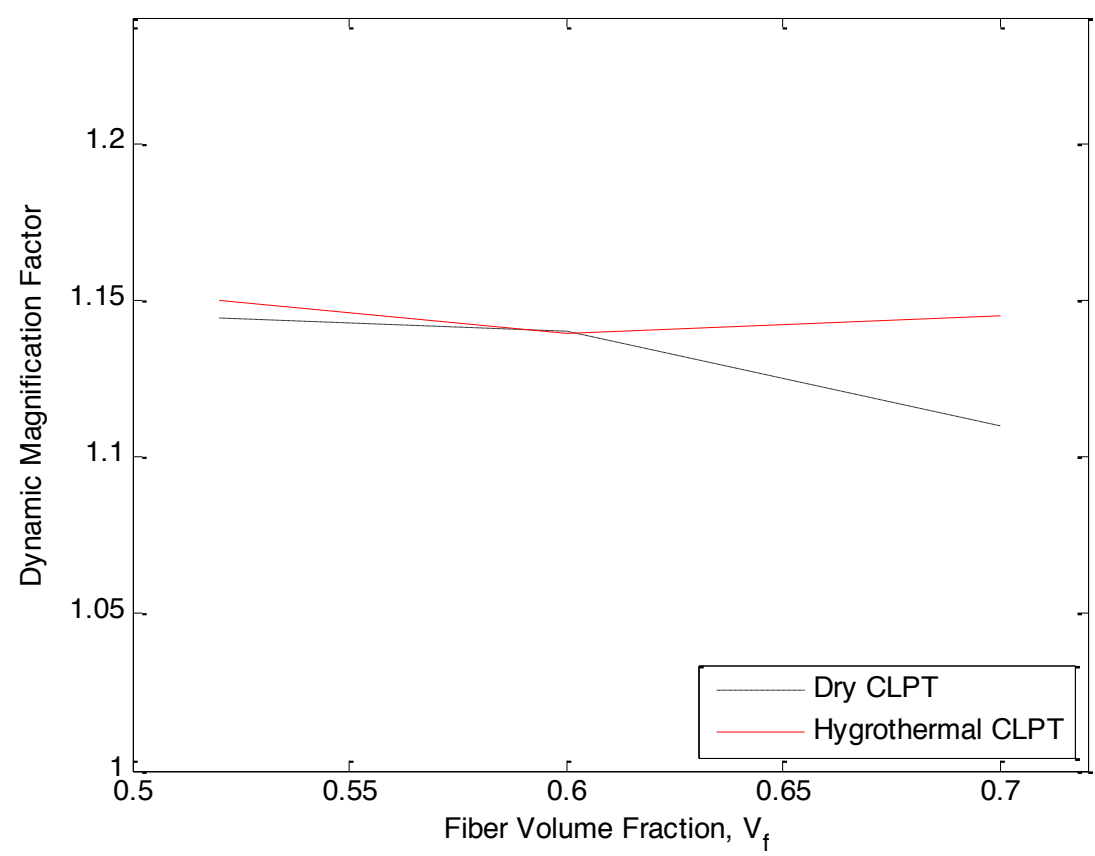

(a) CLPT

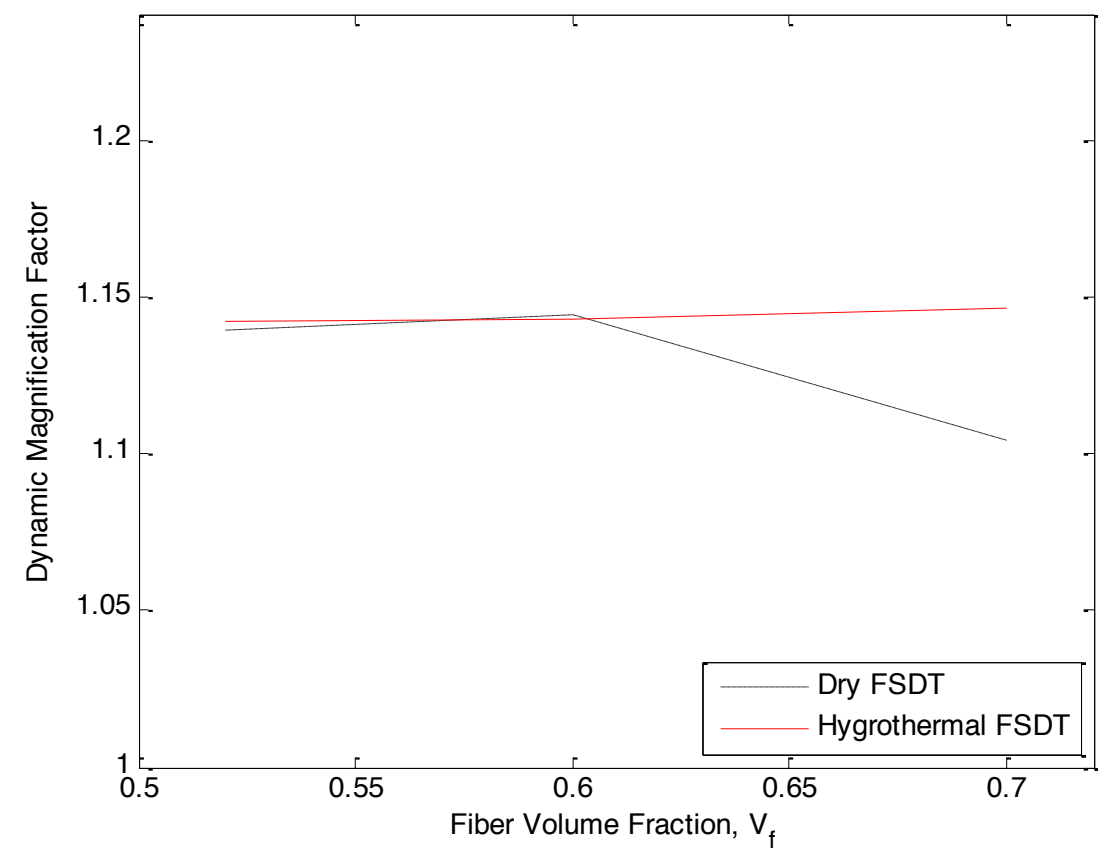

(b) FSDT

Figure 6.22 Dynamic magnification factor for a $[0 / 90 / \pm 45]_{T}$ laminate 


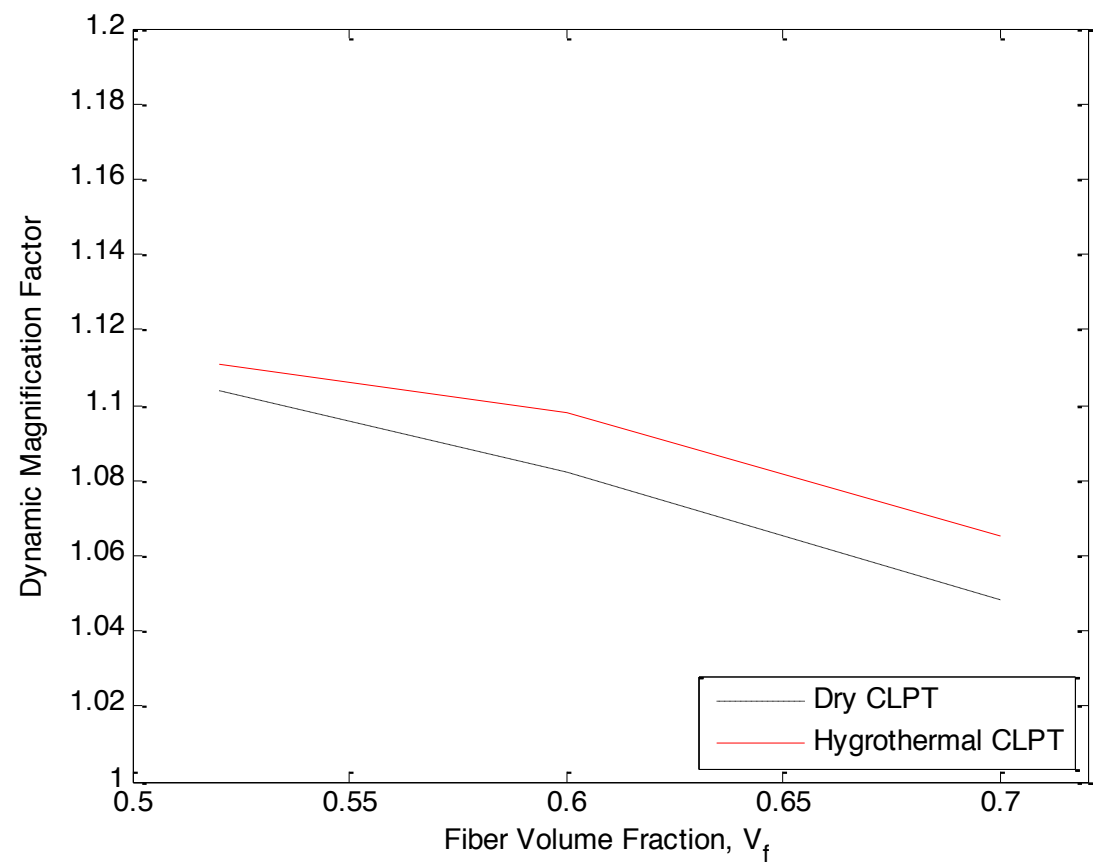

(a) CLPT

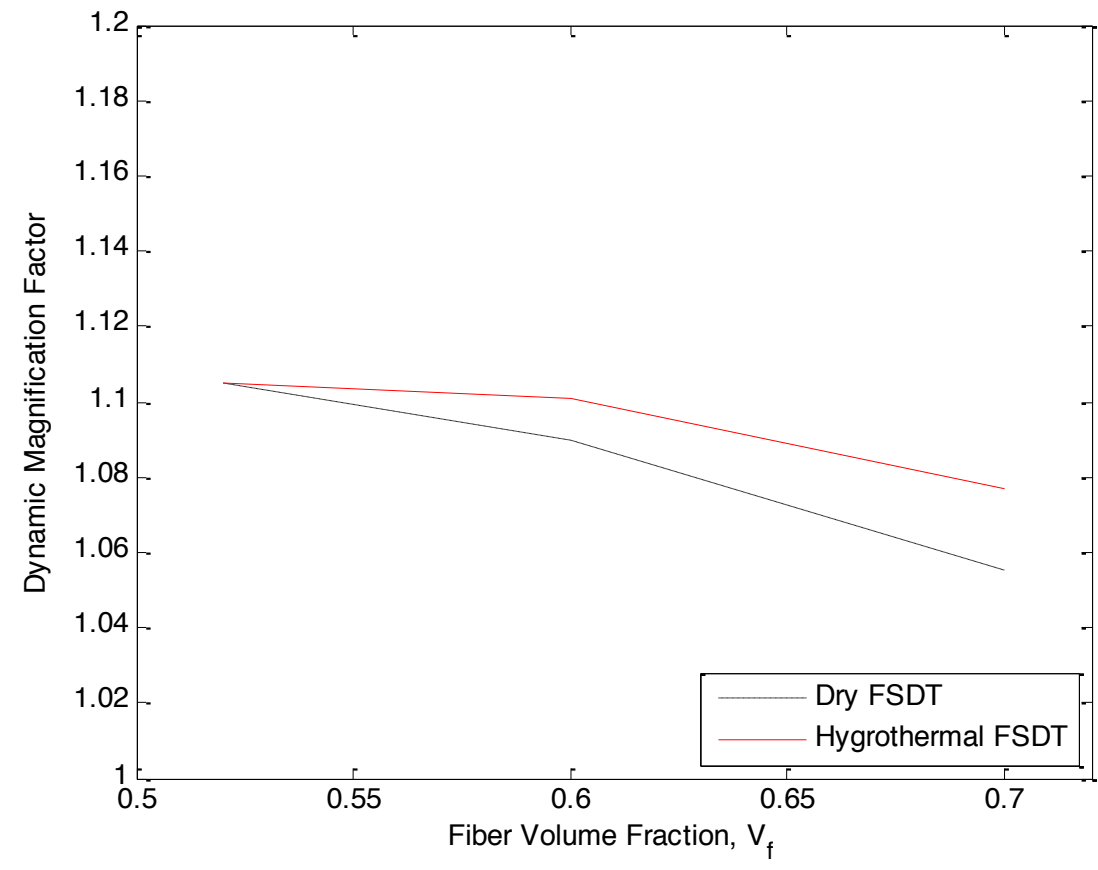

(b) FSDT

Figure 6.23 Dynamic magnification factor for a $[0 / 90 / \pm 30]_{s}$ laminate 
It is observed, as expected, as the fiber volume fraction increases, the deflection decreases for the same laminate configuration, which is due to increased stiffness of the laminate corresponding to a higher volume of fibers. The ply-orientations also affect the dynamic behavior of the beam.

It can also be seen that as the fiber volume fraction increases, the dynamic magnification factor decreases; the one exception being in the case of $[0 / 90 / \pm 45]_{\top}$ where the dynamic magnification factor increases when $V_{f}=0.7$. In dry conditions, the dynamic magnification factor is the highest for $[0 / 90 / \pm 45]_{T}$ comparatively. These results can help a designer choose the right ply orientation and the right fiber volume fraction to control the dynamic behavior of laminated beams. 


\section{CHAPTER 7 \\ FAILURE ANALYSIS}

\subsection{Introduction}

In this chapter, the focus is on the stresses across the cross section of a composite beam subjected to a moving load in a dry environment. The state of stress is a precursor for failure analysis. The first step in this procedure involves determining the off-axis strains from the displacement distributions; the second step consists of computing the ply off-axis stresses from the off-axis strains with the aid of the off-axis material stiffness matrix. Then using the stress transformation matrix, the on-axis stresses at the top and bottom of each ply is determined. The on-axis stresses are compared with the ply strength values to determine the safety factor. as the detailed procedure for failure analysis is explained in Section 2.9.Similar to the hygrothermal analysis in Chapter 6, three different laminate stacking sequences, $[0 / \pm 20]_{S},[0 / 90 / \pm 45]_{T}$ and $[0 / 90 / \pm 30]_{S}$, are considered; only one fiber-volume fraction, namely, 0.6 is employed after several observations it is determined that the maximum stresses occur in a moving load analysis at mid-span, when the load is at the mid-span of the beam as well. Thus for failure analysis in this part of the study, the ply on-axis stresses at this instant are computed and compared with their corresponding strengths. 


\subsection{Properties}

The dimensions and material properties of the S-glass/epoxy are given in Table 7.1 and the tensile, compressive and shear strengths are given in Table 7.2.

Table 7.1 Dimensions and properties of S-glass/epoxy composite

\begin{tabular}{|c|c|}
\hline Length, $L$ & $1 \mathrm{~m}$ \\
\hline Width, $b$ & $0.05 \mathrm{~m}$ \\
\hline Total thickness, $h$ & $0.07 \mathrm{~m}$ \\
\hline Longitudinal modulus, $E_{1}$ & $55 \mathrm{GPa}$ \\
\hline Transverse modulus, $E_{2}$ & $16 \mathrm{GPa}$ \\
\hline Longitudinal shear modulus, $G_{12}$ & $7.6 \mathrm{GPa}$ \\
\hline Transverse shear modulus, $G_{13}$ & $7.6 \mathrm{GPa}$ \\
\hline Density, $\rho$ & $1993 \mathrm{~kg} / \mathrm{m}^{3}$ \\
\hline In-plane poisson's ratio, $v_{12}$ & 0.28 \\
\hline Fiber volume fraction, $V_{f}$ & 0.6 \\
\hline
\end{tabular}

Table 7.2 Tensile, compressive and shear strengths of S-glass/epoxy composite

\begin{tabular}{|c|c|}
\hline Longitudinal tensile strength, $F_{1 t}$ & $1620 \mathrm{MPa}$ \\
\hline Transverse tensile strength, $F_{2 t}$ & $40 \mathrm{MPa}$ \\
\hline Longitudinal compressive strength, $F_{1 c}$ & $690 \mathrm{MPa}$ \\
\hline Transverse compressive strength, $F_{2 c}$ & $140 \mathrm{MPa}$ \\
\hline In-plane shear strength, $F_{6}$ & $60 \mathrm{MPa}$ \\
\hline
\end{tabular}




\subsection{Convergence Study}

A convergence study is done to decide on how many elements are to be used in the finite element analysis for the failure analysis. This convergence study is done on a $[0 / 90 / \pm 45]_{T}$ lay-up composite beam with the properties as given earlier in Table 7.1. A static load, $P=-10 \mathrm{kN}$, is applied at mid-span of the simply-supported beam first; then a point load of the same magnitude moves from the left-end of the beam to the right-end of the beam at $V=30 \mathrm{~m} / \mathrm{s}$. For both the statics and dynamics cases, the maximum normal stresses, $\sigma_{x}$, are computed at a distance of $x=L / 4$ and $x=L / 2$ from the left-end of the beam. In the case of the moving-load problem, the stresses are determined when the load is at mid-span. The numbers of elements used for this study are $3,4,5,6$, and 7 . The maximum normal stresses at $x=L / 4$ for different total number of elements are plotted in Figure 7.1 and listed in Table 7.3; the corresponding quantities at $x$ $=L / 2$ are found in Figure 7.2 and Table 7.4 


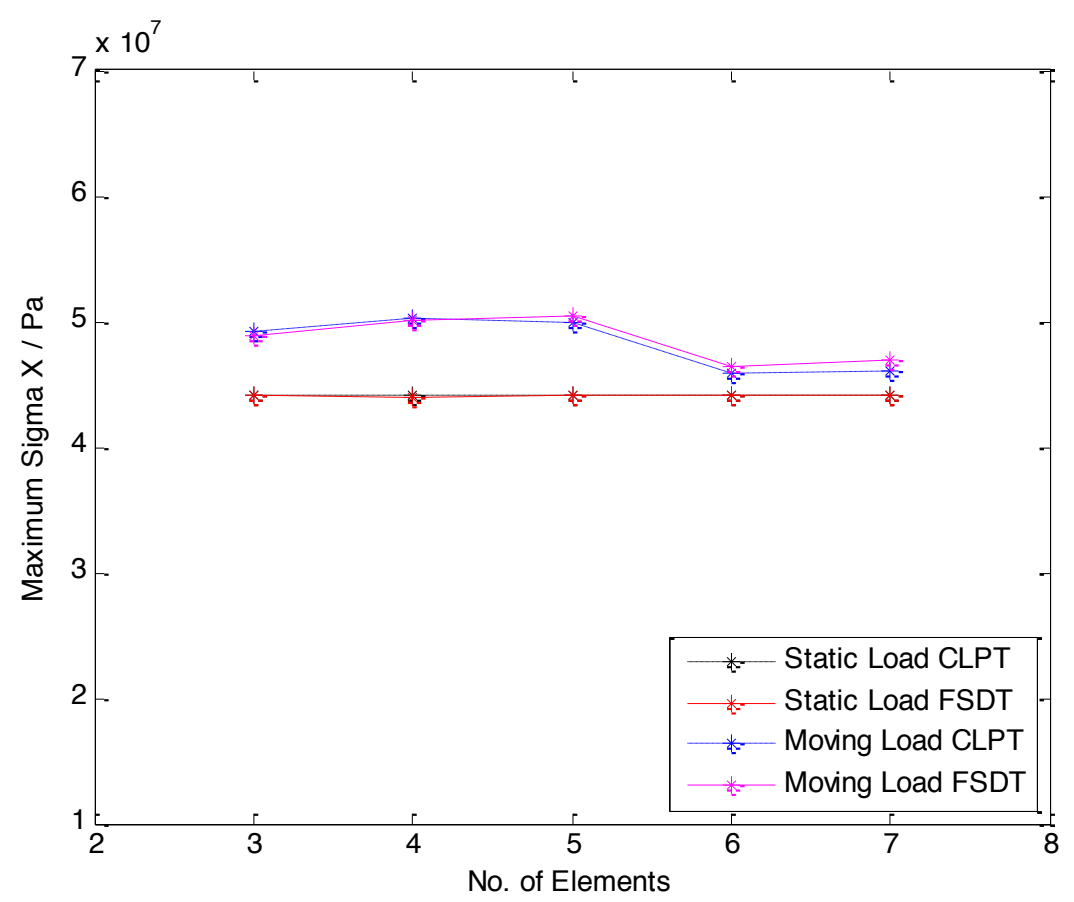

Figure 7.1 Maximum normal stress at $x=L / 4$ for $3,4,5,6$, and 7 elements

Table 7.3 Maximum normal stress for $3,4,5,6$, and 7 elements at $x=L / 4$

\begin{tabular}{|c|c|c|c|c|}
\hline \multirow{3}{*}{$\begin{array}{c}\text { Number } \\
\text { of } \\
\text { elements }\end{array}$} & \multicolumn{4}{|c|}{ Maximum normal stress $\left(\mathrm{N} / \mathrm{m}^{2}\right)$} \\
\hline & \multicolumn{2}{|c|}{ Static analysis } & \multicolumn{2}{|c|}{ Dynamic analysis } \\
\hline & CLPT & FSDT & CLPT & FSDT \\
\hline 3 & $4.4068 \mathrm{E}+07$ & $4.4071 \mathrm{E}+07$ & $4.9242 \mathrm{E}+07$ & $4.8920 \mathrm{E}+07$ \\
\hline 4 & $4.4102 E+07$ & 4.3997E+07 & $5.0176 \mathrm{E}+07$ & $5.0122 \mathrm{E}+07$ \\
\hline 5 & $4.4096 \mathrm{E}+07$ & $4.4072 E+07$ & $4.9910 \mathrm{E}+07$ & $5.0431 \mathrm{E}+07$ \\
\hline 6 & $4.4063 E+07$ & $4.4064 \mathrm{E}+07$ & $4.5930 \mathrm{E}+07$ & $4.6331 \mathrm{E}+07$ \\
\hline 7 & $4.4053 E+07$ & $4.4072 E+07$ & $4.5985 \mathrm{E}+07$ & $4.7003 E+07$ \\
\hline
\end{tabular}

The convergence study indicates that there is a considerable difference between 5- and 6-element cases for the static load and dynamic load analyses; therefore we shall be using 5 elements for the failure analysis. 


\subsection{Stress Analysis for Different Lay-ups of a Composite}

\section{Beam}

A simply-supported beam is considered for this part of the analysis with a concentrated load of $P=-10 \mathrm{kN}$ that moves from the left-end of the beam to the right-end of the beam at $V=30 \mathrm{~m} / \mathrm{s}=108 \mathrm{~km} / \mathrm{hr}$. As discussed earlier, there are three different laminate stacking sequences of a S-glass/epoxy composite material used for analysis with properties given in Table 7.1 and Table 7.2. These lay-ups are $[0 / \pm 20]_{\mathrm{S}},[0 / 90 / \pm 45 /]_{\mathrm{T}}$ and $[0 / 90 / \pm 30]_{\mathrm{s}}$. For all three lay-ups, a careful observation of the time-dependent stresses, has revealed, that the maximum stresses occur at the mid-span of the beam when the load is at the mid-span of the beam as well. Thus for failure analysis, the maximum on-axis stresses $\left(\sigma_{1}, \sigma_{2}, \sigma_{6}\right)$ at this instant are captured and compared with their corresponding strengths. This comparison is done as described in Section 2.9 using both CLPT and FSDT. Then the factors of safety are determined based on the maximum normal stress theory as outlined in Equation (2.6).

\subsection{1 $[0 / \pm 20]_{s}$ Composite Beam}

\subsubsection{Strain and Stress Analysis}

The off-axis longitudinal, transverse, and shear strains at the mid span of the beam are listed in Tables $7.4,7.5,7.6$, respectively. Since these strain components are linear across the cross section of the laminate, just the values at the top and bottom of the laminate are listed. 
Table 7.4 Normal strain at the top and bottom of a $[0 / \pm 20]_{s}$ laminated composite beam

\begin{tabular}{|c|c|c|c|}
\hline \multicolumn{2}{|c|}{ Ply } & \multicolumn{2}{c|}{$\varepsilon_{x}$} \\
\cline { 3 - 4 } & CLPT & FSDT \\
\hline $\begin{array}{c}0^{\circ} \\
(\text { Top of laminate) }\end{array}$ & Top & $-1.0740 \mathrm{E}-03$ & $-1.0765 \mathrm{E}-03$ \\
\hline $\begin{array}{c}0^{\circ} \\
\text { (Bottom of } \\
\text { laminate) }\end{array}$ & Bottom & $1.0740 \mathrm{E}-03$ & $1.0765 \mathrm{E}-03$ \\
\hline
\end{tabular}

Table 7.5 Transverse strain at the top and bottom of a $[0 / \pm 20]_{s}$ laminated composite beam

\begin{tabular}{|c|c|c|c|}
\hline \multicolumn{2}{|c|}{ Ply } & \multicolumn{2}{|c|}{$\varepsilon_{y}$} \\
\cline { 3 - 4 } & CLPT & FSDT \\
\hline $\begin{array}{c}0^{\circ} \\
\text { (Top of laminate) }\end{array}$ & Top & $3.5496 \mathrm{E}-04$ & $3.5580 \mathrm{E}-04$ \\
\hline $\begin{array}{c}0^{\circ} \\
\text { (Bottom of } \\
\text { laminate) }\end{array}$ & Bottom & $-3.5496 \mathrm{E}-04$ & $-3.5580 \mathrm{E}-04$ \\
\hline
\end{tabular}

Table 7. 6 Shear strain at the top and bottom of a $[0 / \pm 20]_{s}$ laminated composite beam

\begin{tabular}{|c|c|c|c|}
\hline \multicolumn{2}{|c|}{ Ply } & \multicolumn{2}{|c|}{$\gamma_{x y}$} \\
\cline { 3 - 4 } & CLPT & FSDT \\
\hline $\begin{array}{c}0^{\circ} \\
(\text { Top of laminate) }\end{array}$ & Top & $1.3024 \mathrm{E}-04$ & $1.3076 \mathrm{E}-04$ \\
\hline $\begin{array}{c}0^{\circ} \\
\text { (Bottom of } \\
\text { laminate) }\end{array}$ & Bottom & $-1.3024 \mathrm{E}-04$ & $-1.3076 \mathrm{E}-04$ \\
\hline
\end{tabular}


The off-axis longitudinal, transverse and shear stresses along the crosssection of the laminate at mid-span are calculated from the off-axis strains using the ply off-axis material stiffness matrix and plotted in Figures 7.2, 7.3 and 7.4, respectively, and listed in Tables 7.7, 7.8, and 7.9, respectively.

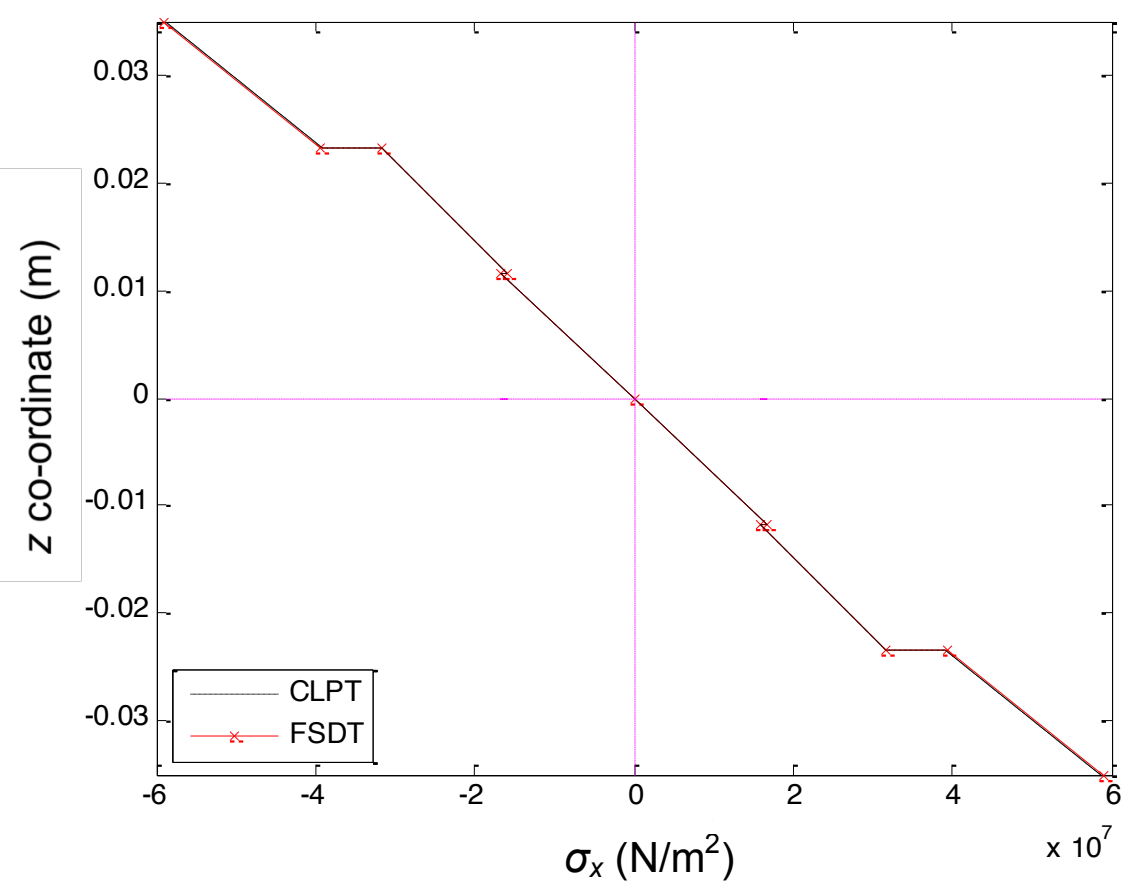

Figure 7.2 Longitudinal stress distribution, $\sigma_{x}$, for a $[0 / \pm 20]_{s}$ composite beam 


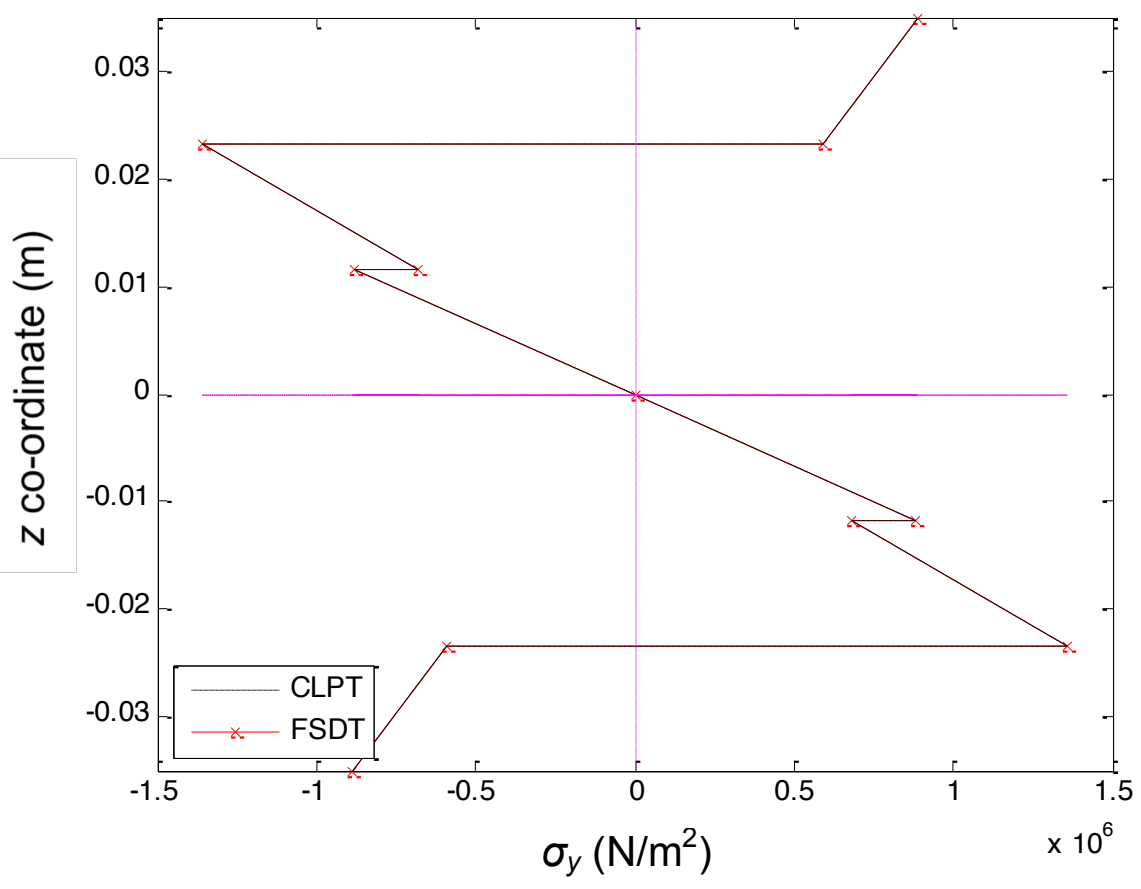

Figure 7.3 Transverse stress distribution, $\sigma_{y}$, for a $[0 / \pm 20]_{s}$ laminated composite beam

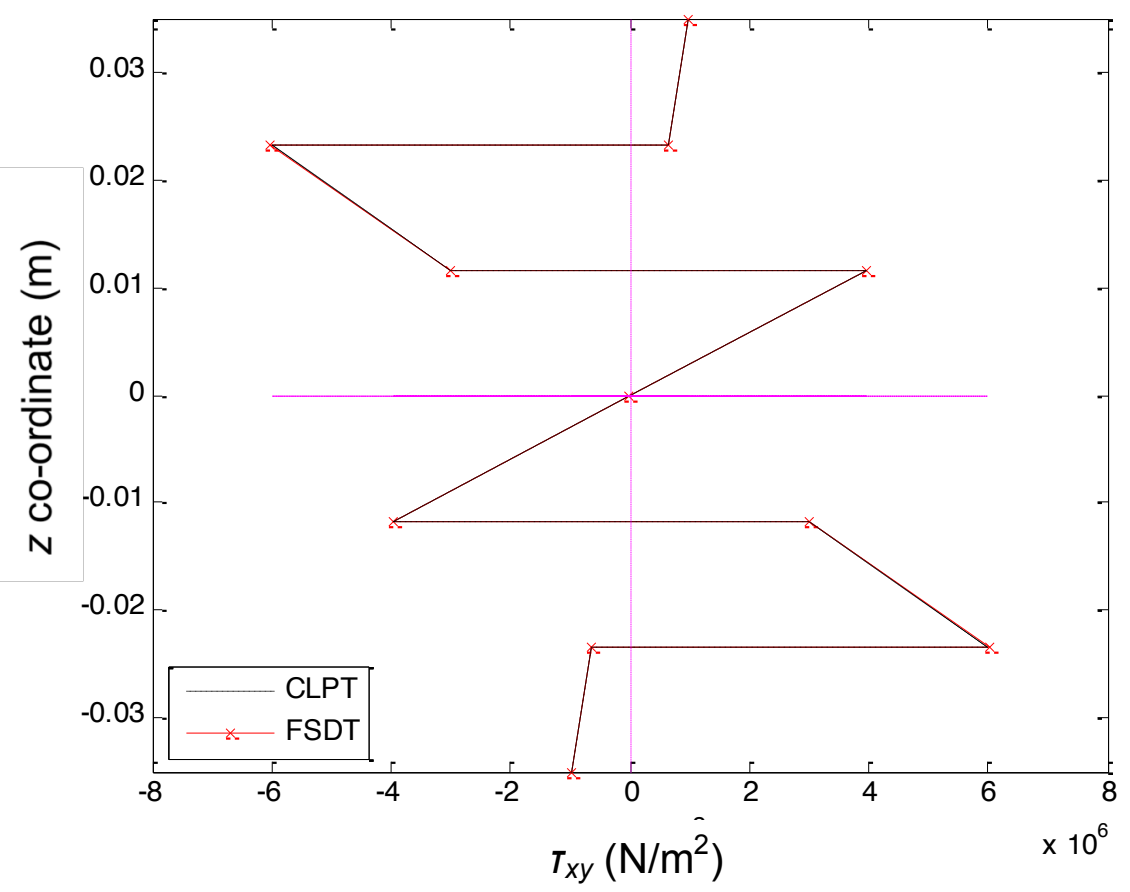

Figure 7.4 Shear stress distribution, $\tau_{x y}$, for a $[0 / \pm 20]_{s}$ laminated composite beam 
Table 7.7 Longitudinal stress along the cross-section of a $[0 / \pm 20]_{s}$ laminated composite beam

\begin{tabular}{|c|c|c|c|}
\hline \multirow{2}{*}{ Ply } & \multicolumn{2}{c|}{$\sigma_{x}\left(\mathbf{N} / \mathbf{m}^{2}\right)$} \\
\cline { 3 - 4 } $\begin{array}{c}0^{2} \\
(\text { Top of laminate })\end{array}$ & Top & $-5.8819 \mathrm{E}+07$ & $-5.8959 \mathrm{E}+07$ \\
\cline { 2 - 4 } & Bottom & $-3.9213 \mathrm{E}+07$ & $-3.9306 \mathrm{E}+07$ \\
\hline \multirow{2}{*}{$20^{\circ}$} & Top & $-3.1704 \mathrm{E}+07$ & $-3.1778 \mathrm{E}+07$ \\
\cline { 2 - 4 } & Bottom & $-1.5852 \mathrm{E}+07$ & $-1.5889 \mathrm{E}+07$ \\
\hline \multirow{2}{*}{$-20^{\circ}$} & Top & $-1.6762 \mathrm{E}+07$ & $-1.6803 \mathrm{E}+07$ \\
\cline { 2 - 4 } & Bottom & $1.6523 \mathrm{E}+01$ & $3.0406 \mathrm{E}+00$ \\
\hline \multirow{2}{*}{$-20^{\circ}$} & Top & $1.6523 \mathrm{E}+01$ & $3.0406 \mathrm{E}+00$ \\
\cline { 2 - 4 } & Bottom & $1.6763 \mathrm{E}+07$ & $1.6803 \mathrm{E}+07$ \\
\hline \multirow{2}{*}{$20^{\circ}$} & Top & $1.5852 \mathrm{E}+07$ & $1.5889 \mathrm{E}+07$ \\
\cline { 2 - 4 } & Bottom & $3.1704 \mathrm{E}+07$ & $3.1778 \mathrm{E}+07$ \\
\hline $0^{\circ}$ & Top & $3.9213 \mathrm{E}+07$ & $3.9306 \mathrm{E}+07$ \\
\hline $\begin{array}{c}\text { Bottom of } \\
\text { laminate })\end{array}$ & Bottom & $5.8819 \mathrm{E}+07$ & $5.8959 \mathrm{E}+07$ \\
\hline
\end{tabular}


Table 7.8 Transverse stress along the cross-section of a $[0 / \pm 20]_{\mathrm{s}}$ laminated composite beam

\begin{tabular}{|c|c|c|c|}
\hline \multirow{2}{*}{ Ply } & \multicolumn{2}{c|}{$\sigma_{y}\left(\mathbf{N} / \mathbf{m}^{2}\right)$} \\
\cline { 3 - 4 } $\begin{array}{c}2 \\
\text { (Top of laminate })\end{array}$ & Top & $8.8829 \mathrm{E}+05$ & $8.9029 \mathrm{E}+05$ \\
\cline { 2 - 4 } & Bottom & $5.9219 \mathrm{E}+05$ & $5.9353 \mathrm{E}+05$ \\
\hline \multirow{2}{*}{$20^{\circ}$} & Top & $-1.3557 \mathrm{E}+06$ & $-1.3586 \mathrm{E}+06$ \\
\cline { 2 - 4 } & Bottom & $-6.7783 \mathrm{E}+05$ & $-6.7931 \mathrm{E}+05$ \\
\hline \multirow{2}{*}{$-20^{\circ}$} & Top & $-8.8104 \mathrm{E}+05$ & $-8.8332 \mathrm{E}+05$ \\
\cline { 2 - 4 } & Bottom & $3.5722 \mathrm{E}-01$ & $6.5734 \mathrm{E}-02$ \\
\hline \multirow{2}{*}{$-20^{\circ}$} & Top & $3.5722 \mathrm{E}-01$ & $6.5734 \mathrm{E}-02$ \\
\cline { 2 - 4 } & Bottom & $8.8104 \mathrm{E}+05$ & $8.8332 \mathrm{E}+05$ \\
\hline \multirow{2}{*}{$20^{\circ}$} & Top & $6.7783 \mathrm{E}+05$ & $6.7931 \mathrm{E}+05$ \\
\cline { 2 - 4 } & Bottom & $1.3557 \mathrm{E}+06$ & $1.3586 \mathrm{E}+06$ \\
\hline $0^{\circ}$ \\
$\begin{array}{c}\text { (Bottom of } \\
\text { laminate) }\end{array}$ & Top & $-5.9220 \mathrm{E}+05$ & $-5.9353 \mathrm{E}+05$ \\
\cline { 2 - 4 } & Bottom & $-8.8829 \mathrm{E}+05$ & $-8.9029 \mathrm{E}+05$ \\
\hline
\end{tabular}


Table 7.9 Shear stress along the cross-section of a $[0 / \pm 20]_{s}$ laminated composite beam

\begin{tabular}{|c|c|c|c|}
\hline \multirow{2}{*}{\multicolumn{2}{|c|}{ Ply }} & \multicolumn{2}{c|}{$\tau_{x y}\left(\mathrm{~N} / \mathrm{m}^{2}\right)$} \\
\cline { 3 - 4 } $\begin{array}{c}0^{\circ} \\
\text { (Top of laminate) }\end{array}$ & Top & $9.8985 \mathrm{E}+05$ & $9.9378 \mathrm{E}+05$ \\
\cline { 2 - 4 } & Bottom & $6.5990 \mathrm{E}+05$ & $6.6252 \mathrm{E}+05$ \\
\hline \multirow{2}{*}{$20^{\circ}$} & Top & $-5.9977 \mathrm{E}+06$ & $-6.0104 \mathrm{E}+06$ \\
\cline { 2 - 4 } & Bottom & $-2.9988 \mathrm{E}+06$ & $-3.0052 \mathrm{E}+06$ \\
\hline \multirow{2}{*}{$-20^{\circ}$} & Top & $3.9555 \mathrm{E}+06$ & $3.9656 \mathrm{E}+06$ \\
\cline { 2 - 4 } & Bottom & $-3.5074 \mathrm{E}+00$ & $-6.4542 \mathrm{E}-01$ \\
\hline \multirow{3}{*}{$-20^{\circ}$} & Top & $-3.5074 \mathrm{E}+00$ & $-6.4542 \mathrm{E}-01$ \\
\cline { 2 - 4 } & Bottom & $-3.9555 \mathrm{E}+06$ & $-3.9657 \mathrm{E}+06$ \\
\hline \multirow{2}{*}{$20^{\circ}$} & Top & $2.9989 \mathrm{E}+06$ & $3.0052 \mathrm{E}+06$ \\
\cline { 2 - 4 } & Bottom & $5.9977 \mathrm{E}+06$ & $6.0104 \mathrm{E}+06$ \\
\hline $0^{\circ}$ & Top & $-6.5990 \mathrm{E}+05$ & $-6.6252 \mathrm{E}+05$ \\
\hline $\begin{array}{c}\text { (Bottom of } \\
\text { laminate) }\end{array}$ & Bottom & $-9.8985 \mathrm{E}+05$ & $-9.9378 \mathrm{E}+05$ \\
\hline
\end{tabular}

The longitudinal, transverse and shear stresses in the lamina co-ordinate system (on-axis stresses) transformed from the laminate co-ordinate system are listed in Tables 7.10, 7.11, and 7.12, respectively. 
Table 7.10 On-axis longitudinal stress of a $[0 / \pm 20]_{s}$ composite beam

\begin{tabular}{|c|c|c|c|}
\hline \multirow{2}{*}{\multicolumn{2}{|c|}{ Ply }} & \multicolumn{2}{|c|}{$\sigma_{1}\left(\mathbf{N} / \mathbf{m}^{2}\right)$} \\
\hline & & \multirow{2}{*}{$\begin{array}{c}\text { CLPT } \\
-5.8819 \mathrm{E}+07\end{array}$} & \multirow{2}{*}{$\begin{array}{c}\text { FSDT } \\
-5.8959 E+07\end{array}$} \\
\hline & Top & & \\
\hline (Top of laminate) & Bottom & $-3.9213 E+07$ & $-3.9306 \mathrm{E}+07$ \\
\hline \multirow{2}{*}{$20^{\circ}$} & Top & $-3.2009 E+07$ & $-3.2083 E+07$ \\
\hline & Bottom & $-1.6005 E+07$ & $-1.6041 \mathrm{E}+07$ \\
\hline \multirow{2}{*}{$-20^{\circ}$} & Top & $-1.7447 E+07$ & $-1.7490 E+07$ \\
\hline & Bottom & $1.6887 E+01$ & $3.1075 E+00$ \\
\hline \multirow{2}{*}{$-20^{\circ}$} & Top & $1.6887 \mathrm{E}+01$ & $3.1075 E+00$ \\
\hline & Bottom & $1.7447 \mathrm{E}+07$ & $1.7490 \mathrm{E}+07$ \\
\hline \multirow{2}{*}{$20^{\circ}$} & Top & $1.6005 \mathrm{E}+07$ & $1.6041 \mathrm{E}+07$ \\
\hline & Bottom & $3.2009 E+07$ & $3.2083 E+07$ \\
\hline \multirow{2}{*}{$\begin{array}{c}0^{\circ} \\
\text { (Bottom of } \\
\text { laminate) }\end{array}$} & Top & $3.9213 E+07$ & $3.9306 \mathrm{E}+07$ \\
\hline & Bottom & $5.8819 E+07$ & $5.8959 E+07$ \\
\hline
\end{tabular}


Table 7.11 Transverse stress for the lamina of a $[0 / \pm 20]_{s}$ laminated composite beam

\begin{tabular}{|c|c|c|c|}
\hline \multirow{2}{*}{ Ply } & \multicolumn{2}{c|}{$\sigma_{2}\left(\mathrm{~N} / \mathrm{m}^{2}\right)$} \\
\cline { 3 - 4 } \multirow{2}{*}{$\begin{array}{c}0^{\circ} \\
(\text { Top of laminate) }\end{array}$} & Top & $8.8829 \mathrm{E}+05$ & $8.9029 \mathrm{E}+05$ \\
\cline { 2 - 4 } & Bottom & $5.9219 \mathrm{E}+05$ & $5.9353 \mathrm{E}+05$ \\
\hline \multirow{2}{*}{$20^{\circ}$} & Top & $-1.0505 \mathrm{E}+06$ & $-1.0536 \mathrm{E}+06$ \\
\cline { 2 - 4 } & Bottom & $-5.2524 \mathrm{E}+05$ & $-5.2678 \mathrm{E}+05$ \\
\hline \multirow{2}{*}{$-20^{\circ}$} & Top & $-1.9626 \mathrm{E}+05$ & $-1.9649 \mathrm{E}+05$ \\
\cline { 2 - 4 } & Bottom & $-6.1955 \mathrm{E}-03$ & $-1.1401 \mathrm{E}-03$ \\
\hline \multirow{2}{*}{$-20^{\circ}$} & Top & $-6.1955 \mathrm{E}-03$ & $-1.1401 \mathrm{E}-03$ \\
\cline { 2 - 4 } & Bottom & $1.9626 \mathrm{E}+05$ & $1.9649 \mathrm{E}+05$ \\
\hline \multirow{2}{*}{$20^{\circ}$} & Top & $5.2524 \mathrm{E}+05$ & $5.2678 \mathrm{E}+05$ \\
\cline { 2 - 4 } & Bottom & $1.0505 \mathrm{E}+06$ & $1.0536 \mathrm{E}+06$ \\
\hline $\begin{array}{c}0^{\circ} \\
(\text { Bottom of } \\
\text { laminate) }\end{array}$ & Top & $-5.9220 \mathrm{E}+05$ & $-5.9353 \mathrm{E}+05$ \\
\cline { 2 - 4 } & Bottom & $-8.8829 \mathrm{E}+05$ & $-8.9029 \mathrm{E}+05$ \\
\hline
\end{tabular}


Table 7.12 Shear stress for the lamina of a $[0 / \pm 20]_{s}$ laminated composite beam

\begin{tabular}{|c|c|c|c|}
\hline \multirow{2}{*}{ Ply } & \multicolumn{2}{c|}{$\sigma_{6}\left(\mathbf{N} / \mathbf{m}^{2}\right)$} \\
\cline { 3 - 4 } $\begin{array}{c}0^{\circ} \\
(\text { Top of laminate) }\end{array}$ & Top & $9.8985 \mathrm{E}+05$ & $9.9378 \mathrm{E}+05$ \\
\cline { 2 - 4 } & Bottom & $6.5990 \mathrm{E}+05$ & $6.6252 \mathrm{E}+05$ \\
\hline \multirow{2}{*}{$20^{\circ}$} & Top & $5.1592 \mathrm{E}+06$ & $5.1722 \mathrm{E}+06$ \\
\cline { 2 - 4 } & Bottom & $2.5796 \mathrm{E}+06$ & $2.5861 \mathrm{E}+06$ \\
\hline \multirow{2}{*}{$-20^{\circ}$} & Top & $-2.0741 \mathrm{E}+06$ & $-2.0786 \mathrm{E}+06$ \\
\cline { 2 - 4 } & Bottom & $2.5089 \mathrm{E}+00$ & $4.6169 \mathrm{E}-01$ \\
\hline \multirow{3}{*}{$-20^{\circ}$} & Top & $2.5089 \mathrm{E}+00$ & $4.6169 \mathrm{E}-01$ \\
\cline { 2 - 4 } & Bottom & $2.0741 \mathrm{E}+06$ & $2.0786 \mathrm{E}+06$ \\
\hline \multirow{2}{*}{$20^{\circ}$} & Top & $-2.5796 \mathrm{E}+06$ & $-2.5861 \mathrm{E}+06$ \\
\cline { 2 - 4 } & Bottom & $-5.1592 \mathrm{E}+06$ & $-5.1722 \mathrm{E}+06$ \\
\hline $0^{\circ}$ & Top & $-6.5990 \mathrm{E}+05$ & $-6.6252 \mathrm{E}+05$ \\
\cline { 2 - 4 }$\left(\begin{array}{c}\text { Bottom of } \\
\text { laminate) }\end{array}\right.$ & Bottom & $-9.8985 \mathrm{E}+05$ & $-9.9378 \mathrm{E}+05$ \\
\hline
\end{tabular}

\subsubsection{Failure Analysis}

The maximum stresses in tension and compression in the lamina coordinate system, $\sigma_{1}, \sigma_{2}$ and $\sigma_{6}$, are listed in Table 7.13. 
Table 7.13 Maximum stresses in material co-ordinates for a $[0 / \pm 20]_{s}$ composite beam

\begin{tabular}{|c|c|c|}
\hline \multirow{2}{*}{ Type } & \multicolumn{2}{|c|}{ Maximum stress $\mathbf{( N / \mathbf { m } ^ { 2 } )}$} \\
\cline { 2 - 3 } & CLPT & FSDT \\
\hline$\sigma_{1 t}$ & $5.8819 \mathrm{E}+07$ & $5.8959 \mathrm{E}+07$ \\
\hline $\operatorname{abs}\left(\sigma_{1 c}\right)$ & $5.8819 \mathrm{E}+07$ & $5.8959 \mathrm{E}+07$ \\
\hline$\sigma_{2 t}$ & $1.0505 \mathrm{E}+06$ & $1.0536 \mathrm{E}+06$ \\
\hline $\operatorname{abs}\left(\sigma_{2 c}\right)$ & $1.0505 \mathrm{E}+06$ & $1.0536 \mathrm{E}+06$ \\
\hline $\operatorname{abs}\left(\sigma_{6}\right)$ & $5.1592 \mathrm{E}+06$ & $5.1722 \mathrm{E}+06$ \\
\hline
\end{tabular}

Using Equation (2.57), the factors of safety for the beam are calculated and listed in Table 7.14.

Table 7.14 Factor of safety for the stresses with their corresponding Strengths for a $[0 / \pm 20]_{s}$ laminated composite beam

\begin{tabular}{|c|c|c|}
\hline \multirow{2}{*}{ Type } & \multicolumn{2}{|c|}{ Factor of safety } \\
\cline { 2 - 3 } & CLPT & FSDT \\
\hline$n_{1 t}$ & 27.54 & 27.48 \\
\hline$n_{1 c}$ & 11.73 & 11.70 \\
\hline$n_{2 t}$ & 38.08 & 37.97 \\
\hline$n_{2 c}$ & 133.27 & 132.88 \\
\hline$n_{6}$ & 11.63 & 11.60 \\
\hline
\end{tabular}

Thus, for design purposes, the overall factor of safety for a $[0 / \pm 20]_{s}$ simplysupported beam subjected to a moving load of magnitude $10 \mathrm{kN}$ is 11.63 using CLPT or 11.60 using FSDT. 


\subsection{2 $[0 / 90 / \pm 45]_{\mathrm{T}}$ Composite Beam}

\subsubsection{Strain and Stress Analysis}

The strains and stresses are plotted and listed in the following tables for a $[0 / 90 / \pm 45]_{T}$ S-glass/epoxy composite beam.

The longitudinal, transverse and shear strains across the laminate are listed in Table 7.15, Table 7.16 and Table 7.17. Since they are linear along the cross-section of the laminate, just the top and bottom of the laminate strains are listed below.

Table 7.15 Normal strain at the top and bottom of a $[0 / 90 / \pm 45]_{T}$ laminated composite beam

\begin{tabular}{|c|c|c|c|}
\hline \multicolumn{2}{|c|}{ Ply } & \multicolumn{2}{|c|}{$\varepsilon_{x}$} \\
\cline { 3 - 4 } & CLPT & FSDT \\
\hline $\begin{array}{c}-45^{\circ} \\
(\text { Top of laminate) }\end{array}$ & Top & $-2.3841 \mathrm{E}-03$ & $-2.4033 \mathrm{E}-03$ \\
\hline $\begin{array}{c}0^{\circ} \\
\text { (Bottom of } \\
\text { laminate) }\end{array}$ & Bottom & $1.5997 \mathrm{E}-03$ & $1.6125 \mathrm{E}-03$ \\
\hline
\end{tabular}


Table 7.16 Transverse strain at the top and bottom of a $[0 / 90 / \pm 45]_{\mathrm{T}}$ laminated composite beam

\begin{tabular}{|c|c|c|c|}
\hline \multicolumn{2}{|c|}{ Ply } & \multicolumn{2}{|c|}{$\varepsilon_{y}$} \\
\cline { 3 - 4 } & CLPT & FSDT \\
\hline $\begin{array}{c}-45^{\circ} \\
\text { (Top of laminate) }\end{array}$ & Top & $9.6098 \mathrm{E}-04$ & $9.6874 \mathrm{E}-04$ \\
\hline $\begin{array}{c}0^{\circ} \\
\text { (Bottom of } \\
\text { laminate) }\end{array}$ & Bottom & $-5.2822 \mathrm{E}-04$ & $-5.3246 \mathrm{E}-04$ \\
\hline
\end{tabular}

Table 7.17 Shear strain at the top and bottom of a $[0 / 90 / \pm 45]_{\mathrm{T}}$ laminated composite beam

\begin{tabular}{|c|c|c|c|}
\hline \multicolumn{2}{|c|}{ Ply } & \multicolumn{2}{|c|}{$\gamma_{x y}$} \\
\cline { 3 - 4 } & CLPT & FSDT \\
\hline $\begin{array}{c}-45^{\circ} \\
\text { (Top of laminate) }\end{array}$ & Top & $-3.0145 \mathrm{E}-04$ & $-3.0393 \mathrm{E}-04$ \\
\hline $\begin{array}{c}0^{\circ} \\
\text { (Bottom of } \\
\text { laminate) }\end{array}$ & Bottom & $1.0909 \mathrm{E}-04$ & $1.1005 \mathrm{E}-04$ \\
\hline
\end{tabular}

The longitudinal, transverse and shear stresses along the cross-section of the laminate are plotted below in Figure 7.5, Figure 7.6 and Figure 7.7 and are listed in Table 7.18, Table 7.19 and Table 7.20. 


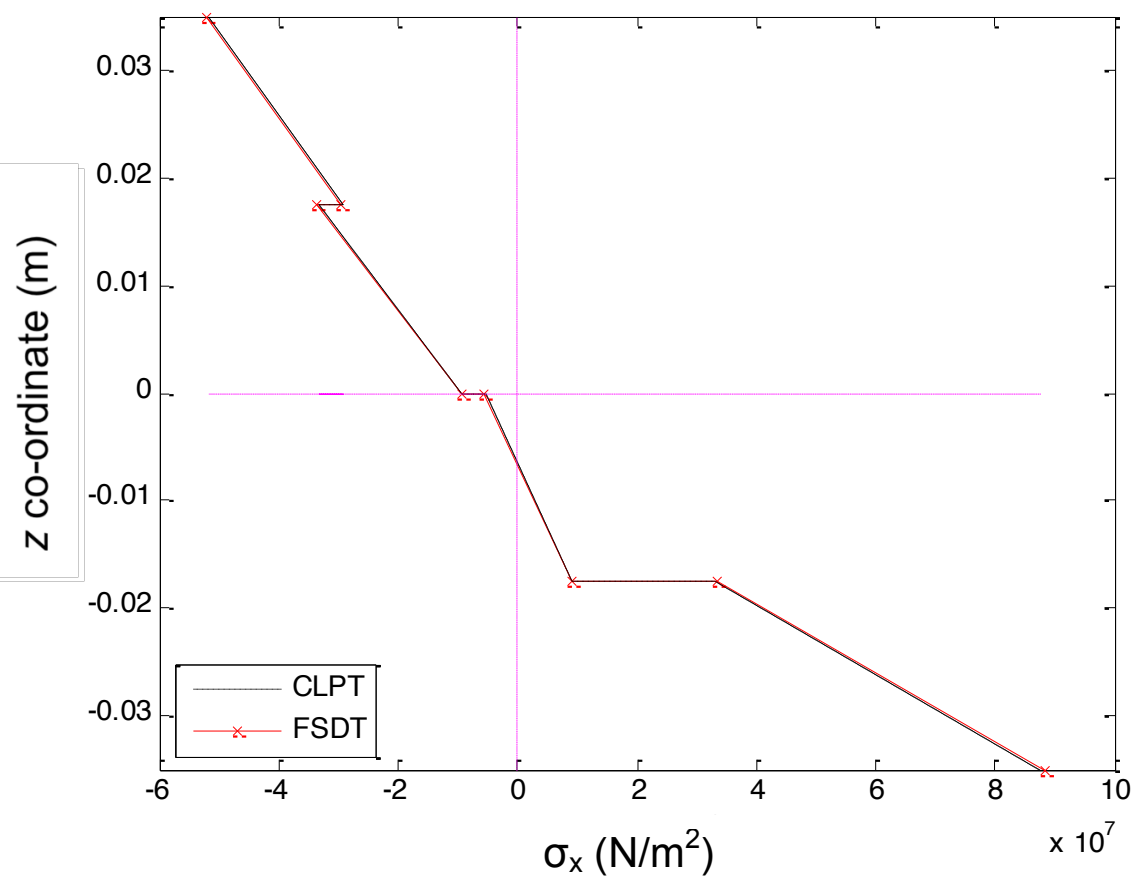

Figure 7.5 Longitudinal stress distribution, $\sigma_{x}$, for a [0/90/ \pm 45$]$ T laminated composite beam

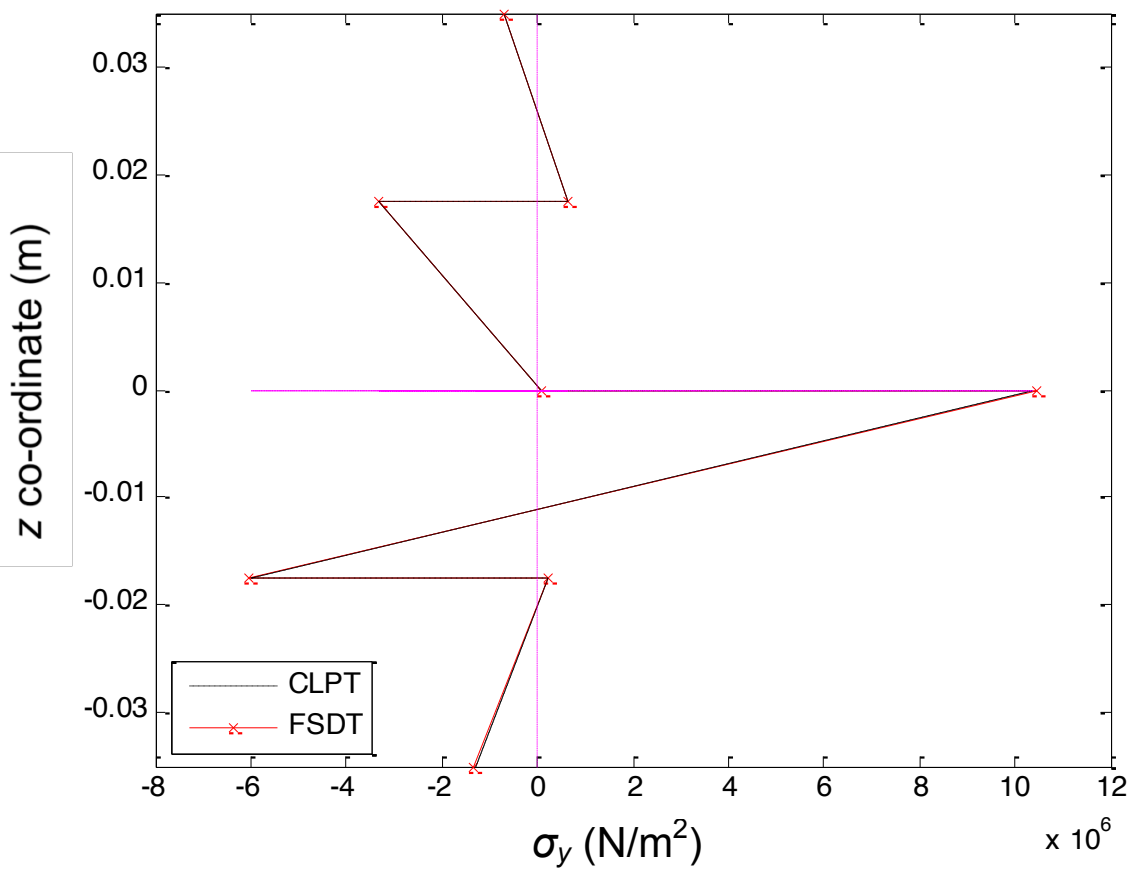

Figure 7.6 Transverse stress distribution, $\sigma_{y}$, for a $[0 / 90 / \pm 45] \mathrm{T}$ laminated composite beam 


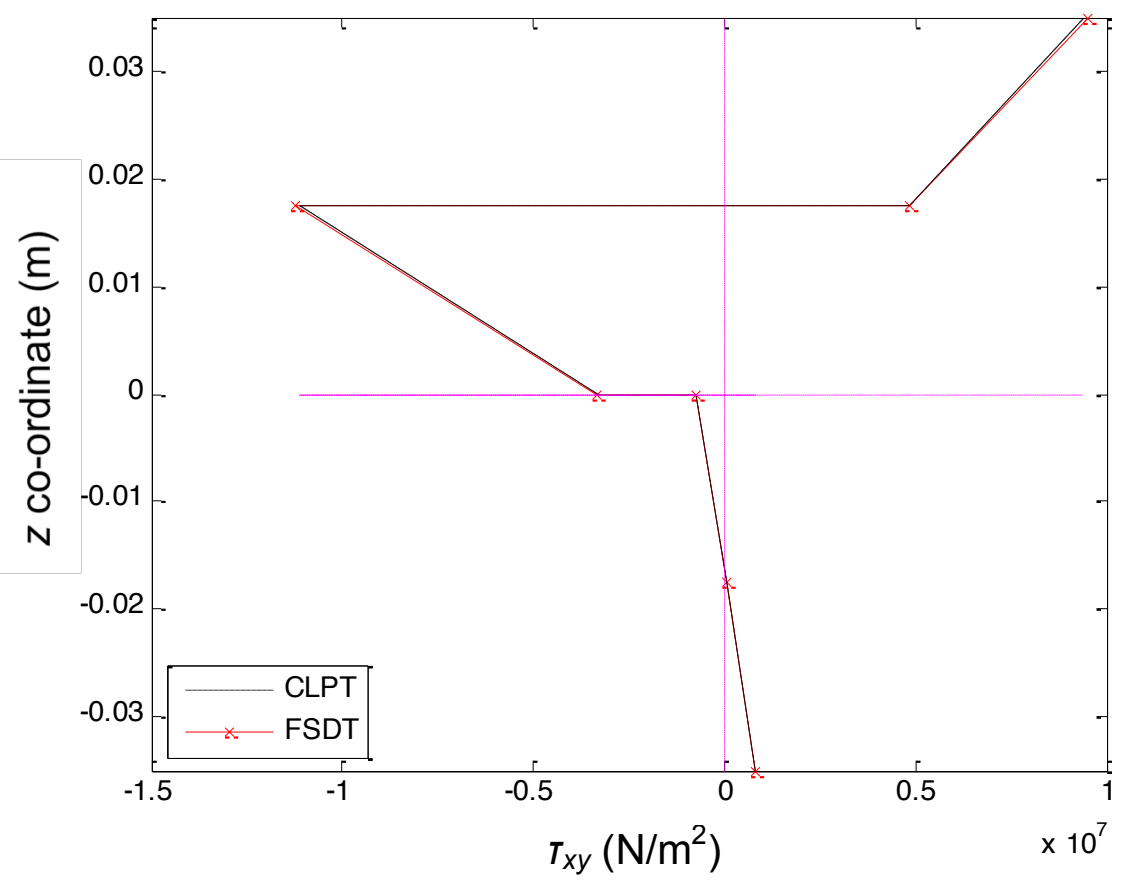

Figure 7.7 Shear stress distribution, $\tau_{x y}$, for a $[0 / 90 / \pm 45] \mathrm{T}$ laminated composite beam

Table 7.18 Longitudinal stress along the cross-section of a $[0 / 90 / \pm 45]_{\mathrm{T}}$ laminated composite beam

\begin{tabular}{|c|c|c|c|}
\hline \multirow{2}{*}{ Ply } & \multicolumn{2}{c|}{$\sigma_{x}\left(\mathbf{N} / \mathbf{m}^{2}\right)$} \\
\cline { 3 - 4 } & & CLPT & FSDT \\
\hline \multirow{2}{*}{$\begin{array}{c}-45^{\circ} \\
\text { (Top of laminate) }\end{array}$} & Top & $-5.1526 \mathrm{E}+07$ & $-5.1941 \mathrm{E}+07$ \\
\cline { 2 - 4 } & Bottom & $-2.9394 \mathrm{E}+07$ & $-2.9632 \mathrm{E}+07$ \\
\hline \multirow{2}{*}{$45^{\circ}$} & Top & $-3.3361 \mathrm{E}+07$ & $-3.3632 \mathrm{E}+07$ \\
\cline { 2 - 4 } & Bottom & $-9.1815 \mathrm{E}+06$ & $-9.2567 \mathrm{E}+06$ \\
\hline \multirow{2}{*}{$90^{\circ}$} & Top & $-5.4296 \mathrm{E}+06$ & $-5.4742 \mathrm{E}+06$ \\
\cline { 2 - 4 } & Bottom & $9.1704 \mathrm{E}+06$ & $9.2432 \mathrm{E}+06$ \\
\hline \multirow{2}{*}{$0^{\circ}$} & Top & $3.3265 \mathrm{E}+07$ & $3.3530 \mathrm{E}+07$ \\
\hline $\begin{array}{c}\text { Bottom of } \\
\text { laminate) }\end{array}$ & Bottom & $8.7613 \mathrm{E}+07$ & $8.8315 \mathrm{E}+07$ \\
\hline
\end{tabular}


Table 7.19 Transverse stress along the cross-section of a $[0 / 90 / \pm 45]_{T}$ laminated composite beam

\begin{tabular}{|c|c|c|c|}
\hline \multirow{2}{*}{ Ply } & \multicolumn{2}{c|}{$\sigma_{y}\left(\mathrm{~N} / \mathrm{m}^{2}\right)$} \\
\cline { 3 - 4 } & Top & $-6.8118 \mathrm{E}+05$ & $-6.8635 \mathrm{E}+05$ \\
\hline \multirow{2}{*}{$\begin{array}{c}-45^{\circ} \\
\text { (Top of laminate) }\end{array}$} & Bottom & $6.5352 \mathrm{E}+05$ & $6.5869 \mathrm{E}+05$ \\
\cline { 2 - 4 } & Top & $-3.3139 \mathrm{E}+06$ & $-3.3411 \mathrm{E}+06$ \\
\cline { 2 - 4 } $45^{\circ}$ & Bottom & $6.8942 \mathrm{E}+04$ & $6.9219 \mathrm{E}+04$ \\
\hline \multirow{2}{*}{$90^{\circ}$} & Top & $1.0381 \mathrm{E}+07$ & $1.0465 \mathrm{E}+07$ \\
\cline { 2 - 4 } & Bottom & $-6.0079 \mathrm{E}+06$ & $-6.0559 \mathrm{E}+06$ \\
\hline $\begin{array}{c}0^{\circ} \\
\text { (Bottom of } \\
\text { laminate) }\end{array}$ & Top & $2.1490 \mathrm{E}+05$ & $2.1653 \mathrm{E}+05$ \\
\cline { 2 - 4 } & Bottom & $-1.3150 \mathrm{E}+06$ & $-1.3258 \mathrm{E}+06$ \\
\hline
\end{tabular}

Table 7.20 Shear stress along the cross-section of a $[0 / 90 / \pm 45] \mathrm{T}$ laminated composite beam

\begin{tabular}{|c|c|c|c|}
\hline \multirow{2}{*}{ Ply } & \multicolumn{2}{c|}{$\tau_{x y}\left(\mathrm{~N} / \mathbf{m}^{2}\right)$} \\
\cline { 3 - 4 } & & CLPT & FSDT \\
\hline \multirow{2}{*}{$\begin{array}{c}-45^{\circ} \\
\text { (Top of laminate) }\end{array}$} & Top & $9.4142 \mathrm{E}+06$ & $9.4895 \mathrm{E}+06$ \\
\cline { 2 - 4 } & Bottom & $4.8209 \mathrm{E}+06$ & $4.8598 \mathrm{E}+06$ \\
\hline \multirow{2}{*}{$45^{\circ}$} & Top & $-1.1132 \mathrm{E}+07$ & $-1.1223 \mathrm{E}+07$ \\
\cline { 2 - 4 } & Bottom & $-3.2808 \mathrm{E}+06$ & $-3.3075 \mathrm{E}+06$ \\
\hline \multirow{2}{*}{$90^{\circ}$} & Top & $-7.3097 \mathrm{E}+05$ & $-7.3677 \mathrm{E}+05$ \\
\cline { 2 - 4 } & Bottom & $4.9077 \mathrm{E}+04$ & $4.9794 \mathrm{E}+04$ \\
\hline $0^{\circ}$ & Top & $4.9077 \mathrm{E}+04$ & $4.9794 \mathrm{E}+04$ \\
\hline $\begin{array}{c}\text { Bottom of } \\
\text { laminate) }\end{array}$ & Bottom & $8.2912 \mathrm{E}+05$ & $8.3635 \mathrm{E}+05$ \\
\hline
\end{tabular}


The longitudinal, transverse and shear stresses about the lamina coordinate system transformed from the laminate co-ordinate system are listed in Table 7.21, Table 7.22 and Table 7.23.

Table 7.21 Longitudinal stress for the lamina of a $[0 / 90 / \pm 45]_{T}$ laminated composite beam

\begin{tabular}{|c|c|c|c|}
\hline \multirow{2}{*}{ Ply } & \multicolumn{2}{c|}{$\sigma_{1}\left(\mathbf{N} / \mathbf{m}^{2}\right)$} \\
\cline { 3 - 4 } & CLPT & FSDT \\
\hline \multirow{2}{*}{$\begin{array}{c}-45^{\circ} \\
\text { (Top of laminate) }\end{array}$} & Top & $-3.5518 \mathrm{E}+07$ & $-3.5803 \mathrm{E}+07$ \\
\cline { 2 - 4 } & Bottom & $-1.9191 \mathrm{E}+07$ & $-1.9346 \mathrm{E}+07$ \\
\hline \multirow{2}{*}{$45^{\circ}$} & Top & $-2.9470 \mathrm{E}+07$ & $-2.9709 \mathrm{E}+07$ \\
\cline { 2 - 4 } & Bottom & $-7.8370 \mathrm{E}+06$ & $-7.9012 \mathrm{E}+06$ \\
\hline \multirow{2}{*}{$90^{\circ}$} & Top & $1.0381 \mathrm{E}+07$ & $1.0465 \mathrm{E}+07$ \\
\cline { 2 - 4 } & Bottom & $-6.0079 \mathrm{E}+06$ & $-6.0559 \mathrm{E}+06$ \\
\hline $0^{\circ}$ & Top & $3.3265 \mathrm{E}+07$ & $3.3530 \mathrm{E}+07$ \\
\hline $\begin{array}{c}\text { (Bottom of } \\
\text { laminate) }\end{array}$ & Bottom & $8.7613 \mathrm{E}+07$ & $8.8315 \mathrm{E}+07$ \\
\hline
\end{tabular}


Table 7.22 Transverse stress for the lamina of a $[0 / 90 / \pm 45]_{T}$ laminated composite beam

\begin{tabular}{|c|c|c|c|}
\hline \multirow{2}{*}{ Ply } & \multicolumn{2}{c|}{$\sigma_{2}\left(\mathrm{~N} / \mathbf{m}^{2}\right)$} \\
\cline { 3 - 4 } & & CLPT & FSDT \\
\hline \multirow{2}{*}{$\begin{array}{c}-45^{\circ} \\
\text { Top of laminate) }\end{array}$} & Top & $-1.6689 \mathrm{E}+07$ & $-1.6824 \mathrm{E}+07$ \\
\cline { 2 - 4 } & Bottom & $-9.5493 \mathrm{E}+06$ & $-9.6267 \mathrm{E}+06$ \\
\hline \multirow{2}{*}{$45^{\circ}$} & Top & $-7.2055 \mathrm{E}+06$ & $-7.2638 \mathrm{E}+06$ \\
\cline { 2 - 4 } & Bottom & $-1.2755 \mathrm{E}+06$ & $-1.2863 \mathrm{E}+06$ \\
\hline \multirow{2}{*}{$90^{\circ}$} & Top & $-5.4296 \mathrm{E}+06$ & $-5.4742 \mathrm{E}+06$ \\
\cline { 2 - 4 } & Bottom & $9.1704 \mathrm{E}+06$ & $9.2432 \mathrm{E}+06$ \\
\hline \multirow{2}{*}{$\begin{array}{c}\text { (Bottom of } \\
\text { laminate) }\end{array}$} & Top & $2.1490 \mathrm{E}+05$ & $2.1653 \mathrm{E}+05$ \\
\cline { 2 - 4 } & Bottom & $-1.3150 \mathrm{E}+06$ & $-1.3258 \mathrm{E}+06$ \\
\hline
\end{tabular}

Table 7.23 Shear stress for the lamina of a $[0 / 90 / \pm 45]_{\mathrm{T}}$ laminated composite beam

\begin{tabular}{|c|c|c|c|}
\hline \multirow{2}{*}{ Ply } & \multicolumn{2}{c|}{$\sigma_{6}\left(\mathrm{~N} / \mathrm{m}^{2}\right)$} \\
\cline { 3 - 4 } & Top & $-2.5422 \mathrm{E}+07$ & $-2.5628 \mathrm{E}+07$ \\
\hline \multirow{2}{*}{$\begin{array}{c}-45^{\circ} \\
\text { Top of laminate) }\end{array}$} & Bottom & $-1.5024 \mathrm{E}+07$ & $-1.5145 \mathrm{E}+07$ \\
\cline { 2 - 4 } & Top & $1.5024 \mathrm{E}+07$ & $1.5145 \mathrm{E}+07$ \\
\hline \multirow{2}{*}{$45^{\circ}$} & Bottom & $4.6252 \mathrm{E}+06$ & $4.6630 \mathrm{E}+06$ \\
\hline \multirow{2}{*}{$90^{\circ}$} & Top & $7.3097 \mathrm{E}+05$ & $7.3677 \mathrm{E}+05$ \\
\cline { 2 - 4 } & Bottom & $-4.9077 \mathrm{E}+04$ & $-4.9794 \mathrm{E}+04$ \\
\hline $\begin{array}{c}0^{\circ} \\
\text { (Bottom of } \\
\text { laminate) }\end{array}$ & Top & $4.9077 \mathrm{E}+04$ & $4.9794 \mathrm{E}+04$ \\
\cline { 2 - 4 } & Bottom & $8.2912 \mathrm{E}+05$ & $8.3635 \mathrm{E}+05$ \\
\hline
\end{tabular}




\subsubsection{Failure Analysis}

The maximum stresses in tension and compression for the lamina coordinate system, $\sigma_{1}, \sigma_{2}$ and $\sigma_{6}$, are listed below in Table 7.24.

Table 7.24 Maximum stresses on material co-ordinates for a $[0 / 90 / \pm 45]_{T}$ laminated composite beam

\begin{tabular}{|c|c|c|}
\hline \multirow{2}{*}{ Type } & \multicolumn{2}{|c|}{ Maximum stress $\mathbf{( N / \mathbf { m } ^ { 2 } )}$} \\
\cline { 2 - 3 } & CLPT & FSDT \\
\hline$\sigma_{1 t}$ & $8.7613 \mathrm{E}+07$ & $8.8315 \mathrm{E}+07$ \\
\hline$a b s\left(\sigma_{1 c}\right)$ & $3.5518 \mathrm{E}+07$ & $3.5803 \mathrm{E}+07$ \\
\hline$\sigma_{2 t}$ & $9.1704 \mathrm{E}+06$ & $9.2432 \mathrm{E}+06$ \\
\hline$a b s\left(\sigma_{2 c}\right)$ & $1.6689 \mathrm{E}+07$ & $1.6824 \mathrm{E}+07$ \\
\hline$a b s\left(\sigma_{6}\right)$ & $1.5024 \mathrm{E}+07$ & $1.5145 \mathrm{E}+07$ \\
\hline
\end{tabular}

Since none of the conditions from Equation (2.60) occur, thus failure does not occur and from Equation (2.62), the factor of safety for the laminate are calculated and listed below in Table 7.25. 
Table 7.25 Factor of safety for the stresses with their corresponding strengths for a $[0 / 90 / \pm 45]_{T}$ laminated composite beam

\begin{tabular}{|c|c|c|}
\hline \multirow{2}{*}{ Type } & \multicolumn{2}{|c|}{ Factor of safety } \\
\cline { 2 - 3 } & CLPT & FSDT \\
\hline$n_{1 t}$ & 18.49 & 18.34 \\
\hline$n_{1 c}$ & 19.43 & 19.27 \\
\hline$n_{2 t}$ & 4.36 & 4.33 \\
\hline$n_{2 c}$ & 8.39 & 8.32 \\
\hline$n_{6}$ & 3.99 & 3.96 \\
\hline
\end{tabular}

Thus, for design purpose, since we take the minimum value of the above Factor of Safety value, we shall take Factor of Safety for a $[0 / 90 / \pm 45]_{T}$ laminated composited beam to be as 3.99 using CLPT or 3.96 using FSDT.

\subsection{3 $[0 / 90 / \pm 30]_{s}$ Composite Beam}

\subsubsection{Strain and Stress Analysis}

The strains and stresses are plotted and listed in the following tables for a $[0 / 90 / \pm 30]_{s}$ S-glass/epoxy composite beam.

The longitudinal, transverse and shear strains across the laminate are listed in Table 7.26, Table 7.27 and Table 7.28. Since they are linear along the cross-section of the laminate, just the top and bottom of the laminate strains are listed below. 
Table 7.26 Normal strain at the top and bottom of a $[0 / 90 / \pm 30]_{s}$ laminated composite beam

\begin{tabular}{|c|c|c|c|}
\hline \multicolumn{2}{|c|}{ Ply } & \multicolumn{2}{c|}{$\varepsilon_{x}$} \\
\cline { 3 - 4 } & CLPT & FSDT \\
\hline $\begin{array}{c}0^{\circ} \\
(\text { Top of laminate) }\end{array}$ & Top & $-1.4136 \mathrm{E}-03$ & $-1.4303 \mathrm{E}-03$ \\
\hline $\begin{array}{c}0^{\circ} \\
\text { (Bottom of } \\
\text { laminate) }\end{array}$ & Bottom & $1.4136 \mathrm{E}-03$ & $1.4303 \mathrm{E}-03$ \\
\hline
\end{tabular}

Table 7.27 Transverse strain at the top and bottom of a $[0 / 90 / \pm 30]_{s}$ laminated composite beam

\begin{tabular}{|c|c|c|c|}
\hline \multicolumn{2}{|c|}{ Ply } & \multicolumn{2}{|c|}{$\varepsilon_{y}$} \\
\cline { 3 - 4 } & CLPT & FSDT \\
\hline $\begin{array}{c}0^{\circ} \\
(\text { Top of laminate) }\end{array}$ & Top & $2.6267 \mathrm{E}-04$ & $2.6576 \mathrm{E}-04$ \\
\hline $\begin{array}{c}0^{\circ} \\
\text { (Bottom of } \\
\text { laminate) }\end{array}$ & Bottom & $-2.6267 \mathrm{E}-04$ & $-2.6576 \mathrm{E}-04$ \\
\hline
\end{tabular}

Table 7.28 Shear strain at the top and bottom of a $[0 / 90 / \pm 30]_{s}$ laminated composite beam

\begin{tabular}{|c|c|c|c|}
\hline \multicolumn{2}{|c|}{ Ply } & \multicolumn{2}{|c|}{$\gamma_{x y}$} \\
\cline { 3 - 4 } & CLPT & FSDT \\
\hline $\begin{array}{c}0^{\circ} \\
\text { (Top of laminate) }\end{array}$ & Top & $8.5156 \mathrm{E}-05$ & $8.6120 \mathrm{E}-05$ \\
\hline $\begin{array}{c}0^{\circ} \\
\text { (Bottom of } \\
\text { laminate) }\end{array}$ & Bottom & $-8.5156 \mathrm{E}-05$ & $-8.6120 \mathrm{E}-05$ \\
\hline
\end{tabular}


The longitudinal, transverse and shear stresses along the cross-section of the laminate are plotted below in Figure 7.8, Figure 7.9 and Figure 7.10 and are listed in Table 7.29, Table 7.30 and Table 7.31.

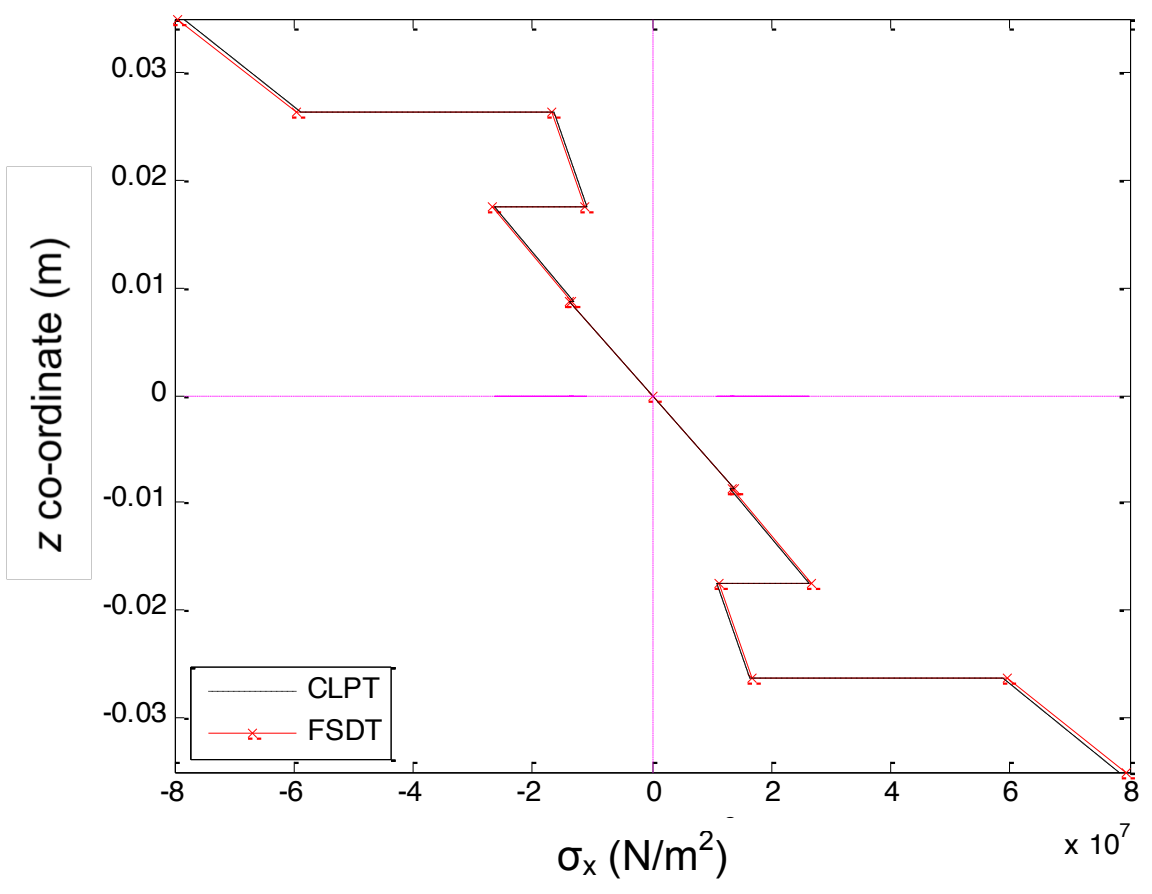

Figure 7.8 Longitudinal stress distribution, $\sigma_{x}$, for a $[0 / 90 / \pm 30]_{\mathrm{s}}$ laminated composite beam 


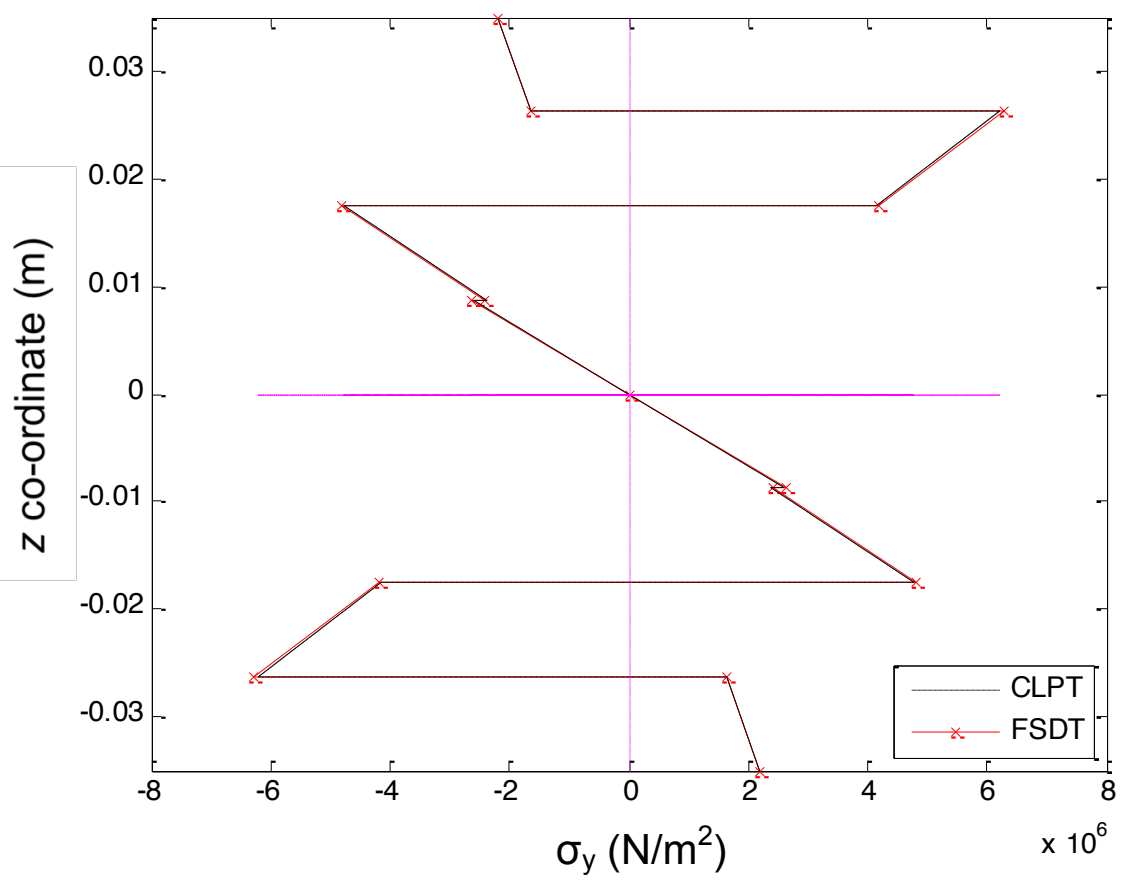

Figure 7.9 Transverse stress distribution, $\sigma_{v}$, for a $[0 / 90 / \pm 30]_{\mathrm{s}}$ laminated composite beam

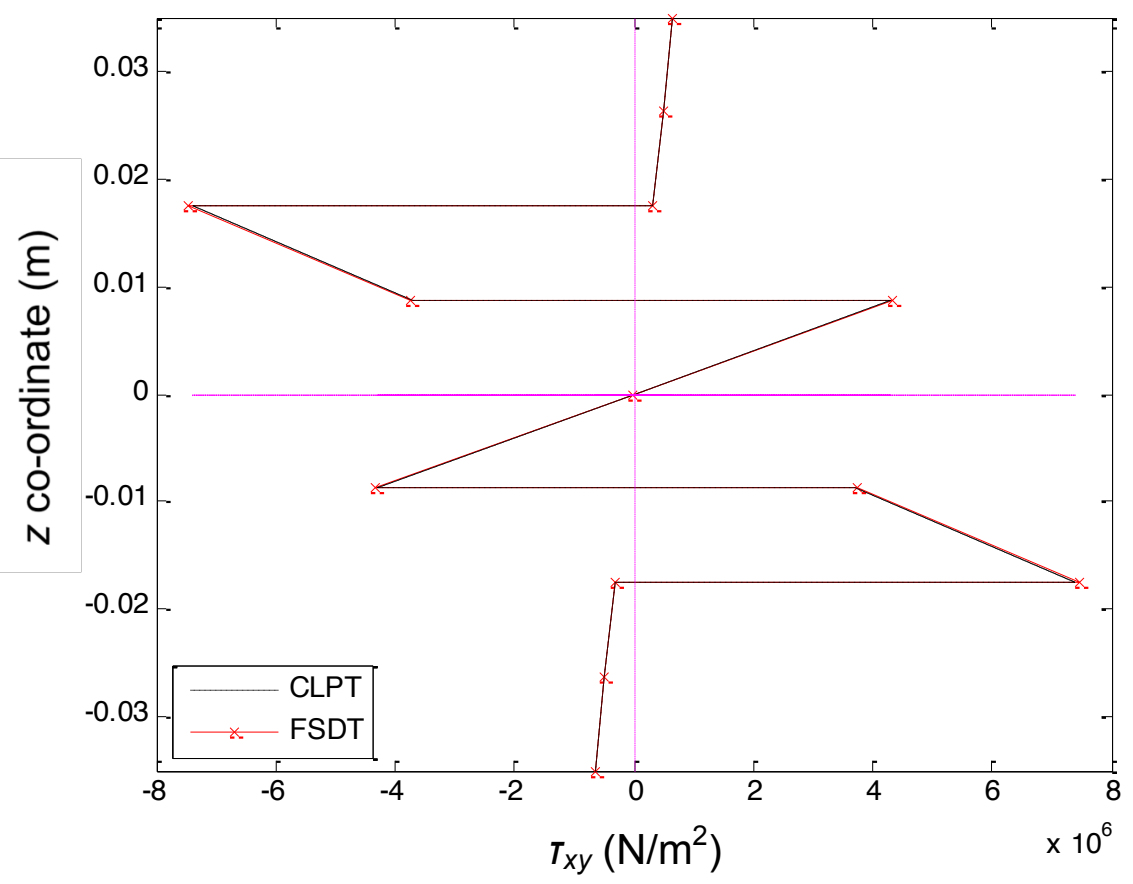

Figure 7.10 Shear stress distribution, $\tau_{x y}$, for a $[0 / 90 / \pm 30]_{\mathrm{s}}$ laminated composite beam 
Table 7.29 Longitudinal stress along the cross-section of a $[0 / 90 / \pm 30]_{\mathrm{s}}$ laminated composite beam

\begin{tabular}{|c|c|c|c|}
\hline \multirow{2}{*}{\multicolumn{2}{|c|}{ Ply }} & \multicolumn{2}{|c|}{$\sigma_{x}\left(\mathbf{N} / \mathrm{m}^{2}\right)$} \\
\hline & & \multirow{2}{*}{$\begin{array}{c}\text { CLPT } \\
-7.8361 \mathrm{E}+07\end{array}$} & \multirow{2}{*}{$\begin{array}{c}\text { FSDT } \\
-7.9284 \mathrm{E}+07\end{array}$} \\
\hline & Top & & \\
\hline (Top of laminate) & Bottom & $-5.8771 E+07$ & $-5.9463 E+07$ \\
\hline \multirow{2}{*}{$90^{\circ}$} & Top & $-1.6456 E+07$ & $-1.6650 \mathrm{E}+07$ \\
\hline & Bottom & $-1.0971 \mathrm{E}+07$ & $-1.1100 \mathrm{E}+07$ \\
\hline \multirow{2}{*}{$30^{\circ}$} & Top & $-2.6408 E+07$ & $-2.6719 \mathrm{E}+07$ \\
\hline & Bottom & $-1.3204 E+07$ & $-1.3360 \mathrm{E}+07$ \\
\hline \multirow{2}{*}{$-30^{\circ}$} & Top & $-1.3724 E+07$ & $-1.3886 E+07$ \\
\hline & Bottom & 8.3158E-01 & $1.5352 \mathrm{E}+01$ \\
\hline \multirow{2}{*}{$-30^{\circ}$} & Top & 8.3158E-01 & $1.5352 E+01$ \\
\hline & Bottom & $1.3724 \mathrm{E}+07$ & $1.3886 \mathrm{E}+07$ \\
\hline \multirow{2}{*}{$30^{\circ}$} & Top & $1.3204 \mathrm{E}+07$ & $1.3360 \mathrm{E}+07$ \\
\hline & Bottom & $2.6408 E+07$ & $2.6719 E+07$ \\
\hline \multirow{2}{*}{$90^{\circ}$} & Top & $1.0971 \mathrm{E}+07$ & $1.1100 E+07$ \\
\hline & Bottom & $1.6456 \mathrm{E}+07$ & $1.6650 \mathrm{E}+07$ \\
\hline \multirow{2}{*}{$\begin{array}{c}0^{\circ} \\
\text { (Bottom of } \\
\text { laminate) }\end{array}$} & Top & $5.8771 \mathrm{E}+07$ & $5.9463 E+07$ \\
\hline & Bottom & $7.8361 \mathrm{E}+07$ & $7.9284 \mathrm{E}+07$ \\
\hline
\end{tabular}


Table 7.30 Transverse stress along the cross-section of a $[0 / 90 / \pm 30]_{s}$ laminated composite beam

\begin{tabular}{|c|c|c|c|}
\hline \multirow{2}{*}{\multicolumn{2}{|c|}{ Ply }} & \multicolumn{2}{|c|}{$\sigma_{y}\left(\mathbf{N} / \mathbf{m}^{2}\right)$} \\
\hline & & \multirow{2}{*}{$\begin{array}{c}\text { CLPT } \\
-2.1802 E+06\end{array}$} & \multirow{2}{*}{$\begin{array}{c}\text { FSDT } \\
-2.2058 \mathrm{E}+06 \\
\end{array}$} \\
\hline & Top & & \\
\hline (Top of laminate) & Bottom & $-1.6351 \mathrm{E}+06$ & $-1.6544 E+06$ \\
\hline \multirow{2}{*}{$90^{\circ}$} & Top & $6.2272 \mathrm{E}+06$ & $6.3006 \mathrm{E}+06$ \\
\hline & Bottom & $4.1515 E+06$ & $4.2004 E+06$ \\
\hline \multirow{2}{*}{$30^{\circ}$} & Top & $-4.7642 \mathrm{E}+06$ & $-4.8204 E+06$ \\
\hline & Bottom & $-2.3821 E+06$ & $-2.4102 E+06$ \\
\hline \multirow{2}{*}{$-30^{\circ}$} & Top & $-2.5975 E+06$ & $-2.6281 \mathrm{E}+06$ \\
\hline & Bottom & 1.1869E-01 & $2.1911 \mathrm{E}+00$ \\
\hline \multirow{2}{*}{$-30^{\circ}$} & Top & 1.1869E-01 & $2.1911 \mathrm{E}+00$ \\
\hline & Bottom & $2.5975 \mathrm{E}+06$ & $2.6281 \mathrm{E}+06$ \\
\hline \multirow{2}{*}{$30^{\circ}$} & Top & $2.3821 \mathrm{E}+06$ & $2.4102 E+06$ \\
\hline & Bottom & $4.7642 \mathrm{E}+06$ & 4.8204E+06 \\
\hline \multirow{2}{*}{$90^{\circ}$} & Top & $-4.1515 E+06$ & $-4.2004 \mathrm{E}+06$ \\
\hline & Bottom & $-6.2272 E+06$ & $-6.3006 E+06$ \\
\hline \multirow{2}{*}{$\begin{array}{l}0^{\circ} \\
\text { (Bottom of } \\
\text { laminate) }\end{array}$} & Top & $1.6351 \mathrm{E}+06$ & 1.6544E+06 \\
\hline & Bottom & $2.1802 E+06$ & $2.2058 \mathrm{E}+06$ \\
\hline
\end{tabular}


Table 7.31 Shear stress along the cross-section of a $[0 / 90 / \pm 30]_{s}$ laminated composite beam

\begin{tabular}{|c|c|c|c|}
\hline \multicolumn{2}{|c}{ Ply } & \multicolumn{2}{c|}{$\tau_{x y}\left(\mathrm{~N} / \mathrm{m}^{2}\right)$} \\
\cline { 3 - 4 } \multirow{2}{*}{$\begin{array}{c}0^{\circ} \\
\text { (Top of laminate) }\end{array}$} & Top & $6.4719 \mathrm{E}+05$ & $6.5451 \mathrm{E}+05$ \\
\hline \multirow{2}{*}{$90^{\circ}$} & Bottom & $4.8539 \mathrm{E}+05$ & $4.9089 \mathrm{E}+05$ \\
\cline { 2 - 4 } & Top & $4.8539 \mathrm{E}+05$ & $4.9089 \mathrm{E}+05$ \\
\cline { 2 - 4 } & Bottom & $3.2359 \mathrm{E}+05$ & $3.2726 \mathrm{E}+05$ \\
\hline \multirow{2}{*}{$30^{\circ}$} & Top & $-7.3871 \mathrm{E}+06$ & $-7.4744 \mathrm{E}+06$ \\
\cline { 2 - 4 } & Bottom & $-3.6936 \mathrm{E}+06$ & $-3.7372 \mathrm{E}+06$ \\
\hline \multirow{2}{*}{$-30^{\circ}$} & Top & $4.2813 \mathrm{E}+06$ & $4.3316 \mathrm{E}+06$ \\
\cline { 2 - 4 } & Bottom & $-2.4267 \mathrm{E}-01$ & $-4.4801 \mathrm{E}+00$ \\
\hline \multirow{2}{*}{$-30^{\circ}$} & Top & $-2.4267 \mathrm{E}-01$ & $-4.4801 \mathrm{E}+00$ \\
\cline { 2 - 4 } & Bottom & $-4.2813 \mathrm{E}+06$ & $-4.3316 \mathrm{E}+06$ \\
\hline \multirow{2}{*}{$30^{\circ}$} & Top & $3.6936 \mathrm{E}+06$ & $3.7372 \mathrm{E}+06$ \\
\cline { 2 - 4 } & Bottom & $7.3871 \mathrm{E}+06$ & $7.4744 \mathrm{E}+06$ \\
\hline \multirow{2}{*}{$90^{\circ}$} & Top & $-3.2359 \mathrm{E}+05$ & $-3.2726 \mathrm{E}+05$ \\
\hline & Bottom & $-4.8539 \mathrm{E}+05$ & $-4.9089 \mathrm{E}+05$ \\
\hline 0 & Top & $-4.8539 \mathrm{E}+05$ & $-4.9089 \mathrm{E}+05$ \\
\hline \multirow{2}{*}{$\begin{array}{c}\text { (Bottom of } \\
\text { laminate) }\end{array}$} & Bottom & $-6.4719 \mathrm{E}+05$ & $-6.5451 \mathrm{E}+05$ \\
\hline
\end{tabular}

The longitudinal, transverse and shear stresses about the lamina coordinate system transformed from the laminate co-ordinate system are listed in Table 7.32, Table 7.33 and Table 7.34. 
Table 7.32 Longitudinal stress for the lamina of a $[0 / 90 / \pm 30]_{s}$ laminated composite beam

\begin{tabular}{|c|c|c|c|}
\hline \multirow{2}{*}{\multicolumn{2}{|c|}{ Ply }} & \multicolumn{2}{|c|}{$\sigma_{1}\left(\mathbf{N} / \mathbf{m}^{2}\right)$} \\
\hline & & \multirow{2}{*}{$\begin{array}{c}\text { CLPT } \\
-7.8361 \mathrm{E}+07\end{array}$} & \multirow{2}{*}{$\begin{array}{c}\text { FSDT } \\
-7.9284 \mathrm{E}+07 \\
\end{array}$} \\
\hline & Top & & \\
\hline (Top of laminate) & Bottom & $-5.8771 \mathrm{E}+07$ & $-5.9463 E+07$ \\
\hline \multirow{2}{*}{$90^{\circ}$} & Top & $6.2272 \mathrm{E}+06$ & $6.3006 \mathrm{E}+06$ \\
\hline & Bottom & $4.1515 E+06$ & $4.2004 E+06$ \\
\hline \multirow{2}{*}{$30^{\circ}$} & Top & $-2.7394 \mathrm{E}+07$ & $-2.7717 E+07$ \\
\hline & Bottom & $-1.3697 E+07$ & $-1.3859 E+07$ \\
\hline \multirow{2}{*}{$-30^{\circ}$} & Top & $-1.4650 \mathrm{E}+07$ & $-1.4823 E+07$ \\
\hline & Bottom & $8.6352 E-01$ & $1.5942 \mathrm{E}+01$ \\
\hline \multirow{2}{*}{$-30^{\circ}$} & Top & $8.6352 \mathrm{E}-01$ & $1.5942 \mathrm{E}+01$ \\
\hline & Bottom & $1.4650 \mathrm{E}+07$ & $1.4823 \mathrm{E}+07$ \\
\hline \multirow{2}{*}{$30^{\circ}$} & Top & 1.3697E+07 & 1.3859E+07 \\
\hline & Bottom & $2.7394 \mathrm{E}+07$ & 2.7717E+07 \\
\hline \multirow{2}{*}{$90^{\circ}$} & Top & $-4.1515 E+06$ & $-4.2004 E+06$ \\
\hline & Bottom & $-6.2272 E+06$ & $-6.3006 E+06$ \\
\hline \multirow{2}{*}{$\begin{array}{l}0^{\circ} \\
\text { (Bottom of } \\
\text { laminate) }\end{array}$} & Top & $5.8771 \mathrm{E}+07$ & $5.9463 \mathrm{E}+07$ \\
\hline & Bottom & $7.8361 \mathrm{E}+07$ & $7.9284 \mathrm{E}+07$ \\
\hline
\end{tabular}


Table 7.33 Transverse stress for the lamina of a $[0 / 90 / \pm 30]_{s}$ laminated composite beam

\begin{tabular}{|c|c|c|c|}
\hline \multirow{2}{*}{\multicolumn{2}{|c|}{ Ply }} & \multicolumn{2}{|c|}{$\sigma_{2}\left(\mathbf{N} / \mathbf{m}^{2}\right)$} \\
\hline & & \multirow{2}{*}{$\begin{array}{c}\text { CLPT } \\
-2.1802 E+06\end{array}$} & \multirow{2}{*}{$\begin{array}{c}\text { FSDT } \\
-2.2058 \mathrm{E}+06 \\
\end{array}$} \\
\hline & Top & & \\
\hline (Top of laminate) & Bottom & $-1.6351 \mathrm{E}+06$ & $-1.6544 E+06$ \\
\hline \multirow{2}{*}{$90^{\circ}$} & Top & $-1.6456 E+07$ & $-1.6650 \mathrm{E}+07$ \\
\hline & Bottom & $-1.0971 E+07$ & $-1.1100 \mathrm{E}+07$ \\
\hline \multirow{2}{*}{$30^{\circ}$} & Top & $-3.7777 \mathrm{E}+06$ & $-3.8221 \mathrm{E}+06$ \\
\hline & Bottom & $-1.8888 E+06$ & $-1.9110 E+06$ \\
\hline \multirow{2}{*}{$-30^{\circ}$} & Top & $-1.6715 E+06$ & $-1.6912 \mathrm{E}+06$ \\
\hline & Bottom & 8.6749E-02 & $1.6015 \mathrm{E}+00$ \\
\hline \multirow{2}{*}{$-30^{\circ}$} & Top & 8.6749E-02 & $1.6015 E+00$ \\
\hline & Bottom & $1.6715 \mathrm{E}+06$ & $1.6912 \mathrm{E}+06$ \\
\hline \multirow{2}{*}{$30^{\circ}$} & Top & $1.8888 \mathrm{E}+06$ & $1.9110 \mathrm{E}+06$ \\
\hline & Bottom & $3.7777 \mathrm{E}+06$ & $3.8221 \mathrm{E}+06$ \\
\hline \multirow{2}{*}{$90^{\circ}$} & Top & $1.0971 \mathrm{E}+07$ & $1.1100 \mathrm{E}+07$ \\
\hline & Bottom & $1.6456 \mathrm{E}+07$ & $1.6650 \mathrm{E}+07$ \\
\hline \multirow{2}{*}{$\begin{array}{l}0^{\circ} \\
\text { (Bottom of } \\
\text { laminate) }\end{array}$} & Top & $1.6351 \mathrm{E}+06$ & 1.6544E+06 \\
\hline & Bottom & $2.1802 \mathrm{E}+06$ & $2.2058 \mathrm{E}+06$ \\
\hline
\end{tabular}


Table 7.34 Shear stress for the lamina of a $[0 / 90 / \pm 30]_{s}$ laminated composite beam

\begin{tabular}{|c|c|c|c|}
\hline \multirow{2}{*}{ Ply } & \multicolumn{2}{c|}{$\sigma_{6}\left(\mathrm{~N} / \mathbf{m}^{2}\right)$} \\
\cline { 3 - 4 }$\left(\begin{array}{c}0^{\circ} \\
\text { (Top of laminate) }\end{array}\right.$ & Top & $6.4719 \mathrm{E}+05$ & $6.5451 \mathrm{E}+05$ \\
\cline { 2 - 4 } & Bottom & $4.8539 \mathrm{E}+05$ & $4.9089 \mathrm{E}+05$ \\
\hline \multirow{2}{*}{$90^{\circ}$} & Top & $-4.8539 \mathrm{E}+05$ & $-4.9089 \mathrm{E}+05$ \\
\cline { 2 - 4 } & Bottom & $-3.2359 \mathrm{E}+05$ & $-3.2726 \mathrm{E}+05$ \\
\hline \multirow{2}{*}{$30^{\circ}$} & Top & $5.6784 \mathrm{E}+06$ & $5.7452 \mathrm{E}+06$ \\
\cline { 2 - 4 } & Bottom & $2.8392 \mathrm{E}+06$ & $2.8726 \mathrm{E}+06$ \\
\hline \multirow{3}{*}{$-30^{\circ}$} & Top & $-2.6774 \mathrm{E}+06$ & $-2.7090 \mathrm{E}+06$ \\
\cline { 2 - 4 } & Bottom & $1.8736 \mathrm{E}-01$ & $3.4589 \mathrm{E}+00$ \\
\hline \multirow{2}{*}{$-30^{\circ}$} & Top & $1.8736 \mathrm{E}-01$ & $3.4589 \mathrm{E}+00$ \\
\cline { 2 - 4 } & Bottom & $2.6774 \mathrm{E}+06$ & $2.7090 \mathrm{E}+06$ \\
\hline \multirow{2}{*}{$30^{\circ}$} & Top & $-2.8392 \mathrm{E}+06$ & $-2.8726 \mathrm{E}+06$ \\
\cline { 2 - 4 } & Bottom & $-5.6784 \mathrm{E}+06$ & $-5.7452 \mathrm{E}+06$ \\
\hline \multirow{2}{*}{$90^{\circ}$} & Top & $3.2359 \mathrm{E}+05$ & $3.2726 \mathrm{E}+05$ \\
\hline & Bottom & $4.8539 \mathrm{E}+05$ & $4.9089 \mathrm{E}+05$ \\
\hline $0^{\circ}$ & Top & $-4.8539 \mathrm{E}+05$ & $-4.9089 \mathrm{E}+05$ \\
\hline $\begin{array}{c}\text { (Bottom of } \\
\text { laminate) }\end{array}$ & Bottom & $-6.4719 \mathrm{E}+05$ & $-6.5451 \mathrm{E}+05$ \\
\hline
\end{tabular}

\subsubsection{Failure Analysis}

The maximum stresses in tension and compression for the lamina coordinate system, $\sigma_{1}, \sigma_{2}$ and $\sigma_{6}$ are listed below in Table 7.35. 
Table 7.35 Maximum stresses on material co-ordinates for a $[0 / 90 / \pm 30]_{\mathrm{s}}$ laminated composite beam

\begin{tabular}{|c|c|c|}
\hline \multirow{2}{*}{ Type } & \multicolumn{2}{|c|}{ Maximum stress $\mathbf{( N / \mathbf { m } ^ { 2 } )}$} \\
\cline { 2 - 3 } & CLPT & FSDT \\
\hline$\sigma_{1 t}$ & $7.8361 \mathrm{E}+07$ & $7.9284 \mathrm{E}+07$ \\
\hline$a b s\left(\sigma_{1 c}\right)$ & $7.8361 \mathrm{E}+07$ & $7.9284 \mathrm{E}+07$ \\
\hline$\sigma_{2 t}$ & $1.6456 \mathrm{E}+07$ & $1.6650 \mathrm{E}+07$ \\
\hline$a b s\left(\sigma_{2 c}\right)$ & $1.6456 \mathrm{E}+07$ & $1.6650 \mathrm{E}+07$ \\
\hline$a b s\left(\sigma_{6}\right)$ & $5.6784 \mathrm{E}+06$ & $5.7452 \mathrm{E}+06$ \\
\hline
\end{tabular}

Since none of the conditions from Equation (2.60) occur, thus failure does not occur and from Equation (2.62), the factor of safety for the laminate are calculated and listed below in Table 7.36.

Table 7.36 Factor of safety for the stresses with their corresponding strengths for a $[0 / 90 / \pm 30]_{s}$ laminated composite beam

\begin{tabular}{|c|c|c|}
\hline \multirow{2}{*}{ Type } & \multicolumn{2}{|c|}{ Factor of safety } \\
\cline { 2 - 3 } & CLPT & FSDT \\
\hline$n_{1 t}$ & 20.67 & 20.43 \\
\hline$n_{1 c}$ & 8.81 & 8.70 \\
\hline$n_{2 t}$ & 2.43 & 2.40 \\
\hline$n_{2 c}$ & 8.51 & 8.41 \\
\hline$n_{6}$ & 10.57 & 10.44 \\
\hline
\end{tabular}

Thus, for design purpose, since we take the minimum value of the above Factor of safety value, we shall take Factor of Safety for a $[0 / 90 / \pm 30]_{\text {s }}$ laminated composited beam to be as 2.43 using CLPT and 2.40 using FSDT. 


\section{CHAPTER 8 \\ CONCLUSIONS AND RECOMMENDATIONS}

\subsection{Contributions}

1. A uniformly-distributed load, static and moving loads on a composite laminated beam are modeled in MATLAB using CLPT and FSDT.

2. Hygrothermal analysis is carried out on symmetric and asymmetric composite laminated beams subjected to a moving load, with different fiber volume fractions.

3. Failure Analysis is done on symmetric and asymmetric laminated composite beams subjected to a moving load under dry conditions.

\subsection{Conclusions}

1. Hygrothermal Analysis and Stress Analysis of laminated composite beams under the effect of moving loads using finite element method is successfully carried out with the use of MATLAB.

2. Dynamic magnification factors are calculated for isotropic and composite beams and compared with previous authors, showing excellent agreement. The maximum dynamic magnification factor occurs at a higher velocity ratio than 1 .

3. The ply orientation influences the dynamic behavior of a beam subjected to moving load. The dynamic magnification factors in dry and hygrothermal conditions for the laminates considered generally follow similar pattern. As the fiber volume fraction increases, the dynamic 
magnification factor generally decreases; the one exception being in the case of $[0 / 90 / \pm 45]$ where the dynamic magnification factor increases when $V_{f}=0.7$.

4. In dry and hygrothermal conditions, the [0/90/ \pm 45$]$ laminate has the highest dynamic magnification factor when compared to $[0 / \pm 20]_{s}$ and $[0 / 90 / \pm 30]_{s}$ laminates.

5. Failure Analysis on a simply-supported beam subjected to a moving load under dry conditions indicates none of the three lay-ups, $[0 / \pm 20]_{s}$, $[0 / 90 / \pm 45]_{T}$ and $[0 / 90 / \pm 30]_{s}$, fail due to the applied moving load of $10 \mathrm{kN}$.

6. The lowest factors of safety for the laminates $[0 / \pm 20]_{s}$ and $[0 / 90 / \pm 45]$ are in in-plane shear whereas for $[0 / 90 / \pm 30]_{s}$, it is in transverse tension.

7. Based on these results a designer can choose the right ply orientations to control the dynamic behavior of laminated beams.

\subsection{Future Recommendations}

1. Moving mass analysis may be performed on the beams. The results can be compared with the present study.

2. Since in this study, only a single moving load is considered for analysis, multiple loads in the future can be considered.

3. The effects of different moisture contents on the dynamic deflections of laminates may also be calculated.

4. Stresses under hygrothermal conditions can be considered including the effect of residual stresses. 


\section{REFERENCES}

Adams, D. F. and Miller, A. K., 1977, "Hygrothermal Microstresses in a Unidirectional Composite Exhibiting Inelastic Material Behavior," Journal of Composite Materials, Volume 11, No. 3, pp. 285-299.

Barbero, E. J., 1999, "Introduction to Composite Materials Design," Taylor and Francis, New York

Barbero, E. J., 2011, "Introduction to Composite Materials Design," Taylor and Francis, New York

Bathe, K.J. and Wilson, E.L., 1976, "Numerical Methods in Finite Element Analysis," Prentice-Hall, Inc., Englewood Cliffs, New Jersey

Borovkov, A., Avdeev, I., and Artemyev, A., 1999, "Finite Element Stress, vibration and buckling analysis of laminated beams with the use of refined elements," St. Petersburg State Technical University, Russia

Bouadi, H. and Sun, C.T., 1989, "Hygrothermal Effects on the Stress Field of Laminated Composites," Journal of Reinforced Plastics and Composites, Volume 8 , No. $40-54$

Cairns, D.S. and Adams, D.F. 1983, "Moisture and Thermal Expansion Properties of unidirectional Composite Materials and the Epoxy Matrix," Journal of Reinforced Plastics and Composites, Volume 2, No. 239-255

Chamis, C. C., 1983, "Simplified Composite Micromechanics Equations for Hygral, Thermal and Mechanical Properties," NASA Technical Memorandum 83320. Prepared for the Thirty-eighth Annual Conference of Society of the 
Plastics Industry (SPI), Reinforced Plastics/Composite Institute, Houston, TX, pp. $1-10$

Chandrasekaran, G., 2000, "Dynamic Analysis of a Composite Moving Beam," Master's Thesis, West Virginia University, Morgantown, WV

Environmental Effects on Composite Materials, Vol. 2, George S. Springer, Ed.

Haisler, W. E., 2012, "Bending and Extension of Thin Plates"

Hexcel Composites, Hexcel Corporation, Pleasanton, California.

Hyer, M. W., 1997, "Stress Analysis of Fiber-Reinforced Composite Materials," Virginia Polytechnic Institute and State University, WCB McGraw-Hill

Kadivar, M.H. and Mohebpur, S.R., 1997, "Forced Vibration of Unsymmetric Laminated Composite Beams under the Action of Moving Loads," Journal of composites Science and Technology, Volume 58, No. 10

Kadivar, M.H. and Mohebpur, S.R., 1998, "Finite element dynamic analysis of unsymmtetric composite laminated beams with shear effect and rotary inertia under the action of moving loads," Finite Element in Analysis and Design, Volume 29, No 259-273

Kavipurapu, P. K., 2005, "Forced Vibration and Hygrothermal Analysis of Composite Laminated Beams under the Action of Moving Loads," Master's Thesis, West Virginia University, Morgantown, WV

Kiral, B.G., Kiral, Z. and Baba, B.O., 2004, "Dynamic Behavior of Laminated Composite Beams Subjected to a Moving Load," Journal of Applied Sciences, Volume 4, No. 271-276 
Komorowski, J. P., 1983, "Hygrothermal Effects in Continuous Fiber Reinforced Composites" National Aeronautical Establishment, Scientific and Technical Publications, Ottawa, Canada.

Meirovitch, L. "Analytical Methods in Vibrations," The Macmillan Company, New York

Mikita, Y. and Taya, M. 1985, "Stress Field in a Coated Continuous Fiber Composite Subjected to Thermo-Mechanical Loadings" Journal of Composite Materials, Volume 19, No. 554-578

Nagappan, G., 2004, "Analysis of Composite Moving Beams using Higher Order Shear Deformation Theory," Master's Thesis, West Virginia University, Morgantown, WV

Pipes, R. B., Vinson, J. R. and Chou, T. W., 1976, "On the Hygrothermal Response of Laminated Composite Systems," Journal of Composite Materials, Volume 10, No. 2, pp. 129-148.

Rao, S. S., 2007, "Mechanical Vibrations," Dorling Kindersley Pvt. Ltd., India (licensees of Pearson Education in South Asia).

Reddy, J. N., 1997, "Mechanics of Laminated Composite Plates Shells: Theory and Analysis," CRC Press, Boca Raton, Fla.

Sarae, W., Kim, S. J., Kim, J. H. and Ha, S. K., 2010, "Transient Moisture Distribution and Hygrothermal Stress Analysis of Composite Laminates using Equivalent Diffusion Methods," Journal of Composite Materials, Volume 44, No. 20. 
Shen, C. H. and Springer, G. S., 1976, "Effects of Moisture and Temperature on the Tensile Strength of Composite Materials," Journal of Composite Materials, Volume 11, January 1977, pp. 2-6.

Shen, C. H. and Springer, G. S., 1977, "Moisture Absorption and Desorption of Composite Material," Journal of Composite Materials, Volume 10, January 1976, No. 1, pp. 2-20.

Shokrieh, M. M. and Kamali, S. M., 2005, "Theoretical and Experimental Studies on Residual Stresses in Laminated Polymer Composites," Journal of Composite Materials, Volume 39, pp. 2213-2225.

Soden, P.D., Hinton, M.J. and Kaddour, A.S., 1998, "Lamina Properties, Lay-up Configurations and loading conditions for a range of fiber-reinforced composite laminates," Journal of Composite Materials, Volume 58, pp.11011022

Sreeram, T.R. and Sivaneri, N. T., 1997, "FE-Analysis of a Moving Beam using Lagrangian Multiplier Method," International Journal of Solids and Structures, Volume 35, No. 28-29.

Srihari, S. and Rao, R.M.V.G.K., 1999, "Hygrothermal Characterization and Diffusion Studies on Glass Epoxy Composites," Journal of Reinforced Plastics and Composites, Volume 18, pp. 942-953

Sun, C.T. and Chin, H., 1987, "Analysis of Asymmetric Composite Laminates," AIAA Journal, Volume 26, No. 6. 
Taheri, M.R., 1987, "Dynamic response of plates to moving loads: Structural impedance and finite element methods," PhD Dissertation, Purdue University, IN

Timoshenko, S.P. and Kreiger, S.W., "Theory of Plates and Shells," McGraw-Hill

Tita, V., Carvalho, J. and Lirani, J., 2003, “Theoretical and Experimental Dynamic Analysis of Fiber-Reinforced Composite Beams", Journal of Composite Beams, Volume 25, No. 3.

Todo, M., Nakamura, T. and Takahashi, K. 2000, "Effects of Moisture Absorption on the Dynamic Interlaminar Fracture Toughness of Carbon/Epoxy Composites," Journal of Composite Materials, Volume 34, No. 630-648

Tsai, S. W. and Hahn, H. T., 1980, "Introduction to Composite Materials," Technomic Publishing Co. Inc.

Tsai, S. W., 2008, "Theory of Composites Design," Think Composites

Upadhyay, P.C. and Lyons, J. S., 2000, "Effect of Hygrothermal Environment on the Bending of PMC Laminates under Large Deflection," Journal of Reinforced Plastics and Composites, Volume 19, pp. 465-491

Upadhyay, P.C. and Lyons, J. S., 2000, "Hygrothermal Effect on the Large Deflection Bending of Asymmetric PMC Laminates," Journal of Reinforced Plastics and Composites, Volume 19, pp. 1094-1111

Upadhyay, P.C., Murthy, K. Guru and Lyons, J. S., 1996, "Stress Field in Coated Continuous Fiber-Reinforced Polymeric Composite Due to Hygrothermal Loading," Journal of Reinforced Plastics and Composites, Volume 15, pp. $619-650$ 
Vennam, S., 2006, "Hygrothermal Effects on Free Vibration Characteristics of Rotating Composite Beams," Master's Thesis, West Virginia University, Morgantown, WV

Wang, C. H. and Tsai, C. L., 2010, "Theoretical Study for Moisture Diffusion in a Carbon/Epoxy Composite Laminate Accompanies by Thermal Conduction," Journal of Composite Materials, Volume 44, pp. 2233-2243

Whitcomb, J. and Tang, X., 2002, "Micromechanics of Moisture Diffusion in Composites with Impermeable Fibers," Journal of Composite Materials, Volume 36, pp. 1093-1101. 